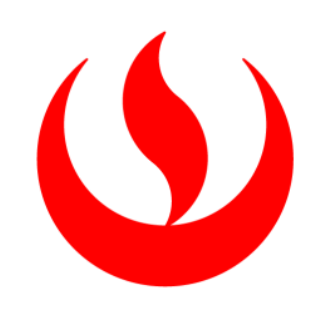

UNIVERSIDAD PERUANA DE CIENCIAS APLICADAS

FACULTAD DE INGENIERÍA

Carrera de Ingeniería Industrial

\title{
PROPUESTA DE MEJORA EN EL PROCESO DE COMPRAS DE LAS PYMES EXPORTADORAS DEL SECTOR TEXTIL DE CONFECCIONES DE PRENDAS DE VESTIR DE TEJIDO DE PUNTO DE ALGODÓN, APLICANDO HERRAMIENTAS DE LEAN MANUFACTURING
}

Tesis para optar el título profesional de: Ingeniero Industrial

\author{
Autores: \\ Oré Mayorga, Elia Victoria (0000-0002-5393-5585) \\ Ramos Valle, Milagritos del Rosario (0000-0002-3696-5547)
}

Asesor: Carvallo Munar, Edgardo Gabriel (0000-0002-5317-5061)

Lima, 08 de Noviembre de 2018 
A nuestros padres por ser el pilar fundamental en todo lo que somos, en toda nuestra educación, tanto académica, como en la vida, por el apoyo incondicional pefectamente mantenido a través del tiempo y a todos aquellos familiares y amigos que con sus palabras de aliento nos ayudaron a terminar este gran paso de vida. 


\section{AGRADECIMIENTO}

Agradecemos a Dios por bendecirnos la vida, por guiarnos a lo largo de nuestra existencia, ser el apoyo y fortaleza en aquellos momentos de dificultad y de debilidad.

Gracias a nuestros padres : José y Emma ; y, Victor y Elia, por su amor, trabajo y sacrificio en todos estos años. Gracias a ustedes hemos logrado llegar hasta aquí y convertirnos en lo que somos.

Agradecemos a nuestros docentes de la Facultad de Ingeniería, por haber compartido sus conocimientos a lo largo de la preparación de nuestra profesión, de manera especial, al Ing. Edgardo Carvallo Munar asesor de nuestro proyecto de investigación quien ha guiado con su conocimiento, dirección, enseñanza y colaboración permitiendo el desarrollo de este trabajo. 


\section{RESUMEN}

El principal desafío de las Pymes del sector textil de confecciones es el nivel de competitividad que se vive en la actualidad. Las empresas textiles, deben tener la capacidad de atender los diferentes pedidos en el tiempo establecido por el cliente final. En este contexto, es fundamental desarrollar métodos o herramientas que mejoren los procesos deficientes del sector.

El objetivo principal del proyecto es rediseñar el proceso de compra con herramientas de lean manufacturing: Estandarización y Just in Time, alineados a eliminar los procesos innecesarios, elevar los niveles de productividad, reducir inventario, costos y tiempo de entrega e incrementar la satisfacción del cliente mejorando su competitividad en el mercado globalizado a través de los términos de agilidad, velocidad de respuesta y flexibilidad.

Para el desarrollo del proyecto, se realiza una investigación previa sobre la metodología lean manufacturing, donde se estudian las aplicaciones de cada una de las herramientas y casos de éxito de PYMES a nivel mundial.

Luego, se rediseña el proceso de compras del sector texil exportador orientado a las necesidades de las PYMES peruanas, acompañado de un plan de implementación de los módulos propuestos basadas en herramientas de lean manufacturing.

Finalmente, el modelo propuesto es validado por juicio de expertos, dos usuarios de las empresas del sector textil y cuatro expertos en la aplicación de las herramientas Lean, a través de ocho criterios establecidos inicialmente se pudo determinar la viabilidad de la propuesta.

Palabras clave: Lean Manufacturing en el sector textil, proceso de compras, Just-in -time, Estandarización, reducción del Lead Time. 


\section{ABSTRACT}

The main challenge of the SMEs of the garment textile sector is the level of competitiveness that is experienced today. The textile companies must have the capacity to attend the different orders in the time established by the final client. In this context, it is essential to develop methods or tools that improve the deficient processes of the sector.

The main objective of the project is to redesign the purchasing process with lean manufacturing tools: Standardization and Just in Time, aligned to eliminate unnecessary processes, raise productivity levels, reduce inventory, costs and delivery time and increase customer satisfaction improving its competitiveness in the globalized market through the terms of agility, response speed and flexibility.

For the development of the project, a preliminary research is made on the lean manufacturing methodology, where the applications of each of the tools and success cases of SMEs are studied worldwide.

Then, the purchasing process of the export textile sector oriented to the needs of Peruvian SMEs is redesigned, accompanied by an implementation plan of the proposed modules based on lean manufacturing tools.

Finally, the proposed model is validated by expert judgment, two users of textile companies and four experts in the application of Lean tools, through eight criteria initially established it was possible to determine the viability of the proposal.

Keywords: Lean Manufacturing in the textile sector, purchasing process, just-in-time, standardization, reduction of the lead time. 


\section{Tabla de Contenidos}

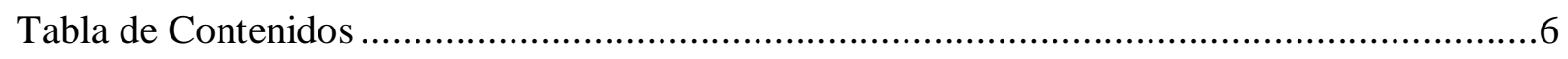

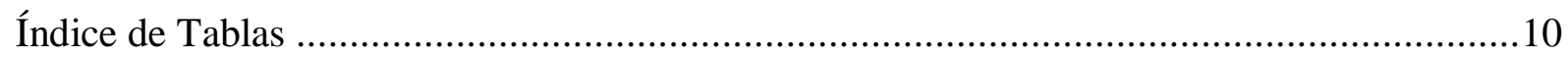

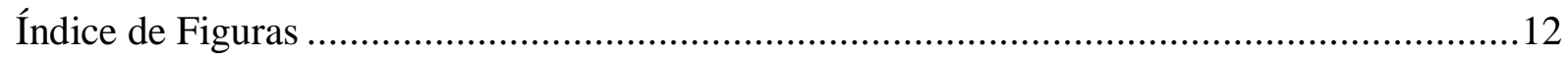

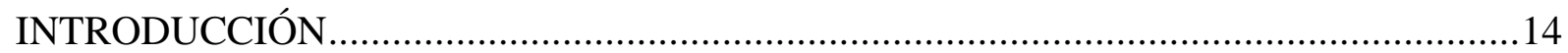

CAPITULO I: MARCO TEÓRICO Y ESTADO DEL ARTE.........................................15

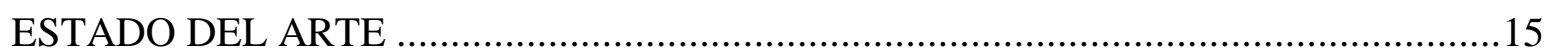

HISTORIA Y ANTECEDENTES DE LEAN MANUFACTURING...........................15

DESCRIPCIÓN DE LA SITUACIÓN ACTUAL DE LA APLICACIÓN DEL MÉTODO

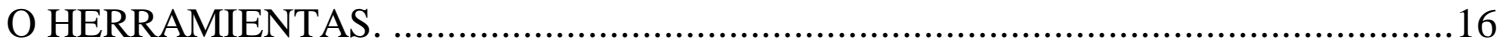

MODELO DE REFERENCIA DE OPERACIONES (SCOR) ............................... 18

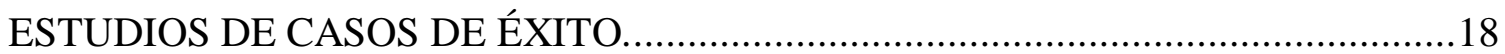

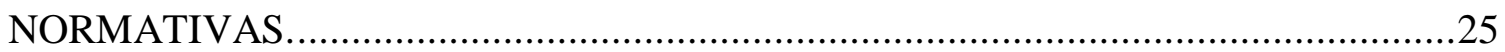

APLICACIÓN DE LEAN MANUFACTURING EN EL SECTOR TEXTIL................27

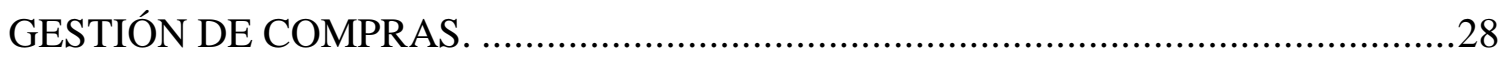

IMPACTO EN LAS COMPRAS DE LOS PRODUCTOS TEXTILES. ......................29

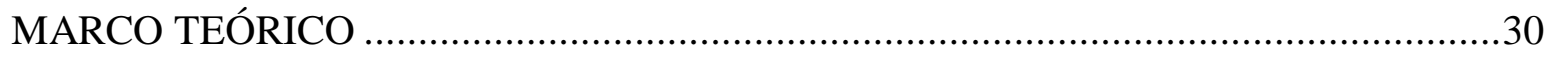

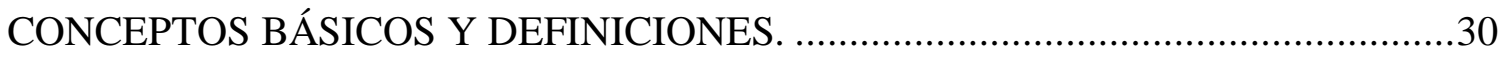

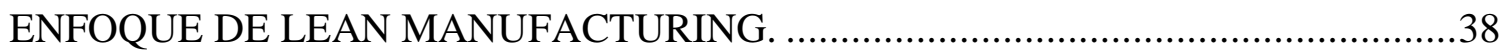

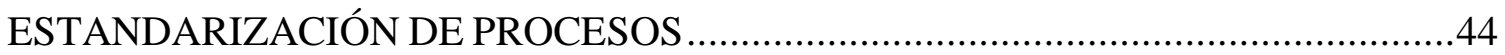

PROCESO DEL SECTOR TEXTIL DE CONFECCIONES. .....................................52

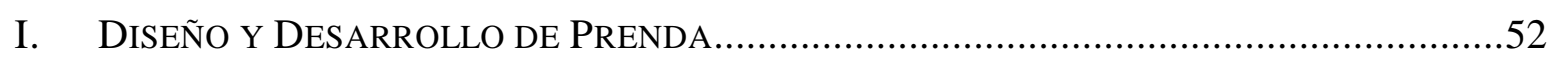

II. COMPRAS DE MATERIALES, INSUMOS O MATERIA PRIMA .......................................52

III. RECEPCION Y ALMACENAMIENTO DE MATERIALES. .......................................52

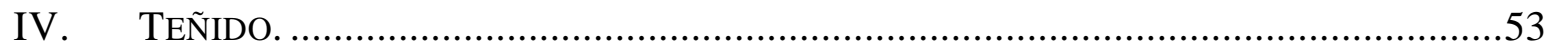

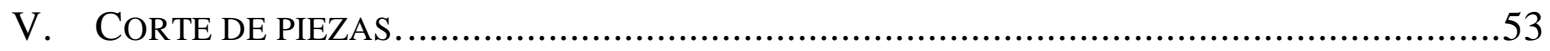

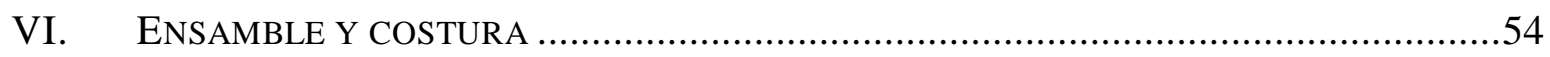

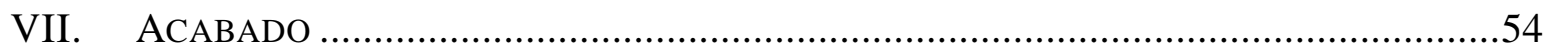

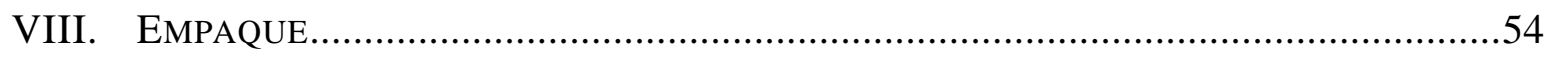

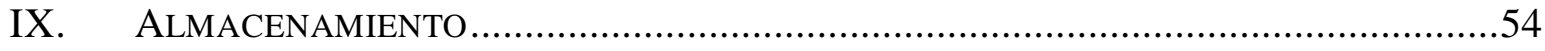

PROCESO DE COMPRAS EN EL SECTOR TEXTIL DE CONFECCIONES. ...........54 


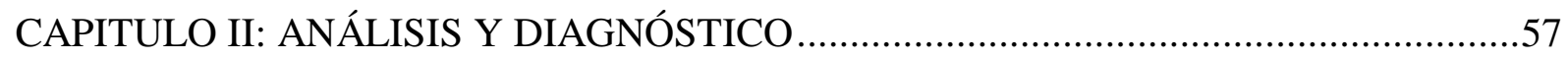

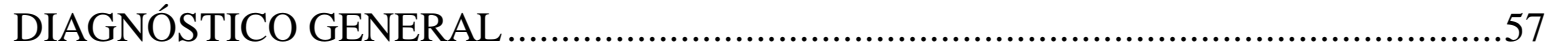

SITUACIÓN ACTUAL DE LAS PYMES EN EL PERÚ. ..........................................57

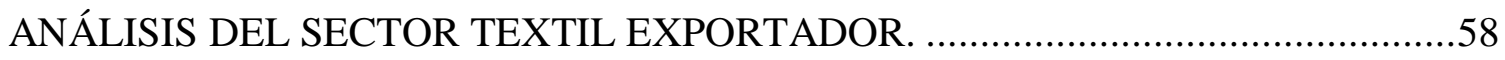

DIAGNÓSTICO GRUPAL DEL SECTOR TEXTIL ..................................................64

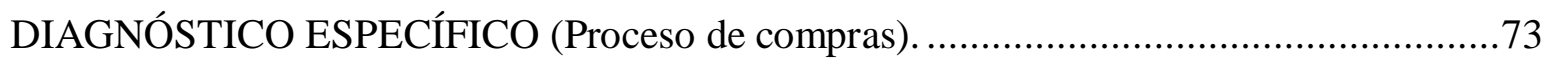

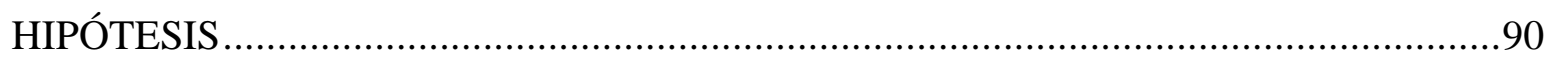

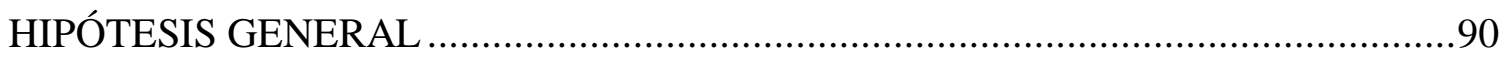

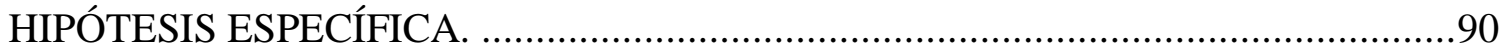

CAPITULO III: DISEÑO Y DESARROLLO DE LA PROPUESTA DE MEJORA .............91

3.1. IMPLEMENTACIÓN DE LA HERRAMIENTA DE ESTANDARIZACIÓN. .....93

3.1.1. DISEÑO DE LA PROPUESTA.......................................................... 93

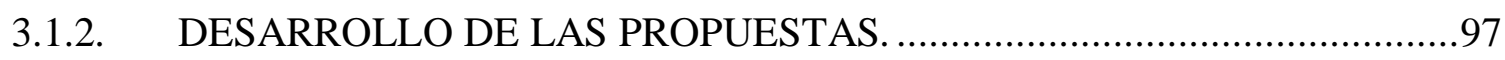

3.2. IMPLEMENTACIÓN DE LA HERRAMIENTA DE JUST IN TIME.................122

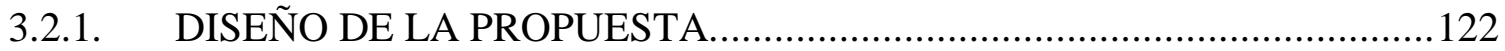

3.2.2. DESAROLLO DE LA PROPUESTA........................................................ 127

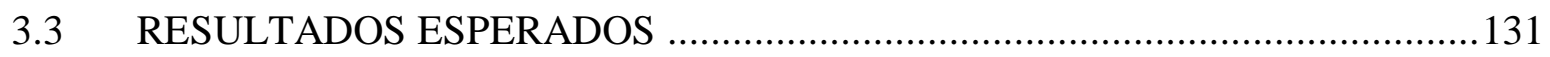

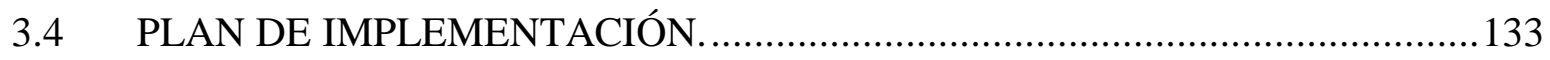

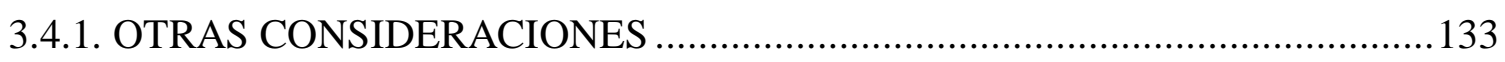

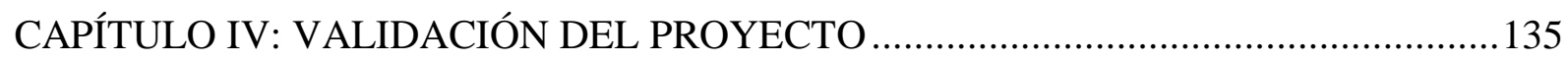

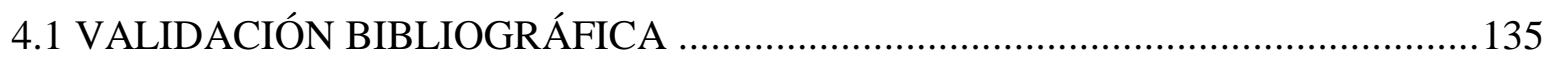

4.1.1 VALIDACIÓN DE FUENTES BIBLIOGRÁFICAS POR TIPO.........................135

4.1.2 VALIDACIÓN DE LOS REQUISITOS DE LOS ARTÍCULOS UTILIZADOS

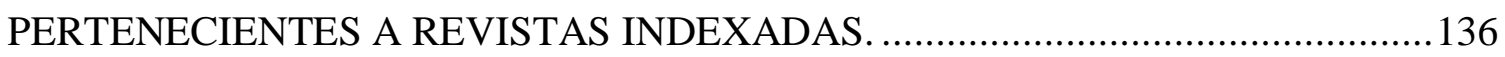

4.2. VALIDACIÓN DE ENTREGABLES: OBJETIVOS Y DE LOS CAPÍTULOS I, II Y

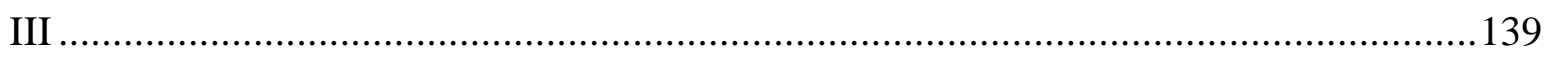

4.2.1 VERIFICACIÓN DEL CUMPLIMIENTO DE OBJETIVOS ............................139

4.2.2 VALIDACIÓN DE ENTREGABLES POR CAPÍTULOS. .................................140

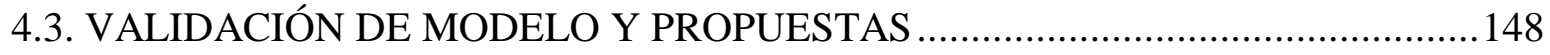

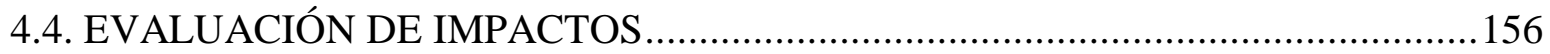

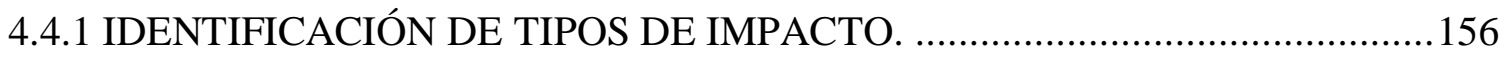

4.4.2 SELECCIÓN DE METODOLOGÍA PARA LA EVALUACIÓN DE IMPACTOS

4.4.3 EVALUACIÓN DE IMPACTO DE LAS PROPUESTAS.................................. 160 


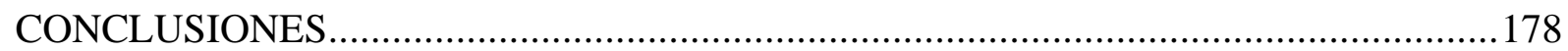

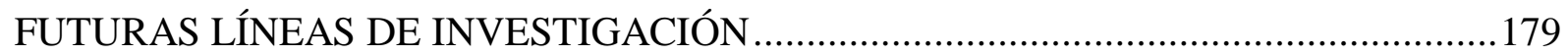

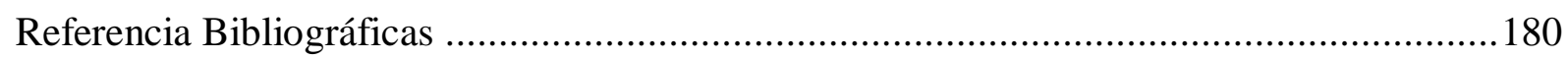

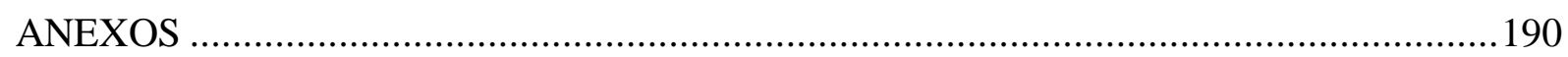

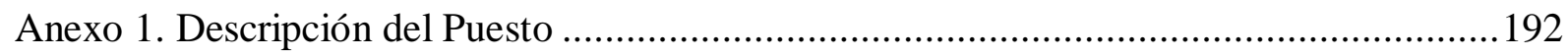

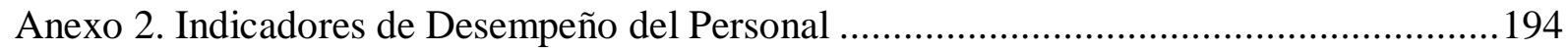

Anexo 3. Evaluación de Desempeño del Personal ...............................................................198

Anexo 4. Plan de Acción para mejorar el desempeño del personal .....................................199

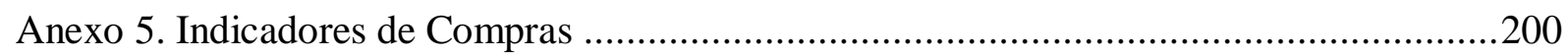

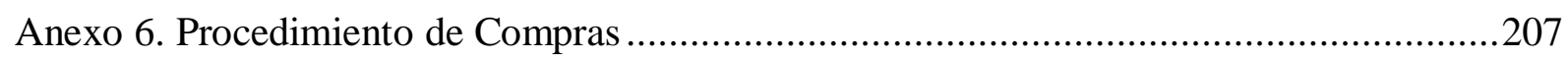

Anexo 7 : Solicitud de Información del Proveedor........................................................225

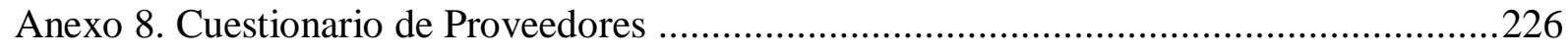

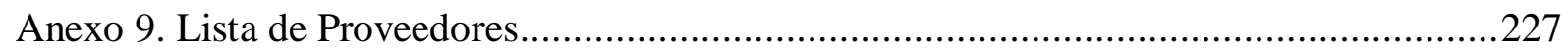

Anexo 10. Ejemplo de criterio de evaluación de la matriz AHP .......................................228

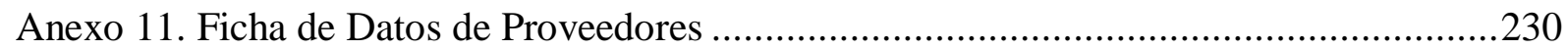

Anexo 12. Ficha de Evaluación de Proveedores ...............................................................231

Anexo 13. Procedimiento de Seguimiento de Proveedores, Materiales y Servicios..............232

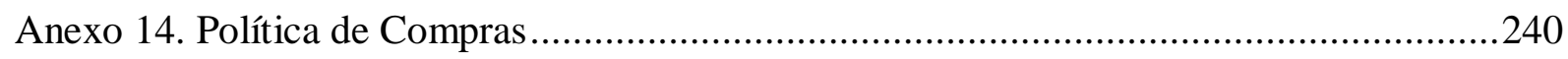

Anexo 15. Procedimiento de Seguimiento de Compras .................................................242

Anexo 16. Procedimiento de Seguimiento de Proveedores, Materiales y Servicios..............247

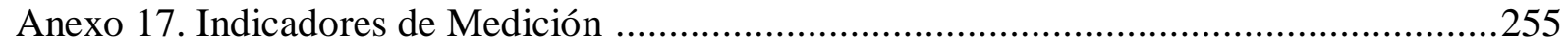

Anexo 18. Indicadores de Medición de Desempeño del Proceso .......................................257

Anexo 19. Formato de Entrevista para medir el desempeño ............................................263

Anexo 20. Cuestionario de Evaluación de Desempeño......................................................264

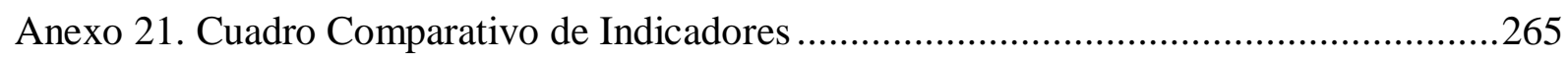

Anexo 22. Programa de Educación Just in Time ............................................................266

Anexo 23. Programación de Notificación Tipo Pull ............................................................270

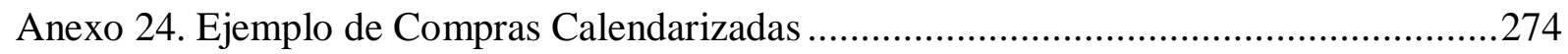

Anexo 25. Ejemplo de Planeamiento de Requerimiento de Materiales ..............................279

Anexo 26. Plan Estratégico con Proveedores ....................................................................281

Anexo 27. Política de Pago a Proveedores …..................................................................285

Anexo 28. Guía Básica para la Auditoría ........................................................................289

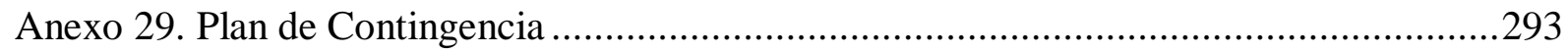




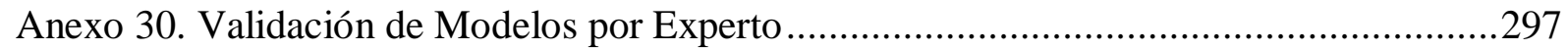

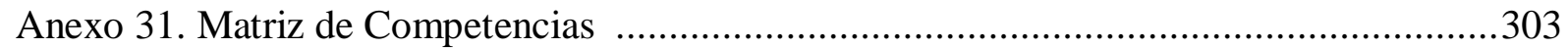




\section{Índice de Tablas}

Tabla 1. Segmento empresarial por Unidad Impositiva Tributaria. .....................................31

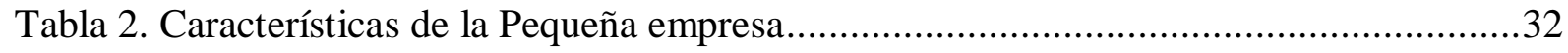

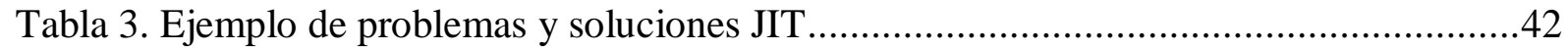

Tabla 4. Formato para la selección de indicadores ........................................................49

Tabla 5. Empresas según Segmento empresarial 2014-2015..........................................57

Tabla 6. Crecimiento del Producto Bruto Interno 2016 - 2017. .........................................59

Tabla 7. Exportaciones por Sector Económico - No tradicional 2016 .................................62

Tabla 8. Proyección de las exportaciones peruanas 2016-2017 .......................................65

Tabla 9. Exportaciones por Sectores Económicos - No Tradicional ..................................65

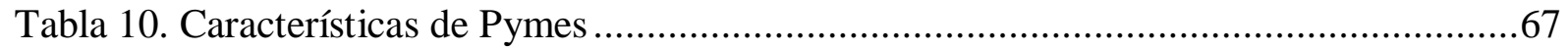

Tabla 11. Distritos Según Facturación e Impacto Económico .............................................67

Tabla 13. Comparación de Lead Time por proceso de la industria textil de confecciones ......71

Tabla 14. Fuente de los Lead Time estándar obtenidos ......................................................71

Tabla 15. Comparación del Lead Time estándar del proceso de Compras ...........................75

Tabla 16. Problemas identificados que generan un Lead time excesivo en el proceso de

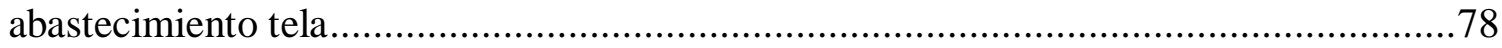

Tabla 17. Ejemplo de Impacto económico por reducción de 7 días aproximadamente de Lead

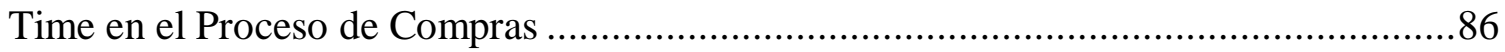

Tabla 18. Impacto Económico en el Sector Textil Estudiado .............................................8

Tabla 19. Resumen de Proceso crítico (Compras), Desperdicios, Impacto/Trascendencia y

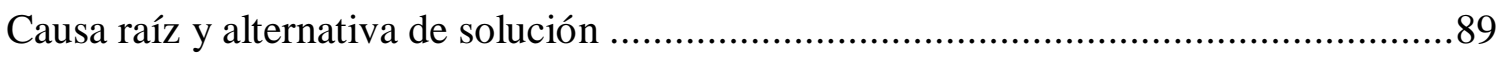

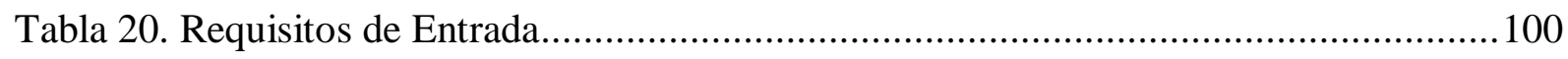

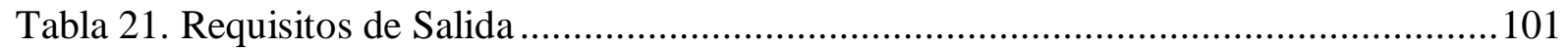

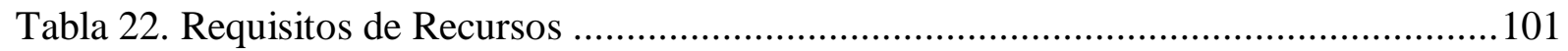

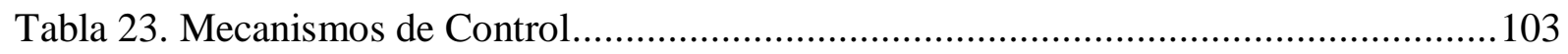

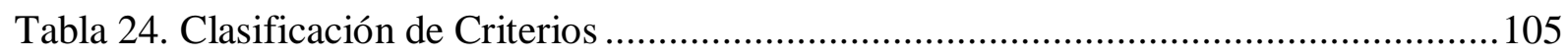

Tabla 25. Aspectos considerar para la solicitud de proveedores .......................................109

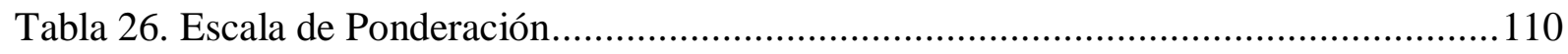

Tabla 27. Niveles de calificación para Homologación........................................................111

Tabla 28. Stakeholders Involucrados en el proceso de compras .........................................128 
Tabla 29. Tipo de Referencia Bibliográfica

Tabla 30. Lista de artículos académicos pertenecientes a revistas indexadas utilizados en la investigación 136

Tabla 31. Validación de Objetivos 139

Tabla 32. Validación del capítulo 1 ..... 141

Tabla 33. Validación del capítulo 2 ..... 143

Tabla 34. Validación del capítulo 3. 146

Tabla 35. Matriz de Validación de propuestas. 153

Tabla 36. Validación promedio de los modelos. 154

Tabla 37. Tipos de impacto y relación con el proyecto de investigación..... 157

Tabla 38. Metodología de evaluación de Impacto 159

Tabla 39. Lista de Stakeholders identificados en el Brainstorming. 161

Tabla 40. Matriz de Identificación de Stakeholders de ICRA ............................................ 161

Tabla 41. Escala de valoración para la identificación de stakeholders ................................163

Tabla 42. Matriz de Identificación de Stakeholder Claves .................................................163

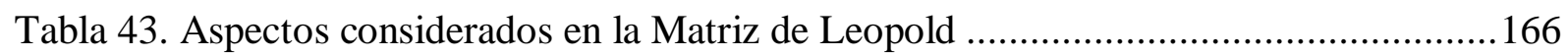

Tabla 44. Validación del Impacto de las propuestas (Matriz de Leopold)...........................169

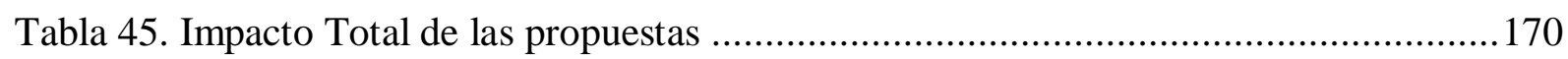

Tabla 46. Evaluación de Riesgos y Acción de Contingencia ..............................................176 


\section{Índice de Figuras}

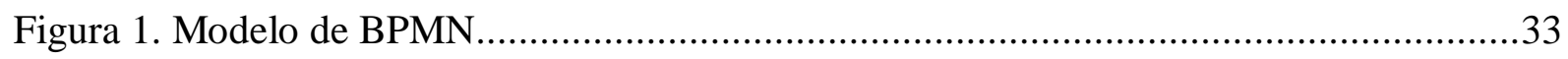

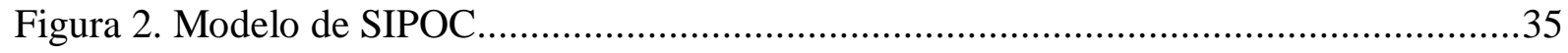

Figura 3. Posiciones por países por Competitividad Empresarial.........................................36

Figura 4. Formato de la Matriz de Leopold a utilizar....................................................... 38

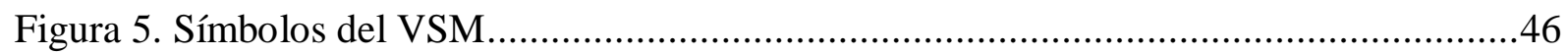

Figura 6. Ejemplo de Mapa de Flujo de Valor ..............................................................47

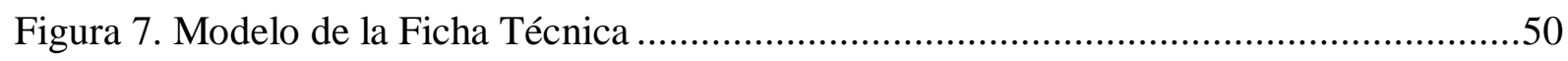

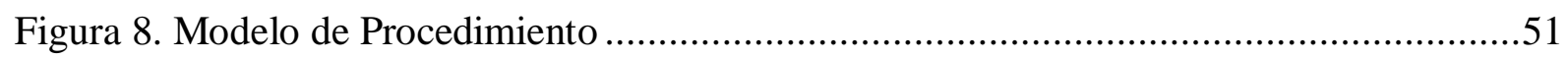

Figura 9. Diagrama de flujo del proceso de Compras Estándar Nacional .............................55

Figura 10. Empresas según actividad económica Perú - 2015 _..........................................58

Figura 11. Situación de la Manufactura no primaria en exportaciones 2016 .......................60

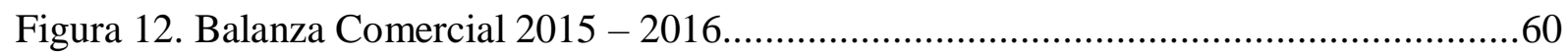

Figura 13. Variación porcentual en exportaciones del Sector Tradicional y No Tradicional 2016

Figura 14. Empresas manufactureras según actividad económica 2015 .............................61

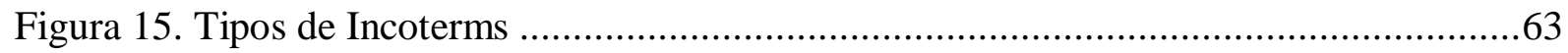

Figura 16. Distribución de las exportaciones según país de destino 2016 ...........................66

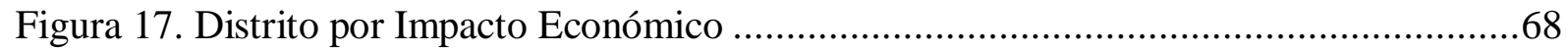

Figura 18. Diagrama de Procesos Críticos en la Industria Textil de Confecciones .................70

Figura 19. Desperdicios identificados en la Industria Textil de Confecciones........................70

Figura 20. Lead time como factor crítico de los procesos .................................................73

Figura 21. Tiempos Internos y Externos en el proceso de compra .....................................74

Figura 22. Representación de Lead Time promedio de materias primas ..............................75

Figura 23. Porcentaje de Compras por tipo de materia Prima .............................................76

Figura 24. Adquisición de tela cruda Vs Tela procesada .................................................77

Figura 25. Porcentaje de Compras nacionales Vs. Compras internacionales de Tela para la confección .77

Figura 26. Mapa de flujo de valor actual del proceso de Compra de tela en el sector Textil de confeccione .80 
Figura 27. Flujograma del proceso de Compra del sector textil de confección de prenda de vestir de tejido punto

Figura 28. Esquema de Causa- raíz del problema de Retraso en la entrega por parte del

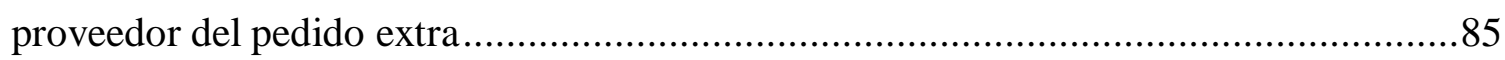

Figura 29. .Impacto Económico reduciendo el Lead Time en el proceso de Compras ............87

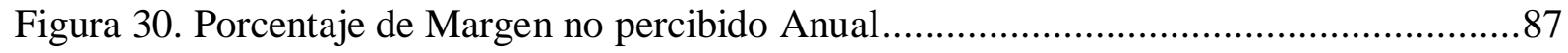

Figura 31. Esquema de Herramienta de Lean Manufacturing aplicado para alcanzar el objetivo principal

Figura 32. Diagrama de Relación de Procesos de Confección de prendas de vestir (T-Shirt). 92

Figura 33. Esquema del diseño del sistema de compras estandarizado .93

Figura 34. Propuesta de solución- sistema de compras estandarizado.................................95

Figura 35. Cadena de valor de compras/ abastecimiento .98

Fuente : Rodríguez, B. Programa logístico modalidad virtual at Universidad Manuela Beltrán.

Figura 36. Proceso de Evaluación ..... .99

Figura 37. Sipoc del Proceso de Compras 104

Figura 38. Diagrama de flujo del Proceso de Compra 107

Figura 39. Método de selección, Evaluación y Homologación 108

Figura 40. Etapas para la evaluación . 111

Figura 41. Procedimiento de Selección, evaluación y homologación de proveedores 114

Figura 42. Procedimiento de Seguimiento a las Compras 116

Figura 43. Procedimiento de seguimiento a Proveedores. 117

Figura 44. Fases de la gestión de Desempeño 118

Figura 45. Diseño del sistema de compras Justo a Tiempo 122

Figura 46. Propuesta de solución Compras Just in Time. 124

Figura 47. Modelo de guía para implementar Justo a Tiempo.....

Figura 48. VSM Futuro debido a la Implementación. 132

Figura 49. Porcentaje de Validez por dimensión evaluado. 155

Figura 50. Identificación de Stakeholders según Mitchell, Agle y Wood.. 162

Figura 51. Validación del Impacto por Stakeholder. 


\section{INTRODUCCIÓN}

Las empresas exportadoreas de la industria textil y confecciones de prendas de vestir, en su esfuerzo por mantenerse competitivos en el mercado, suelen comprender básicamente dos aspectos que configuran la denominada competencia basada en el tiempo: "entregas rápidas" y entregas en fecha"; por ello, se ven forzadas a tener la capacidad de atender los diferentes pedidos en el tiempo establecido por el cliente final.

La industria nacional, está sufriendo una serie de problemas que han mermado su desarrollo y dinamismo en grandes, medianas y pequeñas empresas del sector textil-confección,entre los principales se encuentra, la falta de capacitación de empresarios y emprendedores en métodos o herramientas que mejoren sus procesos, exigencias del mercado, decisiones gubernamentales orientadas a la subvaluación y al ingreso de precios dumping, ocasionando en muchos casos el cierre de sus plantas en el Perú, abuso y explotación del personal operativo, y la reducción de salarios y puestos de trabajo a fin de minimizar costos, además de las dificultades que se presentan en los procesos internos como son las Compras, las cuales se realizan con un Lead Time de 10 días estableciendo ese tiempo como estándar de la industria textil. Sin embargo, mediante el trabajo de campo realizado y a través de la elaboración de un Value Stream Mapping se obtuvo un Lead time de 14 días en promedio excediendo en 4 al estándar, esto se traduce en una pérdida económica en cada una de las empresas del sector textil exportador.

El presente estudio pretende hacer un análisis exhaustivo de la aplicación de Lean Manufacturing y su desempeño en PYME's del sector textil exportador en el Perú, y demostrar las ventajas y beneficios que implica su implementación. En este sentido, las propuestas que surgen tienen como objetivo eliminar los proceso innecesarios, elevar los niveles de productividad, reducir inventario, costos y tiempo de entrega e incrementar la satisfacción del cliente mejorando su competitividad en el mercado globalizado a través de los términos de agilidad, velocidad de respuesta y flexibilidad. 


\section{CAPITULO I: MARCO TEÓRICO Y ESTADO DEL}

\section{ARTE}

El presente capítulo se ha desarrollado con el objetivo de detallar y explicar los elementos teóricos que se utilizarán en el desarrollo de la investigación con la intención de diseñar un plan. Además, se explica los temas relacionados y antecedentes en general que se refieren a la investigación. En primer lugar, se describe la situación económica actual del Perú. De la misma manera, se analiza sobre la situación actual de las empresas peruanas y los niveles que éstas presentan en nuestro país, enfocándose en PYMES (Pequeña y mediana empresa) del sector textil exportador. Así mismo, se hace mención de la aplicación de la metodología de Lean Manufacturing, principios, características, herramientas y desperdicios. Finalmente, se desarrolla el análisis del proceso de Compras en el sector textil justificando la importancia mediante el impacto económico y trascendencia que representan los desperdicios identificados en el proceso.

\section{ESTADO DEL ARTE}

\section{HISTORIA Y ANTECEDENTES DE LEAN MANUFACTURING.}

El término "lean manufacturing" o "manufactura esbelta" fue utilizado por primera vez por James Womack, Daniel T. Jones y Daniel Roos en el libro "The Machine that Changed the World" (2007), enfocándose principalmente en la eliminación de desperdicios o muda. Sin embargo, Lean manufacturing se desarrolló en su mayor parte en industrias japonesas, principalmente en Toyota quienes buscaban reconstruir su economía después de la segunda guerra mundial inventando el Sistema de Producción Toyota (Toyota Production Sistem, TPS).

Lean Manufacturing puede considerarse como un enfoque sistemático para identificar y eliminar los desperdicios en operaciones a través de la mejora continua, reduciendo los costos operativos del sistema y satisfaciendo el deseo de los clientes de obtener el máximo valor al menor precio (Abdulmalek y Rajgopal, 2007). La metodología Lean se considera como un método exitoso para mejorar el rendimiento general de una organización. 
El enfoque se centra en la reducción de costos mediante la eliminación de las actividades sin valor añadido; la aplicación de una filosofía de gestión permite la identificación y eliminación de residuos de cada etapa de la cadena de producción respectiva de energía, tiempo, movimiento y recursos similares a lo largo del flujo de valor de un producto (Rahani y Al-Ashraf, 2012). Los principios Lean, definen el valor del producto o servicio según lo percibido por el cliente para luego hacer el flujo en línea con el cliente y luchar por la perfección a través de la mejora continua mediante la separación de la actividad de valor añadido (VA) y la actividad sin valor añadido (NVA) (Sundara, Balajib y Kumar, 2014).

La aplicación Lean se guía por 5 pasos simples a partir de la identificación del valor del proceso, determinando el flujo de valor del mismo, centrándose en el flujo del proceso, las configuraciones del factor de atracción y trabajando hacia la perfección del proceso.

\section{DESCRIPCIÓN DE LA SITUACIÓN ACTUAL DE LA APLICACIÓN DEL MÉTODO O HERRAMIENTAS.}

Las empresas están expuestas a la presión competitiva global de las condiciones cambiantes del mercado, cada vez más empresas se enfrentan al desafío de procesos de producción. Al mismo tiempo, se produce un aumento de requisitos en cuanto a flexibilidad, diversidad de variantes, complejidad de logística, transparencia y plazos de entrega cortos junto con un enfoque de cliente de la organización de producción (Dombrowski, 2015). Las empresas de la industria textil y de la confección operan en mercados internacionales competitivos caracterizados por la liberalización del comercio y deben abordar cambios rápidos en las preferencias de los consumidores y en la tecnología de producción. Por lo tanto, mejorar la competitividad es crucial para la supervivencia de las empresas. La competitividad del sector a menudo depende de que sus empresas alcancen su potencial de producción (Kapelko y Oude, 2015). La reacción de muchas empresas es implementar Sistemas de Producción Lean. En el pasado, se han utilizado métodos de Sistemas de Producción Lean (LPS) para identificar los residuos en los procesos de producción y desarrollo de productos. Lean, ofrece un enfoque para eliminar los residuos y aumentar el valor del cliente en todos los procesos. La selección de los métodos contenidos en el LPS puede adaptarse individualmente a los requisitos y condiciones respectivas de la empresa correspondiente. Por lo tanto, la identificación de los métodos necesarios es una decisión individual para cada LPS. La consideración de los efectos de los métodos dentro del sistema socio-técnico de un LPS es crucial porque los efectos de los 
diferentes métodos LPS proporcionan información importante para el apoyo en la toma de decisiones de la organización.

Lean Manufacturing puede considerarse como una configuración de prácticas/herramientas, porque las relaciones entre los elementos de la producción lean no son ni explícitas ni precisas en términos de linealidad o causalidad. Un enfoque de configuración ayuda a explicar cómo un sistema delgado se diseña a partir de la interacción de sus elementos constituyentes tomados en conjunto, en contraposición a diseñar el sistema un elemento a la vez. Desde un punto de vista teórico, la producción esbelta se ve como un sistema fuertemente acoplado donde los elementos constituyentes se mantienen unidos en la dependencia mutua. Por un lado, los efectos de autorefuerzo de este tipo de dependencia mutua contribuyen al rendimiento superior asociado con la producción racional (Shah y Ward, 2003) y lo hacen raro, valioso y difícil de imitar por los competidores.

El uso racional de diferentes técnicas de Lean Manufacturing se convierte en una de las razones claves para su éxito. Algunas de las iniciativas de mejora continua más populares son Kaizen, Lean Manufacturing o Lean Thinking, Six Sigma, Balance Score Card o Cuadro de Mando Integral y Lean-Six Sigma, entre muchas otras de sostenida vigencia en la actualidad. Es importante destacar que todas estas metodologías comparten una gran cantidad de conceptos, con lo cual los aportes que van haciendo cada una de ellas a medida que van mostrando su madurez y solidez no va haciendo otra cosa que complementar todo lo anterior con miradas desde nuevos puntos de vista y proponiendo nuevos métodos. Mientras las definiciones de estas metodologías pueden ser diferentes, sus objetivos son similares: a través de pequeñas mejoras incrementales estas buscan minimizar los desperdicios y hacer un adecuado uso de los recursos de tal forma que se logre satisfacer las necesidades tanto del cliente interno como externo y se demuestren resultados en la reducción de costos, mejora de la calidad, desempeño y satisfacción de los empleados y en los resultados financieros favorables. Al implementar cualquier proceso de negocio, este principio permite enfocarse en la estandarización de las operaciones y acciones que contribuyen a la unificación de la reducción de costos al implementar estas operaciones. Por ejemplo: El principio de "estandarización y flexibilidad" se centra en la capacidad de la empresa para cambiar una actividad, manteniendo al mismo tiempo la unificación máxima de ciertas operaciones y actividades; capacidad para reducir los costos de producción asociados con la implementación de operaciones estándar y unificadas (Khamidullina, et al., 2016). 


\section{MODELO DE REFERENCIA DE OPERACIONES (SCOR).}

El Supply Chain Council (2006:2), define al SCOR como "un modelo desarrollado para describir todas las actividades que una empresa ejecuta mediante fases para satisfacer la demanda de los clientes. El modelo se organiza teniendo en cuenta los cinco procesos básicos que se llevan a cabo en la empresa: planeación, aprovisionamiento, producción, distribución y devoluciones". Además, la metodología SCOR ayuda a las compañías a detectar los problemas de su cadena de suministro, identificando según sus objetivos y mejoras en su desempeño.

Desde el marco de aplicabilidad del modelo de referencia operacional (SCOR) primeramente se hace una caracterización de la cadena identificando los agentes, las relaciones existentes desde los proveedores de segundo nivel hasta los clientes y el estado actual, luego se hace una evaluación y un análisis a partir de una serie de indicadores en cada uno de los niveles permitiendo gestionar la cadena en cada uno de sus procesos (Herrera y Herrera, 2016).El alcance del modelo SCOR abarca todos los procesos desde los proveedores hasta los clientes; por lo tanto se constituye en un medio para lograr un análisis profundo y también el mejoramiento total de la cadena de suministro.

\section{ESTUDIOS DE CASOS DE ÉXITO.}

Analyzing the benefits of lean tools: a consumer durables manufacturing company case study. (Análisis de los beneficios de las herramientas lean: Caso de estudio de una empresa dedicada a la fabricación de bienes.)

\section{Análisis de la situación actual}

El estudio se realiza a una empresa de mediana escala que se dedica a la fabricación de bienes que necesita mejorar sus operaciones en una de sus líneas de montaje de molino húmedo de mesa. Además, el presente trabajo se centra en la implementación de herramientas lean y en el desarrollo de diferentes estrategias para eliminar los residuos. Las influencias estratégicas de las herramientas lean se mide por medio de dos métricas lean: la tasa de penetración y el tiempo de "muelle-paro". 
La compañía estaba bajo severa presión internamente para mejorar sus operaciones de línea de montaje. En los últimos años, la compañía ha probado muchas opciones con grandes inversiones de capital; sin embargo, los resultados obtenidos no fueron significativos. En la búsqueda de la coherencia, la dirección decidió implementar herramientas lean. Después de varias lluvias de ideas y un estudio a fondo de la planta, se observó que la línea de montaje del molino húmedo consistía en varias actividades que no agregaban valor:

- Alto tiempo de entrega.

- Acumulación de inventario alto que ocupa el $40 \%$ de la planta.

- Flujo de material innecesario.

- La fatiga humana en el manejo de materiales (10\% del tiempo de espera).

- Energía subutilizada del hombre.

- Mala gestión de inventario.

\section{Análisis de la metodología}

Se aplicó un método para dirigir las actividades mediante un mapeo de flujo de valor. Para visualizar las actividades sin valor añadido se decidió construir primero el mapa de flujo de valor del estado actual de la empresa.

Toda la información necesaria de varios departamentos se recopiló para construir el flujo de valor de estado actual. También se recopilaron y documentó adecuadamente la información relativa a la línea de montaje, como el tiempo de ciclo en cada estación de trabajo, el tiempo de inactividad de la máquina para cada proceso, el inventario, el tiempo de cambio, el tiempo de preparación, el número de trabajadores y las horas de funcionamiento por día.

\section{Análisis de los resultados}

Este estudio evidencia las ventajas al aplicar las herramientas lean en una fábrica. Una combinación de herramientas lean es utilizada para analizar, evaluar y mejorar la situación actual. La eficacia de las técnicas lean se sustenta de manera sistemática con la ayuda de diversas medidas. Además, los beneficios de las herramientas son evidentes a partir de la producción mejorada como se puede ver en este caso: 
- El takt-time se reduce en un $26 \%$.

- El tiempo de ciclo se reduce en un $8 \%$.

- La producción de la línea de montaje se incrementa en un $23 \%$.

- La tasa magra se incrementa del $31 \%$ al $43 \%$.

- Mejora en la puntuación 5s.

- El transporte y la utilización innecesaria del espacio de suelo se reducen.

Lean manufacturing implementation a gear shaft manufacturing company using value stream mapping. (Implementación de la lean manufacturing en una empresa de fabricación de eje de engranaje utilizando mapeo de valores.)

\section{Análisis de la situación actual}

La investigación presentada en este artículo se basa en la implementación de lean en la producción de ejes de engranajes y cajas de engranajes en la empresa Star Engineers situado en la zona industrial de Chennai, India.

\section{Análisis de la metodología}

La metodología aplicada en este caso está orientada básicamente a la elaboración de un VSM: Identificación del producto, preparar el estado actual, revisión de la información, preparar el mapa del estado fututo y ejecutar cambios.

\section{$\underline{\text { Análisis de los resultados }}$}

El propósito de esta investigación fue desarrollar un mapa de flujo de valor para el proceso de fabricación del eje del engranaje usado en cajas de engranajes. Los experimentos llevados a cabo por estas actividades periféricas indicaron que la aplicación de VSM en la fabricación del eje de engranajes ayuda en la reducción del tiempo de fabricación de 30 minutos a 27 minutos por eje y satisfacer la demanda del cliente. Este trabajo de investigación se centró en el examen de VSM tomando una amplia base de observación en una sola industria. La investigación se puede extender además en el despliegue de industrias manufactureras similares con otras herramientas lean, como 5S, Kaizen, TPM, SMED, etc. 
A methodology for effective implementation of lean strategies and its performance evaluation in manufacturing organizations. (Una metodología para la implementación efectiva de las estrategias lean y la evaluación de su desarrollo en empresas manufactureras)

\section{Análisis de la situación actual}

La empresa se especializa en la investigación, desarrollo, fabricación, comercialización, ventas y servicio de productos de conmutación de baja y media tensión. Todos sus productos han sido ampliamente probados tanto en laboratorios internos como externos. La compañía tiene actualmente cuatro líneas de fabricación principales que son el control eléctrico y la línea de montaje del cubículo de la comunicación, la línea de montaje automática del circuito de OSM, la línea de fabricación del cable y la línea de ensamblaje del interruptor. Esta investigación se centró principalmente en el montaje de cubículos de control eléctrico y comunicación o en el ensamblaje del cubículo de módulo de control eléctrico RC-01.

\section{Análisis de la metodología}

Se desarrollaron matrices continuas de medición del desempeño en términos de eficiencia y efectividad, ya que resultan ser los métodos apropiados para la evaluación continua del rendimiento lean. Permitieron identificar sistemáticamente los desechos de fabricación, seleccionar herramientas adecuadas, identificar indicadores de desempeño relevantes, lograr una mejora significativa en el desempeño y establecer una cultura racional en la organización. La metodología propuesta mediante los siguientes pasos:

Detalles de producción y proceso, definir el equipo, variables de rendimiento, mapa de proceso actual, medición del desempeño y diseño de un nuevo proceso: herramienta lean, técnicas y mejora continua.

\section{$\underline{\text { Análisis de los resultados }}$}

Los resultados del estudio mostraron que los grandes fabricantes eran más propensos a implementar estas técnicas que los pequeños fabricantes estadounidenses. Aunque algunas de las técnicas proporcionaron mejores resultados dependiendo del tamaño de la empresa, en muchos casos la implementación produjo un aumento en los residuos, el costo y el tiempo de producción de un fabricante (Tiwari, et al., 2007). Debido a la selección inadecuada de estrategias lean, los cambios pueden causar interrupciones en el proceso mismo a mejorar. La 
mayoría de los métodos propuestos no estaban respaldados por la implementación práctica y por lo tanto la validación no podía ser garantizada. La brecha actual exige el desarrollo de una metodología eficaz de implementación de estrategias lean tomando en consideración los principios lean y el contexto organizacional.

An analysis of the status of resource flexibility and lean manufacturing in a textile machinery manufacturing compayny. (Análisis del estado de la flexibilidad de los recursos y la fabricación lean en una compañía de producción de maquinaria textil.)

\section{$\underline{\text { Análisis de la situación actual }}$}

Se ha realizado un estudio detallado de casos en Friends Engineering Works (FEW), ubicado en Sanoli Road, Panipat (Haryana). La empresa se dedica a la elaboración de maquinarias de fabricación textil, telar de potencia semiautomática, telar de pinzas flexible, caja de gota, dobby, jacquard, deformación, bobinadora, telar de yute y accesorios asociados. FEW se estableció en el año 1984 para la reparación y el trabajo de la maquinaria de fabricación de textiles. En cuanto a su capacidad de producción actual, la empresa produce más de 70 telares de energía semiautomática, 70 cajas de caída, 10 dobby, 3 máquinas de urdimbre, 2 jacquards, 2 devanadoras y accesorios por mes.

El trabajo que se llevó a cabo tiene como objetivo analizar minuciosamente las prácticas que se siguen para gestionar la flexibilidad de los recursos (mano de obra y máquinas) y examinar las dificultades y limitaciones que enfrenta la industria mientras implementa el marco FSM (Sushil, 1994) en sus sistemas.

\section{Análisis de la metodología}

Para el presente estudio, se utilizaron los libros Koste et al. (2004) y Soriano-Meier y Forrester (2002). El primero forma la base para la identificación de los factores de flexibilidad de los recursos y el segundo para los factores de lean manufacturing. Además, se seleccionaron diez factores que contribuyen a la flexibilidad laboral, siete factores que contribuyen a la flexibilidad de la maquinaria y nueve factores que contribuyen a la fabricación esbelta. El peso de algunos factores es más que el de los otros y por eso, para determinar sus pesos relativos, se utilizó el proceso de jerarquía analítica visto en (AHP) (Saaty, 1990).

Cada factor se comparó con los otros factores en pares y tres expertos, un gerente industrial, un ejecutivo de producción senior y un académico, fueron elegidos para cubrir las diferentes áreas 
y aumentar la fiabilidad de la AHP. También se utilizó el paradigma de Situación-ActorProceso y Aprendizaje-Actuación-Acción (SAP-LAP) del FSM para analizar el estudio de caso y para desarrollar un conjunto de directrices / aprendizajes (Sushil, 2001). Por último, los problemas de aprendizaje se han sintetizado para desarrollar un sistema que mejore la flexibilidad de los recursos y ayude a lograr la fabricación lean.

\section{$\underline{\text { Análisis de los resultados }}$}

La compañía ha alcanzado un nivel muy bajo de Lean Manufacturing (47,40 \%), además integró con éxito el 77,55\% de las funciones mediante el 60,84\% de equipos multifuncionales, el $40,85 \%$ de JIT, el 44,94\% de extracción de materias primas, el 56,70\% de cero defectos y el 39,07\% de mejora continua para lograr la fabricación. La empresa también fue capaz de eliminar sólo el 39,09\% de residuos del sistema de producción mediante la implementación del 40,29\% de descentralización y el 44,29\% de los sistemas de información vertical.

En conclusión, el presente estudio pone en evidencia el hecho de que es posible planificar la flexibilidad de los recursos manteniendo el Lean Manufacturing en mente. Por lo tanto, se concluye que hay un amplio margen para enfocarse en las estrategias que pueden cambiar positivamente la actitud de los trabajadores hacia el cambio; además, se deben instalar más máquinas que tengan una productividad uniforme incluso en caso de cambio de operaciones y operadores. También hay un amplio margen para lograr un mayor grado de Lean Manufacturing, centrándose en la flexibilidad de los recursos y eliminando diferentes desechos del sistema de fabricación.

Production flow analysis through value stream mapping: a lean manufacturing process case study. (Análisis del flujo de producción a través del mapeo de flujo de valor: un estudio de un caso de proceso aplicando Lean Manufacturing.)

\section{Análisis de la situación actual}

La compañía está implicada en el proyecto de cooperación de las industrias automotrices de Malasia-Japón (MAJAICO) desde 2006. Actualmente SMC ha comenzado con éxito la producción en masa y la entrega del 50\% para Perusahaan Otomobil Kedua Sendirian Berhad (PERODUA) y 50\% para Perusahaan Otomobil Nasional (PROTON). Algunos ejemplos de los componentes del motor producidos incluyen la polea de la bomba de agua, el colector de admisión, el árbol de levas de la tapa, el conjunto del volante, el conjunto del cuerpo del tapón, el conjunto del brazo basculante y el soporte del filtro de aceite. Sin embargo, parte de los 
componentes de la transmisión incluye el conjunto de carril de cambio, la palanca de cambio de marcha atrás y el conjunto de horquilla de liberación del embrague. El componente del freno incluye parcialmente el cubo delantero, el conjunto de la pinza de freno, el tambor de freno y el disco delantero.

Para llevar a cabo todo, la gerencia había seleccionado una orden de producto importante, el montaje delantero del disco nombrado D54T. Después de dos años, el producto Front Disc D54T, SMC no logró su pronóstico de producción diaria. La gerencia propuso el enfoque lean como modo de abordar la cuestión de la eliminación de residuos, para mantener mejor su control de inventario, mejorar la calidad del producto, y capaz de un mejor control operacional.

El objetivo del proyecto era identificar la ventaja potencial de la implementación de lean y desarrollar un mapa de estado futuro agradable. El equipo se centró en tres técnicas de fabricación lean para la nivelación de sus procesos a través de minimizar el proceso de WIP, la mejora del tiempo takt y minimizar el manejo para eliminar o al menos reducir el tiempo de cambio / manipulación.

\section{Análisis de la metodología}

El VSM es una herramienta eficaz para la práctica de Lean Manufacturing. El VSM se aplicó a todo el flujo del proceso en un método de tres pasos en la que primero está la elaboración de un diagrama que muestra el material real y los flujos de información o estado actual sobre cómo funciona el proceso real y se crea mientras se camina por la línea de producción. En segundo lugar, se produce un mapa del estado futuro para identificar las causas profundas de los desechos y mediante mejoras en el proceso que podrían dar un gran impacto financiero al proceso, un flujo de proceso deficiente.

Estas mejoras se llevan a cabo, se realizó un plan de implementación como parte y se corrigieron detalles parciales para obtener los objetivos del proyecto, también se aplicó kaizen (mejora continua) y poka-yoke. El mapa de un flujo de valor simple es un ejemplo de mapa de flujo de material.

El SMC y el equipo kaizen estudiaron el mapa del estado actual en la línea de montaje D45T. Luego, un conjunto de actividades kaizen se iniciaron y fueron implementadas en un esfuerzo por optimizar la productividad de la línea de montaje. El proceso de montaje es monitoreado y durante la fase de monitoreo se hace una evaluación continua de cualquier discrepancia o 
imperfección en el producto. Se hacen las contramedidas necesarias para asegurar la efectividad del nuevo VSM del estado futuro y de esta manera se logra aumentar la productividad de la línea.

Análisis de los resultados

Después de realizar el estudio se determinó que el uso del VSM mejoró el enfoque en las iniciativas Lean Production, ya que reveló residuos obvios y ocultos que afectaron la productividad de la producción D45T. Además, hubo una cantidad significativa de tiempo en que los productos gastados en el sistema de producción usualmente estaban esperando y sin valor agregado. La evidencia cuantitativa mostró que muchas de las herramientas lean tienen un impacto esperado relacionado con la reducción de este tiempo de espera. La evaluación de estas mejoras mediante el uso de la evaluación del tiempo de ciclo pone en evidencia el impacto económico de las mejoras de tiempo.

Por otro lado, el VSM aplicado para evaluar el impacto esperado de un cambio en el proceso de producción dio como resultado ahorros (tasas de rechazo más bajas), y en cierta medida, una visión positiva debido al hecho de que había brechas sustanciales entre el trabajo estandarizado y el trabajo real; lo que significaba que los trabajadores no seguían estrictamente los estándares de montaje y la improvisación del SOP podría ser un factor clave en la sostenibilidad de la mejora continua en la planta de producción, ya que los operadores son plenamente conscientes del compromiso a largo plazo para las practicas lean.

\section{NORMATIVAS.}

En el sector en estudio se identifican 3 normas relacionadas al proceso de compras:

- NTP ISO 3635:2009 DESIGNACION DE TALLA PARA PRENDAS DE VESTIR, trata sobre las definiciones y procedimientos de medición del cuerpo humano. Define las dimensiones del cuerpo y el procedimiento de medición del cuerpo humano. Se aplica para las prendas de vestir de hombres, mujeres y niños.

- NTP 243.019:1985 (revisada el 2011) CONFECCIONES, trata sobre los requisitos de las camisetas de algodón en crudo, descrudadas o blanqueadas, para su uso como ropa interior o exterior. No especifica el aspecto general, el grado de blancura, el lustre ni la suavidad de las camisetas. 
- NTP 231.105:1981 (Revisada el 2010) HILOS Y FIBRAS TEXTILES, trata sobre el establecimiento de métodos para determinar la masa comercial de un embarque de hilos y fibras textiles.

Además, es importante mencionar que se toma como referencia para el desarrollo del diseño de la propuesta las directrices, los principios y normativas establecidas en la ISO 9001.

\section{ISO 9001 APLICADA EN COMPRAS}

El proceso de compras queda en mayor medida en manos de terceros, la norma ISO 9001, establece la necesidad de articular los mecanismos internos necesarios para garantizar que el proceso de compras se realiza de manera satisfactoria, desde la emisión del pedido hasta la recepción del producto o servicios suministrados, por tanto en este proyecto de investigación tomará como base los requisitos de la norma mencionada para ser aplicado tanto en las actividades del proceso y en la selección y acuerdos con los proveedores (Global O2, 2013).

Requisitos:

1. Evaluación periódica de proveedores y subcontratistas, de manera que se asegure la capacidad para cumplir con los requisititos de compras, por ello es importante definir:

- Criterios objetivos

- Criterios relacionados con la calidad del producto/servicio.

2. Reevaluación periódica de proveedores y subcontratistas.

- El resultado de esta reevaluación debe ser informado a las personas implicadas en el proceso de compras.

3. La identificación y comunicación constante de requisitos del producto con el proveedor.

- Lugar de entrega

- Cantidad

- Transporte/Almacenamiento

4. Definir criterios de aceptación y rechazo en recepción.

5. En caso que el servicio suministrado se realice en las instalaciones del proveedor se debe comunicar el método de verificación de la información de compra. 
6. Establecer mecanismos de la gestión de incidencias que pueden producirse en el proceso de compras, analizando las causas y estableciendo las acciones pertinentes para evitar su repetición.

\section{APLICACIÓN DE LEAN MANUFACTURING EN EL SECTOR TEXTIL.}

En la era actual de competencia feroz, las organizaciones manufactureras hacen implacables esfuerzos para mejorar su rendimiento para la supervivencia exitosa (Hokoma et al., 2008). El sector textil viene sufriendo un impacto trascendental debido a la competitividad mundial, por ende, requieren evaluar sus procesos productivos con el fin de permanecer en el mercado cada vez más competitivo.

En la actualidad, el sector contribuye representativamente a la economía del país mediante las confecciones textiles que realizan y exportan a diferentes partes del mundo. Sin embargo, con los diferentes cambios en la industria y las tendencias que se presentan hoy en día es necesario evaluar y mejorar los procesos productivos mediante la aplicación de diferentes metodologías.

Una variedad de conductores tiene un impacto en la manufactura, incluyendo el aumento de la competencia, presiones, clientes más exigentes, ciclos de vida del producto más cortos, mercado y la llegada de un gran número de tecnologías que permiten el manejo de costos, la calidad y la eficiencia de los activos, pero otras métricas, como la agilidad, flexibilidad y rapidez al mercado, se han vuelto críticas. La manufactura esbelta es algo más que simplemente reducir costos en la fábrica (Chauhan, 2016) .

Las PYMES se enfrentarán a dificultades en la implementación de todas las prácticas de LM debido a cuatro posibles limitaciones: el liderazgo, la experiencia financiera, experiencia lean y la cultura de organización (Achanga et al., 2006). Por lo tanto, uno de los esfuerzos que podrían hacer las PYMES es implementar prácticas seleccionadas que sean viables para la capacidad de su empresa (Rose et al., 2013).

Lean Manufacturing es una filosofía de producción que tiene mucho que ver en este sector, debido a que considera que cualquier actividad que consuma recursos, pero no crear valor para el cliente final, deben ser eliminados (Womack et al, 1990; Shah y Ward, 2007; Antony, 2011). Según Sohal (1996), Lean Manufacturing elimina procesos innecesarios, alinea procesos en flujo continuo y resuelve problemas a través de procesos continuos por lo que resolvería los problemas del sector mediante la implementación de herramientas de Lean. 


\section{GESTIÓN DE COMPRAS.}

El aprovisionamiento incluye al proceso de compras, que consiste en adquirir los suministros, insumos y servicios de proveedores en las cantidades, momento y tiempo adecuado, para el desarrollo de las operaciones y la generación de ventajas competitivas sostenibles relacionadas con el desempeño financiero de la empresa y la capacidad de respuesta a clientes internos y externos (Chen et al., 2004).

Un fabricante debe determinar y gestionar su estrategia de compra sobre la base de su estrategia de negocio y una comprensión profunda de sus productos (Watts et al., 1995) y sus componentes (Drake y Lee, 2009) para lograr "compras estratégicas" (Drake et al., 2013).

La gestión logística suele impactar en la eficiencia y eficacia de los procesos empresariales, ya que los centros de abastecimiento suelen ubicarse en lugares lejanos a los centros de transformación, comercialización y consumo; por lo cual se hace necesario planificar, controlar y mejorar los procesos logísticos, buscando un adecuado uso de recursos, reducción de costos de operación y cumplimiento de los volúmenes de producción que demanda el mercado (Arango, 2009).

Las compras ejercen un rol estratégico y requiere una adecuada gestión en las organizaciones, debido a que pueden representar entre el $40 \%$ y $60 \%$ del valor de las ventas del producto final, y por estos motivos una pequeña reducción en esos costos puede conllevar a un aumento de la eficiencia y rentabilidad de las empresas (Grzybowska y Gajdzik, 2014). Dentro de las actividades del proceso de compras, se resalta la importancia de evaluar y seleccionar proveedores, debido a que allí se genera la decisión de crear relaciones entre las empresas y agentes externos, los cuales deben garantizar la entrega de referencias, cantidades, calidad y tiempos pactados (Pagell, 2004; Ho et al, 2010). Por su parte, Zheng et al, (2007) describe el impacto estratégico del aprovisionamiento en la productividad y competitividad de las empresas de diferentes sectores empresariales, demostrando cómo las compras de productos de mala calidad generan ineficiencias y sobrecostos en los procesos logísticos. De la misma manera, Dudek y Satdler (2005), plantean que un enfoque de planificación colaborativa y de negociación de manera centralizada, sería demasiado complejo a la hora de implementarlo. La coordinación "Aguas arriba" entrega resultados que no son los mejores. Estos autores proponen un modelo de negociación entre proveedor y comprador basado en contratos, programación matemática y soluciones basadas en agentes (Ramos et al., 2015). 
- Las funciones de la gestión de aprovisionamiento:

- Adquirir los materiales necesarios para la elaboración o comercialización de productos.

- Gestionar el almacenaje de los productos, manteniendo los stocks mínimos de cada material.

- Controlar los inventarios y los costes asociados a los mismos.

- Los objetivos del aprovisionamiento son:

- Calcular las necesidades de la empresa logrando un inventario suficiente para que la producción no carezca de materias primas y demás suministros.

- Minimizar la inversión en inventarios.

- Establecer un sistema de información eficiente (Casanovas, 2011).

- Beneficios que proporciona la gestión adecuada de la cadena de suministro.

- Mejora de la calidad: Cuando los problemas potenciales se identifican y abordan rápidamente en un proceso, habrá un mínimo de reelaboración en el sistema y una mejora máxima en la calidad general del producto final.

- Aumento de la productividad: Con la aplicación de técnicas Lean, se permite a las empresas producir más con los recursos disponibles y erradicar las actividades sin valor añadido.

- Mejora de la satisfacción del cliente: entregan productos de calidad a sus clientes antes de lo solicitado. Aumentar la satisfacción del cliente puede lograrse reduciendo los plazos de entrega en hasta un $90 \%$ y aumentando la entrega temprana a cerca del $100 \%$.

- Costos operativos reducidos: A través de la mejora de la calidad, la satisfacción del cliente y la productividad, las organizaciones que operan de manera Lean pueden reducir sustancialmente el costo de las operaciones (Fourie y Umeh, 2017).

\section{IMPACTO EN LAS COMPRAS DE LOS PRODUCTOS TEXTILES.}

De acuerdo con Kotler y Amstrong, hoy en día las empresas tienen que gestionar las relaciones con los clientes de manera rentable. Sin embargo, el entorno competitivo y las crecientes expectativas de los clientes obligan a las empresas a buscar nuevos métodos y herramientas de 
creación de valor para los clientes. Los principios y modelos del marketing tradicional se han vuelto insuficientes y deben completarse con nuevas soluciones experimentales. En el mercado textil las empresas pueden desarrollar tecnologías, introducir nuevos productos, proponer una estrategia de distribución atractiva y utilizar nuevas herramientas de comunicación (Grębosz y Wrońska, 2013).

Mejorar el desempeño de la innovación es esencial para el crecimiento de la productividad en la industria. Por lo tanto, se deben emprender actividades innovadoras para mejorar el rendimiento de la industria. Es crucial para crear condiciones óptimas dentro y fuera de la empresa, y para encontrar e implementar soluciones innovadoras que se corresponden con los retos actuales en la empresa o la industria (Pawęta y Mikołajczyk 2016). En el Oslo Manual mencionan que, la innovación es la implementación de un producto nuevo o significativamente mejorado (bueno o servicio), un proceso, un nuevo método de marketing, o un nuevo método de organización en las prácticas comerciales, la organización del lugar de trabajo o las relaciones externas.

De la misma manera, las empresas también pueden utilizar algunas soluciones experimentales propuestas por el marketing sensorial. El marketing sensorial podría ser de suma importancia para los minoristas ya que, se encontró que los estímulos tenían un estado de sentimiento y compra del consumidor por comportamientos (Pawęta y Mikołajczyk 2016).

\section{MARCO TEÓRICO}

\section{CONCEPTOS BÁSICOS Y DEFINICIONES.}

\section{PYMES.}

Definición:

Al momento de definir el término PYME, no se llega a una definición absoluta, debido a que ésta sufre de variantes dependiendo al país que la cite y el enfoque que se le dé. Las diferencias se presentan cuando se habla acerca del número de trabajadores que la deben componer y el monto de facturación anual que debe tener para estar considerada dentro del rango pequeña o mediana empresa (Visa empresarial, 2013).

La legislación peruana define a la PYME (Pequeña y Mediana Empresa) como: “...la unidad económica constituida por una persona natural o jurídica, bajo cualquier forma de organización 
o gestión empresarial contemplada en la legislación vigente, que tiene como objeto desarrollar actividades de extracción, transformación, producción, comercialización de bienes o prestación de servicios (...) debiendo contar con las siguientes características (Ver Tabla 1):

Características:

Pequeña empresa:

- Número total de trabajadores de (11) hasta un máximo de cincuenta (50).

- Niveles de ventas anuales entre 150 y 1700 UIT.

- Medianas empresas:

- Número total de trabajadores de (51) hasta un máximo de (250).

- Niveles de ventas anuales superiores a 1700 hasta 2300 UIT (Instituto Nacional de Estadística e Informática, 2015).

Tabla 1. Segmento empresarial por Unidad Impositiva Tributaria.

\begin{tabular}{|lc|}
\hline \multicolumn{1}{|c|}{ Segmento empresarial } & $\begin{array}{c}\text { Unidades Impositivas } \\
\text { Tributarias (UIT) }\end{array}$ \\
\hline Microempresa & Hasta 150 \\
\hline Pequeña empresa & Mayor de 150 hasta 1700 \\
\hline Mediana empresa & Mayor de 1700 hasta 2300 \\
\hline Gran empresa & Mayor de 2300 \\
\hline
\end{tabular}

Fuente : Sunat - Año 2016

Si bien no existe un consenso mundial en cuanto a la definición de PYME, sí existe un objetivo en común sobre ellas, el cual consiste en brindar oportunidades de trabajo a gran parte de la población, lo cual ayuda a combatir la pobreza y las tasas de desempleo (Visa empresarial, 2013). (Ver Tabla 2) 
Pequeña empresa:

Tabla 2. Características de la Pequeña empresa

\begin{tabular}{|c|}
\hline PEQUEÑA EMPRESA \\
\hline Remuneración Mínima Vital (RMV) \\
\hline Jornada de trabajo de 8 horas \\
\hline Descanso semanal y en dias feriados \\
\hline Remuneración por trabajo en sobretiempo \\
\hline Descanso vacacional de $\mathbf{1 5}$ días calendarios \\
\hline $\begin{array}{c}\text { Cobertura de seguridad social en salud a través } \\
\text { del ESSALUD }\end{array}$ \\
\hline Cobertura Previsional \\
\hline $\begin{array}{l}\text { Indemnización por despido de } 20 \text { días de } \\
\text { remuneración por año de servicios (con un } \\
\text { tope de } 120 \text { días de remuneración) }\end{array}$ \\
\hline $\begin{array}{l}\text { Cobertura de Seguro de Vida y Seguro } \\
\text { Complementario de trabajo de Riesgo (SCTR) }\end{array}$ \\
\hline $\begin{array}{c}\text { Derecho a percibir } 2 \text { gratificaciones al año } \\
\text { (Fiestas Patrias y Navidad) }\end{array}$ \\
\hline $\begin{array}{c}\text { Derecho a participar en las utilidades de la } \\
\text { empresa }\end{array}$ \\
\hline $\begin{array}{l}\text { Derecho a la Compensación por Tiempo de } \\
\text { Servicios (CTS) equivalente a } 15 \text { dias de } \\
\text { emuneración por año de servicio con tope de } 90 \\
\text { días de remuneración. }\end{array}$ \\
\hline $\begin{array}{l}\text { Derechos colectivos según las normas del } \\
\text { Régimen General de la actividad privada. }\end{array}$ \\
\hline
\end{tabular}

Fuente : Sunat - Año 2017

\section{BPMN (Business Process Modeling Notation).}

\section{Definición}

Un modelo y notación de proceso de negocio estándar que proporciona a las empresas la capacidad de entender sus procedimientos internos de negocio en una notación gráfica y les da a las organizaciones la capacidad de comunicar estos procedimientos de una manera estándar. Además, la notación gráfica facilita la comprensión de las colaboraciones de desempeño y las transacciones comerciales entre las organizaciones. Esto asegura que las empresas se comprendan a sí mismos y los participantes en su negocio y permite a las organizaciones para adaptarse a circunstancias internas.

Características:

- Proporciona un lenguaje gráfico común, con el fin de facilitar su comprensión a los usuarios de negocios.

- Integra las funciones empresariales. 
- Utiliza una Arquitectura Orientada por Servicios (SOA), con el objetivo de adaptarse rápidamente a los cambios y oportunidades del negocio.

- Combina las capacidades del software y la experiencia de negocio para optimizar los procesos y facilitar la innovación del negocio.

En la Figura 1, se presenta el ejemplo de modelo utilizado en el presente trabajo.

Figura 1. Modelo de BPMN

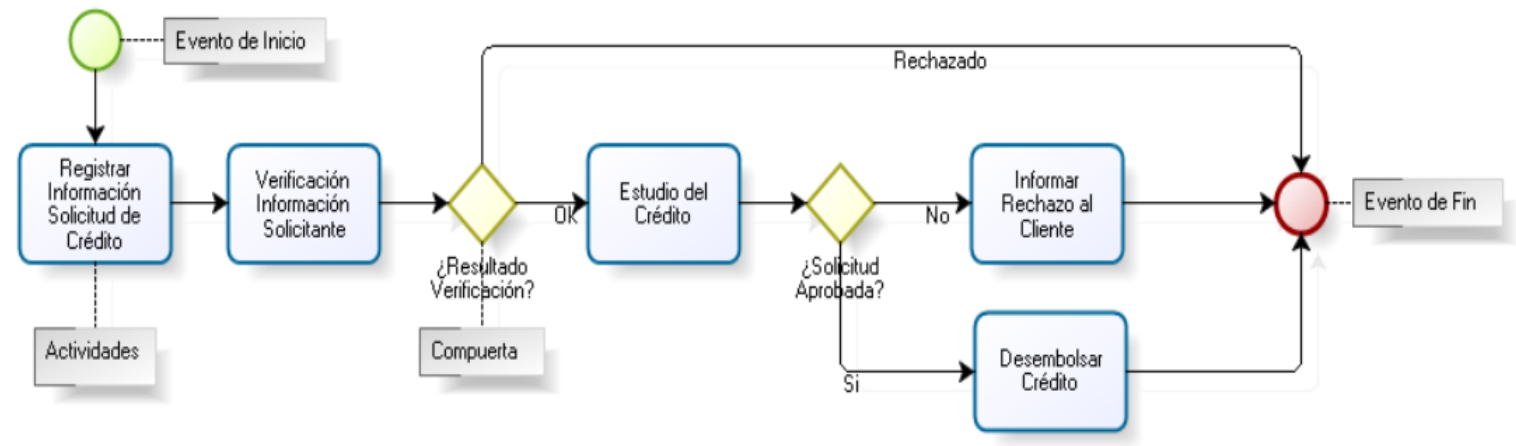

Fuente : Bizagi Process Modeler

Dentro del diagrama existe un conjunto de elementos gráficos que permite realizar la presentación gráfica. A continuación, se detalla cada uno de esto elementos que describen el comportamiento del proceso.

- Actividades; que representan el trabajo realizado.

- Eventos; indican el inicio y el fin del proceso.

- Elementos de decisión; conocidos como compuerta que indican una división en el camino.

- Líneas de secuencia; que conectan a los elementos y muestra como fluye el proceso (Manual Bizagi Process Modeler, 2009).

\section{DIAGRAMA SIPOC.}

Definición:

SIPOC significa Proveedores, Entradas, Procesos, Productos y Clientes. El análisis SIPOC es una metodología para la mejora de procesos empleando análisis basados en la representación 
esquemática de elementos clave de un proceso, a saber, Proveedores, Entradas del proceso, Proceso en sí, Resultados del proceso y Clientes (receptores del proceso) (Kumar, 2011).

- Supplier (Proveedor): Las organizaciones y departamentos que proporcionan los procesos principales con información clave, materiales u otros recursos.

- Input (Entrada): Los recursos provistos por los proveedores y restringidos en forma de indicadores, es decir, los requerimientos de este departamento para los departamentos anteriores.

- Process (Proceso): Un conjunto de actividades que hacen que el cambio de entrada y convertir en salida, a través del cual la organización busca hacer que la entrada agregue valor.

- Output (Salida): La salida del proceso es productos o servicios, y restringida en forma de indicadores, es decir, los requisitos de los departamentos posteriores para este departamento.

- Customer (Cliente): Persona, organización o proceso que recibe la salida. No sólo se refiere al cliente externo, sino que también incluye al cliente interno. Por ejemplo, el cliente interno del departamento de compras es el departamento de producción y el cliente interno del departamento de producción es el departamento de gestión de calidad.

El uso de SIPOC se utiliza para analizar la relación sinérgica entre los departamentos ascendente y descendente y consiste principalmente en identificar las funciones de este departamento a través de una relación tan lógica como "proveedor interno". Proporcionan mayor énfasis en una mejor cooperación entre los departamentos que puede traer el cumplimiento de los beneficios integrados óptimos (CAO, 2015).

Pasos para la realización del SIPOC (Technologies Group, 2015)

- Identificar el proceso y sus límites.

- Identificar las salidas.

- Identificar los clientes para cada salida.

- Hacer una lista de requerimientos para cada salida.

- Identificar entradas, 
- Identificar proveedor para cada entrada.

- Hacer una lista de requerimiento para cada entrada.

En la Figura 2, se muestra el modelo del diagrama que se utiliza en esta investigación.

Figura 2. Modelo de SIPOC

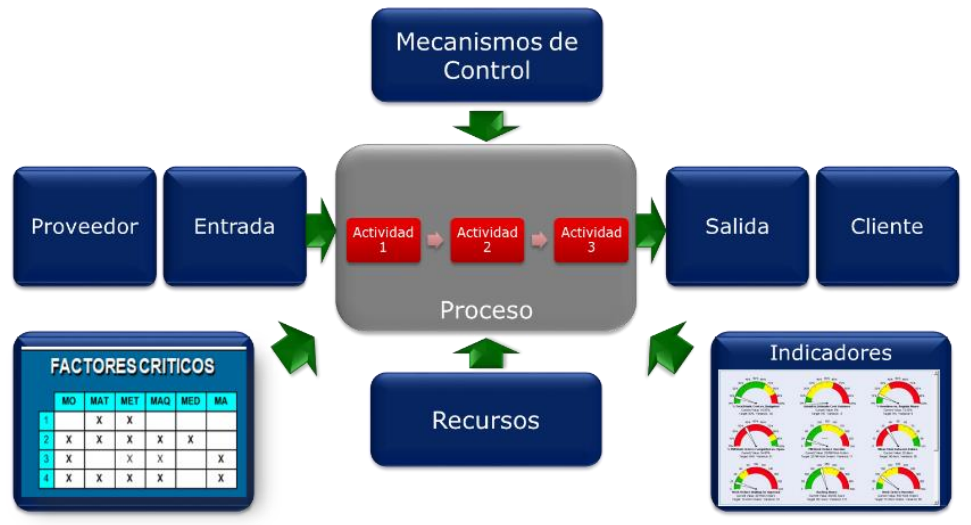

Fuente : Material de clase UPC - Gestión por Procesos

\section{COMPETITIVIDAD.}

Definición:

Según Porter (2007), la competitividad de una nación depende de la capacidad de su industria para innovar y perfeccionarse. Las empresas obtienen ventajas frente a los mejores competidores del mundo debido a la presión y el desafío. Se benefician de tener rivales domésticos fuertes, proveedores nacionales agresivos y clientes locales exigentes. Las relaciones que establecen las empresas con sus competidores directos, con sus proveedores y clientes dentro de un mercado, y las que construyen con otros agentes gubernamentales y no gubernamentales en una región, pueden ser fuentes para la creación de ventaja competitiva para ésta. El autor menciona 4 factores que permiten desarrollar y conservar la ventaja competitiva de la empresa, estas son:

- La eficiencia: Un negocio por lo general se encarga de transformar insumos en productos y los insumos son factores básicos de producción. En este sentido, la eficiencia es la cantidad de insumos que se necesitan para producir un producto determinado. En la medida en que la empresa requiera menos insumos para producir un producto será más eficiente. 
- La calidad: La calidad de un producto se ve reflejada en el nivel de satisfacción que este da al cliente final. Un producto es de calidad cuando los clientes perciben que sus atributos le proporcionan mayor utilidad que la de su competencia.

- La innovación: Se refiere al acto de crear nuevos productos e implementarlos en el mercado. Estos productos pueden surgir de la mejora de un producto o ser algo novedoso que responde a una necesidad latente en la sociedad.

- La capacidad de respuesta al cliente: Las empresas pueden hacer mejor su trabajo de tal manera que ello se vea reflejado en lograr una mayor capacidad de respuesta por parte del cliente. También, influye la necesidad de adaptar bienes y servicios a las demandas únicas de los clientes individuales o grupos de clientes para lograr la respuesta del cliente.

- Según el World Economic Forum (WEF), en su "Informe Global de Competitividad (WEF- IGC 2016-2017)" el Perú, se ubica en el puesto 67. Sube 2 posiciones respecto al informe anterior. Mantenemos la tercera posición a nivel países de Sudamérica detrás de Chile y Colombia (Véase Figura 3) y continuamos en la sexta posición entre los países de Latinoamérica y el Caribe. Mejoramos en 6 de los 12 pilares: Instituciones (116 a 106), Salud y Educación Básica (100 a 98), Educación Superior y Capacitación (82 a 80), Eficiencia del Mercado laboral (64 a 61) Sofisticación de mercados financieros (30 a 26), Preparación Tecnológica (92 a 88), Sofisticación empresarial (81 a 78).

Figura 3. Posiciones por países por Competitividad Empresarial

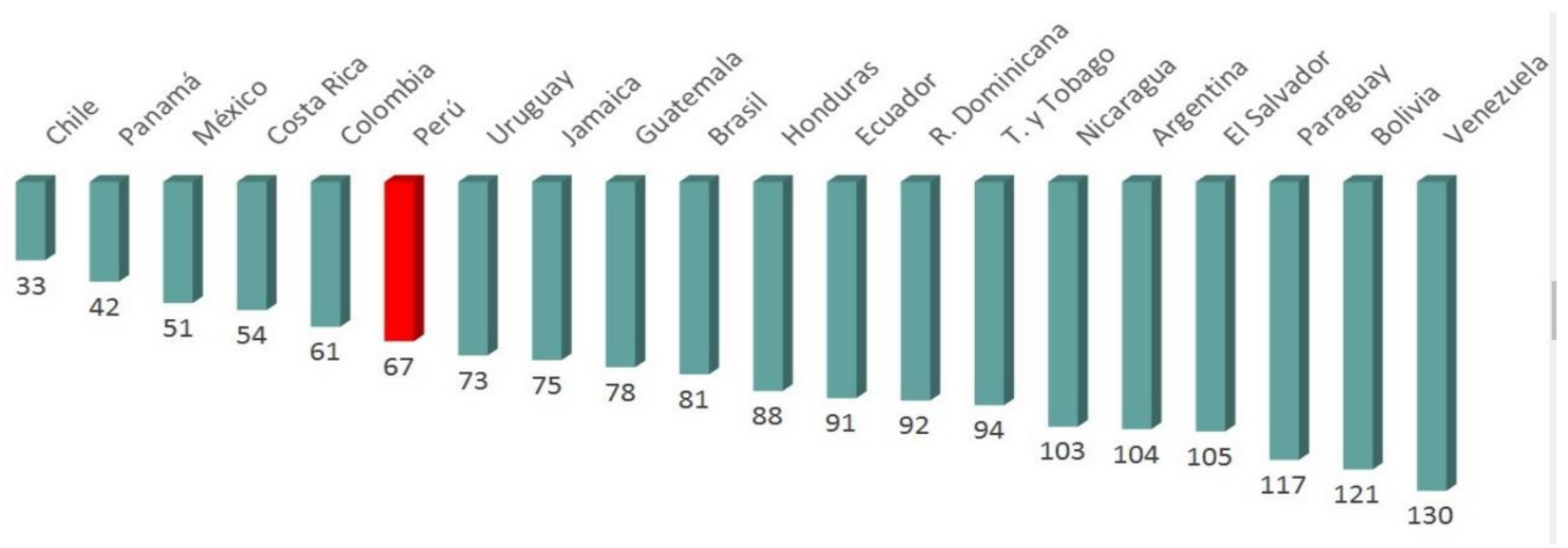

Fuente : World Economic Forum (WEF) 


\section{MATRIZ LEOPOLD.}

\section{Definición:}

La matriz de Leopold es una de las matrices de interacción más conocidas, la eficacia de este método se destaca mejor en combinación con otros métodos que estudian el impacto. Popescu $(2007,72)$ muestra que generalmente "la matriz de impacto representa una tabla de entrada doble que permite la visión gráfica unitaria de las relaciones entre las diferentes categorías de elementos que interfieren en un proceso de evaluación del impacto sobre el medio ambiente". El método sugiere que en cada una de las celdas que corresponden a estas posiciones, debe dibujarse una diagonal, de modo que se pueda presentar información diferente, con respecto a: la amplitud de la interacción observada y la importancia de esta interacción (Neacsu y Patrau, 2014).

La elección de un modelo de toma de decisiones enfrenta el reto de presentar adecuadamente los procesos naturales dinámicos, espaciales, distributivos y no lineales (Hwang y Masud, 1979), con numerosas preguntas complejas para las cuales los tomadores de decisiones no pueden proporcionar respuestas precisas y completas. En la situación en la que se requiere un enfoque holístico, es aconsejable utilizar el modelo más simple disponible que pueda generar el resultado solicitado (Kicošev et al., 2015).

La Matriz Leopold permite evaluar en cada interacción dos dimensiones: magnitud e importancia. (Ver Figura 4)

- Magnitud: Esta dimensión permite valorar el grado del impacto o de la alteración potencial que puede ser provocada.

- Importancia: Permite valorar el nivel de significancia del potencial impacto, es decir, en qué medida es importante el impacto para cada interacción. Para fines del trabajo de investigación, se ha visto conveniente utilizar las siguientes escalas para la magnitud del impacto: 
Figura 4. Formato de la Matriz de Leopold a utilizar

\begin{tabular}{|c|c|c|c|c|c|}
\hline & & & & & \\
\hline & & Model 1 & Model 2 & Model $n$ & TOTAL \\
\hline \multirow{3}{*}{ Skateholders 1} & Aspecto 1 & & & & \\
\hline & Aspecto 2 & & & & \\
\hline & Aspecto 3 & & & & \\
\hline \multirow{3}{*}{ Skateholders 2} & Aspecto 1 & & & & \\
\hline & Aspecto 2 & & & & \\
\hline & Aspecto 3 & & & & \\
\hline \multirow{4}{*}{ Skateholders n } & Aspecto 1 & & & & \\
\hline & Aspecto 2 & & & & \\
\hline & Aspecto 3 & & & & \\
\hline & TOTAL & & & & \\
\hline
\end{tabular}

Fuente : Elaboración Propia basada en Universidad Nacional de Río Negro- Año 2013

\section{ENFOQUE DE LEAN MANUFACTURING.}

\section{Lean Manufacturing.}

Lean se compone de una serie de principios, conceptos y técnicas diseñadas para eliminar el despilfarro y establecer un sistema de producción eficiente, justo a tiempo, que permite realizar entregas a los clientes de los productos requeridos, cuando son requeridos, en la cantidad requerida, en la secuencia requerida y sin defectos.

"Lean Manufacturing (LM) es una disposición de técnicas y actividades para dirigir una industria de producción o una operación de servicio. Dependiendo de la aplicación, las técnicas y actividades difieren respectivamente en consecuencia. Sin embargo, tienen el mismo principio básico: eliminación de todas las actividades sin valor añadido y los residuos de la empresa (...)"

Rahani y Muhammad (2012:1727) 
El objetivo de Lean Supply es proporcionar productos de buena calidad a bajo precio, centrándose en la eliminación de residuos, mientras que la oferta ágil tiene como objetivo proporcionar una respuesta rápida y flexible a las necesidades más variables de los clientes centrándose en el tiempo de entrega y el nivel de servicio (Naylor et al. Robertson y Jones, 1999) (Agarwal et al., 2006) (Zhang y Sharifi, 2007) (Drake et al.,2013).

\section{Principios de Lean Manufacturing.}

Valor desde el punto de vista del cliente

Es el valor que se agrega a un proceso o a los niveles de satisfacción de un cliente, se considera que algo tiene valor cuando el cliente está dispuesto a pagar por ello.

\section{- Cadena de Valor}

Este representa cada paso desde el inicio hasta el final del proceso, donde se identifica cuáles son los pasos que no agregan valor al proceso y los residuos, en lo posible estos deben ser eliminados. Cada paso del proceso debe agregar valor al producto, este no necesariamente es monetario, pero debe ser algo que el cliente desea o está dispuesto a pagar.

- Flujo del producto

Este principio se basa en la idea de que el producto debe fluir a través de cada proceso. Cada vez que el producto se detiene, el flujo se interrumpe y trae consigo sobrecostos y tiempo extra.

\section{- Procesos "Pull"}

Producir por órdenes del cliente. El objetivo de este proceso es producir solo lo que el cliente quiere, si el fabricante intenta adelantarse a la demanda, entonces existe la posibilidad de que se fabrique más productos de los que se va a vender, en consecuencia, se generan costos extra como almacenamiento, control de materiales y de mano de obra.

- Persecución de la perfección

Este es el objetivo en cada proceso de mejora, por ello aquellos procesos o actividades que proporcionan mayor beneficio a la producción deben ser priorizados, este se basa en la eficiencia del proceso para tener cero defectos (Borris, 2012). 


\section{Desperdicios.}

El desperdicio es todo recurso como material, equipo, mano de obra, instalación, tiempo del empleado que no es necesario o no contribuye en el proceso de manufactura o transformación a generar los atributos deseados por el cliente, a lo que llama valor del producto. Como principal fuente de desperdicios se han identificado la sobreproducción, las esperas, el transporte, el procesamiento inadecuado, movimientos innecesarios del personal y exceso de inventarios de materias primas, productos en proceso y productos terminados (Pérez, 2007).

\section{SOBREPRODUCCION}

El desperdicio por sobreproducción es el resultado de fabricar más cantidad de la requerida o de invertir o diseñar equipos con mayor capacidad de la necesaria. La sobreproducción es un desperdicio crítico porque no incita a la mejora, ya que parece que todo funciona correctamente. Además, producir en exceso significa perder tiempo en fabricar un producto que no se necesita para nada, lo que representa claramente un consumo inútil de material que a su vez provoca un incremento de los transportes y del nivel de los almacenes (EOI, 2013).

\section{ESPERA}

Tiempo en el cual operadores o máquinas se quedan parados esperando los elementos requeridos para completar una tarea (información, materiales, insumos, documentos, firmas, etc.) (Borda, 2012). El desperdicio por tiempo de espera es el tiempo perdido como resultado de una secuencia de trabajo o un proceso ineficiente. Los procesos mal diseñados pueden provocar que unos operarios permanezcan parados mientras otros están saturados de trabajo. Por ello, es preciso estudiar a conciencia cómo reducir o eliminar el tiempo perdido durante el proceso de fabricación (EOI, 2013).

\section{TRANSPORTE INNECESARIO}

El desperdicio por transporte es el resultado de un movimiento o manipulación de material innecesario. Las máquinas y las líneas de producción deberían estar lo más cerca posible y los materiales deberían fluir directamente desde una estación de trabajo a la siguiente sin esperar en colas de inventario. En este sentido, es importante optimizar la disposición de las máquinas y los trayectos de los suministradores. Además, cuantas más veces se mueven los artículos de un lado para otros mayores son las probabilidades de que resulten dañados (EOI, 2013). 


\section{SOBRE PROCESAMIENTO}

Cualquier esfuerzo o tiempo gastados y que no añada valor a la Cadena de Valor. Duplicación de pruebas sin un propósito claramente definido, recolectar más datos de los necesarios, etc. (Borda, 2012).

\section{INVENTARIOS}

El despilfarro por almacenamiento es el resultado de tener una mayor cantidad de existencias de las necesarias para satisfacer las necesidades más inmediatas. El hecho de que se acumule material, antes y después del proceso, indica que el flujo de producción no es continuo. El mantenimiento de almacenes permite mantener los problemas ocultos, pero nunca los resuelve (EOI, 2013).

\section{MOVIMIENTOS INNECESARIOS}

Cualquier desplazamiento de personas (en la búsqueda de materiales o información) o equipamiento que no agregue valor al producto o servicio. Esto se debe estaciones de trabajo mal diseñadas, etc. Este desperdicio provoca cansancio en el operario, por lo tanto, la eficiencia disminuye y además puede ocasionar problemas de salud en el trabajador.

\section{Producto Defectuosos}

El despilfarro derivado de los errores es uno de los más aceptados en la industria, aunque significa una gran pérdida de productividad porque incluye el trabajo extra que debe realizarse como consecuencia de no haber ejecutado correctamente el proceso productivo la primera vez. Los procesos productivos deberían estar diseñados a prueba de errores, para conseguir productos acabados con la calidad exigida, eliminando así cualquier necesidad de retrabajo o de inspecciones adicionales. También debería haber un control de calidad en tiempo real, de modo que los defectos en el proceso productivo se detecten justo cuando suceden, minimizando así el número de piezas que requieren inspección adicional y/o repetición de trabajos (EOI, 2013).

\section{Herramientas de la filosofía Lean Manufacturing}

\section{JUST IN TIME}

Definición 
"Just in Time", quiere decir Justo a Tiempo, es una filosofía que define la forma en que debería optimizarse un sistema de producción y está orientado a la demanda.

Se trata de entregar materias primas o componentes a la línea de fabricación de forma que lleguen justo a tiempo a medida que se necesitan en el proceso. De esta manera, la empresa adquiere la capacidad para entregar al mercado el producto solicitado, en un tiempo breve, en la cantidad requerida, evitando los costos que no producen valor añadido, también se obtendrán precios competitivos. (Ver Tabla 3)

Tabla 3. Ejemplo de problemas y soluciones JIT

\begin{tabular}{|c|c|c|}
\hline Problema (rocas) & SOLUCIÓN TRADICIONAL & SOLUCión JIT \\
\hline - Máquina poco fiable & - Stock de seguridad grande & - Mejorar la fiabilidad \\
\hline - Zonas con cuellos de botella & $\begin{array}{l}\text { - Programación mejor y más } \\
\text { compleja }\end{array}$ & $\begin{array}{l}\text { - Aumentar la capacidad } \\
\text { y la polivalencia de los } \\
\text { operarios y máquinas }\end{array}$ \\
\hline - Tamaños de lote grandes & - Almacenar & $\begin{array}{l}\text { Reducir el tiempo de } \\
\text { preparación }\end{array}$ \\
\hline - Plazos de fabricación largos & $\begin{array}{l}\text { - Acelerar algunos pedidos en } \\
\text { base a prioridades }\end{array}$ & $\begin{array}{l}\text { Reducir esperas, etc., } \\
\text { mediante sisterna de } \\
\text { arrastre }\end{array}$ \\
\hline - Calidad deficiente & - Aumentar los controles & $\begin{array}{l}\text { - Mejorar los procesos y/o } \\
\text { proveedores }\end{array}$ \\
\hline
\end{tabular}

Fuente : Universitat de Barcelona - Año 2012

Aplicación

La aplicación del JIT se puede dividir en 5 fases (Universitat de Barcelona, 2012):

Primera fase: Cómo poner el sistema en marcha

Se establecen las bases sobre las que se construye la aplicación, para ello se exige un cambio en la actitud de la empresa y se considera el compromiso, análisis de coste y beneficio, selección del equipo del proyecto e identificar la planta piloto.

Segunda fase: Mentalización, clave del éxito

Implica la educación del personal, acerca de la aplicación de la metodología en la industria, de tal manera que los empleados empiecen a aplicar la metodología en sus puestos de trabajo.

Tercera fase: Mejorar los procesos

Se refiere a cambios físicos del proceso de fabricación que mejoraran el flujo de trabajo. 
Los cambios de proceso tienen tres formas principales:

- Reducir el tiempo de preparación de las máquinas.

- Mantenimiento preventivo.

- Cambiar a líneas de flujo.

Cuarta fase: Mejoras en el control

La forma en que se controle el sistema de fabricación determinará los resultados globales de la aplicación del JIT. El principio de la búsqueda de la simplicidad proporciona la base del esfuerzo por mejorar el mecanismo de control de fabricación:

- Sistema tipo arrastre.

- Control local .

- Control estadístico de procesos.

- Calidad en el origen.

Quinta fase: Relación cliente- proveedor

Esta fase inicia en paralelo con la parte de la fase 2, 3 y 4, ya que se necesita tiempo para discutir los requisitos del JIT con los proveedores y clientes. Es importante la selección y control de proveedores en base a criterios lógicos. Con el JIT, el resultado neto es un aumento de la calidad, suministros a bajo coste, entrega a tiempo con una mayor seguridad tanto para el proveedor como para el cliente.

\section{JITP- Just in time purchasing}

La colaboración entre la empresa y sus proveedores estratégicos o socios es la parte más importante para el inicio del proceso productivo de la empresa. Para ello existen ciertas formas de colaboración, una de las más utilizadas en para incrementar la competitividad y reducir tiempos de entrega es la filosofía "Just in time purchasing" (JITP).

En tal sentido, para desarrollar la colaboración con el socio estratégico se va a utilizar el JITP. Como se sabe, una de las principales características de esta filosofía es la utilización de lotes pequeños para la producción y las compras, que conlleva al frecuente reabastecimiento por 
parte del proveedor. De esta manera, el objetivo principal es disminuir al mínimo las posibilidades de desabastecimiento de materiales estratégicos como son las telas, hilos y otros materiales, ya que, en el peor de los casos, la falta de estos paralizaría la producción en la línea de confección, lo cual llevaría a generar elevados costos de oportunidad perdida por futuras ventas no realizadas. En adición, se utiliza esta herramienta para reducir los excesivos niveles de inventario de materias primas, que actualmente ocupan gran parte del almacén y generan elevados costos de almacenamiento. Y, por último, otro de los motivos por el cual se va a utilizar el JITP, es que para el cálculo del EOQ (Economic order quantity) no se necesita de algún software especializado, sino sólo recopilar información pertinente, tales como los costos logísticos y cantidades de demanda de cierto material en específico.

\section{Aplicación}

La aplicación del JITP en una empresa requiere de la colaboración entre el proveedor y el comprador; así como de la realización de ciertas actividades claves, tales como la capacitación al personal implicado en el proceso productivo, incluido el personal encargado del abastecimiento de materiales, el transporte de los materiales y las cantidades de pedido al proveedor (Ortiz, 2014).

\section{ESTANDARIZACIÓN DE PROCESOS}

\section{Definición}

La estandarización junto con las 5S y SMED supone uno de los cimientos principales de Lean Manufacturing. Se define como descripciones escritas y gráficas que ayudan a comprender las técnicas más eficaces y fiables de una fábrica y nos proveen los conocimientos precisos.

Berger sugirió que el trabajo estándar es la herramienta básica para la mejora continua. El trabajo estándar se refiere al método más seguro y eficaz para llevar a cabo un trabajo en el menor tiempo repetible como resultado de la utilización de recursos como personas, máquinas y material eficazmente. Una vez establecido el trabajo estandarizado, es posible controlar y mejorar el diseño del trabajo con respecto a la demanda con aceleraciones en el trabajo (Berger, 1997).

\section{¿Por qué estandarizar?}


La estandarización de procesos, hoy en día es una herramienta que genera una ventaja competitiva para muchas organizaciones, porque es una manera de anclar las mejoras, si conseguimos una mejora y no se estandariza esta prevalecerá en un periodo de tiempo corto y caerá, mientras que, si se crea una hoja estándar de trabajo, esa mejora quedaría a disposición de todos los colaboradores de compra, de esa manera se realiza un mismo trabajo de actividades que agregan valor en el tiempo establecido. La estandarización es un proceso vital en una organización, ya que mantiene las mismas condiciones y produce los mismos resultados.

Beneficios de su aplicación:

- Es la mejor forma de preservar el conocimiento y la experiencia.

- Proveen una forma de medir el desempeño.

- Muestran la relación entre las causas y efecto.

- Suministra una base para el mantenimiento y mejoramiento de la forma de hacer el trabajo.

- Proporcionan una base para el entrenamiento.

- Proveen una base para prevenir la recurrencia de errores (Fondo PYME, 2012).

¿Cómo se aplica en una pequeña o mediana empresa?

Si la empresa es mediana o pequeña no debe pretender cargar con estándares muy sofisticados y manuales muy gruesos. Las pequeñas empresas cambian su estructura o funciones con mucha facilidad y frecuencia, por ello para que el estándar funcione debe mantenerse actualizado.

Se debe involucrar a todo el personal de trabajo en el área y comunicar los cambios al cliente del proceso y proveedores.

Objetivos de su aplicación:

- Proporcionar instrucciones estándares precisas para la ejecución de las actividades en el proceso de compras y capacitar a los trabajadores.

- Eliminar el reproceso de compras.

- Reducir el Lead Time de 17 a 10 días. 
Características en su aplicación

- Ser descripciones simples y claras de los mejores métodos para producir cosas.

- Proceder de mejoras hechas con las mejores técnicas y herramientas disponibles en cada caso.

- Garantizar su cumplimiento.

- Considerarlos siempre como puntos de partida para mejoras posteriores.

\section{VALUE STREAM MAP (VSM)}

El Mapa de la Cadena de Valor o VSM es un modelo gráfico que representa la cadena de valor, mostrando tanto el flujo de materiales como el flujo de información desde el proveedor hasta el cliente. Tiene por objetivo plasmar de una manera sencilla las actividades productivas que agregan y no valor al sistema productivo para identificar donde se producen los mayores desperdicios del proceso (EOI, 2013). Para la aplicación de esta herramientas existen simbologías definidas (Ver Figura 5), aunque no existe una forma específica de mapear el flujo de las actividades.

Figura 5. Símbolos del VSM

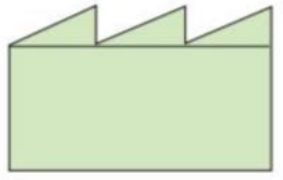

Cliente/Proveedor

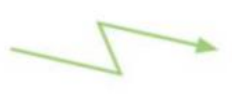

Información electrónica

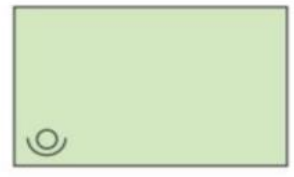

Proceso

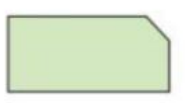

Kanban

de producción

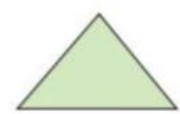

Inventario

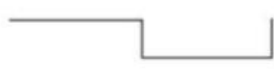

Segmento de escala temporal

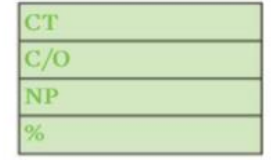

Tabla datos

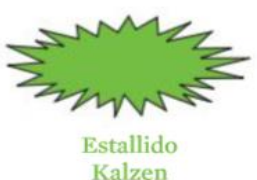

Fuente : EOI - Lean Manufacturing- Año 2013

Los datos plasmados en el VSM deben reflejar la realidad y desconfiando de los facilitados por el sistema de información. (Ver Figura 6) 
Asimismo, los datos del proceso importantes a colocar son:

- Tiempo de ciclo (CT): Tiempo que pasa entre la fabricación de un producto o pieza completa y la siguiente.

- Tiempo de cambio de modelo (C/O): Tiempo que toma para cambiar un tipo de proceso a otro.

- Número de personas (NP) requeridas para realizar un proceso en particular.

- Plazo de entrega (LT): Tiempo que se necesita para que una pieza o producto cualquiera recorra un proceso o una cadena de valor de principio a fin.

Figura 6. Ejemplo de Mapa de Flujo de Valor

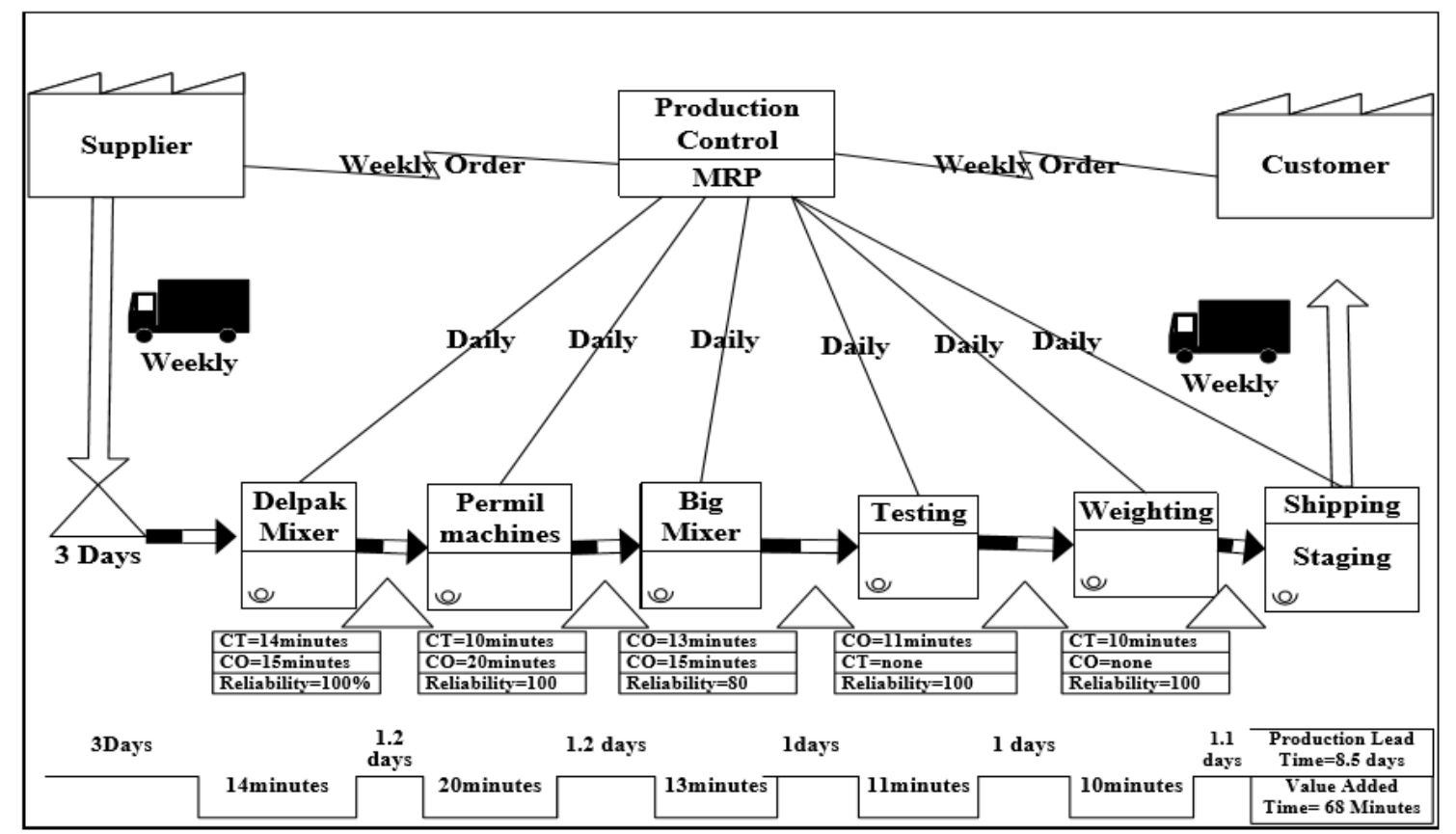

Fuente : Mohd Jafri y Mojib S.- Año 2015

\section{Indicadores claves.}

Los indicadores clave de desempeño o también llamados KPI's, son métricas financieras o no financieras que miden el comportamiento de un proceso o actividad de manera que sirva como guía para alcanzar los objetivos y metas fijados en el plan estratégico de la organización. El uso de estos indicadores permite el seguimiento y evaluación periódica de las variables clave de la organización, y la comparación en el tiempo con las metas y estándares del mercado (Vázquez, 2013). 
Como primer filtro, para la determinación de indicadores se utiliza los criterios de la metodología de selección de objetivos SMART ${ }^{1}$.

- Específico: que sea claro sobre qué, donde, cuándo, y cómo va a cambiar la situación.

- Medible: que sea posible cuantificar los fines y beneficios.

- Realizable: que sea posible de lograr a partir de la situación actual.

- Realista: que sea posible obtener el nivel de cambio reflejado en el objetivo.

- Limitado en el tiempo: que establezca un periodo de tiempo en el que se debe completar cada uno de ellos.

De la misma manera, la tipología del indicador se caracteriza dependiendo de la meta a la que se quiere hacer seguimiento. A continuación, se mencionan las siguientes tipologías (Guía Metodológica para la formulación de indicadores, 2009):

- Gestión, cuantifica los recursos físicos, humanos y financieros utilizados en el desarrollo de las acciones, y mide la cantidad de acciones, procesos, procedimientos y operaciones realizadas durante de la etapa de implementación.

- Producto, cuantifica los bienes y servicios producidos y/o provisionados a partir de una determinada intervención.

- Efecto: mide los cambios resultantes en el bienestar de la población objetivo de la intervención como consecuencia de la entrega de los productos.

Como segundo filtro, para la selección de indicadores se utiliza la metodología CREMA desarrollada por el Banco Mundial. La selección debe ser estratégica y concentrarse en escoger los que permitan contar la información de mejor calidad, esto quiere decir aquellos indicadores que poseen 20 como puntaje mínimo. En la Tabla 4, se muestra el formato que se utiliza para la selección de indicadores en esta investigación.

\footnotetext{
${ }^{1}$ La palabra inglesa que significa inteligente y bajo esta metodología se utiliza como acrónimo de los objetivos Specific (Específico), Measurable (Medible). Achivable (Realizable), Realistic (Realista) y Time-Bound (Limitado en el tiempo) (Drucker, 1954).
} 
Tabla 4. Formato para la selección de indicadores

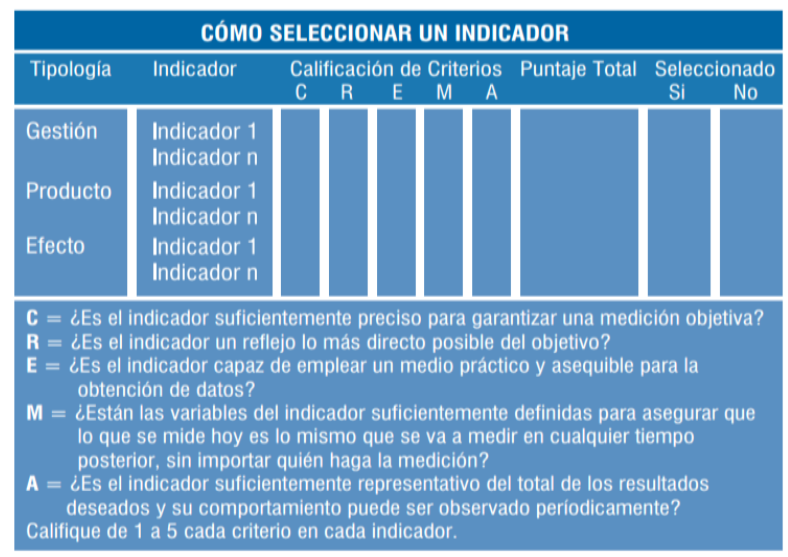

Fuente : Adaptado de UNDP - Año 2002

Para la formulación de Indicadores se tiene en cuenta los siguientes pasos:

1. Identificar el objetivo del indicador.

2. Identificar el tipo o naturaleza del indicador.

3. Definir las variables del indicador.

4. Definir los parámetros de comparación.

5. Definir periodicidad.

6. Definir responsable de medición.

7. Definir responsable de análisis.

8. Documentar indicador.

Una vez realizado los filtros definidos anteriormente, es necesario registrar toda la información asociada al indicador. En la figura 7, se presenta la ficha técnica que se realiza para cada indicador, en esta se considera el nombre del indicador; el objetivo, donde se plantea el porcentaje de mejora o incremento que se desea alcanzar, este se define de acuerdo al criterio de cada empresa; la fórmula del cálculo; el nivel de referencia, que es una simbología que representa el nivel del porcentaje objetivo definido anteriormente donde se observan tres colores, el rojo representa que se debe poner énfasis en la mejora del indicador, ya que es menor a 57\%, el color amarillo significa que se encuentra medianamente bien, pero de igual manera se necesitan mejoras en el sistema, y el verde representa un nivel satisfactorio, estos porcentajes también se definen a criterio de la empresa; responsable de gestión, usualmente el encargado de gestionar el indicador es el encargado del proceso; fuente de información, en la cual se coloca de donde se obtiene la información para hallar el porcentaje; frecuencia de medición y de reporte; el responsable del reporte que usualmente es el encargado u otros colaboradores del 
área. Finalmente, los usuarios son aquellas personas o procesos a los que se dirige el informe del indicador.

Figura 7. Modelo de la Ficha Técnica

\begin{tabular}{|c|c|c|}
\hline \multirow{3}{*}{$\begin{array}{l}\text { Logo } \\
\text { Empresa }\end{array}$} & \multirow{3}{*}{ FICHA TECNICA DE INDICADOR } & Código: PRO-IC-02 \\
\hline & & \begin{tabular}{|l|} 
Versión: 01 \\
\end{tabular} \\
\hline & & \begin{tabular}{|l|} 
Pág. 1 de 1 \\
\end{tabular} \\
\hline \multicolumn{3}{|c|}{ 1. Nombre: } \\
\hline \multicolumn{3}{|c|}{ 2. Objetivo: } \\
\hline \multicolumn{3}{|c|}{ 3. Fórmula de Cálculo: } \\
\hline \multicolumn{3}{|c|}{ 4. Nivel de Referencia: } \\
\hline \multicolumn{3}{|c|}{$\square$ Mayor a $67 \%$} \\
\hline \multicolumn{3}{|c|}{ Entre 57\% y $67 \%$} \\
\hline \multicolumn{3}{|c|}{ Menor a $57 \%$} \\
\hline \multicolumn{3}{|l|}{ | } \\
\hline \multicolumn{3}{|c|}{ 5. Responsable de Gestión: } \\
\hline \multicolumn{3}{|c|}{ 6. Fuente de Información: } \\
\hline \multicolumn{3}{|c|}{ 7. Frecuencia de Medición: } \\
\hline \multicolumn{3}{|c|}{ 8. Frecuencia de Reporte: } \\
\hline \multicolumn{3}{|c|}{ 9. Responsable del Reporte: } \\
\hline \multicolumn{3}{|c|}{ 10. Usuarios: } \\
\hline 11. Obser & nes: & \\
\hline
\end{tabular}

Fuente : Adaptado del material de clase del curso de Gestión por procesos

\section{Procedimiento}

\section{Definición}

Forma específica de llevar a cabo una actividad o un proceso. Los procedimientos se expresan en documentos que contienen el objeto y el campo de aplicación de una actividad; qué debe hacerse y quién debe hacerlo; cuándo, dónde y cómo se debe llevar a cabo; qué materiales, equipos y documentos deben utilizarse; y cómo debe controlarse y registrarse (Arias, 2014 ).

Los procedimientos definen la secuencia de pasos a realizar en cada tarea. La estructura planteada para este trabajo es el siguiente (Ver Figura 8). En el formato siguiente, se detalla: Objetivo, responsabilidad y alcance, documentos a consultar, definiciones, condiciones básicas, desarrollo del procedimiento, registro y anexo. De la misma manera, cada procedimiento tiene un código que lo identifica y paginación. 
Figura 8. Modelo de Procedimiento

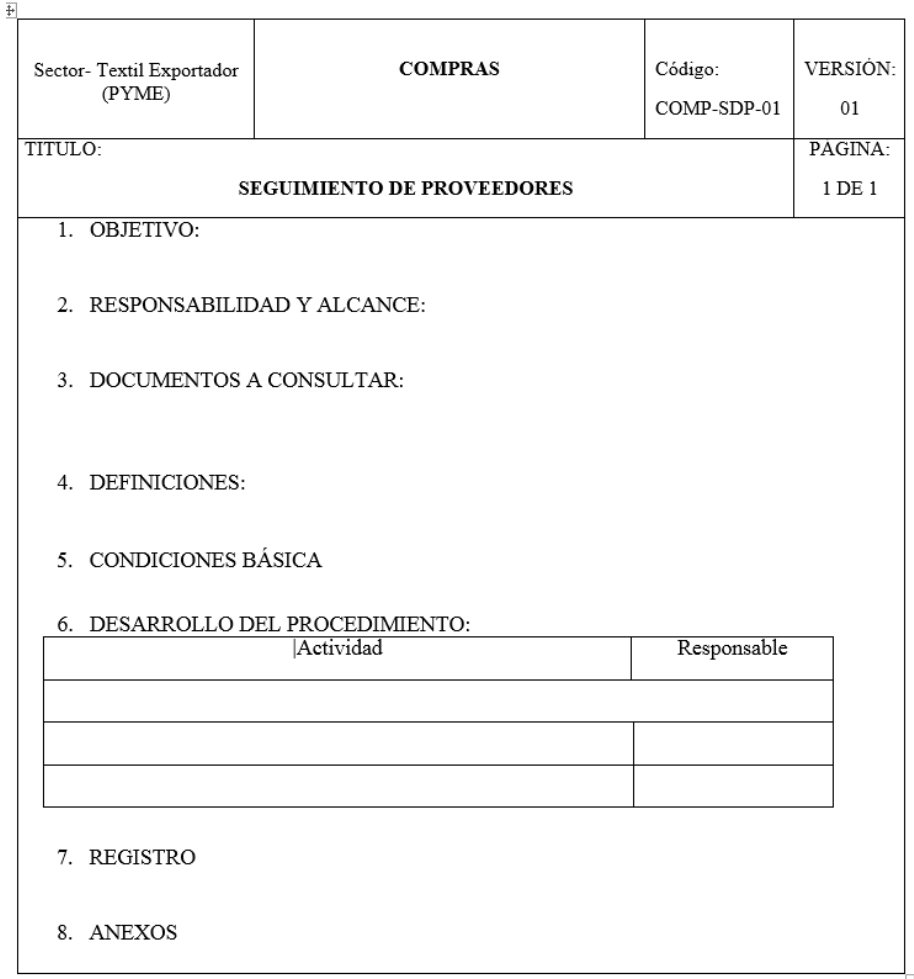

Fuente : Material de clase UPC-Gestión por procesos.

\section{MRP (PRM): Planeamiento De Requerimiento de materiales.}

\section{Definición}

El Plan de Requerimientos de Materiales o simplemente MRP por sus siglas en inglés (Material Requirements Planning) es una metodología que permite administrar el inventario y planificar pedidos de partes y piezas con demanda dependiente.

Es un método principalmente utilizado para programar partes, materiales y suministros de alto valor y hechos a la medida, cuya demanda se conoce relativamente bien (Ballou, 2004).

\section{Aplicación}

Para llevar a cabo un Plan de Requerimientos de Materiales (MRP) se necesitan 3 elementos:

- Plan Maestro de la Producción (PMP).

- Estructura del Producto, Lista de Materiales o Bill of Materials (BOM).

- $\quad$ Registro del Inventario (IRF). 
Por otra parte, la estructura del producto o Bill of Materials (BOM) detalla cuántas partes y piezas se necesitan para obtener una unidad de producto final y cómo dicho producto se compone.

Finalmente se necesita el Registro del Inventario (Inventory Record File o IRF) (tanto para productos con demanda dependiente e independiente) que contiene la información del inventario disponible y el tiempo de espera (o lead time) asociado a cada producto.

\section{PROCESO DEL SECTOR TEXTIL DE CONFECCIONES.}

\section{Diseño y DESARROLlo DE PRENDA}

El Proceso de Diseño y Desarrollo de Prenda, se encarga de transformar los requisitos del cliente en especificaciones técnicas, que serán utilizadas posteriormente en los diferentes procesos de confección. Los resultados de este proceso, podrían incluir en algún caso, no aceptar la realización de un nuevo producto. Este proceso es clave dentro de la cadena de valor, porque de la eficiencia por determinar las especificaciones técnicas, depende la productividad del proceso de confección (Padilla, 2012).

\section{COMPRAS DE MATERIALES, INSUMOS O MATERIA PRIMA}

Compras o aprovisionamiento es un proceso logístico que viabiliza la operatividad de las empresas al garantizar el flujo de entrada y la disponibilidad de todos los productos y/o servicios que se requieran, los cuales son ofrecidos por proveedores (Drake, 2013). El proceso de compras en el contexto del sector textil debe permitir la descripción de los insumos y suministros a adquirir en una orden de compra, identificar, evaluar y seleccionar los proveedores, y realizar el seguimiento y control con el fin que los productos que se adquieren cumplan con las condiciones planificadas en calidad, referencias y tiempos de entregas (Van der Valk y Rozemeijer, 2009; Rogerson et al, 2014).

\section{RECEPCION Y ALMACENAMIENTO DE MATERIALES.}

Consiste en la recepción de la materia prima como es la tela, cierres, botones, hilos, etiquetas, bolsas de polietileno, ganchos, e insumos que sean necesarios para la elaboración de las prendas (polos de algodón de tejido punto). 
IV. TEÑIDO.

El proceso de teñido comienza cuando se lleva al laboratorio los requerimientos del cliente mediante un "Lap Dip" que es una muestra pequeña del tejido con el color elegido. El laboratorio realiza las pruebas al tejido usando el programa "Data Color" (Sistema computarizado para medir el color) que mediante el "Espectrofotómetro" (Equipo para medir el color) arroja la receta del color evaluado.

Luego con esa receta se inicia el proceso de reproducción del color donde se realizan los ensayos necesarios. Luego dicha receta es trasladada al área de "Tintorería" para que realice la reproducción de la misma en función a la capacidad de las "Barcas de teñido".

El proceso de teñido se realiza en las "Barcas de teñido" (Ollas de temperatura de gran capacidad). Para realizarlo se utilizan diversos químicos, colorantes y auxiliares de teñido. Estos últimos potencian los efectos y mejoran la calidad, firmeza y estabilidad del teñido. El proceso de teñido consta de tres etapas: Descrude o blanqueo químico, teñido "reactivo" (algodón) y teñido "disperso" (poliéster) y por último la etapa de jabonado - teñido reactivo o lavado reductivo - teñido disperso.

\section{CORTE DE PIEZAS.}

En esta parte se colocan los rollos de tela en la mesa de corte y se llevan a cabo las siguientes actividades:

- Tendido: La tela es extendida en varias pilas encima de las mesas de corte para que pueda ser cortada simultáneamente.

- Moldeado: Se ubican los patrones, previamente diseñados según las exigencias de la producción, sobre la tela, y se marcan para que indiquen donde se debe llevar a cabo el corte.

- Corte: En esta etapa, el corte puede darse de diferentes formas, las más usadas son el corte manual, el corte por presión o troquelado y el corte automático. El corte manual es el que se emplea más comúnmente dado que es elemental. El corte por presión o troquelado depende de la marcada empleada y consiste en ejercer presión de la máquina de corte contra la tela, en este tipo de corte se pueden usar distintos tipos de máquinas como son la cortadora por presión de elementos, cortadora por presión de marcada entera, cortadora por presión de paneles y cortadora por presión a tela suelta. Por último, el corte automático se lleva a 
cabo mediante una cuchilla que sigue las coordenadas dadas por un ordenador central, esta forma de corte sólo requiere la intervención del operario para el control del proceso y el mantenimiento del equipo.

\section{ENSAMBLE Y COSTURA}

En este proceso las prendas toman la forma final y las piezas que han sido adecuadas son unidas en los puestos de cosido, los que generalmente son ocupados por un operario por máquina. Durante este proceso el operario también realiza una inspección visual para asegurar que las partes cortadas sean de acuerdo a las especificaciones de los modelos preestablecidos (Secretaría de Economía, 2010).

VII. ACABADO

En esta parte del proceso se realiza los cortes de los hilos sobrante y la colocación de botones, etiquetas, ojales entre otros, para conseguir el producto final.

\section{EMPAQUE}

En esta etapa se realiza el plegado, embolsado y embalado de las prendas y puede ser de forma manual o mecánica, aquí pueden usarse un conjunto de automatismos que se ajustan a la presentación del producto final y hacen más sencilla esta parte del proceso. El embalado de las prendas se puede dar en cajas o ensogado de las bolsas de producto terminado (IYM, 2008).

\section{AlMACENAMIENTO}

Para finalizar, las prendas confeccionadas son organizadas según modelos tallas y colores en el almacén de producto terminado, donde se dan las condiciones adecuadas para que se mantengan en óptimo estado para su distribución.

\section{PROCESO DE COMPRAS EN EL SECTOR TEXTIL DE CONFECCIONES.}

Definición

El proceso de compras presenta una serie de actividades que permiten poder realizar efectivamente la compra de un producto específico o de varios. Para realizar este proceso se necesita identificar la necesidad de realizar la compra, la selección de proveedor, aprobación, 
selección y generación de orden de compra y seguimiento y control del mismo hasta recepcionar la mercadería. (Ver Figura 9)

Figura 9. Diagrama de flujo del proceso de Compras Estándar Nacional

\section{Flujograma de la función de compras locales}

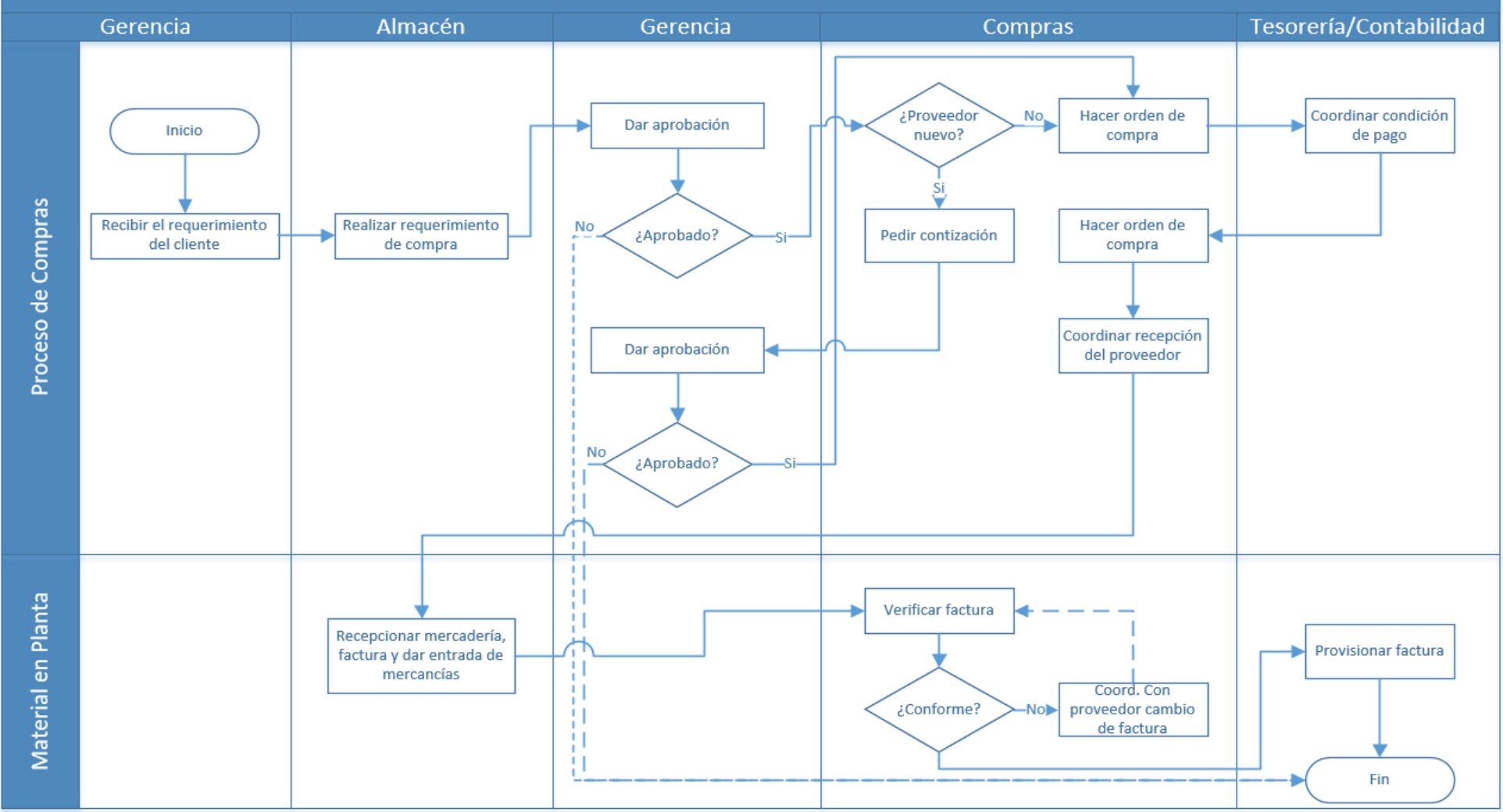

Fuente : Ortiz, J- Año 2014

Asimismo, se identifican desperdicios en el proceso de compras:

- Primer tipo: Desperdicios en el proceso propio de la empresa.

- Recuentos, almacenamiento, traslados, programación.

- Segundo tipo: Desperdicios en las relaciones y mecanismos de control.

- Cotizaciones, selección de proveedores, evaluación de compra, emisión de órdenes de compras, etc.

- Tercer tipo: Desperdicios en los procesos de los proveedores.

\section{Indicadores:}

- Indicadores de Innovación: sirven para realizar la medición de los nuevos productos que se adquieren en la empresa; además de los nuevos proveedores o servicios utilizados. 
- Indicadores de servicios: Mide las cantidades abastecidas y los tiempos de entrega del pedido.

- Indicadores de coste: Mide el costo de los productos o servicios adquiridos para realizar la producción y darle valor agregado al producto, así como los cambios de los costes y las causas que los provocan.

- Indicadores de calidad: Miden el coste de los productos o servicios adquiridos.

- Indicadores de flexibilidad: Miden la efectividad con la que los productos o servicios adquiridos se acoplan al flujo de materiales de la empresa (August, 2011). 


\section{CAPITULO II: ANÁLISIS Y DIAGNÓSTICO}

En este capítulo se analiza al sector textil exportador detallando la situación actual y analizando problemas comunes en el proceso de compras por medio de las características de la investigación. Se examina desde el impacto en la economía peruana, estrato empresarial, actividades y determinación del sector. De la misma manera, se analiza los datos obtenidos en las encuestas realizadas que permiten establecer la hipótesis y objetivos de la investigación.

\section{DIAGNÓSTICO GENERAL}

\section{SITUACIÓN ACTUAL DE LAS PYMES EN EL PERÚ.}

El Directorio Central de Empresas y Establecimientos elaborado por el INEI, ha registrado hasta diciembre de 2015, 2 millones 42 mil 992 empresas que desarrollan actividades económicas en el territorio nacional, esta cifra representa un incremento de $8,5 \%$ respecto al año anterior.

En la Tabla 5 se muestra la distribución por tamaño de empresas en el Perú. Como se puede apreciar el 94,6\% de las unidades económicas del país son microempresas cuyas ventas anuales superan los 577 mil 500 soles. El 4,4\% se encuentran en el segmento de la pequeña empresa y el 0,6\% pertenecen a la gran y mediana empresa. El 0,4\% restante corresponde a las empresas que pertenecen a la administración pública (INEI, 2015). Cabe resaltar que la pequeña empresa creció 16,1\% en el 2015 respecto al año anterior, las grandes y medianas empresas crecieron en $9,8 \%$.

Tabla 5. Empresas según Segmento empresarial 2014-2015

\begin{tabular}{|c|c|c|c|c|}
\hline \multirow{2}{*}{ Segmento empresarial } & \multirow{2}{*}{2014} & \multicolumn{2}{|c|}{2015} & \multirow{2}{*}{$\begin{array}{c}\operatorname{Var}{ }^{2} \\
2015 / 1\end{array}$} \\
\hline & & Absoluto & Porcentaje & \\
\hline Total & 1883531 & 2042992 & 100,0 & 8,5 \\
\hline Micro empresa & 1787857 & 1933525 & 94,6 & 8,1 \\
\hline Pequeña empresa & 77503 & 89993 & 4,4 & 16,1 \\
\hline Gran y mediana empresa & 11380 & 12494 & 0,6 & 9,8 \\
\hline Administración pública & 6791 & 6980 & 0,4 & 2,8 \\
\hline
\end{tabular}

Fuente : INEI- Directorio Central de Empresas y Establecimientos 
Según la ubicación geográfica, el 47,0 \% del total de las unidades económicas se encuentran ubicadas en la Provincia de Lima y la Provincia Constitucional del Callao, lo cual confirma el grado de concentración empresarial en estos ámbitos geográficos.

\section{Sector económico:}

La actividad económica se define como el proceso mediante el cual se producen bienes y servicios que cubren las necesidades de la población. Como se observa en la Figura 10, en el año 2015 la actividad económica con mayor número de empresas es comercio y reparación de vehículos automóviles y motocicletas con $45,5 \%$ del total de unidades empresariales, esto es una cifra de 929 mil 231 empresas. Le siguen, otros servicios con 14,6\%, y en la cuarta posición se encuentran las Industrias manufactureras con $8,2 \%$.

Figura 10. Empresas según actividad económica Perú - 2015

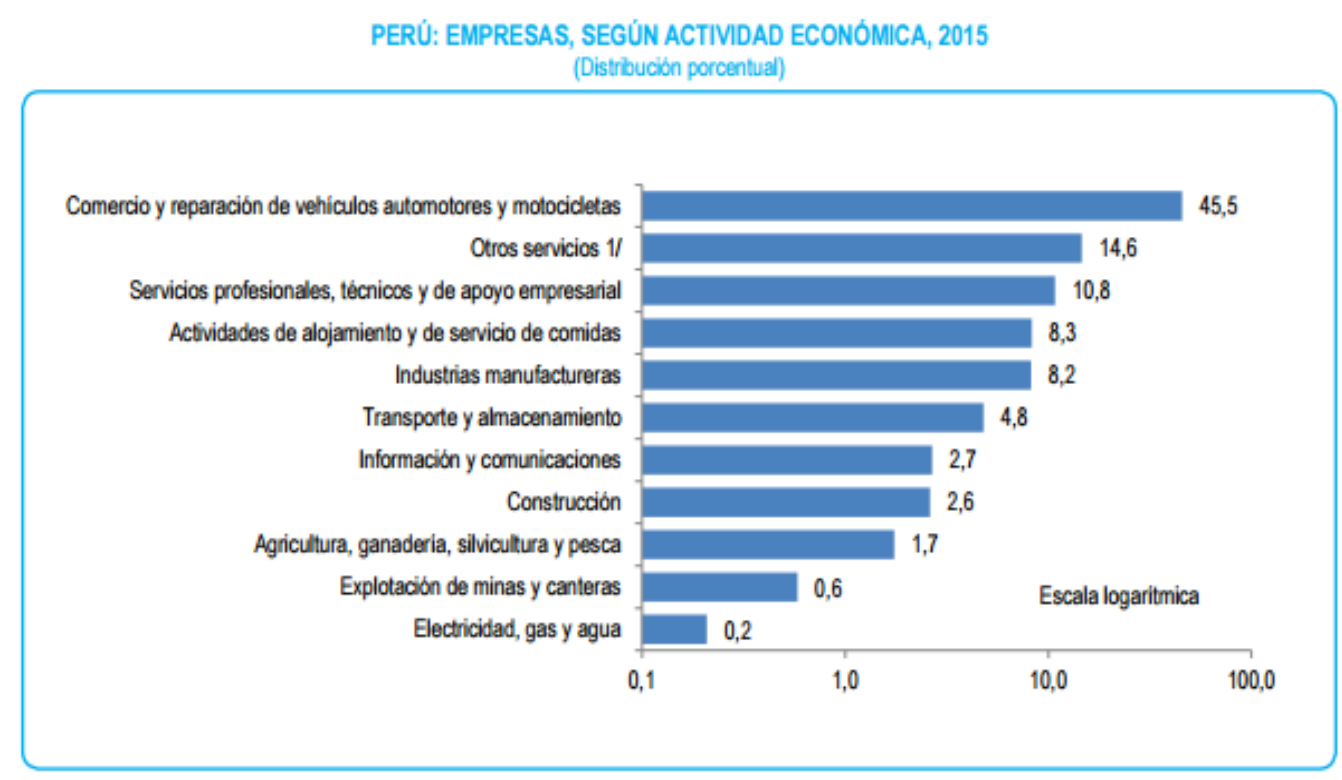

Fuente : INEI- Directorio Central de Empresas y Establecimientos

\section{ANÁLISIS DEL SECTOR TEXTIL EXPORTADOR.}

La industria textil en el Perú genera 1,9\% del PBI total y de ella dependen mil puestos de trabajo, directo y millones de personas indirectamente (INEI 2016), uno de los problemas de este sector es la subvaluación y el ingreso de precios dumping de las importaciones de hilados, tejidos y prendas de vestir que en su mayoría provienen de países asiáticos como China, India, etc. En el año 2015 el gobierno de Ollanta Humala dejó sin efecto las medidas de defensa contra el dumping en la importación de confecciones, lo cual afectó directamente a muchas empresas del sector; por tal motivo, muchas empresarios deciden cerrar sus plantas en el Perú, a raíz de 
esta situación las empresas buscan minimizar sus costos, pero en muchas ocasiones esto significa reducción de personal o abuso de este con horas excesivas de trabajo y sueldos bajos, por esta razón las pequeñas y medianas empresas necesitan otra alternativa que les proporcione mayores beneficios y se mantenga en el tiempo, y esto se puede lograr a través de la mejora de sus procesos, reducción de desperdicios y compromiso total.

El Banco Central de Reserva del Perú (BCRP 2015) indica en su último reporte de inflación que para el año 2017 se espera que el PBI presente un crecimiento de 4.6\%, pero esta recuperación económica se da gracias al Producto Bruto Interno Primario (minería, pesca y agropecuario) que creció 6.6\% en el 2015 y se espera que crezca 8.7\% este año. (Ver Tabla 6)

Tabla 6. Crecimiento del Producto Bruto Interno 2016 - 2017.

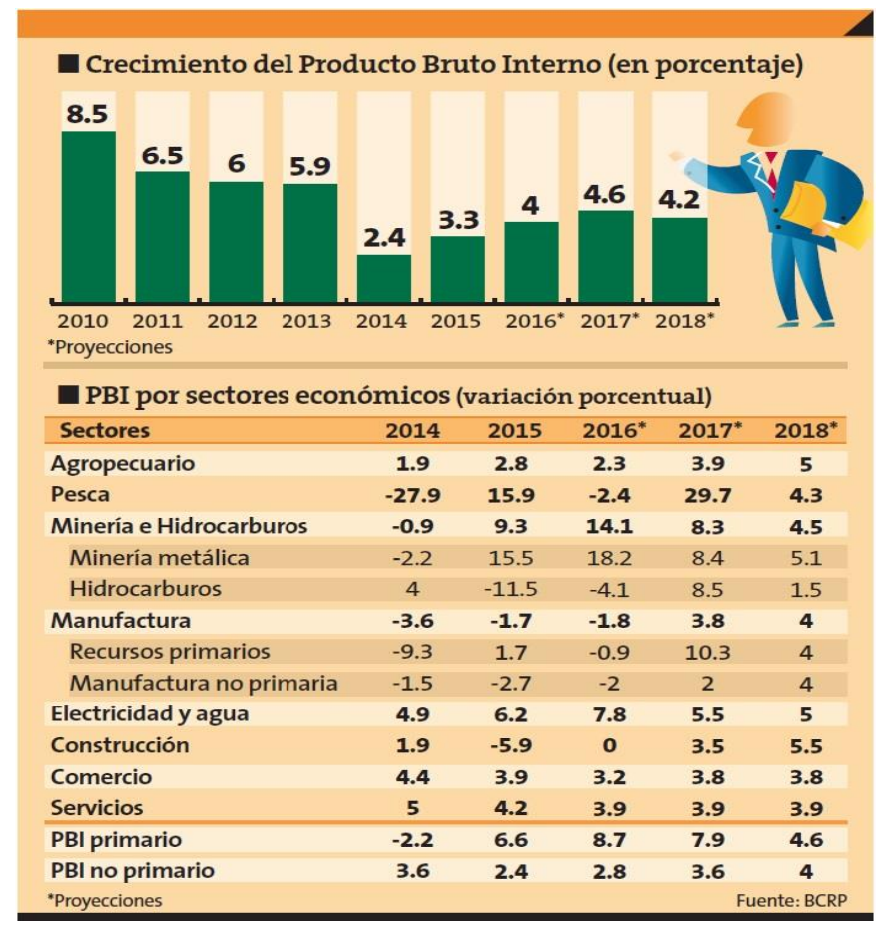

Fuente : BCRP- Año 2015

Con respecto a la manufactura no primaria, vino registrando un desempeño negativo entre enero y mayo del 2016 (1.4\%), según cifras del Ministerio de la Producción (Produce).

En el Reporte Semanal de Julio del 2016 presentado por Scotiabank indican que dentro de la industria de bienes intermedios, se redujo la manufactura de productos textiles y de confecciones, hilados y prendas, explicada en parte por un menor consumo en el mercado local ante la condiciones climáticas anormales, así como también por la caída de las exportaciones textiles (-12.5\%), dado el bajo crecimiento de prendas exportadas hacia Estados Unidos 
(principal destino exportador), ante el mayor ingreso de prendas asiáticas, así como por la menor demanda por parte de países de la región como Ecuador, Colombia, Chile y Brasil (Reporte Semanal de Scotiabank, 2016). (Ver Figura 11)

Figura 11. Situación de la Manufactura no primaria en exportaciones 2016

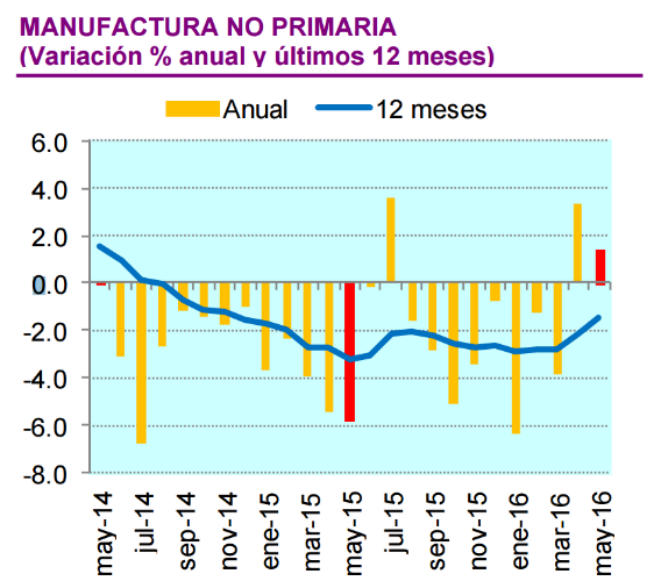

Fuente : Reporte Semanal Scotiabank - Año 2015

Para que un país sea considerado país exportador, su nivel de exportaciones debe representar 29\% de su PBI, según el Banco Mundial. El Perú desde el año 2001 viene creciendo a pasos agigantados sus niveles de exportación y se ha diversificado los productos a exportar, durante el mes de mayo del 2016 las exportaciones crecieron 4,81\% con respecto al mismo periodo del año anterior (ADEX, 2016). Esta situación se ve reflejada en el incremento de puestos de trabajo en todo el país, solo en la región de Lima Metropolitana en el 2017 se incrementó 1,3\% respecto al primer trimestre del 2016. Si bien se ha visto un incremento en las exportaciones, en los productos no tradicionales no sucede lo mismo, estos presentaron una reducción de $2.9 \%$ con respecto al 2015. (Ver figura 12).

Figura 12. Balanza Comercial 2015 - 2016

\begin{tabular}{|c|c|c|c|c|c|c|}
\hline \multicolumn{7}{|c|}{$\begin{array}{l}\text { Balanza Comercial } \\
\text { (US\$ Millones) }\end{array}$} \\
\hline & \multicolumn{3}{|c|}{ Noviembre } & \multicolumn{3}{|c|}{ Enero - Noviembre } \\
\hline & 2015 & 2016 & Var. \% & 2015 & 2016 & Var. \% \\
\hline 1. Exportaciones & 2914 & 3187 & $9,4 \%$ & 30471 & 31982 단 & $5,0 \%$ \\
\hline Productos Tradicionales & 1927 & 2229 & $15,7 \%$ & 20672 & 22414 둔 & $8,4 \%$ \\
\hline Productos no Tradicionales & 987 & 958 & $-2,9 \%$ & 9798 & 9568 & $-2,4 \%$ \\
\hline 2. Importaciones & 3123 & 3087 & $-1,2 \%$ & 35010 & 33034 र & $-5,6 \%$ \\
\hline Bienes de Consumo & 823 & 779 & $-5,4 \%$ & 8175 & 7922 V & $-3,1 \%$ \\
\hline Insumos & 1266 & 1331 & $5,1 \%$ & 15217 & $14400 \sqrt{7}$ & $-5,4 \%$ \\
\hline Bienes de Capital & 1034 & 977 & $-5,5 \%$ & 11607 & 107087 & $-7,7 \%$ \\
\hline Otros bienes & 0,5 & 0,6 & 술 $21,0 \%$ & 11,3 & $3,7 \square$ & $-67,5 \%$ \\
\hline 3. Saldo Comercial & $-209,4$ & 100,0 & $-147,8 \%$ & $-4539,4$ & $-1051,9$ ? & $-76,8 \%$ \\
\hline
\end{tabular}

Fuente : Balanza Comercial 2015 - 2016 
Se puede observar en la Figura 13 que, en el sector no tradicional, las medianas empresas han tenido una caída de $2.3 \%$ con respecto al 2015. Tomando en cuenta la situación actual del sector textil exportador y el análisis realizado, el presente trabajo se enfoca en las pequeñas y medianas empresas, ya que ambas representan el 5\% del total de empresas en el Perú, a pesar que no es una cantidad muy significativa las ventas de estas representan el 13\% de lo exportado, esto debido a que no aprovechan el total de su capacidad productiva, recursos y no cuentan con procesos y estrategias de trabajo definidas.

Figura 13. Variación porcentual en exportaciones del Sector Tradicional y No Tradicional 2016

\begin{tabular}{|c|c|c|c|}
\hline \multicolumn{4}{|c|}{ Sector Tradicional } \\
\hline Enero-Noviembre & : 2015 & 2016 & Var.\% \\
\hline Grande & 20163,0 & 20329,4 亿 & $0,8 \%$ \\
\hline Mediana & 452,6 & 707,5 个 & $56,3 \%$ \\
\hline Pequeña & 54,9 & $1264,3 \hat{~}$ & $2203 \%$ \\
\hline Micro & 1,8 & 113,1 & $6013 \%$ \\
\hline Total & 20672,3 & 22414,3 亿 & $8,4 \%$ \\
\hline
\end{tabular}

\begin{tabular}{|lrrr|}
\hline \multicolumn{5}{|c|}{ Sector No Tradicional } \\
\hline Enero-Noviembre: & 2015 & 2016 & Var.\% \\
Grande & 6515,2 & $6258,6 \downarrow$ & $-3,9 \%$ \\
Mediana & 2591,1 & $2530,6 \downarrow$ & $-2,3 \%$ \\
Pequeña & 594,5 & $609,0 \curlyvee$ & $2,4 \%$ \\
Micro & 97,5 & $169,5 \curlyvee$ & $73,9 \%$ \\
Total & $\mathbf{9 7 9 8 , 3}$ & $\mathbf{9 5 6 7 , 7}$ & $\mathbf{- 2 , 4 \%}$ \\
\hline
\end{tabular}

Fuente : Sunat

Manufactura

Se entiende por actividad manufacturera a la transformación física o química de materia prima en productos destinados al consumidor. Para diciembre del 2015, el número de empresas manufactureras se incrementaron en un 3,6\% respecto al año anterior, es decir, representó una cifra de 167 mil 647, siendo el 93,6\% microempresas, 5,4\% pequeñas empresas y el 1,0\% gran y mediana empresa. Asimismo, el 51,1\% de las empresas manufactureras se concentran en la ciudad de Lima (INEI, 2015).

Figura 14. Empresas manufactureras según actividad económica 2015

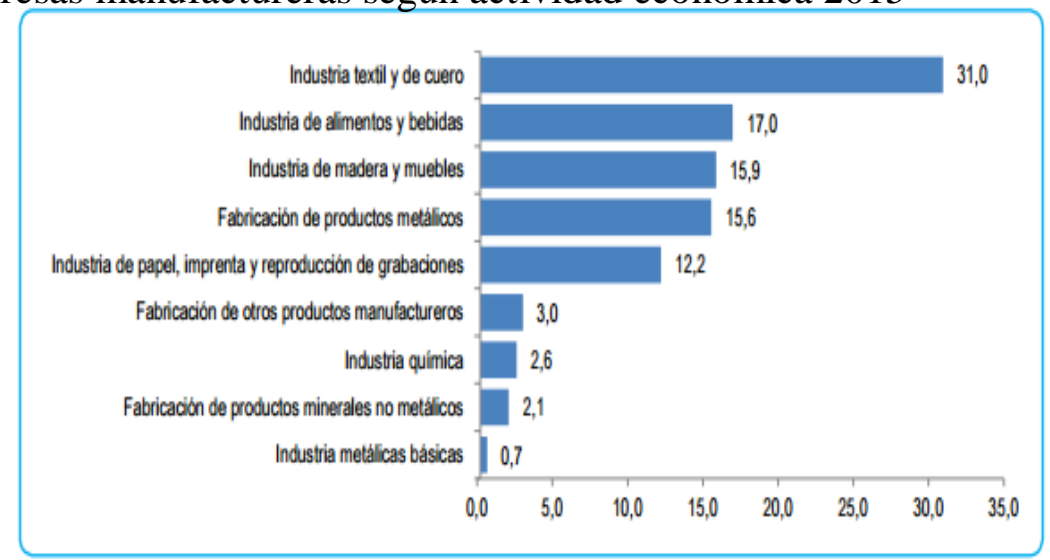

Fuente: INEI- Directorio Central de Empresas y Establecimientos 
Las actividades más representativas de la industria manufacturera son la industrial textil y de cuero con $31,0 \%$, le siguen la industria de alimentos y bebidas con $17,0 \%$, la industria de madera y muebles con $15,9 \%$, la fabricación de productos metálicos $(15,5 \%)$ y la industria de papel, imprenta y reproducción de grabaciones con 12,2\%. (Ver Figura 14) (INEI, 2015).

En este sentido se puede afirmar que existe correlación directa entre el crecimiento exportador y el crecimiento económico del país. Para citar un ejemplo: cuando crece la exportación de prendas de vestir, no solo se benefician los exportadores sino también los proveedores de materia prima, bolsas, cajas, etc., los productores o fabricantes de las prendas, las entidades financieras y la sociedad en general, ya que una empresa que exporta se encuentra formalizada por ende paga impuestos y contribuye al desarrollo del país, además genera puestos de trabajo para más personas.

Si bien las exportaciones se han incrementado, el sector textil es uno de los que menos se ha visto favorecido, la exportación de Prendas de Vestir de punto muestra una baja de $-2.2 \%$ en el 2016 con respecto al año 2015 (Véase Tabla 7). Por ello, en este proyecto de investigación se ha tomado el sector Textil exportador, puesto que es un indicador esencial para el crecimiento económico del país y para mostrar los productos nacionales al mercado internacional.

Tabla 7. Exportaciones por Sector Económico - No tradicional 2016

\begin{tabular}{|c|c|c|c|c|c|c|}
\hline \multirow[b]{2}{*}{ Exportaciones por Sectores Económicos } & \multicolumn{3}{|c|}{ Millones US\$ FOB } & \multicolumn{3}{|c|}{ Miles de Toneladas } \\
\hline & $\mid \begin{array}{c}\text { Ene - May } \\
2015\end{array}$ & $\begin{array}{c}\text { Ene - May } \\
2016\end{array}$ & $\begin{array}{c}\text { Var. \% } \\
\text { Ene - May } \\
16 / 15\end{array}$ & $\begin{array}{c}\text { Ene - May } \\
2015\end{array}$ & $\mid \begin{array}{c}\text { Ene - May } \\
2016\end{array}$ & $\begin{array}{c}\text { Var. \% } \\
\text { Ene - May } \\
16 / 15\end{array}$ \\
\hline Total No Tradicional & 4,355 & 4,075 & $-6.4 \%$ & 4,984 & 4,490 & $-9.9 \%$ \\
\hline Agropecuario y Agroindustrias & 1,605 & 1,642 & $2.3 \%$ & 921 & 984 & $6.8 \%$ \\
\hline Animales Vivos T Productos Del Reino Animal & 67 & 62 & $-7.3 \%$ & 37 & 37 & $1.1 \%$ \\
\hline Flores y Plantas Vivas & 3 & 3 & $-15.0 \%$ & 1 & 1 & $-17.1 \%$ \\
\hline Hortalizas & 365 & 360 & $-1.4 \%$ & 172 & 178 & $3.8 \%$ \\
\hline Legumbres & 14 & 21 & $54.6 \%$ & 9 & 18 & $86.1 \%$ \\
\hline Frutas & 751 & 784 & $4.4 \%$ & 468 & 488 & $4.3 \%$ \\
\hline Cereales & 63 & 50 & $-19.5 \%$ & 16 & 26 & $61.0 \%$ \\
\hline Otros Productos Vegetales & 83 & 96 & $15.5 \%$ & 34 & 40 & $18.4 \%$ \\
\hline Colorantes Naturales & 1 & 2 & $220.8 \%$ & 0 & 0 & $126.9 \%$ \\
\hline Grasas y Aceites De Animales O Vegetales & 20 & 19 & $-5.5 \%$ & 14 & 23 & $68.7 \%$ \\
\hline Otros Productos De La Industria Alimentaria & 226 & 229 & $1.3 \%$ & 151 & 150 & $-0.4 \%$ \\
\hline Bebidas, Liquidos Alcohólicos y Vinagres & 13 & 16 & $23.4 \%$ & 19 & 22 & $13.1 \%$ \\
\hline Textil & 200 & 148 & $-25.8 \%$ & 28 & 24 & $-15.8 \%$ \\
\hline Fibras & 49 & 30 & $-38.4 \%$ & 9 & 8 & $-12.4 \%$ \\
\hline Hilados & 59 & 49 & $-16.9 \%$ & 5 & 4 & $-28.8 \%$ \\
\hline Tejidos & 81 & 60 & $-25.5 \%$ & 12 & 11 & $-9.7 \%$ \\
\hline Otros Tejidos & 1 & 1 & $-39.8 \%$ & 0 & 0 & $-44.3 \%$ \\
\hline Otras Confecciones & 9 & 8 & $-16.0 \%$ & 2 & 1 & $-36.9 \%$ \\
\hline Prendas De Vestir & 355 & 338 & $-4.8 \%$ & 9 & 9 & $-3.4 \%$ \\
\hline Prendas De Vestir De Punto & 328 & 317 & $-3.3 \%$ & 8 & 8 & $-2.2 \%$ \\
\hline Prendas De Vestir De Tejido Plano & 27 & 21 & $-22.7 \%$ & 1 & 1 & $-18.4 \%$ \\
\hline Pesca & 474 & 353 & $-25.7 \%$ & 202 & 105 & $-48.0 \%$ \\
\hline Pescado & 144 & 144 & $0.4 \%$ & 34 & 30 & $-11.0 \%$ \\
\hline
\end{tabular}

Fuente : SUNAT - Año 2016

Debido a las grandes transformaciones de la economía, los clientes son cada vez más exigentes, informados y conscientes del papel importante que juegan, porque son quienes valoran el producto. Los cambios de hábitos, estilos de vida y preferencias han transformado el panorama 
cultural, social y económico del mundo, obligando a las empresas a ser más flexibles, adecuar los productos y servicios a las necesidades del cliente (Rajadell, 2010).

La aplicación de las herramientas de Lean Manufacturing puede lograr la mejora de procesos y reducción de desperdicios, pero su aplicación debe ser constante, sistemática y de compromiso total, además como consecuencia de su aplicación puede mejorar el entorno laboral de la organización.

\section{$\underline{\text { Exportación }}$}

¿Qué implica?

- Vender nuestros productos al exterior.

- Comprometerse en vender productos de calidad.

- Comprometerse en cumplir plazos y obligaciones.

- Tener en cuenta que se debe producir lo que se demanda.

- Contar con oferta exportable.

Las empresas medianas y pequeñas textiles exportan los productos de tejido punto con el incoterm $^{2}$ FOB (Free On Board), es decir entrega la mercadería pasando la borda del buque, desde ese momento el comprador asume todos los riesgos, costos a partir de ese momento. (Ver Figura 15)

Figura 15. Tipos de Incoterms

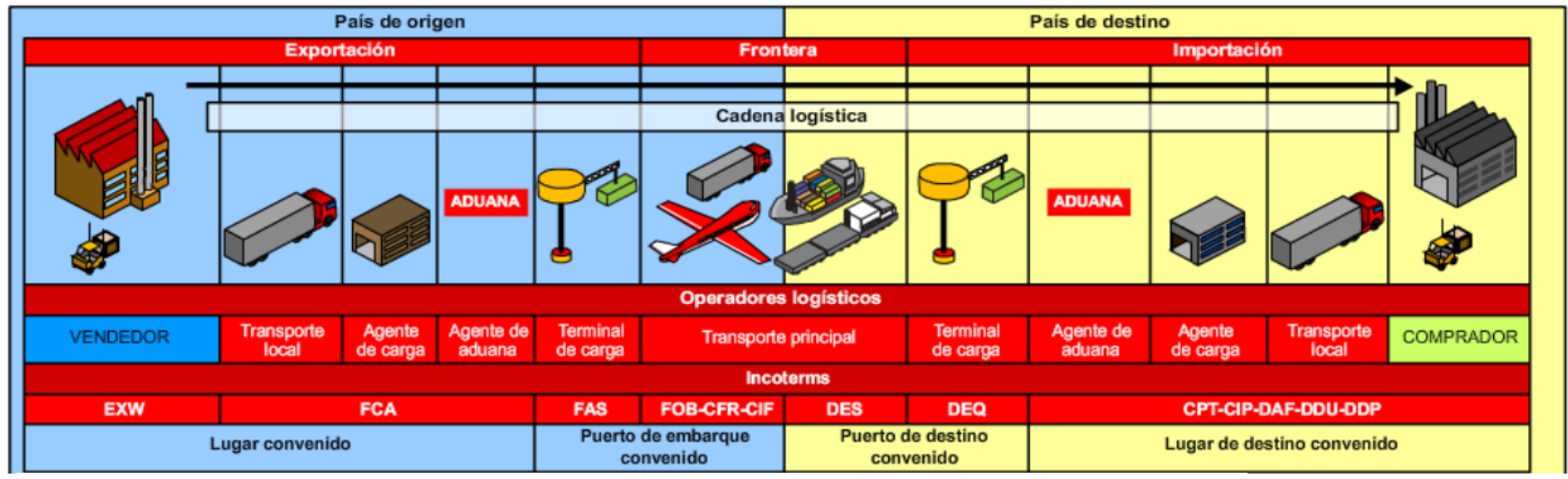

Fuente: Cámara de Comercio de Bogotá: Logística y distribución física

\footnotetext{
${ }^{2}$ Representa un término universal que define una transacción entre importador y exportador, de forma que ambas partes entiendan las tareas, costos, riesgos y responsabilidades, así como el manejo logístico y de transportación desde la salida del producto hasta la recepción por el país importador.
} 


\section{DIAGNÓSTICO GRUPAL DEL SECTOR TEXTIL}

El sector de confecciones necesita ser reinventado como lo indica Carlos Lozada (Vicepresidente de ADEX), por ello es importante la aplicación de nuevas técnicas de trabajo y mejora de procesos para que las PYMES utilicen su capacidad total de producción sin caer en el incumplimiento de pedidos o atrasos, si esto se logra entonces el subsector de confecciones de prendas de vestir alcanzará o posiblemente supere el 3.2\% que se pronostica para este año, en consecuencia las exportaciones peruanas se incrementarán en 9.6\% al generar US\$ 38.647 millones.

Entre el 2012 y el 2016, aproximadamente 779 empresas del sector textil-confecciones dejaron de exportar o desaparecieron proporcionalmente a la reducción de envíos, esto debido a la falta de competitividad. Esta cantidad es relevante, ya que una PYME puede tener en promedio 50 trabajadores, eso significa que se perdieron un poco más de 38000 puestos de trabajo, esta situación de desempleo ha ido mejorando levemente, pero no es suficiente para la recuperación total del sector y de la economía del país. Según el último Reporte de Inflación del Banco Central de Reserva del Perú (BCRP 2015) para el 2017 el PBI se ha revisado a la baja de 4.6\% a $4.3 \%$ y para el 2018 se espera que se mantenga en $4.2 \%$.

\section{Tipo de Investigación}

El trabajo de investigación es (exploratorio, descriptiva y explicativa) exploratoria por qué, mediante la revisión de literatura se busca profundizar en los desperdicios que presenta el sector textil. Descriptiva por qué, se analiza las causas de los desperdicios en los procesos críticos encontrados. Explicativa por qué, se encuentra las razones de las causas mediante el levantamiento de información.

\section{Alcance}

El presente estudio se basa en la investigación del sector de textil exportador en empresas ubicadas en Ate, La Victoria, San Juan de Lurigancho (SJL), Santa Anita, Santiago de Surco, Chorrillos, Miraflores, San Luis y Comas. La investigación abarca únicamente empresas de confecciones de prendas de vestir de tejido de punto para medianas y pequeñas empresas.

El estudio se llevar acabo en el año 2016 - 2017; sin embargo, los datos serán evaluados desde el año 2011 observando las diferentes tendencias del sector estudiado. 
Cabe mencionar que el proyecto no incluye la implementación del estudio en el sector sino en el diseño de la propuesta para la implementación.

Producto, espacio temporal, población y contexto

Se analiza la data histórica de los últimos 3 años de las exportaciones peruanas y se observa que la exportación de productos no tradicionales de las prendas de vestir representa mayor ingreso monetario del 2014 al 2016 pero con tendencia negativa y con una proyección optimista para el 2017. Teniendo presente esta información nuestro tema de investigación se orientará en el sector de prendas de vestir. (Ver Tabla 8)

Tabla 8. Proyección de las exportaciones peruanas 2016-2017

\begin{tabular}{|c|c|c|c|c|c|c|c|}
\hline \multirow{2}{*}{ Sectores } & \multicolumn{4}{|c|}{ Millones de US\$ } & \multicolumn{3}{|c|}{ Var. \% } \\
\hline & 2014 & 2015 & 2016 & 2017 & $2015 / 2014$ & $2016 / 2015$ & $2017 / 2016$ \\
\hline Total & 38,656 & 33,689 & 35,248 & 38,647 & $-12.8 \%$ & $4.6 \%$ & $9.6 \%$ \\
\hline Sector Tradicional & 26,921 & 22,776 & 24,524 & 27,246 & $-15.4 \%$ & $7.7 \%$ & $11.1 \%$ \\
\hline Agro Tradicional & 859 & 719 & 830 & 971 & $-16.3 \%$ & $15.4 \%$ & $17.0 \%$ \\
\hline Pesca Tradicional & 1,733 & 1,457 & 1,262 & 1,350 & $-15.9 \%$ & $-13.4 \%$ & $7.0 \%$ \\
\hline Petróleo & 4,721 & 2,377 & 2,000 & 2,040 & $-49.6 \%$ & $-15.9 \%$ & $2.0 \%$ \\
\hline Mineria Tradicional| & 19,606 & 18,222 & 20,433 & 22,885 & $-7.0 \%$ & $12.1 \%$ & $12.0 \%$ \\
\hline Sector No Tradicional & 11,735 & 10,913 & 10,723 & 11,401 & $-7.0 \%$ & $-1.7 \%$ & $6.3 \%$ \\
\hline Agropecuario y Agroindustrias & 4,236 & 4,410 & 4,727 & 5,389 & $4.1 \%$ & $7.2 \%$ & $14.0 \%$ \\
\hline Textil & 620 & 432 & 349 & 335 & $-30.4 \%$ & $-19.3 \%$ & $-4.0 \%$ \\
\hline Prendas de Vestir & 1,187 & 899 & 841 & 868 & $-24.3 \%$ & $-6.4 \%$ & $3.2 \%$ \\
\hline Pesca & 1,156 & 933 & 855 & 783 & $-19.3 \%$ & $-8.3 \%$ & $-8.3 \%$ \\
\hline Metal - Mecanico & 599 & 544 & 474 & 464 & $-9.2 \%$ & $-12.9 \%$ & $-2.0 \%$ \\
\hline Quimico & 1,521 & 1,403 & 1,339 & 1,389 & $-7.8 \%$ & $-4.5 \%$ & $3.7 \%$ \\
\hline Siderurgico y Metalurgico & 1,060 & 998 & 945 & 965 & $-5.9 \%$ & $-5.3 \%$ & $2.1 \%$ \\
\hline Mineria no Metalica & 666 & 698 & 645 & 654 & $4.9 \%$ & $-7.6 \%$ & $1.5 \%$ \\
\hline Maderas & 171 & 152 & 130 & 126 & $-11.2 \%$ & $-14.3 \%$ & $-3.0 \%$ \\
\hline Varios & 518 & 445 & 418 & 426 & $-14.2 \%$ & $-6.1 \%$ & $2.0 \%$ \\
\hline
\end{tabular}

Fuente : Gerencia de Estudios Económicos de ADEX

Según las exportaciones por sector económico, el sector de prenda de vestir, en particular de punto, a pesar de presentar una baja de 2.2\% en el periodo 2015 a 2016 aporta más a las exportaciones en comparación de tejido plano (Ver Tabla 9). Por lo tanto, nuestro estudio se basa en este tipo de prendas (prendas de vestir de punto).

Tabla 9. Exportaciones por Sectores Económicos - No Tradicional

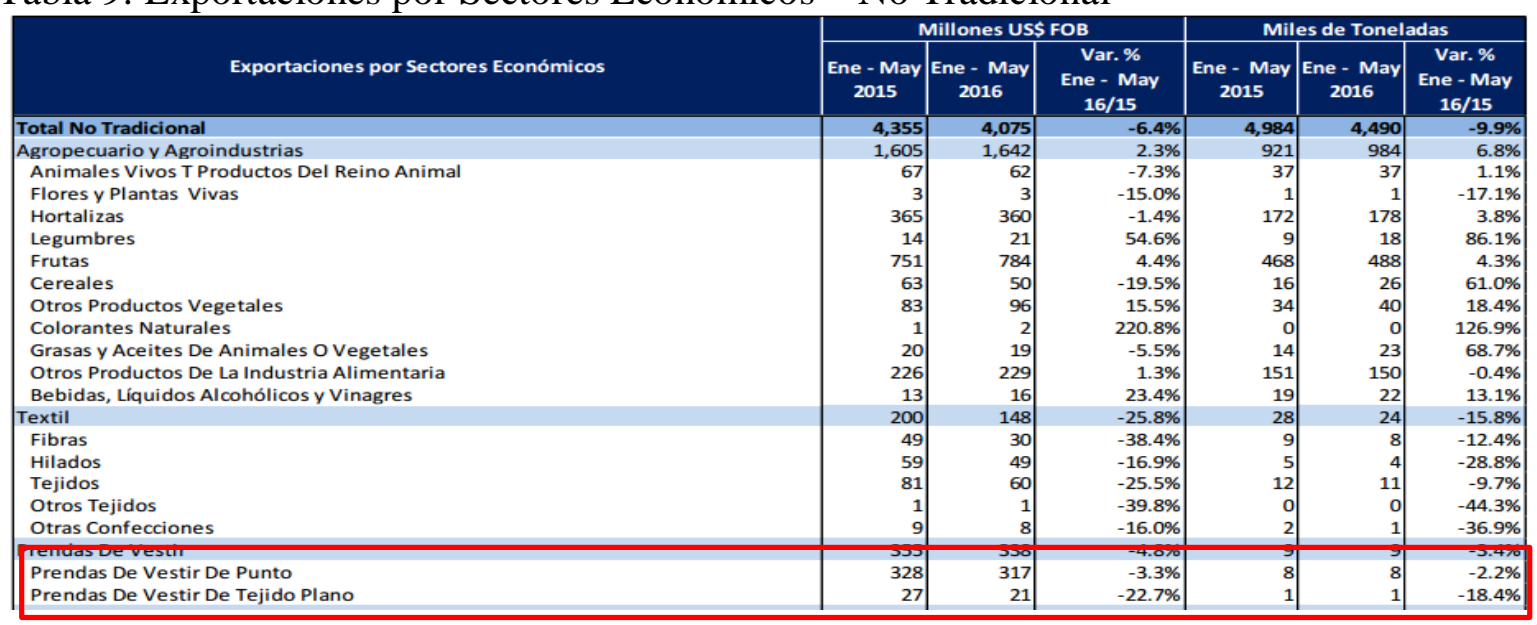


La mayor cantidad de prendas con un $50.2 \%$ se exporta a Estados Unidos, siendo este el mercado que da mayor influencia sobre el balance comercial de Perú y con ello en la economía peruana (ver Figura 16). Este mercado es conocido por tener altos estándares de calidad ante lo cual la industria de prendas de vestir requiere aplicar metodologías de alto impacto.

Figura 16. Distribución de las exportaciones según país de destino 2016

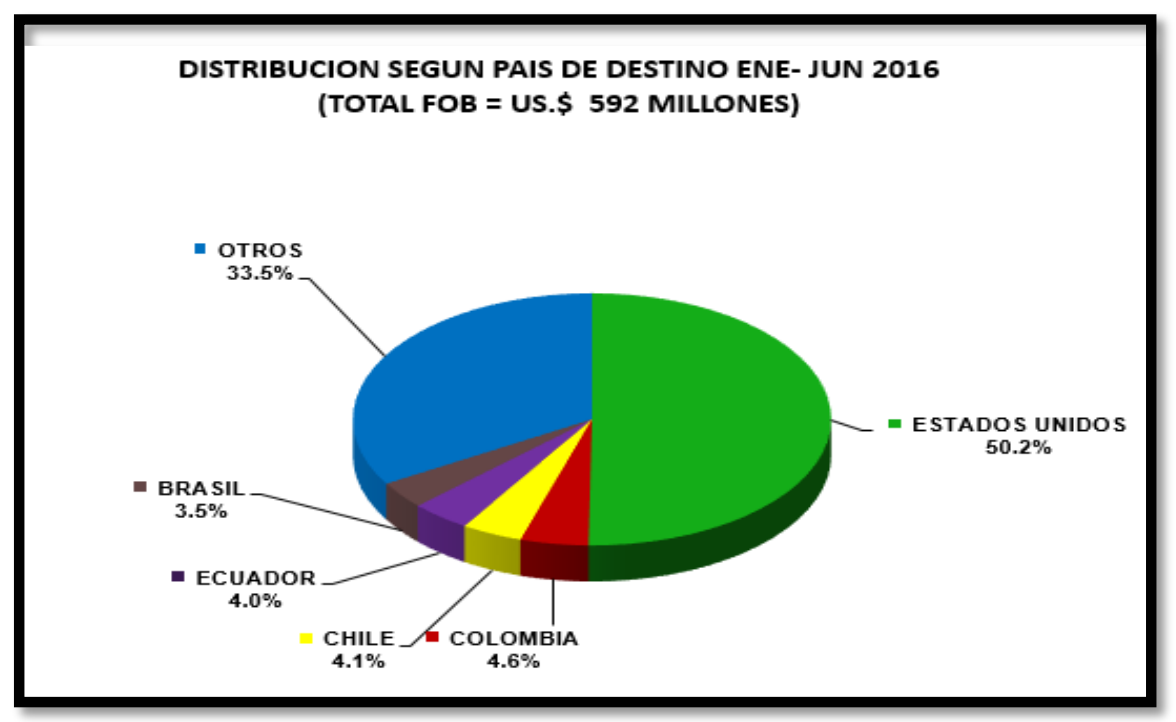

Fuente : SUNAT-Estadística de Exportación del Sector Textil y Confecciones

Para llevar a cabo la segmentación de distritos e identificar el tamaño de muestra se consideran las caracteristicas de las Pymes (Ver Tabla 10). Luego se utiliza la base de datos de ADEX, se realiza un filtro por partida arancelaria (6114.20.00), esta partida pertenece a las prendas de vestir de punto de algodón. En base a lo mencionado, se obtiene las empresas con mayor facturación e impacto económico, para el cual se toma en cuenta el valor FOB (millones de US\$) de exportaciones del año 2016. Como resultado se obtiene una población de 144 PYMES exportadoras. (Ver Tabla 11)

De la población mencionada se identifican los 9 distritos con mayor impacto económico, siendo estos: Ate, La Victoria, San Juan de Lurigancho, Santa Anita, Santiago de Surco, Chorrillos, Miraflores, San Luis y Comas, los cuales representan aproximadamente el 80\% de las exportaciones (Valor FOB en Miles US\$). 
Tabla 10. Características de Pymes

\begin{tabular}{|c|c|c|c|}
\hline Medianas & 1700 UIT & a & 2300 UIT \\
\hline Pequeñas & 150 UIT & a & 1700 UIT \\
\hline 1 UIT (2017) & \multicolumn{3}{|c|}{ S/. 4,050.00 } \\
\hline Tipo de cambio & 3.25 & Fecha de tipo de cambio 18/03/2017 \\
\hline
\end{tabular}

Fuente : Sunat- Año 2017

Tabla 11. Distritos Según Facturación e Impacto Económico

\begin{tabular}{|c|c|c|c|c|}
\hline DISTRITO & CANTIDAD & $\begin{array}{c}\text { VALOR FOB } \\
\text { 2016(Miles US\$) }\end{array}$ & \begin{tabular}{c|}
$\%$ \\
ACUMULADO
\end{tabular} & $\begin{array}{c}\text { CANT. } \\
\text { ACUMULADO }\end{array}$ \\
\hline ATE & 21 & 11940.86 & $14.88 \%$ & 21 \\
\hline LA VICTORIA & 34 & 11342.75 & $29.02 \%$ & 55 \\
\hline SAN JUAN & & & & \\
\hline LURIGANCHO & 28 & 9208.62 & $40.50 \%$ & 83 \\
\hline SANTA ANITA & 5 & 7116.26 & $49.37 \%$ & 88 \\
\hline SANTIAGO DE SURCO & 12 & 6014.63 & $56.87 \%$ & 100 \\
\hline CHORRILLOS & 13 & 5966.31 & $64.31 \%$ & 113 \\
\hline MIRAFLORES & 16 & 3891.94 & $69.16 \%$ & 129 \\
\hline SAN LUIS & 8 & 3707.14 & $73.78 \%$ & 137 \\
\hline COMAS & 7 & 3707.04 & $78.40 \%$ & 144 \\
\hline EL AGUSTINO & 6 & 2117.22 & $81.04 \%$ & 150 \\
\hline LINCE & 10 & 2040.86 & $83.59 \%$ & 160 \\
\hline SAN MARTIN DE PORRES & 5 & 1968.04 & $86.04 \%$ & 165 \\
\hline SAN ISIDRO & 7 & 1618.86 & $88.06 \%$ & 172 \\
\hline SURQUILLO & 4 & 1319.64 & $89.70 \%$ & 176 \\
\hline LURIN & 4 & 1009.27 & $90.96 \%$ & 180 \\
\hline JESUS MARIA & 4 & 861.33 & $92.03 \%$ & 184 \\
\hline SAN MIGUEL & 8 & 770.24 & $92.99 \%$ & 192 \\
\hline MAGDALENA DEL MAR & 5 & 723.46 & $93.90 \%$ & 197 \\
\hline CARABAYLLO & 1 & 643.13 & $94.70 \%$ & 198 \\
\hline SAN BORJA & 4 & 628.60 & $95.48 \%$ & 202 \\
\hline BREÑA & 1 & 593.96 & $96.22 \%$ & 203 \\
\hline PUEBLO LIBRE & 7 & 511.94 & $96.86 \%$ & 210 \\
\hline LA MOLINA & 5 & 504.55 & $97.49 \%$ & 215 \\
\hline SAN JUAN & & & & \\
\hline MIRAFLORES & 7 & 455.27 & $98.06 \%$ & 222 \\
\hline LOS OLIVOS & 2 & 386.52 & $98.54 \%$ & 224 \\
\hline LIMA & 7 & 325.40 & $98.94 \%$ & 231 \\
\hline BARRANCO & 2 & 229.60 & $99.23 \%$ & 233 \\
\hline SURCO & 3 & 222.17 & $99.51 \%$ & 236 \\
\hline VILLA EL SALVADOR & 1 & 129.46 & $99.67 \%$ & 237 \\
\hline INDEPENDENCIA & 5 & 115.38 & $99.81 \%$ & 242 \\
\hline
\end{tabular}




\begin{tabular}{|l|r|r|r|r|} 
PACHACAMAC & 2 & 99.28 & $99.94 \%$ & 244 \\
\hline CALLAO & 2 & 24.21 & $99.97 \%$ & 246 \\
\hline VENTANILLA & 1 & 22.50 & $99.99 \%$ & 247 \\
\hline BELLAVISTA & 1 & 5.04 & $100.00 \%$ & 248 \\
\hline Total general & 248 & 80221.47 & \multicolumn{2}{|c}{}
\end{tabular}

Fuente : Elaboración del Grupo de Investigación, tomado de Base de Datos ADEX

Figura 17. Distrito por Impacto Económico

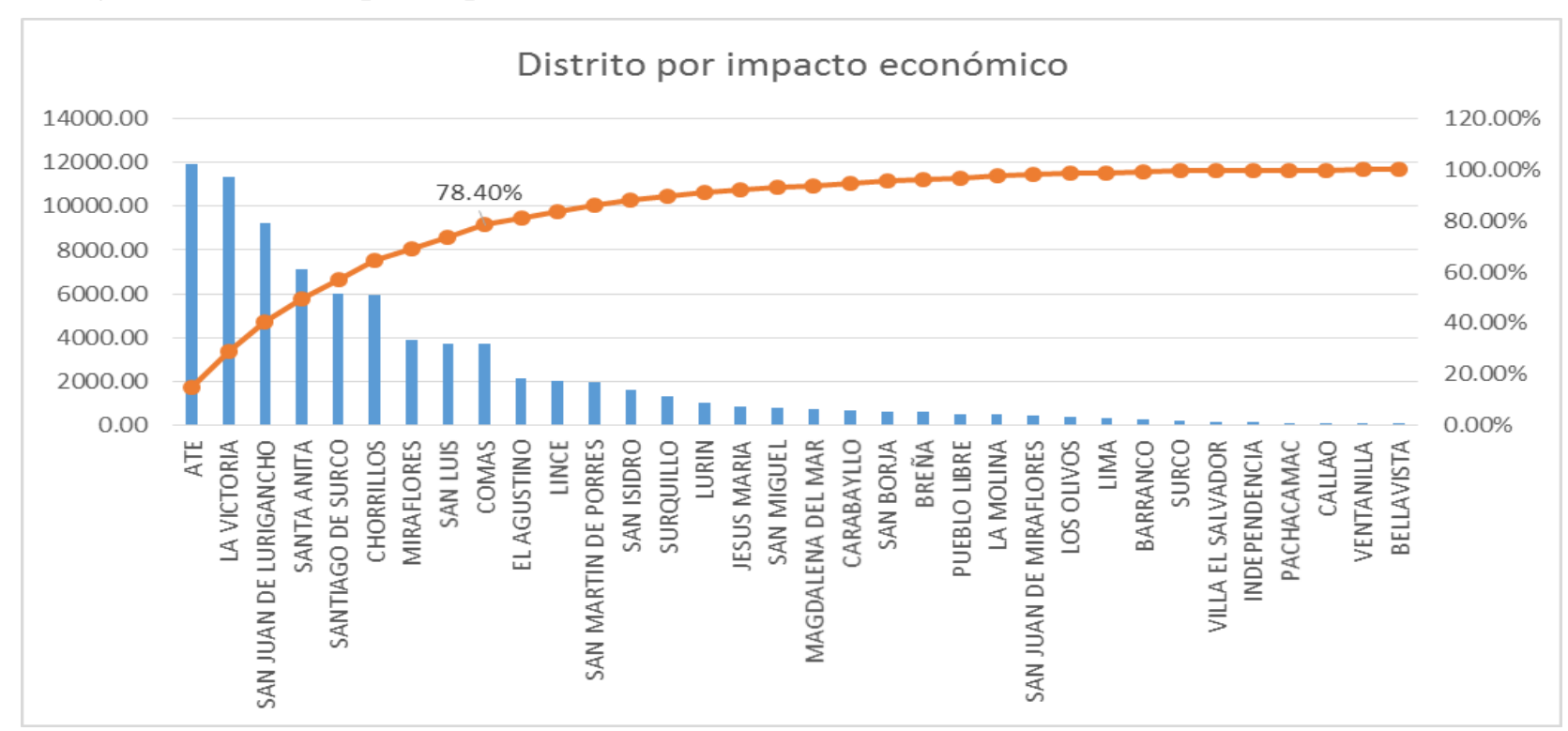

Fuente : Elaboración del Grupo de Investigación

Debido a que el proyecto de investigación no es validado directamente en cada una de las empresas encuestadas, para comprobar la efectividad de la aplicación de las técnicas de Lean Manufacturing, se realiza la validación del trabajo de investigación mediante la metodología de juicio de expertos en la materia.

\section{Tamaño de Muestra}

Para realizar la investigación se decide aplicar una encuesta con preguntas de los procesos clave, las cuales serán útiles para identificar procesos críticos y desperdicios en la cadena de valor.

Se realiza el cálculo de la muestra significativa donde se van a realizar las encuestas que nos va a permitir identificar la situación actual del sector (Ver Tabla 12). 
Tabla 12. Datos considerados para el cálculo de la muestra

\begin{tabular}{|c|c|c|c|c|}
\hline $\begin{array}{c}\text { Tamaño } \\
\text { de } \\
\text { Población }\end{array}$ & $\begin{array}{c}\text { Nivel de } \\
\text { Confianza }\end{array}$ & $\begin{array}{c}\text { Probabilidad } \\
\text { de éxito }\end{array}$ & $\begin{array}{c}\text { Probabilidad } \\
\text { de fracaso }\end{array}$ & Precisión \\
\hline 144 & $\begin{array}{c}90 \%- \\
\mathrm{z}=1.65\end{array}$ & $50 \%$ & $50 \%$ & $5 \%$ \\
\hline Fórmula & \multicolumn{3}{|c|}{$n=\frac{N x Z_{a}^{2} x p x q}{d^{2} x(N-1)+Z_{a}^{2} x p x q}$} \\
\cline { 1 - 2 }
\end{tabular}

Fuente : Elaboración del Grupo de Investigación

$\mathrm{N}=$ tamaño de la población

$\mathrm{Z}=$ nivel de confianza

$\mathrm{p}=$ probabilidad de éxito

$\mathrm{q}=$ probabilidad de fracaso

d = precisión (Error máximo admisible)

El el nivel de confianza elegido (90\%) es debido a que no se tiene acceso a todas las empresas filtradas (144) para poder realizar el trabajo de campo. Además, otro factor importante es el tiempo de estudio, éste no es suficiente para ejecutar la implementación de la propuesta a desarrollar. De acuerdo a los factores mencionados, se aplica la fórmula de muestreo y se obtiene como valor representativo 46 empresas, muestra significativa considerando la cantidad de empresas e impacto economico del sector, que es lo que presenta mayor disminución evidenciado en el \% negativo del sector no tradicional en la Pymes. Para la realizar las encuentas se eligirá las empresas aleatoriamente en los 9 distritos mencionados anteriormente.

Las encuestas realizadas se dividen en 11 procesos identificados según el proceso productivo del sector textil exportador, gracias a estas se obtiene como procesos críticos a: Costura, Corte, Diseño de producto, Acabado y Compras.

En la Figura $N^{\circ} 18$ se muestra el porcentaje acumulado de los procesos críticos identificados. 
Figura 18. Diagrama de Procesos Críticos en la Industria Textil de Confecciones

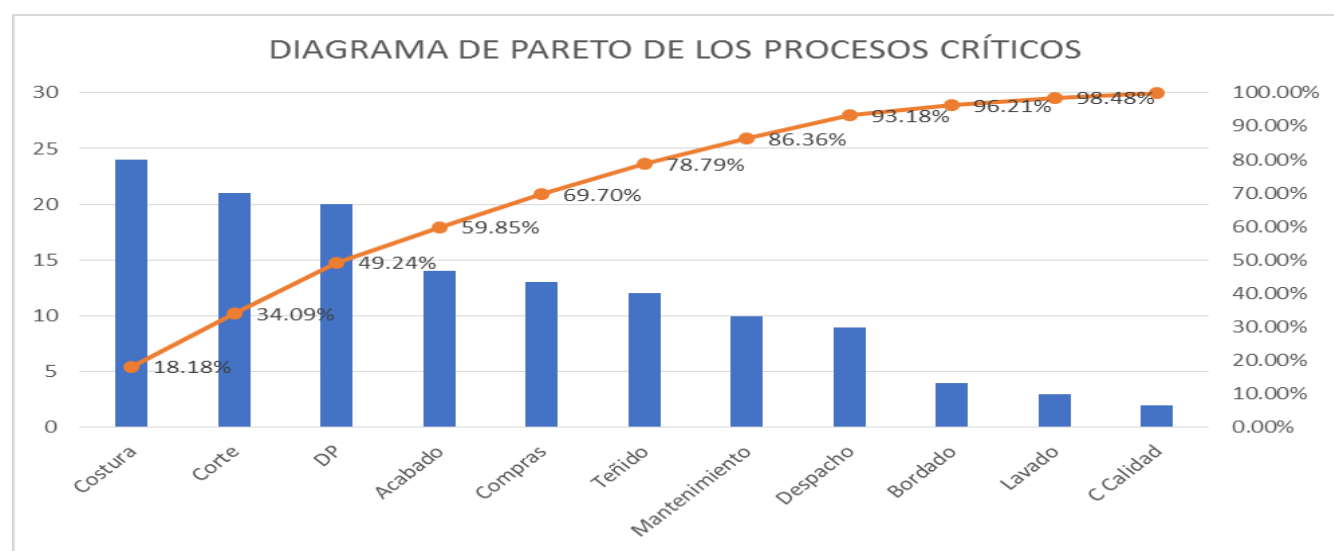

Fuente : Elaboración propia

Asimismo, con la información recopilada de las encuestas se identifican en los procesos críticos antes mencionados los siguientes desperdicios: espera, defectos, sobre procesamiento e inventario. (Ver Figura 19)

Figura 19. Desperdicios identificados en la Industria Textil de Confecciones

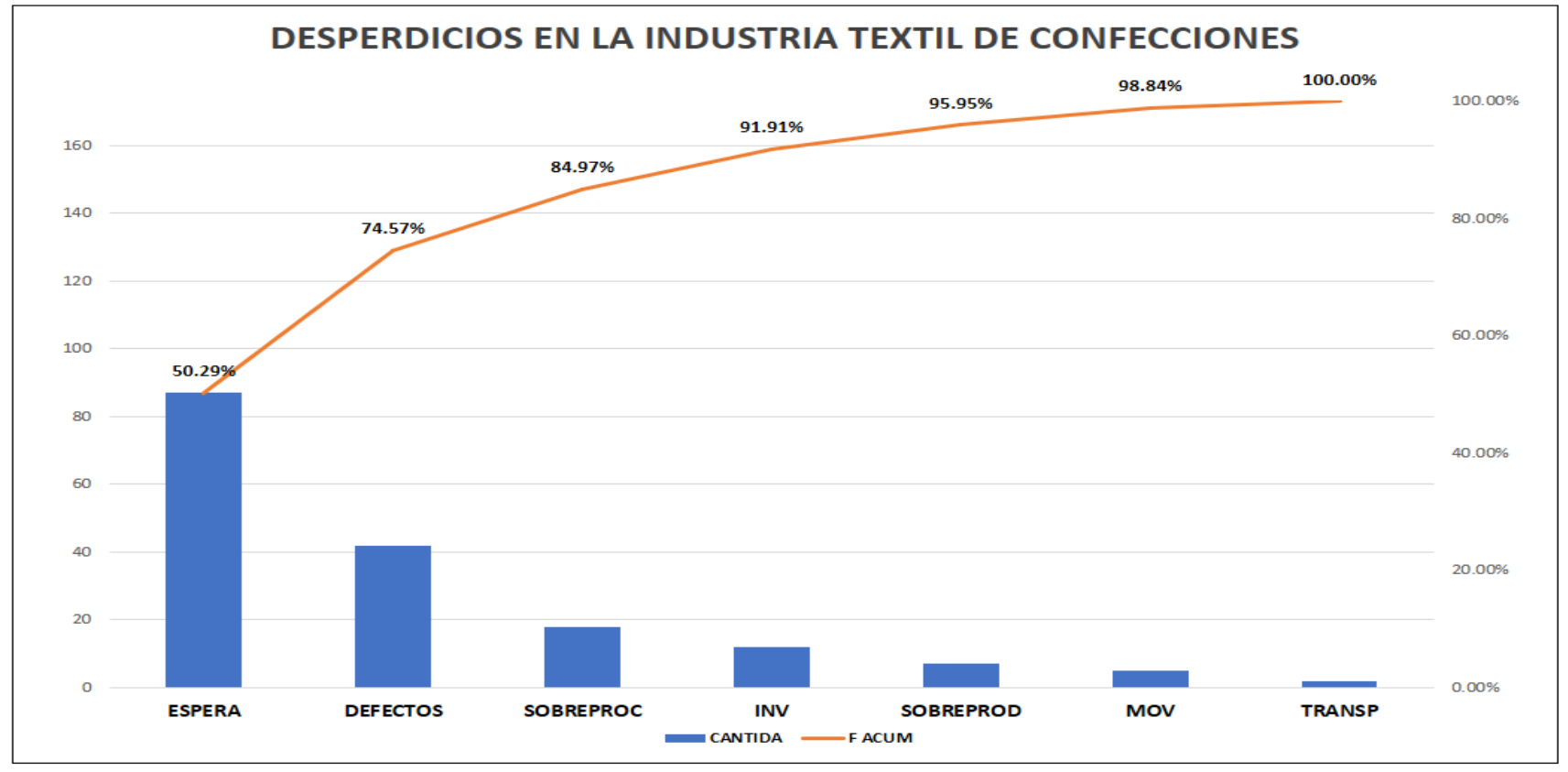

Fuente : Elaboración del Grupo de Investigación

Para asegurar la elección de los procesos críticos del sector se realiza una comparación de los Lead Time estándar del mercado con los datos obtenidos en las encuestas. De esta manera, se pudo afirmar los procesos críticos seleccionados, ya que presentan diferencias en el Lead Time de cada uno. (Ver Tabla 13) 
Tabla 13. Comparación de Lead Time por proceso de la industria textil de confecciones

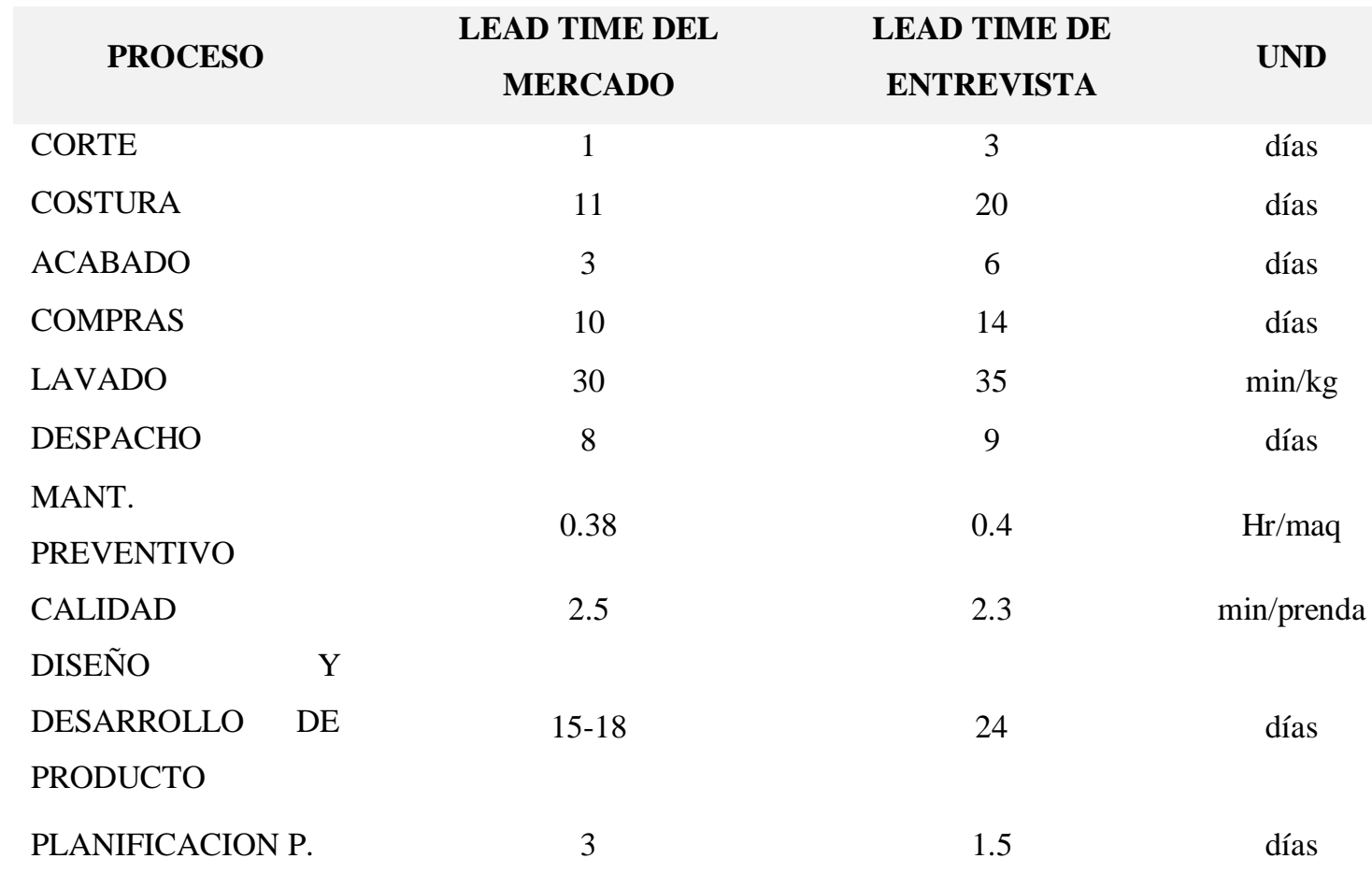

Fuente : Elaboración del Grupo de Investigación

Los datos estándar se obtienen de la revisión de literatura, en la Tabla 14 se observa las fuentes de donde se consulta dicha información.

Tabla 14. Fuente de los Lead Time estándar obtenidos

PROCESO FUENTE DE LEAD TIME ESTÁNDAR

Carvallo Munar, Edgardo Gabriel (2014)

COSTURA Propuesta de aplicación de conceptos de manufactura esbelta a una línea de producción de costura de una empresa de confecciones de tejido de punto para exportación

Bonillas Pastor, Elsie (2007)

CORTE Diseño de un sistema de producción modular en una empresa de confecciones.

Lamas Neciosup, Luis Alfonso (2015)

ACABADOS propuestas para mejorar la Planificación y Control de la Producción en una empresa de confección textil. Tesis de Pregrado.

Marín Valderra, J (2011)

COMPRAS Propuesta de rediseño de la cadena de abastecimiento de la empresa de confecciones GAF. 
DISEÑO Y Urquizo, Giovanna 2006, Análisis de desarrollo de producto para prendas de vestir DESARROLLO para exportación, PUCP 1-108

$\mathrm{DE}$

\section{PRODUCTO}

Fuente : Elaboración del Grupo de Investigación

\section{Justificación del criterio de comparación de Lead Time}

En la actualidad se está viviendo en un entorno de continua internacionalización que da lugar a que exista una mayor competencia a nivel nacional e internacional. Ante esta situación las empresas tienen que prepararse y tener un nivel de competitividad que les permita desenvolverse. Las empresas de la industria textil y confecciones, principalmente las empresas exportadoras de prendas de vestir, en su esfuerzo por mantenerse competitivos en el mercado, suelen comprender básicamente dos aspectos, que configuran la denominada competencia basada en el tiempo (time based competition): «entregas rápidas» y «entregas en fecha». (Garvin, 1994; pp 78), siendo el tiempo de entrega fundamental para este tipo de negocio, ya que sus operaciones van encaminadas a una mayor velocidad de desarrollo, de la mano de una entrega rápida. Es muy importante que las empresas del sector textil exportador, tengan la capacidad de atender los diferentes pedidos en el tiempo establecido por el cliente final, tiempo que cada vez más reducido.

Una de las ventajas que tiene el sector textil exportador peruano es que nos encontramos cerca del mercado individual más grande del mundo, que es Estados Unidos de Norteamérica.

Es por ello, que para este proyecto se considera el lead time para cada uno de los procesos como el factor crítico del sector, factor que será analizado a profundidad con finalidad de reducir los tiempos estimados para cada proceso y así poder entregar los pedidos en el tiempo establecido por el cliente final, llegando hacer competitivos en el mercado exportador de prendas de vestir. 
Figura 20. Lead time como factor crítico de los procesos

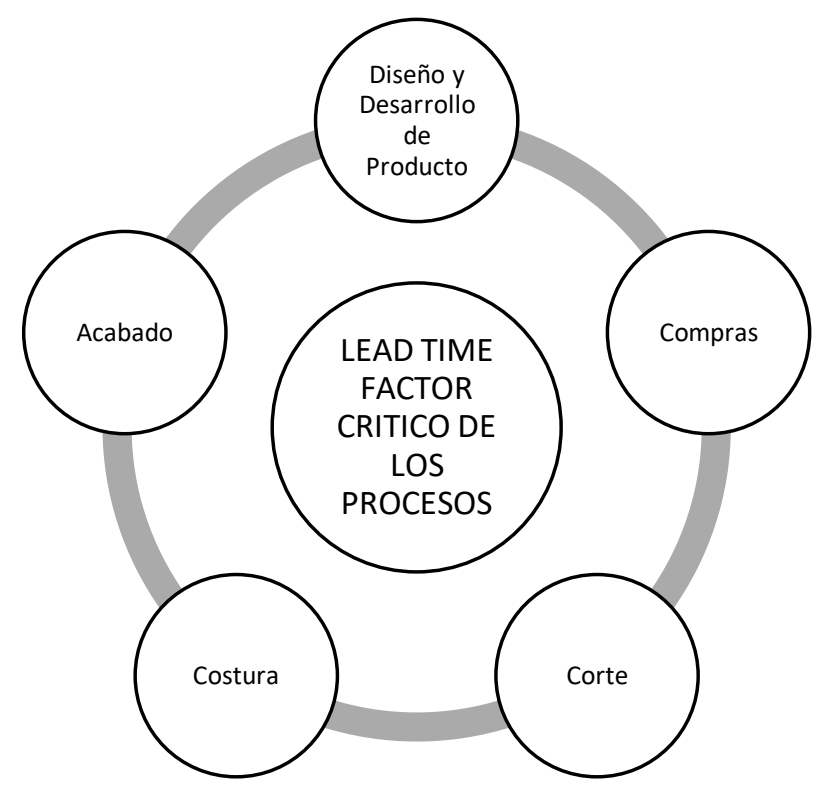

Fuente : Elaboración propia-Año 2017

\section{DIAGNÓSTICO ESPECÍfICO (Proceso de compras).}

Todas las industrias tienen ciertas complejidades en su cadena de suministro. Existen ciertas características que diferencian unas de otras. La cadena de suministros en la industria textil carece de colaboración entre las partes que la componen, debido a que su misma estructura compleja no facilita este intercambio de información. En tal sentido, para que las empresas textiles logren éxito, es recomendable incentivar una colaboración estrecha dentro de la cadena de suministro con la finalidad de asegurar una mejor calidad del producto y un mejor despacho del mismo; así mismo, se proveen valiosas capacidades para la solución de problemas.

Una de las variables más importantes en este proceso es el Lead time ${ }^{3}$, este se vuelve primordial para el éxito, ya que si reducimos el lead time, se obtiene rapidez para realizar los productos y se logra una mejora en el nivel de servicio.

\section{Analizando el proceso de compras en el sector textil}

El proceso de compras se caracteriza por realizarse en base a un sistema pull, puesto que se produce una orden en base a un pedido o cuando la demanda actúa. Se desempeña de forma

\footnotetext{
${ }^{3}$ Tiempo que transcurre desde que se inicia un proceso de producción hasta que se completa.
} 
autónoma. Por ende, lo que se busca es controlar la variabilidad del proceso debido a las variaciones de la demanda.

El sistema de producción de este sector es lote por lote, ya que se trabaja bajo pedidos. Sólo después del contrato o del encargo de un determinado producto es que la empresa produce para el cliente. Una buena gestión de compras asegura lograr las adquisiciones de los materiales con la calidad necesaria, en cantidad suficiente y con costo mínimo que garantice la satisfacción del consumidor en el momento que él lo requiera. De la misma manera, en la Figura 21 se puede observar los tiempos internos y externos en el proceso de compras, lo que facilita la identificación de tiempos que pueden ser manejados por la empresa y aquellos que no pueden controlar. Es decir, actividad híbrida como es el caso de evaluación de cotización y el seguimiento y abastecimiento donde el tiempo es determinado por el proveedor.

Figura 21. Tiempos Internos y Externos en el proceso de compra

TIEMPOS INTERNOS Y EXTERNOS EN EL PROCESO DE COMPRAS

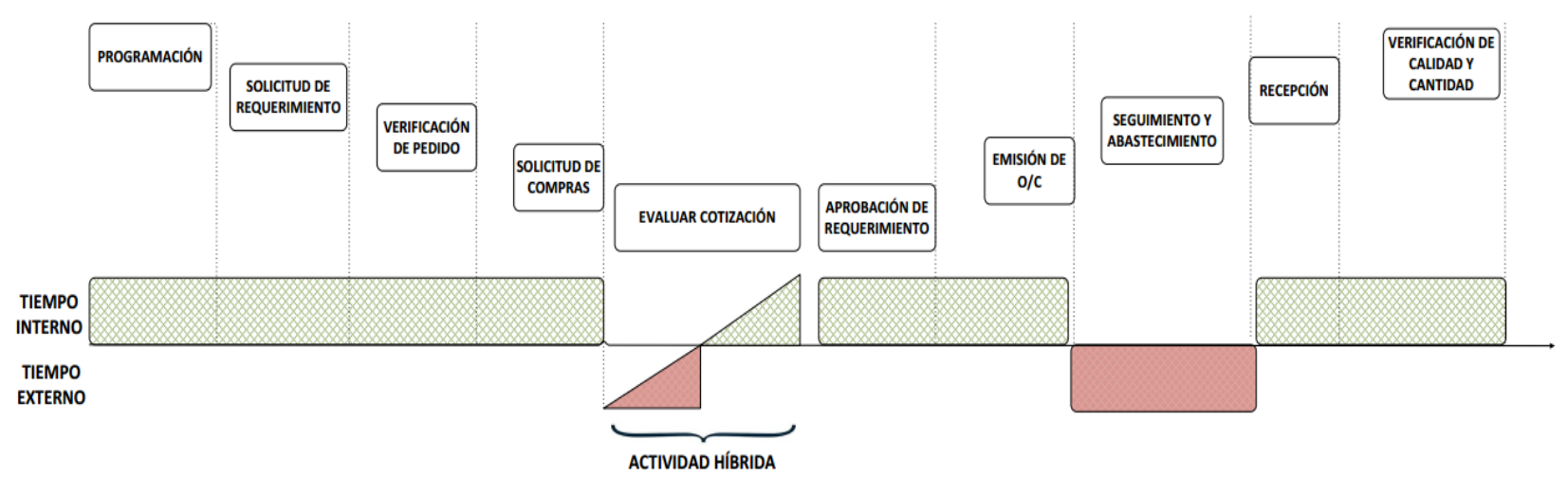

Fuente : Elaboración propia- Año 2017

\section{Desarrollo del Diagnóstico}

Según el trabajo de investigación de Marín Juliana (2011), las compras más representativas de este sector es el de telas, hilos y etiquetas. Estas compras se realizan con un lead time de 10 días estableciendo ese tiempo como estándar de la industria textil en compras. Sin embargo, mediante el trabajo de campo se obtuvo un lead time de 14 días en promedio excediendo en 4 al estándar del sector (Véase en la Tabla 15). Debido a lo mencionado, el proceso de compras resulta como proceso crítico en el sector textil exportador. 
Tabla 15. Comparación del Lead Time estándar del proceso de Compras

ITEM Lead time estándar Nacional Lead Time sector estudiado

$\begin{array}{lcc}\text { Tela procesada } & 4 \\ \text { Etiquetas } & 10 \text { días } & 14 \text { días } \\ \text { Hilos } & 8 \text { días } & 12 \text { días } \\ & 1 \text { día } & 2 \text { días }\end{array}$

Fuente : Elaboración propia

Las compras pueden realizarse en diferentes órdenes de compras separadas y autónomas, pero que serán utilizadas para un mismo pedido, estas se realizan una vez se obtenga la aprobación (Ver Figura 26). Además, se puede observar en la Figura 22, que el lead time de telas marca el inicio de la producción de los T-shirt, por lo que es ideal trabajar en la reducción del lead time de tela reduciendo la holgura existente al mismo nivel del lead time de etiquetas o incluso menos. Si bien es cierto, el lead time de etiqueta es considerable debido a los 4 días demás que presenta según el estándar del sector, este tiene holgura para llegar hasta el proceso en el cual se necesita su ingreso, por lo que el lead time de tela es más importante.

Figura 22. Representación de Lead Time promedio de materias primas

\section{REPRESENTACIÓN GRÁFICA DE LOS LEAD TIME DE LAS MATERIAS PRIMAS PARA UN PEDIDO}

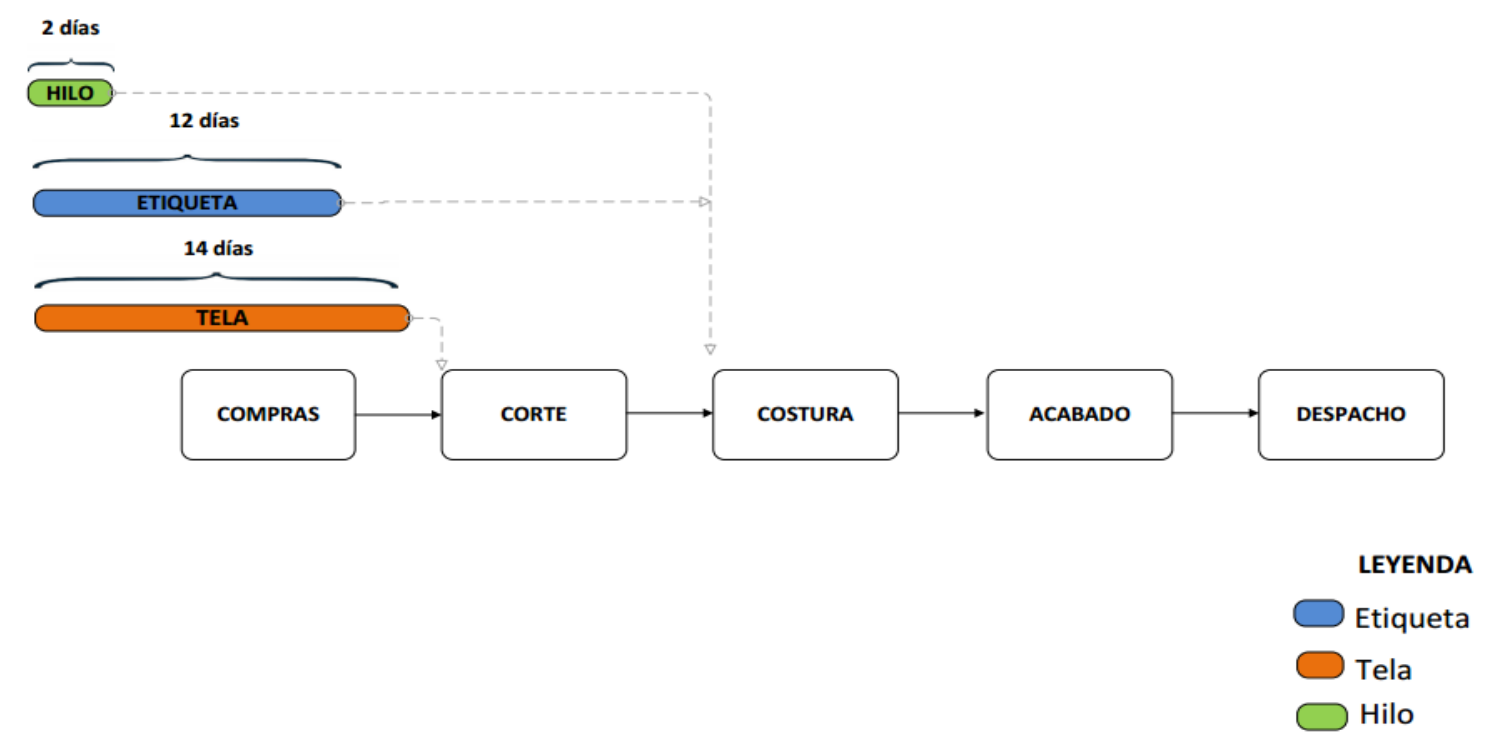

Fuente : Elaboración propia- Año 2017

\footnotetext{
${ }^{4}$ Tela teñida, lista para suministrar a fabricantes de productos textiles.
} 
Según encuestas realizadas a las pequeñas y medianas empresas del sector textil de confecciones, la Tela es el producto más importante para iniciar la producción de las prendas que serán exportadas, por ello el Lead Time de la adquisición de esta afecta en mayor medida a las Pyme's del sector. (Ver Figura 23)

Las otras materias primas también son importantes, pero pueden llegar en el trascurso del proceso productivo.

Figura 23. Porcentaje de Compras por tipo de materia Prima

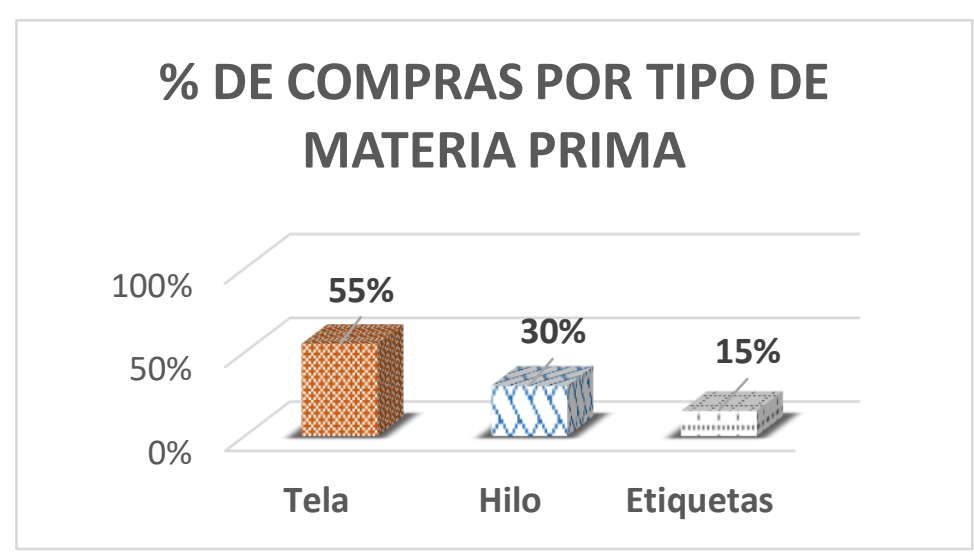

Fuente : Elaboración propia- Año 2017

De acuerdo a lo mencionado, las compras de tela ascienden a un $55 \%$ como prioridad al momento de realizar las compras, siguiendo la de hilos con un $33 \% \mathrm{y}$, por último, pero no menos importantes las etiquetas con un $15 \%$.

De la misma manera, cabe mencionar que en este sector se realizan compras de diferentes tipos de tela como: tela cruda, que va adquirir el color especificado según ficha técnica una vez comprada o la tela procesada de punto de algodón (tela teñida, lista para suministrar a fabricantes de productos textiles), esta última ingresa directamente al proceso de confección una vez comprada y recepcionada. Para este trabajo se realiza un enfoque en la adquisición de tela teñida lista para la confección, puesto que la mayoría del sector textil entrevistado lo adquiere de esa manera ya que el costo es menor y no necesitan maquinaria adicional para hilar o teñir la tela.. (Ver Figura 24). 
Figura 24. Adquisición de tela cruda Vs Tela procesada

\section{ADQUISICIÓN DE TELA CRUDA VS TELA PROCESADA}

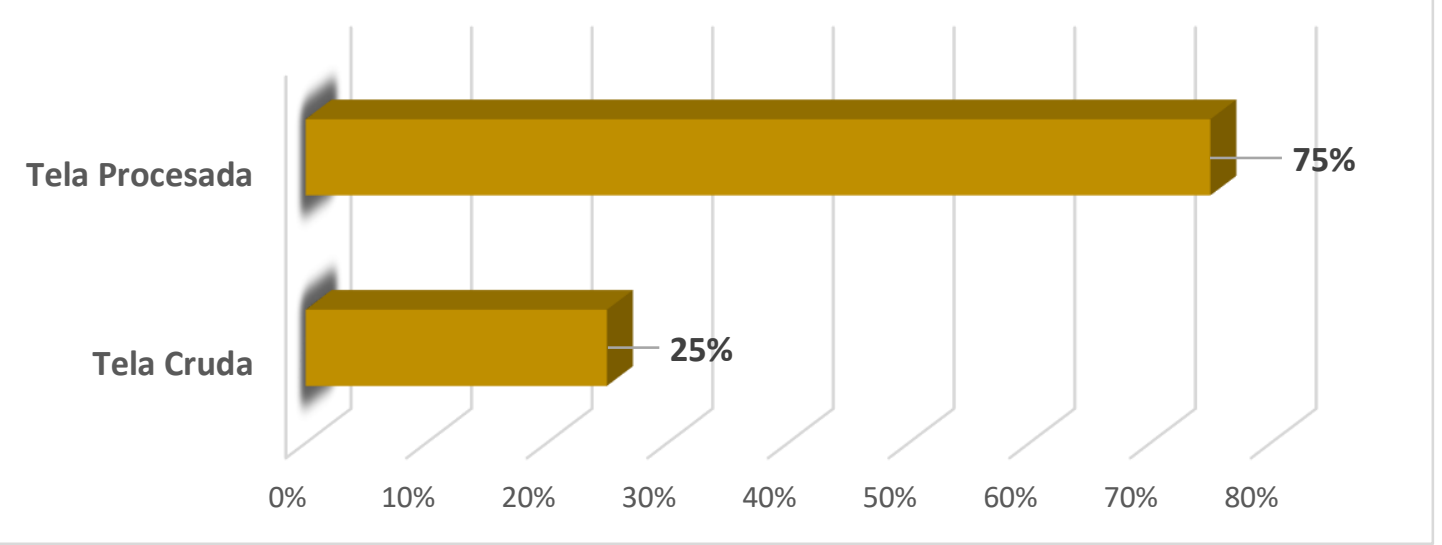

Fuente : Elaboración propia- Año 2017

Así mismo, según las encuestas realizadas las compras de las diferentes empresas del sector textil son nacionales e internacionales. A continuación, se presenta el siguiente gráfico.

Figura 25. Porcentaje de Compras nacionales Vs. Compras internacionales de Tela para la confección

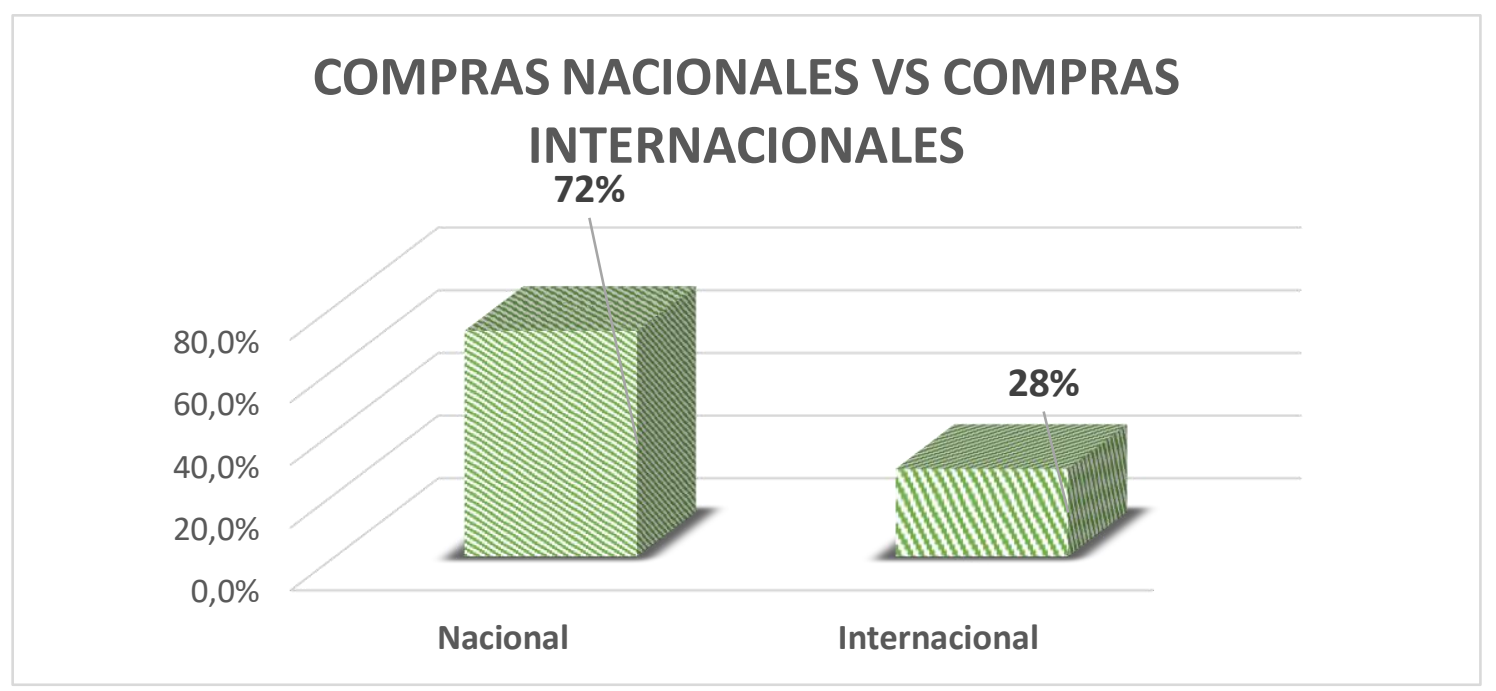

Fuente : Elaboración propia- Año 2017

En el gráfico se puede observar que el mayor porcentaje de compras de este sector es realizado a nivel nacional (72\%). En base a los resultados de las encuestas se puede decir que esto se debe a la facilidad de acceso a la empresa (cercanía de proveedores), mayor confiabilidad detectando claramente su proveniencia y tiempo de entrega. 
Mediante este análisis realizado en el proceso de compras, se determina la delimitación de la investigación donde se evidencia que la compra más importante es el de la tela procesada (lista para la confección), la cual se adquiere en territorio nacional.

Problema que ocasiona el Lead Time excesivo en el abastecimiento de tela (proceso de compras)

La falta de colaboración entre los componentes de la cadena de suministros textil y la poca colaboración entre los proveedores de materiales y el fabricante de las prendas desarrollan problemas que impactan en la competitividad del sector.

Los problemas que generan lead time excesivo en el proceso de abastecimiento según revisión de literatura son:

Errores en la generación del pedido.

No cuentan con personal capacitado.

No existe una adecuada planeación de compra.

No mantienen una relación con los proveedores.

Materiales con desperfectos.

Retraso para realizar el pedido.

Restricción de presupuesto para realizar las compras.

(Prado, 2014) y (Escobar, 2007)

Los problemas que el lead time sea excesivo en el proceso de abastecimiento en sector textil estudiado contrastando con la revisión de literatura son:

Tabla 16. Problemas identificados que generan un Lead time excesivo en el proceso de abastecimiento tela

\begin{tabular}{|l|c|}
\hline PROBLEMAS & $\%$ \\
\hline Error de cálculo en las cantidades de los materiales a comprar. & $20 \%$ \\
\hline Retraso en atender los requerimientos. & $25 \%$ \\
\hline Restricción de presupuesto para realizar las compras. & $5 \%$ \\
\hline Defectos en los materiales recepcionados. & $15 \%$ \\
\hline Retraso en la entrega por parte del proveedor para la atención del pedido extra. & $\mathbf{3 5 \%}$ \\
\hline
\end{tabular}

Fuente : Elaboración propia - Año 2017

NOTA: La ponderación se realiza según las encuestas realizadas en el trabajo de campo. 
Según la tabla anterior, el problema con mayor frecuencia mediante la realización de encuesta y revisión de la literatura es: Retraso en la entrega pedidos de compra por parte del proveedor para la atención del pedido extra con un $35 \%$ de representatividad dentro de todos los problemas.

Para visualizar todo el proceso de compras y entender completamente el flujo de información y materiales, es necesario detallar los sub procesos con tiempos y cantidad de inventario mediante el VSM (Mapa de flujo de valor), esto se lleva a cabo gracias a la información obtenida de las encuestas, de esta manera se observa la situación actual del proceso de compras identificando actividades que no agregan valor para posteriormente eliminarlas. (Ver Figura 26) 
Figura 26. Mapa de flujo de valor actual del proceso de Compra de tela en el sector Textil de confeccione

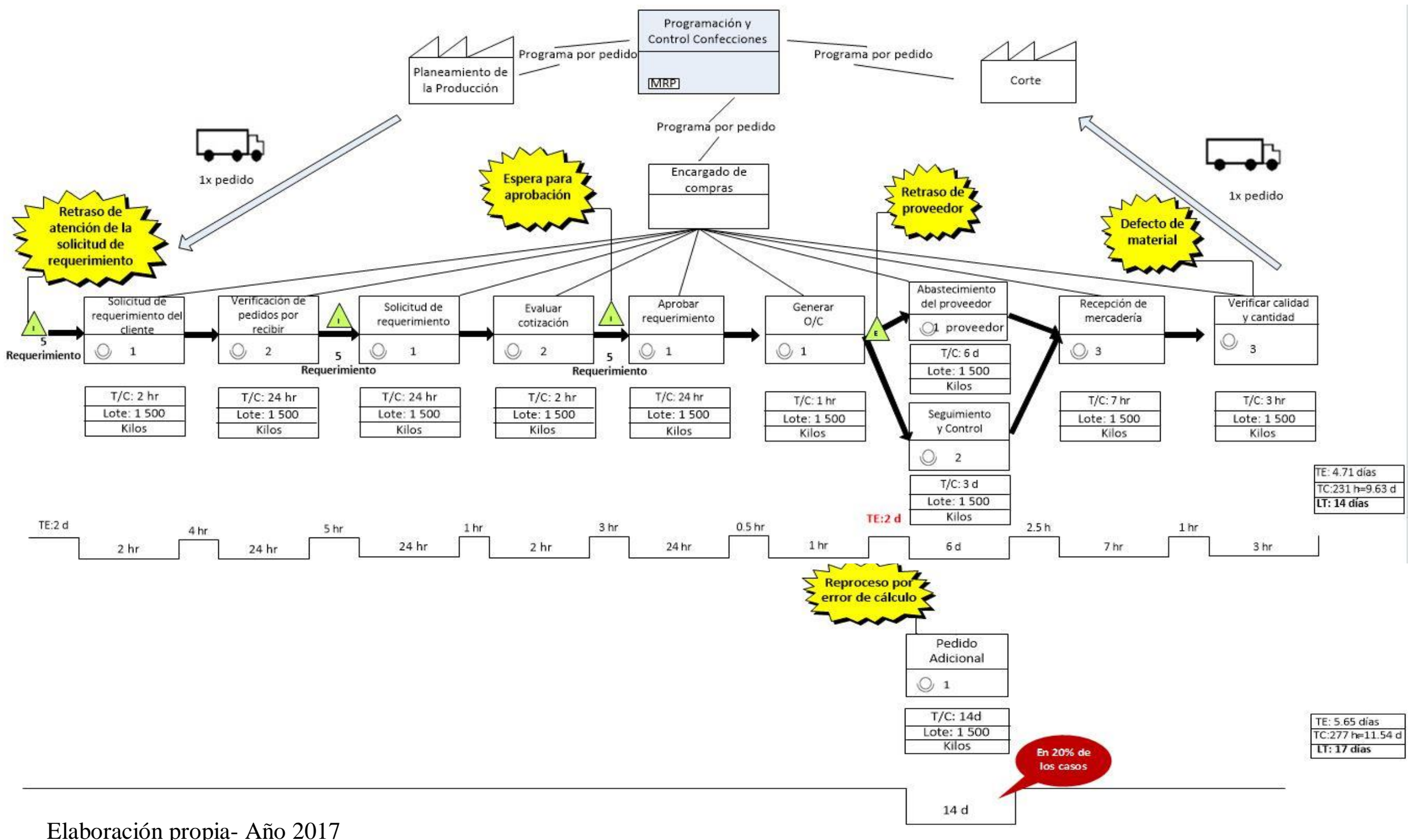

Elaboración propia- Año 2017 
El VSM del proceso de compra de tela muestra los detalles escondidos que aportan ineficiencia al proceso facilitando la identificación de problemas para solucionarlos con la aplicación de las herramientas lean. Como se puede observar en el VSM, al inicio del proceso de compras se evidencia uno de los problemas identificados anteriormente como es el retraso de atención de órdenes de compra, ya que se espera tener 5 órdenes para recién atender la solicitud de requerimiento, siendo el tiempo de espera de 2 días. Asimismo, existe espera para aprobar la cotización, ya que demoran en evaluar los costos del pedido. Según el análisis realizado al sector, en promedio los proveedores tienen 2 días de incumplimiento generando un retraso en el tiempo de entrega del pedido. También, el proceso de verificar la calidad y cantidad del pedido asciende a 3 horas, puesto que en ocasiones se detectan defectos de material. Finalmente, el error en cálculo comenzando por una nueva "solicitud de requerimiento" para un mismo pedido, lo que origina un reproceso de compras y trae consigo el retraso o la incertidumbre del cumplimiento de la entrega del pedido por parte del proveedor, esto sucede en el $20 \%$ de los casos. (Ver Figura 26)

\section{De esa forma se presentan dos casos:}

- De todas las órdenes de compra emitidas el 80\% representa al primer caso, donde se observa que el Lead Time promedio del proceso de compras es de 14 días, estos días engloban una serie de actividades innecesarias que se evidencian en: el retraso de la atención de la solicitud de requerimiento, espera para la aprobación, retraso por parte del proveedor para la entrega de las necesidades y las fallas que presenta el material.

- El segundo caso es cuando ocurre el reproceso de la orden de compra por error de cálculo, obteniendo un lead time general 28 días, debido a que se vuelve a realizar la actividad de compra desde el inicio. Sin embargo, este pedido adicional representa 2.8 días, ya que se da solo el $20 \%$ de los casos. Es decir, 14 días más del pedido adicional multiplicado por el $20 \%$, en total suman 2.8 y si se adiciona los 14 días que se demoran en realizar el proceso de compras, da como resultado 17 días en consecuencia del reproceso por haber calculado mal. Además, trae consigo la incertidumbre de la atención del proveedor para el pedido extra.

Cabe mencionar que el alcance del proceso es desde la recepción de solicitud de requerimiento del cliente (proceso de planeamiento de la producción), evaluación de cotización, selección del proveedor, aprobación de la solicitud, generación de orden de compra, seguimiento del 
proveedor, recepción de mercadería y verificación de la calidad. De la misma manera, existen restricciones del proceso como; condiciones de pago y lugar de recepción de mercadería. Se realiza el flujograma del proceso de compras según el trabajo de campo realizado para analizar las secuencias que presenta. 
Figura 27. Flujograma del proceso de Compra del sector textil de confección de prenda de vestir de tejido punto

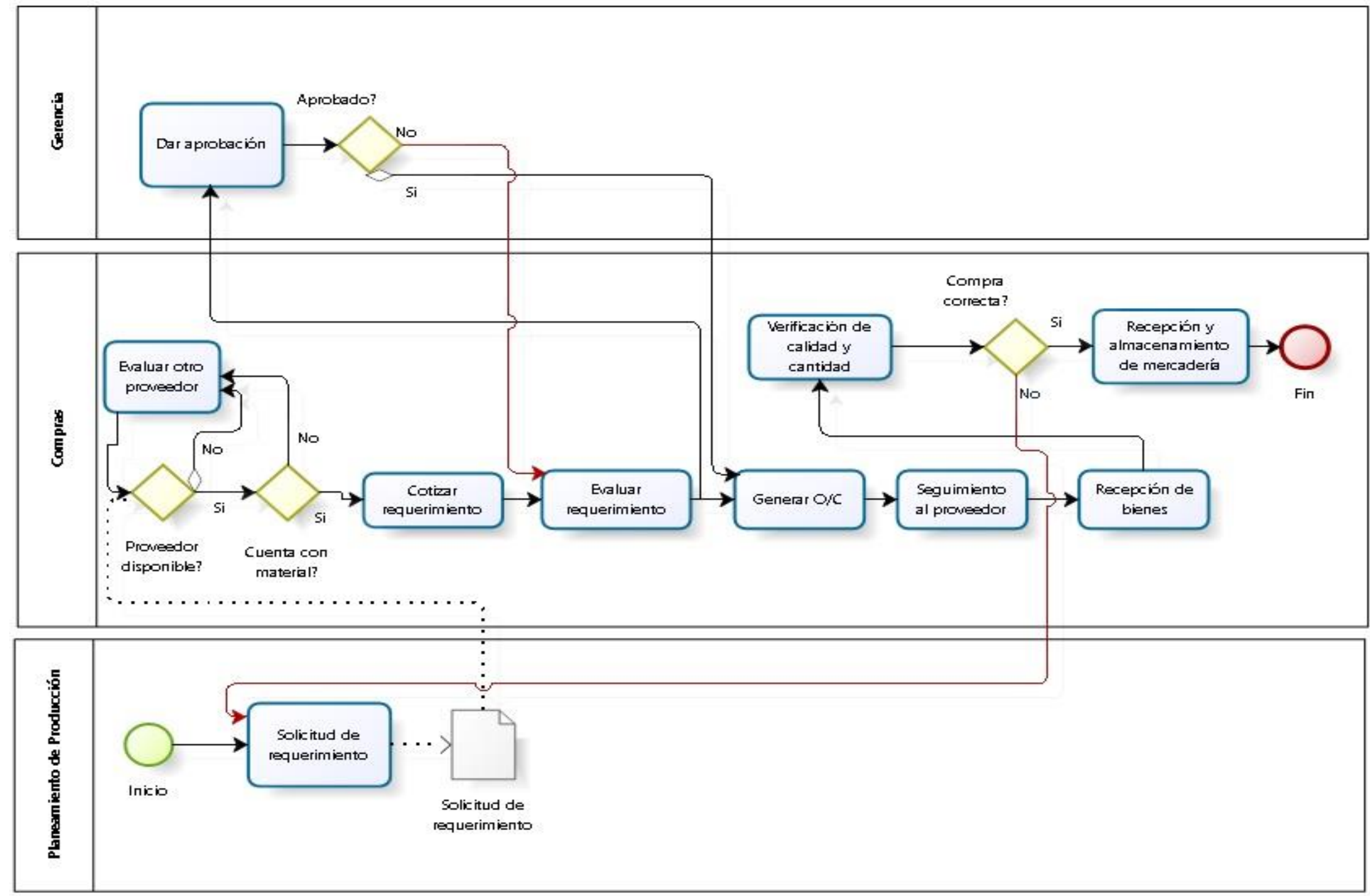

Fuente: Elaboración Propia- Año 2017 
Del flujograma presentado se puede observar las secuencias de las actividades que se realizan en el proceso de compras, además también se presentan las relaciones que tiene con los involucrados y las tareas específicas a realizar en el proceso. De la misma manera, se analiza la situación actual en el proceso donde se evidencia que no cuentan con relaciones estables con los proveedores debido a que evalúan cada vez que quieren realizar las compras lo cual genera un retraso, las órdenes demoran en ser aprobadas y no se realiza las compras correctas por lo que vuelven a realizar la solicitud de requerimiento. El flujograma permite comprender el proceso de compras y además identificar los problemas y oportunidades de mejora que en este caso coincide con los problemas detectado en el VSM planteado que genera un lead time excesivo en el abastecimiento de tela.

El proceso de compras ocupa una posición importante en la mayor parte de las organizaciones, ya que las partes, componentes y suministros adquiridos por lo general representan $40 \%$ a $60 \%$ del valor de ventas de un producto final. Esto significa que las reducciones de costo relativamente pequeñas obtenidas en la adquisición de materiales pueden tener un gran impacto en las utilidades que mejoras similares en otras áreas de costos-ventas de la organización (Ballou, 2004).

Por lo tanto, se puede afirmar que la función de compras posee hoy en día un rol estratégico dentro de una organización. Una vez analizado la situación del sector mencionado se concluye que el problema principal que hace crítico el proceso de compras es el del lead time excesivo en el proceso de abastecimiento de telas que principalmente según lo identificado en el sector se debe al retraso en la entrega por parte del proveedor del pedido extra. De acuerdo a lo mencionado, se procede a determinar las causas por las cuales el proveedor no cumple satisfactoriamente las órdenes de compra emitidas de los pedidos. 
Figura 28. Esquema de Causa- raíz del problema de Retraso en la entrega por parte del proveedor del pedido extra

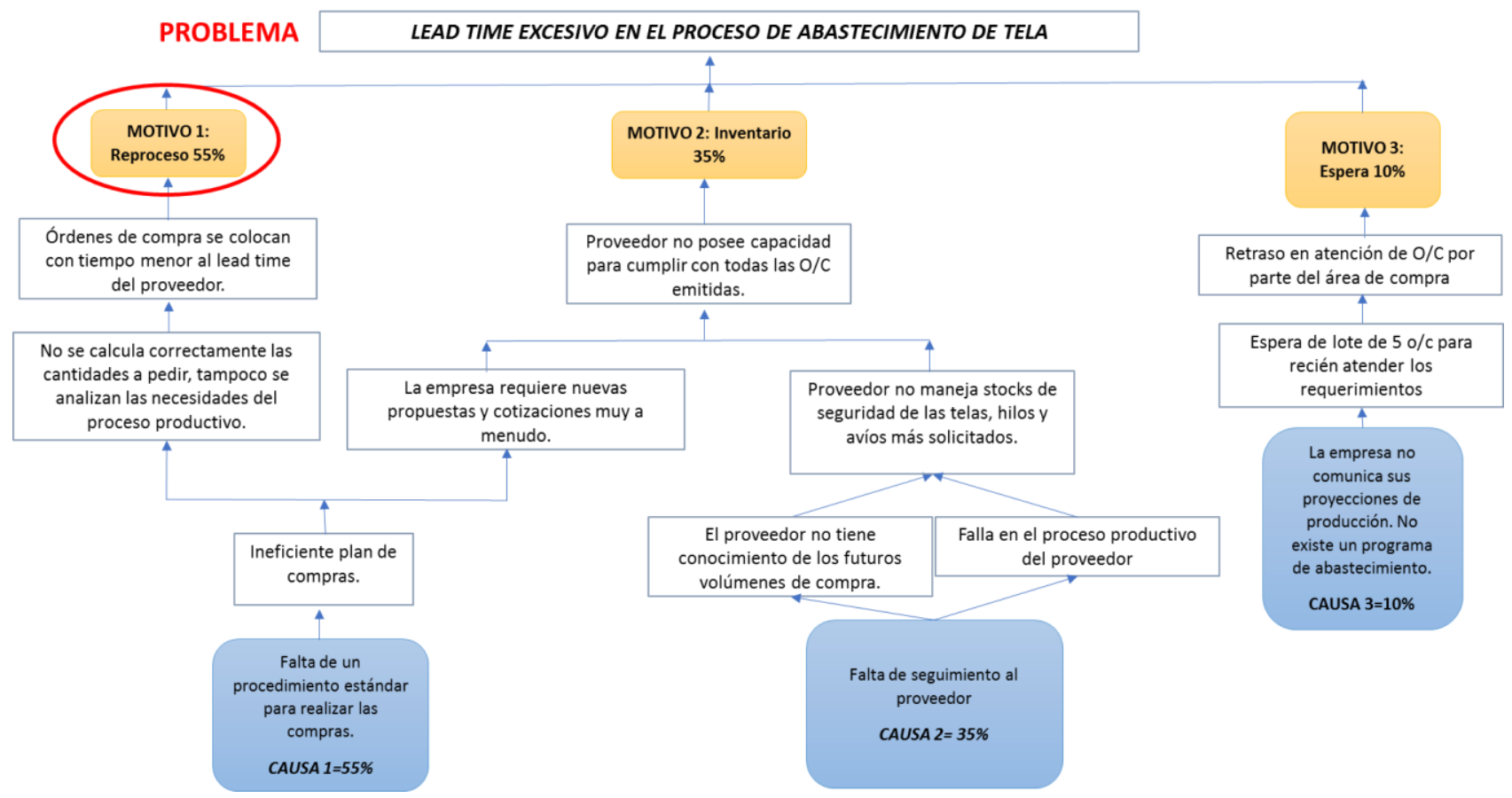

Fuente : Elaboración Propia- Año 2017

*Referencia (Valderrama, 2011)

Se identifican que las causas raíz del problema son: Falta de un procedimiento para realizar las compras, la empresa no comunican sus proyecciones de producción, no existen procedimientos para el seguimiento del proveedor, ya que la empresa tiene como política no compartir ninguna información con sus proveedores (Ver Figura 28).Todo lo mencionado genera la elaboración de órdenes de compras inadecuadas por lo que el lead time asciende a 4 días de más como se observa en el VSM mostrado. Además de que, en un $20 \%$ de casos se tiene que volver a realizar el proceso de elaboración de órdenes de compras desde el proceso inicial que trae mayor probabilidad de incumplimiento del proveedor por la incorrecta emisión de órdenes de compras lo que hace un total de 7 días.

\section{Impacto Económico}

Es preciso señalar la importancia de corregir este problema, pues debido a ello no se llega a concretar las ventas en el tiempo acordado. Son 4 días aproximadamente de lead time excesivo que 
presenta actualmente el abastecimiento de tela y que en algunos casos se adiciona 3 días más (debido al reproceso de compras que ocurre en un $20 \%$ de los casos); ocasiona en total 7 días aproximadamente de lead time. Por lo mencionado, es importante y considerable la reducción del lead time, debido a que otorga mayor flexibilidad, capacidad de respuesta y el aporte a las prioridades competitivas claves de este sector. Además, es importante mencionar que se debe de hacer pedidos de acuerdo a la necesidad con las cantidades y en el tiempo adecuado. En tal sentido, para efecto de calcular el impacto económico de este problema, se va a determinar el costo de oportunidad perdida si no se trabaja en la redución del lead time, es decir se va a determinar la cantidad de pedidos que se dejan de atender por el lead time actual. Para ello, se tiene que calcular la cantidad de pedidos anuales que atienden, el margen de ganancia por pedido y también el tiempo de atención (días) que le dedican a atender los pedidos.

\begin{tabular}{|l|c|}
\hline \multicolumn{2}{|c|}{ Consideraciones para el cálculo } \\
\hline 1 polo $=$ & $120 \mathrm{gr}$ \\
\hline Margen de ganancia por pedido $=$ & $12 \%$ \\
\hline Precio de exportación FOB $=$ & $\$ 5.00$ \\
\hline
\end{tabular}

Tabla 17. Ejemplo de Impacto económico por reducción de 7 días aproximadamente de Lead Time en el Proceso de Compras

\begin{tabular}{|l|c|}
\hline \multicolumn{2}{|c|}{ IMPACTO ECONÓMICO } \\
\hline Tiempo para atender un pedido & 60 a 90 días \\
\hline Promedio de pedidos anuales & 6 \\
\hline Unidades promedio por pedido & 15000 \\
\hline Precio de Venta Promedio (und) & S/. 16.50 \\
\hline Total venta por pedido & S/. 247,500.00 \\
\hline Margen percibido & S/. 29,700.00 \\
\hline Margen promedio Anual & S/. 178,200.00 \\
\hline \multicolumn{2}{|c|}{ CON LA REDUCCIÓN DE LEAD TIME } \\
\hline Tiempo para atender un pedido & 53 a 83 días \\
\hline Días ganados al año reduciendo el Lead time & 42 \\
\hline Se puede atender un pedido (und) & 10000 \\
\hline Total venta por un pedido de 10000 & S/. 165,000.00 \\
\hline Margen promedio no percibido Anual & S/. 19,800.00 \\
\hline
\end{tabular}

Fuente : Elaboración propia - Año 2017 
Figura 29. .Impacto Económico reduciendo el Lead Time en el proceso de Compras

\section{IMPACTO ECONÓMICO REDUCIENDO EL LEAD TIME EN EL PROCESO DE COMPRAS}

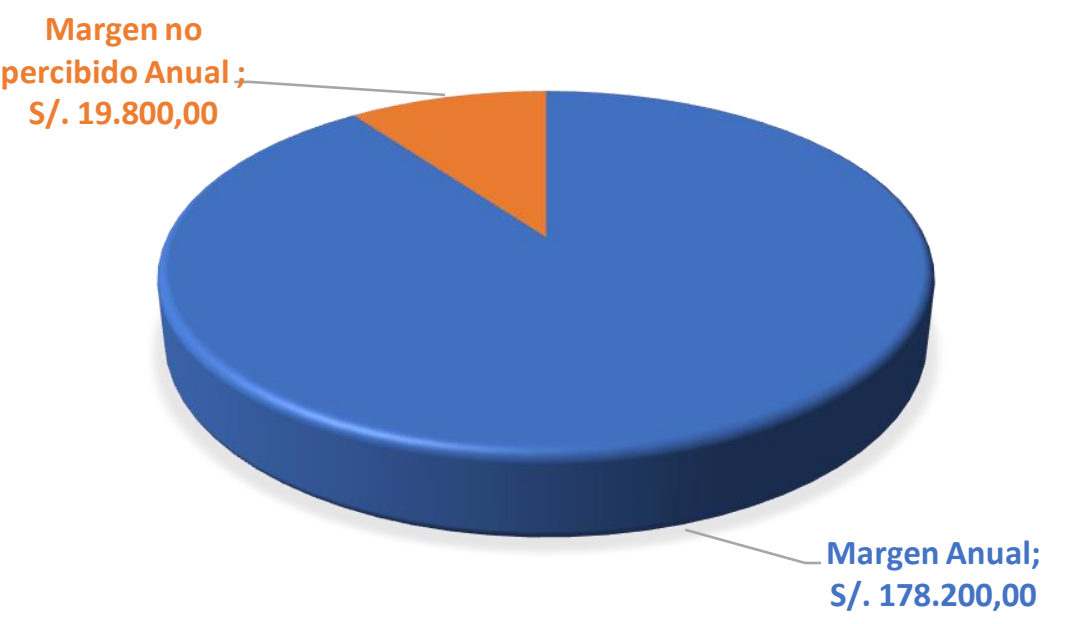

Fuente : Elaboración propia - Año 2017

De acuerdo a los cálculos realizados las empresas del sector en estudio dejan de ganar en promedio s/. 198000.000 por un pedido de 10000 prendas. Esto evidencia lo crucial que es el tiempo para este sector, puesto que pueden elaborar otro pedido al año si el lead time de abastecimiento de tela disminuyera.

Figura 30. Porcentaje de Margen no percibido Anual

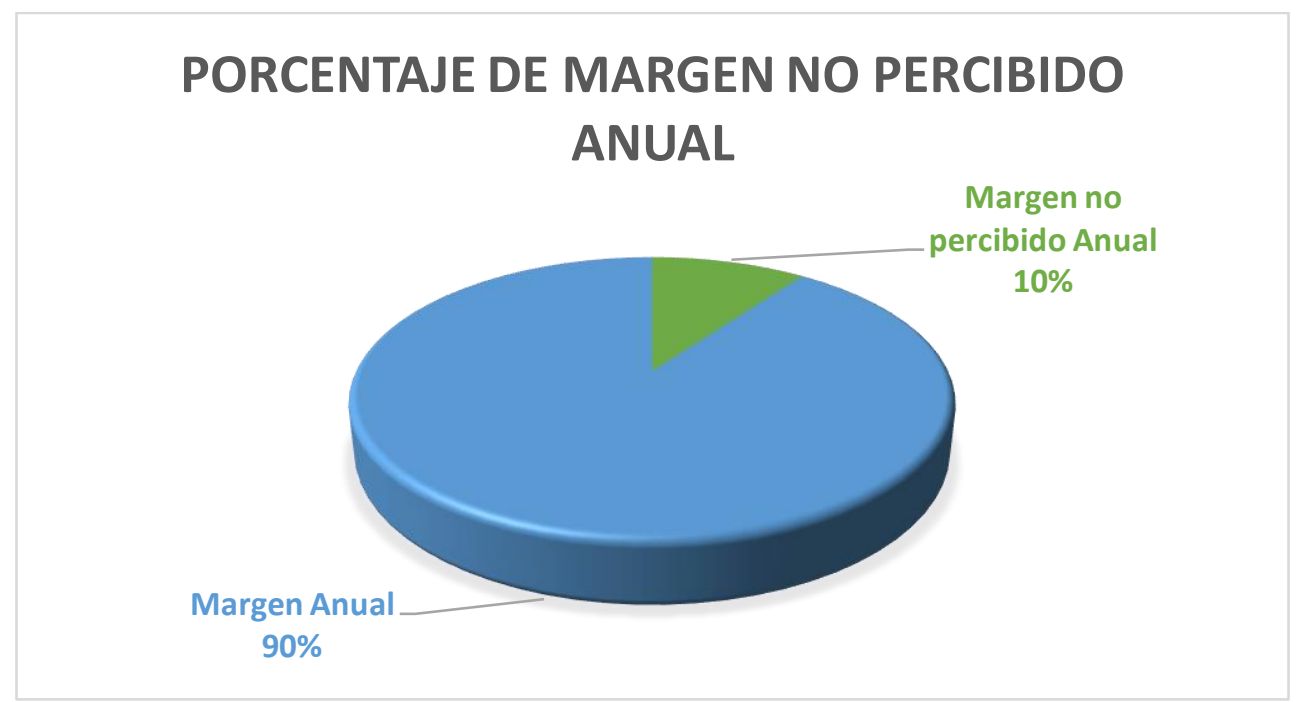

Fuente : Elaboración propia - Año 2017 
Como se puede observar en la Figura $\mathrm{N}^{\circ} 30$, existe un margen no percibido de $10 \%$ debido al problema de lead time excesivo en el proceso de abastecimiento de tela.

Siguiendo con los datos determinados lineas arriba, se calcula el incremendo de las exportaciones (Valor FOB) en el sector textil estudiado como resultado de la aplicación de las propuestas de mejora. (Ver Tabla 18).

Tabla 18. Impacto Económico en el Sector Textil Estudiado

\begin{tabular}{|c|c|c|}
\hline $\begin{array}{l}\text { VALOR FOB REAL } 2016 \\
\text { (estudio) }\end{array}$ & $\begin{array}{l}\text { VALOR FOB CON } \\
\text { MEJORA }\end{array}$ & $\begin{array}{c}\text { INCREMENTO DE } \\
\text { EXPORTACIÓN DEL SECTOR } \\
\text { CON PROPUESTA (Miles US\$) }\end{array}$ \\
\hline $80,221.47$ & $92,621.47$ & $12,400.00$ \\
\hline
\end{tabular}

Fuente : Elaboración propia- Año 2017

De la Tabla 18, se observa que el incremento de las exportaciones desarrollando la propuesta sería de \$12,400 (Miles US\$), lo cual refleja un 15\% de incremento en la facturación del sector textil de prendas de vestir de tejido de punto.

Figura 31. Esquema de Herramienta de Lean Manufacturing aplicado para alcanzar el objetivo principal

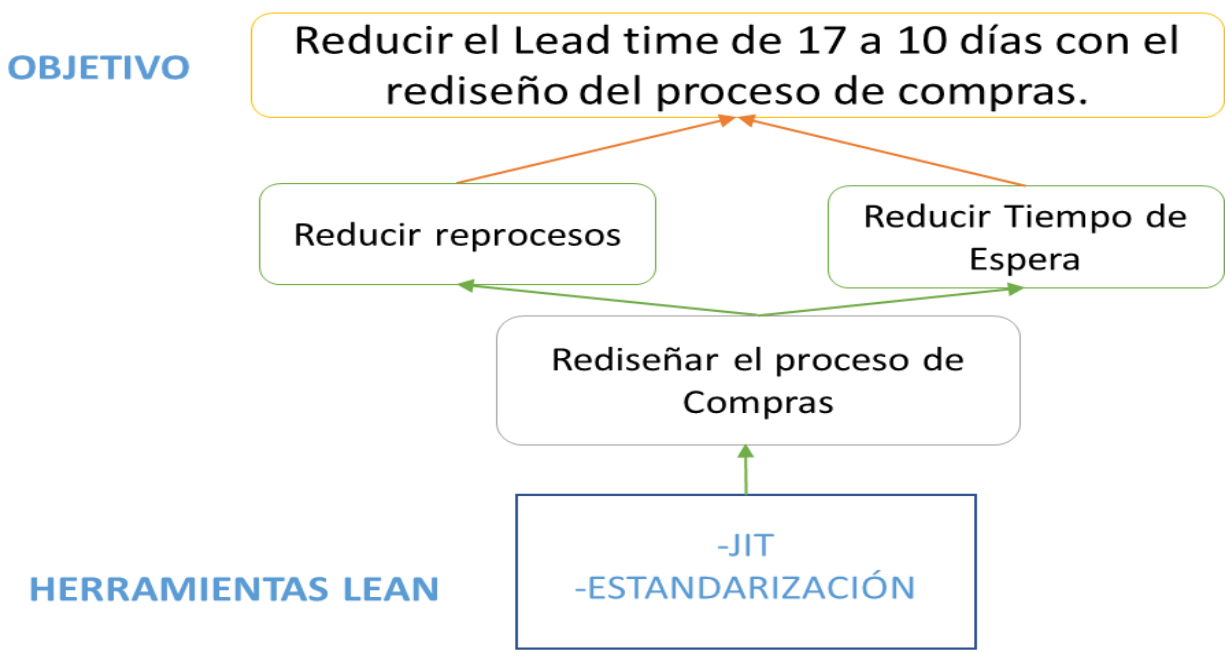

Fuente : Elaboración propia- Año 2017 
NOTA: Se trabaja en base a los 17 días aproximadamente, puesto que engloba el reproceso existente. Son 14 días aproximadamente del proceso de compras según VSM elaborado con los datos del sector. Además, en el $20 \%$ de los casos existe el reproceso de compras que ocasiona que vuelva a pedirse considerando 14 días más, en total 28 días. Considerando que sólo en el $20 \%$ de los casos se vuelve a realizar el proceso de compras el lead time asciende a 2.8 días. Finalmente, si se suma 14 días del proceso de compras más 2.8 días del $20 \%$ de los casos en el reproceso (14 días más) el total a reducir es igual a 17 días aproximadamente.

\section{DIAGNÓSTICO}

En el sector textil exportador de confecciones existen diversos procesos críticos, entre ellos el de compras, debido al Lead Time excesivo en el proceso de abastecimiento de tela que se genera por el retraso de la entrega por parte del proveedor del pedido extra que asciende a 17 días en promedio, siendo 10 días el estándar del mercado. El principal motivo es: el reproceso de los requerimientos, inventario de materia prima y defectos en los productos abastecidos, que son causados por el ineficiente plan al momento de definir las compras, la falta de flujo de información entre los procesos de compra y planeamiento de la producción; además de la inexistencia de procedimientos de seguimiento y al proveedor.

Finalmente, se realiza un resumen especificando el proceso crítico seleccionado. A través de este resumen se puede observar el desperdicio, impacto y trascendencia. (Ver Tabla $\mathrm{N}^{\mathrm{o}} 19$ )

Tabla 19. Resumen de Proceso crítico (Compras), Desperdicios, Impacto/Trascendencia y Causa raíz y alternativa de solución

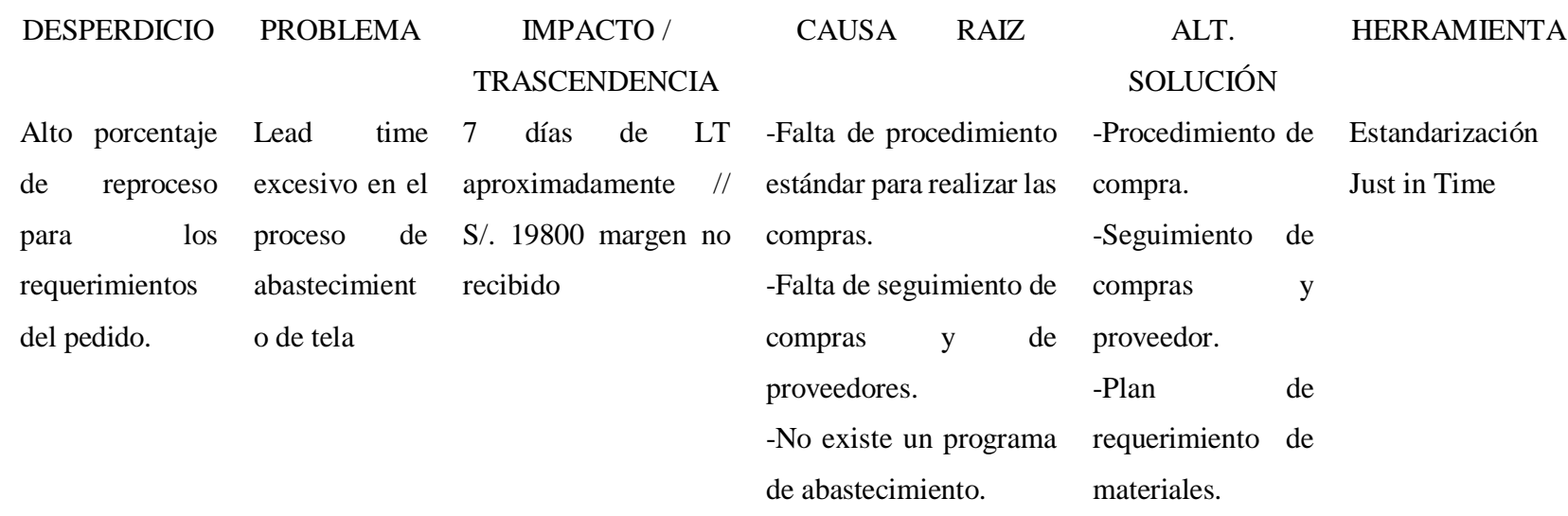

Fuente : Elaboración propia- Año 2017 


\section{HIPÓTESIS}

\section{HIPÓTESIS GENERAL}

Mediante la aplicación de las herramientas de Lean Manufacturing se disminuye el número de desperdicios existentes en los procesos críticos de las PYMES del sector textil exportadoras de prendas de vestir de tejido de punto de algodón, lo cual tendrá un efecto en el incremento de la productividad reduciendo el lead time del procesos y reducción de costos.

\section{HIPÓTESIS ESPECÍFICA.}

Mediante la aplicación de las herramientas de Lean Manufacturing: Just in Time, VSM y Estandarización se logra rediseñar el proceso de compras mediante un Plan de flujo de información entre el proceso de Compras, Planeamiento de la producción y los proveedores, el cual ayuda a reducir los reprocesos de las órdenes de compra y el inventario de materia prima, insumos y materiales. Por lo tanto, disminuye el lead time que permite mayor flexibilidad en el proceso productivo y respuesta al cliente mejorando la competitividad del sector. 


\section{CAPITULO III: DISEÑO Y DESARROLLO DE LA PROPUESTA DE MEJORA}

En el siguiente capítulo, se presenta una propuesta de modelo de éxito del proceso de compras enfocado en el sector textil exportador de prendas de vestir de tejido de punto de algodón. Esto se realiza en base al diseño de la propuesta y desarrollo, obteniendo resultados mediante la implementación de las herramientas de Lean Manufacturing. De la misma manera, se desarrolla el plan para la implementación estableciendo métodos, procedimientos y otras consideraciones que garanticen la ejecución del proyecto.

\section{EVALUACIÓN DE ATERNATIVAS DE SOLUCIÓN}

Mediante la revisión de la literatura y del levantamiento de información del sector textil exportador, se identifica que el problema más frecuente y con mayor impacto en el proceso de compras es el exceso de lead time en el abastecimiento de tela, esto ocasiona que la producción de prendas no se cumpla en el tiempo planificado, esta situación se puede revertir si se logra controlar a los proveedores y reorganizar las actividades que conforman el proceso de compras. Por tal motivo, se rediseña el proceso de compras mediante la aplicación de herramientas de Lean Manufacturing tales como Estandarización y Compras Justo a Tiempo.

\section{DIAGRAMA RELACIONAL DE PROCESOS}

Establecer relaciones que existen entre las diferentes áreas ayuda a mejorar la sinergia de los procesos. Para iniciar la aplicación de las herramientas mencionadas, se debe detallar cómo inicia el proceso de compras. Asimismo, se debe conocer al proveedor y cliente del proceso y tener comunicación constante o desarrollar un sistema de flujo de información efectivo para iniciar el proceso de compra. (Ver Figura 32) 
Figura 32. Diagrama de Relación de Procesos de Confección de prendas de vestir (T-Shirt).

\section{RELACIÓN DEL PROCESO DE COMPRAS CON OTROS PROCESOS DE LA CONFECCIÓN DE PRENDAS DE VESTIR}

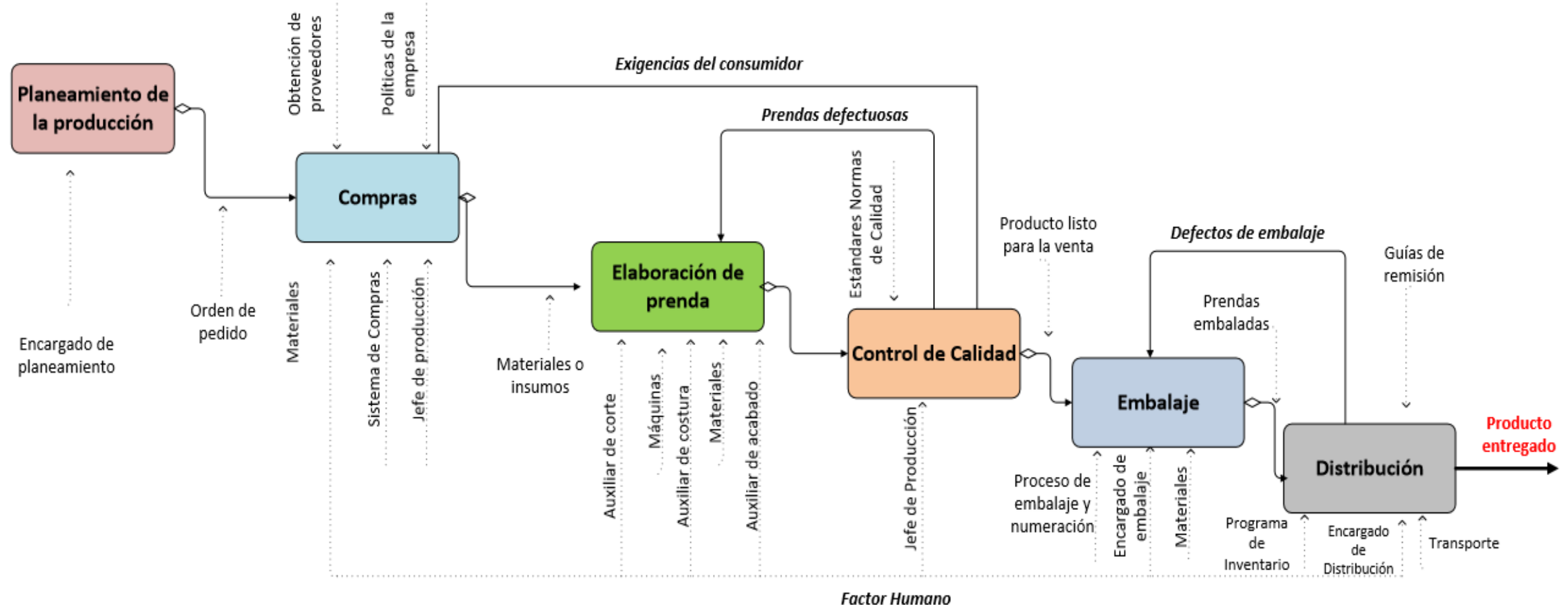

Fuente : Elaboración propia- Año 2017 
Esta operación en cadena inicia cuando el área o encargado de planeamiento de la producción emite el requerimiento de materia prima de acuerdo a los requerimientos de su cliente. En el sector evaluado se observa que en la mayoría de casos las empresas poseen entre uno a tres clientes fijos, por lo cual es más sencillo conocer el tipo de producto, las características y algunas veces las cantidades, ya que esta depende de la demanda que tengan sus clientes directos. Luego de la recepción del pedido en la oficina de compras, se entrega la orden de pedido para iniciar con el proceso de Compras que se detalló en el capítulo anterior, una vez que la empresa se abastece de los materiales se inicia la elaboración de las prendas, siendo el primer proceso Corte, al cual ingresará la tela y dará inicio a la confección.

\subsection{IMPLEMENTACIÓN DE LA HERRAMIENTA DE ESTANDARIZACIÓN.}

En base al diagnóstico realizado se desarrolla la herramienta de Estandarización, la cual permite definir el criterio óptimo y único en la ejecución de las actividades realizadas en la operación, permitiendo la eliminación de la variabilidad del proceso.

\subsubsection{DISEÑO DE LA PROPUESTA.}

Se plantea el rediseño del Sistema de compras estandarizado, este consiste en el desarrollo de 5 módulos, las cuales se muestran en la Figura 33.

Figura 33. Esquema del diseño del sistema de compras estandarizado

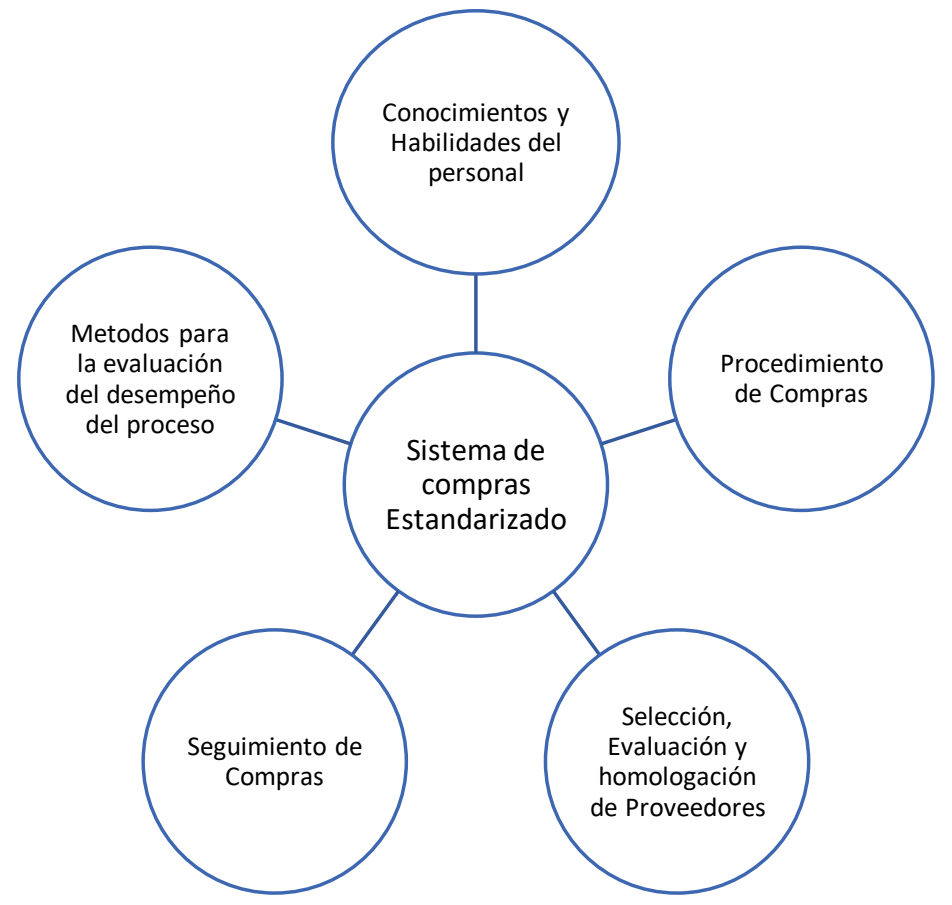


En cada una de las estrategias mencionadas se van a utilizar diversas herramientas de fácil aplicación, las cuales se nombran a continuación:

Conocimiento y habilidades del personal:

- Perfil del encargado del proceso de compras.

- Indicadores de desempeño del personal.

Procedimiento de compras

SIPOC del proceso de abastecimiento de compras, el cual incluye: entradas, salidas, recursos, indicadores, factores críticos y controles.

- Indicadores del proceso.

- Procedimiento de Compras: En el cual se define el alcance y las actividades del proceso.

Selección, evaluación y homologación de proveedores

- Método de selección, evaluación y homologación de proveedores.

- Políticas y condiciones de compra.

- Procedimiento de evaluación y homologación de proveedores.

Seguimiento de compras

- Procedimiento de seguimiento a las compras.

- Procedimiento para el seguimiento del proveedor.

- Indicadores de medición.

Métodos para la evaluación del desempeño del proceso

- Sistema de medición del desempeño del proceso. 
En este sentido, se escoge dicho sistema, ya que su implementación considerando los puntos mencionados apuntan directamente hacia la solución de las causas raíces del problema. (Ver Figura $34)$.

Figura 34. Propuesta de solución- sistema de compras estandarizado.

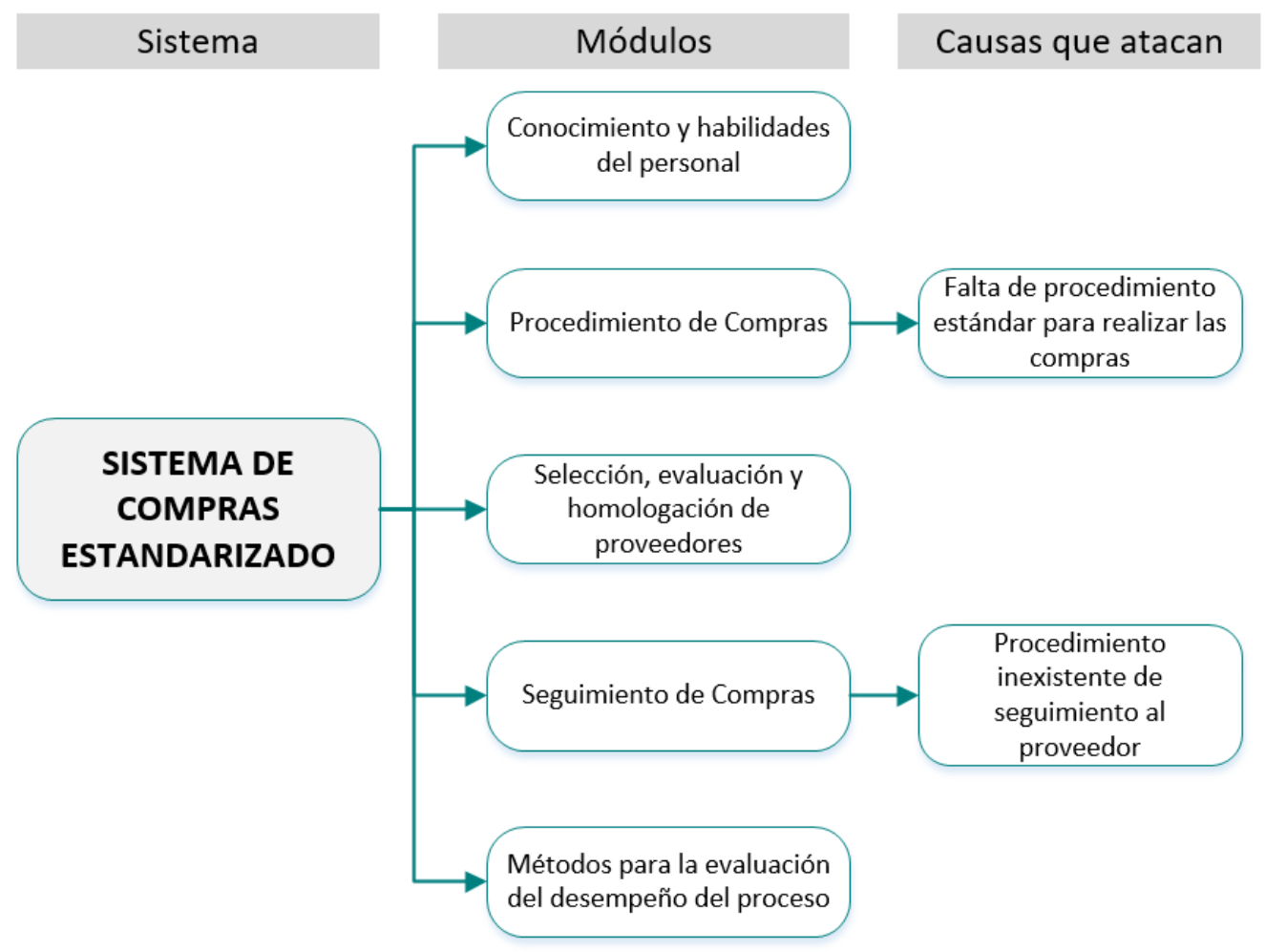

Para que la propuesta de estandarización del Sistema de compras sea efectiva, se propone el desarrollo de 5 módulos.

El segundo de ellos, se enfoca en el desarrollo de un Procedimiento de compras, el cual busca resolver directamente la causa raíz de falta de un procedimiento estándar para realizar las compras.

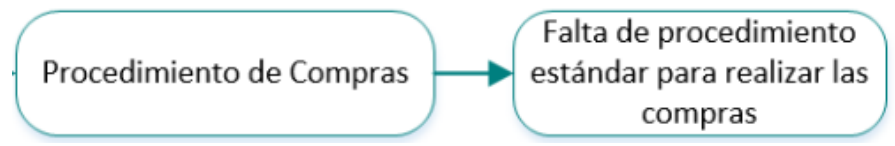

En el cuarto módulo se desarrolla el Seguimiento de compras, en el cual se establecen procedimientos e indicadores, además se incluye el seguimiento a los proveedores y materiales, de esta manera se busca asegurar la calidad, tiempos de entrega y cumplimiento de las características del producto abastecido. 


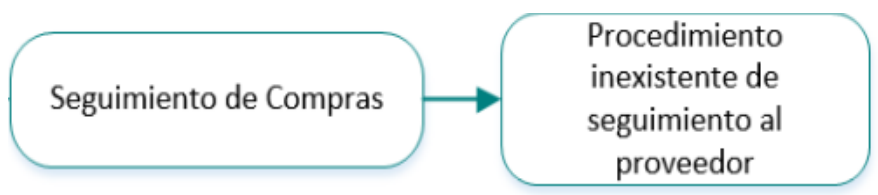

Los módulos Selección, evaluación y homologación de proveedores, Conocimientos y habilidades del personal y Métodos para la evaluación del desempeño del proceso son considerados como actividades de soporte esenciales que complementan y aseguran la sostenibilidad del sistema, el primero es de suma importancia, ya que resuelve los problemas de incumplimiento de entrega de pedidos, lo cual es común en gran parte de las empresas encuestadas, el siguiente módulo se enfoca en el aseguramiento del personal adecuado para realizar las funciones de compra, por ello incluye el análisis del perfil, competencias y las habilidades que se necesitan para el desarrollo de las actividades, y el último módulo de soporte sirve para la evaluación del desempeño del proceso, que mediante el desarrollo de métodos propuestos se busca medir los cambios establecidos e identificar oportunidades de mejora en el proceso.

Selección, evaluación y homologación de proveedores

En este contexto, se procede a describir de forma general cómo se desarrolla cada una de las estrategias mencionadas del Sistema de Compras Estandarizado.

En primer lugar, se aplica la estrategia de Conocimiento y habilidades del personal, en la cual se detalla el perfil del encargado del proceso y las actividades que este realiza, además se hace mención de los indicadores que deben de utilizarse para medir el desempeño de los trabajadores.

En segundo lugar, se realiza el Procedimiento de compras, en el cual se desarrolla el SIPOC del proceso, en este se establecen los proveedores, clientes y los recursos utilizados para llevar a cabo el proceso de compras. Asimismo, se definen los indicadores esenciales para gestionar el proceso tales como: Pedidos entregados a tiempo, Calidad de los pedidos generados, Nivel de cumplimiento de proveedores, Entregas perfectamente recibidas, entre otros que buscan medir la variabilidad del proceso en cada compra realizada. A través de la aplicación de estos se pueden detectar oportunidades de mejora. En el SIPOC antes desarrollado se aprecian algunos controles para gestionar los factores críticos identificados en el proceso: mano de obra, métodos y medición. Por 
último, se plantea el procedimiento de compras, en el cual se describen las actividades del proceso de compras a detalle y los responsables de cada una de ellas.

En tercer lugar, se realiza la Selección, evaluación y homologación de proveedores, todo ello en base a criterios establecidos previamente (costo, calidad, disponibilidad, tiempo de entrega), con la finalidad de poseer una cartera de proveedores confiables que cumplan con los requisitos que establece la empresa como prioridad.

Luego, se establecen las políticas y condiciones de compra y se define la mecánica de lo que será el sistema de control y desarrollo de proveedores, donde se toman en cuenta indicadores de medición.

En cuarto lugar, se realiza el Seguimiento de Compras, en donde se proporciona un procedimiento para realizar el seguimiento a los pedidos de materiales y otro enfocado en el seguimiento a proveedores. Asimismo, se definen indicadores que permiten demostrar los efectos del seguimiento realizado.

En quinto y último lugar, se plantean los Métodos para la evaluación del desempeño del proceso, que consta de tres fases y sirve para comparar el desempeño previo. De esta manera, se presentan indicadores que permiten detectar la situación e identificar futuras mejoras.

\subsubsection{DESARROLLO DE LAS PROPUESTAS.}

Para iniciar el desarrollo de la propuesta se toma en cuenta la cadena de valor que debe tener el sistema, la cual se plantea en la Figura 35, esta es una poderosa herramienta de análisis que sirve como lineamiento para llevar a cabo el proceso de compras, ya que representa de forma global las estrategias que se aplican más adelante. 
Figura 35. Cadena de valor de compras/ abastecimiento

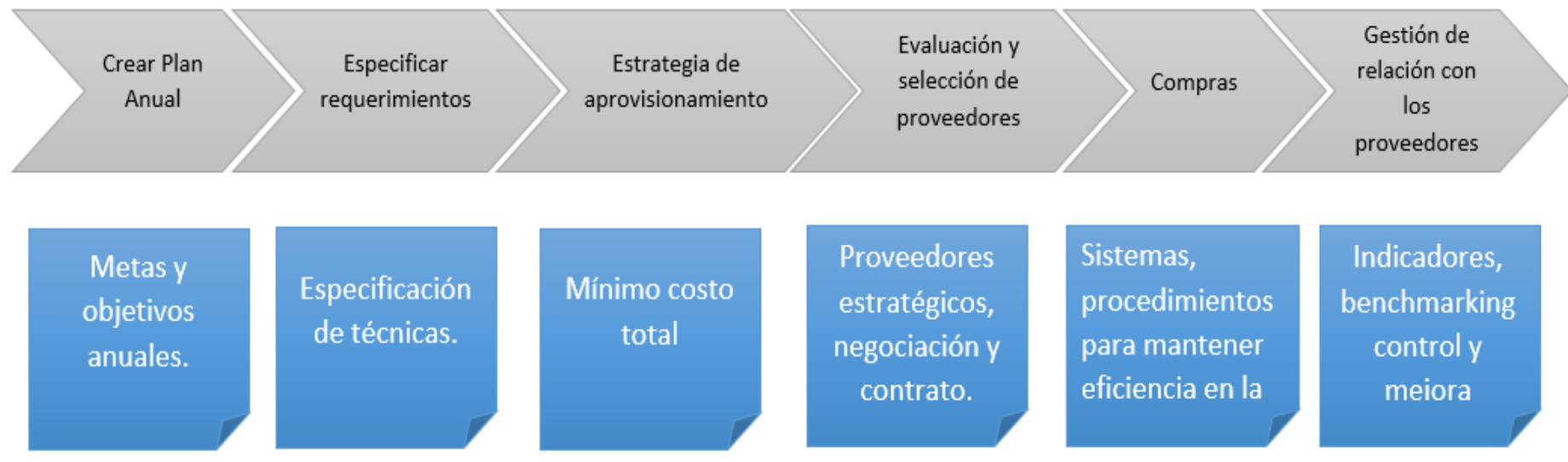

Fuente : Rodríguez, B. Programa logístico modalidad virtual at Universidad Manuela Beltrán.

\section{Conocimientos y habilidades del personal.}

\section{Perfil del encargado del proceso.}

Se analiza, describe los roles y actividades claves del puesto que la persona debe tener o desarrollar para ser eficaz y eficiente en las exigencias del puesto. Además, se mencionan las competencias necesarias para el puesto que permite a la organización alcanzar su propósito mediante la fuerza laboral. (Ver anexo $\mathrm{N}^{\circ} 1$ )

En el formato se especifica de forma sistemática y concisa la información del análisis del puesto.

\section{Indicadores de desempeño del personal.}

Los indicadores establecidos proporcionan información cuantitativa respecto al logro propuesto y de esta manera se logra realizar evaluación de desempeño para mejorar los resultados de la empresa. Los indicadores que se mencionan (Ver anexo $\mathrm{N}^{\circ} 2$ ), cumplen con los objetivos estratégicos de la organización como el de seleccionar a las personas apropiadas para puesto correcto.

- El primer indicador mide la eficiencia de proceso de integración de los recursos humanos para los puestos de trabajo. $\mathrm{CS}=\mathrm{n}^{\circ}$ candidatos admitidos $/ \mathrm{n}^{\circ}$ candidatos examinados. 
- El segundo indicador mide el ausentismo laboral e identifica el descontento y aptitud de los empleados.

- En el indicador de eficacia se mide los logros y metas que cumplen en el área de compras.

- Porcentaje de aplicabilidad de la formación al puesto valora la aplicación, por parte de los trabajadores de la formación recibida en el desempeño de las funciones o tareas habituales (Conecta Pyme, 2015).

\section{Evaluación de desempeño}

Mediante las competencias fijadas en el perfil del encargado de compras, se evalúa a la persona involucrada.

El cuadro muestra el proceso de evaluación de la persona encargada de realizar las compras.

Figura 36. Proceso de Evaluación

RRHH entrega

formularios al

evaluado

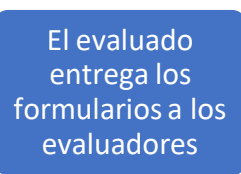

El evaluado

entrega los

evaluadores

\section{Evaluadores \\ procesan la \\ información}

\section{Se realiza el \\ informe de \\ evaluación}

Se entrega el informe al área correspondiente

Fuente : Elaboración Propia- Año 2017

El objetivo del siguiente formato propuesto, se basa en la calificación tanto de la persona evaluada como el del evaluador para ver si la persona ubicada en el área de trabajo correspondiente sigue cumpliendo con las competencias y comportamientos esperado en puesto de trabajo. (Ver anexo $\mathrm{N}^{\circ} 3$ ).

De la misma manera, cuando el resultado no es satisfactorio el jefe de inmediato debe de realizar instrucciones y orientaciones verbales. Además, de preparar un plan de acción con entrenamiento para mejorar el desempeño con fecha, inicio, fecha de revisiones y emisión de reporte de evaluación. (Ver anexo $\mathrm{N}^{\circ} 4$ ).

Así mismo, la evaluación del desempeño laboral permite analizar el rendimiento individual, para así establecer los objetivos estratégicos y alinear las funciones y tareas de los colaboradores. Además, reconocer las fortalezas y debilidades para crear programas de capacitación y establecer 
medidas entre desempeño y resultado esperado. El desempeño equivale a las conductas que tuvo la persona en el periodo evaluado. Mientras que el resultado muestra los logros de los objetivos propuestos.

\section{Procedimiento de compras}

\section{SIPOC del Proceso de Compras}

La empresa debe conocer claramente el proceso de compras, esto incluye los objetivos del área, el alcance, las entradas del proceso y actividades que se realizan para ejecutar las actividades de compra. Para ello, se utiliza la herramienta SIPOC, el cual es un instrumento de caracterización del proceso, en este documento se describe a grandes rasgos las especificaciones del proceso. Asimismo, actúa como soporte de información que resume las características relevantes para el control de las actividades definidas en el diagrama de flujo del proceso, así como para la gestión del mismo (Universidad del Valle, 2015).

La elaboración del SIPOC consiste en dos pasos:

\section{PRIMER PASO:}

Identificación de los requisitos de la E/S/R- Entradas, salidas y recursos.

Los datos registrados en el SIPOC son obtenidos de las entrevistas a los dueños del proceso.

\section{ENTRADAS}

Tabla 20. Requisitos de Entrada

\begin{tabular}{|l|l|l|}
\hline \multicolumn{1}{|c|}{ Entrada } & \multicolumn{1}{|c|}{ Proveedor } & \multicolumn{1}{c|}{ Requisitos } \\
\hline $\begin{array}{l}\text { E1: Solicitud de requerimiento de } \\
\text { compra. }\end{array}$ & Planeamiento de la producción & $\begin{array}{l}* \text { Cantidades exactas del material } \\
* \text { Fechas de entrega del producto }\end{array}$ \\
\hline E2: Especificaciones de material. & Planeamiento de la producción & $\begin{array}{l}* \text { Cantidad } \\
* \text { Colores SALIDAS } \\
\text { *Material }\end{array}$ \\
\hline $\begin{array}{l}\text { E3: Programa de compra (PRM, } \\
\text { Compra calendarizada) }\end{array}$ & Departamento de compras & $\begin{array}{l}* \text { Comunicación constante con el } \\
\text { proveedor } \\
* \text { Fechas de entrega } \\
\text { Fecha de emisión de O/C }\end{array}$ \\
\hline
\end{tabular}

Fuente : Elaboración propia- Año 2017 
Tabla 21. Requisitos de Salida

\begin{tabular}{|l|l|l|}
\hline \multicolumn{1}{|c|}{ Salida } & \multicolumn{1}{|c|}{ Cliente } & \multicolumn{1}{|c|}{ Requisitos } \\
\hline P1: Productos recepcionados & Proceso de corte & $\begin{array}{l}* \text { Entregas dentro del plazo establecido. } \\
* \text { Cumplir con los requerimientos } \\
\text { solicitados. } \\
* \text { Verificados por el responsable de } \\
\text { almacén. }\end{array}$ \\
\hline P2: Factura & Contabilidad & Ninguna \\
\hline P3: Registro de compra & Departamento de compras & $*$ Nota de entrega de material \\
\hline P4: Control de compra y registro & Proveedor & $*$ Registro de productos no conformes \\
\hline P5: Evaluación del proveedor & Departamento de compras & $\begin{array}{l}* \text { Ficha de evaluación de Proveedores } \\
* \text { Reporte de productos no conforme } \\
* \text { Fecha de entrega de material }\end{array}$ \\
\hline
\end{tabular}

Fuente : Elaboración propia-Año 2017

\section{RECURSOS}

Tabla 22. Requisitos de Recursos

\begin{tabular}{|l|l|l|}
\hline \multicolumn{1}{|c|}{ Recurso } & \multicolumn{1}{|c|}{ Proveedor } & \multicolumn{1}{c|}{ Requisitos } \\
\hline R1: PRM & $\begin{array}{l}\text { Planeamiento de la producción y } \\
\text { Departamento de compras }\end{array}$ & $\begin{array}{l}\text { * Cantidades exactas del material } \\
\text { solicitado } \\
\text { *Saldos disponibles de material } \\
\text { *Lead Time de entrega de productos. }\end{array}$ \\
\hline R2: Calendario de compras & Departamento de compras & $\begin{array}{l}\text { * Coordinación con Planeamiento de la } \\
\text { producción } \\
\text { * Fecha de requerimiento } \\
\text { *Fecha de emisión de O/C } \\
\text { *Fecha de entrega de producto }\end{array}$ \\
\hline R3: Equipos (Computadoras) & Departamento de compras & $\begin{array}{l}\text { *En buen estado } \\
\text { *Mantenimiento periódico de las } \\
\text { máquinas }\end{array}$ \\
\hline R4: Oficinas & Departamento de compras & $\begin{array}{l}\text { *Con computadoras y sodtware office } \\
\text { Espacios adecuados y asientos } \\
\text { ergonómicos. }\end{array}$ \\
\hline R5: Asistente o auxiliar de compra & Departamento de compras & $\begin{array}{l}\text { *Competente } \\
\text { *Manejo de Office a nivel intermedio }\end{array}$ \\
\hline
\end{tabular}

Fuente : Elaboración propia- Año 2017 


\section{SEGUNDO PASO:}

Identificar los Factores Críticos de éxito: Consiste en identificar los factores críticos para asegurar el éxito del proceso.

Los factores críticos identificados son mano de obra, debido a que en muchos casos el personal que realiza las actividades de compra no está calificado para realizarlas o no ha recibido las indicaciones adecuadas para llevar a cabo su función, debido a la ausencia de un procedimiento de trabajo estándar y medición en el proceso de compras; debido a la ineficiencia en la gestión y control del proceso.

Identificar controles y evaluar situación: Consiste en identificar los mecanismos de control que se están implementando para asegurar que dicho aspecto crítico se encuentre bajo control.

Para hacer frente a los factores críticos antes mencionados, se definen 8 controles:

Control 1 (C1), a través del Procedimiento de compras se busca mejorar el método de trabajo de todas las actividades en el departamento de compras, de esta manera se logra reducir los tiempos de atención del requerimiento del cliente interno, eliminar las actividades que no agregan valor y eliminar la acumulación de órdenes de compra. Asimismo, en el procedimiento se presentan los lineamientos para evaluar si la cotización va acorde con el requerimiento de la empresa.

Control 2 (C2), busca llevar a cabo y con eficiencia la aprobación del requerimiento, para ello se utiliza de guía la Política de compras dispuesta por la empresa, de esta manera se busca reducir el tiempo en el que se realiza esta actividad.

Control 3 (C3), el Procedimiento de Seguimiento de proveedores y materiales permite tener un lineamiento para realizar el abastecimiento y seguimiento al proveedor y la recepción de mercadería, en ambas actividades se continúa evaluando al proveedor, y estos tienen conocimiento de que están siendo evaluados en todo el proceso.

Control 4 (C4), en el Programa de abastecimiento se desarrolla el planeamiento de las compras utilizando como herramienta el PRM (Planificación de los requerimientos de material) y las compras calendarizadas, de esta manera se busca eliminar el reproceso de las órdenes de compra y por ende el tiempo de abastecimiento del proveedor, debido a que se anticipa la información al 
proveedor, el cual podrá planificar su capacidad de producción. Asimismo, estas herramientas permiten comparar entre el tiempo estimado y el tiempo real de recepción de la mercadería, de esta forma se puede mejorar el pronóstico de compras y verificar si la entrega cumple con el requerimiento.

Control 5 (C5), el Reporte de producto no conforme permite identificar y llevar un registro de los productos que no cumplen con las especificaciones o presentan fallas, la aplicación de este ayuda a incrementar la eficiencia en la verificación de la calidad y cantidad.

Control 6 (C6), los Indicadores de evaluación del proveedor son esenciales para medir el desempeño de proveedor desde que se realiza el pedido hasta que lo entrega, estos serán clave para motivar al proveedor a reducir su tiempo de abastecimiento del producto, lo cual le dará mayor puntaje al momento de ser evaluado.

Control 7 (C7), la Descripción del puesto de trabajo en las actividades de generar la O/C, abastecimiento y seguimiento al proveedor, y verificación de la calidad es importante debido a que el personal asignado a realizar estas actividades debe tener cierto conocimiento de las características que se deben verificar para que el producto sea considerado de calidad o para que se pueda emitir la orden, de igual manera para realizar el seguimiento al proveedor y aplicar los indicadores de medición, el personal debe tener cierto conocimiento y criterio lógico.

Control 8 (C8), debido a que la mano de obra es crítica en las actividades de Generar la O/C, Abastecimiento y seguimiento del proveedor y la Verificación de la calidad, es importante evaluar el desempeño de los responsables de dichas actividades, para corregir prácticas inadecuadas que tornan ineficiente al proceso y pueden ser las causantes del reproceso de ciertas actividades.

Tabla 23. Mecanismos de Control

MECANISMOS DE CONTROL

C1: Procedimiento de compras (MET1, MET2, MET3,MET4,MET5, MET6, MET7,MET8,MET9,MED4)

C2: Cumplimiento de políticas de compra (MET5,MED5)

C3: Procedimiento de Seguimiento de proveedores y materiales (MET7,MED7,MET8,MED8)

C4: Programa de abasteciemiento (PRM,Compras calendarizadas) (MET8, MED8, MET2)

C5: Reporte de producto no conforme (MET9,MED9)

C6: Indicadores de evaluación del proveedor (MED7,MED8)

C7: Descripción del Puesto de Trabajo (MO6,MO7,MO9)

C8: Evaluaciones de desempeño (MO6,MO7,MO9)

Fuente : Elaboración propia- Año 2017 
Figura 37. Sipoc del Proceso de Compras

\begin{tabular}{|c|}
\hline MECANISMOS DE CONTROL \\
\hline C1: Procedimiento de compras (MET1, MET2, MET3,MET4,MET5,MET6,MET7,MET8,MET9,MED4) \\
\hline C2: Cumplimiento de políticas de compra (MET5,MED5) \\
\hline C3: Procedimiento de Seguimiento de proveedores y materiales (MET7,MED7,MET8,MED8) \\
\hline C4: Programa de abasteciemiento (PRM,Compras calendarizadas) (MET8, MED8,MET2) \\
\hline C5: Reporte de producto no conforme (MET9,MED9) \\
\hline C6: Indicadores de evaluación del proveedor (MED7,MED8) \\
\hline C7: Descripción del Puesto de Trabajo (MO6,MO7,MO9) \\
\hline C8: Evaluaciones de desempeño (MO6,MO7,MO9) \\
\hline
\end{tabular}

PROVEEDOR
\begin{tabular}{|c|c|}
\hline Planeamiento de la producción & Solicitud de requerimiento de compra \\
\hline Planeamiento de la producción & Especificaciones del material \\
\hline Departamento de compras & $\begin{array}{c}\text { Programa de compra } \\
\text { (PRM, Compra calendarizada) }\end{array}$ \\
\hline
\end{tabular}

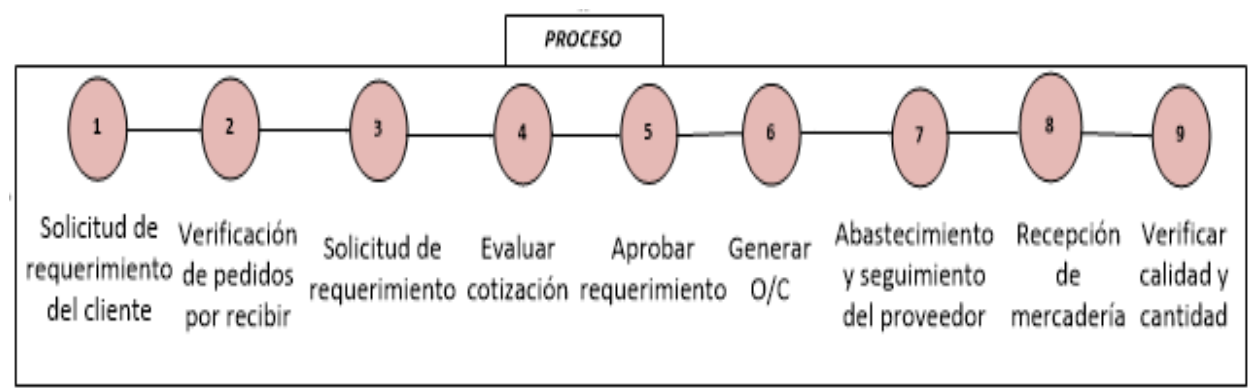

\begin{tabular}{|c|c|}
\multicolumn{1}{c}{ SALIDAS } \\
\begin{tabular}{|c|c|}
\hline Productos recepcionados & Proceso de Corte \\
\hline Factura & Contabilidad \\
\hline & \\
Registro de compra & Departamento de compras \\
\hline Control de compra y registro & Proveedor \\
\hline Evaluación del proveedor & Departamento de compras \\
\hline
\end{tabular}
\end{tabular}

\begin{tabular}{|c|c|}
\multicolumn{2}{c}{ RECURSO } \\
\hline PRM & $\begin{array}{c}\text { Planeamiento de la producción } \\
\text { y Departamento de compras }\end{array}$ \\
\hline Calendario de compras & Departamento de compras \\
\hline Equipos (Computadoras) & Departamento de compras \\
\hline Oficinas & Departamento de compras \\
\hline Asistente o auxiliar de compra & Departamento de compras \\
\hline
\end{tabular}

\begin{tabular}{|c|}
\hline INDICADORES \\
\hline Pedidos entregados a tiempo (\%) \\
\hline Calidad de los Pedidos Generados (\%) \\
\hline Entregas perfectamente recibidas (\%) \\
\hline Nivel de cumplimiento de proveedores (\%) \\
\hline Variación del desempeño del proveedor (\%) \\
\hline Variación del tiempo de atención de una O/C \\
$(\%)$ \\
\hline Variación del desempeño de los trabajadores \\
$(\%)$
\end{tabular}

\begin{tabular}{|c|c|c|c|c|c|c|}
\hline \multicolumn{7}{|c|}{ FACTORES CRÍTICOS } \\
\hline & MO & MAT & MET & MAQ & MED & MA \\
\hline 1 & & & $x$ & & & \\
\hline 2 & & & $x$ & & & \\
\hline 3 & & & $x$ & & & \\
\hline 4 & & & $x$ & & $x$ & \\
\hline 5 & & & $x$ & & & \\
\hline 6 & $x$ & & $x$ & & & \\
\hline 7 & $x$ & & $x$ & & $x$ & \\
\hline 8 & & & $x$ & & $x$ & \\
\hline 9 & $x$ & & $x$ & & $x$ & \\
\hline
\end{tabular}

Fuente: Elaboración propia- Año 2017 


\section{Indicadores del proceso.}

Para realizar la selección de dichos indicadores se utilizó una Matriz CREMA de Selección de indicadores (Departamento Nacional de Planeación de Bogotá, 2009). (Ver Tabla 24)

Tabla 24. Clasificación de Criterios

\begin{tabular}{|c|c|c|c|c|c|c|c|c|c|}
\hline \multirow{2}{*}{ TIPOLOGÍA } & \multirow{2}{*}{ INDICADOR } & \multicolumn{5}{|c|}{ CALIFICACIÓN DE CRITERIOS } & \multirow{2}{*}{$\begin{array}{c}\text { PUNTAJE } \\
\text { TOTAL }\end{array}$} & \multicolumn{2}{|c|}{ SELECCIONAD0 } \\
\hline & & $\mathrm{C}$ & $\mathbf{R}$ & $\mathrm{E}$ & $\mathrm{M}$ & $\mathrm{A}$ & & SI & N0 \\
\hline \multirow{6}{*}{$\begin{array}{c}\text { Indicadores de } \\
\text { producto }\end{array}$} & Pedidos entregados a tiempo & 5 & 5 & 4 & 5 & 5 & 24 & $\mathrm{x}$ & \\
\hline & Calidad de los pedidos generados & 4 & 3 & 4 & 4 & 5 & 20 & $x$ & \\
\hline & Desviación presupuestaria & 2 & 1 & 2 & 2 & 1 & 8 & & $\mathrm{x}$ \\
\hline & Entregas perfectamente recibidas & 4 & 5 & 5 & 5 & 5 & 24 & $x$ & \\
\hline & Incentivos de negociación & 2 & 1 & 3 & 2 & 2 & 10 & & $\mathrm{x}$ \\
\hline & Nivel de cumplimiento de proveedores & 4 & 5 & 4 & 3 & 4 & 20 & $x$ & \\
\hline \multirow{3}{*}{ Indicadores de efecto } & Variación del tiempo de atención de una $\mathrm{O} / \mathrm{C}$ & 4 & 4 & 4 & 4 & 4 & 20 & $x$ & \\
\hline & Variación del desempeño del proveedor & 4 & 4 & 4 & 4 & 4 & 20 & $x$ & \\
\hline & Variación del desempeño de los trabajadores & 4 & 4 & 4 & 4 & 4 & 20 & $x$ & \\
\hline
\end{tabular}

*El puntaje total deberá ser mayor 0 igual a 20 para seleccionar el indicador.

Fuente : Elaboración propia- Año 2017

De la matriz, los indicadores seleccionados para medir y controlar el proceso de compras son: (Ver anexo $\left.\mathrm{N}^{\circ} 5\right)$.

\section{INDICADORES DE PRODUCTO:}

COMP-FTI-01 Pedidos entregados a tiempo (\%).

COMP-FTI-02 Calidad de los pedidos generados (\%).

COMP-FTI-04 Entregas perfectamente recibidas (\%).

COMP-FTI-03 Nivel de cumplimiento de proveedores (\%).

\section{INDICADORES DE EFECTO:}

COMP-FTI-07 Variación del tiempo de atención de una O/C.

COMP-FTI-06 Variación del desempeño de los trabajadores.

COMP-FTI-05 Variación del desempeño del proveedor. 


\section{Procedimiento de compras}

En el procedimiento de compra (COMP-PDC-01) se especifica el objetivo, responsable y alcance del proceso, para la elaboración de este documento se consultó la Política de compras y el Procedimiento de Selección, evaluación y homologación de proveedores. También, se definen las condiciones básicas del proceso, en ellas se incorporan lineamientos que deben ser ejecutados con el fin de reducir el tiempo de atención de los requerimientos y las órdenes de compra; por ejemplo, el requerimiento de compra del cliente interno y del proveedor deben ser atendidos dentro de las 24 horas desde su recepción, de esta manera se evita generar stock de órdenes y por ende se reduce el Lead Time del proceso. Finalmente, se especifican las actividades desde la Solicitud de requerimiento del cliente interno hasta el registro de la evaluación del proveedor. (Ver Anexo $\mathrm{N}^{\circ}$ 6)

En la Figura 38, se presenta el diagrama de flujo del Procedimiento de Compras. 
Figura 38. Diagrama de flujo del Proceso de Compra

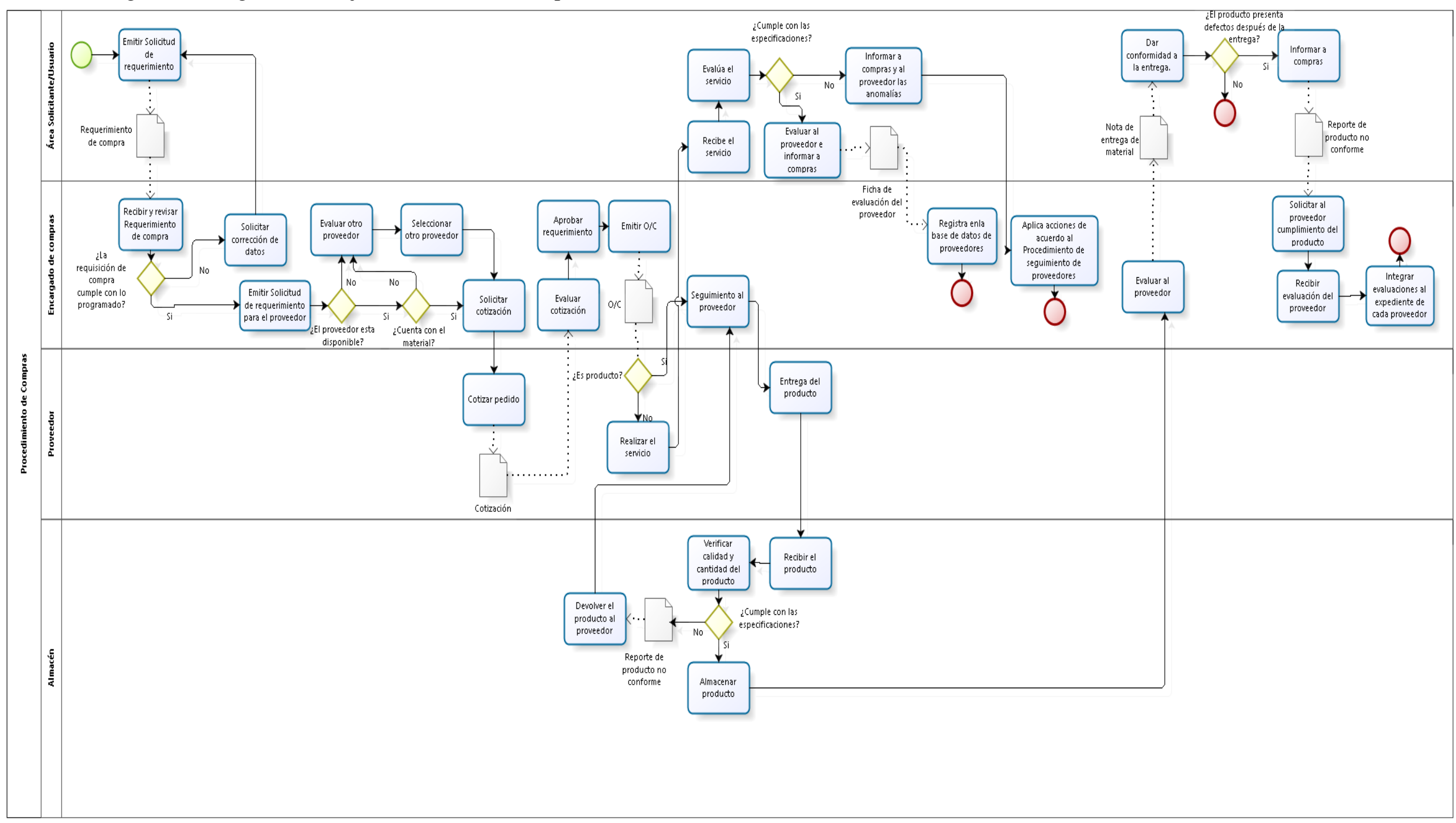

Fuente : Elaboración propia- Año 2017 


\section{Selección, evaluación y homologación de proveedores.}

\section{Método de selección, evaluación y homologación.}

Según Park, Shin y Chang, señalan que la selección de proveedores está compuesta por dos fases:

Fase 1: se crea un grupo de proveedores donde se registran a aquellos que previamente fueron evaluados de acuerdo a criterios tales como capacidad tecnológica y situación financiera.

Fase 2: se asignan a los proveedores que suministran los materiales de manera directa. En tal sentido, este paso se basa en criterios tales como el costo, el tiempo de entrega y la calidad.

Figura 39. Método de selección, Evaluación y Homologación

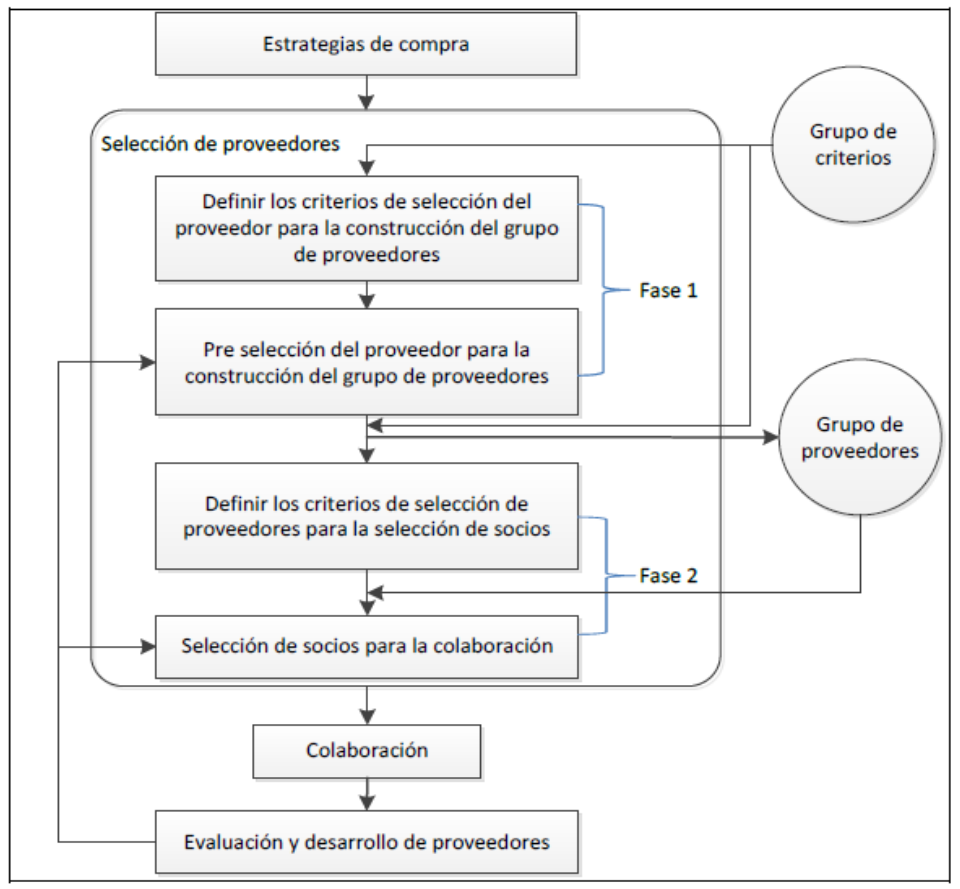

Fuente : Park, Shin y Chang- Año $2010: 8$

- Búsqueda de Información del proveedor:

Es aquí donde se toma en cuenta todas las fuentes de información existentes para poder localizar dichas empresas. Entre éstas: sitios web, recomendaciones, prensas, directorios telefónicos, etc. 
- Solicitud de Información:

Una vez terminado la recopilación de los posibles proveedores se inicia el contacto directo o vía telefónica para solicitar citas con encargados de ventas o enviar correspondencia solicitando la información necesaria para nuestra selección de proveedores según los aspectos mencionados en la Tabla 25.

Tabla 25. Aspectos considerar para la solicitud de proveedores

\begin{tabular}{|c|c|c|}
\hline \multicolumn{3}{|c|}{ Aspectos que se desean conocer de los proveedores } \\
\hline $\begin{array}{c}\text { Condiciones referidas a la } \\
\text { calidad }\end{array}$ & Condiciones Económicas & Otras condiciones \\
\hline Calidad de los productos & Precio unitario & $\begin{array}{l}\text { Periodo de validez de la } \\
\text { oferta }\end{array}$ \\
\hline Materiales Utilizados & Descuento comercial & $\begin{array}{l}\text { Causas de terminación del } \\
\text { contrato }\end{array}$ \\
\hline Características técnicas & $\begin{array}{l}\text { Rappels (Descuentos por } \\
\text { volumen de compra) } \\
\end{array}$ & $\begin{array}{l}\text { Circunstancias que pueden } \\
\text { dar lugar a revisiones en los } \\
\text { precios }\end{array}$ \\
\hline Periodo de Garantía & \begin{tabular}{|l} 
Forma de Pago \\
\end{tabular} & Plazo de entrega \\
\hline $\begin{array}{l}\text { Formación de los usuarios, } \\
\text { si fuese necesario }\end{array}$ & Plazo de Pago & Embalajes especiales \\
\hline Servicio postventa & Precios de envases y embalajes & Cualquier otra información \\
\hline $\begin{array}{l}\text { Servicio de atención al } \\
\text { cliente }\end{array}$ & Pago del transporte & \\
\hline $\begin{array}{l}\text { Otras informaciones que se } \\
\text { necesite conocer }\end{array}$ & Pago del Seguro & \\
\hline & $\begin{array}{l}\text { Recargos por aplazamiento de } \\
\text { pago }\end{array}$ & \\
\hline
\end{tabular}

Fuente : Mailxmail- Proveedores compra-venta

Así mismo, es importante que el proveedor permita realizar visitas a sus instalaciones para cerciorarnos de una manera directa del proceso de fabricación, las especificaciones técnicas, calidad, etc. Por medio de una carta hacia los proveedores se puede pedir información de la misma, se puede utilizar un formato establecido solicitando precios, remisión de catálogos, etc. (Ver anexo $\mathrm{N}^{\circ} 7$ ).

De la misma manera, se envía un cuestionario con las preguntas de interés a los posibles proveedores con la finalidad de recabar más información. (Ver anexo N8)

Una vez recaudada la información, se registra en la lista de proveedores para visualizar de forma global los datos. (Ver anexo $\mathrm{N}^{\circ}$ ) 
- Evaluación y selección de proveedores.

Existe la comparación de los criterios de selección que permiten retroalimentar, tanto al cliente como al proveedor respecto a los requisitos de calidad, disponibilidad, costo y tiempo. La ponderación se realiza en base a la técnica del proceso analítico jerárquico o AHP. Para este otro caso es necesario generar una escala de valores del 1 al 9, con la finalidad de poder realizar las comparaciones de los criterios previamente establecidos. (Ver Tabla 26)

Tabla 26. Escala de Ponderación

\begin{tabular}{|lll|}
\hline Intensity of importance & \multicolumn{1}{c}{ Definition } & \multicolumn{1}{c}{ Explanation } \\
\hline 1 & Equal importance & $\begin{array}{c}\text { Two criteria contribute equally to the } \\
\text { objective } \\
\text { Experience and judgement slightly } \\
\text { favour one over another } \\
\text { Experience and judgement strongly } \\
\text { favour one over another } \\
\text { criterion is strongly favoured and its } \\
\text { dominance is demonstrated in } \\
\text { practice }\end{array}$ \\
9 & Strong importance & $\begin{array}{c}\text { Importance of one over another } \\
\text { affirmed on the highest possible order }\end{array}$ \\
$2,4,6,8$ & Absolute importance & $\begin{array}{c}\text { Used to represent compromise between } \\
\text { the priorities listed above }\end{array}$ \\
Reciprocals of above & Intermediate values & $\begin{array}{l}\text { If criterion } i \text { has one of the above non-zero numbers assigned } \\
\text { to it when compared with criterion } j \text {, then } j \text { has the } \\
\text { reciprocal value when compared with } i\end{array}$ \\
\hline
\end{tabular}

Fuente : Lee y Drake- Año $2010: 14$

El encargado de compras debe realizar las matrices de comparación por pares de los criterios. La resolución del método de comparación se encuentra en (Ver anexo $\mathrm{N}^{\circ} 10$ ).

Además, en este punto, se recomienda elaborar una ficha por proveedor, una base de datos y un cuadro comparativo de las condiciones de compra y sus características, de esta forma se puede tomar una decisión de manera más fácil para que el proveedor forme parte del panel de posibles proveedores de la organización. (Ver anexo $\mathrm{N}^{\circ} 11$ ).

- Homologación de Proveedores.

Una vez realizada la evaluación y selección del proveedor es crucial realizar la homologación de proveedores para gestionar y controlar a los proveedores beneficiando en calidad, tiempo, precio y riesgo en el abastecimiento (Société Générale de Surveillance). 
Figura 40. Etapas para la evaluación

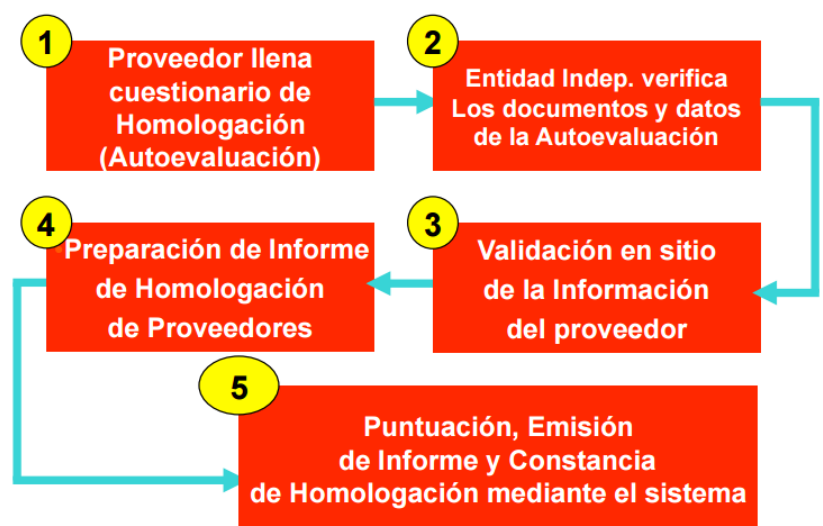

Fuente : SGS

El informe de homologación se realiza considerando los niveles de calificación estándar. Este informe contiene resultados numéricos, así como un breve comentario de los resultados obtenidos.

En lo referente a la Homologación, los niveles de calificación estándar son los mencionados en la Tabla 27.

Tabla 27. Niveles de calificación para Homologación

\begin{tabular}{|l|l|}
\hline \multicolumn{1}{|c|}{ NIVELES } & \multicolumn{1}{|c|}{ OBSERVACIONES } \\
\hline NIVEL A (90\% A 100\%) & $\begin{array}{l}\text { Cuentan con un sistema de gestión de la } \\
\text { calidad que permiten satisfacer los } \\
\text { requerimientos de sus clientes. }\end{array}$ \\
\hline NIVEL B+(80 A 90\%) & $\begin{array}{l}\text { Proveedores válidos para ofrecer bienes o } \\
\text { servicios. Trabajan con procedimientos } \\
\text { debidamente implantados, teniendo } \\
\text { ciertas limitaciones. Los suministros } \\
\text { quedarán sujetos a inspecciones } \\
\text { periódicas aleatorias. }\end{array}$ \\
\hline NIVEL B- (75\% A 80\%) & $\begin{array}{l}\text { Proveedores válidos para ofrecer bienes o } \\
\text { servicios. Trabajan con algunos }\end{array}$ \\
\hline
\end{tabular}




\begin{tabular}{|l|l|}
\hline & $\begin{array}{l}\text { procedimientos implantados, pero con } \\
\text { limitaciones. Los suministros estarán } \\
\text { sujetos a inspecciones frecuentes, lo que } \\
\text { supone un costo por recepción de los } \\
\text { bienes y servicios. }\end{array}$ \\
\hline NIVEL C (55\% A 75\%) & $\begin{array}{l}\text { Son proveedores que ofrecen bienes y } \\
\text { servicios, pero con serias restricciones, no } \\
\text { realizando controles sistemáticos en sus } \\
\text { procesos. Estarán sometidos a } \\
\text { inspecciones rigurosas en todos los bienes } \\
\text { y servicios suministrados, lo que supone } \\
\text { un alto costo por recepción. }\end{array}$ \\
\hline NIVEL D (0\% A 55\%) & $\begin{array}{l}\text { Son aquellos proveedores que, por su } \\
\text { sistema de trabajo y organización, no } \\
\text { reúnen los requisitos necesarios para } \\
\text { proveer a sus clientes habitualmente. }\end{array}$ \\
\hline
\end{tabular}

Fuente : SGS

Es necesario que se realice un intenso trabajo de mejora en los aspectos mencionados.

El procedimiento de puntuación se realiza por méritos, mediante un cálculo directo de las preguntas calificadas con puntuación positiva, considerando los pesos definidos para cada pregunta (igual a 1). De acuerdo a lo declarado en el cuestionario, a lo observado por el evaluador y a las evidencias presentadas, se asignan los méritos correspondientes. Para obtener la calificación final y el nivel alcanzado de evaluación, se realiza un promedio ponderado de la calificación parcial de cada uno de los aspectos considerados en la homologación con los pesos definidos para cada actividad.

Después de haber realizado la homologación es necesario seguir evaluando a los proveedores con la finalidad de que se encuentren alineados a los objetivos y estrategias de la empresa. (Ver anexo $\mathrm{N}^{\circ} 12$ ) 


\section{Procedimiento de evaluación y homologación de Proveedores.}

Se realiza el procedimiento de evaluación y homologación de proveedores (COMP-PRO-01) para establecer la manera de hacerlo considerando cada etapa del proceso de evaluación y homologación de proveedores. En el procedimiento se encuentra los objetivos, responsabilidades, documentos a consultar, condiciones básicas para que el procedimiento pueda ponerse en marcha, las actividades a realizar y además se puede encontrar formatos que facilitan el entendimiento y desarrollo del procedimiento. (Ver anexo $\mathrm{N}^{\circ} 13$ )

En la Figura 41, se presenta el diagrama de flujo del procedimiento de Selección, Evaluación y Homologación de Proveedores. 
Figura 41. Procedimiento de Selección, evaluación y homologación de proveedores

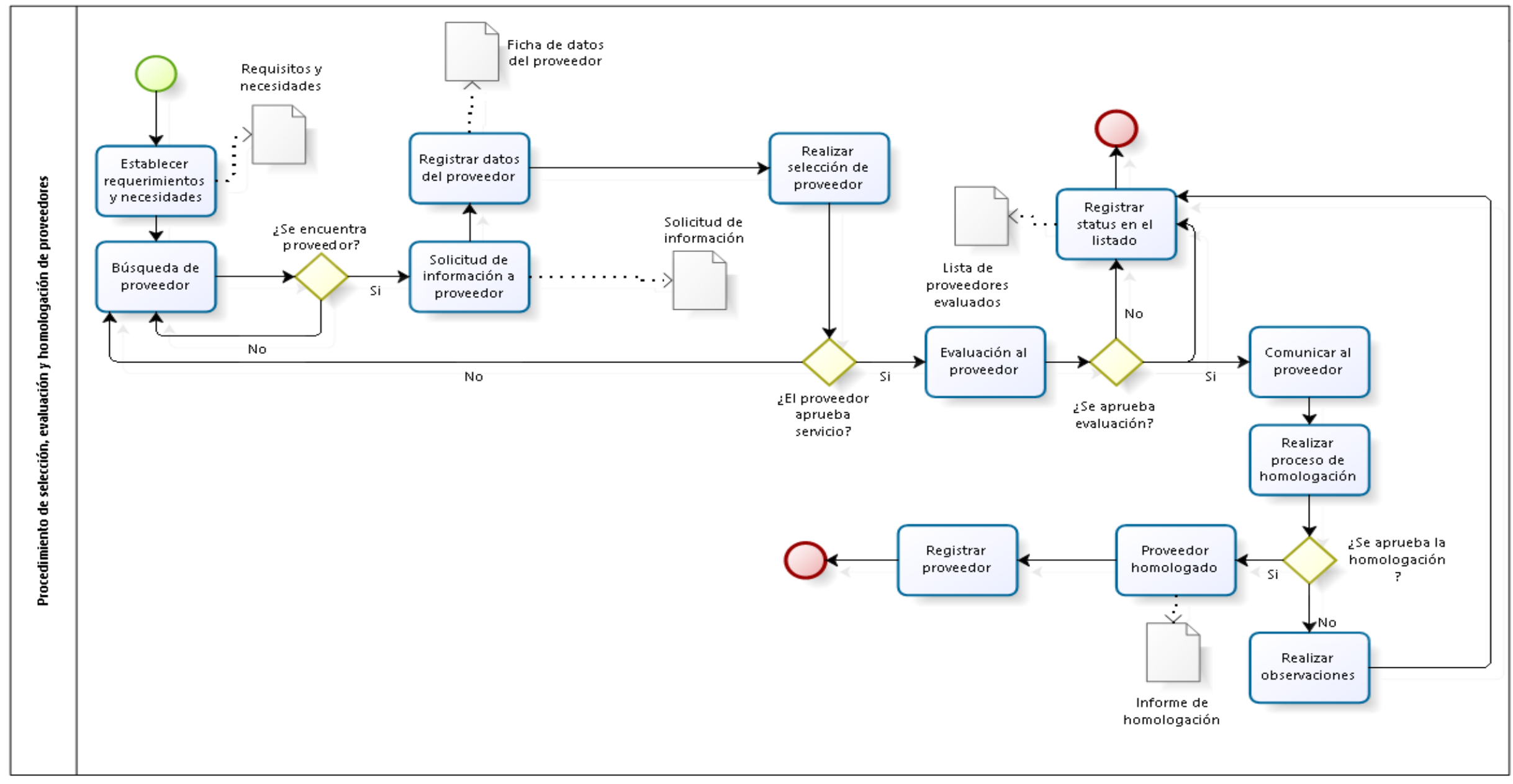

Fuente : Elaboración propia- Año 2017 


\section{Políticas de Compras.}

La actividad de compras constituye una de las funciones clave de la empresa por su elevado impacto económico, medioambiental y social. Se establece las siguientes pautas básicas de actuación para que la actividad de compras se desarrolle correctamente, de acuerdo con los criterios y las finalidades de los intereses corporativos, la estructura ética y la política de desarrollo sostenible del sector. Estas políticas serán aplicadas y consideradas al momento en que la organización proceda a la adquisición de productos o servicios para sus operaciones habituales.

En esta política se encuentra puntos esenciales a tomar en cuenta para la obtención de productos o servicios, determina la correcta relación que tendrá la empresa con sus proveedores para conseguir mejores resultados. (Ver anexo $\left.\mathrm{N}^{\circ} 14\right)$.

\section{Seguimiento de compras}

Procedimiento de seguimiento a las compras.

En este documento (COMP-SC-01) se describe el modo en que el sector debe realizar el seguimiento de compras cuyo impacto incide sobre el producto final adquirido, el alcance del procedimiento es desde la emisión de la solicitud de requerimiento por parte del cliente interno hasta que se abaste el pedido. El procedimiento consta de 4 partes: Solicitud de requerimiento de compra, determinar recepción de pedidos, aprobación de la orden de compra y abastecimiento del proveedor.

En la Figura 42, se presenta el diagrama de flujo del Procedimiento de seguimiento a las compras. (Ver anexo $\mathrm{N}^{\circ} 15$ ) 
Figura 42. Procedimiento de Seguimiento a las Compras

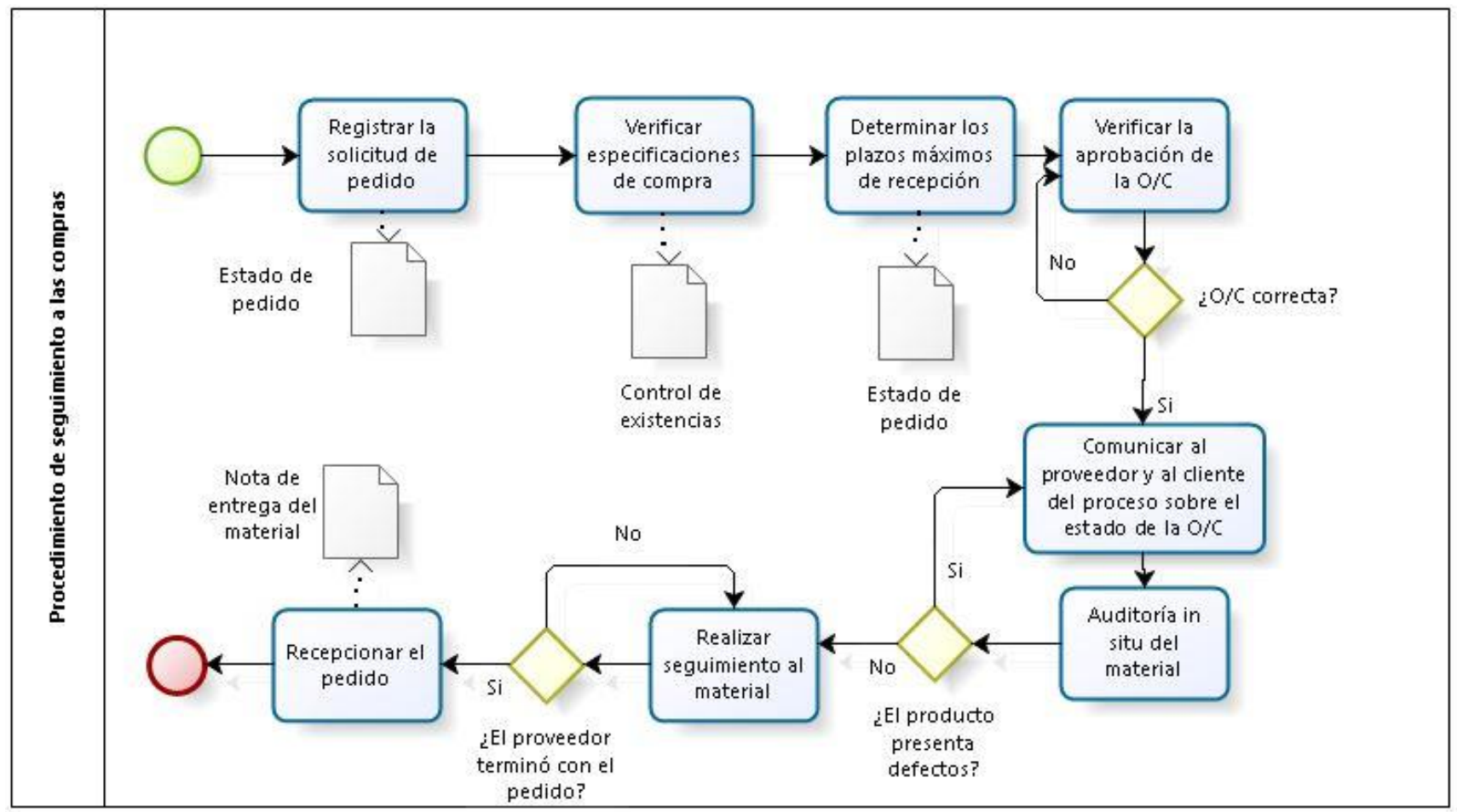

Fuente : Elaboración propia- Año 2017

Procedimiento de seguimiento de Proveedores.

En este documento (COMP-SDP-01) se describe el modo de realizar el seguimiento a aquellos proveedores cuyo resultado incide significativamente sobre el producto adquiridos, ya que la elección del proveedor adecuado asegura el cumplimiento de las políticas de compra que establece la empresa. (Ver Figura 43) 
Figura 43. Procedimiento de seguimiento a Proveedores.

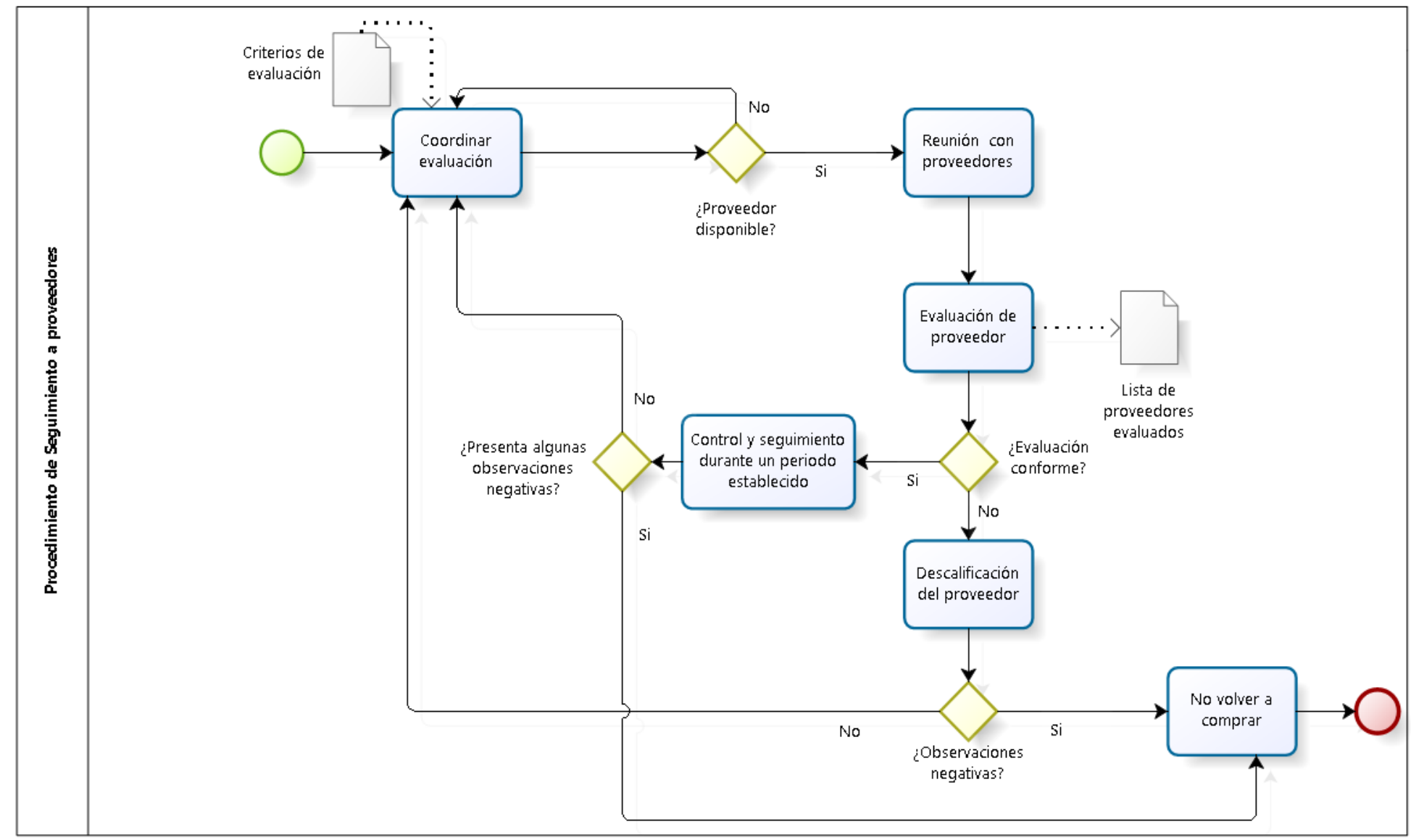

Fuente : Elaboración propia- Año 2017

El procedimiento consta de 4 partes: Coordinar la evaluación de proveedores, reunión de proveedores, seguimiento de proveedores y descalificación de proveedores en caso lo requiera. (Ver anexo $\left.\mathrm{N}^{\circ} 16\right)$

Indicadores de Medición.

Índice de cumplimiento de la Orden de compra (PRO-IC-01): Muestra el porcentaje de órdenes de compra correctamente elaboradas por el departamento de compras. (Ver anexo $\left.\mathrm{N}^{\circ} 17\right)$

Porcentaje de pedido devuelto al proveedor (PRO-IC-02): Muestra el porcentaje de pedidos devueltos al proveedor por incumplimiento de las características del material indicadas en la orden de compra.

\section{Métodos para la evaluación del desempeño del proceso.}

Sistema de medición de desempeño 
Es responsabilidad del área o de los encargados del proceso, realizar la evaluación de desempeño del proceso, para el mejoramiento continuo. Desde el momento de la inducción de la implementación del sistema, se debe explicar al colaborador en que consiste el nuevo método de trabajo, cuáles son los beneficios de su implementación. El proceso se encuentra definido en tres fases (Ver Figura 44), recomendable ejecutar cada año y que se detalla a continuación.

Figura 44. Fases de la gestión de Desempeño

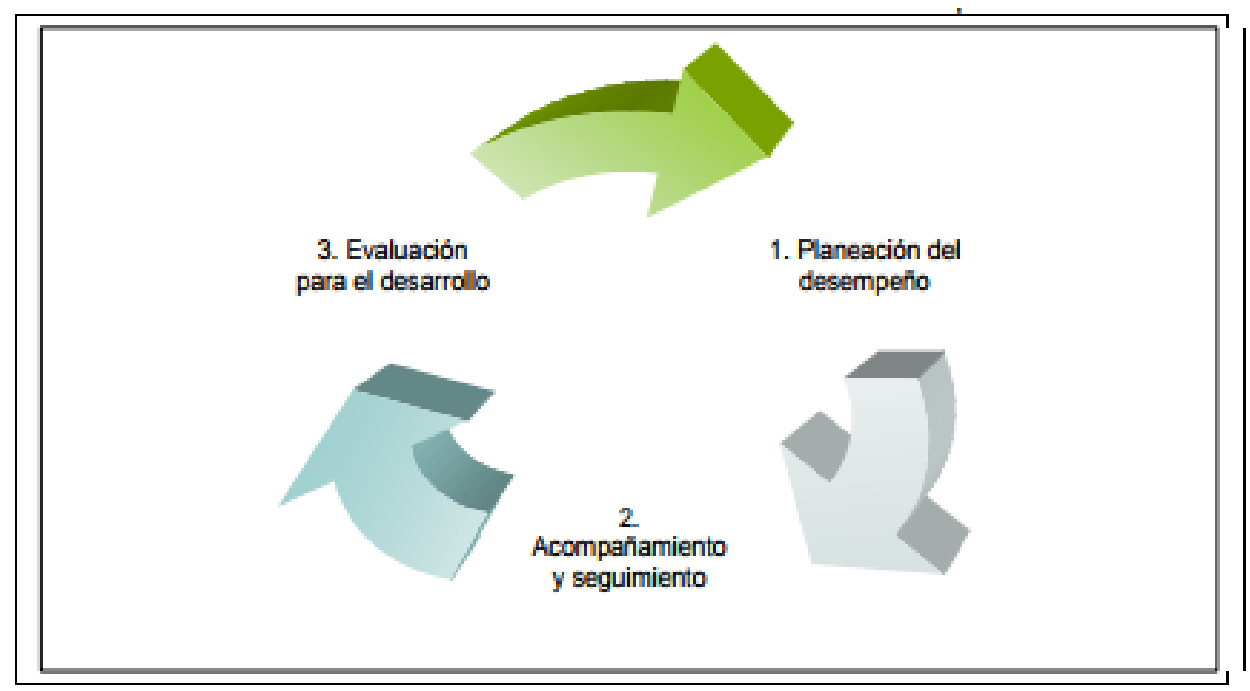

Fuente : Montoya, C.

\section{Fase 1: PLANEACION DEL DESEMPEÑO}

Este consiste en el diseño del formato de evaluación que toda la organización va a utilizar, de acuerdo a los criterios que considera pertinente a evaluar y que debe ser entregado y explicado por el encargado de compras a los Stakeholders del proceso.

\subsection{Identificación de criterios de evaluación del desempeño}

En una primera etapa se seleccionan los criterios, a través de los cuales se va a evaluar el sistema.

- Tener identificados a sus proveedores y clientes internos

- Tener una misión claramente definida

- Disponer de objetivos cuantitativos y cualitativos para satisfacer las expectativas de su cliente, así como indicadores de cumplimiento.

- El proceso debe tener límites concretos de comienzo a fin. 
- El auxiliar como su jefe inmediato directo, deben trabajar sobre el formato de evaluación del desempeño del proceso (PRO-EDP-01) en su versión original para que ambos puedan diligenciarlo y comentarlo posteriormente.

- Con suficiente anticipación se debe citar a cada uno de los participantes del proceso de evaluación; disponer de un lugar apropiado para realizar la evaluación del desempeño y calcular el tiempo necesario para efectuarla.

- Tener un amplio conocimiento del formato que se va a utilizar en el proceso.

- Desarrollar la sección de evaluación de desempeño a través de una reunión, en presencia de los colaboradores del área donde se propone y debate las alternativas respectivas de calificación; además de efectuar las aclaraciones que solicite el empleado.

- Facilitar la comunicación entre los procesos involucrados, es recomendable recibir opiniones de los diferentes procesos para mejorar el sistema.

- Confrontar, para efectos de seguimiento, los planes y compromisos propuestos con los logrados; analizar las posibles causas que faciliten o impiden su logro.

- Tener en cuenta el desempeño y resultado comprobables del proceso, no basarse en suposiciones.

- Orientar el diálogo entre el jefe inmediato y auxiliares de tal manera que permita establecer objetivos, detectar fortalezas y debilidades, conocer la calidad del desempeño en sus diferentes manifestaciones y establecer una oportunidad concreta de mejoramiento y desarrollo del proceso.

- Preparar el material y establecer claramente el momento y el propósito de cada una de las secciones de la evaluación.

- Tener asignados con claridad unos recursos y ser realizable con aquellos disponibles. Uso adecuado de la tecnología de la información.

- Estar normalizado y documentado, enfatizando en la prevención de errores y contemplando la posibilidad de ser mejorado. Asimismo, se ha definido la sistemática para auditar su cumplimiento y eficacia.

- Mostrar con claridad las interacciones con otros procesos internos y del cliente.

- Ser un proceso lo más sencillo y fácil de realizar posible, lo que normalmente requiere que el número de pasos y de personas involucradas se reduzca (Fernández, 2010). 


\subsection{Definición de indicadores}

Optimización del presupuesto asignado (DES-FTI-01): Este indicador evidencia cómo el departamento de compras está utilizando el presupuesto que se le asignó; gracias a este también se puede saber si se está optimizando el presupuesto; es decir, si se están adquiriendo los productos necesarios al costo adecuado, dentro de las condiciones y plazos de entrega requeridos.

Tiempo de valor añadido (DES-FTI-02): Muestra la proporción sobre el tiempo que realmente se le está dando valor al producto. Este indicador se obtiene como la relación entre el tiempo de valor no añadido, en el cual no se aporta valor al producto (ya sea almacenado, transportado, inspeccionado, etc.) y el tiempo de valor añadido, es decir; el tiempo en el que se hace una operación que el cliente si valora (Vázquez, 2013).

Efectividad en el cumplimiento de tareas (DES-FTI-03): Muestra si se está cumpliendo los objetivos del departamento de compras en cuanto a tiempo y forma de trabajo.

Sinergia entre el Departamento de compras y Planeamiento de producción (DES-FTI-04): Este indicador muestra el nivel de comunicación y organización existente entre ambos departamentos (Zamudio, 2016).

Ciclo de la orden de compra (DES-FTI-05): Indicador que controla el tiempo que transcurre entre el momento que el cliente interno realiza el pedido y el momento en que éste recibe físicamente la mercancía. Este indicador debe expresarse en ciclo normal de reorden, por lo tanto, debe calcularse excluyendo los pedidos urgentes y los pedidos programados (Monroy, s.f).

Productividad del proceso (DES-FTI-06): Mide la cantidad de pedidos completos abastecidos por hora de mano de obra trabajada (Marín, s.f). (Ver anexo $\mathrm{N}^{\circ} 18$ )

\subsection{Diseño de métodos para recoger la información}

Se establece métodos para realizar la calificación y extraer datos que proporcionen información para evaluar el desempeño. 


\section{Entrevistas}

Este método de evaluación se desarrolla a través de entrevistas realizadas al trabajador por su superior jerárquico inmediato con el propósito de analizar el desempeño laboral del empleado en un periodo determinado. (Ver anexo $\mathrm{N}^{\circ} 19$ )

Gracias a la entrevista se puede planear conjuntamente con el evaluado un plan de acción para su desarrollo en el cargo y en la organización.

\section{Cuestionarios}

Este método se sirve de un formulario donde se cruzan los factores de evaluación del desempeño con su grado de variación, posibilitando una visión integrada y resumida de las características de desempeño más destacadas por la empresa y la situación de cada trabajador ante ellas. Este cuestionario es realizado de manera anónima bajo el formato (Ver anexo $\mathrm{N}^{\circ} 20$ )

\section{Fase 2: ACOMPAÑAMIENTO Y SEGUIMIENTO}

El objetivo de esta fase es realizar un monitoreo y brindar soporte para el cambio de metodología de trabajo y lograr las metas planteadas. Esta fase es de suma importancia en el proceso, ya que permite dar retroalimentación permanente al sistema y que los planes se mantengan vigente, se mejoren o se sustituyan en caso de que lo amerite.

\subsection{Ejecución de métodos para recoger información}

Se aplican los métodos mencionados para recoger información a todas aquellas personas que han participado en la transición del método de trabajo o que indirectamente fueron involucradas.

\section{Fase 3: EVALUACIÓN PARA EL DESARROLLO}

Esta fase tiene como objetivo realizar un análisis sobre el cumplimiento de las metas y el nivel alcanzado con respecto a lo establecido en la fase 1, así como compartir, comunicar e identificar los aspectos favorables y a mejorar sobre el desempeño evidenciado (Montoya, s.f).

\subsection{Análisis y comunicación de los resultados.}

En este punto se realiza el consolidado de todos los indicadores propuestos con la finalidad de observar el impacto de la implementación. Se consolida mediante un cuadro de comparación. (Ver anexo $\left.\mathrm{N}^{\circ} 21\right)$ 
Asimismo, para la comunicación de los resultados se convoca a una reunión al personal del área y gerencia para dar a conocer los resultados obtenidos y se puedan generar ideas que contribuyan a la mejora del proceso. El personal operativo conocerá sobre los resultados mediante sus jefes directo o mediante la publicación de estos en medios no verbales como periódico mural, correos masivos, etc.

\subsection{IMPLEMENTACIÓN DE LA HERRAMIENTA DE JUST IN TIME}

\subsubsection{DISEÑO DE LA PROPUESTA.}

Se plantea el rediseño del Sistema de compras Justo a Tiempo, este consiste en el desarrollo de 5 estrategias clave, las cuales se muestran en la Figura 45.

Figura 45. Diseño del sistema de compras Justo a Tiempo

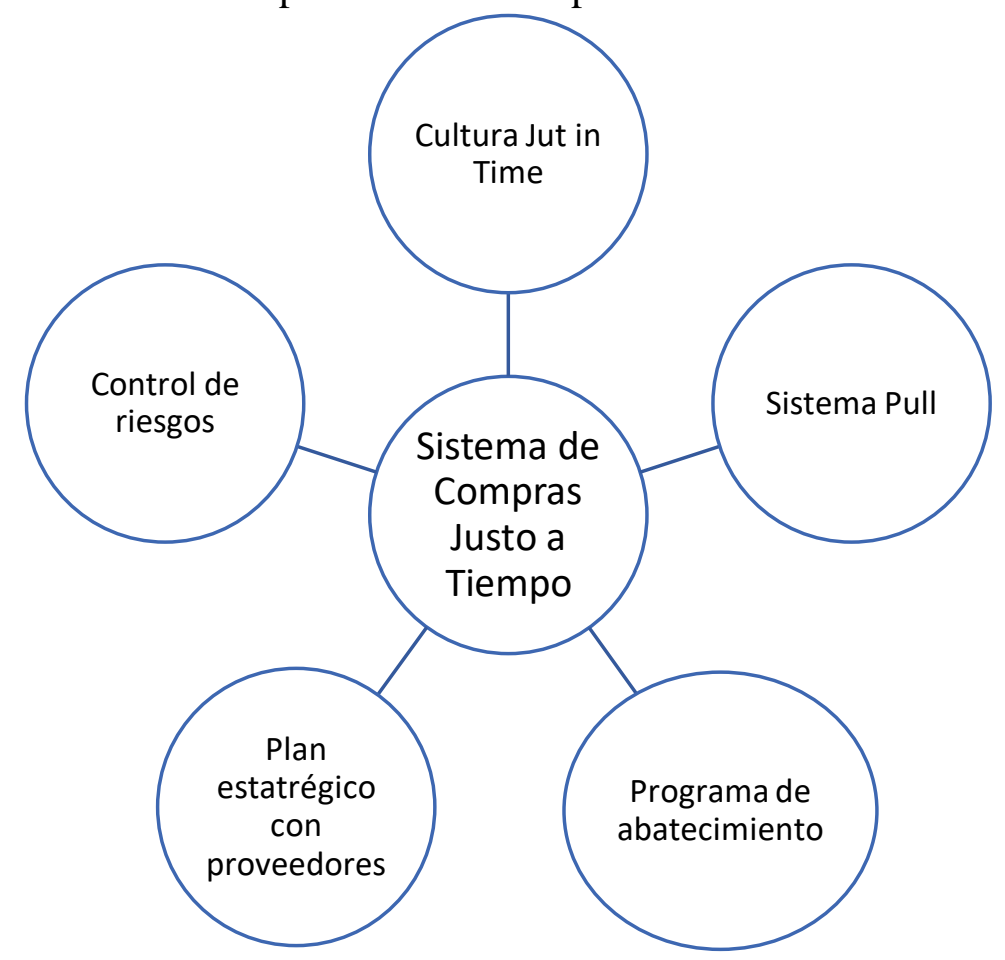

Fuente : Elaboración propia- Año 2017

En cada una de las estrategias mencionadas se van a utilizar diversas herramientas de fácil aplicación, las cuales se nombran a continuación:

1. Cultura Just in Time.

- Programa de educación y motivación al personal. 
2. Método Sistema Pull.

- Método para aplicación del sistema.

- Plan de requisitos establecidos.

3. Programa de abastecimiento.

- Plan o calendario de abastecimiento (sistema de compras calendarizadas): Desarrollo de un caso práctico.

- Utilización de PRM (Planeamiento de requerimiento de materiales): Desarrollo de un caso práctico.

4. Plan estratégico con Proveedores.

- Política de pagos a proveedores

- Plan estratégico con proveedores

- Plan de auditoría in Situ

5. Control de Riesgos.

- Plan de contingencia

- En este sentido, se escoge dicho sistema, ya que su implementación considerando los puntos mencionados apuntan directamente hacia la solución de las causas raíces del problema. (Ver Figura 46) 
Figura 46. Propuesta de solución Compras Just in Time.

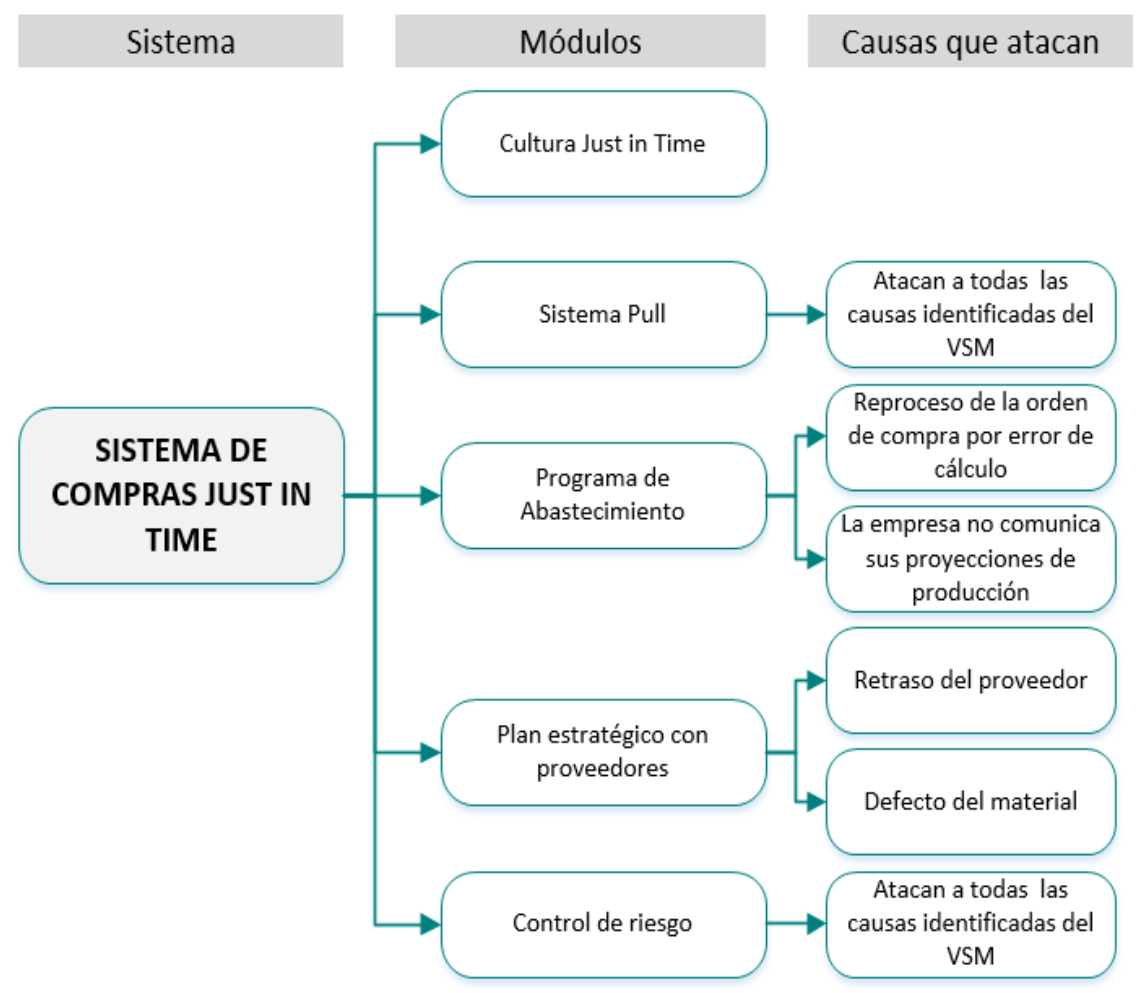

Fuente : Elaboración propia- Año 2017

Para que la propuesta del Sistema de compras Justo a Tiempo sea efectiva se propone el desarrollo de 5 módulos.

El primero módulo se basa en el desarrollo de una Cultura Just in Time, esta sirve de soporte para la implementación gradual del sistema Justo a Tiempo, el objetivo es lograr que los trabajadores e implicados se adapten a la metodología de trabajo propuestas y sean capaces de mantenerla en el tiempo.

\section{Cultura Just in Time}

El segundo módulo, es el desarrollo de un Sistema Pull que aplica a todo el proceso de compras y directamente a todas las causas identificadas en el VSM, de esta manera se busca eliminar el inventario de requerimientos y órdenes de compra, y las esperas por aprobación; además, agilizar el flujo de información. 


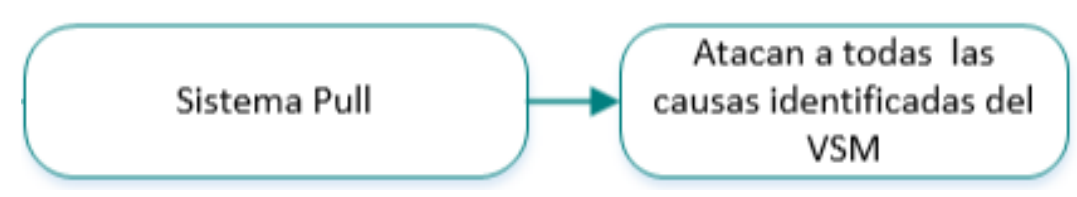

El tercero se centra en la ejecución de un Programa de Abastecimiento, el cual busca solucionar el problema de la falta de comunicación de las proyecciones a los proveedores; es decir, hacer eficiente el flujo de información entre empresa y proveedor, en este módulo es importante la participación del proveedor del proceso de compras que es el proceso de Planeamiento de la producción, ya que ellos proporcionarán la información base para dar inicio al planeamiento de compras.

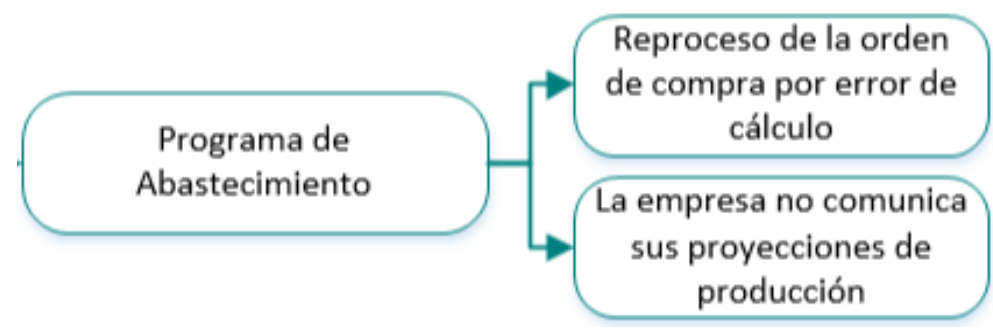

En el cuarto módulo se desarrolla el Plan estratégico con proveedores, con el objetivo de evitar el retraso de los proveedores de 2 días, ya que se plantea un plan de auditoría in situ; en consecuencia, con la inspección del proceso se podrá reducir o eliminar el defecto del material.

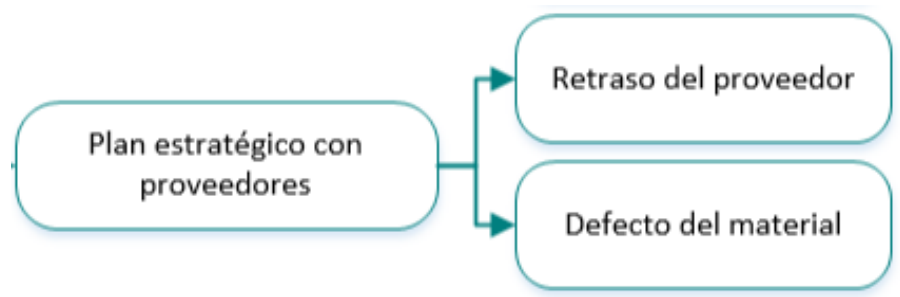

En el quinto módulo se desarrolla el Control de riesgos, el cual ataca a todas las causas del Lead Time excesivo en el abastecimiento de telas mostrados en el VSM.

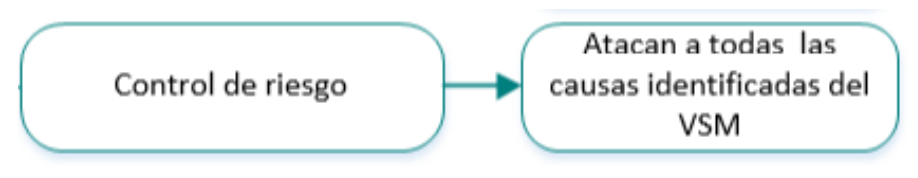

En este contexto se procede a describir de forma general cómo se desarrollarán cada una de las estrategias mencionadas del Sistema de Compras Justo a Tiempo. 
En primer lugar, se realiza el Programa de educación y motivación al personal, donde se desarrolla un programa para que los trabajadores se adapten a la nueva metodología de trabajo y la aplicación de la metodología permanezca en el tiempo.

El objetivo es proporcionar una compresión de la filosofía Just in time y la aplicación.

En segundo lugar, se realiza Método de Sistema Pull, se va a definir qué documento necesita cada cliente interno y participante del proceso, el tipo de documento y tiempo límite que debe llegar este a cada participante. De esta forma, se logrará establecer requisitos y límites de tiempo para que suministren los materiales y componentes de forma oportuna en el momento que se necesita. Además, con este punto se quiere lograr eliminar los desperdicios de espera o retraso y asegurar que toda la información este clara y concisa para poder generar el pedido.

En tercer lugar, se realiza el Programa de abastecimiento este sirve como un sistema para facilitar el flujo de información entre la empresa y el proveedor para que haya capacidad de previsión por parte de este último, para ello se plantea un sistema de compras calendarizadas y el uso de un sistema de planeación de compras que sirva como herramienta de programación, esta consiste en realizar un consolidado de fechas importantes de pedidos y entregas de tal manera que se le comunica a los proveedores en qué fechas deben abastecer el pedido.

En cuarto lugar, se realiza un Plan estratégico con los Proveedores, donde se define una política de pagos, de tal manera que el proveedor se sienta motivado e inicie a tiempo la producción para cumplir con la fecha acordada, programa de negociación con proveedores; es decir, acciones que se deben llevar a cabo para generar relación, facilidades y confianza con el proveedor. Así mismo, se realiza el Plan de auditoría in situ para asegurar la calidad, el cumplimiento de las especificaciones, la cantidad y por ende evitar errores para asegurar el tiempo de entrega previamente establecido.

En el quinto y último lugar, se realiza un Control de riesgo, donde se realiza un plan para actuar ante la presencia de cualquier error que se cometa en el proceso de compras, en cuanto a cantidades, fechas de abastecimiento, especificaciones y detalles técnicos. Asimismo, se define cómo se debe actuar en casos que el proveedor no cumpla con las especificaciones, de esta manera los trabajadores del área de compra sabrán cómo actuar para que el pedido no se detenga y el abastecimiento se dé a tiempo. 


\subsubsection{DESAROLLO DE LA PROPUESTA.}

\subsubsection{Cultura Just in Time.}

Programa de educación y motivación al personal.

El programa tiene como objetivo principal desarrollar una cultura de trabajo bajo la metodología Just in time que permite realizar las actividades necesarias para que los procesos, operarios y proveedores cumplan con sus responsabilidades definidas y de esa manera que identifiquen, detecten y eliminen sistemáticamente de los desperdicios que se presente.

Figura 47. Modelo de guía para implementar Justo a Tiempo

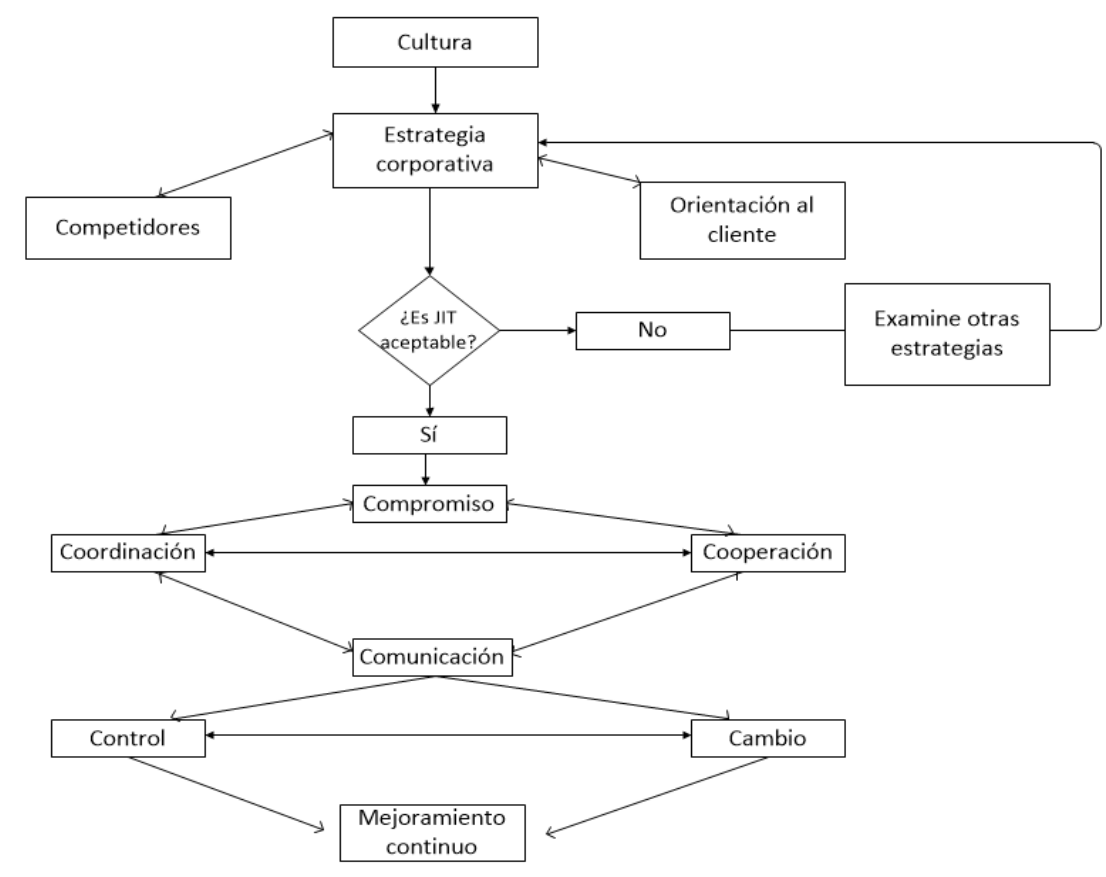

Fuente : Guía para la Implementar la filosofía Justo a Tiempo

De esta manera, se realiza un programa de educación Just in time (COMP-PE-01) con la finalidad de que el personal esté preparado para los cambios a realizar y se alinean a los procedimientos establecidos. (Ver anexo $\mathrm{N}^{\circ} 22$ ).

\subsubsection{Sistema Pull.}

Método para aplicación del sistema.

Para ello se realiza una Programación de Notificación tipo Pull (COMP-PNP-01), en cual tiene por objetivo realizar un mapeo de los productos y las compras, a través de la programación de 
notificaciones se puede tener un registro de la frecuencia con la que se pide un mismo producto y generar una programación más exacta para el siguiente pedido. (Ver anexo $\mathrm{N}^{\circ 23}$ )

Plan de requisitos establecidos.

Con el objetivo de tomar en cuenta las necesidades de los involucrados en el proceso de compras, es necesario saber que documentos necesita cada uno de ellos. En la Tabla 28, se muestran los Stakeholders o involucrados en el proceso de compras, así como los documentos que requiere cada uno de ellos para realizar sus funciones, la forma de comunicación y los respectivos emisores de los requerimientos que solicitan.

Tabla 28. Stakeholders Involucrados en el proceso de compras

\begin{tabular}{|c|c|c|c|c|}
\hline Stakeholders & Importancia & Requerimiento & $\begin{array}{c}\text { Forma de } \\
\text { comunicación }\end{array}$ & Emisor \\
\hline \multirow[b]{2}{*}{ Gerencia } & \multirow{2}{*}{$\begin{array}{l}\text { Es la persona o grupo de personas } \\
\text { que dirigen la empresa, su rol es } \\
\text { esencial ya que se encargan de } \\
\text { tomar las principales decisiones y } \\
\text { en muchos casos aprueban las } \\
\text { órdenes de compra y cambios en un } \\
\text { proceso, además coordinan y } \\
\text { supervisan el trabajo. }\end{array}$} & $\begin{array}{l}\text { Informes de } \\
\text { eficiencia }\end{array}$ & Informes & $\begin{array}{c}\text { Encargado o } \\
\text { Auxiliar de } \\
\text { compras. }\end{array}$ \\
\hline & & $\begin{array}{l}\text { Permisos de } \\
\text { compra }\end{array}$ & $\begin{array}{l}\text { Documento en } \\
\text { papel. }\end{array}$ & $\begin{array}{c}\text { Encargado o } \\
\text { Auxiliar de } \\
\text { compras. }\end{array}$ \\
\hline \multirow{3}{*}{$\begin{array}{l}\text { Dirección de } \\
\text { compras }\end{array}$} & \multirow{3}{*}{$\begin{array}{l}\text { La dirección de compras es } \\
\text { responsable de conocer las } \\
\text { necesidades de los clientes internos, } \\
\text { liderar el abastecimiento, la } \\
\text { selección de proveedores, } \\
\text { negociación de precios y } \\
\text { condiciones de compras, además de } \\
\text { velar por la calidad de los } \\
\text { productos abastecidos. }\end{array}$} & $\begin{array}{c}\text { Plan de } \\
\text { Producción } \\
\text { mensual }\end{array}$ & $\begin{array}{c}\text { Documento } \\
\text { informático o } \\
\text { en papel }\end{array}$ & $\begin{array}{l}\text { Planeamiento de la } \\
\text { Producción }\end{array}$ \\
\hline & & $\begin{array}{l}\text { Inventario de } \\
\text { materiales }\end{array}$ & $\begin{array}{c}\text { Documento } \\
\text { informático o } \\
\text { en papel }\end{array}$ & $\begin{array}{l}\text { Planeamiento de la } \\
\text { Producción }\end{array}$ \\
\hline & & $\begin{array}{l}\text { Requerimiento } \\
\text { de compra }\end{array}$ & $\begin{array}{l}\text { Documento } \\
\text { informático }\end{array}$ & $\begin{array}{l}\text { Planeamiento de la } \\
\text { Producción }\end{array}$ \\
\hline \multirow[t]{2}{*}{ Proveedores } & $\begin{array}{l}\text { Son los responsables de facilitar los } \\
\text { insumos para la fabricación de los } \\
\text { productos, no solo en lo que se } \\
\text { refiere a materia prima, sino } \\
\text { también a servicios. Constituyen } \\
\text { los procesos claves de suministros. }\end{array}$ & $\begin{array}{c}\text { Plan de } \\
\text { abastecimiento }\end{array}$ & $\begin{array}{l}\text { Documento } \\
\text { informático o } \\
\text { en papel }\end{array}$ & $\begin{array}{c}\text { Encargado o } \\
\text { Auxiliar de } \\
\text { compras. }\end{array}$ \\
\hline & $\begin{array}{l}\text { Integran las funciones de } \\
\text { planificación y mando de la }\end{array}$ & $\begin{array}{l}\text { Ventas / } \\
\text { Demanda }\end{array}$ & $\begin{array}{l}\text { Documento } \\
\text { informático }\end{array}$ & Ventas \\
\hline
\end{tabular}




\begin{tabular}{|c|c|c|c|c|}
\hline $\begin{array}{l}\text { Planeamiento } \\
\text { de la } \\
\text { producción }\end{array}$ & $\begin{array}{l}\text { producción; a partir de la } \\
\text { utilización de diversas herramientas } \\
\text { que facilitan la toma de decisiones. }\end{array}$ & $\begin{array}{l}\text { Cronograma de } \\
\text { abastecimiento }\end{array}$ & $\begin{array}{l}\text { Documento } \\
\text { informático }\end{array}$ & Compras \\
\hline \multirow{2}{*}{$\begin{array}{c}\text { Cliente: } \\
\text { Corte }\end{array}$} & \multirow{2}{*}{$\begin{array}{l}\text { Es importante su participación en } \\
\text { las compras ya que aportan en la } \\
\text { aprobación del producto } \\
\text { recepcionado, al ser el cliente del } \\
\text { proceso aprueba la calidad final del } \\
\text { producto obtenido. }\end{array}$} & $\begin{array}{l}\text { Cantidad de } \\
\text { materiales } \\
\text { adquiridos }\end{array}$ & $\begin{array}{l}\text { Documento } \\
\text { informático }\end{array}$ & Compras \\
\hline & & $\begin{array}{l}\text { Fecha de } \\
\text { llegada de } \\
\text { materiales }\end{array}$ & $\begin{array}{l}\text { Documento } \\
\text { informático }\end{array}$ & Compras \\
\hline Finanzas & $\begin{array}{l}\text { Se encarga de registrar la } \\
\text { información de compras y sirven de } \\
\text { apoyo para la toma de decisiones } \\
\text { de costos de producción. }\end{array}$ & $\begin{array}{l}\text { Órdenes de } \\
\text { compras } \\
\text { aprobadas }\end{array}$ & $\begin{array}{l}\text { Documento } \\
\text { informático }\end{array}$ & Compras/Gerencia \\
\hline
\end{tabular}

Fuente : Elaboración propia- Año 2017

\subsubsection{Programa de abastecimiento.}

Sistema de compras calendarizada.

Un plan de compras es una técnica muy utilizada para llevar de forma eficiente el control de las mismas, ya que contiene el programa de las compras que se realizarán en un periodo determinado, ya sean materias primas, materiales terminados o servicios. Este plan se convierte en el presupuesto de compras, el cual se integra al presupuesto general de la empresa. Toda esta información se incluye en los pagos que se realizarán a futuro, y se integra cada uno de los artículos que se necesitan en la empresa para producir (SoyConta, 2013). El objetivo de esta herramienta es que haya capacidad de previsión por parte del proveedor para que no haya incumplimiento de pedido. En el presente trabajo, se desarrolla a través de un ejemplo un modelo de compras calendarizadas, en la cual es importante tener la información de la fecha del requerimiento, pedido y entrega del material solicitado. (Ver anexo $\mathrm{N}^{\circ} 24$ )

Desarrollo de un PRM (Planeación de requerimiento de materiales).

El plan de materiales de compras y fabricación denominado Plan de Pedidos, es una salida fundamental del sistema PRM, pues este contiene los pedidos planificados de todos los productos. La aplicación de esta herramienta beneficia al departamento de Compras, ya que podrá reducir al mínimo la aceleración de pedidos a proveedores que usualmente ocupa mucho tiempo al personal de dicha área. Por otro lado, proporcionando la información de los informes de pedidos planificados a tiempo a los proveedores, estos pueden planificar su capacidad 
adecuadamente antes de recibir los pedidos concretos (Flores, 2013). En el Anexo N²5, se plantea un ejemplo que demuestra la aplicación de dicha herramienta en las compras.

\subsubsection{Plan estratégico con Proveedores.}

El Plan estratégico con Proveedores (COMP-PEP-01) consta de 3 módulos que forman la base para fomentar confianza, seguridad y comunicación y por ende afianzar la relación entre la empresa y los proveedores. (Ver anexo $\mathrm{N}^{\circ} 26$ )

-Acuerdos y modalidades de pagos: Se define la Política de pago a proveedores (COMP-PPP01), de tal manera que se establecen los lineamientos de pago por los productos o servicios, que favorecen al proveedor y a la empresa y que deben ser cumplidos tal como se indica. (Ver anexo $\left.\mathrm{N}^{\circ} 27\right)$

-Programa de asociación con proveedores: Se definen estrategias de negociación con los proveedores; es decir, acciones que se deben llevar a cabo para generar relación, facilidades y confianza con el proveedor. (Ver anexo $\left.\mathrm{N}^{\circ} 26\right)$

-Auditoría in situ: Realizar un Plan de auditoría in situ (COMP-PA-01) (Ver anexo 26); es decir, en la planta del proveedor, para asegurar la calidad, el cumplimiento de las especificaciones, la cantidad y por ende evitar errores para asegurar el tiempo de entrega. Para llevar a cabo la auditoría se toma como base la Guía básica para la auditoría (COMP-GA-01), en donde se detallan las responsabilidades del auditor líder y la secuencia de la auditoría. (Ver anexo $\left.\mathrm{N}^{\circ} 28\right)$

Estas estrategias buscan asegurar el tiempo de abastecimiento y ayudar en la reducción de 2 días de retraso del proveedor y le dé prioridad al pedido.

\subsubsection{Control de riesgo.}

Plan de Contingencia.

Se realiza el Plan de Contingencia (COMP-PCG-01) con el objetivo de proveer información oportuna sobre los procedimientos a seguir para enfrentar posibles fallas en el proceso de compras, de esta forma se busca minimizar el impacto sobre la empresa, clientes y trabajadores; además, tener control total del sistema. En el Plan de contingencia se describen dos medidas: Medida de carácter preventivo, que se adelanta a las situaciones de error o falla, y Medida ante 
eventualidades durante el proceso de compras, donde se describen acciones cuando ocurre la eventualidad. (Ver anexo $\mathrm{N}^{\circ} 29$ ).

\subsection{RESULTADOS ESPERADOS}

Con la aplicación de las herramientas de Estandarización y Compras Justo a Tiempo aplicadas, se espera lograr reducir el Lead Time de 17 a 10 días. Asimismo, eliminar los 5 desperdicios identificados en el VSM inicial: Retraso en la atención de la solicitud de requerimiento, espera por aprobación, retraso de proveedor, defecto de material y reproceso por error de cálculo. (Ver Figura 48 ) 
Figura 48. VSM Futuro debido a la Implementación.

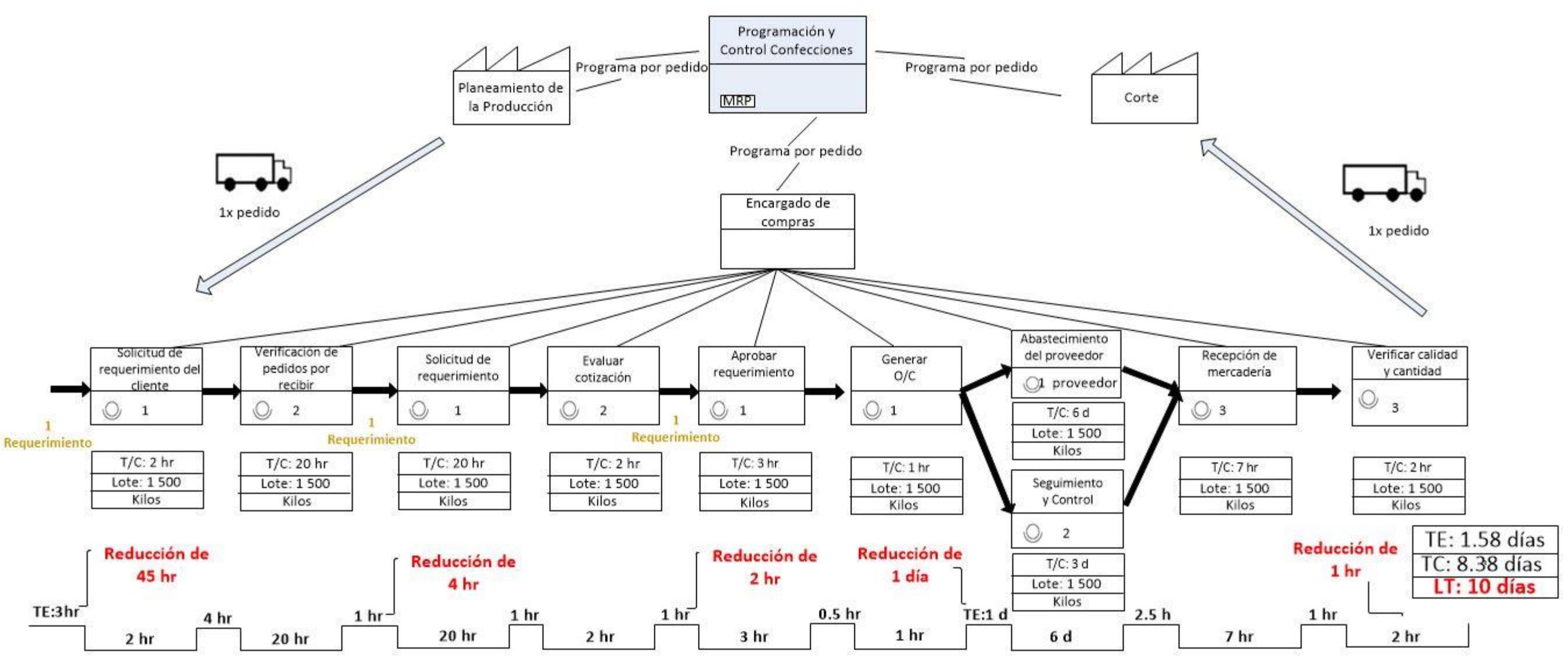

Fuente : Elaboración propia- Año 2017 


\subsection{PLAN DE IMPLEMENTACIÓN.}

\subsubsection{OTRAS CONSIDERACIONES.}

1.- Reunión con la gerencia

1.1 Proponer la estandarización como herramienta de solución.

1.2 Establecer las condiciones básicas para la implementación

1.3 Establecer objetivos de la empresa en base a la implementación

2.- Analizar la situación actual de las compras en la empresa

2.1 Funciones de los empleados del área

2.2 Métodos de trabajo

2.3 Método de Selección, evaluación y homologación de proveedores

2.4 Medir el Lead Time del proceso

3.- Comunicación y formación

3.1 Identificar a los involucrados del proceso

3.2 Capacitar al personal

4.- Implementación de la herramienta/documentación

4.1 Instaurar los procedimientos establecidos

5.- Evaluación del desempeño

5.1 Evaluar a los trabajadores

5.1.1 Aplicar encuestas

\subsubsection{Cuestionario/Entrevistas}

5.2 Evaluar de indicadores del proceso 
5.3 Comparar resultados

5.4 Plantear estrategias de mejora 


\section{CAPÍTULO IV: VALIDACIÓN DEL PROYECTO}

En el presente capítulo se ha desarrollado cuatro apartados para validar el proyecto. El primero, presenta la validación bibliográfica por tipo y por fuente utilizada en el levantamiento de información. El segundo apartado, muestra la validación de los entregables tanto de objetivos como de los capítulos elaborados. En el tercer apartado, se analiza y evidencia la validación del proyecto mediante juicio de expertos. Finalmente, se evalúa el impacto del proyecto tomando en cuenta los riesgos que se puedan presentar para contrarrestarlos con planes de contingencia.

\subsection{VALIDACIÓN BIBLIOGRÁFICA}

\subsubsection{VALIDACIÓN DE FUENTES BIBLIOGRÁFICAS POR TIPO.}

Tabla 29. Tipo de Referencia Bibliográfica

TIPO DE REFERENCIA BIBLIOGRÁFICA

Artículo científico sobre el tema específico

Artículo científico sobre otros temas

Libro sobre el tema específico

Libro sobre otros temas

Normas, leyes y reglamentos

Informes y reportes institucionales

Información de página web

Tesis

TOTAL

\begin{tabular}{cl} 
CANTIDAD & \multicolumn{1}{c}{$\%$} \\
24 & $28 \%$ \\
12 & $14 \%$ \\
5 & $6 \%$ \\
5 & $6 \%$ \\
2 & $2 \%$ \\
23 & $27 \%$ \\
5 & $6 \%$ \\
10 & $11 \%$ \\
$\mathbf{8 5}$ & $\mathbf{1 0 0 \%}$
\end{tabular}

Fuente : Elaboración propia- Año 2017

En la tabla anterior, se observa la cantidad de referencias bibliográficas por tipo. Para el desarrollo del trabajo de investigación se utilizaron artículos científicos sobre la aplicación de la metodología en específico y sobre otros temas relacionados a la industria textil. 
Se logró cumplir con uno de los requisitos del trabajo de investigación, dado que se presentaron 24 fuentes académicas de revistas científicas indexadas con factor de impacto, lo cual da soporte a la calidad de información utilizada en el trabajo. Cabe recalcar que esta cantidad representa el 28\% del total de la bibliografía consultada, con antigüedad menor a 5 años (2012-2016), lo cual respalda su contenido vigente. Solo el $2 \%$ de las fuentes utilizadas son normas, leyes o reglamentos aplicados al sector textil y al proceso de compras.

\subsubsection{VALIDACIÓN DE LOS REQUISITOS DE LOS ARTÍCULOS UTILIZADOS PERTENECIENTES A REVISTAS INDEXADAS.}

La validación de los artículos pertenecientes a revistas científicas indexadas, se realiza a través de una tabla donde se evalúa el cumplimiento de los requisitos mínimos para ser utilizados en el desarrollo del capítulo 1,2 y 3. La tabla 30 contiene la lista de artículos, el factor de impacto, autor y la revista indexada a la cual pertenecen.

Tabla 30. Lista de artículos académicos pertenecientes a revistas indexadas utilizados en la investigación

\begin{tabular}{|c|c|c|c|c|c|c|c|c|}
\hline & Artículo & Autor & Tema & $\begin{array}{c}\text { Año de } \\
\text { Publicación }\end{array}$ & Revista & $\begin{array}{c}\text { Indexada } \\
\text { Si/No }\end{array}$ & $\begin{array}{c}\text { Factor } \\
\text { Impacto }\end{array}$ & Cuartil \\
\hline 1 & $\begin{array}{c}\text { Production Flow } \\
\text { Analysis through } \\
\text { Value Stream } \\
\text { Mapping: A Lean } \\
\text { Manufacturing } \\
\text { Process Case } \\
\text { Study }\end{array}$ & $\begin{array}{c}\text { RAHANI Y } \\
\text { MUHAMMAD }\end{array}$ & $\begin{array}{c}\text { Engineering } \\
\text { (miscellaneous) }\end{array}$ & 2012 & $\begin{array}{c}\text { Procedia } \\
\text { Engineering } \\
\text { (Journal) }\end{array}$ & $\mathrm{Si}$ & 0.28 & Q3 \\
\hline 2 & $\begin{array}{l}\text { A Review on Lean } \\
\text { Manufacturing } \\
\text { Implementation } \\
\text { Techniques }\end{array}$ & $\begin{array}{c}\text { SUNDARA, R., } \\
\text { BALAJIB, A. Y } \\
\text { SATHEESH } \\
\text { KUMAR, R. }\end{array}$ & $\begin{array}{c}\text { Engineering } \\
\text { (miscellaneous) }\end{array}$ & 2014 & $\begin{array}{c}\text { Procedia } \\
\text { Engineering } \\
\text { (Journal) }\end{array}$ & $\mathrm{Si}$ & 0.28 & Q3 \\
\hline 3 & $\begin{array}{c}\text { Lean } \\
\text { Manufacturing } \\
\text { Implementation in } \\
\text { a gear shaft } \\
\text { manufacturing } \\
\text { company using } \\
\text { value stream } \\
\text { mapping }\end{array}$ & $\begin{array}{c}\text { NALLUSAMY, } \\
\text { S. }\end{array}$ & $\begin{array}{c}\text { Engineering } \\
\text { (miscellaneous) }\end{array}$ & 2016 & $\begin{array}{c}\text { International } \\
\text { Journal of } \\
\text { Engineering } \\
\text { Research in } \\
\text { Africa }\end{array}$ & $\mathrm{Si}$ & 0.13 & Q4 \\
\hline
\end{tabular}




\begin{tabular}{|c|c|c|c|c|c|c|c|c|}
\hline & Artículo & Autor & Tema & $\begin{array}{c}\text { Año de } \\
\text { Publicación }\end{array}$ & Revista & $\begin{array}{l}\text { Indexada } \\
\text { Si/No }\end{array}$ & $\begin{array}{l}\text { Factor } \\
\text { Impacto }\end{array}$ & Cuartil \\
\hline 4 & \begin{tabular}{|c|} 
A methodology for \\
effective \\
implementation of \\
lean strategies \\
and its \\
performance \\
evaluation in \\
manufacturing \\
organizations \\
\end{tabular} & $\begin{array}{c}\text { AZHARUI, K. y } \\
\text { KAZI, A } \\
\end{array}$ & $\begin{array}{c}\text { Business, } \\
\text { Management } \\
\text { and Accounting } \\
\text { (miscellaneous) }\end{array}$ & 2013 & $\begin{array}{c}\text { Business } \\
\text { Process } \\
\text { Management } \\
\text { Journal }\end{array}$ & $\mathrm{Si}$ & 0.57 & Q1 \\
\hline 5 & \begin{tabular}{|} 
An analysis of the \\
status of resource \\
flexibility and lean \\
manufacturing in \\
a textile \\
machinery \\
manufacturing \\
company
\end{tabular} & CHAUHAN, G. & $\begin{array}{l}\text {-Business, } \\
\text { Management } \\
\text { and Accounting } \\
\text {-Strategy and } \\
\text { Management }\end{array}$ & 2016 & $\begin{array}{c}\text { International } \\
\text { Journal of } \\
\text { Organizational } \\
\text { Analysis }\end{array}$ & $\mathrm{Si}$ & 0.25 & Q3 \\
\hline 6 & \begin{tabular}{|} 
Logistic strategies \\
in purchasing \\
process of \\
metallurgical \\
companies
\end{tabular} & $\begin{array}{c}\text { GRZYBOWSKA } \\
\text {, Katarzyna y } \\
\text { GAJDZIK, } \\
\text { Bozena }\end{array}$ & $\begin{array}{l}\text { Engineering } \\
\text { Mechanics of } \\
\text { Materials }\end{array}$ & 2014 & $\begin{array}{l}\text { METALURGIJA } \\
\text { (croatia) }\end{array}$ & $\mathrm{Si}$ & 0.44 & Q2 \\
\hline 7 & \begin{tabular}{|} 
Constructing the \\
integrated \\
strategic \\
performance \\
indicator system \\
for manufacturing \\
companies. \\
\end{tabular} & $\begin{array}{c}\text { CAO, Yanlong } \\
\text { y Otros }\end{array}$ & $\begin{array}{l}\text {-Business, } \\
\text { Management } \\
\text { and Accounting } \\
\text { - Strategy and } \\
\text { Management }\end{array}$ & 2015 & $\begin{array}{l}\text { International } \\
\text { Journal of } \\
\text { Production } \\
\text { Research (UK) }\end{array}$ & $\mathrm{Si}$ & 1.46 & Q1 \\
\hline 8 & \begin{tabular}{|c|} 
Production line \\
analysis via value \\
stream mapping: a \\
lean \\
manufacturing \\
process of color \\
industry \\
\end{tabular} & $\begin{array}{l}\text { MOHD, J y } \\
\text { MOJIB, S }\end{array}$ & $\begin{array}{l}\text { Engineering / } \\
\text { Industrial and } \\
\text { Manufacturing } \\
\text { Engineering }\end{array}$ & 2015 & $\begin{array}{c}\text { Procedia } \\
\text { Manufacturing } \\
\text { (Netherlands) }\end{array}$ & $\mathrm{Si}$ & 0.1 & Q4 \\
\hline 9 & $\begin{array}{c}\text { The lean and agile } \\
\text { purchasing } \\
\text { portfolio model }\end{array}$ & $\begin{array}{c}\text { DRAKE, Paul; } \\
\text { DONG, Lee y } \\
\text { HUSSAIN, } \\
\text { Matloub }\end{array}$ & $\begin{array}{c}\text { Business, } \\
\text { Management } \\
\text { and Accounting } \\
\text { Strategy and } \\
\text { Management }\end{array}$ & 2013 & $\begin{array}{l}\text { Supply Chain } \\
\text { Management } \\
\text { (UK) }\end{array}$ & $\mathrm{Si}$ & 1.86 & Q1 \\
\hline 10 & $\begin{array}{l}\text { Knowledge Gap } \\
\text { and Its Impact on } \\
\text { Product and } \\
\text { Process Quality }\end{array}$ & RAMANAN, L & $\begin{array}{c}\text { Engineering } \\
\text { (Miscellaneous) }\end{array}$ & 2015 & $\begin{array}{c}\text { Applied } \\
\text { Mechanics and } \\
\text { Materials } \\
\text { (Switzerland) }\end{array}$ & $\mathrm{Si}$ & 0.12 & Q4 \\
\hline 11 & $\begin{array}{c}\text { An international } \\
\text { comparison of } \\
\text { productivity } \\
\text { change in the } \\
\text { textile and } \\
\text { clothing industry: } \\
\text { a bootstrapped } \\
\text { Malmquist index } \\
\text { approach. } \\
\end{array}$ & $\begin{array}{c}\text { KAPELKO, } \\
\text { MAGDAENA \& } \\
\text { OUDE ALFONS }\end{array}$ & $\begin{array}{l}\text { Economics and } \\
\text { Econometrics }\end{array}$ & 2015 & $\begin{array}{l}\text { Empirical } \\
\text { Economics } \\
\text { (Germany) }\end{array}$ & $\mathrm{Si}$ & 0.61 & Q2 \\
\hline 12 & $\begin{array}{c}\text { Methodology } \\
\text { Based on SCOR } \\
\text { Model Applied to } \\
\text { a Maintenance } \\
\text { Services Company. }\end{array}$ & $\begin{array}{l}\text { HERRERA, } \\
\text { GERMAN \& } \\
\text { HERRERA, } \\
\text { JUAN }\end{array}$ & $\begin{array}{c}\text { Political Science } \\
\text { and International } \\
\text { Relations }\end{array}$ & 2016 & $\begin{array}{c}\text { Utopia y Praxis } \\
\text { Latinoamerican } \\
\text { a }\end{array}$ & $\mathrm{Si}$ & 0.11 & Q4 \\
\hline
\end{tabular}




\begin{tabular}{|c|c|c|c|c|c|c|c|c|}
\hline & Artículo & Autor & Tema & $\begin{array}{c}\text { Año de } \\
\text { Publicación }\end{array}$ & Revi sta & $\begin{array}{c}\text { Indexada } \\
\text { Si/No } \\
\end{array}$ & $\begin{array}{c}\text { Factor } \\
\text { Impacto }\end{array}$ & Cuartil \\
\hline 13 & \begin{tabular}{|} 
Assessment of the \\
influence of a \\
anthropogenic \\
factors on \\
elements of the \\
ecological \\
network in \\
Vojvodina (Serbia) \\
using the Leopold
\end{tabular} & \begin{tabular}{|} 
Kicosev, \\
Vesna; \\
Romelic, \\
Jovan; \\
Belic,Andelka, \\
otros
\end{tabular} & $\begin{array}{c}\text { Agricultural and } \\
\text { Biological } \\
\text { Sciences } \\
\text { (miscellaneous) }\end{array}$ & 2015 & $\begin{array}{l}\text { Archives of } \\
\text { Biological } \\
\text { Sciences } \\
\text { (Serbia) }\end{array}$ & Si & 0.2 & Q3 \\
\hline 14 & \begin{tabular}{|c|} 
A study on Lean \\
Manufacturing \\
implementation in \\
Malaysian \\
automotive \\
component \\
industry. \\
\end{tabular} & $\begin{array}{c}\text { Rose, M; } \\
\text { Deros, B y } \\
\text { Rahman, M. }\end{array}$ & $\begin{array}{c}\text { Automotive and } \\
\text { Mechanical } \\
\text { Engineering }\end{array}$ & 2013 & $\begin{array}{c}\text { International } \\
\text { Journal of } \\
\text { Automotive and } \\
\text { Mechanical } \\
\text { Engineering } \\
\text { (Malaysia) }\end{array}$ & $\mathrm{Si}$ & 0.44 & Q2 \\
\hline 15 & $\begin{array}{c}\text { Development of } \\
\text { the procurement } \\
\text { principles and } \\
\text { Management } \\
\text { System of the } \\
\text { Lean Production } \\
\text { technology } \\
\end{array}$ & $\begin{array}{c}\text { KHAMIDULLIN } \\
\text { A, ALFIYA; } \\
\text { PURYAEV, } \\
\text { AIDAR }\end{array}$ & $\begin{array}{c}\text { Business, } \\
\text { Management } \\
\text { and Accounting }\end{array}$ & 2016 & $\begin{array}{l}\text { Academy of } \\
\text { Strategic } \\
\text { Management } \\
\text { Journal (US) }\end{array}$ & $\mathrm{Si}$ & 0.14 & Q4 \\
\hline 16 & $\begin{array}{c}\text { The Development } \\
\text { and } \\
\text { Implementation } \\
\text { Lean } \\
\text { Manufacturing in } \\
\text { Indonesian } \\
\text { Furniture Industry }\end{array}$ & $\begin{array}{c}\text { SUHARDI, } \\
\text { BAMBANG; } \\
\text { SAHADEWO, } \\
\text { AKIYUMAS; } \\
\text { WIDYO,PRING } \\
\text { GO }\end{array}$ & Engineering & 2015 & $\begin{array}{c}\text { Applied } \\
\text { Mechanics and } \\
\text { Materials } \\
\text { (Switzerland) }\end{array}$ & $\mathrm{Si}$ & 0.12 & Q4 \\
\hline 17 & $\begin{array}{c}\text { Application of } \\
\text { lean tools in the } \\
\text { supply chain of a } \\
\text { maintenance } \\
\text { environment } \\
\end{array}$ & $\begin{array}{l}\text { C.J. FOURIE1* } \\
\& \text { N.E. UMEH1 }\end{array}$ & $\begin{array}{l}\text { Industrial and } \\
\text { Manufacturing } \\
\text { Engineering }\end{array}$ & 2017 & $\begin{array}{l}\text { South African } \\
\text { Journal of } \\
\text { Industrial } \\
\text { Engineering }\end{array}$ & SI & 0.23 & Q2 \\
\hline 18 & \begin{tabular}{|} 
Muti-agent system \\
model for the \\
optimization of \\
softwood industry \\
supply chain
\end{tabular} & \begin{tabular}{|} 
MARIO RAMOS \\
THOMAS \\
MANESS, \\
DAVID \\
SALINAS
\end{tabular} & $\begin{array}{l}\text { Industrial and } \\
\text { Manufacturing } \\
\text { Engineering }\end{array}$ & 2015 & $\begin{array}{l}\text { Maderas: } \\
\text { Ciencia y } \\
\text { Tecnologia } \\
\text { (Chile) }\end{array}$ & SI & 0.56 & Q1 \\
\hline 19 & \begin{tabular}{|c|} 
Areas for \\
Improving the \\
Innovation \\
Performance of the \\
Textile Industry in \\
Russia \\
\end{tabular} & $\begin{array}{c}\text { Elena Pawęta, } \\
\text { Bożena } \\
\text { Mikołajczyk }\end{array}$ & $\begin{array}{l}\text { Industrial and } \\
\text { Manufacturing } \\
\text { Engineering }\end{array}$ & 2016 & $\begin{array}{c}\text { Fibres and } \\
\text { Textiles in } \\
\text { Eastern Europe } \\
\text { (Poland) }\end{array}$ & SI & 0.32 & Q2 \\
\hline 20 & $\begin{array}{l}\text { Sensory Impact on } \\
\text { the Purchase of } \\
\text { Textile Products }\end{array}$ & $\begin{array}{l}\text { Magdalena } \\
\text { Grębosz, } \\
\text { Barbara } \\
\text { Wrońska } \\
\end{array}$ & $\begin{array}{l}\text { Industrial and } \\
\text { Manufacturing } \\
\text { Engineering }\end{array}$ & 2013 & $\begin{array}{c}\text { Fibres and } \\
\text { Textiles in } \\
\text { Eastern Europe } \\
\text { (Poland) }\end{array}$ & SI & 0.32 & Q2 \\
\hline
\end{tabular}

Fuente : Elaboración propia- Año 2017

Para la elaboración de la tabla presentada, se tomaron en cuenta 20 artículos científicos con antigüedad no mayor a 5 años; es decir, entre el año 2012 y 2017, los cuales fueron empleados para la elaboración y sustento de los tres primeros capítulos. Todos ellos hacen referencia a la aplicación de la metodología Lean en la cadena de abastecimiento y en otros rubros, las compras 
en el sector textil, casos de estudio y el uso de herramientas Lean como el VSM (Value Stream Map).

\subsection{VALIDACIÓN DE ENTREGABLES: OBJETIVOS Y DE LOS CAPÍTULOS I, II Y III}

El presente apartado, tiene como propósito validar los objetivos y entregables de los capítulos 1, 2 y 3 del presente trabajo de investigación, basándose en los indicadores de logro definidos en el Plan de Tesis.

\subsubsection{VERIFICACIÓN DEL CUMPLIMIENTO DE OBJETIVOS}

En la Tabla 31, se identifica y verifica el cumplimiento de objetivos de acuerdo al plan de tesis elaborado.

Tabla 31. Validación de Objetivos

\begin{tabular}{lll}
\multicolumn{1}{c}{ OBJETIVOS } & \multicolumn{1}{c}{ ESTADO } & \multicolumn{1}{c}{ DESCRIPCIÓN } \\
& Cumplido & El trabajo muestra la elaboración detallada del \\
Elaboración del estado del & & estado del arte y marco teórico, el cual presenta \\
arte y marco teórico. & la situación actual de la metodología Lean \\
& & $\begin{array}{l}\text { Manufacturing, modelos de éxitos, establece } \\
\text { términos y definiciones del sector textil- } \\
\end{array}$ \\
& confecciones exportador y gestión de compras.
\end{tabular}

Diagnóstico del proceso en Cumplido estudio, análisis e interpretación.

Proponer alternativas de Cumplido solución, aplicación, adaptación y/o mejora del método.

Validación de la solución de Cumplido Ingeniería Sistemática,
Se presenta el análisis de la situación actual de las pymes exportadoras del sector textilconfecciones, el levantamiento de información de campo y se presenta claramente la problemática, motivos y causas principales que desencadenan el impacto negativo en el sector.

Se proponen alternativas de solución mediante el diseño y desarrollo de herramientas de Lean Manufacturing. Estas son: Sistema de compras estandarizado y Compras justo a tiempo, las cuales están alineadas a erradicar las causas raíces que generan problemas en el sector estudiado. De esta manera, mediante el desarrollo de procedimiento y métodos de trabajo, se va a lograr la mejora del proceso de compras

Se utiliza la validación por juicios de expertos; para ello, se toma en cuenta la metodología de 
Funcional, Económica y

Replicabilidad.

Evaluación y análisis del Cumplido impacto de ingeniería en función a costos/ beneficio, internamente, social ambiental y político.

Fuente : Elaboración propia- Año 2017
Leopold para la calificación del trabajo de investigación midiendo el impacto generado en el sector.

De acuerdo a la información obtenida del sector estudiado, se logra evidenciar el impacto económico que es la no percepción del margen de ganancia debido al lead time excesivo en el abastecimiento de tela. Se demuestra detalladamente cuanto es lo que dejan de percibir las empresas del sector textil por el lead time excesivo.

Como se pudo mostrar en la tabla anterior se logró cumplir con todos objetivos que se plantearon inicialmente. El primero de ellos, se logró gracias a la exhaustiva búsqueda de información que permite clarificar y contextualizar el trabajo de investigación. El segundo objetivo, se logró mediante el trabajo de campo que se realizó con las 46 empresas seleccionadas mediante la delimitación del estudio. Se obtuvo información primordial que con el uso de herramientas de ingeniería se pudo determinar el diagnóstico del proceso crítico, problema y causas principales. El tercer objetivo, se logró a través de las propuestas de solución planteadas basados en la metodología de Lean Manufacturing que mediante la aplicación permitió la mejora del proceso crítico beneficiando al sector. El cuarto objetivo, se llevó a cabo mediante la validación por juicios de expertos basado en la metodología de Leopold, que permitió realizar el análisis e impacto generado en el sector estudiado. El último objetivo, se logra a través de las encuestas realizadas y al levantamiento de información, que en paralelo permitió evidenciar el margen no percibido que ocasiona el lead time excesivo del abastecimiento de tela.

\subsubsection{VALIDACIÓN DE ENTREGABLES POR CAPÍTULOS.}

Se analiza y valida cada capítulo elaborado siguiendo los criterios de evaluación de la rúbrica determinada. Se establecen rubros a evaluar, criterios, estado, y se realiza una descripción de acuerdo al logro alcanzado. 


\section{Capítulo 1}

Tabla 32. Validación del capítulo 1

$\begin{array}{ccc}\text { RUBROS A EVALUAR } & \text { CRITERIO } \\ & \text { PARA } & \text { DESCRIPCIÓN } \\ & \text { EVALUAR }\end{array}$

\section{ESTADO DEL ARTE METODOLOGÍA}

INVESTIGACIÓN

Presenta la
información del
estado del arte de la
metodología,
entorno de la
industria y marco
normativo de
forma pertinente y
completa, a la
hilvanado las ideas
sustentadas en la
investigación
realizada.

La investigación es sostenida con 20 o más artículos de investigación de bases de datos indexadas con una antigüedad no mayor a 5 años y factor de impacto

Presenta 5 casos de éxito relacionados a la investigación CASOS DE ÉXITO realizada y al
Cumplido Presenta información adecuada del estado del arte de la metodología utilizada en el trabajo de investigación detallando antecedentes, situación actual de la aplicación de las herramientas que abarcan la filosofía Lean Manufacturing de forma pertinente y completa, sustentando ideas en la investigación realizada y evidenciando el levantamiento de información adecuada. De la misma manera, presenta casos de éxito basándose en la aplicación de la metodología en diferentes industrias, demostrando ventajas y desventajas a tomar en cuenta para el estudio.

No obstante, el estudio realizado muestra detalladamente normativas que involucran al sector, permitiendo soportar el estudio y tener en cuenta las condiciones definidas.
Cumplido

La investigación es sostenida con 20 artículos de investigación de base de datos indexados con una antigüedad no mayor a 5 años, con factor de impacto y que pertenece al tema de estudio.
Cumplido investigación, uno de ellos relacionado al sector estudiado.
Presenta 5 casos éxitos relacionados con la 
sector de la

empresa en estudio
- Analyzing the benefits of lean tools: a consumer durables manufacturing company case study.

- Lean Manufacturing implementation a gear shaft manufacturing company using value stream mapping.

- A methodology for effective implementation of lean strategies and its performance evaluation in manufacturing organizations.

- An analysis of the status of resource flexibility and lean manufacturing in a textile machinery manufacturing company

- Production flow analysis through value stream mapping: a lean manufacturing process case study.

Se comunica de
manera clara y
precisa, utilizando
una redacción
$100 \%$ profesional,
sin errores de
redacción u
ortografía. Aplica
correctamente el
formato de
gráficos, tablas y
bibliografía.

Cumplido

El estudio presenta una comunicación clara, precisa, utiliza una redacción $100 \%$ profesional, sin errores de redacción u ortografía. Así mismo, aplica correctamente el formato de gráficos, tablas y bibliografía.
ESTRUCTURA

FORMAL Y DE COMUNICACIÓN

Fuente : Elaboración propia- Año 2017

Como se puede observar en la tabla anterior, la validación del entregable del capítulo 1 cumple con todos criterios de evaluación.

Mediante el primer criterio de evaluación que es el Estado de Arte y la Metodología, se obtuvo el levantamiento de información adecuada que permitió alinear y enfocar las ideas al sector estudiado considerando la situación actual del mercado y de la metodología utilizada. Así mismo, el segundo criterio realiza la validación para la investigación, que consiste en confirmar las referencias de los artículos utilizados bajo las condiciones que se mencionan en la tabla. 
Dentro de estos artículos, se rescataron 5 casos de éxitos relacionados a la investigación del sector estudiado que evidenció la aplicación de la metodología Lean Manufacturing y además se observó los resultados obtenidos. El último criterio de evaluación que se encuentra en el entregable del capítulo 1 es el de la estructura formal y de comunicación, en la descripción realizada en la tabla anterior, se observa el cumplimiento satisfactorio de este criterio.

\section{Capítulo 2}

Tabla 33. Validación del capítulo 2

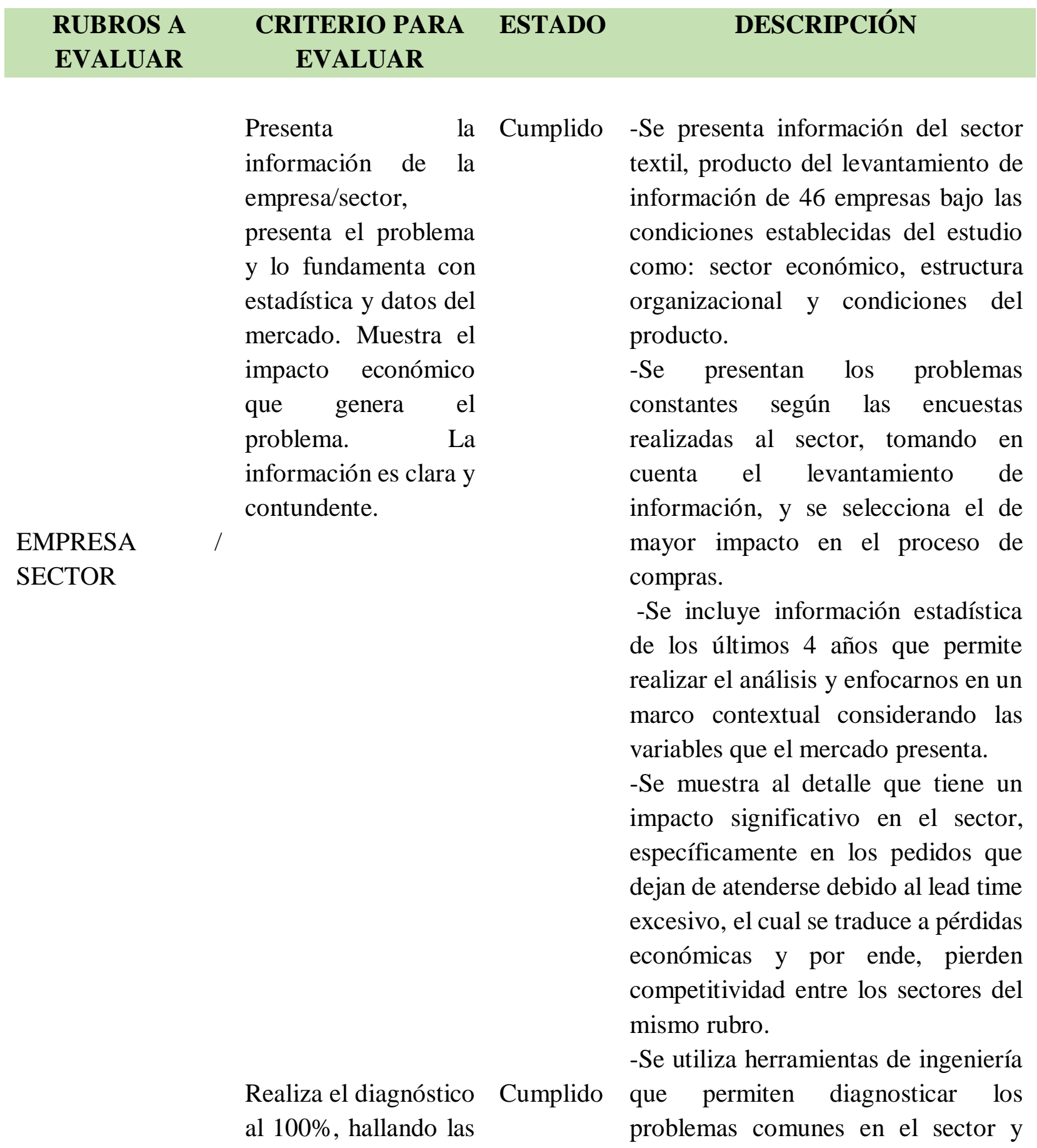




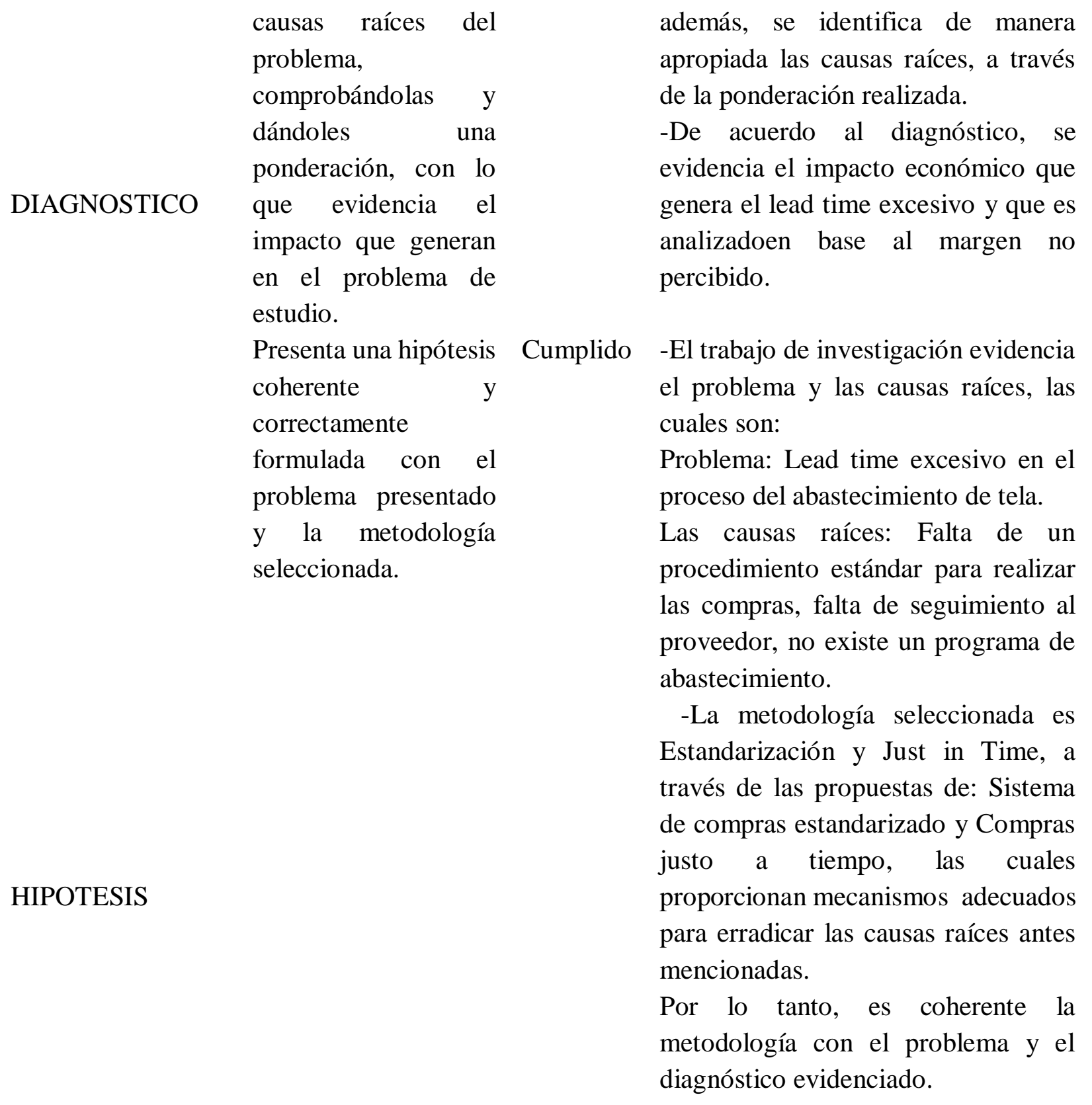

Se comunica de Cumplido -El trabajo de investigación comunica manera clara y ideas claras y precisas utilizando una precisa, utilizando redacción $100 \%$ profesional. 
COMUNICACIÓN una redacción $100 \%$

profesional, $\quad \sin$

errores de redacción u

ortografía. Aplica

correctamente el

formato de gráficos $\mathrm{y}$

tablas.
-El trabajo de investigación no presenta errores de redacción ni de ortografía y aplica correctamente los formatos de gráficos y tablas.

Fuente : Elaboración propia- Año 2017

Como se puede observar en tabla anterior, la validación del entregable del capítulo 2 cumple con todos los criterios de evaluación.

El primer criterio, evalúa la información adecuada del sector estudiado que recae prácticamente en el trabajo de campo identificando los problemas y causas que desencadenan impactos económicos negativos. Cabe mencionar, que se incluyó información estadística de los últimos 4 años para poder realiza el análisis.

De la misma manera, el estado del segundo criterio de la evaluación del diagnóstico se cumple, ya que se demostró el diagnósticco del problema del "Lead time excesivo en el abastecimiento de tela", mediante la utilización de las herramientas de ingeniería como el VSM, identificando los desperdicios comunes en el proceso de compras y determinando las causas raíces. Lo mencionado permitió evaluar el impacto económico generado en el sector de acuerdo al margen no percibido.

El tercer criterio de evaluación es el de la hipótesis, que presenta como estado "cumplido" puesto que, la hipótesis planteada es: Mediante la aplicación de las herramientas de Lean Manufacturing: Just in Time, VSM y Estandarización; se logró rediseñar el proceso de compras mediante un plan de flujo de información entre el proceso de compras, planeamiento de la producción y los proveedores, el cual ayudó a reducir los reprocesos de las órdenes de compra y el inventario de materia prima, insumos y materiales. Por lo tanto, mediante el cumplimiento de la hipótesis, se concluyó que la reducción del lead Time permite mayor flexibilidad en el proceso productivo y respuesta al cliente mejorando la competitividad del sector.

El último criterio que también se valida es el de comunicación, ya que el capítulo presenta ideas claras y precisas como se menciona en la descripción. 


\section{Capítulo 3}

Tabla 34. Validación del capítulo 3

\begin{tabular}{|c|c|c|c|c|}
\hline $\begin{array}{l}\text { RUBROS } \\
\text { EVALUAR }\end{array}$ & $\mathbf{A}$ & $\begin{array}{l}\text { CRITERIO PARA } \\
\text { EVALUAR }\end{array}$ & ESTADO & DESCRIPCIÓN \\
\hline $\begin{array}{l}\text { DISEÑO DE } \\
\text { PROPUESTAS }\end{array}$ & LAS & $\begin{array}{l}\text { El } 100 \% \text { de las } \\
\text { propuestas } \\
\text { corresponden } \\
\text { directamente a las } \\
\text { causas-raíz más } \\
\text { relevantes del } \\
\text { diagnóstico, y están } \\
\text { dentro del ámbito } \\
\text { de la Ingeniería } \\
\text { Industrial. Diseño } \\
\text { de la propuesta al } \\
100 \%\end{array}$ & Cumplido & 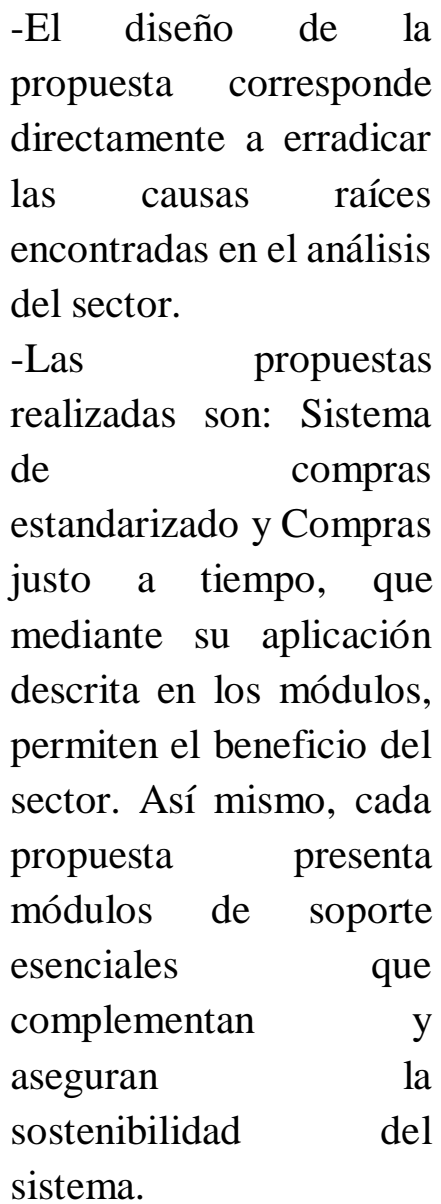 \\
\hline
\end{tabular}

Las propuestas han

Cumplido Las propuestas están sido desarrolladas al $80 \%$ con un alto desarrolladas al $100 \%$. nivel de detalle. El $\mathrm{Se} \quad$ evidencia detalladamente las uso de

DESARROLLO DE metodologías y LAS PROPUESTAS herramientas de la propuestas que a través de métodos, indicadores y procedimientos Ingeniería

Industrial se evidencia muy claramente. permiten rediseñar el proceso de compras reduciendo el lead time excesivo. 


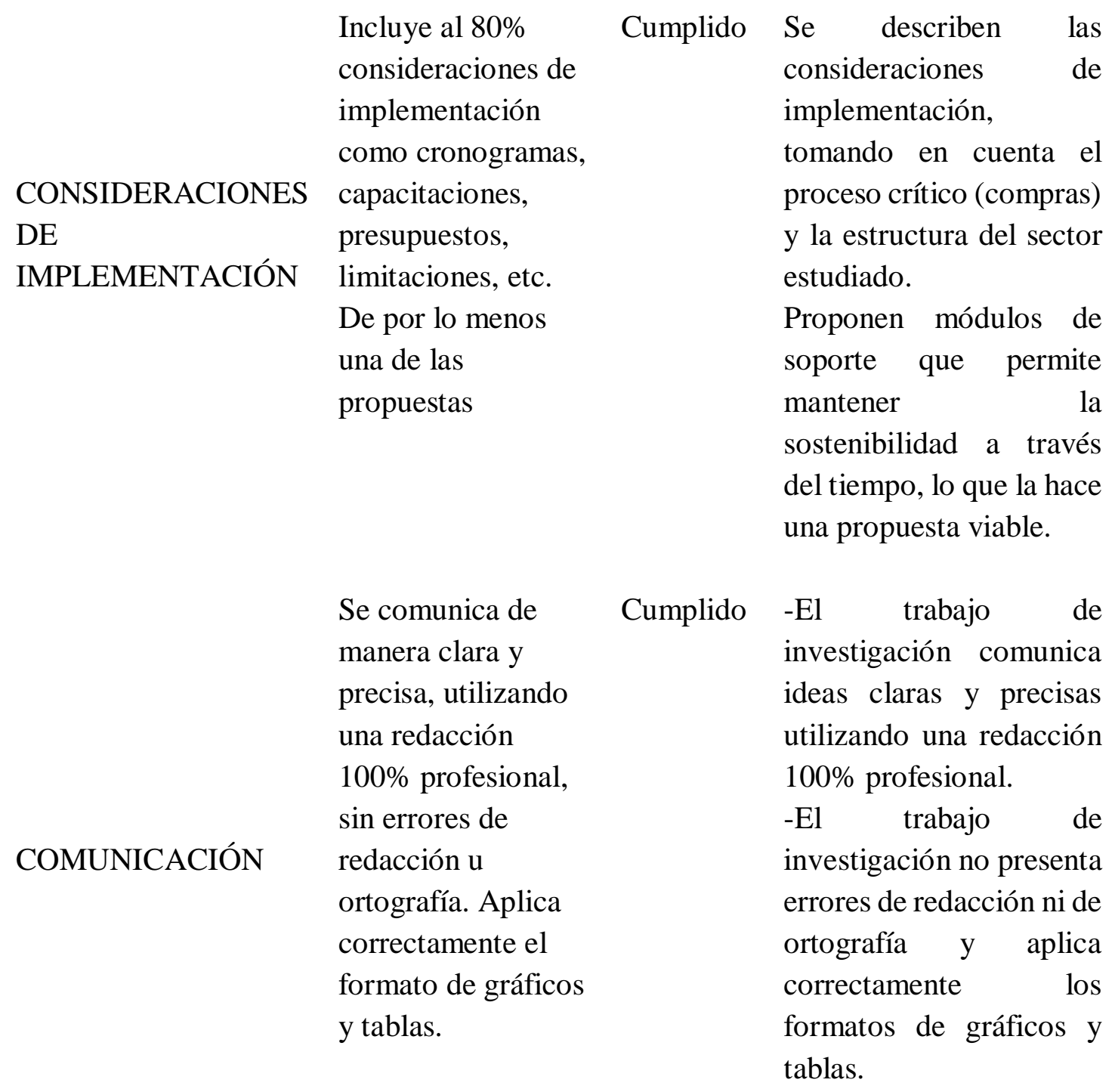

Fuente : Elaboración propia- Año 2017

El entregable del capítulo 3 cumple con todos criterios de evaluación. El primer criterio, evalúa el diseño de las propuestas que corresponde directamente a erradicar las causas raíces como se menciona en la descripción. Así mismo, se describen las dos propuestas que contienen módulos tanto operativos como de soporte y que complementan y aseguran la sostenibilidad del sistema beneficiando al sector textil.

El segundo criterio, evalúa el desarrollo de las propuestas que presenta el trabajo de investigación. Se evidenció detalladamente las propuestas alineadas a eliminar las causas identificas. Se mencionó una serie de métodos, procedimientos e indicadores que permiten reducir el lead time. 
El tercer criterio que se validó es el de consideraciones de implementación, desarrollado gracias al estudio del sector realizado, tomando como base el proceso crítico de compra. Asimismo, el desarrollo de los módulos de soporte permiten que la propuesta se mantenga sostenible a través del tiempo.

El último criterio de evaluación del entregable del capítulo 3 es la comunicación, el trabajo presentó ideas claras y precisas con una redacción 100\% profesional.

\subsection{VALIDACIÓN DE MODELO Y PROPUESTAS}

La validación de las propuestas Lean desarrolladas paras las PYME's exportadoras del sector textil, consiste en presentar el juicio de 6 expertos ( 2 usuarios y 4 investigadores), los usuarios son aquellos profesionales que poseen experiencia de trabajo en el área de compras y afines de alguna de las Pyme's del sector textil elegidos aleatoriamente de la base de datos de las empresas encuestadas; por otro lado, los investigadores son expertos en el proceso de compras y en la metodología aplicada en empresas extranjeras del sector textil u otro rubro, los cuales fueron elegidos aleatoriamente de los artículos de las revistas indexadas utilizados en el desarrollo del proyecto de investigación.

Los expertos evaluaron las propuestas mediante ocho criterios definidos por el Grupo de Investigación: Estructura, Hallazgos, Pertinencia, Viabilidad, Innovación, Medición, Replicabilidad y Sostenibilidad. 


\section{Resumen bibliográfico de expertos}

\section{Usuarios:}

\begin{tabular}{|c|c|c|}
\hline 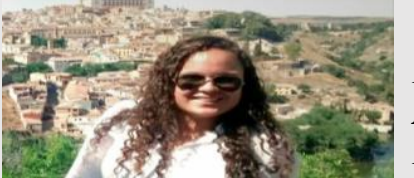 & $\begin{array}{l}\text { Prisilla Quezada } \\
\text { Ingeniera Industrial } \\
\text { Master en Alta Direcció } \\
\text { Lima-Perú }\end{array}$ & (27 años) \\
\hline & Educación & USAT-Chic layo \\
\hline & Cargos & $\begin{array}{l}\text { RAINTEX -Jefe de Compras } \\
\text { ATELIER-Jefe de producción } \\
\text { MIGLORESAT-Asistente Comercial }\end{array}$ \\
\hline & Logros & $\begin{array}{l}\text { Proyecto de optimización y reducción de } \\
\text { costos - Fincyt } \\
\text { Implementación de un sistema de } \\
\text { seguimiento de costos y codificación del } \\
\text { manual de funciones para el almacén- } \\
\text { Raintex }\end{array}$ \\
\hline & Email & pquezada@raintex.pe \\
\hline
\end{tabular}

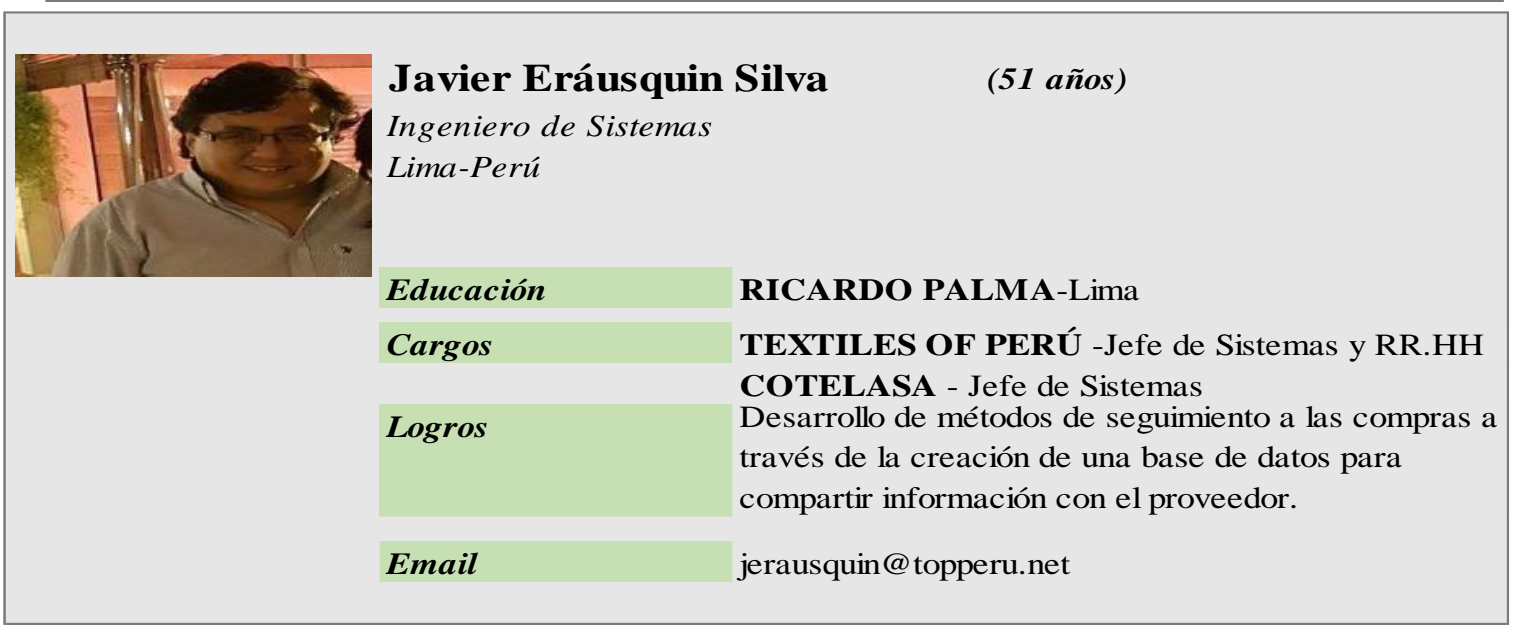




\section{Investigadores:}

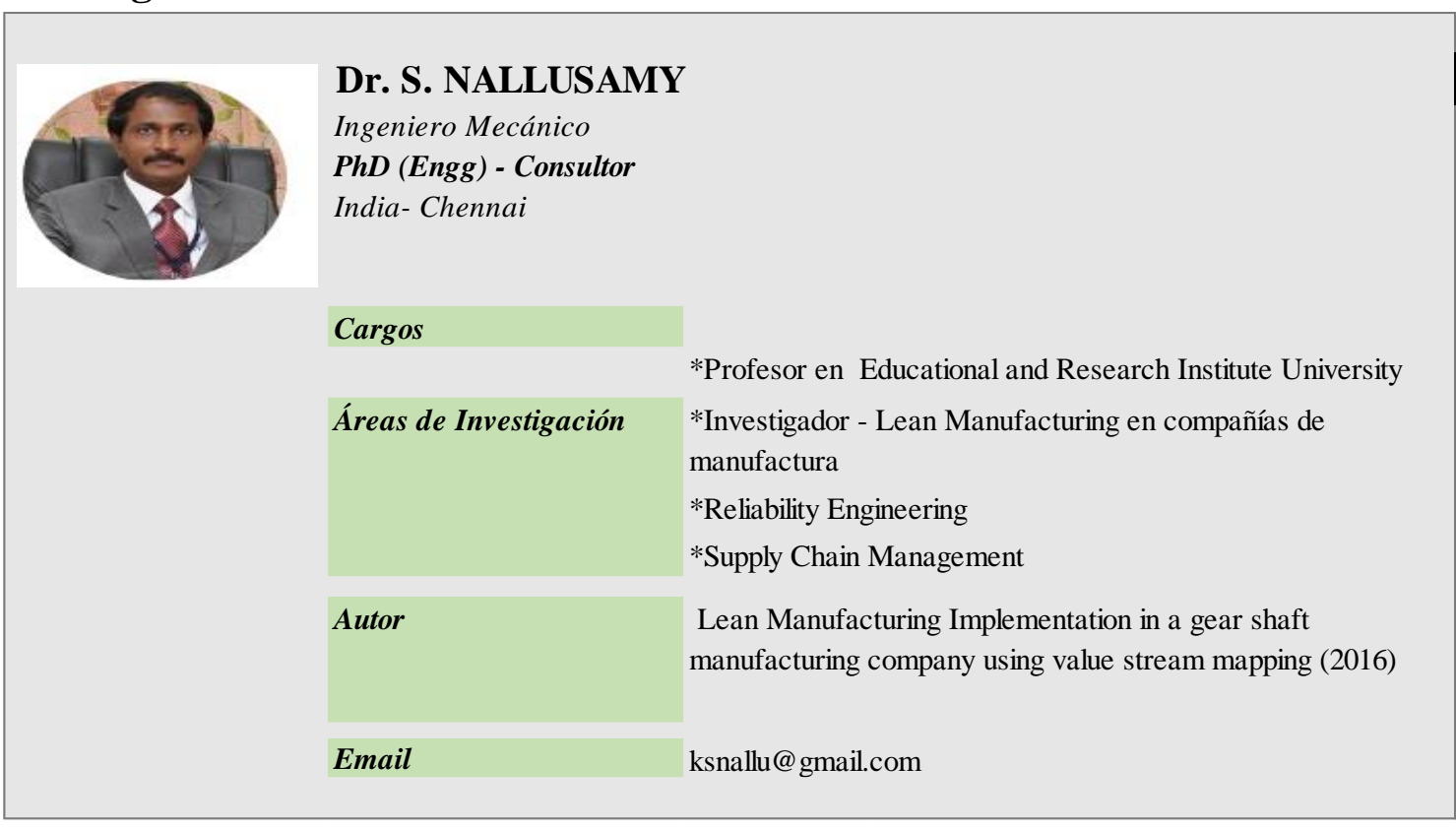

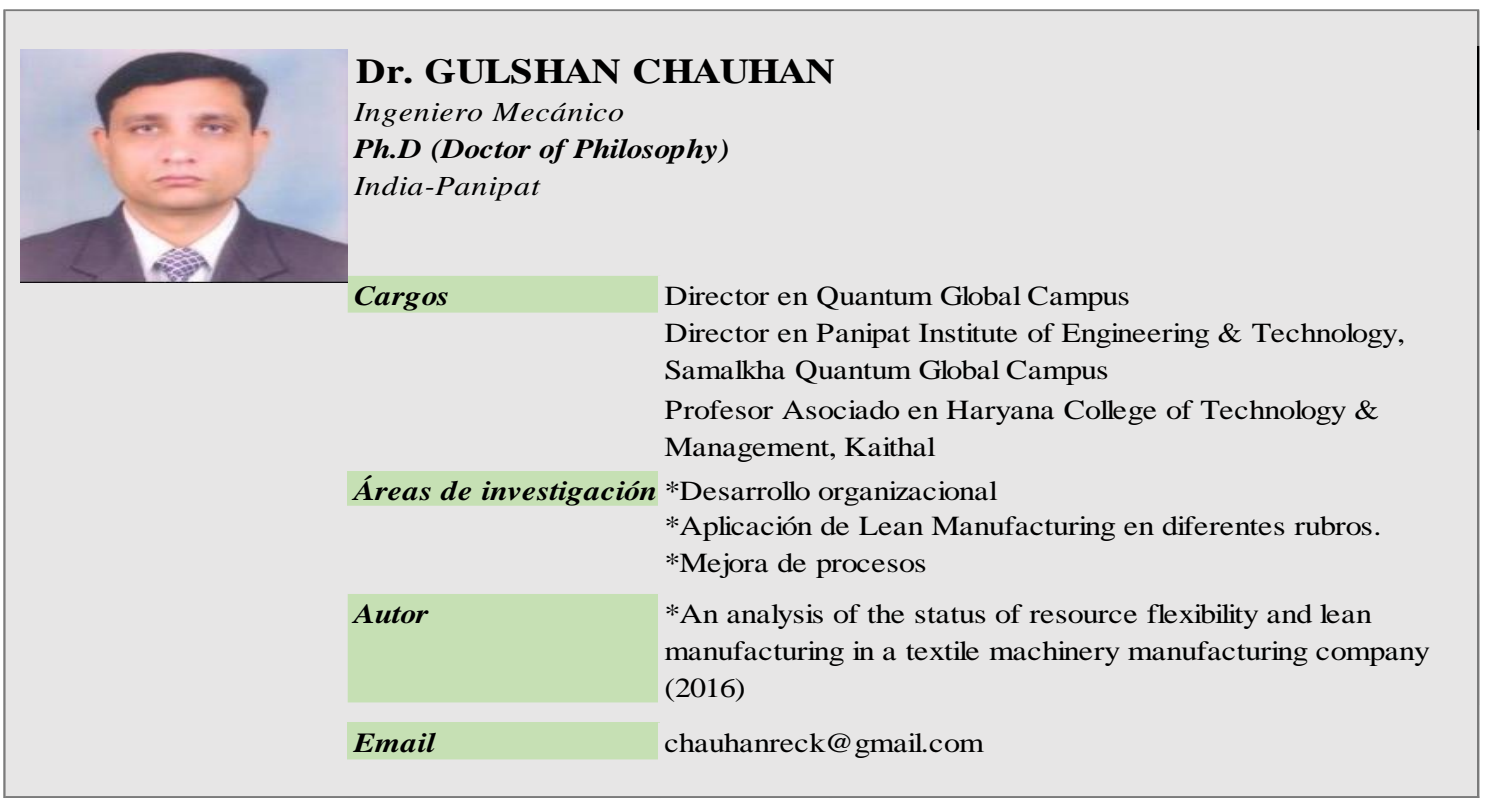




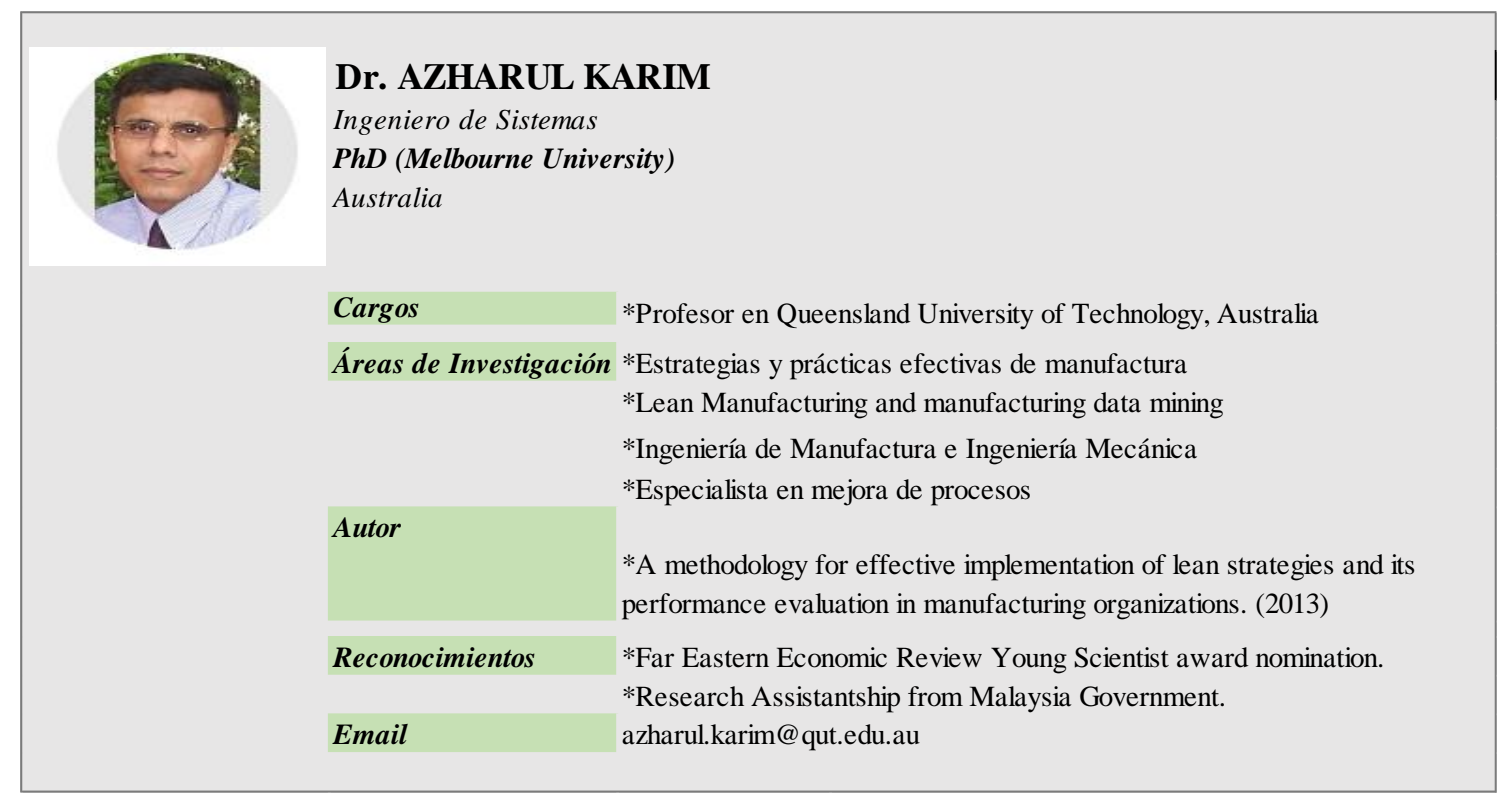

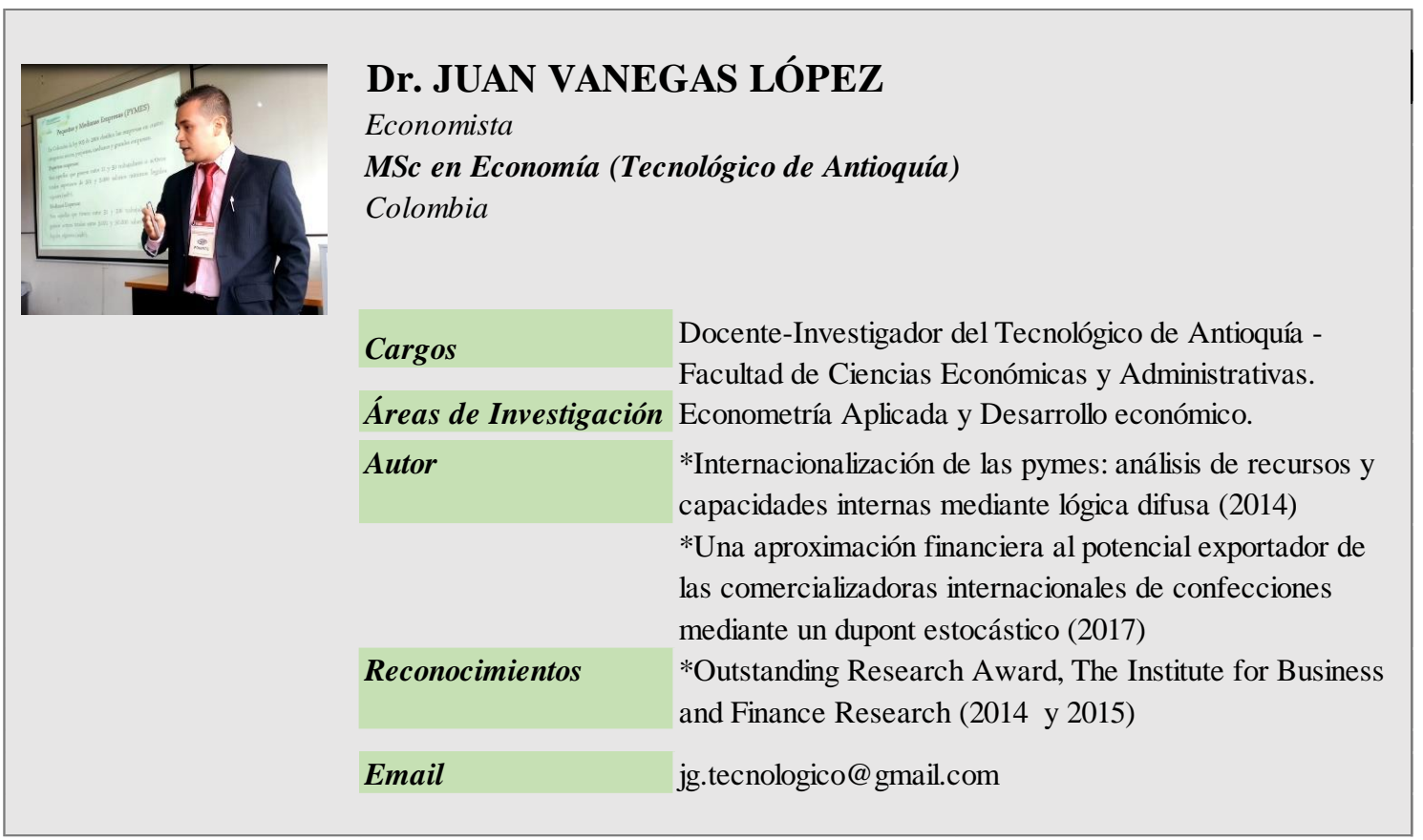

El proceso de evaluación y validación se llevó a cabo de dos formas, la primera con 2 usuarios o empresas, elegidas aleatoriamente de la base de datos de empresas encuestadas; para ello, se realizó una entrevista a los responsables o implicados en el proceso de compras de la compañía en la cual laboran, este encuentro consistió en lo siguiente:

- Presentación de las integrantes del proyecto de investigación.

- Presentación acerca de los objetivos de la investigación.

- Presentación breve acerca de las propuestas lean y su aplicación en las PYME's del sector textil. 
- Evaluación del experto a través de la matriz elaborada.

La segunda forma de validación se llevó a cabo con los 4 expertos extranjeros, los cuales fueron elegidos aleatoriamente de los artículos de las revistas indexadas utilizados en el desarrollo del proyecto de investigación, para ello se realizó el contacto vía correo electrónico con el siguiente contenido:

- Presentación de las integrantes del proyecto de investigación.

- Breve resumen de la situación actual de las PYME's del sector textil exportador y su impacto.

La Tabla 35 representa el formato entregado a cada uno de los expertos para la validación respectiva de las propuestas, en la cual se indica la definición de cada uno de los criterios establecidos, mencionados anteriormente. Asimismo, se observa en el Anexo $\mathrm{N}^{\circ} 30$ la calificación de cada validador. 


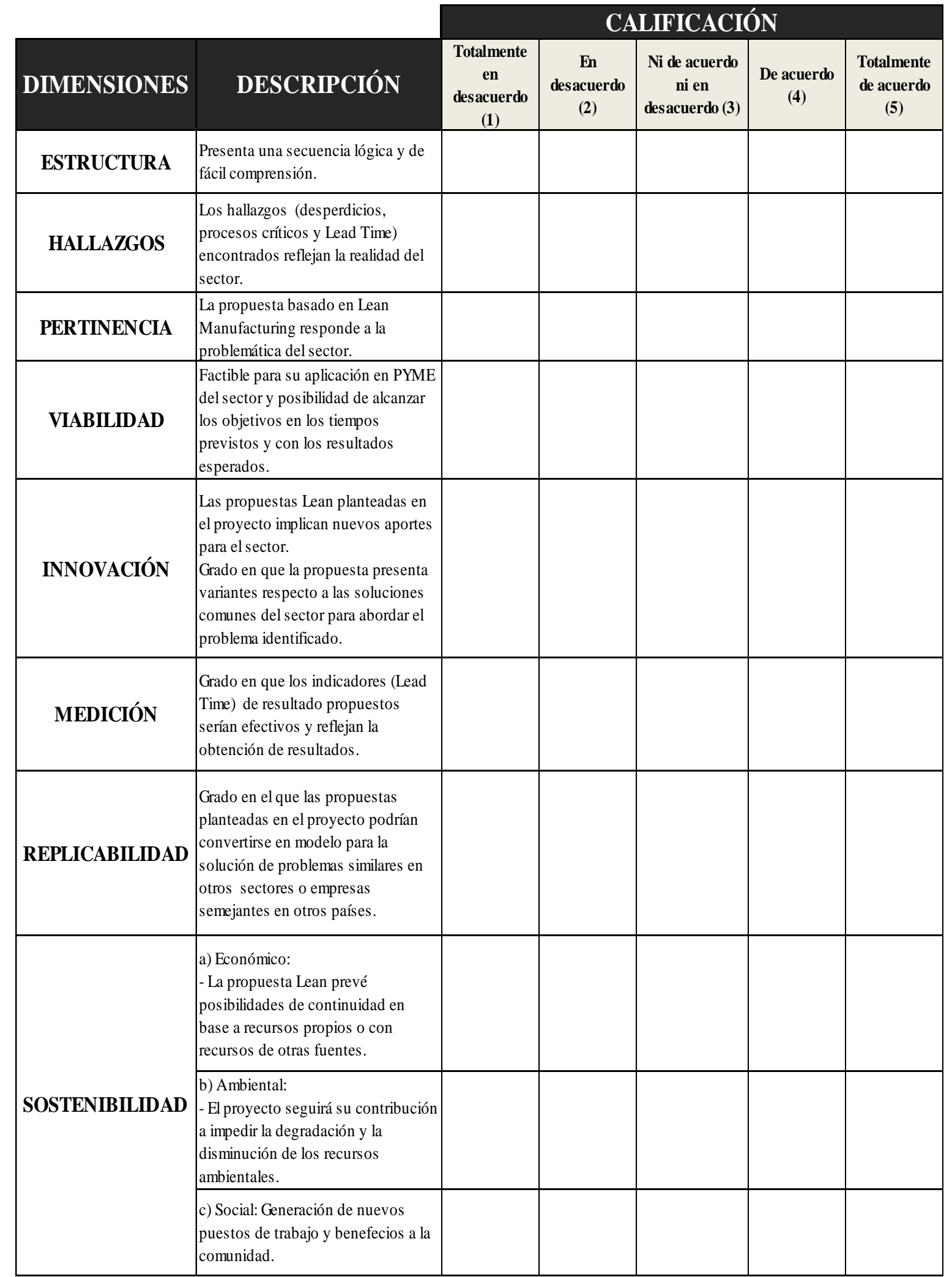

Fuente : Elaboración propia- Año 2017

De la validación realizada por los expertos, se obtiene la siguiente tabla de puntaje promedio de las propuestas. 
Tabla 36. Validación promedio de los modelos.

\begin{tabular}{|c|c|c|c|c|}
\hline DIMENSIONES & DESCRIPCIÓN & PROMEDIO & $\begin{array}{l}\text { PUNTAJE } \\
\text { MÁXIMO }\end{array}$ & $\%$ \\
\hline ESTRUCTURA & $\begin{array}{l}\text { Presenta una secuencia lógica y } \\
\text { de fácil comprensión. }\end{array}$ & 4 & 5 & $70 \%$ \\
\hline HALLAZGOS & $\begin{array}{l}\text { Los hallazgos (desperdicios, } \\
\text { procesos críticos y Lead Time) } \\
\text { encontrados reflejan la realidad } \\
\text { del sector. }\end{array}$ & 4 & 5 & $73 \%$ \\
\hline PERTINENCIA & $\begin{array}{l}\text { La propuesta basado en Lean } \\
\text { Manufacturing responde a la } \\
\text { problemática del sector. }\end{array}$ & 4 & 5 & $83 \%$ \\
\hline VIABILIDAD & $\begin{array}{l}\text { Factible para su aplicación en } \\
\text { PYME del sector y posibilidad de } \\
\text { alcanzar los objetivos en los } \\
\text { tiempos previstos y con los } \\
\text { resultados esperados. }\end{array}$ & 4 & 5 & $80 \%$ \\
\hline INNOVACIÓN & $\begin{array}{l}\text { Las propuestas Lean planteadas en } \\
\text { el proyecto implican nuevos } \\
\text { aportes para el sector. } \\
\text { Grado en que la propuesta } \\
\text { presenta variantes respecto a las } \\
\text { soluciones comunes del sector } \\
\text { para abordar el problema } \\
\text { identificado. }\end{array}$ & 3 & 5 & $63 \%$ \\
\hline MEDICIÓN & $\begin{array}{l}\text { Grado en que los indicadores } \\
\text { (Lead Time) de resultado } \\
\text { propuestos serían efectivos y } \\
\text { reflejan la obtención de } \\
\text { resultados. }\end{array}$ & 4 & 5 & $77 \%$ \\
\hline REPLICABILIDAD & $\begin{array}{l}\text { Grado en el que las propuestas } \\
\text { planteadas en el proyecto podrían } \\
\text { convertirse en modelo para la } \\
\text { solución de problemas similares } \\
\text { en otros sectores o empresas } \\
\text { semejantes en otros países. }\end{array}$ & 3 & 5 & $63 \%$ \\
\hline \multirow{6}{*}{ SOSTENIBILIDAD } & $\begin{array}{l}\text { a) Económico: } \\
\text { - La propuesta Lean prevé } \\
\text { posibilidades de continuidad en } \\
\text { base a recursos propios o con } \\
\text { recursos de otras fuentes. }\end{array}$ & 4 & 5 & $70 \%$ \\
\hline & $\begin{array}{l}\text { b) Ambiental: } \\
\text { - El proyecto seguirá su } \\
\text { contribución a impedir la } \\
\text { degradación y la disminución de } \\
\text { los recursos ambientales. }\end{array}$ & 4 & 5 & $77 \%$ \\
\hline & $\begin{array}{l}\text { c) Social: Generación de nuevos } \\
\text { puestos de trabajo y beneficios a } \\
\text { la comunidad. }\end{array}$ & 3 & 5 & $67 \%$ \\
\hline & & 36 & \multirow{3}{*}{ OPTIMO } & \\
\hline & & 50 & & \\
\hline & & $72 \%$ & & \\
\hline
\end{tabular}

Fuente : Elaboración propia- Año 2017 
Las propuestas planteadas para el proceso de Compras, obtuvieron un puntaje de $72 \%$ por parte de los validadores, según los criterios de evaluación definidos por el Grupo de Investigación, lo cual significa que los modelos planteados son aplicables en el sector textil exportador de confecciones y que su desarrollo en estas empresas puede generar beneficios económicos, sociales y ambientales para aquellas que lo apliquen. (Ver Tabla 36)

Figura 49. Porcentaje de Validez por dimensión evaluado.

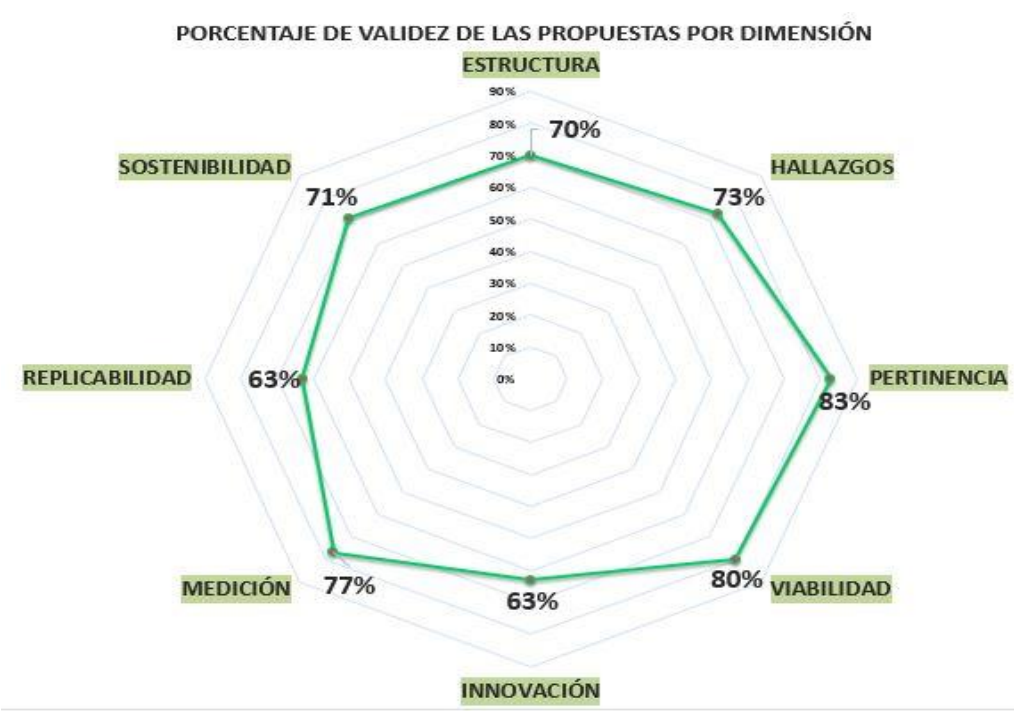

Fuente : Elaboración propia- Año 2017

Asimismo, de la validación se observó que los criterios con mayor validez son: Pertinencia (83\%), Viabilidad (80\%) y Medición (77\%); es decir, que las propuestas son aplicables al sector en estudio porque responden a la problemática de este, es factible su aplicación en las PYME's para que puedan alcanzar sus objetivos, y los indicadores planteados son efectivos para medir el desempeño del proceso. (Ver Figura 49) Por otro lado, el criterio de menor puntaje es la Replicabilidad con 60\%; esto quiere decir, que la replicabilidad de las propuestas es regular en este tipo de empresas del sector, debido a que en su mayoría las pequeñas y medianas empresas del rubro ya poseen una metodología de trabajo y cultura organizacional definida, lo cual dificulta el ingreso de nuevos métodos para realizar sus labores diarias, también esta calificación se da debido a que las herramientas utilizadas ya existen y han sido aplicadas en diversos rubros, pero es importante señalar que en las empresas encuestadas no se tiene conocimiento de la metodología Lean y tampoco han sido aplicadas anteriormente; por ello, se han adaptado las herramientas al rubro y al proceso en cuestión. Asimismo, se debe considerar que los validadores no conocen por completo el sector textil peruano, por ello podrían diferir en algunos aspectos evaluados. 


\subsection{EVALUACIÓN DE IMPACTOS}

\subsubsection{IDENTIFICACIÓN DE TIPOS DE IMPACTO.}

Es de suma importancia evaluar la contribución de un proyecto en diferentes aspectos al logro del propósito, ya que estos cambios son duraderos o pueden prevalecer por un periodo de tiempo en la sociedad, economía, ciencia, tecnología y medio ambiente que mejora o degrada sus indicadores como resultado de la ejecución de acciones de investigación, desarrollo e innovación llevadas a cabo en el proyecto y su sinergia con las acciones administrativas (Rodriguez, s.f). Para llevar a cabo el análisis de impactos que puede generar el desarrollo de las propuestas, primero se evalúan los tipos de impactos a considerar. (Ver Tabla 37) 
Tabla 37. Tipos de impacto y relación con el proyecto de investigación

\begin{tabular}{|c|c|c|c|}
\hline Tipos de impacto & Descripción & $\begin{array}{c}\text { Aplica al } \\
\text { proyecto } \\
\text { Sí/No } \\
\end{array}$ & Relación con el proyecto \\
\hline Tecnológicos & $\begin{array}{c}\text { Mide el nivel de innovación del estudio para } \\
\text { conocer las ventajas y desventajas que tiene } \\
\text { el uso de la tecnología, programas, etc en el } \\
\text { incremento de la eficiencia de las } \\
\text { actividaddes. }\end{array}$ & $\mathbf{S i}$ & $\begin{array}{l}\text { Los ahorros y ganancias generados por el modelo } \\
\text { propuesto, permite a las empresas invertir en nuevas } \\
\text { tecnologías que les ayuden a obtener beneficios como el } \\
\text { incremento de la productividad al optimizar recursos o } \\
\text { nuevos sistemas de comunicación y flujo de información. }\end{array}$ \\
\hline Institucionales & $\begin{array}{c}\text { Medida en que una intervención mejora o } \\
\text { debilita la capacidad de la empresa de hacer } \\
\text { uso más eficiente, equitativo y sostenible de } \\
\text { sus recursos humanos, financieros y } \\
\text { naturales, estos impactos pueden incluir los } \\
\text { efectos intencionales o no intencionales de } \\
\text { una acción. }\end{array}$ & Si & $\begin{array}{l}\text { La implementación de las herramientas Lean permitirá } \\
\text { mantener a la organización ordenada y en constante } \\
\text { capacitación, para ello se aplican ciertos indicadores de } \\
\text { medición que ayudan a medir el nivel alcanzado. Para } \\
\text { que el modelo tenga éxito los trabajadores necesitan } \\
\text { adquirir conocimientos y habilidades, con ello estaran } \\
\text { preparados para utilizar de manera eficiente los recursos. }\end{array}$ \\
\hline Económicos & $\begin{array}{c}\text { Mide la repercusión y los beneficios de } \\
\text { inversiones en infraestructuras, organización } \\
\text { de eventos, así como de cualquier otra } \\
\text { actividad susceptible de generar un impacto } \\
\text { socioeconómico, incluyendo cambios } \\
\text { legislativos y regulatrorios. }\end{array}$ & Sí & $\begin{array}{c}\text { El modelo propuesto permitirá incrementar el valor de la } \\
\text { empresa, debido a que se pueden generar ahorros y } \\
\text { ganancias para los dueños de la empresa. La aplicación } \\
\text { de las herramientas propuestas en el proyecto generan } \\
\text { beneficios económicos muy importantes en el proceso de } \\
\text { compras, ya que gracias a la reducción del Lead Time se } \\
\text { pueden atender más ordenes de compra e incrementar la } \\
\text { eficiencia del proceso. }\end{array}$ \\
\hline Sociales & $\begin{array}{l}\text { Se refiere al cambio efectuado en la } \\
\text { sociedad debido al producto de } \\
\text { investigaciones, estos son cambios que } \\
\text { ocurren en comunidades o personas como } \\
\text { resultado de un cambio inducido } \\
\text { externamente. Son cambios que pueden } \\
\text { afectar el empleo, ingresos, propiedades, } \\
\text { producción, estilo de vida,prácticas } \\
\text { culturales, ambiente, derechos individuales o } \\
\text { colectivos, derechos de propiedad. }\end{array}$ & $\mathbf{S i}$ & $\begin{array}{l}\text { El impacto del proyecto socialmente es de gran } \\
\text { importancia debido a que, la generación de empleo, las } \\
\text { oportunidades de desarrollo profesional, deberían ser } \\
\text { necesidades convertidas en oportunidades estratégicas } \\
\text { por las empresas, los cuales deben ir vinculados a los } \\
\text { lineamientos estratégicos de las empresas. }\end{array}$ \\
\hline Ambientales & $\begin{array}{l}\text { Efecto que produce una acción sobre el } \\
\text { medio ambiente en sus distintos } \\
\text { aspectos.Pueden clasificarse en temporal, } \\
\text { reversible, irreversible y persistente. }\end{array}$ & No & $\begin{array}{c}\text { La aplicación de las herramientas planteadas en el } \\
\text { proyecto en el área de compras no genera un impacto } \\
\text { ambiental, debido a que este es un proceso } \\
\text { administrativo y actualmente se puede documentar los } \\
\text { procesos y mejoras en una base de datos sin necesidad } \\
\text { de hacer uso de recursos como el papel u otros que } \\
\text { puedan dañar al medio ambiente. }\end{array}$ \\
\hline Políticos & $\begin{array}{l}\text { Mide el grado del cumplimiento y } \\
\text { participación de las empresas en el marco } \\
\text { legal y económico que aporte al desarrollo } \\
\text { económico y social del país. }\end{array}$ & $\mathbf{S i}$ & $\begin{array}{c}\text { El desarrollo e incremento del número de empresas } \\
\text { PYME's exportadoras beneficia en gran magnitud al } \\
\text { desarrollo económico del país. Asimismo, el que las } \\
\text { empresas tengan sus procesos documentados y } \\
\text { estandarizados facilitará la formalización del negocio y } \\
\text { que pueda incorporar sistemas de calidad o participar de } \\
\text { procesos de auditoría con mayor facilidad. }\end{array}$ \\
\hline Científicos & $\begin{array}{l}\text { Consituye la evaluación del impacto de la } \\
\text { ciencia y tecnología, las cuales son una } \\
\text { necesidad estratégica para constatar el } \\
\text { desarrollo de una organización e incluso un } \\
\text { país, de su política cientifica y de su gestión } \\
\text { en función de la sociedad y de los seres } \\
\text { humanos que conviven en ella. }\end{array}$ & No & $\begin{array}{l}\text { En el proyecto de investigación no aplica el impacto } \\
\text { científico, debido a que ya existe información acerca de } \\
\text { las herramientas utilizadas y no se utiliza innovación } \\
\text { tecnológica para su aplicación. }\end{array}$ \\
\hline
\end{tabular}

Fuente : Elaboración propia- Año 2017

Según lo descrito en la tabla anterior, los tipos de impacto que son producidos por la aplicación del proyecto en las PYME's del sector textil son: Económico, Social, Político, Tecnológico e 
Institucional, debido a que estos se encuentran directamente relacionados a los resultados que ocasiona la mejora del proceso de compras; por ejemplo, el incremento de la productividad generará mayores ingresos, reducción de costo, mejora en el aprendizaje de los trabajadores a través de las capacitaciones, posible incremento de salarios y mejora del clima laboral.

\subsubsection{SELECCIÓN DE METODOLOGÍA PARA LA EVALUACIÓN DE IMPACTOS}

Para seleccionar la metodología a utilizar para la evaluación del impacto de la aplicación de las propuestas, se realizó el análisis de tres herramientas: la matriz de Leopold, matriz Vertes y la matriz de Marco Lógico. Para ello, se evaluaron sus objetivos, ventajas, desventajas y cuál sería su utilidad en el proyecto. (Ver Tabla 38) 
Tabla 38. Metodología de evaluación de Impacto

\begin{tabular}{|c|c|c|c|c|c|}
\hline & DESCRIPCIÓN & OBJETIYO & YENTAJA & DESYENTAJAS & APLICACION EN EL PROYECTO \\
\hline Matriz de Leopold & $\begin{array}{l}\text { Procedimiento para la } \\
\text { evaluación del impacto } \\
\text { ambiental de un proyecto de } \\
\text { desarrollo y. por tanto, para la } \\
\text { evaluación de sus costos y } \\
\text { beneficios ecológicos (Leopold } \\
\text { et al., } 1971 \text { ) }\end{array}$ & $\begin{array}{l}\text { Garantizar que los impactos de } \\
\text { diversas acciones sean } \\
\text { evaluados y considerados } \\
\text { adecuadamente en la etapa de } \\
\text { planeación del proyecto. }\end{array}$ & $\begin{array}{l}\text {-Obligan a considerar los posibles impactos de } \\
\text { proyectos sobre diferentes factores. } \\
\text { "Incorpora la consideración de magnitud e } \\
\text { importancia de un impacto. } \\
\text { "Permite la comparación de alternativas, } \\
\text { desarrollando una matriz para cada opción. } \\
\text { "Sirve como resumen de la información } \\
\text { contenida en el informe. (Dellavedova M., 2010) }\end{array}$ & $\begin{array}{l}\text {-El proceso de evaluación es subjetivo. } \\
\text { No contempla metodología alguna para } \\
\text { determinar la magnitud ni la importancia } \\
\text { de un impacto. } \\
\text { - No considera la interacción entre } \\
\text { diferentes factores ambientales. } \\
\text { "No distingue entre efectos a corto y } \\
\text { largo plazo, aunque pueden realizarse } \\
\text { dos matrices según dos escalas de } \\
\text { tiempo. } \\
\text { "Los efectos no son enclusivos o } \\
\text { finales, existe la posibilidad de } \\
\text { considerar un efecto dos o más } \\
\text { veces.(Dellavedova M., 2010) }\end{array}$ & $\begin{array}{l}\text { Se aplicará para el proyecto, debido a que esta realiza un } \\
\text { control bidimensional, de magnitud e importancia del factor } \\
\text { evaluado, de esa manera se busca obtener información más } \\
\text { exacta del impacto que genera en el proyecto. Su utilidad radica } \\
\text { en el listado y chequeo de la información cualitativa de relación } \\
\text { causa-efecto, así como en el ordenamiento de los resultados. } \\
\text { Asimismo, mide el impacto sobre los stakeholders clave. }\end{array}$ \\
\hline $\begin{array}{l}\text { Matriz de Marco } \\
\text { Lógico }\end{array}$ & $\begin{array}{l}\text { Herramienta de análisis } \\
\text { estructurado, que facilita el } \\
\text { proceso de identificación, } \\
\text { disen̂́o, ejecución y evalaución } \\
\text { de políticas, programas, } \\
\text { proyectos y disen̂́os } \\
\text { organizacionales, pudiendo } \\
\text { aplicarse en cualquier fase de } \\
\text { los respectivos procesos de } \\
\text { planificación. }\end{array}$ & $\begin{array}{l}\text { Facilitar la comparación de } \\
\text { proyectos entre proyectos de } \\
\text { diferentes temas o áreas y } \\
\text { reducir la brecha comparativa } \\
\text { entre lo planeado y la realidad. }\end{array}$ & $\begin{array}{l}\text {-Utilizado en diferentes etapas del proyecto: } \\
\text { preparación, ejecución, o término. } \\
\text { "Cualquier tipo de proyecto: fomento } \\
\text { productivo o del área social. } \\
\text { 'Terminología uniforme: mayor comunicación, } \\
\text { reduce ambiguedades. } \\
\text { 'Aporta formato preciso sobre objetivos, } \\
\text { indicadores, metas y riesgos. } \\
\text { 'Suministra información para organizar y } \\
\text { preparar en forma lógica la programación } \\
\text { operativa del proyecto. }\end{array}$ & $\begin{array}{l}\text { "Es estático: foto del momento. } \\
\text { "Debe actualizarse, objetivos pierden } \\
\text { vigencia, surgen nuevos objetivos. } \\
\text { "Riequiere expresiones muy claras que } \\
\text { no se presten a interpretaciones. }\end{array}$ & $\begin{array}{l}\text { No es factible su aplicación en el proyecto, debido a que es una } \\
\text { herramienta estática; es decir, que solo se centra en el } \\
\text { momento o situación actual del proceso y lo que se busca en } \\
\text { este trabajo de investigación es una visión del impacto que } \\
\text { pueda tener en el futuro la aplicación de las herramientas } \\
\text { desarrolladas. }\end{array}$ \\
\hline Matriz Yertes & $\begin{array}{l}\text { Herramienta matemática usada } \\
\text { para analizar la complejidad de } \\
\text { los problemas, de la función, } \\
\text { estructura, información y } \\
\text { comportamiento dentro de un } \\
\text { sistema. }\end{array}$ & $\begin{array}{l}\text { Identificar y determinar las } \\
\text { problemáticas de una situación } \\
\text { dada a partir de las relaciones } \\
\text { causa-efecto, para } \\
\text { posteriormente priorizarlas y } \\
\text { lograr detectar cuáles son los } \\
\text { problemas críticos que requieren } \\
\text { de mayor atención. }\end{array}$ & $\begin{array}{l}\text {-Permite enumerar los problemas tangibles que } \\
\text { se dan en una comunidad a los cuales se es } \\
\text { asigna un número o puntaje. } \\
\text { "Identifica y determina de manera precisa las } \\
\text { causas y consecuencias de un problema } \\
\text { específico en una situación problemática. }\end{array}$ & $\begin{array}{l}\text { "Los pasos para su elaboración y } \\
\text { análisis son muy largos. } \\
\text { "Para realizar la evaluación no toma en } \\
\text { cuenta los stakeholders que se ven } \\
\text { afectados, sino los problemas que } \\
\text { existen en el proceso. }\end{array}$ & $\begin{array}{l}\text { Debido a que el proyecto se aplica en diferentes PYMES, cada } \\
\text { una presenta características de trabajo distintas en sus } \\
\text { procesos, y esta al ser una matriz que evalua de acuerdo a los } \\
\text { problemas presentados, limita el análisis de la información y } \\
\text { desarrollar sinergia con los stakeholder, ya que no genera } \\
\text { información específica para cada uno. }\end{array}$ \\
\hline
\end{tabular}

Fuente : Elaboración propia- Año 2017 
Como resultado de la evaluación, se obtuvo que la Matriz de Leopold es la herramienta más adecuada para evaluar el impacto del proyecto, debido a que evalúa el impacto directo sobre los stakeholders claves del proceso. Asimismo, debido a que considera un análisis bidimensional al evaluar la magnitud e importancia, se obtendrá información más exacta y ordenada del impacto.

\subsubsection{EVALUACIÓN DE IMPACTO DE LAS PROPUESTAS.}

El presente apartado, está orientado a evaluar el Impacto de las propuestas desarrolladas para las PYME's del sector textil sobre los stakeholders identificados por el Grupo de Investigación. Para el desarrollo de la investigación, se realizó un brainstorming, además de una matriz de identificación de stakeholders para considerarlos luego y evaluar el impacto sobre los grupos de interés claves. La evaluación de impactos fue realizada a partir de la Matriz de Leopold, la cual tiene como objetivo identificar los impactos positivos y negativos de la implementación de las propuestas desarrolladas en las empresas PYME's del sector textil exportador de confecciones en Lima. La validación de impactos, también fue realizada por los seis expertos mencionadas anteriormente; para ello, se les brindó a los validadores un instructivo donde se mencionaba cómo completar la matriz de impacto.

\section{Indentificación de stakeholders}

La identificación de stakeholders realizada por el Grupo de Investigación se realizó en dos partes. En la primera parte se elaboró un brainstorming (lluvia de ideas), a fin de definir qué grupos de interés que intervienen en el sector serían impactados al implementar las herramientas Lean. Luego, se desarrolla una Matriz de Identificación de Stakeholders, la cual tuvo como propósito hacer un filtro sobre los grupos de interés identificados, para seleccionar a los más relevantes. A continuación, se describirán los pasos mencionados.

\section{Brainstorming}

Esta etapa se realizó en conjunto con el Grupo de Investigación, en el cual se recopiló el aporte de cada integrante, mencionando los principales y posibles grupos de interés del sector en 
estudio y aquellos que podrían ser impactados directa o indirectamente al implementar las herramientas Lean. En la siguiente lista se presentan los stakeholders considerados en esta etapa:

Tabla 39. Lista de Stakeholders identificados en el Brainstorming.

\begin{tabular}{|c|l|}
\hline $\mathbf{N}^{\circ}$ & \multicolumn{1}{|c|}{ Stakeholders } \\
\hline 1 & Pymes \\
\hline 2 & Trabajadores del sector \\
\hline 3 & Estado \\
\hline 4 & Clientes \\
\hline 5 & Competidores \\
\hline 6 & Proveedores \\
\hline 7 & Asociaciones del rubro \\
\hline 8 & Sociedad \\
\hline 9 & Acrededores \\
\hline
\end{tabular}

Fuente : Elaboración de Grupo de Investigación

\section{Matriz de Identificación de Stakeholders}

Para la identificación de los stakeholders de los modelos propuestos por el grupo, se utilizó como base la Matriz de Identificación de Stakeholders propuesto por el ICRA 2009, las cuales se muestran en la Tabla 40.

Tabla 40. Matriz de Identificación de Stakeholders de ICRA

\begin{tabular}{|c|c|c|}
\hline Stakeholders & $\begin{array}{c}\text { Do you consider this person, group or } \\
\text { organisation a key stakeholder? }\end{array}$ & Why or why not? \\
\hline 1 & (yesino) & (reason) \\
\hline 2 & & \\
\hline N & & \\
\hline
\end{tabular}

Fuente : International Centre for development oriental Research in Agriculture- Año 2006 
La matriz se compone de tres columnas, la primera donde se colocan los stakeholders de la organización, en la segunda y tercera columna, responden a la pregunta si el Stakeholder debe ser considerado clave o no y por qué.

Para definir a los stakeholders claves en la investigación, Bernal y Rivas (2012) utilizan la metodología de Mitchell, Agle y Wood, en el cual se establecen tres atributos a evaluar y se definen de la siguiente manera:

- Urgencia: Capacidad de obtener atención y la habilidad de impresionar a los personajes críticos para poder reclamar los intereses y metas que son sensibles al tiempo y que si demoran serán costosos.

- Poder: Habilidad de influenciar en la toma de decisiones de la empresa para poder lograr sus resultados deseados.

- Legitimidad: La capacidad de influencia moral o legal sobre el comportamiento de la empresa (Bernal y Rivas, 2012).

Figura 50. Identificación de Stakeholders según Mitchell, Agle y Wood.

Fuente : Bernal y Rivas (2012)

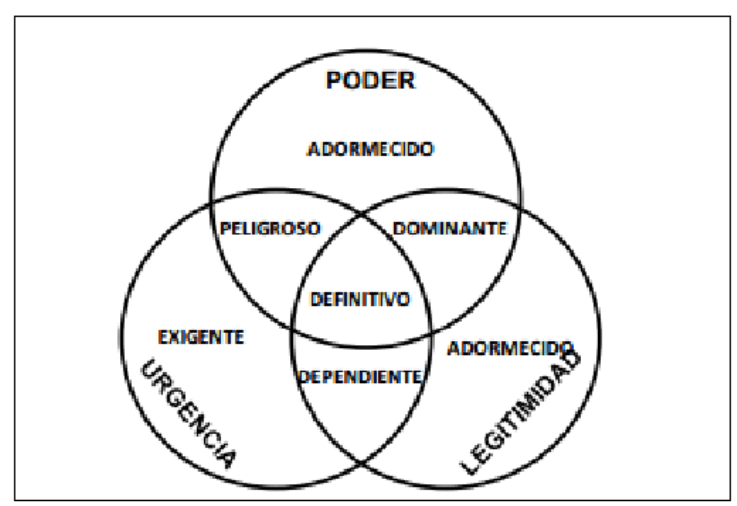

Según el modelo presentado en la Figura $\mathrm{N}^{\circ} 50$, son categorizados como stakeholders definitivos aquellos que posean las tres características básicas. Los que cumplan este requisito tienen mayor prioridad sobre el resto, por ello son considerados clave en la organización.

A partir de esta categorización, se elabora la matriz de identificación donde se aplican los conceptos de la metodología de Mitchell, Agle y Wood antes definida. Para, ello se define una escala de valoración, mostrada en la Tabla 41. 
Tabla 41. Escala de valoración para la identificación de stakeholders

\begin{tabular}{|c|c|}
\hline Calificación & Descripción \\
\hline 1 & Nulo \\
\hline 2 & Leve \\
\hline 3 & Moderado \\
\hline 4 & Alto \\
\hline 5 & Muy Alto \\
\hline
\end{tabular}

Fuente : Elaborado por el Grupo de Investigación

Cada stakeholder propuesto es valorado del 1 al 5 en las tres características básicas mencionadas, aquellos que logran un promedio de 4 o más, son considerados como Stakeholders claves. En la Tabla 42, se muestra la Matriz de Identificación de Stakeholders Claves realizada por el grupo de investigación, a partir del brainstorming.

Tabla 42. Matriz de Identificación de Stakeholder Claves

\begin{tabular}{|c|l|c|c|c|c|c|}
\hline $\mathbf{N}^{\circ}$ & Stakeholders & Poder & Legitimidad & Urgencia & Promedio & $\begin{array}{c}\text { ¿Es un } \\
\text { stakeholder } \\
\text { clave? (si/no) }\end{array}$ \\
\hline 1 & Pymes & 5 & 5 & 5 & 5.0 & SI \\
\hline 2 & $\begin{array}{l}\text { Trabajadores } \\
\text { del sector }\end{array}$ & 4 & 5 & 4 & 4.3 & SI \\
\hline 3 & Estado & 5 & 5 & 5 & 5.0 & SI \\
\hline 4 & Clientes & 5 & 4 & 4 & 4.3 & SI \\
\hline 5 & Competidores & 4 & 3 & 3 & 3.3 & NO \\
\hline 6 & Proveedores & 4 & 5 & 4 & 4.3 & SI \\
\hline 7 & $\begin{array}{l}\text { Asociaciones } \\
\text { del rubro }\end{array}$ & 3 & 3 & 4 & 3.3 & NO \\
\hline 8 & Sociedad & 4 & 5 & 4 & 4.3 & SI \\
\hline 9 & Acrededores & 3 & 4 & 3 & 3.3 & NO \\
\hline
\end{tabular}

Fuente : Elaborado por el Grupo de Investigación

Definición de los Stakeholders identificados

\section{PYMES}

Las herramientas propuestas en el presente trabajo de investigación, están orientados a las pequeñas y medianas empresas del sector textil exportador de prendas de vestir. Es por ello, 
que se debe analizar en primera instancia el impacto que tienen las herramientas a aplicar en las empresas, dentro de este grupo se considera a los dueños de las PYMES, que finalmente toman la decisión de mejorar sus procesos ya que tienen poder dentro de la empresa, por ello sus necesidades e intereses deben ser atendidos. Cada empresa en la cual se aplican las herramientas puede tener diferentes características en cuanto a su entorno y también objetivos diferentes, pero en su mayoría comparten ciertos objetivos principales como son: generación de ganancias e incremento del valor de la empresa.

\section{CLIENTES}

El cliente es uno de los stakeholders más importantes para cualquier empresa, ya que son la razón principal del negocio; por ello, cumplir con sus requerimientos es esencial para mantenerlos en el tiempo. Es importante que las empresas del sector tengan la capacidad para cumplir con las especificaciones del cliente, ya que su incumplimiento podría afectar económicamente a la empresa.

\section{TRABAJADORES DEL SECTOR}

Este grupo está compuesto por todas aquellas personas que laboran en las empresas del sector textil, los trabajadores tienen gran influencia en cuanto a la toma de decisiones y la ejecución de una actividad, ya que las actitudes que tomen se refleja en su trabajo, por ello es de suma importancia entregarle las condiciones e información necesaria para que realicen sus actividades adecuadamente. Para mejorar la productividad de los trabajadores, es necesario responder sus necesidades afines a la organización.

\section{PROVEEDORES}

Conjunto de empresas que abastecen de productos o servicios a las empresas del sector textil, las buenas prácticas que se adopten en la gestión de compras hacen que se trasmita eficiencia y eficacia hacia los proveedores, lo cual genera exigencia al sistema de compras y a los proveedores; por ende, se incrementa la competitividad del proveedor y aumenta la sinergia entre el proveedor y la empresa.

\section{SOCIEDAD}

Grupo de personas que forman parte del entorno de la empresa, es importante su implicancia, debido a que los objetivos de la empresa no solo deben enfocarse en el cliente, sino también 
en las comunidades vecinas donde realizan sus actividades, ya que poseen alta influencia sobre acciones que pueda ejecutar el estado para regular las actividades de la empresa que puedan perjudicar a las zonas aledañas.

\section{ESTADO}

El estado influye en el ámbito legal y tributario; por ello, es de suma importancia cumplir con las normativas vigentes, ya que algunas actividades se encuentran limitadas o reguladas por entidades estatales. El estado es el primer ente en recibir la atención de la empresa, y este incluso puede tomar decisiones sobre la empresa en caso de urgencia.

Impacto de las propuestas sobre los Stakeholders

La evaluación de los posibles impactos generados por la aplicación de las propuestas sobre los stakeholders identificados se realiza a través de la Matriz Leopold. Para ello, se establecen aspectos en los cuales se podría identificar el impacto. A continuación, se presenta la definición para cada aspecto considerado en la Matriz de Leopold. (Ver Tabla 43) 
Tabla 43. Aspectos considerados en la Matriz de Leopold

\begin{tabular}{|c|c|c|}
\hline Stakeholders & Aspecto & Definición \\
\hline \multirow{4}{*}{ PYME } & \multirow{3}{*}{ Económico } & Incremento de productividad \\
\hline & & Incremento del valor de la empresa \\
\hline & & Reducción de costos de producción \\
\hline & Educación & Adquisición de conocimientos \\
\hline \multirow{4}{*}{ Clientes } & Calidad & Cumplimiento de los requerimientos \\
\hline & Precio & Precio de acuerdo al mercado \\
\hline & Tiempo & Entrega a tiempo \\
\hline & Nivel de servicio & Pedido completo y entregado a tiempo \\
\hline \multirow{3}{*}{ Trabajadores } & Económico & Aumento de ingresos \\
\hline & Social & Mejora de clima y carga laboral \\
\hline & Educación & Conocimiento y desarrollo de capacidades \\
\hline \multirow{2}{*}{ Proveedores } & Desarrollo de alianzas & Mejora en la competitividad \\
\hline & Educación & Aporte de conocimientos \\
\hline \multirow{3}{*}{ Sociedad } & Ambiental & $\begin{array}{l}\text { Desarrollo de estrategias para la preservación } \\
\text { del medio ambiente }\end{array}$ \\
\hline & Económico & Incremento en la generación de empleos \\
\hline & Social & Aporte al desarrollo de la comunidad \\
\hline \multirow{3}{*}{ Estado } & Legal & Cumplimiento de leyes y normativas \\
\hline & Económico & Aporte al Producto Bruto Interno (PBI) \\
\hline & Social & $\begin{array}{l}\text { Contribución con la disminución de la pobreza y } \\
\text { del cierre de empresas del rubro }\end{array}$ \\
\hline
\end{tabular}

Fuente : Elaborado por el Grupo de Investigación

A continuación, se definen los posibles impactos que se pueden generar en cada stakeholder clave, debido a la implementación de las herramientas Lean.

- Impacto hacia las PYMES:

El desarrollo de las propuestas tiene un impacto positivo en el aspecto económico, debido a que incrementan la productividad de la empresa que lo aplica, en consecuencia, se incrementa el valor de la empresa, ya que las estrategias, objetivos e iniciativas que se apliquen en las PYME's estarán orientadas al logro de la misma. Cabe mencionar, que el establecimiento de los procedimientos desarrollados son la base y guía para la implementación de las herramientas desarrolladas; además, del desarrollo de estrategias de negociación con los proveedores y la 
disminución del tiempo de abastecimiento puede traer como consecuencia la reducción de los costos de producción.

- Impacto hacia los Clientes:

El impacto hacia los clientes está relacionado con el nivel de servicio, ya sea para el cliente interno del proceso o el cliente final de la empresa. Los objetivos y estrategias de la empresa y de cada área se enfocan en el cumplimiento de las entregas, las cuales deben cumplir con los requerimientos, ser entregados a tiempo y al precio adecuado. Las propuestas desarrolladas presentan un impacto beneficioso y de alta importancia con respecto a la calidad, precio y sobre todo el tiempo con el que se abastece el requerimiento, ya que el modelo busca reducir la brecha del Lead Time existente y asegurar la estabilidad del proceso productivo.

- Impacto hacia los Trabajadores.

El impacto de las propuestas desarrolladas es beneficioso para los trabajadores, ya que ellos representan la fuerza laboral de la empresa, su desempeño impacta directamente sobre el desarrollo de las actividades, por ello con la mejora del proceso, el desarrollo de nuevas herramientas de trabajo que permitan el flujo de información y la reducción o eliminación de errores en el sistema de compras se busca mejorar el clima y la carga laboral. En el aspecto educativo, se centra en el desarrollo de capacidades y conocimientos, que se imparten a través de las capacitaciones y de todo el proceso de implementación; por ello, su impacto es moderado.

- Impacto hacia los Proveedores

El impacto de las propuestas hacia los proveedores es ligeramente beneficioso, ya que la competitividad y el crecimiento de estos no forman parte del plan estratégico y de los objetivos de las PYME’s; sin embargo, son parte del plan de acción del área de compras, ya que se necesita crear sinergia con el proveedor para mejorar el proceso. Además, en el aspecto educativo, se realiza retroalimentación entre ambas partes y por ende aporte de conocimientos que ayuda a que los proveedores mejoren su nivel de servicio.

- Impacto hacia la Sociedad

El impacto hacia la sociedad es ligeramente reducido, debido a que esta no participa directamente en el proceso a mejorar y tampoco forma parte de la estrategia de la empresa, pero 
se relaciona ya que las oportunidades de empleo, desarrollo profesional y cuidado ambiental son necesidades que pueden ser convertidas en estrategias de la empresa.

- Impacto hacia el Estado:

El impacto de las propuestas presenta un impacto ligeramente beneficioso y de importancia baja en el aspecto económico, debido a que este no forma parte de los objetivos de la empresa. Sin embargo, al incrementarse el valor de la PYME puede incrementar el PBI; en cuanto al aspecto legal, sí es beneficioso, ya que la empresa mantendrá la documentación ordenada y la información solicitada por las entidades será transparente. Por último, el impacto en el aspecto social se da debido a que la mejora en el proceso de compras trae como resultado el incremento de las ventas y de la producción; por ende, se requiere de personal, esto contribuye a la generación de empleo y reducción de la pobreza en el país.

De la validación realizada por los expertos antes mencionados, se obtiene la siguiente puntuación. 
Tabla 44. Validación del Impacto de las propuestas (Matriz de Leopold).

\begin{tabular}{|c|c|c|c|c|c|c|c|c|c|c|c|c|c|c|}
\hline \multirow[b]{2}{*}{ Stakeholders } & \multirow[b]{2}{*}{ Aspecto } & \multirow[b]{2}{*}{ Definición } & \multicolumn{2}{|c|}{ PRISILLA QUEZADA } & \multicolumn{2}{|c|}{ JAVIER ERÁUSQUIN } & \multicolumn{2}{|c|}{ AZHARUL KHARIM } & \multicolumn{2}{|c|}{$\begin{array}{l}\text { GULSHAN } \\
\text { CHAUHAN }\end{array}$} & \multicolumn{2}{|c|}{ NALLUSAMY } & \multicolumn{2}{|c|}{ JUAN VANEGAS } \\
\hline & & & 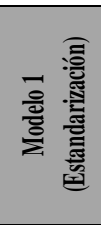 & 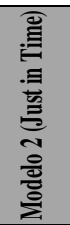 & 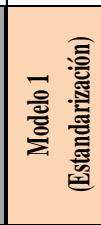 & 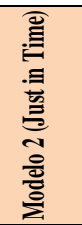 & 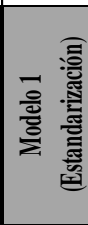 & 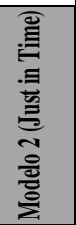 & 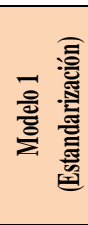 & 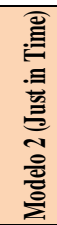 & 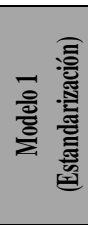 & 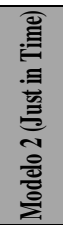 & 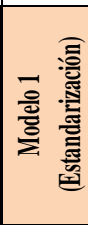 & 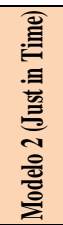 \\
\hline \multirow{4}{*}{ PYME } & \multirow{3}{*}{ Económico } & Incremento de productividad & & & & & & & & & & & & \\
\hline & & Incremento del valor de la empresa & & & & & & & & & & & & \\
\hline & & Reducción de costos de producción & & & & & & & & & & & & \\
\hline & Educación & Adquisición de conocimientos & & & & & & & & & & & & \\
\hline \multirow{4}{*}{ Clientes } & Calidad & Cumplimiento de los requerimientos & & & & & & & & & & & & \\
\hline & Precio & Precio de acuerdo al mercado & & & & & & & & & & & & \\
\hline & Tiempo & Entrega a tiempo & & & & & & & & & & & & \\
\hline & Nivel de servicio & Pedido completo y entregado a tiempo & & & & & & & & & & & & \\
\hline \multirow{3}{*}{ Trabajadores } & Económico & Aumento de ingresos & & & & & & & & & & & & \\
\hline & Social & Mejora de clima y carga laboral & & & & & & & & & & & & \\
\hline & Educación & Conocimiento y desarrollo de capacidades & & & & & & & & & & & & \\
\hline \multirow{2}{*}{ Proveedores } & Desarrollo de alianzas & Mejora en la competitividad & & & & & & & & & & & & \\
\hline & Educación & Aporte de conocimientos & & & & & & & & & & & & \\
\hline \multirow{3}{*}{ Sociedad } & Ambiental & $\begin{array}{l}\text { Desarrollo de estrategias para la preservación del } \\
\text { medio ambiente }\end{array}$ & & & & & & & & & & & & \\
\hline & Económico & Incremento en la generación de empleos & & & & & & & & & & & & \\
\hline & Social & Aporte al desarrollo de la comunidad & & & & & & & & & & & & \\
\hline \multirow{3}{*}{ Estado } & Legal & Cumplimiento de leyes y normativas & & & & & & & & & & & & \\
\hline & Económico & Aporte al Producto Bruto Interno (PBI) & & & & & & & & & & & & \\
\hline & Social & $\begin{array}{l}\text { Contribución con la disminución de la pobreza y } \\
\text { del cierre de empresas del rubro }\end{array}$ & & & & & & & & & & & & \\
\hline
\end{tabular}

Fuente : Elaboración Propia- Año 2017 
Para realizar el cálculo del impacto total por cada stakeholder se promedia los valores de magnitud y de importancia para cada caso. Después, se realiza el cálculo del producto de la magnitud promedio por la importancia promedio por cada stakeholder. Los resultados obtenidos se muestran en la siguiente tabla.

Tabla 45. Impacto Total de las propuestas

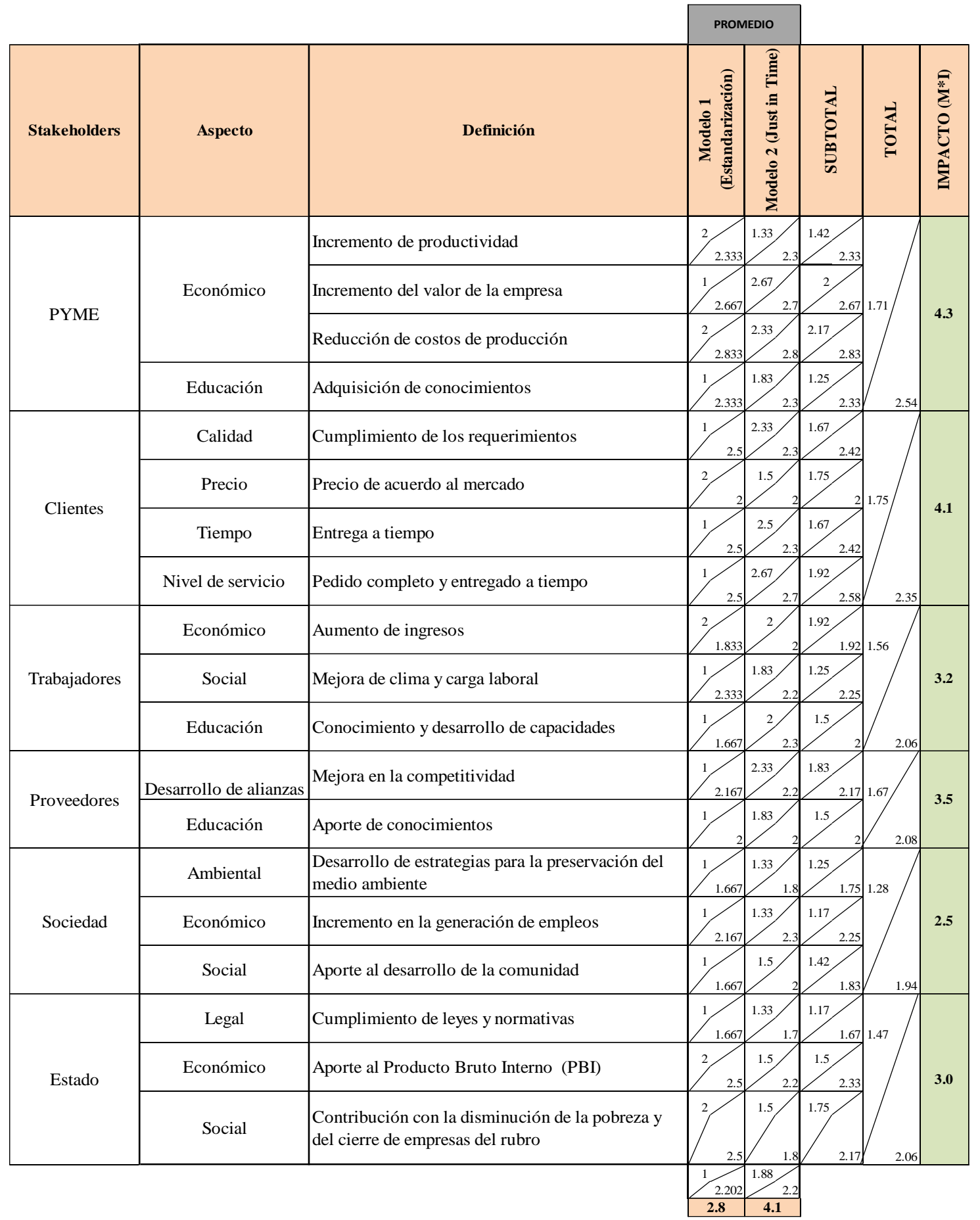

Fuente : Elaboración propia- Año 2017 
Figura 51. Validación del Impacto por Stakeholder

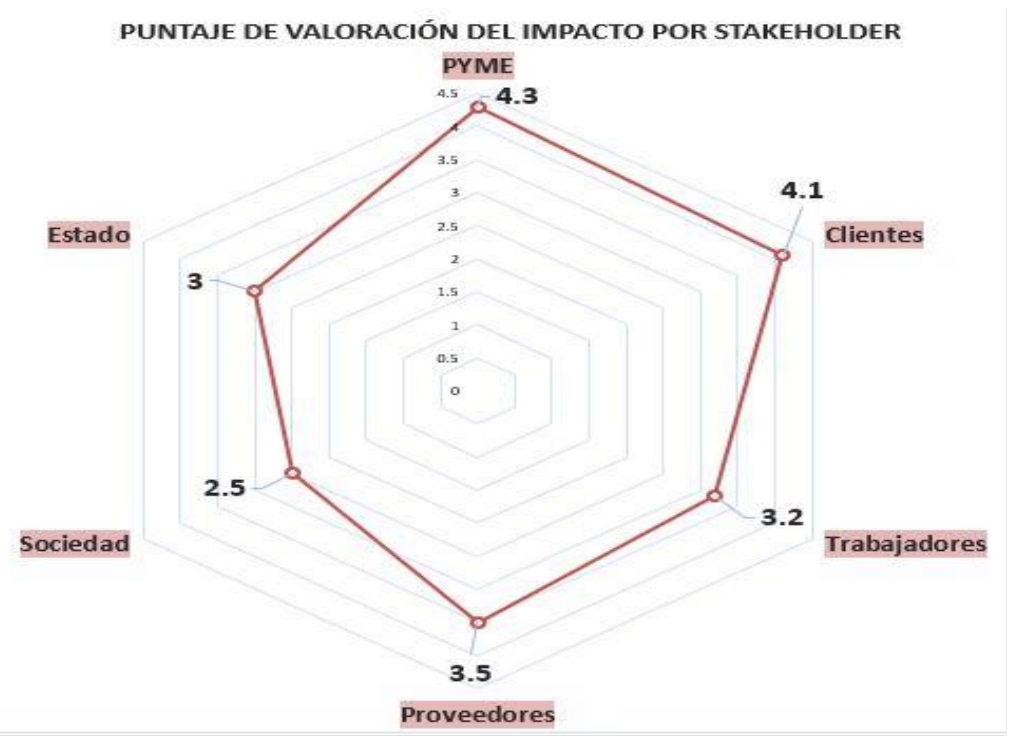

Fuente : Elaboración propia- Año 2017

De la Figura 51 se observa que las PYME's y los Clientes son los más impactados por la aplicación de las propuestas, ambos sobrepasando los 4 puntos. Asimismo, se evidencia que la herramienta que mayor impacta es el de Just in Time con 4.1 puntos (Ver Figura 52), esto debido a que esta propuesta ataca a los desperdicios que poseen mayor tiempo en el proceso de compras, como el abastecimiento de proveedores (2 días) y el reproceso de órdenes de compra, ya que se plantea el desarrollo de las compras calendarizadas, el plan de requerimiento de materiales y el desarrollo de estrategias con el proveedor para disminuir el tiempo de entrega de la tela.

Figura 52. Valoración del Impacto por modelo

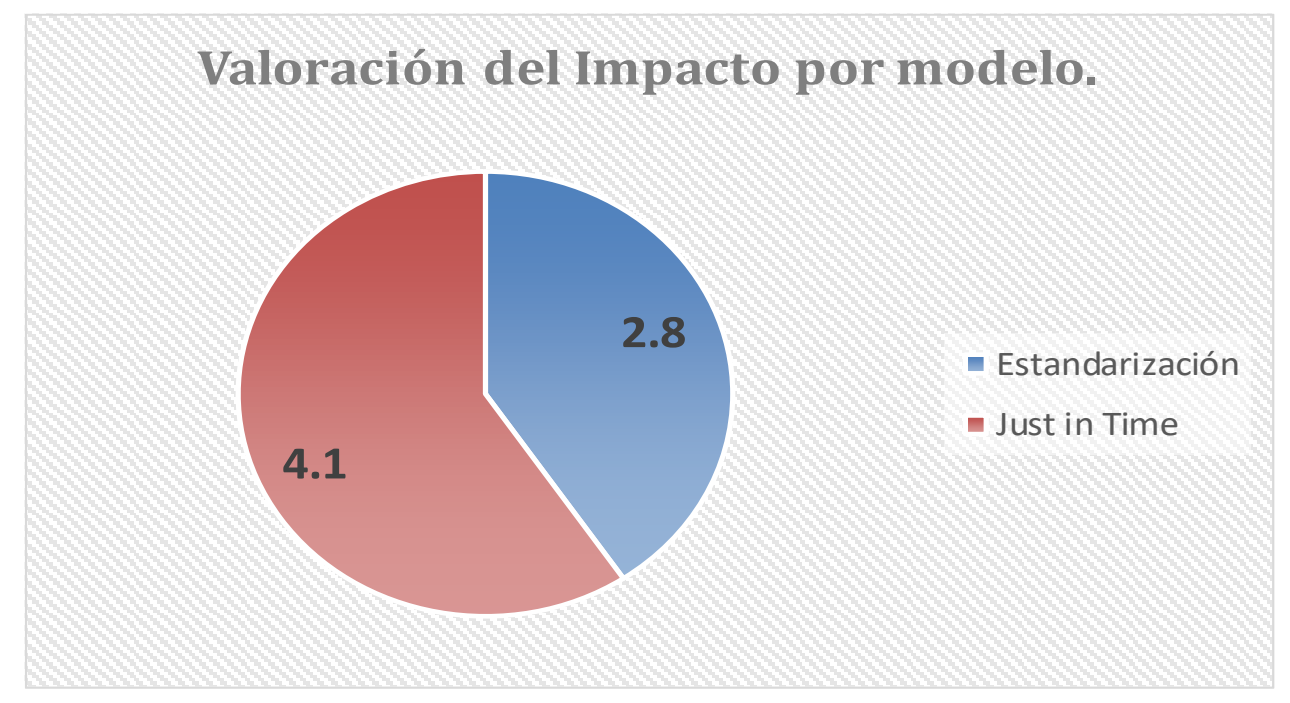

Fuente: Elaboración propia- Año 2017 
A continuación, se describirá el impacto de las propuestas en cada stakeholder:

\section{PYME's}

El impacto a este stakeholder se da en los siguientes aspectos:

- Económico

Las propuestas desarrolladas admiten aumentar el valor de la empresa, ya que se pueden generar tanto ahorros como ganancias para los dueños de las PYME's. Además, las ganancias se consiguen por medio de la captación de nuevos clientes, debido a que el desarrollo de las propuestas les permitiría entrar a mercados mucho más rigurosos y competitivos.

- Educación

Las propuestas desarrolladas le permiten al stakeholder obtener conocimientos de gestión.

\section{Clientes}

Las propuestas desarrolladas tienen repercusiones directas sobre este stakeholder, porque están encaminadas a lograr la satisfacción de los mismos; en consecuencia, se representará mediante la mejora de los siguientes aspectos:

\section{- Tiempo}

Se logra aumentar el nivel de cumplimiento de las entregas de los pedidos, haciendo que el plazo de entrega sea lo más cercano posible o menor a lo solicitado.

\section{- Precio}

Con el fin de mejorar la satisfacción del cliente, las propuestas permiten que las PYME's brinden sus productos a un precio competitivo en el mercado, logrando la reducción de costos asociados al producto tales como los costos logísticos, de producción, entre otros.

\section{- Calidad}

Este aspecto se ve mejorado por el cumplimiento de las especificaciones solicitadas por los clientes, garantizando así la conformidad de los requerimientos solicitados. Además, los impactos que tienen las propuestas en el plazo, precio y la calidad de los productos y/o servicios que ofrecen las PYME's de confección son de gran importancia, ya que les permite tener 
clientes satisfechos consiguiendo la fidelidad de los mismos y, a su vez, garantizar el éxito de las empresas.

-Nivel de servicio

Al reducir el tiempo de entrega y asegurar la calidad del producto el nivel de servicio se incrementa, esto sucede gracias a los procedimientos desarrollados que aseguran de que el producto llegue completo y en las condiciones pactadas.

\section{Trabajadores}

El impacto a este stakeholder se da en los siguientes aspectos:

\section{- Económico}

Uno de los objetivos de las propuestas implica aumentar la rentabilidad de la empresa, por ende, las remuneraciones salariales de los trabajadores se verán incrementadas, de esta forma se contribuye a que los colaboradores se sientan satisfechos mediante la mejora de sus condiciones de vida referente a lo económico.

\section{- Educación}

Para que las propuestas tengan éxito, uno de los supuestos involucra que los trabajadores posean y obtengan conocimientos y habilidades a través de las capacitaciones desarrolladas en todo el proceso de adaptación.

\section{- Social}

El efecto que producen las propuestas implica la satisfacción laboral mediante la identificación de pertenencia a una organización que se preocupe no solo por brindar mejores remuneraciones económicas sino también al bienestar personal, tales como salud, ambiente laboral motivador, seguridad en el empleo y oportunidades de progreso.

\section{Sociedad}

El impacto a este stakeholder se da en los siguientes aspectos:

\section{- Económico}


Al aplicar las propuestas, los empleadores estarán más sensibilizados con la realidad, pues al existir mayor empleo se activa el consumo y la demanda de mayor producción de esa forma funciona el dinamismo del círculo de bienestar social en una nación.

\section{- Social}

El impacto de las empresas que elijan acoger el modelo general propuesto referente a lo profesional se traducirá en brindar mejoras en las oportunidades profesionales, es decir, ampliar conocimientos y capacidades para descubrir una identidad y rol dentro del marco global de una empresa.

\section{- Ambiental}

Uno de los pilares de las propuestas es proteger al medio ambiente mediante herramientas de producción más limpia, por ende, el impacto al medio ambiente será preservar los recursos a futuras generaciones para que estos también sean aprovechados con una conciencia de enfoque de organización verde.

\section{Proveedores}

Se consideró a los proveedores como uno de los stakeholders principales, ya que son fundamentales en las operaciones de las organizaciones. Ambos experimentarán beneficios en temas económicos, gestión y crecimiento. Se consideraron los siguientes aspectos:

\section{- Educación}

Este punto trata sobre la retroalimentación que recibirá el stakeholder, debido a la implementación de las propuestas; ya que, al formar parte del sistema de compras, debe estar preparado tanto como la empresa para el desarrollo de nuevas actividades que permitan mejorar el flujo de información y las relaciones.

\section{- Desarrollo de alianzas}

Trata sobre la interacción que existe entre la compañía y el proveedor, en conjunto deben intercambiar información y resultados para una mejor gestión en sus procesos, lo que traerá como resultado es un aumento en el desarrollo del conocimiento de las operaciones. 


\section{Estado}

Se consideró al Estado como uno de los stakeholders principales, ya que con la rentabilidad y sostenibilidad que tendrán las pequeñas y medianas empresas textiles de confección, el Estado experimentará varios beneficios tanto económicos, sociales y legales. Se consideraron los siguientes aspectos:

- Económico

Este punto trata sobre el desarrollo y el progreso económico del país, modificando los indicadores financieros del país de manera positiva.

- Legal

Trata sobre la sostenibilidad de las medianas empresas pertenecientes al sector.

- Social

Se refiere al acrecentamiento de la empleabilidad y disminución del desempleo en el país, creando nuevas oportunidades y puestos de trabajo para la población.

\subsubsection{EVALUACIÓN DE RIESGOS Y ACCIONES DE CONTINGENCIA.}

De la Matriz de Validación de Impactos (Matriz de Leopold), se observó que dos de los expertos calificaron con puntajes negativos la magnitud del modelo de Estandarización en algunos aspectos definidos que impactan a los stakeholders. El análisis de riesgos y las acciones de contingencia para cada uno de ellos se muestran en la siguiente tabla. 
Tabla 46. Evaluación de Riesgos y Acción de Contingencia

\begin{tabular}{|c|c|c|c|c|}
\hline STAKEHOLDER & ASPECTO & $\begin{array}{c}\text { PUNTAJE } \\
\text { PROMEDIO }\end{array}$ & RIESGO & ACCIÓN DE CONTINGENCIA \\
\hline \multirow[t]{2}{*}{ PYME } & Económico: Incremento de la productividad. & -1 & $\begin{array}{l}\text { El margen de ganancia y la } \\
\text { capacidad productiva de la } \\
\text { empresa disminuya. }\end{array}$ & $\begin{array}{l}\text { Mediante los procedimientos desarrollados tales como: Procedimiento de Compras, Procedimiento de Seguimiento } \\
\text { de las compras, entre otros, se ha tomado en cuenta diferentes consideraciones y condiciones básicas, de tal } \\
\text { manera que el proceso de compras se torne eficiente, de esa forma se podrá reducir el Lead Time del procesoo, es } \\
\text { así como se ganarán días para poder atender pedidos extras y aumentar la capacidad de respuesta y de } \\
\text { producción, por ende el margen de ganancia se incrementa. Sin embargo, el desarrollo de la propuesta no solo } \\
\text { depende del proceso de compras, sino también de los involucrados en el proceso, los cuales influyen para que } \\
\text { exista flujo de información. }\end{array}$ \\
\hline & Educación: Adquisición de conocimientos. & -2 & $\begin{array}{l}\text { Personal no calificado para } \\
\text { desempeñar sus funciones, } \\
\text { por ende el producto y/o } \\
\text { servicio no cumple con los } \\
\text { estándares establecidos. }\end{array}$ & $\begin{array}{l}\text { Para la implementación de las propuestas desarrolladas, se toma como una de las consideraciones básicas la } \\
\text { Comunicación y formación del personal antes, durante y despeús de la implementación, de esta forma se asegura } \\
\text { que la aplicación de la propuesta se lleve a cabo adecuadamente y que los involucrados entiendan el objetivo y } \\
\text { uso de las herramientas. Asimismo, se establecen indicadores de medición del desempeño del proceso y de los } \\
\text { colaboradores. }\end{array}$ \\
\hline \multirow{3}{*}{ CLIENTES } & Calidad: Cumplimiento de los requerimientos. & -2 & \multirow{3}{*}{$\begin{array}{c}\text { Pérdida de la fidelidad del } \\
\text { cliente y daño a la imagen } \\
\text { de la empresa. }\end{array}$} & \multirow{3}{*}{$\begin{array}{l}\text { Para contrarestar el impacto en los tres aspectos mencionados, en cada una de las propuestas desarrolladas se } \\
\text { plantea el Procedimiento de Seguimiento de compras, con el objetivo de asegurar que se cumpla las } \\
\text { características del producto detalladas en el requerimiento del cliente y el tiempo de entrega exacto. Asimismo, se } \\
\text { desarrolla un Plan de auditoría in Situ, en el cual se asegura la calidad de los producto adquiridos y también que } \\
\text { cumpla con la fecha de entrega programada. }\end{array}$} \\
\hline & Tiempo: Entrega a tiempo. & -1.5 & & \\
\hline & Nivel de servicio: Pedido completo y entregado a tiempo. & -3 & & \\
\hline \multirow[b]{2}{*}{ TRABAJADORES } & Social: Mejora de clima y carga laboral. & -2 & $\begin{array}{l}\text { No se adapten a las } \\
\text { actividades o nueva forma } \\
\text { de trabajo. }\end{array}$ & $\begin{array}{l}\text { En el proceso de compras se han determinado roles y actividades de cada persona. Además, si no se cuenta en el } \\
\text { momento necesario con la persona apropiada determinen a un responsable para que continúe el flujo de } \\
\text { información. De esta manera, se logra un clima laboral armonioso ya que todas las funciones están determinadas y } \\
\text { no habrá carga de trabajo. }\end{array}$ \\
\hline & Educación: Conocimiento y desarrollo de capacidades. & -1.5 & Perder fuerza laboral & $\begin{array}{l}\text { Los puesto dentro del proceso se han considerado mediante competencias que determina en que se adapta más y } \\
\text { donde se desenvuelve mejor la persona en su puesto de trabajo. De esta manera, se permite el desarrollo de } \\
\text { capacidades y habilidades. Además, se toma en cuenta las consideraciones y observaciones que tenga tanto en su } \\
\text { puesto como en otro. Todo ello, permite el trabajo conjunto de los empleados con la empresa e identificar } \\
\text { oportunidades de mejora. }\end{array}$ \\
\hline \multirow{2}{*}{ PROVEEDORES } & Desarrollo de alianzas: Mejora en la competitividad. & -3 & \multirow{2}{*}{$\begin{array}{l}\text { Proveedores no cumplen } \\
\text { con las politicas } \\
\text { establecidas. }\end{array}$} & \multirow{2}{*}{$\begin{array}{l}\text { Se ha considerado en el Procedimiento de Selección, Evaluación y Homologación de proveedores detalladamente } \\
\text { la manera en la que un proveedor pasa a ser socio estratégico de la empresa, ya que se busca que se alinie a las } \\
\text { necesidades de las pymes. Mediante las evaluaciones desarrolladas en dicho procedimiento se asegurarán de que } \\
\text { se cuente con proveedores conocedores del nuevo sistema de trabajo y que se aseguren de cumplir con los } \\
\text { requerimientos. }\end{array}$} \\
\hline & Educación: Aporte de conocimientos. & -1 & & \\
\hline
\end{tabular}

Fuente : Elaboración propia- Año 2017 
Si bien es cierto que el proceso de Compras es solo administrativo, necesita el apoyo y compromiso de las demás áreas de la empresa e involucrados en el proceso para la adecuada implementación de las propuestas, ya que la información debe ser compartida y alineada para el cumplimiento de los objetivos y principalmente del requerimiento del cliente interno y externo, de esa forma se busca asegurar al cliente e incrementar la capacidad de respuesta de la empresa que lo aplica. Además, se ha desarrollado un método de evaluación de la metodología que permite evaluar durante la implementación de las herramientas, y luego de la implementación algunos problemas que se presentan en el proceso de Compras, ello permitirá identificar oportunidades de mejora a través del tiempo. 


\section{CONCLUSIONES}

Del presenta trabajo de investigación se puede concluir lo siguiente:

-El principal problema identificado en el proceso de compra de telas de las PYME's exportadoras del sector textil está referido al lead time excesivo en el proceso de abastecimiento de tela que se genera por el retraso de la entrega por parte del proveedor del pedido extra, debido al alto porcentaje de reproceso para los requerimientos del pedido. De las encuestas realizadas, se observó que el Lead Time promedio del proceso de compras es de 17 días, siendo el promedio del mercado de 10 días.

-Como resultado de la aplicación de las herramientas Lean: Compras Justo a Tiempo y Estandarización en el proceso de compras de las PYME's exportadoras, se eliminan los 5 desperdicios existentes identificados inicialmente: Retraso en la atención de la solicitud de requerimiento, espera por aprobación, retraso de proveedor, defecto de material y reproceso por error de cálculo, lo cual significa un incremento en la productividad, reducción de costos, mejorando la competitividad del sector, debido al 15\% de aumento de exportación.

-El costo de implementación de las herramientas desarrolladas, debido a que se trata de cambio de procedimientos y métodos estándar para realizar las órdenes de compra, es insignificante en relación al beneficio ganado de dicha implementación. 


\section{FUTURAS LÍNEAS DE INVESTIGACIÓN}

-Realizar el análisis económico que generaría el uso de un software desarrollado para uso específico de las PYME's del sector textil, que integre la información con los clientes internos con los proveedores y permita el seguimiento de las compras, ya que este tipo de empresas no poseen un software, debido al costo de instalación, mantenimiento y la necesidad de tener al personal capacitado para que opere el sistema.

-Desarrollar un método que facilite los contratos en el que gane tanto el proveedor como el comprador.

-Realizar el análisis de métodos de negociación con los proveedores que permitan el beneficio y satisfacción de las empresas y el proveedor.

-Investigar y desarrollar técnicas y programas que permitan mejorar el ambiente de trabajo en las empresas textiles, el compromiso de los trabajadores y rápida adaptabilidad a los cambios en sus actividades.

-Realizar un estudio de ingeniería de procesos a las plantas de producción de las PYME'S del sector textil exportador que permita determinar si la capacidad instalada y mano de obra disponible es la adecuada.

-Realizar estudios del mercado extranjero para conocer a detalle sus requerimientos, prioridades que toman en cuenta al comprar, expectativas del producto y servicio y potenciales compradores. 


\section{Referencia Bibliográficas}

Abdulmalek, F.A. \& Rajgopal, J. (2007). Analyzing the benefits of lean and value stream mapping via simulation: a process sector case study. International Journal of Production Economics, 107 (1), 223-236.

Asociación de Exportadores. (2016). Boletín Informativo de exportaciones. Recuperado dehttp://www.adexperu.org.pe/images/Boletines/Exportaciones/BOLETIN_DE_E XPORTACIONES_JULIO_2016.pdf.

Advanced Integrated Technologies Group. (2015). Enthronement Green Belt Seis Sigma Esbelto SIPOC. Recuperado de https://genesisyhwh.files.wordpress.com/2011/06/05sipoc.pdf

Amstrong, G. \& Kotler, P. (2009). Marketing. An Introduction. New Jersey, Estados Unidos: Pearson Prentice Hall.

Arango, M., Gil, H. y Zapata, J. (2009). Logística esbelta aplicada al transporte en el sector minero. Boletín de Ciencias de la Tierra, 25(1), 121-136.

Arias, A. (s.f). La gestión por procesos: Los procesos como actividad de valor en la organización.. Universidad Complutense de Madrid. Recuperado de https://aulavirtual.upc.edu.pe/bbcswebdav/pid-7824010-dt-content-rid45485254_1/courses/IN217-1701IX82/Unidad\%202/Semana\%204/Lecturas/documento10142.pdf.

Azharul, K. y Kazi, A. (2013). A methodology for effective implementation of lean strategies and its performance evaluation in manufacturing organizations. Business Process Management Journal, 19 (1), 169-196. 
Ballou, R. (2004). Logística administración de la cadena de suministro. Decisiones de programación de compras y de suministros (tesis de pregrado). Universidad San Pedro, Chimbote, Lima.

Banco Central De Reserva Del Perù (BCRP) (2015). Reporte de Inflación. Recuperado de http://www.bcrp.gob.pe/docs/Publicaciones/ReporteInflacion/2015/diciembre/reporte-de-inflacion-diciembre-2015.pdf.

Berger, A. (1997). Continuous improvement and kaizen: standardization and organizational designs. Integrated Manufacturing Systems, 89 (2), 115-122.

Bernal, A. y Rivas, A. (2012). Modelos para la identificación de Stakeholders y su aplicación a la gestión de los pequeños abastecimientos comunitarios de agua. Revista Lebret, 4, 251-273.

Recuperado

de

http://revistas.ustabuca.edu.co/index.php/LEBRET/article/view/337/337

Bizagi Process Modeler. (2009). Manual Bizagi. Recuperado de file:///C:/Users/MILAGRITOS/Downloads/Manual_De_BizAgi.pdf.

Borda, J. (2012). Control y Aseguramiento de Calidad en una planta textil de 180 toneladas por mes de producción (tesis de pregrado). Universidad Nacional de Ingeniería,Lima, Perú.

Borris, S. (2012). Strategic Lean Mapping: Blending Improvement Processes for the Perfect Solution. New York, Estados Unidos: McGraw-Hill Education.

Cao, Y. y otros. (2015), Constructing the integrated strategic performance indicator system for manufacturing companies. International Journal of Production Research, 53 (13), $4102-4116$.

Casanovas, A. (2011). Estrategias avanzadas de compras y aprovisionamiento Lean buying y Outsourcing. Barcelona, España: Profit Editorial. 
Centro De Informacion y Documnetacion Del InacaL (CID). (2016). Normas Técnicas $\begin{array}{llll}\text { Peruanas } & \text { de } & \text { Textiles. }\end{array}$ https://www.inacal.gob.pe/repositorioaps/data/1/1/1/jer/prensa/files/TEXTILES.pdf.

Chauhan, G. (2016). An analysis of the status of resource flexibility and lean manufacturing in a textile machinery manufacturing company. International Journal of Organizational Analysis, 25 (2), 107-122.

Chen y otros. (2004). Strategic purchasing, supply management, and firm performance. Journal of Operations Management, 22 (5), 505 - 523.

Chowdary, B. V. y George, D. (2011). Application of flexible lean tools for restructuring of manufacturing operations: a case study. Global Journal of Flexible Systems Management, 12(1), 1-8.

Departamento Nacional de Planeación (2009). Guía Metodológica para la formulación de indicadores. Recuperado de https://colaboracion.dnp.gov.co/CDT/Inversiones\%20y\%20finanzas\%20pblicas/Guia \%20Metodologica\%20Formulacion\%20-\%202010.pdf

Dombrowski, U. y Mielke, T. (2015), Ganzheitliche Produktionssysteme. Berlin Springer, 16, 330.

Drake y otros. (2013), The lean and agile purchasing portfolio model. Supply Chain Management, 18, 3-20.

Entidad de Evaluación de AENOR. (2013). Global2: Proceso de compras ISO 9001. Recuperado de http://globalo2.es/iso-9001/.

EOI. (2013). Lean Manufacturing: Conceptos, técnicas e implantación. Recuperado de https://issuu.com/ivanss3/docs/lean_manufacturing._conceptos_t__c

Escobar, J. (2007). El primer escalón de la logística: el abastecimiento. Zona Logística, 39, 31. Férnández, J. (2010). Gestión por procesos. Madrid, España: Editorial ESIC. 
Flores, M. (2013). Propuesta de Implementación de un MRP II para una planta de confecciones textiles (Tesis de maestría). Pontificia Universidad Católica del Perú, Lima, Perú.

Fondo PYME. Estandarización de procesos. Recuperado de http://www.contactopyme.gob.mx/Cpyme/archivos/metodologias/FP20071323/dos_presentaciones_capaciatacion/elemento3/estandarizacion.pdf.

Fourie, C. y Umeh, N. (2017). Application of lean tools in the supply chain of a maintenance environment. South African Journal of Industrial Engineering, 21, 231-237.

Garvin, D.A. (1994). Planificación estratégica de la producción. Harvard Deusto Business Review, 59, 71-85.

GenPart Consulting. (s.f). Casa de Lean Manufacturign. Recuperado de http://www.genpartconsulting.com/

Gomez, F. (2012). Estandarización y Documentación de los procesos Operativos de la Empresa Montaind LTDA. con base en los requisitos de la norma ISO 9001:2008 (tesis de pregrado). Universidad Cesar Vallejo, Lima, Perú.

Grebosz, M. y Wronska, B. (2013). Sensory Impact on the Purchase of Textile Products. Fibres and Textiles in Eastern Europe, 21, 8-12.

Grzybowska, K. y Gajdzik, B. (2014). Logistic strategies in purchasing process of metallurgical companies. Metalurgia, 43 (1), 127-130.

Herrera, G. y Herrera, J. (2016). Methodology Based on SCOR Model Applied to a Maintenance Services Company. Utopia y Praxis Latinoamericana, 21,549-571.

Hokoma, R.A., Khan, M.K. y Hussain, K. (2008). Investigation into the implementation stages of manufacturing and quality techniques and philosophies within the Libyan cement industry. Journal of Manufacturing Technology Management, 19 (7), 893-907. 
International Centre for development oriented Research in Agriculture (ICRA) (2009). Stakeholder Matrices - $\quad$ Guidelines. Recuperado de http://www.icraedu.org/objects/anglolearn/Stakeholder_Matrices-Guidelines(new).pdf Indumentaria y Moda (IYM). (2008). Página de EI Buenos Aries Doclab Institución orientada al desarrollo y creación de proyectos que contiene información sobre el proceso de confección textil. Recuperado de http://indumentariaymoda.com/2008/12/30/elproceso-deproduccion-en-la-industria-textil-ilustrado-arg/.

INFOR. (s.f). Programaciones de notificación de tipo pull. Recuperado de https://docs.infor.com/ln/10.3/es-es/help/td/onlinemanual/000349.html

INFOR. (s.f). Envíos de compras. Recuperado de https://docs.infor.com/ln/10.3/eses/help/td/pur/tdpur3120m000.html

INFOR. (s.f). Línea de envío de compras-Detalles. Recuperado de https://docs.infor.com/ln/10.3/es-es/help/td/pur/tdpur3522m000.html

INFOR. (s.f). Líneas de programación de compras. Recuperado de https://docs.infor.com/ln/10.3/es-es/help/td/pur/tdpur3111m000.html

INFOR. (s.f). Programación de compras-Recepciones. Recuperado de https://docs.infor.com/ln/10.3/es-es/help/td/pur/tdpur3115m200.html

Instituto Nacional de Estadística e Informática (INEI). (2015). Directorio Central de empresas y establecimientos. $\quad$ Recuperado de https://unstats.un.org/unsd/trade/events/2015/aguascalientes/9.-Pane1\%20III\%20$\% 20$ Presentation\%201\%20-\%20INEI\%20Peru.pdf

Instituto Nacional de Estadística e Informática (INEI). (2015). Estructura empresarial. Recuperado de http://www.inei.gob.pe/media/MenuRecursivo/publicaciones_digitales/Est/Lib1382/in dex.html. 
Kapelko, M. y Oude, A. (2015). An international comparison of productivity change in the textile and clothing industry: a bootstrapped Malmquist index approach. Empirical Economics,48, 1499-1523.

Khamidullina, A. y Puryaev, A. (2016). Development of the procurement principles and Management System of the Lean Production technology. Academy of Strategic Management Journal, 15, 26-31.

Kicosev, V. y otros. (2015). Assessment of the influence of a anthropogenic factors on elements of the ecological network in Vojvodina (Serbia) using the Leopold Matrix. Archives of Biological Sciences, 67, 1209-1217.

Marín, J. (2011). Propuesta de rediseño de la cadena de abastecimiento de la empresa de confecciones y definición de los indicadores de gestión (Trabajo de grado). Pontificia universidad javeriana, Bogotá, Colombia.

Marin, J. y Garcia, J. (s.f.). Cálculo de indicadores productivos. Universidad Politécnica de Valencia. Recuperado de https://riunet.upv.es/bitstream/handle/10251/16050/indicadores.pdf?sequence=3

Mohd, J y Mojib, S. (2015). Production line analysis via value stream mapping: a lean manufacturing process of color industry. Procedia Manufacturing, 2, 6-10.

Monroy, E. (2004). Medición de indicadores de gestión logísticos. GS1 Chile. Recuperado de https://es.slideshare.net/etorresmo/indicadores-gestinlogistica

Montoya, C. (s.f). Evaluación del desempeño como herramienta para el análisis del capital humano. Universidad de la Salle. Recuperado de http://www.scielo.org.ar/pdf/vf/v11n1/v11n1a05.pdf

Nallusamy, S. (2016). Lean Manufacturing Implementation in a gear shaft manufacturing company using value stream mapping. International Journal of Engineering Research in Africa, 21, 231-237. 
Neacsu y daneci-patrau. (2014). Leopold matrix and risk matrix used in the management of environmental impact. Economics, Management, and Financial Markets, 9 (4), 262274.

Ortiz, J. (2014). Propuesta de mejora en la gestión de compras de una empresa textil de prendas interiores y exteriores femenina (Tesis de pregrado). Universidad Peruana de Ciencias Aplicadas, Lima, Peru.

Oslo, M. (2005). The Measurement of Scientific and Technological Activities.Paris, Francia: Guidelines for Collecting and Interpreting Technological Innovation Data .

Padilla, E. (2012), Desarrollo de los aspectos metodológicos para la Implementación de un Sistema Integrado de Gestión en la industria textil y confecciones (Tesis de pregrado). Pontificia Universidad Católica del Perú, Lima, Perú.

Pagell, M. (2004), Understanding the factors that enable and inhibit the integration of operations, purchasing and logistics. Journal of Operations Management, 33 (5), 459487.

Pawęta, E. y Mikołajczyk, B. (2016). Areas for Improving the Innovation Performance of the Textile Industry in Russia. Fibres and Textiles in Eastern Europe, 24, 10-14.

Perez, F. (2007). Manufactura Esbelta en la PYME, Pequeños cambios grande resultados. XI Congreso de Ing. De Organización. Madrid, España.

Porter, M. (2007). Competitive Strategy: Techniques for Analyzing Industries and Competitors. New York: Free Press. Recuperado de https://books.google.es/books?hl=es\&lr=\&id=Hn1kNE0OcGsC\&oi=fnd\&pg=PT11\&d $\mathrm{q}=$ michaelporter+competitive\&ots=KJEOmflhFN\&sig=_G9hBzPu5yFVDzVzVTW6c

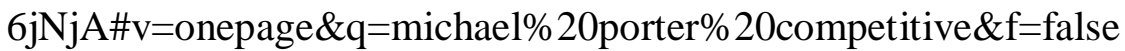

Prado, A. (2014). Medición del rendimiento del proceso de compras y suministro. Ingenium, $22,27-43$. 
Rachna, S. y Ward, P. (2003). Defining and developing measures of lean production. Journal of Operations Management, 25, 785-805.

Rahani y Muhammad (2012), Production Flow Analysis through Value Stream Mapping: A Lean Manufacturing Process Case Study. Procedia Engineering,24, 1727 - 1734.

Rajadell, M. y Sánchez, J. (2010). Lean Manufacturing: la evidencia de una necesidad. Madrid, España: Ediciones Díaz Santos

Rajenthirakumar, D. \& Shankar, R. (2011). Analyzing the benefits of lean tools: a consumer durables manufacturing company case study. International journal of Engineering, 9, 335-339.

Ramanan, L. (2015). Knowledge Gap and Its Impact on Product and Process Quality. Applied Mechanics and Materials, 813-814, 1176-1182.

Ramos, M. y otros. (2015). Muti-agent system model for the optimization of softwood industry supply chain. Maderas: Ciencia y Tecnologia, 17, 613-624.

Reporte Semana Scotiabank.(2016). Enfoques de la semana. Recuperado de http://cdn.agilitycms.com/scotiabankperu/PDFs/semanal/2016/julio/20160704_sem_es.pdf.

Rodriguez, B. (2015). Programa logístico modalidad virtual at Universidad Manuela Beltrán. Recuperado de https://es.slideshare.net/brodriguez85/compras-10638230.

Rose, M. y otros .(2013). A study on Lean Manufacturing implementation in Malaysian automotive component industry. International Journal of Automotive and Mechanical Engineering, 8 , 1467-1476.

Sipper, D. (1997). Production: Planning, Control, and Integration. New York, Estados Unidos: Mcgraw-Hill 
Secretaría de Economía de México (SE). (2010). Página de la Secretaría de Economía que es responsable de formular y conducir las políticas de industria, comercio exterior, interior, abasto y precios del país de México. Recuperado de http://www.economia.gob.mx.

SNI. (2016). Estadística de Información Textil y Confecciones. Recuperado de http://www.comitetextilperu.com/Boletin\%20Textil/docs/EXPOR.pdf.

SoyConta. (2013). Sistema de Compras efectiva. Recuperado de http://www.soyconta.mx/como-tener-un-sistema-de-compras-efectivas-en-unaempresa/

Sundara, R., Balajib, A. y Satheesh, R. (2014). A Review on Lean Manufacturing Implementation Techniques. Procedia Engineering, 97, 1875 - 1885.

Supply Chain Council. (2006). Supply chain operations reference model (SCOR) 8.0. Recuperado de http:// www.supply-chain.org. (Fecha de consulta: 09/06/2017).

UNISANGIL. (s.f). Mapa de procesos. Recuperado de http://www.unisangil.edu.co/index.php?option=com_content $\&$ view=article $\&$ id=326\& Itemid $=578$

Universidad de Guaymas. (2016). Manual de procedimientos. Recuperado de http://www.utguaymas.edu.mx/utg/universidad/manuales/manual-de-procedimientos. Universidad del Valle. (2009). Gestión por procesos en la Universidad del Valle. Recuperado de http://procesos.univalle.edu.co/documentos/CAPACITACION/Cartilla_capacitacion_ procesos.pdf

Universitat de Barcelona. (2012). Concepto del Sistema JIT. Recuperado de http://www.ub.edu/gidea/recursos/casseat/JIT_concepte_carac.pdf. 
Upadhye, N., Deshmukh, S.G. y Garg, S. (2010). Lean manufacturing in biscuit manufacturing plant: a case. International Journal of Advanced Operations Management, 2 (1), 108139.

Van Der Valk, W. y Rozemeijer, F. (2009). Buying business services: Towards a structured service purchasing process. Journal of Services Marketing, 23 (1), 3-10.

Vázquez, J. (2013). Indicadores de evaluación de la implementación de Lean Manufacturing en la industria (Tesis Maestría). Universidad de Valladolid, Soria, España.

Veerender, K. (2011). Supplier performance monitoring and improvement (spmi) through sipoc analysis and pdca model to the iso 9001 qms in sports goods manufacturing industry. Scientific Journal of Logistics, 7 (4), 1-15.

Vilchez, K. (2017). Propuesta de un modelo de éxito de planeamiento estratégico basado en la consolidación de las mejores prácticas de ingeniería industrial de las medianas empresas del sector textile en el rubro confecciones de Lima (Tesis de pregrado). Universidad Peruana de Ciencias Aplicadas, Lima, Perú.

Visa Empresarial. (2013). La PYME y MYPES en el Perú. Recuperado de https://visaempresarial.com/pe/noticias/la-pyme-y-mypes-en-el-peru_126.

World Economic Forum. (2016). The Global Competitiveness Report 2016-2017. Recuperado de http://www3.weforum.org/docs/GCR20162017/05FullReport/TheGlobalCompetitivenessReport2016-2017_FINAL.pdf.

Zamudio, C. (2016). Indicadores de desempeño del Departamento de compras. Recuperado de https://prezi.com/xn3bqp3rcozt/indicadores-de-desempeno-del-departamento-decompras/

Zheng, J. y otros. (2007). An analysis of research into the future of purchasing and supply management. Journal of Purchasing and Supply Management, 13 (1), 69-83. 


\section{ANEXOS}

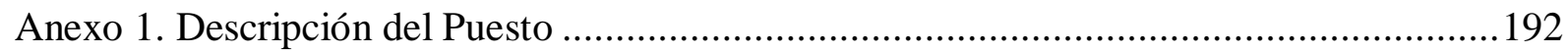

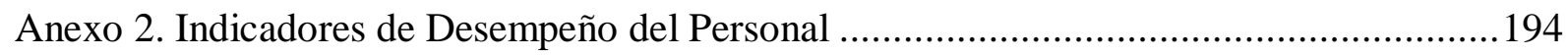

Anexo 3. Evaluación de Desempeño del Personal ............................................................ 198

Anexo 4. Plan de Acción para mejorar el desempeño del personal ..................................... 199

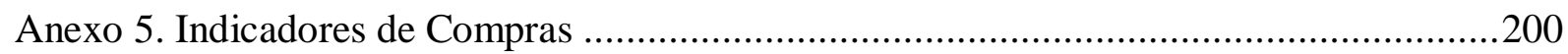

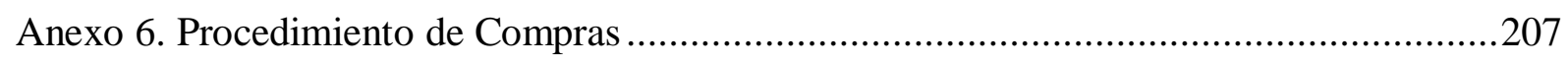

Anexo 7 : Solicitud de Información del Proveedor.........................................................225

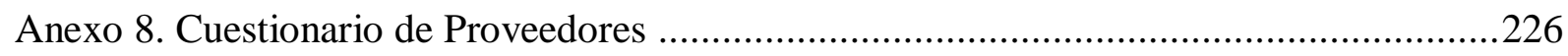

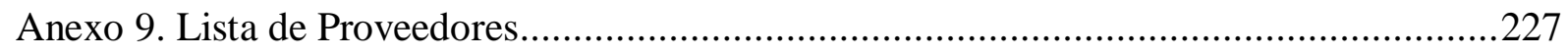

Anexo 10. Ejemplo de criterio de evaluación de la matriz AHP .....................................228

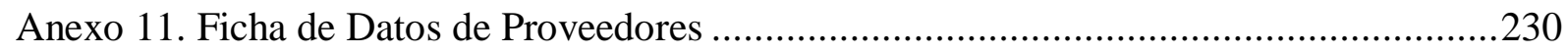

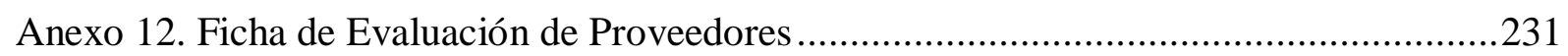

Anexo 13. Procedimiento de Seguimiento de Proveedores, Materiales y Servicios..............232

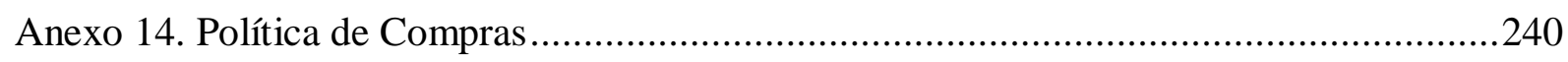

Anexo 15. Procedimiento de Seguimiento de Compras ..................................................242

Anexo 16. Procedimiento de Seguimiento de Proveedores, Materiales y Servicios..............247

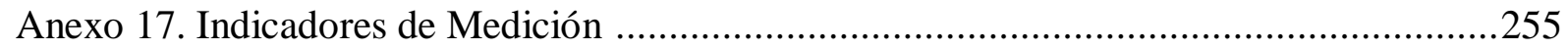

Anexo 18. Indicadores de Medición de Desempeño del Proceso .......................................257

Anexo 19. Formato de Entrevista para medir el desempeño ..........................................263

Anexo 20. Cuestionario de Evaluación de Desempeño......................................................264

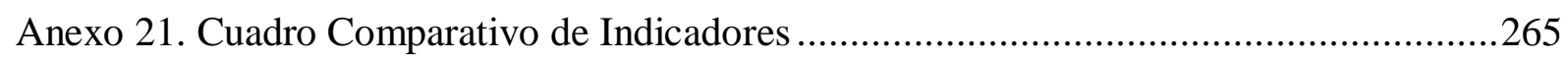

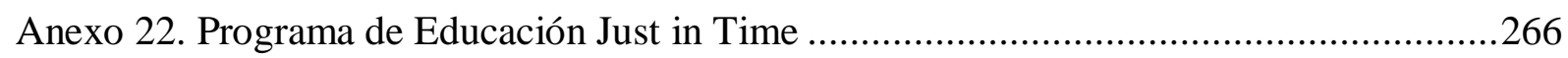

Anexo 23. Programación de Notificación Tipo Pull .......................................................270

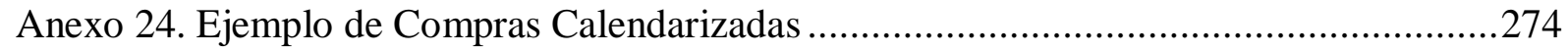

Anexo 25. Ejemplo de Planeamiento de Requerimiento de Materiales ..............................279

Anexo 26. Plan Estratégico con Proveedores .............................................................281

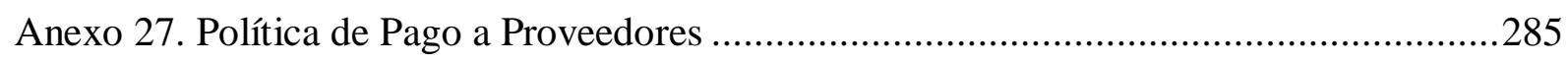

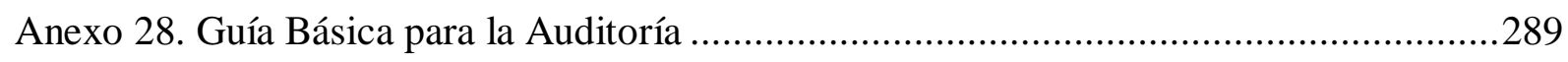

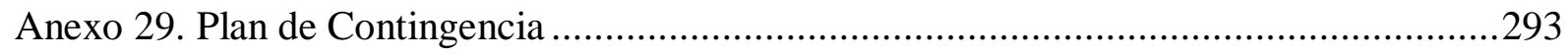

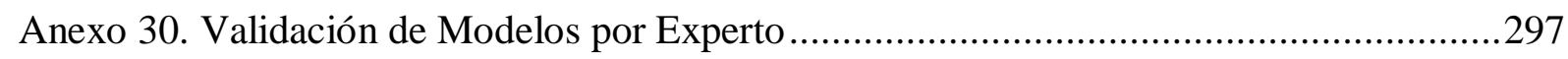




\section{Anexo 1. Descripción del Puesto}

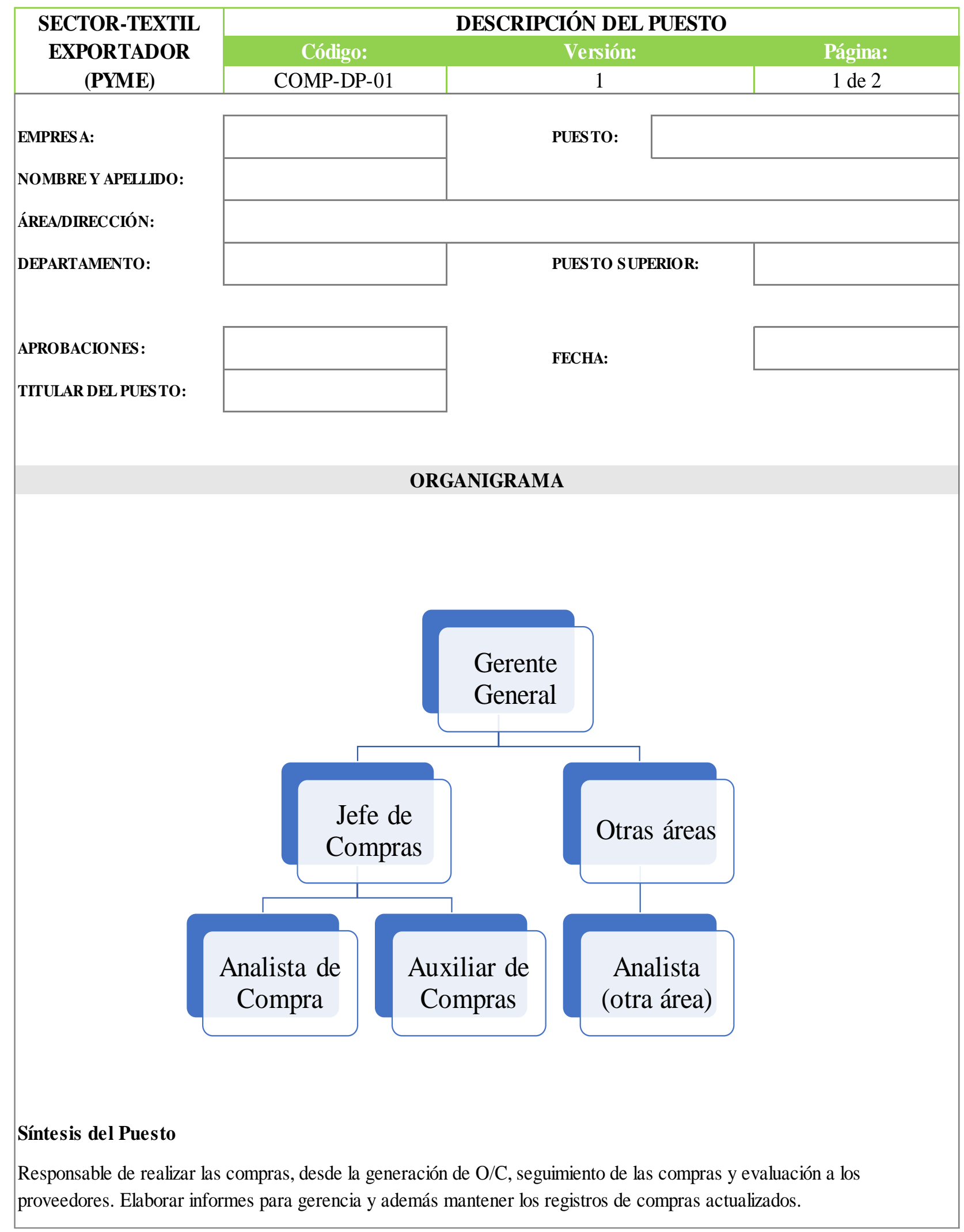




\begin{tabular}{|c|c|c|c|}
\hline \multirow{3}{*}{$\begin{array}{l}\text { SECTOR-TEXTIL } \\
\text { EXPORTADOR } \\
\text { (PYME) }\end{array}$} & \multicolumn{3}{|c|}{ DESCRIPCIÓN DEL PUESTO } \\
\hline & Código: & Versión: & Página: \\
\hline & COMP-DP-01 & 1 & 2 de 2 \\
\hline \multicolumn{4}{|c|}{ Responsabilidad del Puesto } \\
\hline \multicolumn{2}{|c|}{ Actividades / Tareas / Responsabilidades } & \multicolumn{2}{|c|}{ Grado de Rele vancia (alto-me dio-bajo) } \\
\hline \multicolumn{2}{|c|}{ Adquirir material } & \multicolumn{2}{|r|}{ Alto } \\
\hline \multicolumn{2}{|c|}{ Búsqueda de proveedores } & \multicolumn{2}{|r|}{ Alto } \\
\hline \multicolumn{2}{|c|}{ Selección y evaluación de proveedores } & \multicolumn{2}{|r|}{ Alto } \\
\hline \multicolumn{2}{|c|}{ Evaluación de precios } & \multicolumn{2}{|r|}{ Alto } \\
\hline \multicolumn{2}{|c|}{ Seguimiento a las compras } & \multicolumn{2}{|r|}{ Alto } \\
\hline \multicolumn{2}{|c|}{ Documentación y Registro } & \multicolumn{2}{|r|}{ Alto } \\
\hline \multicolumn{4}{|c|}{$\begin{array}{l}\text { Formación Básica: Administrador de empresas, ing. Administrativo, Ing. de producción, Ing de procesos y/o profesiones } \\
\text { afines al cargo. } \\
\text { Experiencia Requerida: preferiblemente } 1 \text { año en áreas financieras y contables. } \\
\text { Idioma: inglés hablado y escrito (Intermedio) }\end{array}$} \\
\hline \multicolumn{3}{|c|}{ COMPETENCIAS } & NIVEL DE REQUERIMIENTO \\
\hline \multicolumn{3}{|c|}{$\begin{array}{l}\text { COMUNICACIÓN } \\
\text { Buenas relaciones personales y servicio al cliente. }\end{array}$} & GRADO A \\
\hline \multicolumn{3}{|c|}{$\begin{array}{l}\text { ORIENTACIÓN AL CLIENTE } \\
\text { Capacidad para brindar un servicio profesional oportuno a los clientes externo, } \\
\text { internos y proveedores }\end{array}$} & GRADO A \\
\hline \multicolumn{3}{|c|}{$\begin{array}{l}\text { FLEXIBILIDAD } \\
\text { Capacidad para adaptarse espontáneamente a situaciones nuevas, trabajando } \\
\text { con un nivel altamente efectivo frente a situaciones variables. }\end{array}$} & GRADO A \\
\hline \multicolumn{3}{|c|}{$\begin{array}{l}\text { TRABAJO EN EQUIPO } \\
\text { Capacidad para dar prioridad al éxito del equipo frente al éxito personal }\end{array}$} & GRADO A \\
\hline \multicolumn{3}{|c|}{$\begin{array}{l}\text { LIDERAZGO } \\
\text { Capacidad para promover la eficacia del equipo, delegar responsabilidades y } \\
\text { supervisarla }\end{array}$} & GRADO A \\
\hline
\end{tabular}


Anexo 2. Indicadores de Desempeño del Personal

\begin{tabular}{|c|c|c|}
\hline $\begin{array}{c}\text { SECTOR-TEXTIL } \\
\text { EXPORTADOR } \\
\text { (PYME) }\end{array}$ & FICHA TÉCNICA DE INDICADOR \\
\hline & CHP-FTI-01 & 1 \\
\hline & \multicolumn{2}{|c|}{$\mathbf{1 .}$ Nombre } \\
\hline & $\%$ de Eficiencia del Proceso de Integración de Recursos Humanos
\end{tabular}

\section{Objetivo}

Lograr 95\% de eficiencia en el proceso de integración de recursos humanos para el puesto de compras.

$$
\begin{gathered}
\text { 3. Fórmula de Cálculo } \\
\mathrm{CS}=\frac{N^{\circ} \text { de candidatos admitidos }}{N^{\circ} \text { de candidatos examinados }} \times 100
\end{gathered}
$$

\section{Nivel de Referencia}

Mayor a $67 \%$
Entre $57 \%$ y $67 \%$
Menor a $57 \%$

Un incremento en el valor del indicador representa una mejora en el resultado.

\section{Responsable de la Gestión}

Responsable de Recursos Humanos

\section{Fuente de Información}

Base de reclutamiento y selección del personal

\section{Frecuencia de Medición}

Anual

\section{Frecuencia de Reporte}

Anual

\section{Responsable del Reporte}

Analista / Auxiliar de Recursos Humanos

10. Usuarios

Alta Dirección

\section{Observaciones}

Este indicador es realizado por el área de Recursos Humanos, evidenciando la selección de empleados para los diferentes puestos laborales de la empresa. 


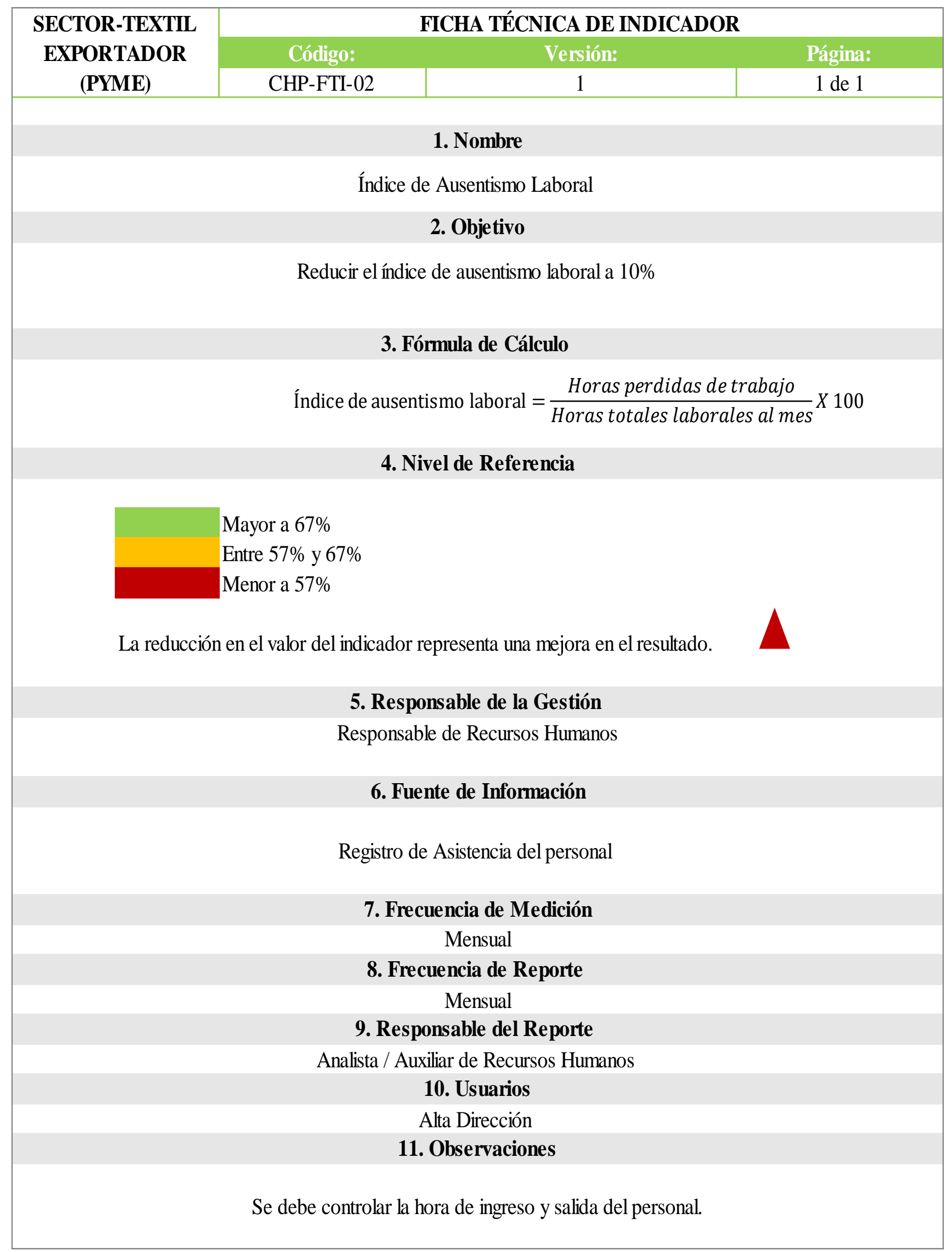




\begin{tabular}{|c|c|c|c|}
\hline \multirow{3}{*}{$\begin{array}{c}\text { SECTOR-TEXTIL } \\
\text { EXPORTADOR } \\
\text { (PYME) }\end{array}$} & \multicolumn{3}{|c|}{ FICHA TÉCNICA DE INDICADOR } \\
\hline & Código: & Versión: & Página: \\
\hline & CHP-FTI-03 & 1 & 1 de 1 \\
\hline \multicolumn{4}{|c|}{ 1. Nombre } \\
\hline \multicolumn{4}{|c|}{ Índice de Eficacia en el Proceso de Compras } \\
\hline \multicolumn{4}{|c|}{ 2. Objetivo } \\
\hline \multicolumn{4}{|c|}{ Aumentar la eficacia en el proceso de compras en $90 \%$. } \\
\hline \multicolumn{4}{|c|}{ 3. Fórmula de Cálculo } \\
\hline \multicolumn{4}{|c|}{ Eficacia en el proceso de compras $=\frac{N^{\circ} \text { de objetivos cumplidos }}{N^{\circ} \text { de Objetivos establecidos por el área }} X 100$} \\
\hline \multicolumn{4}{|c|}{ 4. Nivel de Referencia } \\
\hline \multirow{2}{*}{\multicolumn{4}{|c|}{ El aumento en el valor del indicador representa una mejora en el resultado. }} \\
\hline & & & \\
\hline \multicolumn{4}{|c|}{ 5. Responsable de la Gestión } \\
\hline \multicolumn{4}{|c|}{ Responsable de Compras } \\
\hline \multicolumn{4}{|c|}{ 6. Fuente de Información } \\
\hline \multicolumn{4}{|c|}{ Evaluación de desempeño de los trabajadores } \\
\hline \multicolumn{4}{|c|}{ 7. Frecuencia de Medición } \\
\hline \multicolumn{4}{|c|}{ Semestral } \\
\hline \multicolumn{4}{|c|}{ 8. Frecuencia de Reporte } \\
\hline \multicolumn{4}{|c|}{ Semestral } \\
\hline \multicolumn{4}{|c|}{ 9. Responsable del Reporte } \\
\hline \multicolumn{4}{|c|}{ Analista / Auxiliar de Compras } \\
\hline \multicolumn{4}{|c|}{ 10. Usuarios } \\
\hline \multicolumn{4}{|c|}{ Alta Dirección } \\
\hline \multicolumn{4}{|c|}{ 11. Observaciones } \\
\hline \multicolumn{4}{|c|}{ Establecer objetivos claros y concisos para el desarrollo y aprendizaje del empleado. } \\
\hline
\end{tabular}




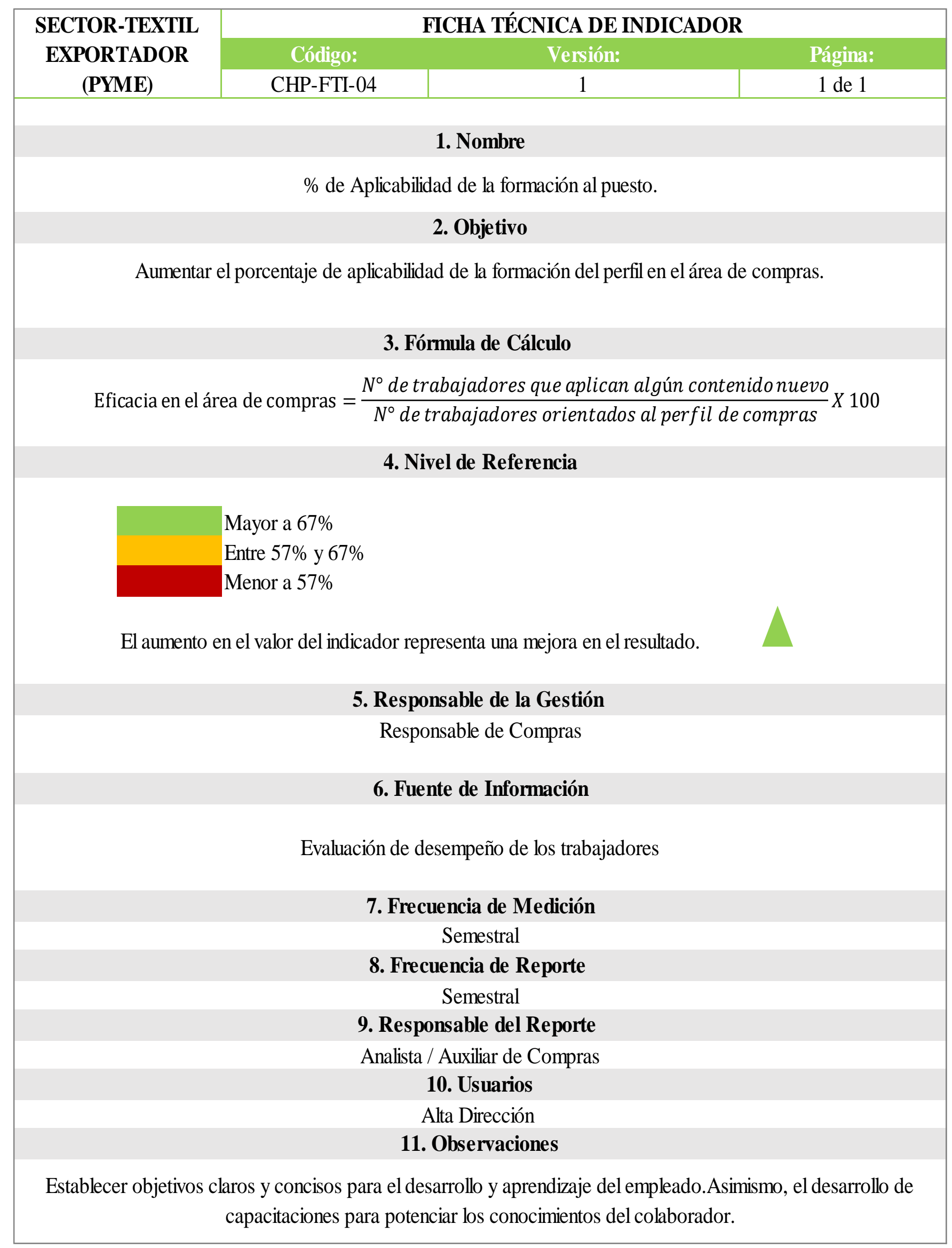




\section{Anexo 3. Evaluación de Desempeño del Personal}

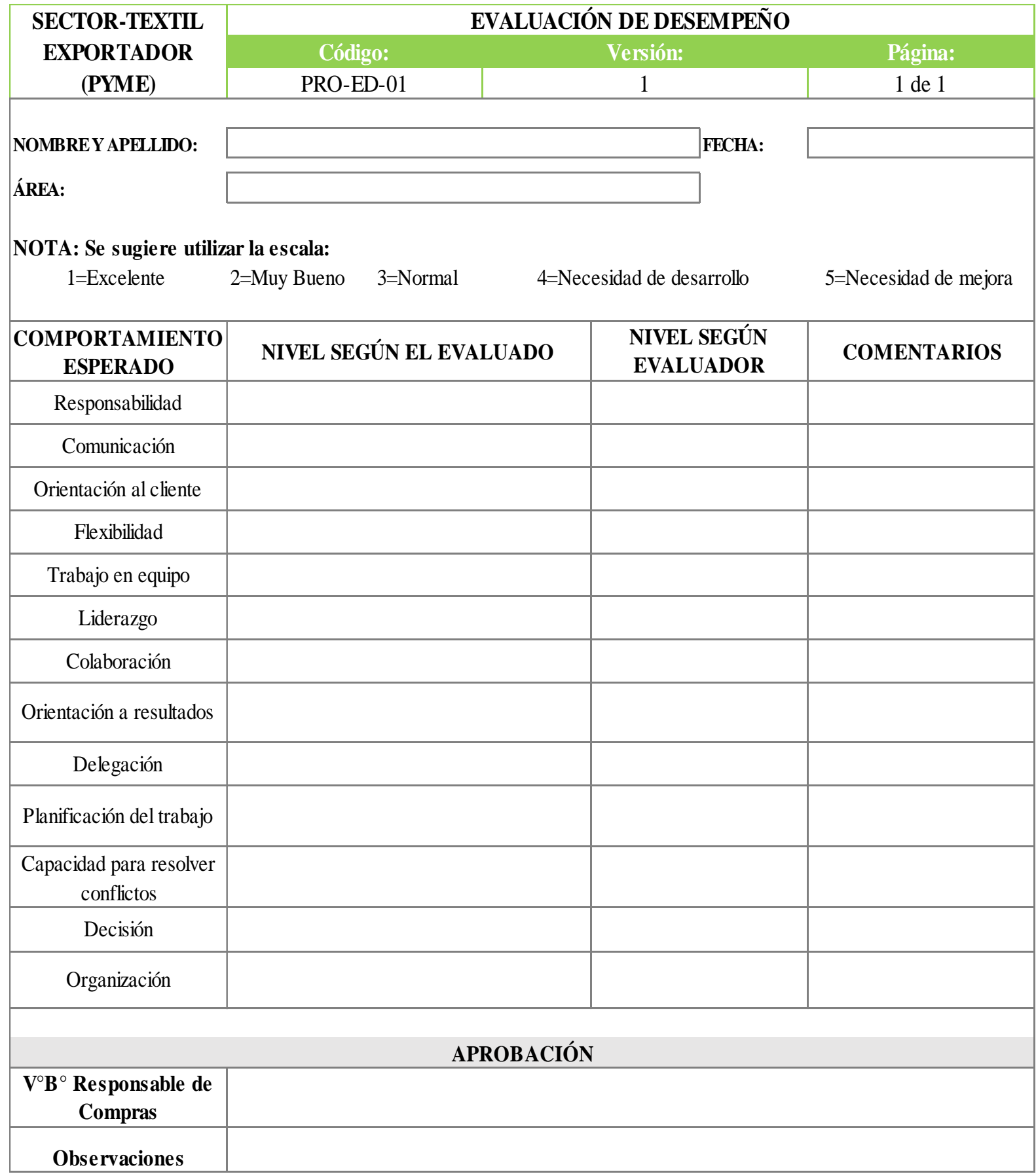




\section{Anexo 4. Plan de Acción para mejorar el desempeño del personal}

\begin{tabular}{|c|c|c|c|c|c|c|c|c|}
\hline \multirow{3}{*}{\multicolumn{2}{|c|}{$\begin{array}{c}\text { SECTOR-TEXTIL } \\
\text { EXPORTADOR (PYME) }\end{array}$}} & \multicolumn{7}{|c|}{ PLAN DE ACCIÓN PARA MEJORAR EL DESEMPEÑO } \\
\hline & & \multicolumn{2}{|c|}{ Código: } & \multicolumn{3}{|c|}{ Versión: } & \multicolumn{2}{|c|}{ Página: } \\
\hline & & \multicolumn{2}{|c|}{ PRO-PAMD-01 } & \multicolumn{3}{|c|}{1} & \multicolumn{2}{|c|}{1 de 1} \\
\hline \multirow{2}{*}{\multicolumn{2}{|c|}{$\begin{array}{l}\text { NOMBREY APELLIDO: } \\
\text { ÁREA: }\end{array}$}} & & & & \multirow{2}{*}{\multicolumn{2}{|c|}{ PERIODO: }} & & \\
\hline & & & & & & & & \\
\hline \multicolumn{9}{|c|}{ INSTRUCCIONES PARA EL EVALUADOR } \\
\hline \multicolumn{9}{|c|}{$\begin{array}{l}\text { 1. El evaluador deberá ser el jefe inmediato que haya supervisado al trabajador en sus labores, por lo menos durante } 6 \text { meses } \\
\text { anteriores. } \\
\text { 2. Determine el desempeo total de su empleado, en áreas y categorías indicadas en este formato. } \\
\text { 3. Revise la evaluación con su empleado en forma personal. } \\
\text { 4. La evaluación deberá ser imparcial, evaluando el periodo integral y no los últimos eventos. } \\
\text { 5. Una vez efectuada la evaluación complete el cuadro resumen, incluya las firmas correspondientes. }\end{array}$} \\
\hline $\begin{array}{l}\text { ACTIVIDADES A } \\
\text { DESARROLLAR }\end{array}$ & OBJETIVO & CONTRIBUCIÓN & INDICADOR & META & REAL & LOGRO & $\%$ PESO & PUNTAJE \\
\hline & & & & & & & & \\
\hline & & & & & & & & \\
\hline & & & & & & & & \\
\hline & & & & & & & & \\
\hline & & & & & & & & \\
\hline & & & & & & & & \\
\hline & & & & & & & & \\
\hline & & & & & & & & \\
\hline & & & & & & & & \\
\hline \multicolumn{9}{|c|}{ APROBACIÓN } \\
\hline \multicolumn{9}{|l|}{$\begin{array}{c}\mathrm{V}^{\circ} \mathrm{B}^{\circ} \text { Responsable } \\
\text { de Compras }\end{array}$} \\
\hline Observaciones & & & & & & & & \\
\hline
\end{tabular}




\section{Anexo 5. Indicadores de Compras}

\begin{tabular}{|c|c|c|c|}
\hline $\begin{array}{c}\text { SECTOR-TEXTIL } \\
\text { EXPORTADOR } \\
\text { (PYME) }\end{array}$ & \multicolumn{3}{|c|}{ FICHA TÉCNICA DE INDICADOR } \\
\hline & COMP-FTI-01 & Vensión: & Página: \\
\hline
\end{tabular}

\section{Nombre}

Pedidos Entregados a Tiempo

\section{Objetivo}

Medir la proporción de entrega de pedidos en la fecha pactada con la empresa, se desea lograr un incremento en la entrega.

\section{Fórmula de Cálculo}

Pedidos entregados a tiempo $(\%)=\frac{N^{\circ} \text { de pedidos entregados a tiempo }}{N^{\circ} \text { total de pedidos entregados }} X 100$

\section{Nivel de Referencia}

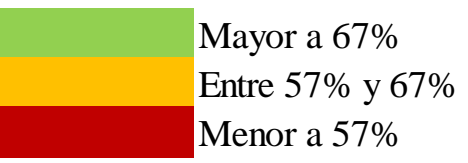

Un incremento en el valor del indicador representa una mejora en el resultado.

\section{Responsable de la Gestión}

Responsable de Compras

\section{Fuente de Información}

Registro de pedido de material (COMP-PDC-F1)

Nota de entrega de material (COMP-PDC-F3)

\section{Frecuencia de Medición}

\section{Anual}

\section{Frecuencia de Reporte}

Anual

\section{Responsable del Reporte}

Asistente de Compras

10. Usuarios

Gestión de Compras y Proveedores

11. Observaciones 


\begin{tabular}{|c|c|c|c|}
\hline $\begin{array}{c}\text { SECTOR-TEXTIL } \\
\text { EXPORTADOR } \\
\text { (PYME) }\end{array}$ & \multicolumn{3}{|c|}{ FICHA TÉCNICA DE INDICADOR } \\
\hline
\end{tabular}

\section{Nombre \\ Calidad de los Pedidos Generados}

\section{Objetivo}

Medir la proporción de pedidos de compras generadas sin retraso, o sin necesidad de información adicional. Se desea lograr un incremento en la calidad de los pedidos generados de $75 \%$.

\section{Fórmula de Cálculo}

Calidad de los pedidos generados $(\%)=\frac{* \text { Pedidos generados correctamente }}{\text { Total de pedidos generados }} X 100$

* Pedidos generados correctamente: Pedidos de compra que poseen la información necesaria, correcta y clara para ser procesado.

\section{Nivel de Referencia}

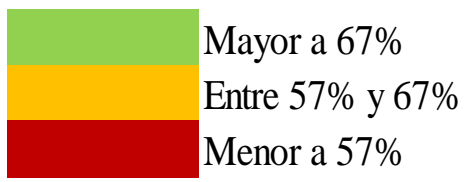

Un incremento en el valor del indicador representa una mejora en el resultado.

\section{Responsable de la Gestión}

Responsable de Compras

\section{Fuente de Información}

Registro de pedido de material (COMP-PDC-F1)

\section{Frecuencia de Medición}

Anual

\section{Frecuencia de Reporte}

Anual

\section{Responsable del Reporte}

Asistente de Compras

\section{Usuarios}

Gestión de Compras y Proveedores

\section{Observaciones}

El impacto que produce la mejora de este indicador, es que a través de su aplicación se puede eliminar gradualmente los problemas inherentes a la generación errática de pedido, como: costo de lanzar pedidos rectificados, esfuerzo de personal de compras para identificar y resolver problemas, entre otros. 


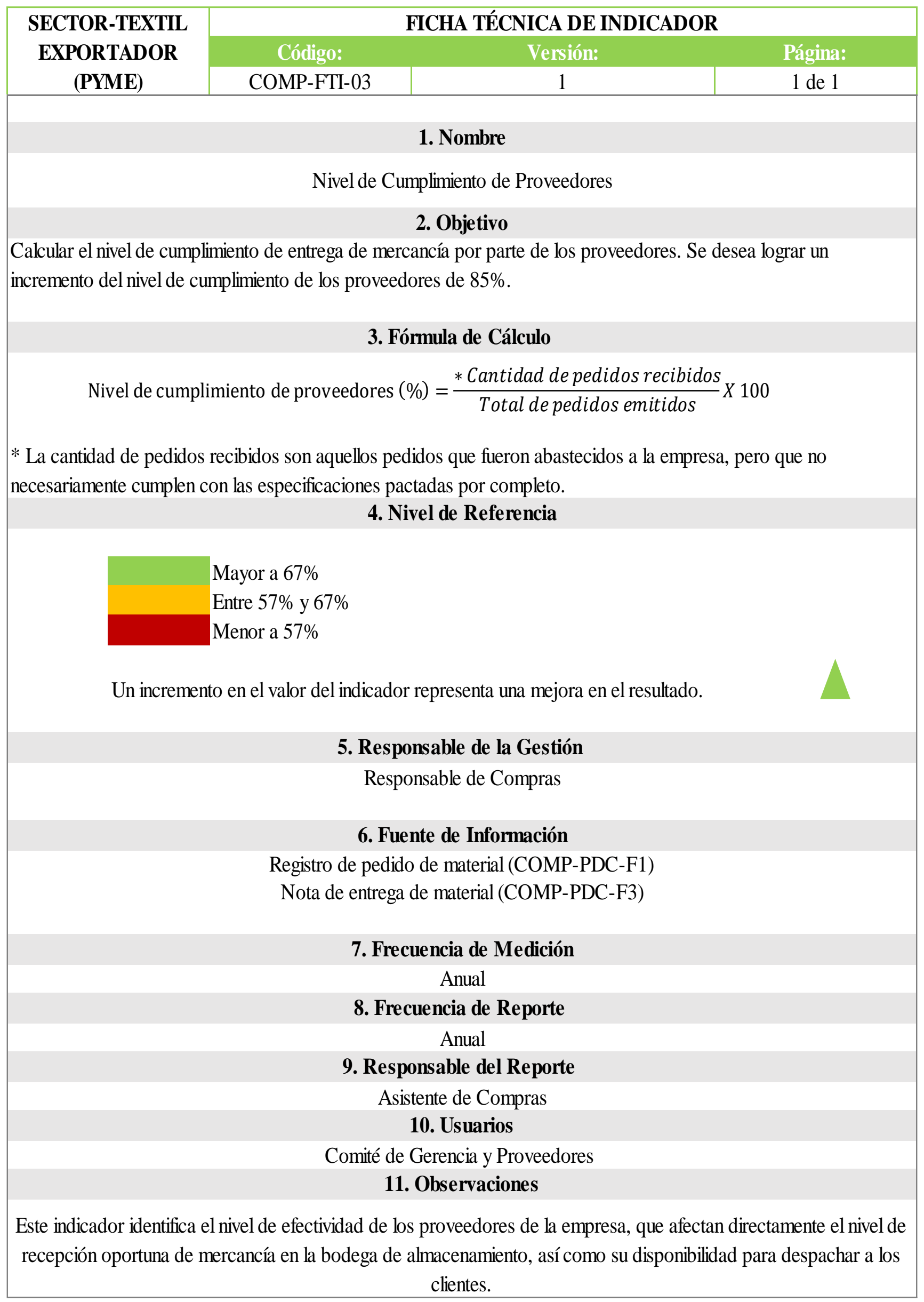




\begin{tabular}{|c|c|c|c|}
\hline \multirow{3}{*}{$\begin{array}{c}\text { SECTOR-TEXTIL } \\
\text { EXPORTADOR } \\
\text { (PYME) }\end{array}$} & \multicolumn{3}{|c|}{ FICHA TÉCNICA DE INDICADOR } \\
\hline & Código: & Versión: & Página: \\
\hline & COMP-FTI-04 & 1 & 1 de 1 \\
\hline \multicolumn{4}{|c|}{ 1. Nombre } \\
\hline \multicolumn{4}{|c|}{ Entregas Perfectamente Recibidas } \\
\hline \multicolumn{4}{|c|}{ 2. Objetivo } \\
\hline \multicolumn{4}{|c|}{$\begin{array}{l}\text { Mide el porcentaje de pedidos que cumplen las especificaciones de calidad y servicio definidas por proveedor. Se } \\
\text { desea lograr un incremento de las entregas perfectamente recibidas de } 85 \% \text {. }\end{array}$} \\
\hline \multicolumn{4}{|c|}{ 3. Fórmula de Cálculo } \\
\hline \multicolumn{4}{|c|}{$\begin{array}{l}\text { Entregas perfectamente recibidas }(\%)=\frac{* \text { Cantidad de pedidos aceptados }}{\text { Total de pedidos emitidos }} \times 100 \\
\text { * Los pedidos aceptados son aquellos que cumplen con todas las características con las que fueron solicitados } \\
\text { (cantidad, tiempo, requerimientos específicos y calidad) }\end{array}$} \\
\hline \multicolumn{4}{|c|}{ 4. Nivel de Referencia } \\
\hline \multicolumn{4}{|c|}{$\begin{array}{l}\text { Mayor a } 67 \% \\
\text { Entre } 57 \% \text { y } 67 \% \\
\text { Menor a } 57 \%\end{array}$} \\
\hline \multicolumn{4}{|c|}{ Un incremento en el valor del indicador representa una mejora en el resultado. } \\
\hline \multicolumn{4}{|c|}{ 5. Responsable de la Gestión } \\
\hline \multicolumn{4}{|c|}{ Responsable de Compras } \\
\hline \multicolumn{4}{|c|}{ 6. Fuente de Información } \\
\hline \multicolumn{4}{|c|}{ Informe de calidad de los pedidos recibidos } \\
\hline \multicolumn{4}{|c|}{ 7. Frecuencia de Medición } \\
\hline \multicolumn{4}{|c|}{ Anual } \\
\hline \multicolumn{4}{|c|}{ 8. Frecuencia de Reporte } \\
\hline \multicolumn{4}{|c|}{ Anual } \\
\hline \multicolumn{4}{|c|}{ 9. Responsable del Reporte } \\
\hline \multicolumn{4}{|c|}{ Asistente de Compras } \\
\hline \multicolumn{4}{|c|}{ 10. Usuarios } \\
\hline \multicolumn{4}{|c|}{ Gestión de Compras y Proveedores } \\
\hline \multicolumn{4}{|c|}{ 11. Observaciones } \\
\hline $\begin{array}{l}\text { Este indicador ayuda a } \\
\text { través de su aplicació } \\
\text { servicio, como: costos }\end{array}$ & $\begin{array}{l}\text { car la mejora en } \\
\text { ede prevenir los } \\
\text { no, costo de vol } \\
\text { ac }\end{array}$ & $\begin{array}{l}\text { equerimien } \\
\text { didos } \sin \mathrm{cu} \\
\text {, retrasos } \\
\text { l, etc. }\end{array}$ & $\begin{array}{l}\text { sedidos; por ello, a } \\
\text { ones de calidad y } \\
\text { sto de inspecciones }\end{array}$ \\
\hline
\end{tabular}




\begin{tabular}{|c|c|c|c|}
\hline \multirow{3}{*}{$\begin{array}{l}\text { SECTOR-TEXTIL } \\
\text { EXPORTADOR } \\
\quad \text { (PYME) }\end{array}$} & \multicolumn{3}{|c|}{ FICHA TÉCNICA DE INDICADOR } \\
\hline & Código: & Vensión: & Página: \\
\hline & COMP-FTI-05 & 1 & 1 de 1 \\
\hline \multicolumn{4}{|c|}{ 1. Nombre } \\
\hline \multicolumn{4}{|c|}{ Variación del Desempeño del Proveedor } \\
\hline \multicolumn{4}{|c|}{$\begin{array}{l}\text { Medir el porcentaje de variación del desempeño del proveedor en un periodo de tiempo determinado, en este se } \\
\text { incluye criterios como entrega a tiempo, cumplimiento de la política de compra, entrega de productos de calidad. Se } \\
\text { desea lograr un incremento del indicador de } 75 \% \text {. }\end{array}$} \\
\hline \multicolumn{4}{|c|}{ 3. Fórmula de Cálculo } \\
\hline \multicolumn{4}{|c|}{ Variación del desempeño del proveedor $(\%)=\frac{\text { Pedidos entregados que cumplen con lo pactado (periodo anterior) }}{\text { Pedidos entregados que cumplen con lo pactado (periodo actual) }} \times 100$} \\
\hline \multicolumn{4}{|c|}{ 4. Nivel de Referencia } \\
\hline \multicolumn{4}{|c|}{$\begin{array}{l}\text { Mayor a } 67 \% \\
\text { Entre } 57 \% \text { y } 67 \% \\
\text { Menor a } 57 \%\end{array}$} \\
\hline \multicolumn{4}{|c|}{ Un incremento en el valor del indicador representa una mejora en el resultado. } \\
\hline \multicolumn{4}{|c|}{ 5. Responsable de la Gestión } \\
\hline \multicolumn{4}{|c|}{ Responsable de Compras } \\
\hline \multicolumn{4}{|c|}{ 6. Fuente de Información } \\
\hline \multicolumn{4}{|c|}{ Nota de Entrega de material (COMP-PDC-F3) } \\
\hline \multicolumn{4}{|c|}{ Seguimiento de Proveedores } \\
\hline \multicolumn{4}{|c|}{ 7. Frecuencia de Medición } \\
\hline \multicolumn{4}{|c|}{ Anual } \\
\hline \multicolumn{4}{|c|}{ 8. Frecuencia de Reporte } \\
\hline \multicolumn{4}{|c|}{ Anual } \\
\hline \multicolumn{4}{|c|}{ 9. Responsable del Reporte } \\
\hline \multicolumn{4}{|c|}{ Responsable de Compras } \\
\hline \multicolumn{4}{|c|}{ 10. Usuarios } \\
\hline \multicolumn{4}{|c|}{ Departamento de Compras } \\
\hline \multicolumn{4}{|c|}{ 11. Observaciones } \\
\hline
\end{tabular}




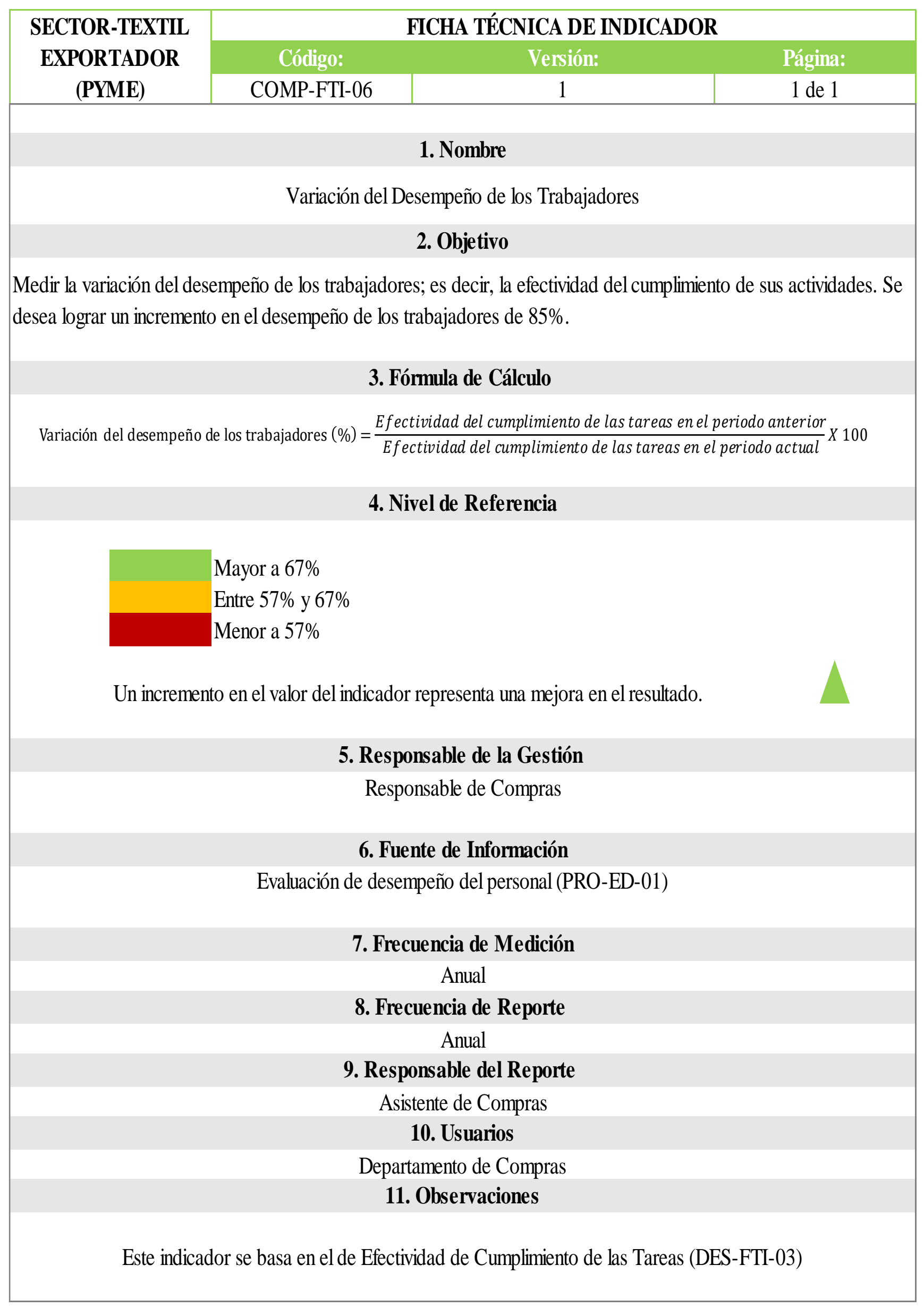




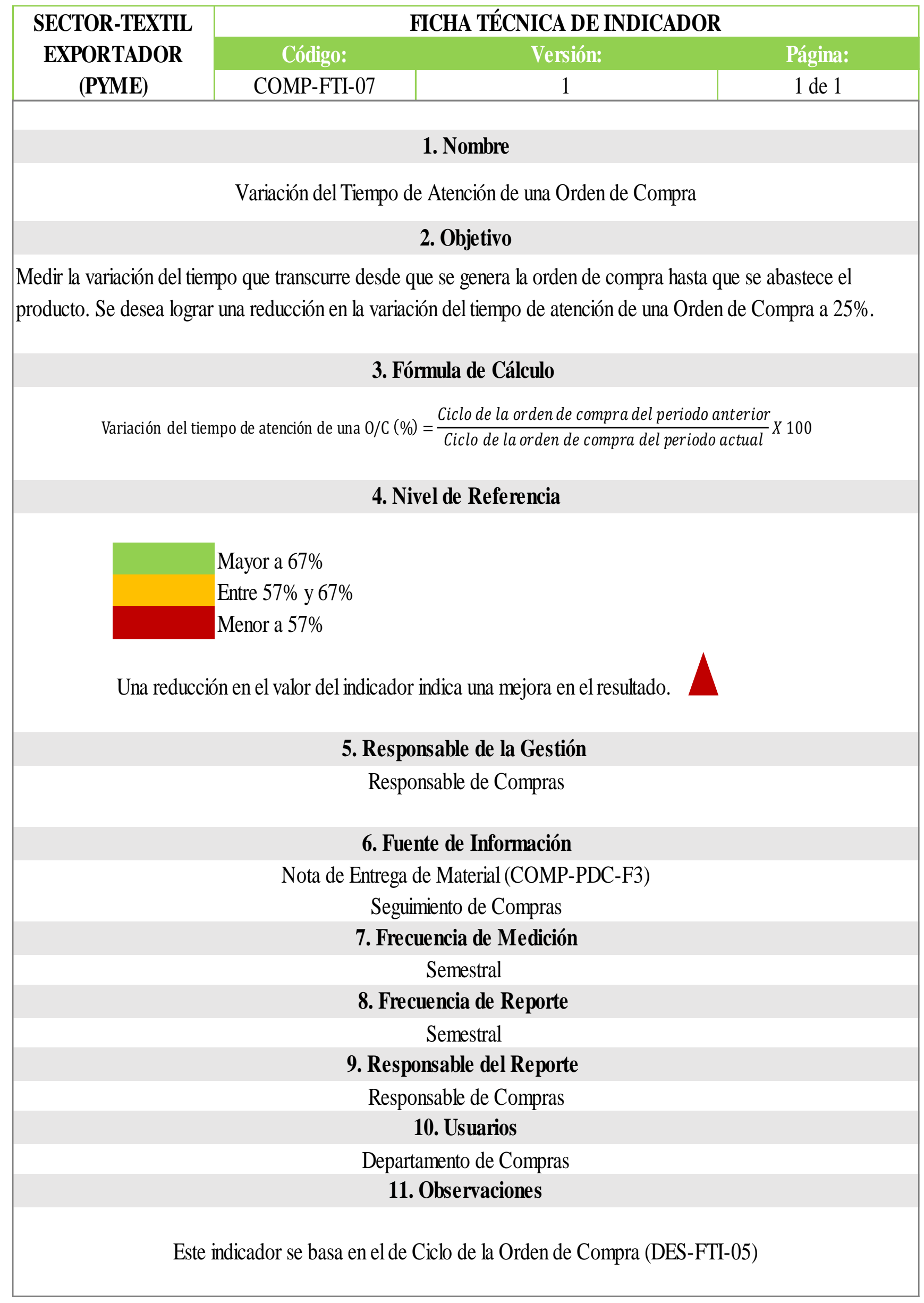


Anexo 6. Procedimiento de Compras

SECTOR-TEXTIL EXPORTADOR (PYME)
PROCEDIMIENTO DE COMPRAS

Versión :

01
Página :

01 de 15

PROCEDIMIENTO

DE COMPRAS 


\section{OBJETIVO:}

Establecer los lineamientos necesarios para realizar la adquisición de materiales y/o servicios.

\section{RESPONSABILIDAD Y ALCANCE:}

El presente procedimiento es realizado por el encargado de compras, este aplica a todos los productos y/o servicios adquiridos por la empresa, desde el envío de la requisición de compra hasta a la verificación del producto y/o servicio.

\section{DOCUMENTOS A CONSULTAR:}

- Política de compras (COMP-PC-01)

- Procedimiento de selección, evaluación y homologación de proveedores (COMPPRO-01)

\section{DEFINICIONES:}

PDC: Procedimiento de compras.

PC: Política de compras.

SR: Solicitud de requerimiento.

FTI: Ficha técnica de indicador.

PRM: Planificación de los requerimientos de material.

\section{CONDICIONES BÁSICAS:}

5.1 El responsable del área solicitante debe solicitar los productos o servicios a través de una Solicitud de requerimiento (PRO-SR-01), especificando claramente los productos a ser adquiridos. En caso contrario, el encargado de compras debe devolver la solicitud con el fin de que se integre de manera completa los datos del producto o servicio solicitado.

5.2 Previo a realizar el requerimiento de compra oficial, el encargado de compras debe verificar si este es de productos o servicios, si es de productos, antes de realizar el requerimiento de compra oficial el departamento de compras debe coordinar con el área de planeamiento sobre la disponibilidad de productos en el almacén y se realiza la verificación de las cantidades tomando de guía el Programa calendario de compras (Anexo $\mathbf{N}^{\circ}$ 24) y el PRM (Anexo $\mathbf{N}^{\circ}$ 25), de esta forma se aseguran de realizar el pedido en las cantidades correctas.

5.3 La requisición de compra debe estar debidamente detallada estableciendo la prioridad, mediante la Solicitud de requerimiento (PRO-SR-01). 


\begin{tabular}{c|c|c|}
\hline Código: & Versión: & Página: \\
\hline COMP-PDC-01 & 01 & 03 de 15 \\
\hline
\end{tabular}

5.4 El requerimiento de compra debe estar firmado por el encargado del departamento que lo solicita, y autorizado por la dirección de compras o la dirección general.

5.5 El departamento de compras debe atender las solicitudes de requerimiento de los clientes internos por orden de llegada y/o prioridad, el mismo día en el que fue emitida.

5.6 El departamento de compras es el único autorizado para hacer los pedidos y negociar directamente con el proveedor.

5.7 El requerimiento de compra para el proveedor debe ser aprobado por orden de pedido, no deben ser acumulados para ser atendidos, en caso no se encuentre el responsable de dar la autorización, se debe asignar a otra persona que asuma dicha responsabilidad.

5.8 No se debe acumular la emisión de órdenes de compra por más de 24 horas.

5.9 Todos los productos y/o servicios deben ser verificados en su recepción antes de aprobarlos para entrar en los diferentes procesos y/o liberar todos los servicios.

5.10 Los productos y/o servicios abastecidos, así como la forma de evaluación de estos están definidos en la siguiente tabla:

TABLA 3.1

\begin{tabular}{|l|c|c|c|c|}
\cline { 2 - 5 } \multicolumn{1}{c|}{} & \multicolumn{4}{c|}{ ELEMENTOS A EVALUAR } \\
\hline Insumo/Servicio & $\begin{array}{c}\text { Cumplimiento en el } \\
\text { tiempo de entrega } \\
\text { acordado }\end{array}$ & $\begin{array}{c}\text { Cumplimiento de las } \\
\text { características indica en } \\
\text { la solicitud de compra }\end{array}$ & $\begin{array}{c}\text { Precio y condiciones de } \\
\text { pago }\end{array}$ & Calidad en el servicio \\
\hline Materia prima & $\mathrm{X}$ & $\mathrm{X}$ & $\mathrm{X}$ & $\mathrm{X}$ \\
\hline Mantenimiento de instalaciones & $\mathrm{X}$ & $\mathrm{X}$ & $\mathrm{X}$ & $\mathrm{X}$ \\
\hline Mobiliario y equipo & $\mathrm{X}$ & $\mathrm{X}$ & $\mathrm{X}$ & $\mathrm{X}$ \\
\hline Capacitación y asesoría & \multicolumn{3}{|c}{} \\
\hline
\end{tabular}

5.11 La selección y contratación del personal externo para realizar las actividades de capacitación y asesoría debe ser realizada por el área solicitante previa autorización de la dirección general.

5.12 El responsable de verificar los productos o servicios solicitados debe ser aquella persona que reciba y/o almacene los productos o bien reciba directamente el servicio, esta persona deberá verificar:

5.12.1 Cumplimiento en el Tiempo de entrega acordado.

5.12.2 Cumplimiento de las características indicadas en la solicitud de compra.

5.12.3 Calidad del producto y/o servicio 
5.13En el caso de la evaluación en el rubro de precio y condiciones de pago, éste será evaluado únicamente por el responsable de compras, en estos casos se puede consultar con la gerencia.

5.14 El encargado de compras debe tener comunicación con el responsable de verificar el producto adquirido, con el fin de que se le proporcione información acerca de la evaluación del proveedor y registrar el formato de evaluación en la Ficha de evaluación de proveedores (REG-FEP-01).

5.15 El responsable de verificar y aprobar los productos y/o servicios adquiridos debe notificar al encargado de compras, cualquier anomalía durante la recepción, para ello se utiliza el Reporte de producto no conforme (Anexo 8.4 COMP-PDC-F2 "Reporte de producto no conforme").

5.16 El registro de dicha verificación puede ser el sello y/o firma de la persona que recibe, verifica y aprueba el producto en la solicitud de compra del producto ya recibido o cualquier documento que el proveedor presente como prueba de recibo del producto y/o servicio.

5.17 Para el caso de evaluación de proveedores se debe considerar lo siguiente:

a. Los proveedores son evaluados una vez que se verifican los productos o servicios solicitados y entregados de acuerdo con los criterios establecidos en el punto 3.12 de las condiciones básicas.

b. Para categorizar al proveedor se debe tomar en cuenta el Procedimiento de selección, evaluación y homologación de proveedores (COMP-PRO-01).

c. Para proveedores nuevos se consideran en evaluación durante la primera compra, en la cual se les evalúa y se catalogan de acuerdo con lo establecido en el (REGFEP-01 "Formato de evaluación de proveedores") del procedimiento de Selección, evaluación y homologación de proveedores.

d. A los proveedores se les reevalúa cada vez que entreguen productos o presten un servicio y el responsable o asistente de compras puede emitir un documento de reclamo, sugerencias o felicitaciones si lo cree conveniente (Anexo 8.6 COMPPDC-F4 "Hoja de reclamaciones, sugerencias y felicitaciones").

e. Los productos o servicios adquiridos que hayan sido aprobados se entregan inmediatamente al usuario solicitante, mediante el formato de entrega que firmará de recibido (Anexo 8.5 COMP-PDC-F3 "Nota de entrega de material") y se lleva el registro del mismo utilizando el (Anexo 8.3 COMP-PDC-F1 "Registro de pedido de material"). 


\section{DESARROLLO DEL PROCEDIMIENTO:}

\section{ACTIVIDADES}

\section{SECUENCIA DE ETAPAS}

\section{RESPONSABLE}

\section{SOLICITAR PRODUCTO Y/O SERVICIO}

Área solicitante $\mathrm{o}$ usuario

1.1 Solicitar el producto y/o servicio a través de la solicitud de requerimiento de compra (PRO-SR-01).

1.2 Dicho requerimiento de compra deberá contener de manera clara todos aquellos datos y especificaciones necesarios para realizar la adquisición del producto y/o servicio, esto podrá incluir:

-Dirección del área solicitante.

-Departamento solicitante.

-Fecha posible de entrega.

-Descripción detallada del producto.

2. RECIBIR Y REVISAR LA REQUISICIÓN DE Encargado de COMPRAS

Compras

2.1 Recibir el requerimiento de compra y revisarlo en base a los datos necesarios para la compra, asícomo los datos del área solicitante o usuario.

2.2 La revisión se realizará considerando:

-Datos del producto o servicio a adquirir.

-Tiempo de entrega.

-Cantidad del producto disponible en almacén.

-Programa calendario de compras (Anexo $\mathrm{N}^{\circ} 24$ ).

-PRM (Anexo $\left.\mathrm{N}^{\circ} 25\right)$

2.3 ¿La requisición de compra cumple?

-Sí, pasa a la etapa 4.

-No autoriza, informa al área solicitante el motivo de no autorización y pasa a la etapa 3.

\section{SOLICITAR CORRECCIÓN}

3.1 Solicita corrección de datos al área solicitante. 
4. EMITIR LA SOLICITUD DE REQUERIMIENTO Encargado de Compras

4.1 Recepcionar la solicitud de requerimiento corregida y emitir la solicitud de requerimiento para el proveedor.
5. EVALUAR
DISPONIBILIDAD
DEL Encargado
de PROVEEDOR
Compras

5.1 ¿El proveedor está disponible?

-Si, pasa a la etapa 6.

-No, se evalúa otro proveedor siguiendo las condiciones de la etapa 7.

6. EVALUAR DISPONIBILIDAD DEL MATERIAL

Encargado de

Compras

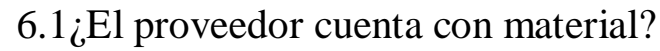

-Si, pasa a la etapa 8 .

-No, se evalúa otro proveedor siguiendo las condiciones de la etapa 7.

7. SELECCIONAR AL PROVEEDOR

Encargado de

Compras

7.1 Seleccionar a los proveedores de acuerdo con el Procedimiento de selección, evaluación y homologación de proveedores (COMP-PRO-01)

7.2 Una vez seleccionado al proveedor, cotiza el requerimiento.
8. EVALUAR COTIZACIÓN
Encargado
Compras

de

8.1. Evaluar la cotización en cuanto a cantidades y precios establecidos por el proveedor.

9. APROBAR REQUERIMIENTO

Encargado de

Compras

9.1 Encargado de compras o gerencia aprueba el requerimiento para el proveedor.

10. ENVIAR ORDEN DE COMPRA

Encargado de

Compras 
10.1 Enviar orden de compra indicando los datos de los productos o servicios a ser adquiridos, dichos datos son obtenidos de la Solicitud de requerimiento de compra (PRO-SR-01).

10.2 Envía orden de compra al proveedor.

11. RECIBIR ORDEN DE COMPRA

Proveedor

11.1 Recibe orden de compra y entrega el producto o servicio solicitado.

11.2 ¿Es producto o servicio?

-Si es producto pasa a actividad 17.

-Si es servicio pasa a actividad 12.1.

\section{ENTREGAR DIRECTO AL ÁREA Proveedor SOLICITANTE O USUARIO}

12.1 Proporciona el servicio directamente en el área solicitante.

\section{RECIBIR SERVICIO}

Área solicitante $\mathrm{o}$ usuario

13.1 Recibe el servicio de acuerdo con lo establecido en la solicitud interna de compra.

\section{EVALUAR EL SERVICIO}

Área solicitante 0 usuario

14.1 Evalúa el servicio durante la prestación del mismo.

14.2 Verifica que el servicio cumpla con lo establecido en la requisición de compra.

14.3 Para la revisión se deberá considerar como mínimo:

-Cumplimiento en el tiempo de entrega acordado.

-Cumplimiento de las características indicadas en la solicitud de compra.

-Calidad en el servicio.

14.4 ¿El servicio cumple con lo especificado?

-Si, pasa a actividad 16.1 .

-No, pasa a actividad 15.1.

\section{INFORMAR A COMPRAS Y AL PROVEEDOR}

Área solicitante 0 usuario

15.1 Informa al responsable de compras las anomalías existentes en el servicio proporcionado.

15.2 El responsable de compras aplica acciones de acuerdo con el Procedimiento de seguimiento de proveedores (COMP-SDP-01). 


\section{EVALUAR AL PROVEEDOR E INFORMAR A Área solicitante o COMPRAS usuario}

16.1 Una vez concluido el servicio y revisado que este cumpla con lo especificado, se evalúa al proveedor considerando lo señalado en la condición básica $\mathrm{n}^{\circ} 10$ establecida en este procedimiento.

16.2 Elabora la Ficha de evaluación de proveedores (REG-FEP-01), calificando a este de acuerdo con las características del servicio proporcionado.

16.3 Una vez evaluado se envía dicha evaluación al responsable de compras el cual procede a registrar en la base de datos de proveedores.

\section{SEGUIMIENTO AL PROVEEDOR}

Responsable/Auxiliar de compras

17.1 Se le hace seguimiento al proveedor, siguiendo el Procedimiento de seguimiento a las compras (COMP-SC-01).

\section{ENTREGAR AL \\ ALMACÉN Proveedor CORRESPONDIENTE}

18.1 Entrega el producto solicitado a almacén para su revisión e ingreso.

\section{RECIBIR PRODUCTO}

Almacén

19.1 Recibe el producto, solicitando al proveedor todos aquellos documentos de compra requeridos, tales como: factura, solicitud de compra, certificados de materiales, así como los que sean requeridos de acuerdo a cada producto. 
20. VERIFICAR EL PRODUCTO

Almacén

20.1 Revisa los productos entregados de acuerdo con lo especificado en la Solicitud de requerimiento interno (PRO-SR-01), para la revisión también se deberá considerar como mínimo:

-Cumplimiento en el tiempo de entrega acordado

-Cumplimiento de las características indicadas en la solicitud de compra

-Calidad y cantidad del producto

20.2 ¿El producto cumple con lo especificado?

$20.3 \mathrm{Si}$, pasa a actividad 22.1

20.4 No, pasa a actividad 21.1

\section{DEVOLVER PRODUCTO E INFORMAR A Almacén COMPRAS}

21.1 Se registra el producto no conforme en el Reporte de producto no conforme (COMP-PDC-F3) y se evita su uso.

21.2 Devuelve el producto al proveedor e informa al responsable de compras las anomalías existentes durante la entrega.

21.3 El responsable de compras aplica acciones de acuerdo con el Procedimiento de seguimiento al proveedor (COMP-SDP-01). Se vuelve a realizar el seguimiento al proveedor para la entrega del producto mejorado.

\section{ALMACENAR PRODUCTO}

Almacén

22.1 Da entrada al producto al área de almacén.

22.2 Registra la entrada a almacén a través de la Nota de entrega de material (COMPPDC-F4)

22.3 Almacena el producto para evitar daño o pérdida del mismo.

22.4 Notifica a compras la conformidad o no del producto para la emisión del cheque correspondiente a través del formato de Reporte de producto no conforme (COMPMC-F3), ya completado en el paso.

23. EVALUAR AL PROVEEDOR E INFORMA A Asistente de

\section{COMPRAS \\ Compras}

23.1 Una vez concluida la entrega y el ingreso del producto a almacén, se evalúa al proveedor. 
23.2 Se evalúa al proveedor considerando lo establecido en el procedimiento de Selección, evaluación y homologación del proveedor (COMP-PRO-01).

23.3 El asistente de compras completa el Formato de evaluación de proveedores (REG-FEP-01), calificando a éste de acuerdo a las características del producto entregado.

23.4 Una vez evaluado se envía dicha evaluación al responsable de compras.

24. ENTREGAR PRODUCTO A ÁREA O PROCESO Asistente de QUE LO REQUIER Compras

24.1 Una vez ingresado y revisado el producto, se entrega al área solicitante o al responsable del proceso que necesita el producto, bajo la Nota de entrega de material (COMP-PDC-F3).

\section{SOLICITAR AL PROVEEDOR EL Asistente de CUMPLIMIENTO DEL PRODUCTO O Compras SERVICIO}

25.1 Si después de la entrega e inspecciones se encuentran diferencias entre lo solicitado y lo entregado, el área solicitante informa a compras dichas diferencias a través de la Reporte de producto no conforme (COMP-PDC-F2), para que sean corregidas, todas las diferencias incidirán directamente en la evaluación y reevaluación realizada a dichos proveedores.

\section{RECIBIR EVALUACIÓN DEL PROVEEDOR \\ Responsable de Compras}

26.1 Recibe de las diferentes áreas la evaluación de los proveedores en la Ficha de evaluación de proveedores (REG-FEP-01)

26.2 Analiza las evaluaciones realizadas con el fin de dar seguimiento al comportamiento de los diferentes proveedores con los que se cuenta, utilizando el Procedimiento de seguimiento de proveedores y materiales (COMP-SDP-01) 
26.3 Integra las evaluaciones al expediente de cada proveedor.

26.4 Notifica a través de la orden de pago, la conformidad del servicio o producto al área de compras.

\section{REEVALUAR AL PROVEEDOR CUANDO Responsable de REALICE UNA NUEVA ENTREGA Compras}

27.1 Cada que se realiza una entrega se reevalúa al proveedor con el fin de verificar el comportamiento que este manifiesta durante el proceso de compra, así mismo esta información será de utilidad para tomar decisiones futuras de compra a proveedores.

28. MANTENER REGISTRO DE EVALUACIÓN DE Responsable de PROVEEDORES Compras

28.1 Mantiene y archiva en el expediente de cada proveedor el seguimiento de las evaluaciones realizadas.

7. REGISTRO:

- Solicitud de requerimientos (PRO-SR-01)

- Registro de pedido de material (COMP-PDC-F1)

- Reporte de producto no conforme (COMP-PDC-F2)

- Nota de entrega de material (COMP-PDC-F3)

8. ANEXOS:

8.1 Formato PRO-SR-01 "Solicitud de requerimientos" - Anexo del Procedimiento de selección, evaluación y homologación de proveedores (COMP-PRO-01)

8.2 Formato PRO-SRP-01 "Solicitud de requerimientos al proveedor"

8.3 Formato COMP-PDC-F1 "Registro de pedido de material"

8.4 Formato COMP-PDC-F2 "Reporte de producto no conforme"

8.5 Formato COMP-PDC-F3 "Nota de entrega de material"

8.6 Formato COMP-PDC-F4 "Hoja de reclamaciones, sugerencias y felicitaciones"

8.7 Diagrama de flujo del procedimiento. 
SECTOR-TEXTIL EXPORTADOR (PYME)
PROCEDIMIENTO DE COMPRAS

\begin{tabular}{c|c|c|} 
Código: & Versión: & Página: \\
\hline COMP-PDC-01 & 01 & 09 de 15
\end{tabular}

8.1 Formato PRO-SR-01 "Solicitud de requerimientos" - Anexo del Procedimiento de selección, evaluación y homologación de proveedores (COMP-PRO-01).

\section{SECTOR-TEXTIL EXPORTADOR (PYME)}

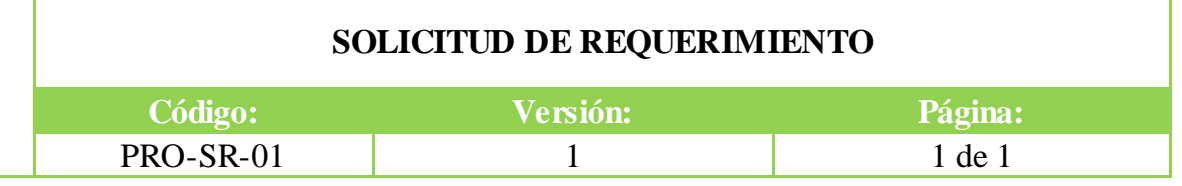
por este medio le solicito los

Encargado de compras materiales e insumos para la elaboración del siguiente requerimiento.

Fecha de requerimiento: / / $\quad$ Para $\mathrm{N}^{\circ}$ de pedido

Cliente:

OBSERVACIONES:

Recursos Materiales a Utilizar:

\begin{tabular}{|c|c|c|c|}
\hline $\mathbf{N}^{\circ}$ & DESCRIPCIÓN DEL MATERIAL & UNIDAD & CANTIDAD \\
\hline & & & \\
\hline & & & \\
\hline & & & \\
\hline & & & \\
\hline & & & \\
\hline & & & \\
\hline & & & \\
\hline
\end{tabular}

Sin mas a que referirme, le saludo.

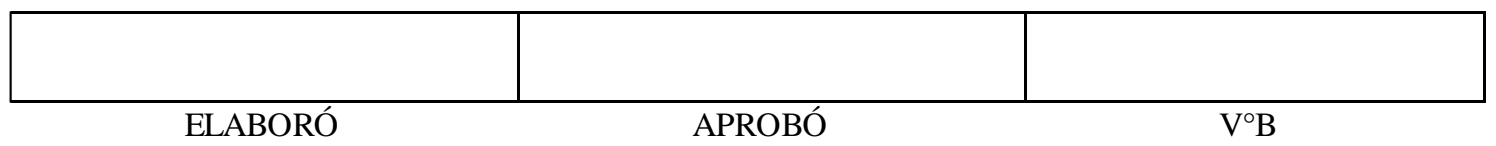


SECTOR-TEXTIL EXPORTADOR (PYME)
PROCEDIMIENTO DE COMPRAS

\begin{tabular}{c|c|c|}
\hline Código: & Versión: & Página: \\
\hline COMP-PDC-01 & 01 & 10 de 15 \\
\hline
\end{tabular}

8.2 Formato PRO-SRP-01 "Solicitud de requerimientos al proveedor"

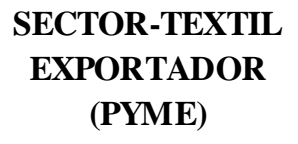

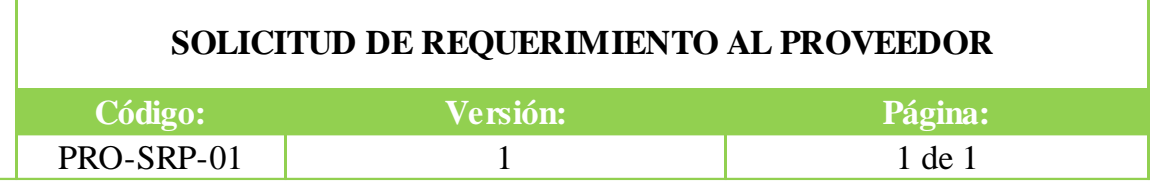

\section{SOLICITUD DE REQUERIMIENTO AL PROVEEDOR}

1 de 1

\section{Señores:}

Por este medio solicitamos la cotización de los materiales mencionados a continuación:

Fecha de requerimiento:

Para $\mathrm{N}^{\circ}$ de pedido:

Cliente:

Plan de entrega:

OBSERVACIONES:

Fecha de Aprobación:

Fecha Próxima Evaluación:

\begin{tabular}{|c|c|c|c|c|}
\hline $\mathbf{N}^{\circ}$ & DESCRIPCIÓN DEL MATERIAL & Fec. De entrega & UNIDAD & CANTIDAD \\
\hline & & & & \\
\hline & & & & \\
\hline & & & & \\
\hline & & & & \\
\hline & & & & \\
\hline & & & & \\
\hline & & & & \\
\hline & & & & \\
\hline & & & & \\
\hline & & & & \\
\hline & & & & \\
\hline & & & & \\
\hline & & & & \\
\hline & & & & \\
\hline & & & & \\
\hline & & & & \\
\hline & & & & \\
\hline & & & & \\
\hline
\end{tabular}

Sin mas a que referirme, le saludo.

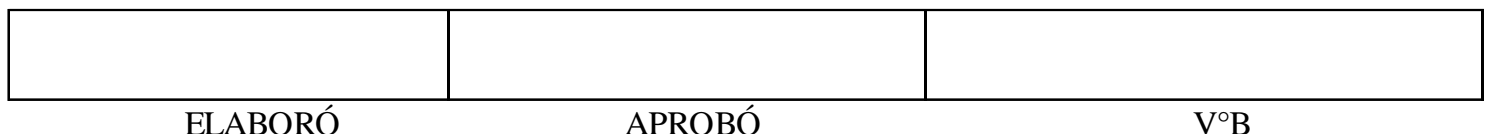


SECTOR-TEXTIL

PROCEDIMIENTO DE COMPRAS

8.3 Formato COMP-PDC-F1 "Registro de pedido de material"

\section{SECTOR-TEXTIL EXPORTADOR (PYME)}

\begin{tabular}{|l|l|}
\hline \multicolumn{2}{|c|}{ REGISTRO D } \\
\hline Código: \\
\hline COMP-PDC-F1 \\
\hline \\
\hline \\
\hline \\
\hline
\end{tabular}

\begin{tabular}{|l|l|}
\hline UNIDAD & \\
PETICIONARIA: & \\
\hline RESPONSABLE: & \\
\hline TELÉFONO/ANEXO: & \\
\hline UNIDAD DE GASTO: & \\
\hline
\end{tabular}

\begin{tabular}{c}
\hline NÚMERO DE PEDIDO \\
(A completar por el área de compra)
\end{tabular}

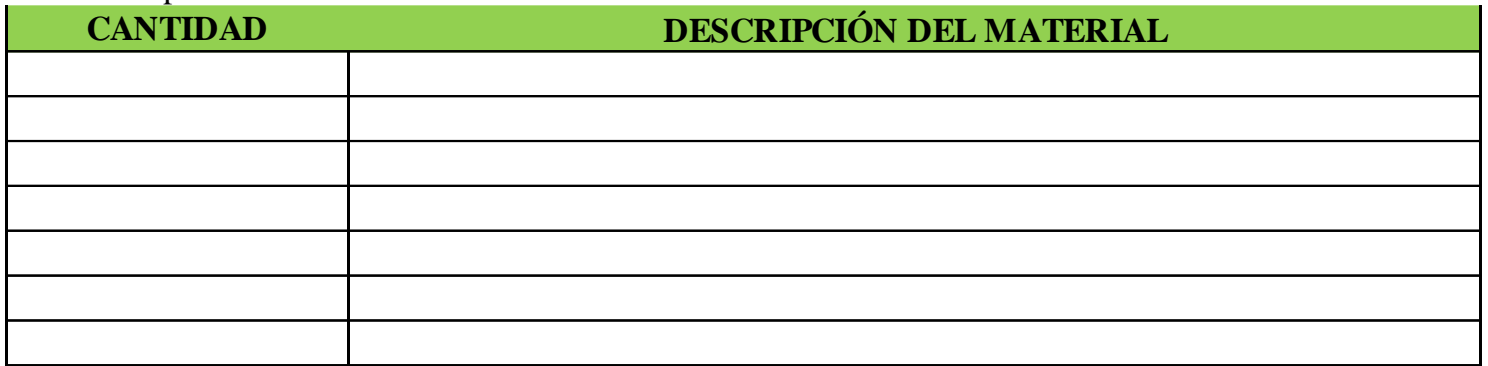

Lima, de

Frimado por:

(persona autorizada de la und. Posicionaria)

CONFORME:

(A completar por la sección de compras) 
SECTOR-TEXTIL EXPORTADOR (PYME)
PROCEDIMIENTO DE COMPRAS

\begin{tabular}{c|c|c|}
\hline Código: & Versión: & Página: \\
\hline COMP-PDC-01 & 01 & 12 de 15 \\
\hline
\end{tabular}

8.4 Formato COMP-PDC-F2 "Reporte de producto no conforme"

\begin{tabular}{|c|c|c|c|}
\hline \multirow{3}{*}{$\begin{array}{c}\text { SECTOR-TEXTIL } \\
\text { EXPORTADOR } \\
\text { (PYME) }\end{array}$} & \multicolumn{3}{|c|}{ REPORTE DE PRODUCTO NO CONFORME } \\
\hline & Código: & Versión: & Página: \\
\hline & COMP-PDC-F2 & 1 & 1 de 1 \\
\hline \multicolumn{4}{|c|}{ INDENTIFICACIÓN } \\
\hline \multicolumn{2}{|c|}{ PRODUCTO NO CONFORME $\mathrm{N}^{\circ}$ : } & \multicolumn{2}{|l|}{ FECHA: } \\
\hline \multicolumn{4}{|c|}{ FECHA DE NO CONFORMIDAD } \\
\hline \multicolumn{2}{|c|}{ CANTIDAD TOTAL DE PEDIDO: } & \multicolumn{2}{|c|}{ CANTIDAD DE PROD. NO CONFORME } \\
\hline \multicolumn{2}{|c|}{ RESPONSABLE DE LA NO CONFORMIDAD: } & & \\
\hline NOMBRE Y CARGO I & IEN REPORTA: & & \\
\hline
\end{tabular}

DESCRIPCIÓN DE LA CONFORMIDAD:

CAUSA DE LA CONFORMIDAD:

\begin{tabular}{|l|ll|}
\hline \multicolumn{2}{|l|}{ ACTIVIDADES A REALIZAR } \\
REPROCESO & & \\
REPEDIDO & & \\
CORRECCIÓN & & \\
ACCIÓN CORRECTIVA/PREVENTA & & \\
OTRA CUAL: & & \\
\hline
\end{tabular}

RESPONSABLE(S) DE EJECUTAR LAS ACTIVIDADES A REALIZAR

RESULTADO DE LAS ACTIVIDADES REALIZADAS

*ESTE ESPACIO ES SOLO PARA EL REPRESENTANTE DE LA DIRECCIÓNO JEFE DEL AREA DE COMPRAS* VERIFICACIÓN FINAL

FECHA:

RESPONSABLE DE LA VERIFICACIÓN FINAL

RESULTADO DE LA VERIFICACIÓN FINAL

\begin{tabular}{|l|l|}
\hline \\
\hline
\end{tabular}

OBSERVACIONES

\begin{tabular}{|l|}
\hline \\
\hline
\end{tabular}

NOMBRE RESPONSABLE DE PROCESO:

NOMBRE REPRESENTANTE DE GERENCIA

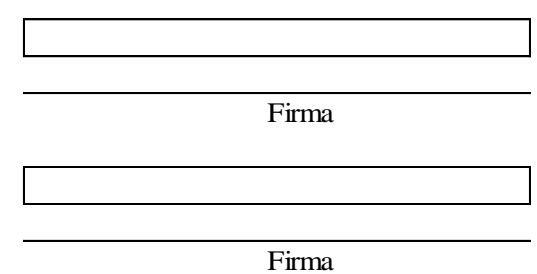


SECTOR-TEXTIL

PROCEDIMIENTO DE COMPRAS

8.5 Formato COMP-PDC-F3 "Nota de entrega de material"

\begin{tabular}{|c|c|c|c|}
\hline $\begin{array}{c}|c| \\
\text { SECTOR-TEXTIL } \\
\text { EXPORTADOR }\end{array}$ & \multicolumn{3}{|c|}{ NOTA DE ENTREGA } \\
\cline { 2 - 3 }$($ PYME) & Código: & Versión: & Página: \\
\hline
\end{tabular}

FECHA:

Hoy, de de se hace entrega a con DNI:

que ocupa el cargo de , de los siguientes materiales.

\begin{tabular}{|l|l|l|l|}
\hline MATERIALES & DESCRIPCIÓN & CANTIDAD & OBSERVACIONES \\
\hline & & & \\
\hline & & & \\
\hline & & & \\
\hline & & & \\
\hline & & & \\
\hline & & & \\
\hline & & & \\
\hline
\end{tabular}

\begin{tabular}{|l|}
\hline ENTREGA: \\
\\
\hline Cargo: \\
\hline
\end{tabular}

\begin{tabular}{|l|}
\hline RECIBE: \\
\\
\hline Cargo: \\
\hline
\end{tabular}


SECTOR-TEXTIL EXPORTADOR (PYME)
PROCEDIMIENTO DE COMPRAS

\begin{tabular}{c|c|c|}
\hline Código: & Versión: & Página: \\
\hline COMP-PDC-01 & 01 & 14 de 15 \\
\hline
\end{tabular}

8.6 Formato COMP-PDC-F4 "Hoja de reclamaciones, sugerencias y felicitaciones"

\begin{tabular}{|c|c|c|c|}
\hline $\begin{array}{c}\text { SECTOR-TEXTIL } \\
\text { EXPORTADOR } \\
\text { (PYME) }\end{array}$ & \multicolumn{3}{|c|}{ HOJA DE RECLAMACIONES, SUGERENCIAS Y FELICITACIONES } \\
\cline { 2 - 4 } & CÓdigo: & Versión: & Página: \\
\hline
\end{tabular}

\begin{tabular}{|l|l|l|}
\hline $\begin{array}{c}\text { Descripción de la reclamación, queja, } \\
\text { sugerencia y/o felicitaciones: }\end{array}$ & Fecha en la que se interpuso: & \\
\hline & \multicolumn{1}{|c|}{ Recibida por (modo) } \\
& - - - Perreo \\
& -Teléfono \\
& -Fax \\
& -Otros \\
\hline
\end{tabular}

\begin{tabular}{|l|}
\hline Análisis de la Reclamación/Queja/Sugerencia \\
\hline Solución: \\
\hline \\
\hline Acciones para aplicar la sugerencia: \\
\hline
\end{tabular}

\begin{tabular}{|l|l|}
\hline Comunicar al reclamante \\
\hline No desea respuesta: & Por e-mail: \\
\hline Por teléfono: & Por fax: \\
\hline Por correo ordinario: & \\
\hline
\end{tabular}

\begin{tabular}{|l|l|}
\hline Fdo. Encargado de compras & Observaciones \\
\hline
\end{tabular}


8.7 Diagrama de flujo del procedimiento

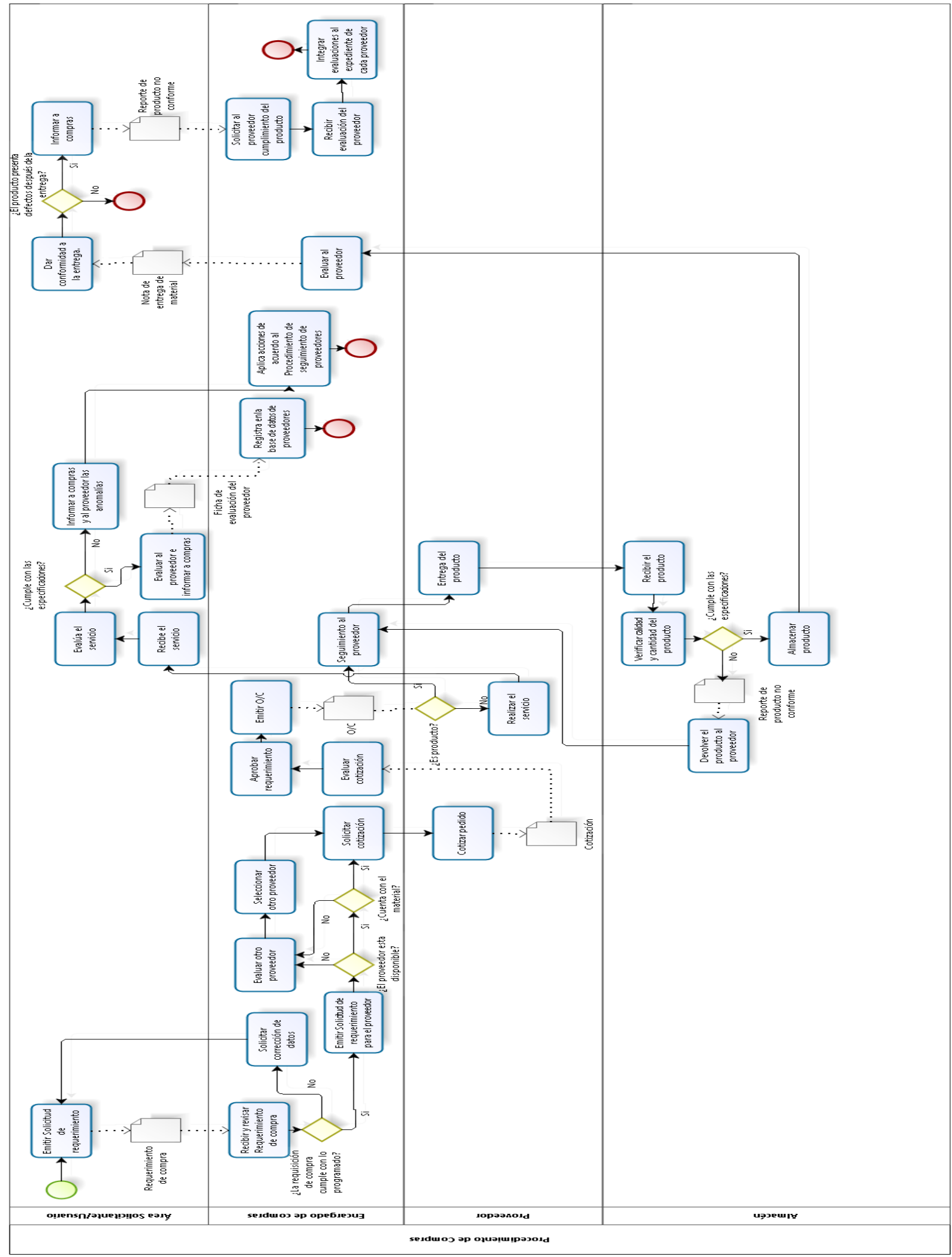




\title{
Anexo 7 : Solicitud de Información del Proveedor
}

\author{
Empresa: \\ Dirección: \\ Tel: \\ E-mail:
}

Lugar y Fecha:

Asunto: Solicitud de Información.

$\mathrm{N}^{\circ}$ :

Señores:

Represento al rubro textil exportador de confecciones de tejido punto, en la actualidad pretendemos ampliar nuestra cartera de proveedores.

Deseamos seleccionar nuevos proveedores, por lo que el análisis que realicemos de los productos, de la relación calidad/precio, primará la calidad sobre el precio. Se valora especialmente la calidad de la tela e hilos.

Asimismo, le agradeceremos nos informen sobre las siguientes condiciones comerciales:

- Precios unitarios.

- Forma de pago.

- Gastos.

- Plazo de pago.

- Descuento comercial

- Plazo de Entrega.

- Devolución de excedentes.

Rogamos que tengan la amabilidad de remitirnos un catálogo detallado de sus productos y, si fuese posible, les agradeceremos que envien un representante comercial para que nos explique de forma directa las características de sus productos y condiciones comerciales.

Dándoles las gracias por anticipado, les saluda atentamente,

Gerente de Compras 


\section{Anexo 8. Cuestionario de Proveedores}

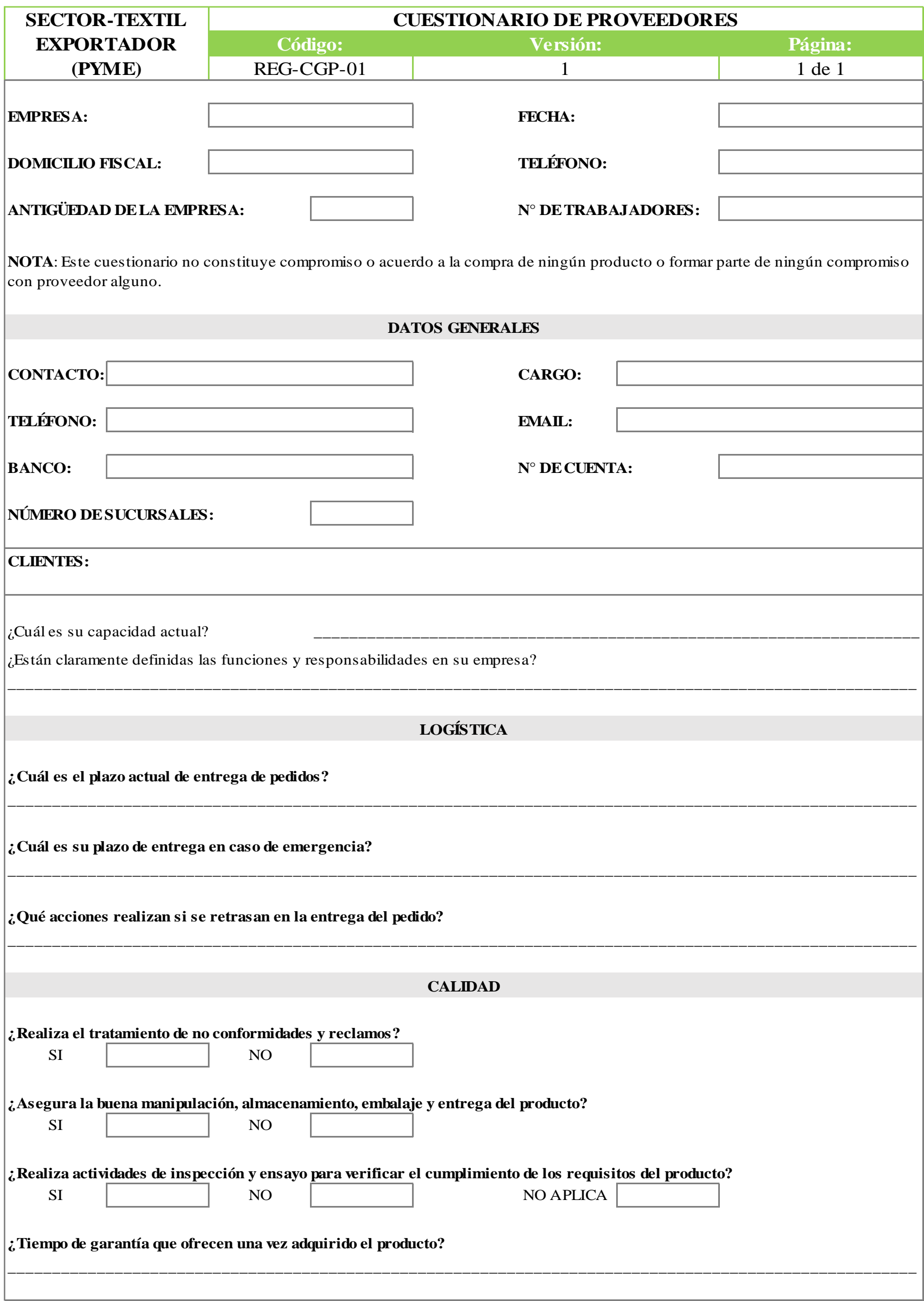


Anexo 9. Lista de Proveedores

\begin{tabular}{|c|c|c|c|c|c|c|c|}
\hline \multirow{3}{*}{\multicolumn{2}{|c|}{$\begin{array}{c}\text { SECTOR-TEXTIL } \\
\text { EXPORTADOR (PYME) }\end{array}$}} & \multicolumn{6}{|c|}{ LISTA DE PROVEEDORES } \\
\hline & & \multirow{2}{*}{\multicolumn{2}{|c|}{$\begin{array}{l}\text { Código: } \\
\text { REG-LP-01 }\end{array}$}} & \multirow{2}{*}{\multicolumn{3}{|c|}{$\begin{array}{c}\text { Versión: } \\
1\end{array}$}} & \multirow{2}{*}{$\begin{array}{l}\text { Página: } \\
1 \text { de } 1 \\
\end{array}$} \\
\hline & & & & & & & \\
\hline PROVEEDOR & DIRECCIÓN & CIUDAD & CONTACTO & TELÉFONO & EMAIL & FORMA DE PAGO & OTRAS CONSIDERACIONES \\
\hline & & & & & & & \\
\hline & & & & & & & \\
\hline & & & & & & & \\
\hline & & & & & & & \\
\hline & & & & & & & \\
\hline & & & & & & & \\
\hline & & & & & & & \\
\hline & & & & & & & \\
\hline & & & & & & & \\
\hline & & & & & & & \\
\hline & & & & & & & \\
\hline
\end{tabular}




\section{Anexo 10. Ejemplo de criterio de evaluación de la matriz AHP}

De acuerdo a la información recopilada de los proveedores, se realiza un cuadro consolidando la información de acuerdo a cada variable establecida que va hacer evaluada para la selección del proveedor.

\begin{tabular}{|l|l|l|l|l|}
\hline & CALIDAD & DIPONIBILIDAD & COSTO & TIEMPO \\
\hline Proveedor 1 & 0.97 & 0.75 & 7.00 & 7.00 \\
\hline Proveedor 2 & 0.87 & 0.70 & 5.00 & 5.00 \\
\hline Proveedor 3 & 0.90 & 0.80 & 6.00 & 6.00 \\
\hline Proveedor 4 & 0.98 & 0.90 & 8.00 & 4.00 \\
\hline
\end{tabular}

Para cada variable se realiza una ponderación dándole prioridad a la fila si es que fue más importante o considerable para la empresa.

\begin{tabular}{|c|c|c|c|c|c|c|c|c|c|}
\hline & \multicolumn{9}{|c|}{ CRITERIO:CALIDAD } \\
\hline & Proveedor 1 & Proveedor 2 & Proveedor 3 & Proveedor 4 & & TRIZ N & IALIZ & & VECTOR PORMEDIO \\
\hline Proveedor 1 & 1 & 7 & 5.00 & 3.00 & 1.48 & 0.88 & 0.94 & 7.50 & 2.70 \\
\hline Proveedor 2 & 0.14 & 1 & 0.33 & 0.20 & 0.21 & 0.13 & 0.06 & 0.50 & 0.22 \\
\hline Proveedor 3 & 0.20 & 3.00 & 1 & 0.20 & 0.30 & 0.38 & 0.19 & 0.50 & 0.34 \\
\hline Proveedor 4 & 0.33 & 5.00 & 5.00 & 1 & 0.49 & 0.63 & 0.94 & 2.50 & 1.14 \\
\hline SUMA & 0.68 & 8.00 & 5.33 & 0.40 & & & & & \\
\hline
\end{tabular}

Del cuadro anterior se puede observar, que el Proveedor 1 obtiene el puntaje de 7 comparado con el Proveedor 2 debido a que, la calidad ofrecida del Proveedor $1=97 \%$ y la del Proveedor $2=87 \%$. Como la variable calidad en este sector es primordial se le da la mayor puntuación al proveedor que ofrezca mayor calidad comparado con otros.

De la misma manera, se realiza los cuadros con las puntuaciones correspondientes para todas las variables establecidas.

\begin{tabular}{|c|c|c|c|c|c|c|c|c|c|}
\hline \multicolumn{10}{|c|}{ CRITERIO: DISPONIBILIDAD } \\
\hline & Proveedor 1 & Proveedor 2 & Proveedor 3 & Proveedor 4 & \multicolumn{3}{|c|}{ MATRIZ NORMALIZADA } & VECTOR PORMEDIO \\
\hline Proveedor 1 & 1.00 & 3.00 & 0.20 & 0.14 & 0.08 & 0.21 & 0.04 & 0.09 & 0.11 \\
\hline Proveedor 2 & 0.33 & 1.00 & 0.33 & 0.14 & 0.03 & 0.07 & 0.07 & 0.09 & 0.06 \\
\hline Proveedor 3 & 5.00 & 3.00 & 1.00 & 0.33 & 0.38 & 0.21 & 0.22 & 0.21 & 0.25 \\
\hline Proveedor 4 & 7.00 & 7.00 & 3.00 & 1.00 & 0.53 & 0.50 & 0.66 & 0.62 & 0.58 \\
\hline SUMA & 13.33 & 14.00 & 4.53 & 1.62 & & & & & \\
\hline
\end{tabular}

Para el cuadro de costo es de manera inversa ya que, el proveedor que ofrezca menor costo será más atractivo para la empresa. Debido a ello, se le asigna mayor puntuación al proveedor que tenga establecido un costo menor comparando con los demás proveedores. En el siguiente cuadro se observa la puntuación que se les da. De la misma manera, es evaluada la variable de tiempo puesto que, es importante el tiempo de abastecimiento que ofrecen los proveedores para que comience el proceso productivo.

\begin{tabular}{|c|c|c|c|c|c|c|c|c|c|}
\hline \multicolumn{10}{|c|}{ CRITRIO: COSTO } \\
\hline & Proveedor 1 & Proveedor 2 & Proveedor 3 & Proveedor 4 & \multicolumn{3}{|c|}{ MATRIZ NORMALIZADA } & VECTOR PORMEDIO \\
\hline Proveedor 1 & 1.00 & 0.33 & 0.33 & 3.00 & 0.14 & 0.18 & 0.05 & 0.32 & 0.17 \\
\hline Proveedor 2 & 3.00 & 1.00 & 3.00 & 5.00 & 0.41 & 0.54 & 0.41 & 0.54 & 0.47 \\
\hline Proveedor 3 & 3.00 & 0.33 & 1.00 & 0.33 & 0.41 & 0.18 & 0.14 & 0.04 & 0.19 \\
\hline Proveedor 4 & 0.33 & 0.20 & 3.00 & 1.00 & 0.05 & 0.11 & 0.41 & 0.11 & 0.17 \\
\hline SUMA & 7.33 & 1.87 & 7.33 & 9.33 & & & & & \\
\hline
\end{tabular}




\begin{tabular}{|c|c|c|c|c|c|c|c|c|c|}
\hline \multicolumn{10}{|c|}{ CRITERI0: TIEMPO } \\
\hline & Proveedor 1 & Proveedor 2 & Proveedor 3 & Proveedor 4 & \multicolumn{3}{|c|}{ MATRIZ NORMALIZADA } & VECTOR PORMEDIO \\
\hline Proveedor 1 & 1.00 & 0.20 & 0.33 & 0.14 & 0.06 & 0.03 & 0.05 & 0.09 & 0.06 \\
\hline Proveedor 2 & 5.00 & 1.00 & 3.00 & 0.20 & 0.31 & 0.15 & 0.41 & 0.12 & 0.25 \\
\hline Proveedor 3 & 3.00 & 0.33 & 1.00 & 0.33 & 0.19 & 0.05 & 0.14 & 0.20 & 0.14 \\
\hline Proveedor 4 & 7.00 & 5.00 & 3.00 & 1.00 & 0.44 & 0.77 & 0.41 & 0.60 & 0.55 \\
\hline SUMA & 16.00 & 6.53 & 7.33 & 1.68 & \multicolumn{3}{|c|}{} \\
\hline
\end{tabular}

Luego de realizar los puntajes de cada variable se procede a elaborar un cuadro bajo el mismo criterio pero en este caso es variable contra variable.

\begin{tabular}{|c|c|c|c|c|c|c|c|c|c|}
\hline \multicolumn{9}{|c|}{ MATRIZ COMPARACIÓN POR PARES } \\
\hline & CALIDAD & DIPONIBILIDAD & COTO & TIEMPO & \multicolumn{3}{|c|}{ MATRIZ NORMALIZADA } & VECTOR PORMEDIO \\
\hline CALIDAD & 1.00 & 0.20 & 0.33 & 3.00 & 0.11 & 0.12 & 0.05 & 0.30 & 0.14 \\
\hline DIPONIBILIDAD & 5.00 & 1.00 & 5.00 & 3.00 & 0.54 & 0.58 & 0.75 & 0.30 & 0.54 \\
\hline COTO & 3.00 & 0.20 & 1.00 & 3.00 & 0.32 & 0.12 & 0.15 & 0.30 & 0.22 \\
\hline TIEMPO & 0.33 & 0.33 & 0.33 & 1.00 & 0.04 & 0.19 & 0.05 & 0.10 & 0.09 \\
\hline SUMA & 9.33 & 1.73 & 6.67 & 10.00 & & & & & \\
\hline
\end{tabular}

Por último se realiza el resumen, los vectores promedio calculados se colocan en fila según la variable mencionada en el cuadro. Por ejemplo, primer cuadro realizado en la parte superior (CALIDAD) los valores del vector promedio fueron: 2.70, 0.22, 0.34, 1.14, 0.14 .

Así mismo, se coloca el vector promedio obtenido de la matriz de comparación por pares en la parte inferior de cuadro de manera horizontal.

\begin{tabular}{|l||l|l|l|l|l|}
\hline & CALIDAD & DIPONIBILIDAD & COSTO & TIEMPO & TOTAL \\
\hline Proveedor 1 & 2.70 & 0.11 & 0.17 & 0.06 & 0.49 \\
\hline Proveedor 2 & 0.22 & 0.06 & 0.47 & 0.25 & 0.20 \\
\hline Proveedor 3 & 0.34 & 0.25 & 0.19 & 0.14 & 0.24 \\
\hline Proveedor 4 & 1.14 & 0.58 & 0.17 & 0.55 & 0.56 \\
\hline \hline Ponderación & 0.14 & 0.54 & 0.22 & 0.09 & \\
\hline
\end{tabular}

Se puede concluir que según la evaluación AHP el proveedor más atractivo es del proveedor 4 ya que, es el que obtuvo mayor puntaje. 


\section{Anexo 11. Ficha de Datos de Proveedores}

\section{SECTOR-TEXTIL EXPORTADOR (PYME)}

FICHA DE DATOS DE PROVEEDORES

Código:

1

Página:

1 de 1

\section{DATOS GENERALES (Campos lenados por el Proveedor)}

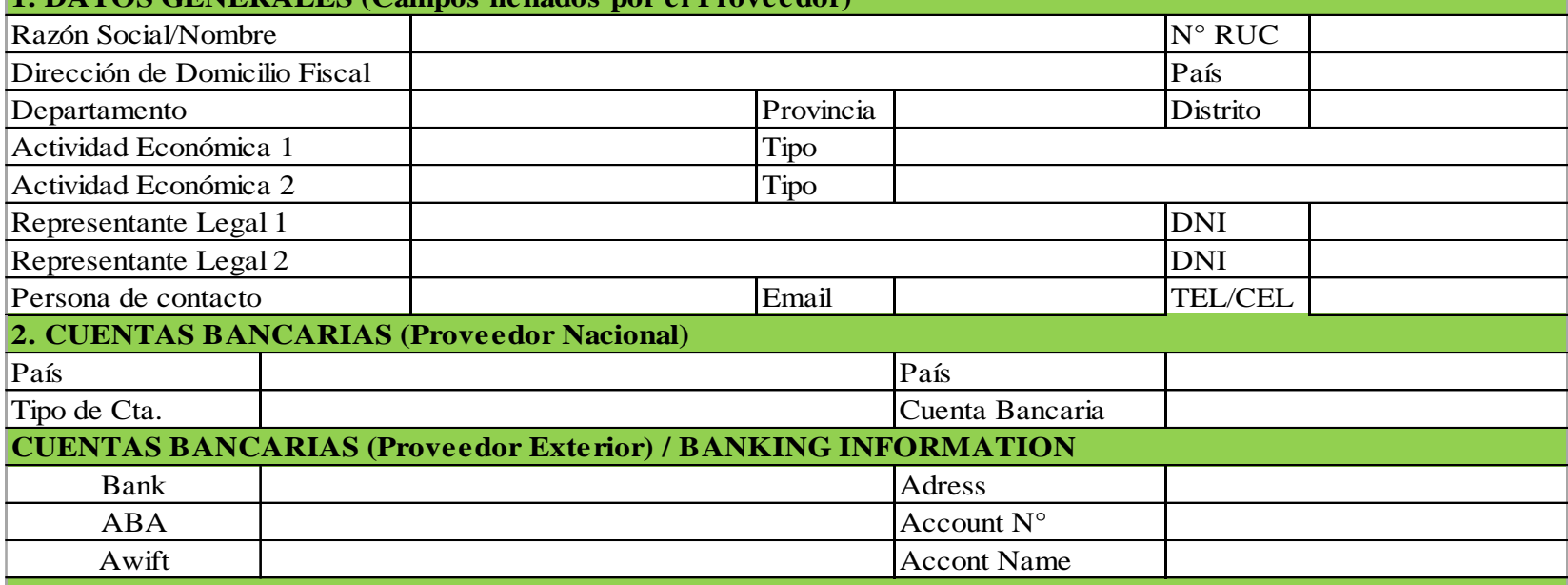

3. OTRAS INSTALACIONES (Oficinas, centro de producción, centro de venta y/o almacén)

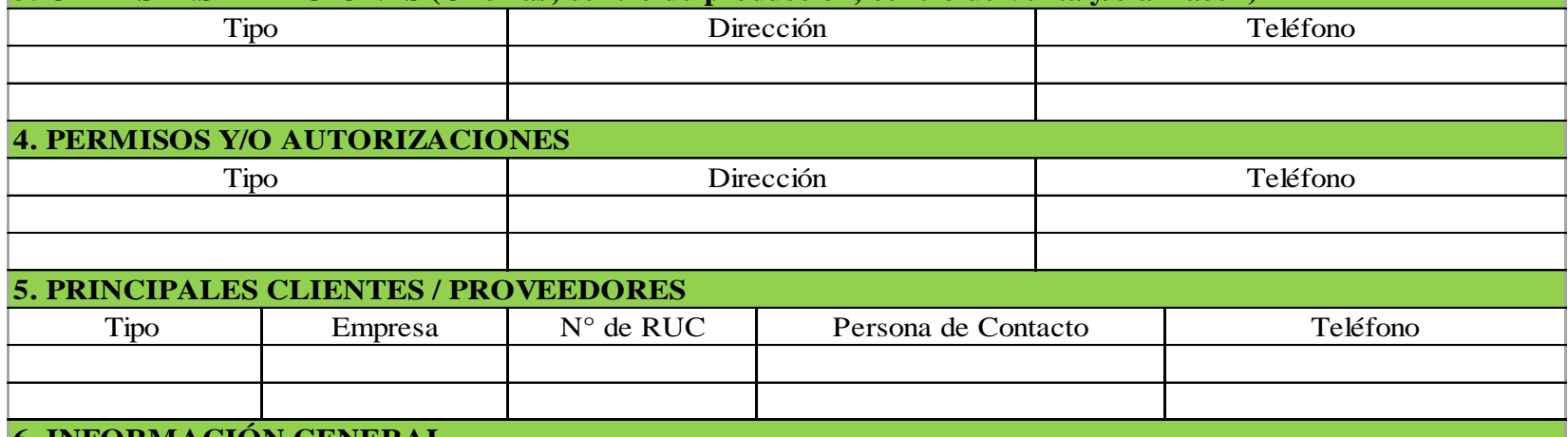

\section{INFORMACIÓN GENERAL}

¿Cuál es el horario de atención?

¿Esta dispuesto a ser auditado por la empresa?

¿Qué sistema informático para el control de inventarios utiliza?

¿Cuenta con política de calidad y/o medio ambiente?

En caso que sí, especifique

¿Cuenta su empresa con certificación ISO 9001, ISO 14001, HACCP u otror?

En caso que sí, especifique

\section{DATOS DE COMPRAS (Campos llenados por Compras)}

Grupo de Compras

Condición de Pago

Observaciones

\section{DATOS MAESTROS}

Observaciones

Creado por Fecha

(*)La información consignada tiene carácter de Declaración Jurada por lo que en caso se detecte falseddad de la misma u omisión de información se aplicaran las consecuencias y acciones legales correspondiente.

(**) Adjunta Ficha Ruc, DNI, Representante Legal, Escritura Pública de contitución, Licencia de Funcionamiento y otas autorizaciones según corresponda.

(***)El presente documento no debe presentar borrones, enmendaduras, datos inconsistentes y/o firmas ilegibles. 


\section{Anexo 12. Ficha de Evaluación de Proveedores}

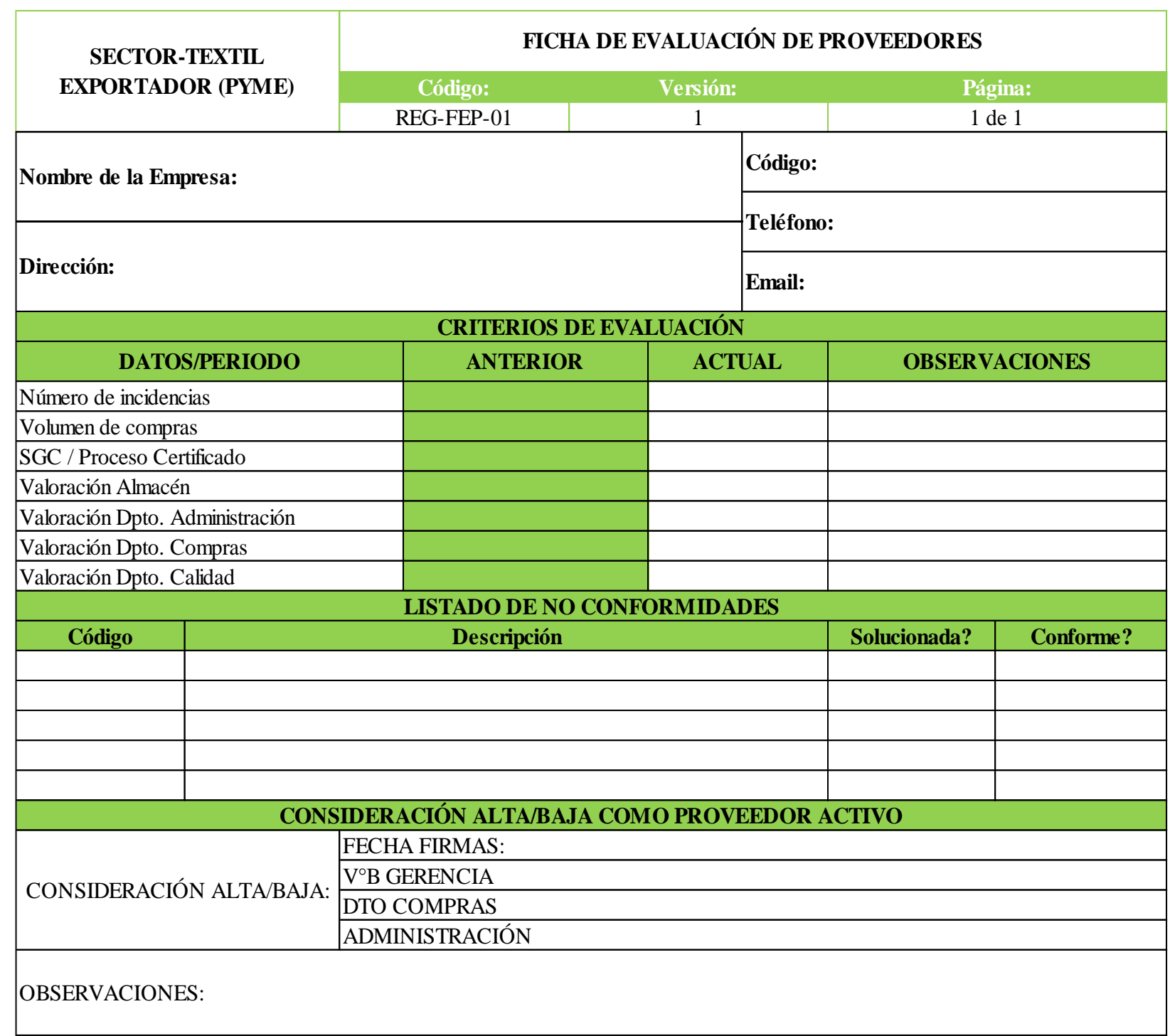


Anexo 13. Procedimiento de Seguimiento de Proveedores, Materiales y Servicios

SECTOR-TEXTIL EXPORTADOR (PYME)
PROCEDIMIENTO DE SEGUIMIENTO DE PROVEEDORES, MATERIALES Y SERVICIOS

\section{Página:}

1 de 8

\section{PROCEDIMIENTO DE SEGUIMIENTO DE} PROVEEDORES, MATERIALES Y SERVICIOS 


\begin{tabular}{|c|c|c|}
\hline Código: & Versión: & Página: \\
\hline COMP-SDP-01 & 01 & 2 de 8 \\
\hline
\end{tabular}

\section{OBJETIVO:}

En este documento se describe el modo en que el sector debe realizar el seguimiento de aquellos proveedores cuyo impacto incide de manera significativa sobre el producto final, es decir, proveedores de material y proveedores de servicios subcontratados como transporte hasta el cliente.

\section{RESPONSABILIDAD Y ALCANCE:}

Es responsabilidad del encargado de compras la elaboración, revisión e implantación de este documento.

\section{DOCUMENTOS A CONSULTAR:}

- Métodos de selección, evaluación y homologación de proveedores.

- Matriz de criticidad de proveedores.

- Proceso de homologación.

\section{DEFINICIONES:}

PN: Proveedor Nuevo; aquel proveedor al que no se ha realizado ningún pedido anteriormente.

PA: Proveedor Activo; Proveedor al que Compras puede realizar pedidos.

PI: Proveedor Inactivo; Proveedor al que no se permite realizar pedidos. $\mathrm{Su}$ estado en la base de datos es Inactivo, imposibilitando la compra a los mismos.

LPE: Listado de Proveedores Evaluados; Listado donde se reflejan los resultados de la evaluación de los proveedores, indicando su estado de Activo o Inactivo para el siguiente periodo de evaluación.

FDP: Ficha de Datos de Proveedores: Ficha donde se resume y recoge la información necesaria del proveedor.

PE: Periodo de Evaluación; Periodo de tiempo entre una evaluación y la siguiente. 
PROCEDIMIENTO DE SEGUIMIENTO DE PROVEEDORES, MATERIALES Y SERVICIOS

\begin{tabular}{|c|c|c|}
\hline Código: & Versión: & Página: \\
\hline COMP-SDP-01 & 01 & 3 de 8 \\
\hline
\end{tabular}

\section{CONDICIONES BÁSICAS:}

5.1 Todos los proveedores deben de estar homologados y realizar una evaluación cada 6 meses para asegurar la continuidad del mismo.

5.2 Un proveedor puede perder su estado activo por razones de: Precios elevados, desaparición de la empresa, incumplimiento de plazos de entrega de maneta repetitiva, incumplimiento de requisitos del pedido, acumulación y/o importancia de incidencias y aparición de proveedores alternativos más interesantes.

\section{DESARROLLO DEL PROCEDIMIENTO:}

\section{ACTIVIDADES \\ SECUENCIA DE ETAPAS \\ RESPONSABLE}

\section{COORDINAR LA EVALUACIÓN}

6.1 Se establece Criterios de evaluación, selección y Encargado de reevaluación de proveedores

Compras

6.2 Realizar coordinaciones con los proveedores para su evaluación.

\section{REUNIÓN DE PROVEEDORES}

6.3 Determinar lo puntos y criterios que se toman en cuenta para la evaluación en la que son sometidos.

Encargado

de

6.4 Realizar y mencionar según el formato PRO-LPE-01 el

status de cada proveedor. (PN, PA Y PI)

\section{SEGUIMIENTO DE PROVEEDORES}

6.5 Monitorear al proveedor en cada $\mathrm{O} / \mathrm{C}$ emitida y registrar en el formato PRO-FDP-01

\section{DESCALIFICACIÓN DEL PROVEEDOR}

Compras

6.6 Registrar en el formato de PRO-LPE-01.

Encargado

de

Compras

Encargado

de

6.7 Tomar en cuenta los Criterios de evaluación, selección y Compras reevaluación de proveedores (Ver anexo 8.1)

\section{REGISTRO:}

7.1 Formato de Ficha de datos de proveedores (Ver Anexo FORMATO PRO-FDP-01)

7.2 Formato de Listado de proveedores evaluados (Ver AnexoFORMATO PRO-LPE-01) 
PROCEDIMIENTO DE SEGUIMIENTO DE PROVEEDORES, MATERIALES Y SERVICIOS

\begin{tabular}{c|c|c|}
\hline Código: & Versión: & Página: \\
\hline COMP-SDP-01 & 01 & 4 de 8 \\
\hline
\end{tabular}

\section{ANEXOS:}

8.1 Criterios de evaluación, selección y reevaluación de proveedores.

8.2 Formato REG-FDP-01 "Ficha de Datos de Proveedores"

8.3 Formato REG-FEP-01 "Ficha de Evaluación de Proveedores"

8.4 Formato PRO-LPE-01 "Listado de Proveedores Evaluados"

8.5 Diagrama de flujo del procedimiento.

8.1 Criterios de evaluación, selección y reevaluación de proveedores.

- CRITERIOS DE EVALUACIÓN DE PROVEEDORES

- PROVEEDORES ALTERNATIVOS

- TARIFA DE PRECIOS

- CERTIFICACIONES (MATERIAL, PROCESO, SISTEMA GESTIÓN)

- COMPROMISO CON NUESTROS REQUISITOS

- CRITERIOS DE SELECCIÓN DE PROVEEDORES

- IMPORTE DEL MATERIAL

- PLAZO DE ENTREGA

- CERTIFICADOS DE CALIDAD Y OTROS DOCUMENTOS

- CRITERIOS DE REEVALUACIÓN DE PROVEEDORES

○ REGISTRO DEINCIDENCIAS

- PROVEEDORES ALTERNATIVOS

- TARIFA DE PRECIOS

- CERTIFICACIONES (MATERIAL, PROCESO, SISTEMA GESTIÓN)

- COMPROMISO CON NUESTROS REQUISITOS 
SECTOR-TEXTIL EXPORTADOR (PYME)
PROCEDIMIENTO DE SEGUIMIENTO DE PROVEEDORES, MATERIALES Y SERVICIOS

Código:

COMP-SDP-01
Versión:

Página:

01

5 de 8

8.2 Formato REG-FDP-01 "Ficha de Datos de Proveedores"

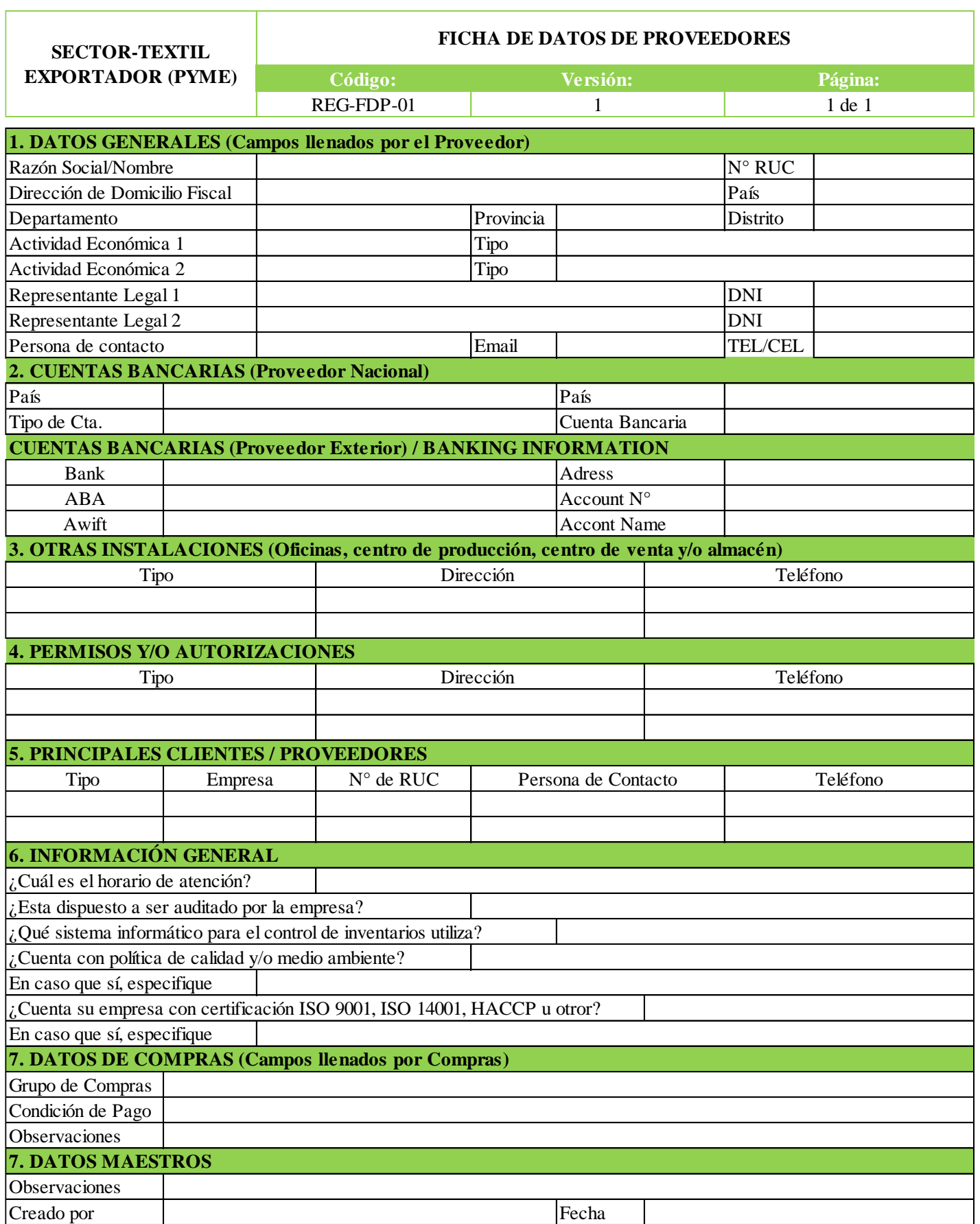

(*)La información consignada tiene carácter de Declaración Jurada por lo que en caso se detecte falseddad de la misma u omisión de información se aplicaran las consecuencias y acciones legales correspondiente.

(**) Adjunta Ficha Ruc, DNI, Representante Legal, Escritura Pública de contitución, Licencia de Funcionamiento y otas autorizaciones según corresponda.

(***)El presente documento no debe presentar borrones, enmendaduras, datos inconsistentes y/o firmas ilegibles.

Proveedor 
SECTOR-TEXTIL EXPORTADOR (PYME)
PROCEDIMIENTO DE SEGUIMIENTO DE PROVEEDORES, MATERIALES Y SERVICIOS

\begin{tabular}{c|c|c}
\hline Código: & Versión: & Página: \\
\hline COMP-SDP-01 & 01 & 6 de 8
\end{tabular}

8.3 Formato REG-FEP-01 "Ficha de Evaluación de Proveedores"

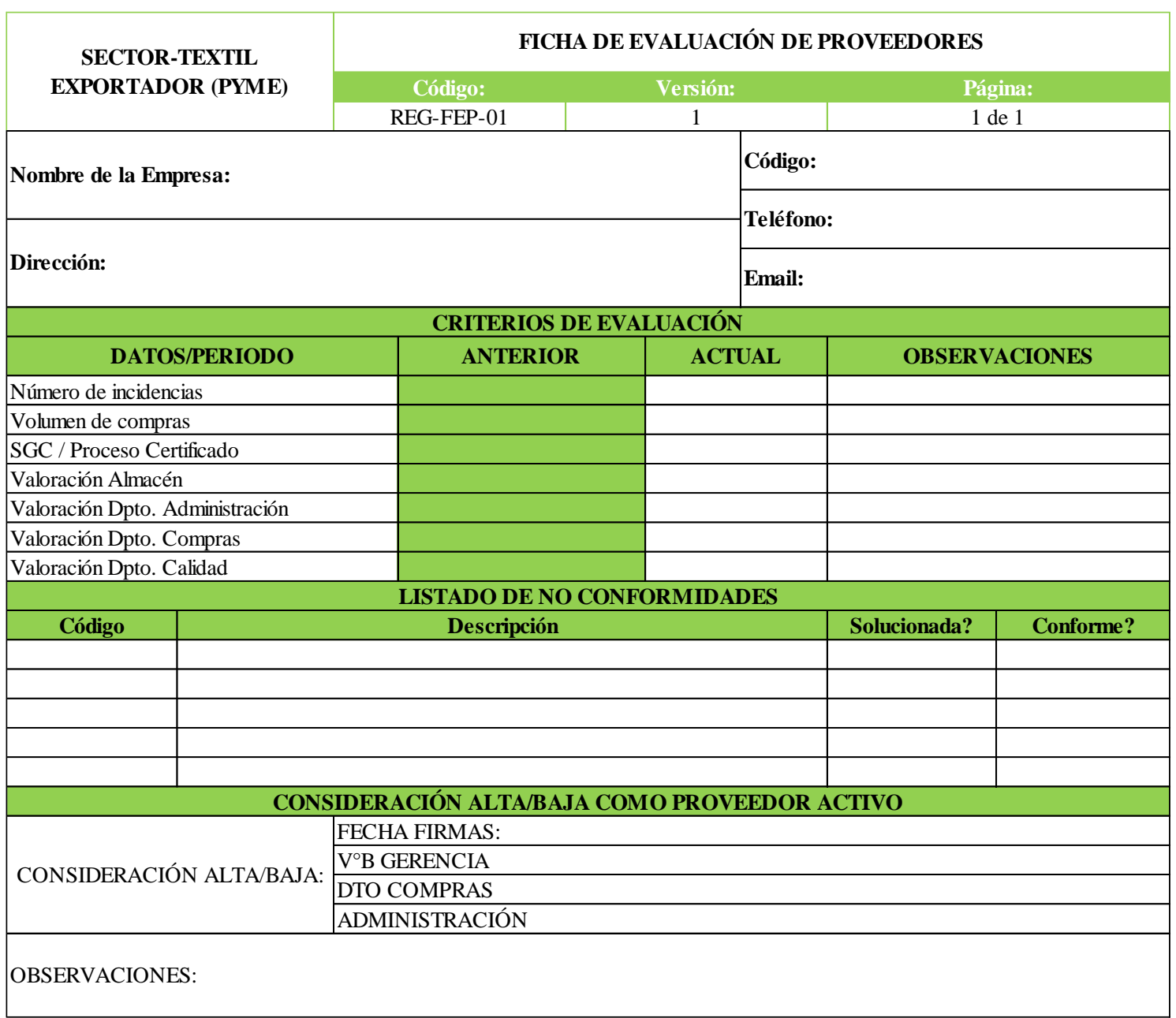


SECTOR-TEXTIL EXPORTADOR (PYME)
PROCEDIMIENTO DE SEGUIMIENTO DE PROVEEDORES, MATERIALES Y SERVICIOS

\begin{tabular}{c|c|c}
\hline Código: & Versión: & Página: \\
\hline COMP-SDP-01 & 01 & 7 de 8 \\
\hline
\end{tabular}

8.4 Formato PRO-LPE-01 "Listado de Proveedores Evaluados"

SECTOR-TEXTIL EXPORTADOR (PYME)
LISTADO DE PROVEEDORES EVALUADOS

\begin{tabular}{|c|c|c|}
\hline Código: & Vensión: & Página: \\
\hline PRO-LPE-01 & 1 & 1 de 1 \\
\hline
\end{tabular}

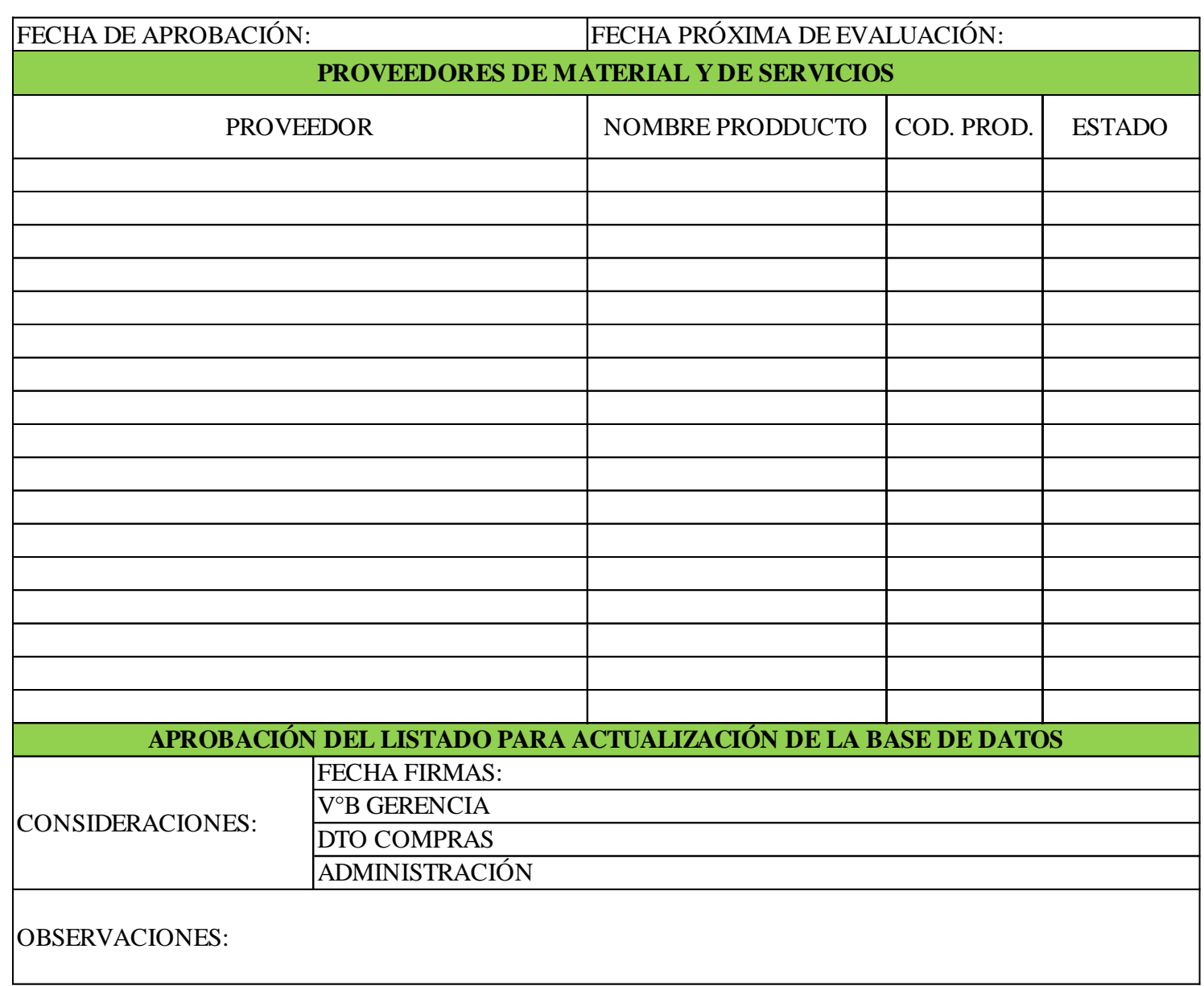




\begin{tabular}{|c|c|c|c|}
\hline \multirow{3}{*}{$\begin{array}{l}\text { SECTOR-TEXTIL } \\
\text { EXPORTADOR } \\
\text { (PYME) }\end{array}$} & \multicolumn{3}{|c|}{$\begin{array}{l}\text { PROCEDIMIENTO DE SEGUIMIENTO DE PROVEEDORES, } \\
\text { MATERIALES Y SERVICIOS }\end{array}$} \\
\hline & Código: & Versión: & Página: \\
\hline & COMP-SDP-01 & 01 & 8 de 8 \\
\hline
\end{tabular}

8.4 Diagrama de flujo del procedimiento.

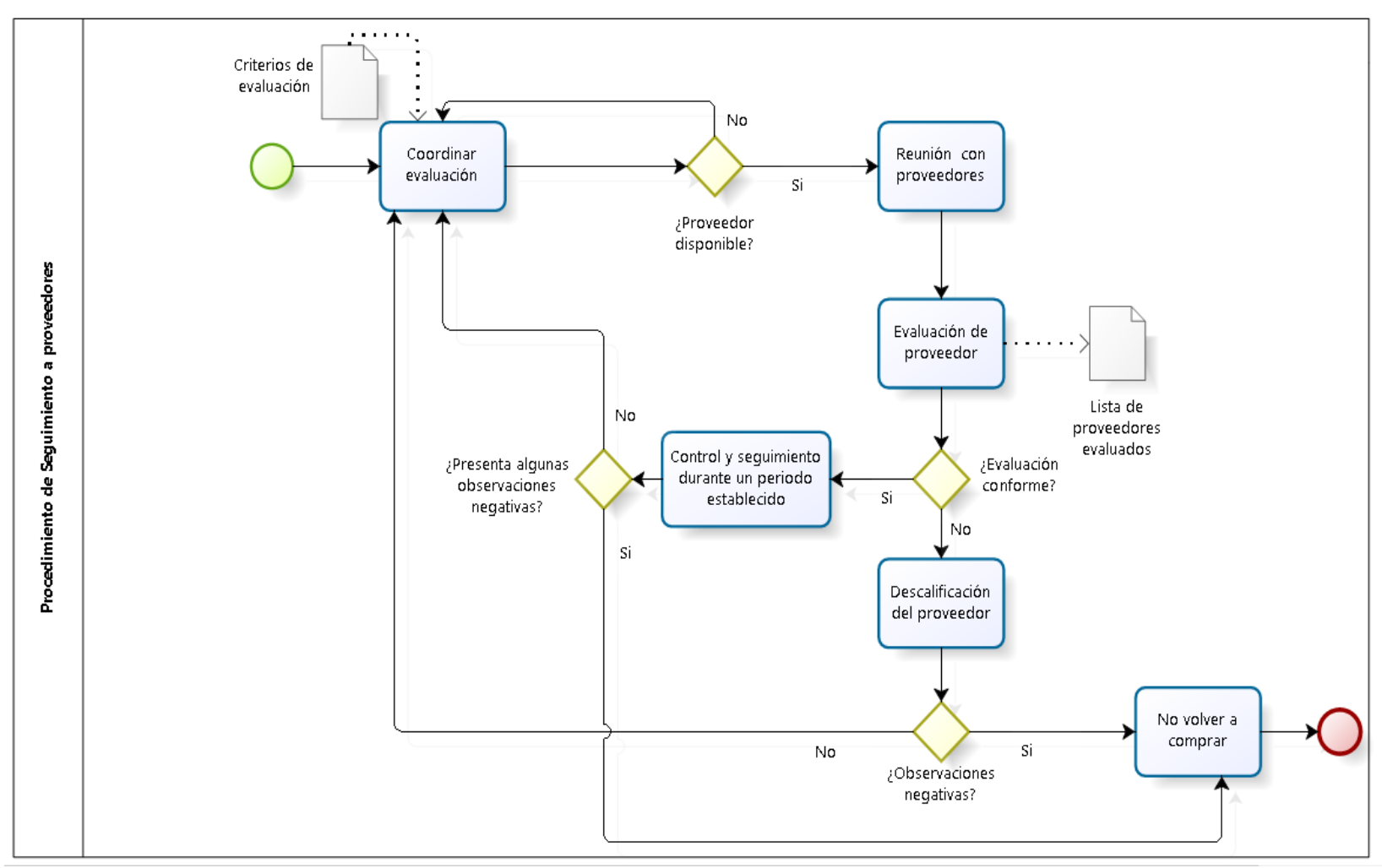




\section{Anexo 14. Política de Compras}

SECTOR-TEXTIL EXPORTADOR (PYME)

\section{POLÍTICA DE COMPRAS}

Código: Versión: Página:

-Evaluación de ofertas y elección de la mejor opción.

-Visitas a proveedores y evaluación de su adecuación. Medición de desempeño con estándares predeterminados o con sistemas de evaluación.

-La actuación con los proveedores debe orientarse a largo plazo, asegurar que se cumplan los compromisos adquiridos por las partes contratantes y permitir la trazabilidad del proceso de compra.

-Para la selección de proveedores, se aplicarán los criterios de concurrencia, objetividad, profesionalidad, transparencia e igualdad de oportunidades. De igual modo, se aplicarán criterios de selección y se priorizará a los proveedores que obtengan un mayor puntaje. -Independencia a los empleadores de la empresa, que adecuarán su actuación a los estándares profesionales establecidos en los procedimientos internos para la contratación y homologación de proveedores elaborados por la entidad, de conformidad con los objetivos de esta política. La compra de bienes o la contratación de servicios deben hacerse con total independencia de decisión, y al margen de cualquier vinculación personal, familiar o económica, que pueda poner en duda los criterios seguidos en la toma de decisiones.

-Objetividad en las decisiones, basadas la valoración de los criterios de selección establecidos. La contratación se realizará garantizando la aplicación de criterios objetivos, ponderados e internamente auditables.

-Mantenimiento de una relación de confianza y un diálogo permanente con los proveedores, mediante la figura del gestor del proveedor, accesible y responsable de llevar las relaciones comerciales a un estado de colaboración mutua.

-Los procesos de compras deben asegurar la calidad del servicio, en las mejores condiciones (técnicas, precio, etc.) y con el mínimo de impacto ambiental, y preservando la seguridad y la salud de los trabajadores.

-Toda compra será tramitada únicamente si realizó la solicitud de requerimiento. Finalmente, no se admitirá la inclusión de cláusulas abusivas o que sean contrarias a la buena fe. 
-Esta Política de Compras es de cumplimiento obligatorio para todos los centros de actividad y empleados de las empresas o sociedades del grupo que intervengan, en cualquier momento, en cualquiera de los procesos de evaluación, homologación, negociación o contratación de bienes, productos y servicios.

Responsable de Compras 
Anexo 15. Procedimiento de Seguimiento de Compras

SECTOR-TEXTIL EXPORTADOR (PYME)
PROCEDIMIENTO DE SEGUIMIENTO DE COMPRAS

1 de 5

\section{PROCEDIMIENTO DE SEGUIMIENTO DE COMPRAS}




\section{OBJETIVO:}

En este documento se describe el modo en que el sector debe realizar el seguimiento de compras cuyo impacto incide de manera significativa sobre el producto final. Se sigue al material pedido a los proveedores.

\section{RESPONSABILIDAD Y ALCANCE:}

Es responsabilidad del encargado de compras la elaboración, revisión e implantación de este documento.

3. DOCUMENTOS A CONSULTAR:

- Procedimiento de compra (COMP-PDC-01).

- Política de compras (COMP-PC-01)

- Procedimiento de Seguimiento de proveedores, materiales y servicios (COMP-SDP-01)

\section{DEFINICIONES:}

DF: Diagrama de Flujo; Representación gráfica de la sucesión de las distintas actividades de un proceso, donde se muestran las unidades/servicios que intervienen en cada operación descrita.

Compra: Se puede entender por compra el acto de por el que se obtiene un material a cambio de un precio.

Material: Elementos agrupados en un conjunto, el cual es, o puede ser, usado con algún fin específico.

O/C: orden de compra emitida por la empresa requiriendo algún material.

\section{CONDICIONES BÁSICAS:}

1.1 Se realiza el seguimiento a cada $\mathrm{O} / \mathrm{C}$, desde el momento que se emite el requerimiento de compra está en base a la necesidad de compra de algún material por parte del área que lo requiera en la empresa.

1.2 El seguimiento de compra se realiza por cada solicitud de requerimiento emitida.

1.3 Tanto el área de compras, producción y la gerencia deben de conocer el status de las $\mathrm{O} / \mathrm{C}$ para la prevención de acontecimientos.

1.4 Al iniciar cada solicitud de requerimiento registrarlo en COMP-SC-F1, de la misma forma para cada actividad evidenciando las fechas programadas y las cantidades, de esa forma se genera información útil para la elaboración del PRM. 
PROCEDIMIENTO DE SEGUIMIENTO DE COMPRAS

\begin{tabular}{|c|c|c|}
\hline Código: & Versión: & Página: \\
\hline COMP-SC-01 & 01 & 3 de 5 \\
\hline
\end{tabular}

6. DESARROLLO DEL PROCEDIMIENTO:

\section{ACTIVIDADES
SECUENCIA DE ETAPAS RESPONSABLE SOLICITUD DE REQUERIMIENTO DE COMPRA}

6.1 Registrar la solicitud de pedidos en el Estado de pedido (COMP-SC-F1).

Encargado de

6.2 Verificar las especificaciones de compra de acuerdo al PCP/Encargado de pedido del cliente interno y existencias en almacén. Asimismo, utilizar el formato de Control de Existencia de materiales (COMP-SC-F3) para asegurar las cantidades exactas del pedido.

\section{DETERMINAR RECECPCIÓN DE LOS PEDIDOS}

6.3 Determinar los plazos máximos de recepción de los pedidos. Registrar los plazos en el Estado de pedido (COMP-

Encargado

de SC-F1).

\section{APROBACIÓN DE O/C}

6.4Verificar la aprobación de la $\mathrm{O} / \mathrm{C}$.

Encargado

de

6.5 ¿La O/C es correcta?

Compras

- Sí, continúa con el punto 6.6

- No, regresa al punto 6.4

6.6 Comunicar al proveedor y al cliente del proceso el estado del pedido.

\section{ABASTECIMIENTO DEL PROVEEDOR}

6.7 Verificar in Situ el proceso del proveedor para garantizar la calidad.

Encargado

de

Compras

6.8 ¿El producto presenta defectos?

- Sí, regresa al punto 6.6

- $\quad$ No, continúa con el punto 6.9

6.9 Realizar seguimiento al material.

6.10 ¿El proveedor termina de atender el pedido?

$\mathrm{Si}$, continua al punto 6.11

No, regresa al punto 6.9

6.11 Recepción del pedido y emisión de una Nota de entrega de material (COMP-PDC-F3), este documento se archiva como prueba de entrega del pedido al cliente interno. 
SECTOR-TEXTIL EXPORTADOR (PYME)

PROCEDIMIENTO DE SEGUIMIENTO DE COMPRAS

Código:

COMP-SC-01
Versión:

01
Página:

4 de 5

\section{REGISTRO:}

7.1 Estado del pedido (COMP-SC-F1)

8. ANEXOS:

8.1 Formato COMP-SC-F1 "Estado del pedido"

8.2 Formato COMP-SC-F3 "Control de existencia de materiales"

8.3 Diagrama de flujo del procedimiento.

8.1 Formato COM-SC-F1 "Estado del pedido"

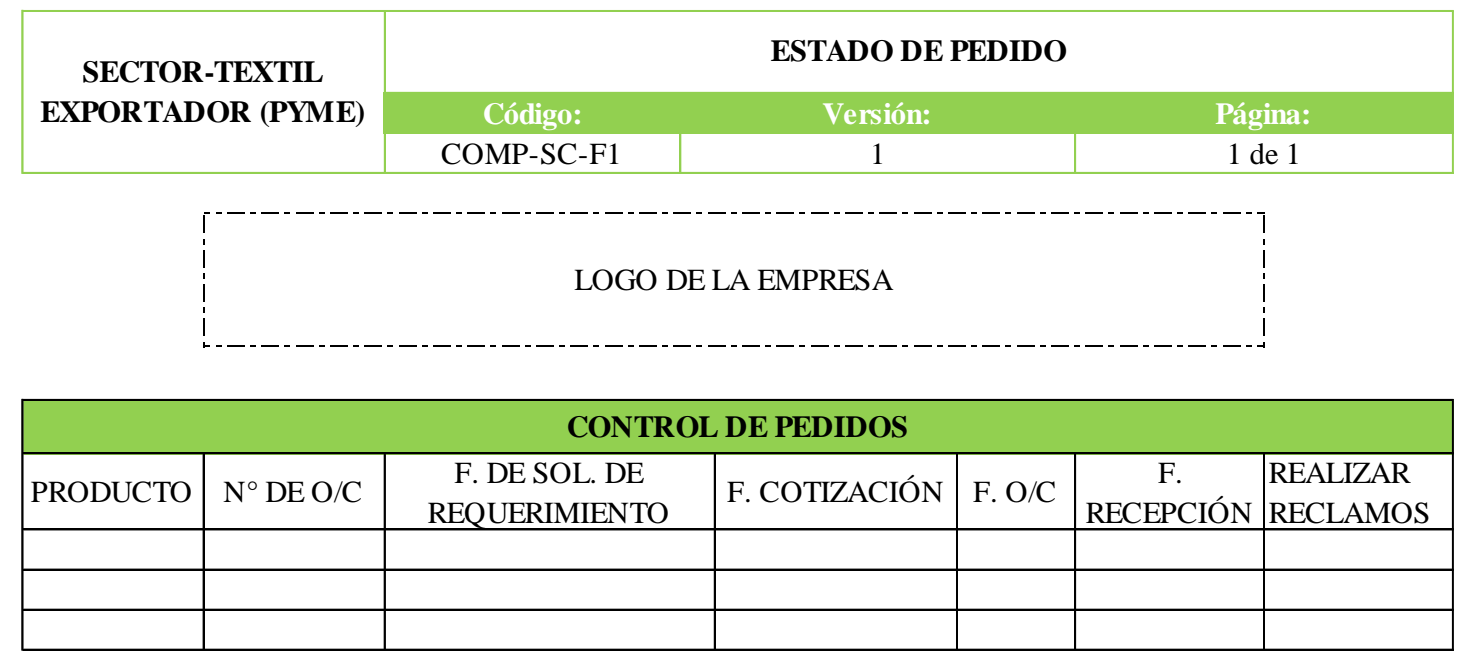

\begin{tabular}{|c|c|c|c|c|c|}
\hline \multicolumn{7}{|c|}{ REGISTRO DE INCIDENCIAS } \\
\hline FECHA & ARTÍCULO & DESCRIPCIÓN & CANTIDAD & MOTIVO & CONDICIÓN \\
\hline & & & & & \\
\hline & & & & & \\
\hline & & & & & \\
\hline
\end{tabular}

\begin{tabular}{|c|c|c|c|c|}
\hline \multicolumn{5}{|c|}{ ALMACÉN } \\
\hline \multirow{2}{*}{ PRODUCTO } & CANTIDAD & $\begin{array}{c}\text { CANTIDAD DE } \\
\text { EXISTENCIAS }\end{array}$ & $\begin{array}{c}\text { CANTIDAD } \\
\text { REQUERIDA }\end{array}$ & $\begin{array}{c}\text { CANTIDAD } \\
\text { A PEDIR }\end{array}$ \\
\hline & & & & \\
\hline & & & & \\
\hline & & & & \\
\hline
\end{tabular}

ELABORADO POR:

FECHA DE ELABORACIÓN

OBSERVACIONES: 
SECTOR-TEXTIL EXPORTADOR

(PYME)
PROCEDIMIENTO DE SEGUIMIENTO DE COMPRAS

\begin{tabular}{c|c|c}
\hline Código: & Versión: & Página: \\
\hline COMP-SC-01 & 01 & 5 de 5 \\
\hline
\end{tabular}

8.2 Formato COMP-SC-F3 "Control de materiales"

SECTOR-TEXTIL EXPORTADOR (PYME)

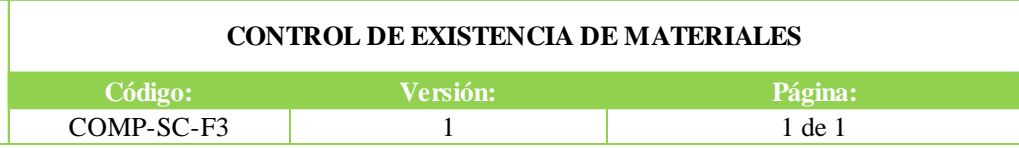

$\mathrm{N}^{\circ}$
ELABORADO POR: FECHA:
HORA:

\begin{tabular}{|l|l|l|l|l|l|c|}
\hline PRODUCTO & DESCRIPCIÓN & UBICACIÓN & UND & $\begin{array}{c}\text { CANT. } \\
\text { INGRESADA }\end{array}$ & $\begin{array}{c}\text { CANT. } \\
\text { UTILIZADA }\end{array}$ & $\begin{array}{c}\text { CANT. } \\
\text { EXISTENTE DE } \\
\text { MAT. }\end{array}$ \\
\hline & & & & & & \\
\hline & & & & & & \\
\hline & & & & & & \\
\hline & & & & & & \\
\hline & & & & & & \\
\hline
\end{tabular}

FIRMA

8.3 Diagrama de flujo del procedimiento.

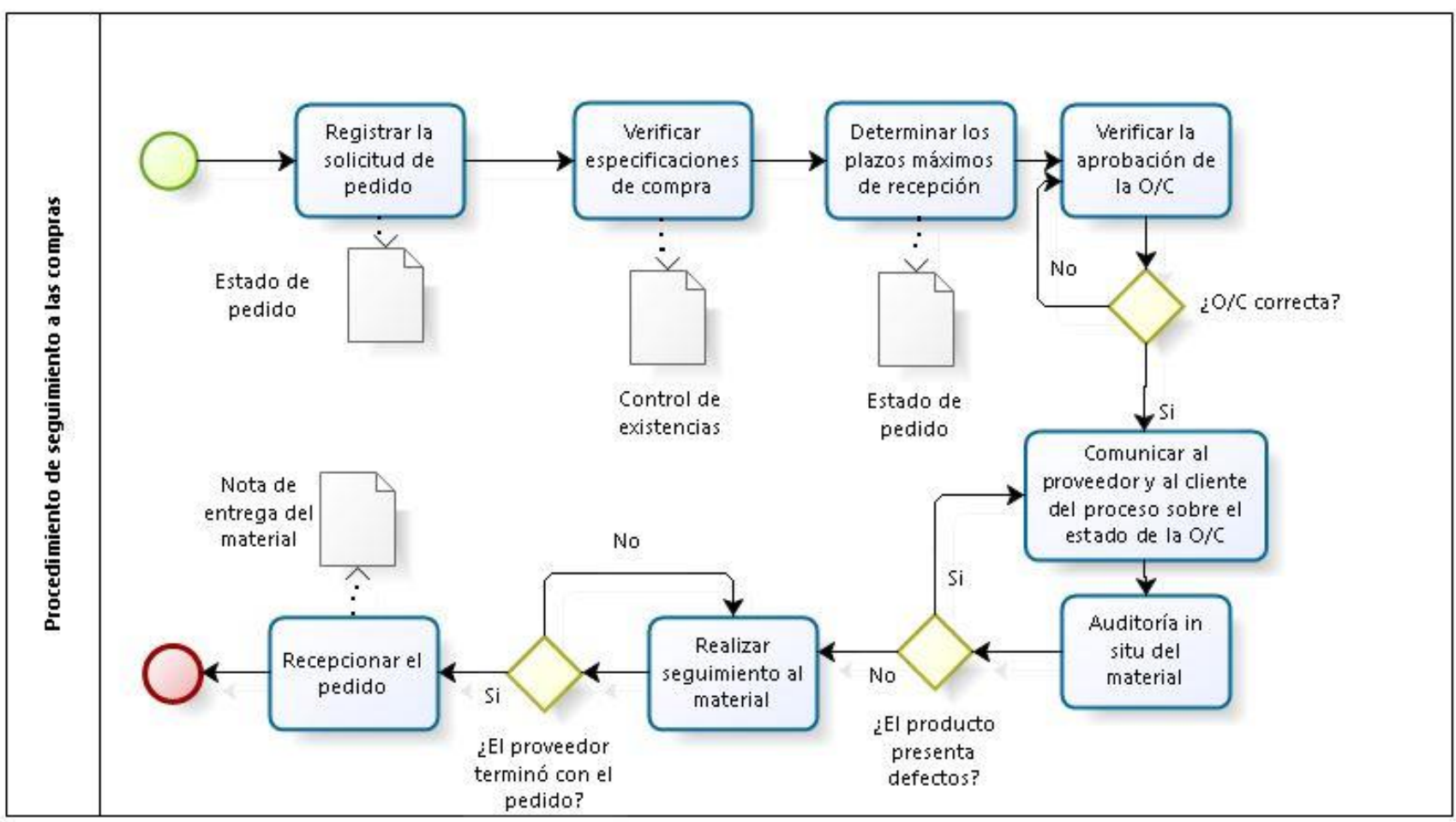


Anexo 16. Procedimiento de Seguimiento de Proveedores, Materiales y Servicios

SECTOR-TEXTIL EXPORTADOR (PYME)
PROCEDIMIENTO DE SEGUIMIENTO DE PROVEEDORES, MATERIALES Y SERVICIOS
Página:

1 de 303

PROCEDIMIENTO DE SEGUIMIENTO DE PROVEEDORES, MATERIALES Y SERVICIOS 


\begin{tabular}{c|c|c|}
\hline Código: & Versión: & Página: \\
\hline COMP-SDP-01 & 01 & 2 de 8 \\
\hline
\end{tabular}

\section{OBJETIVO:}

En este documento se describe el modo en que el sector debe realizar el seguimiento de aquellos proveedores cuyo impacto incide de manera significativa sobre el producto final, es decir, proveedores de material y proveedores de servicios subcontratados como transporte hasta el cliente.

\section{RESPONSABILIDAD Y ALCANCE:}

Es responsabilidad del encargado de compras la elaboración, revisión e implantación de este documento.

\section{DOCUMENTOS A CONSULTAR:}

- Métodos de selección, evaluación y homologación de proveedores.

- Matriz de criticidad de proveedores.

- Proceso de homologación.

\section{DEFINICIONES:}

PN: Proveedor Nuevo; aquel proveedor al que no se ha realizado ningún pedido anteriormente.

PA: Proveedor Activo; Proveedor al que Compras puede realizar pedidos.

PI: Proveedor Inactivo; Proveedor al que no se permite realizar pedidos. Su estado en la base de datos es Inactivo, imposibilitando la compra a los mismos.

LPE: Listado de Proveedores Evaluados; Listado donde se reflejan los resultados de la evaluación de los proveedores, indicando su estado de Activo o Inactivo para el siguiente periodo de evaluación.

FDP: Ficha de Datos de Proveedores: Ficha donde se resume y recoge la información necesaria del proveedor.

PE: Periodo de Evaluación; Periodo de tiempo entre una evaluación y la siguiente.

\section{CONDICIONES BÁSICAS:}

5.1 Todos los proveedores deben de estar homologados y realizar una evaluación cada 6 meses para asegurar la continuidad del mismo. 
SECTOR-TEXTIL

EXPORTADOR

(PYME)
PROCEDIMIENTO DE SEGUIMIENTO DE PROVEEDORES, MATERIALES Y SERVICIOS

\begin{tabular}{|c|c|c|}
\hline Código: & Versión: & Página: \\
\hline COMP-SDP-01 & 01 & 3 de 8 \\
\hline
\end{tabular}

5.2 Un proveedor puede perder su estado activo por razones de: Precios elevados, desaparición de la empresa, incumplimiento de plazos de entrega de maneta repetitiva, incumplimiento de requisitos del pedido, acumulación y/o importancia de incidencias y aparición de proveedores alternativos más interesantes.

6. DESARROLLO DEL PROCEDIMIENTO:

ACTIVIDADES
SECUENCIA DE ETAPAS

COORDINAR LA EVALUACIÓN

6.1 Se establece Criterios de evaluación, selección y Encargado de reevaluación de proveedores

Compras

6.2 Realizar coordinaciones con los proveedores para su evaluación.

\section{REUNIÓN DE PROVEEDORES}

6.3 Determinar lo puntos y criterios que se toman en cuenta para la evaluación en la que son sometidos.

Encargado

de

6.4 Realizar y mencionar según el formato PRO-LPE-01 el status de cada proveedor. (PN, PA Y PI)

\section{SEGUIMIENTO DE PROVEEDORES}

6.5 Monitorear al proveedor en cada O/C emitida y registrar en el formato PRO-FDP-01

\section{DESCALIFICACIÓN DEL PROVEEDOR}

6.6 Registrar en el formato de PRO-LPE-01.

Compras

6.7 Tomar en cuenta los Criterios de evaluación, selección y Compras reevaluación de proveedores (Ver anexo 8.1)

\section{REGISTRO:}

7.1 Formato de Ficha de datos de proveedores (Ver Anexo FORMATO PRO-FDP-01)

7.2 Formato de Listado de proveedores evaluados (Ver AnexoFORMATO PRO-LPE-01) 
SECTOR-TEXTIL EXPORTADOR (PYME)
PROCEDIMIENTO DE SEGUIMIENTO DE PROVEEDORES, MATERIALES Y SERVICIOS

\begin{tabular}{|c|c|c|}
\hline Código: & Versión: & Página: \\
\hline COMP-SDP-01 & 01 & 4 de 8 \\
\hline
\end{tabular}

\section{ANEXOS:}

8.6 Criterios de evaluación, selección y reevaluación de proveedores.

8.7 Formato REG-FDP-01 "Ficha de Datos de Proveedores"

8.8 Formato REG-FEP-01 "Ficha de Evaluación de Proveedores"

8.9 Formato PRO-LPE-01 "Listado de Proveedores Evaluados"

8.10 Diagrama de flujo del procedimiento.

8.5 Criterios de evaluación, selección y reevaluación de proveedores.

- CRITERIOS DE EVALUACIÓN DE PROVEEDORES

- PROVEEDORES ALTERNATIVOS

- TARIFA DE PRECIOS

- CERTIFICACIONES (MATERIAL, PROCESO, SISTEMA GESTIÓN)

- COMPROMISO CON NUESTROS REQUISITOS

- CRITERIOS DE SELECCIÓN DE PROVEEDORES

- IMPORTE DEL MATERIAL

- PLAZO DE ENTREGA

- CERTIFICADOS DE CALIDAD Y OTROS DOCUMENTOS

- CRITERIOS DE REEVALUACIÓN DE PROVEEDORES

- REGISTRO DEINCIDENCIAS

- PROVEEDORES ALTERNATIVOS

- TARIFA DE PRECIOS

- CERTIFICACIONES (MATERIAL, PROCESO, SISTEMA GESTIÓN)

- COMPROMISO CON NUESTROS REQUISITOS 
SECTOR-TEXTIL EXPORTADOR (PYME)
PROCEDIMIENTO DE SEGUIMIENTO DE PROVEEDORES, MATERIALES Y SERVICIOS

Código:

Versión:

Página:

COMP-SDP-01

01

5 de 8

8.6 Formato REG-FDP-01 "Ficha de Datos de Proveedores"

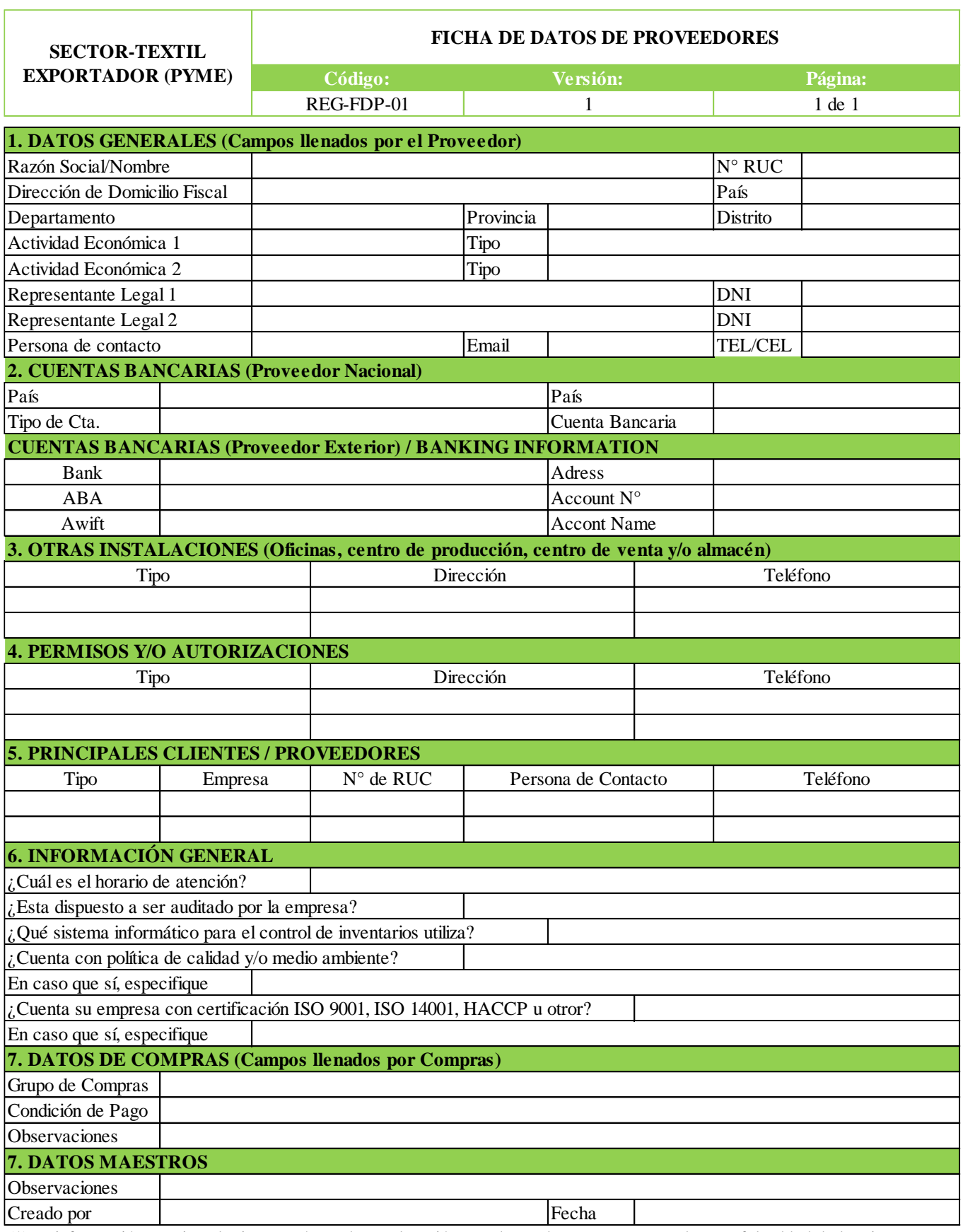

(*)La información consignada tiene carácter de Declaración Jurada por lo que en caso se detecte falseddad de la misma u omisión de información se aplicaran las consecuencias y acciones legales correspondiente.

(**) Adjunta Ficha Ruc, DNI, Representante Legal, Escritura Pública de contitución, Licencia de Funcionamiento y otas autorizaciones según corresponda.

$(* * *)$ El presente documento no debe presentar borrones, enmendaduras, datos inconsistentes y/o firmas ilegibles.

Proveedor

(1)

Comprador

Jefe de Compras 
SECTOR-TEXTIL EXPORTADOR (PYME)
PROCEDIMIENTO DE SEGUIMIENTO DE PROVEEDORES, MATERIALES Y SERVICIOS

\begin{tabular}{c|c|c|}
\hline Código: & Versión: & Página: \\
\hline COMP-SDP-01 & 01 & 6 de 303 \\
\hline
\end{tabular}

8.7 Formato REG-FEP-01 "Ficha de Evaluación de Proveedores"

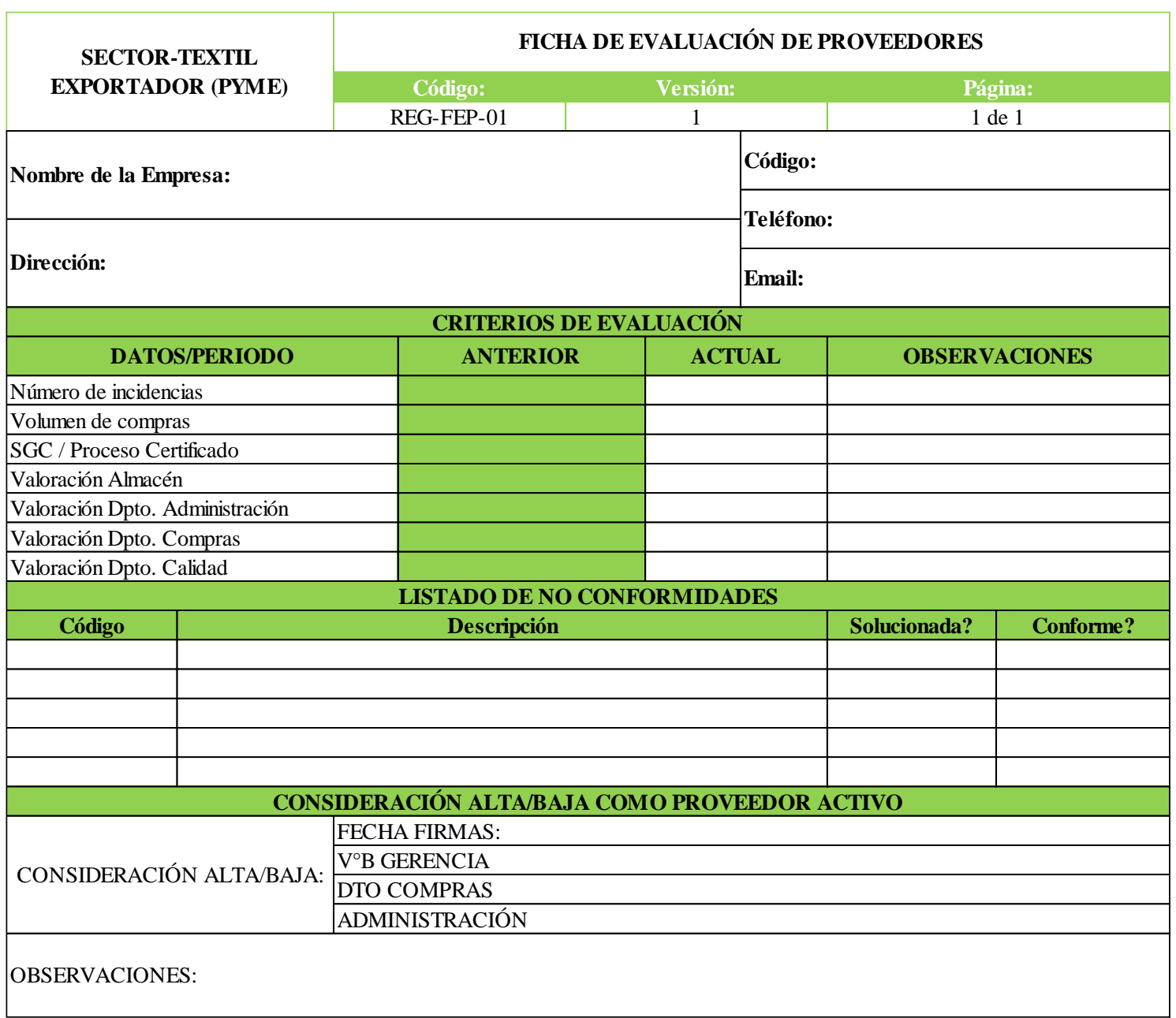


SECTOR-TEXTIL EXPORTADOR (PYME)
PROCEDIMIENTO DE SEGUIMIENTO DE PROVEEDORES, MATERIALES Y SERVICIOS

\begin{tabular}{c|c|c|}
\hline Código: & Versión: & Página: \\
\hline COMP-SDP-01 & 01 & 7 de 303 \\
\hline
\end{tabular}

8.8 Formato PRO-LPE-01 "Listado de Proveedores Evaluados"

SECTOR-TEXTIL EXPORTADOR (PYME)
LISTADO DE PROVEEDORES EVALUADOS

\begin{tabular}{|c|c|c|}
\hline Código: & Versión: & Página: \\
\hline PRO-LPE-01 & 1 & 1 de 1 \\
\hline
\end{tabular}

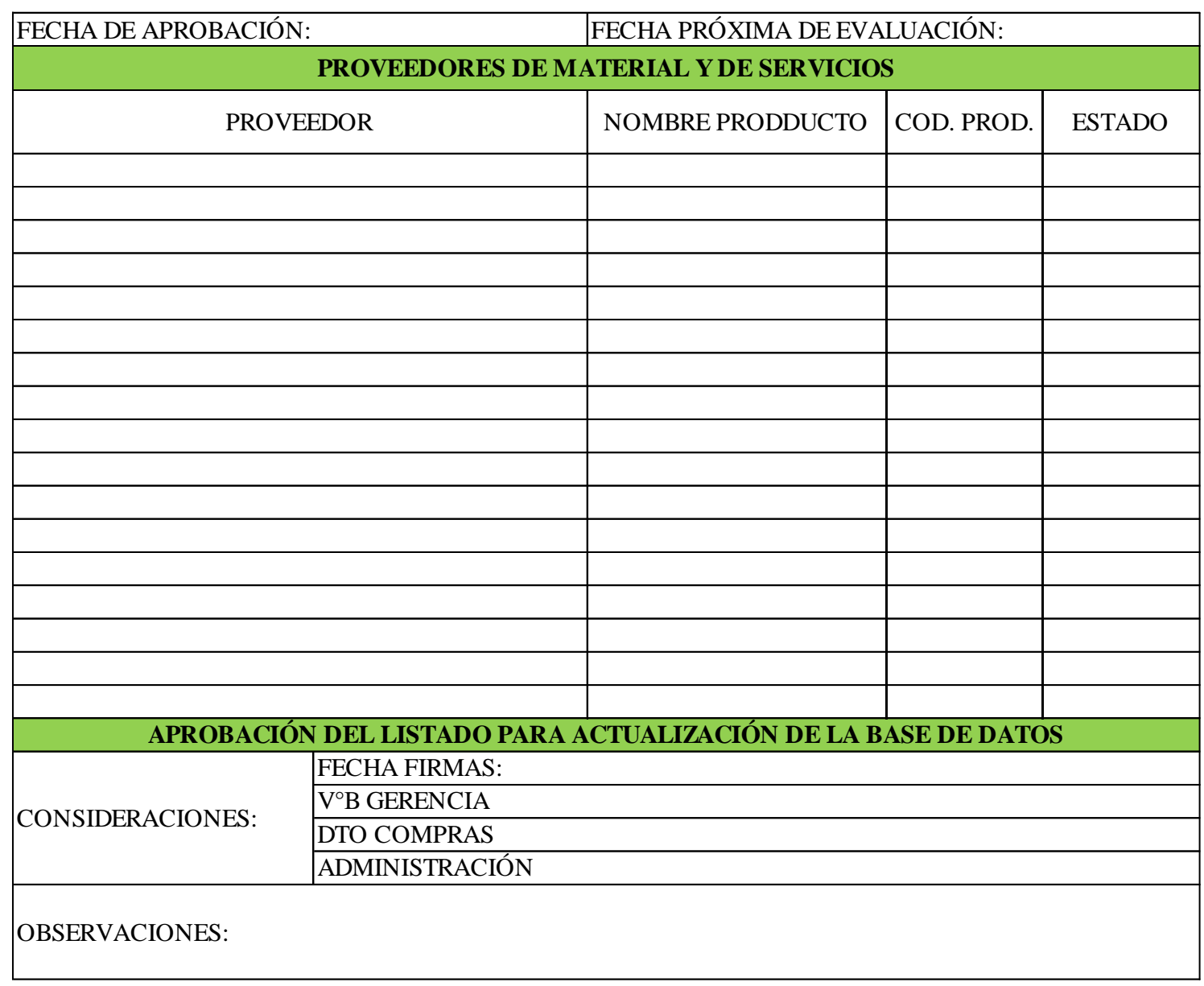


SECTOR-TEXTIL EXPORTADOR (PYME)
PROCEDIMIENTO DE SEGUIMIENTO DE PROVEEDORES, MATERIALES Y SERVICIOS

\begin{tabular}{c|c|c|}
\hline Código: & Versión: & Página: \\
\hline COMP-SDP-01 & 01 & 8 de 8
\end{tabular}

8.4 Diagrama de flujo del procedimiento.

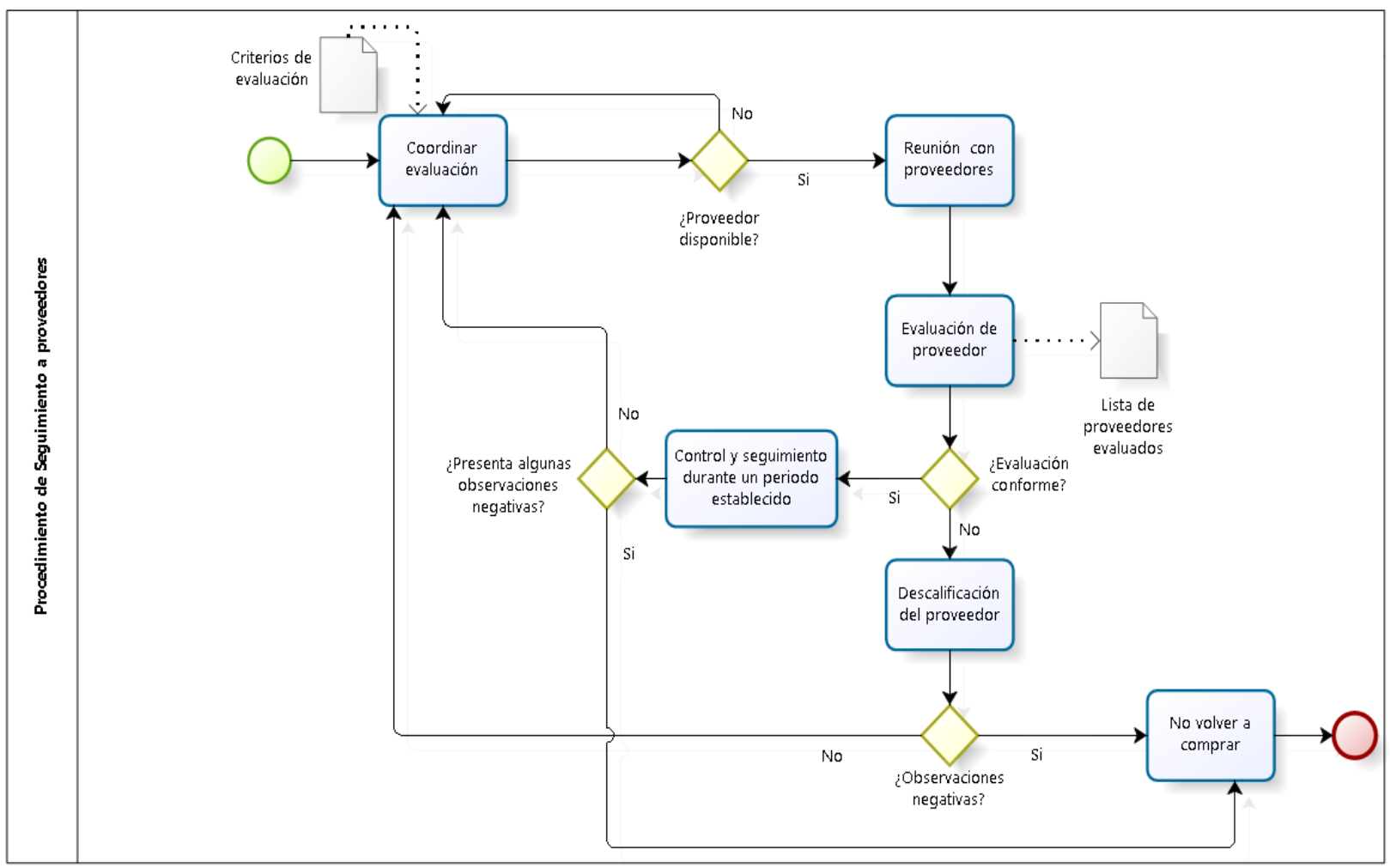




\section{Anexo 17. Indicadores de Medición}

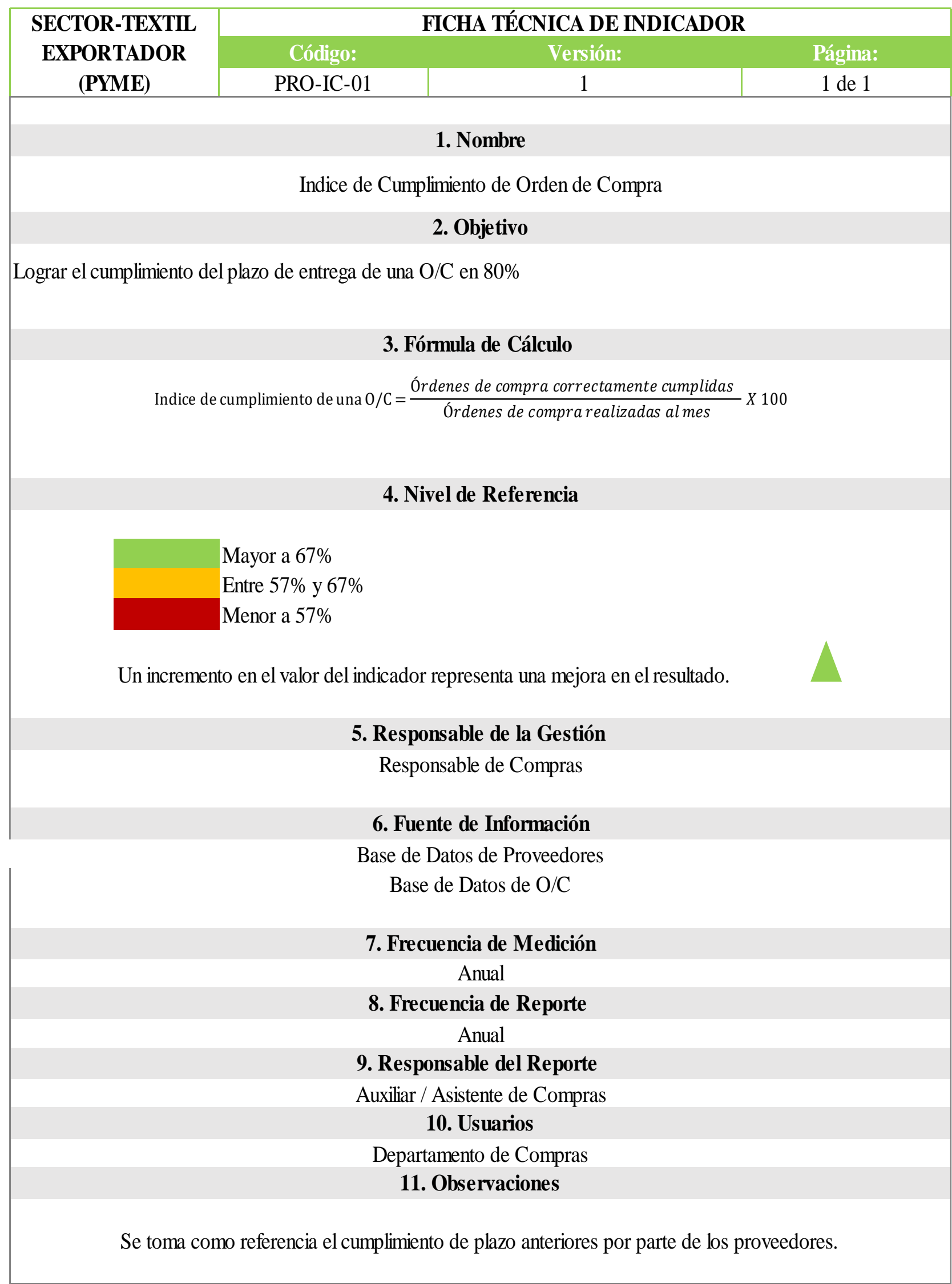




\begin{tabular}{|c|c|c|c|}
\hline \multirow{3}{*}{$\begin{array}{c}\text { SECTOR-TEXTIL } \\
\text { EXPORTADOR } \\
\text { (PYME) } \\
\end{array}$} & \multicolumn{3}{|c|}{ FICHA TÉCNICA DE INDICADOR } \\
\hline & Código: & Versión: & Página: \\
\hline & PRO-IC-02 & 1 & $1 \mathrm{de} 1$ \\
\hline \multicolumn{4}{|c|}{ 1. Nombre } \\
\hline \multicolumn{4}{|c|}{ Porcentaje de Pedido devuelto al Proveedor } \\
\hline \multicolumn{4}{|c|}{ 2. Objetivo } \\
\hline \multicolumn{4}{|c|}{ Lograr el cumplimiento de los requerimientos del pedido por parte del proveedor en $80 \%$} \\
\hline \multicolumn{4}{|c|}{ 3. Fórmula de Cálculo } \\
\hline \multicolumn{4}{|c|}{$\%$ de Pedidos Devueltos al Proveedor $=\frac{N^{\circ}}{\text { Ordenes de compra realizadas al mes }} X 100$} \\
\hline \multicolumn{4}{|c|}{ 4. Nivel de Referencia } \\
\hline \multicolumn{4}{|c|}{$\begin{array}{l}\text { Mayor a } 67 \% \\
\text { Entre } 57 \% \text { y } 67 \% \\
\text { Menor a } 57 \%\end{array}$} \\
\hline \multicolumn{4}{|c|}{ Un incremento en el valor del indicador representa una mejora en el resultado. } \\
\hline \multicolumn{4}{|c|}{ 5. Responsable de la Gestión } \\
\hline \multicolumn{4}{|c|}{ Responsable de Compras } \\
\hline \multicolumn{4}{|c|}{ 6. Fuente de Información } \\
\hline \multicolumn{4}{|c|}{$\begin{array}{l}\text { Base de Datos de Proveedores } \\
\text { Base de Datos de O/C }\end{array}$} \\
\hline \multicolumn{4}{|c|}{ 7. Frecuencia de Medición } \\
\hline \multicolumn{4}{|c|}{ Anual } \\
\hline \multicolumn{4}{|c|}{ 8. Frecuencia de Reporte } \\
\hline \multicolumn{4}{|c|}{ Anual } \\
\hline \multicolumn{4}{|c|}{ 9. Responsable del Reporte } \\
\hline \multicolumn{4}{|c|}{ Auxiliar / Asistente de Compras } \\
\hline \multicolumn{4}{|c|}{ 10. Usuarios } \\
\hline \multicolumn{4}{|c|}{ Departamento de Compras } \\
\hline & & & \\
\hline
\end{tabular}




\section{Anexo 18. Indicadores de Medición de Desempeño del}

\section{Proceso}

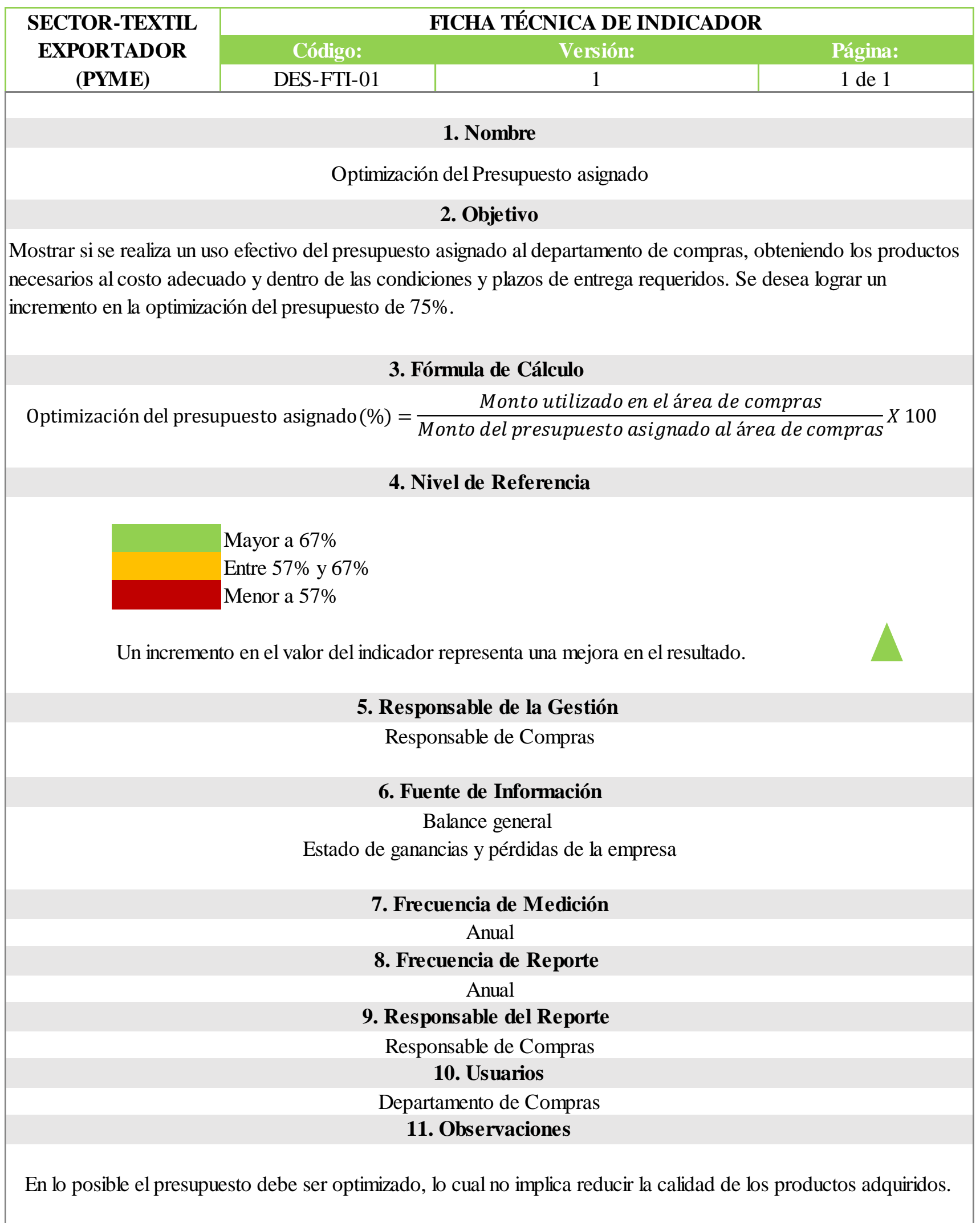




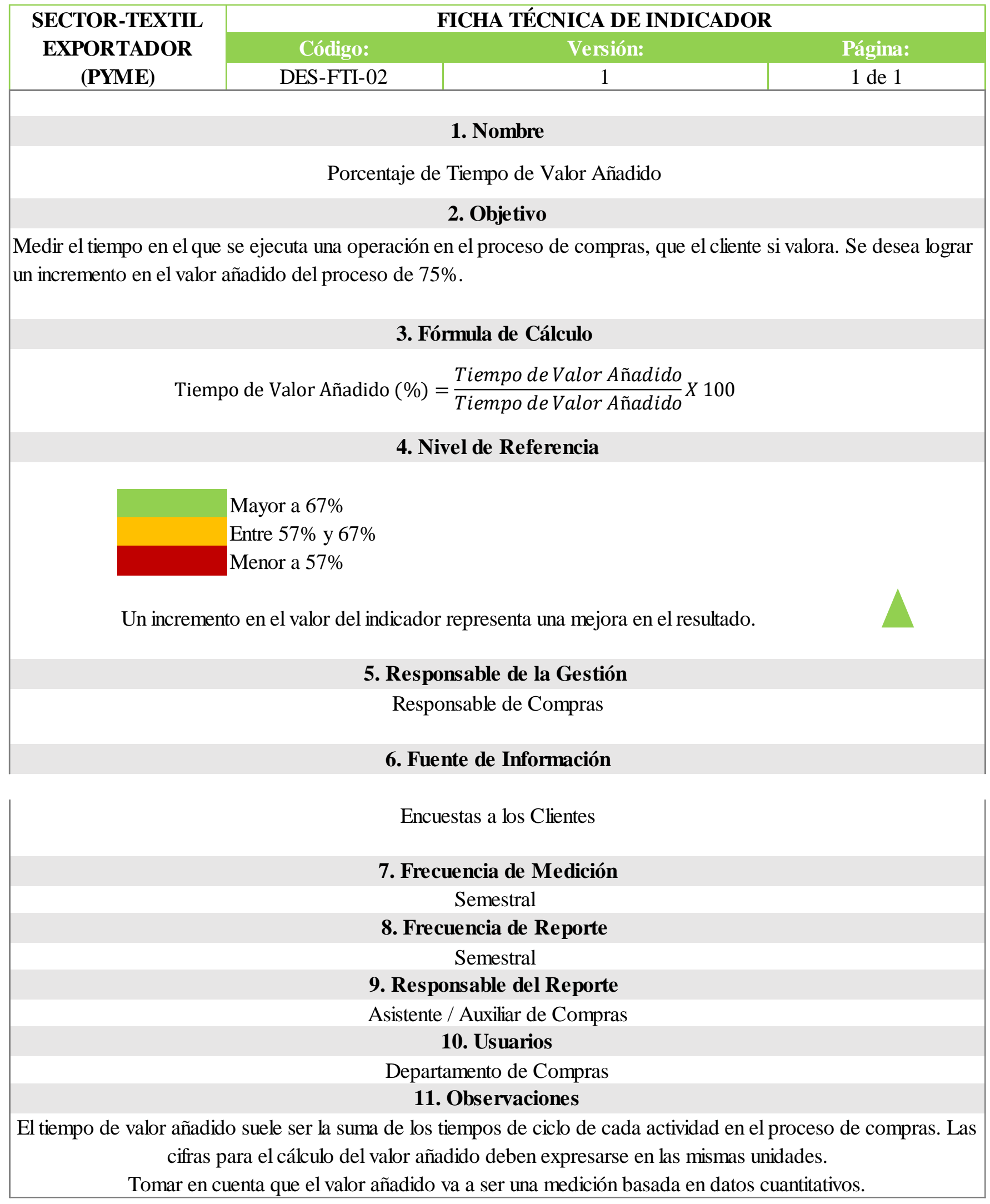




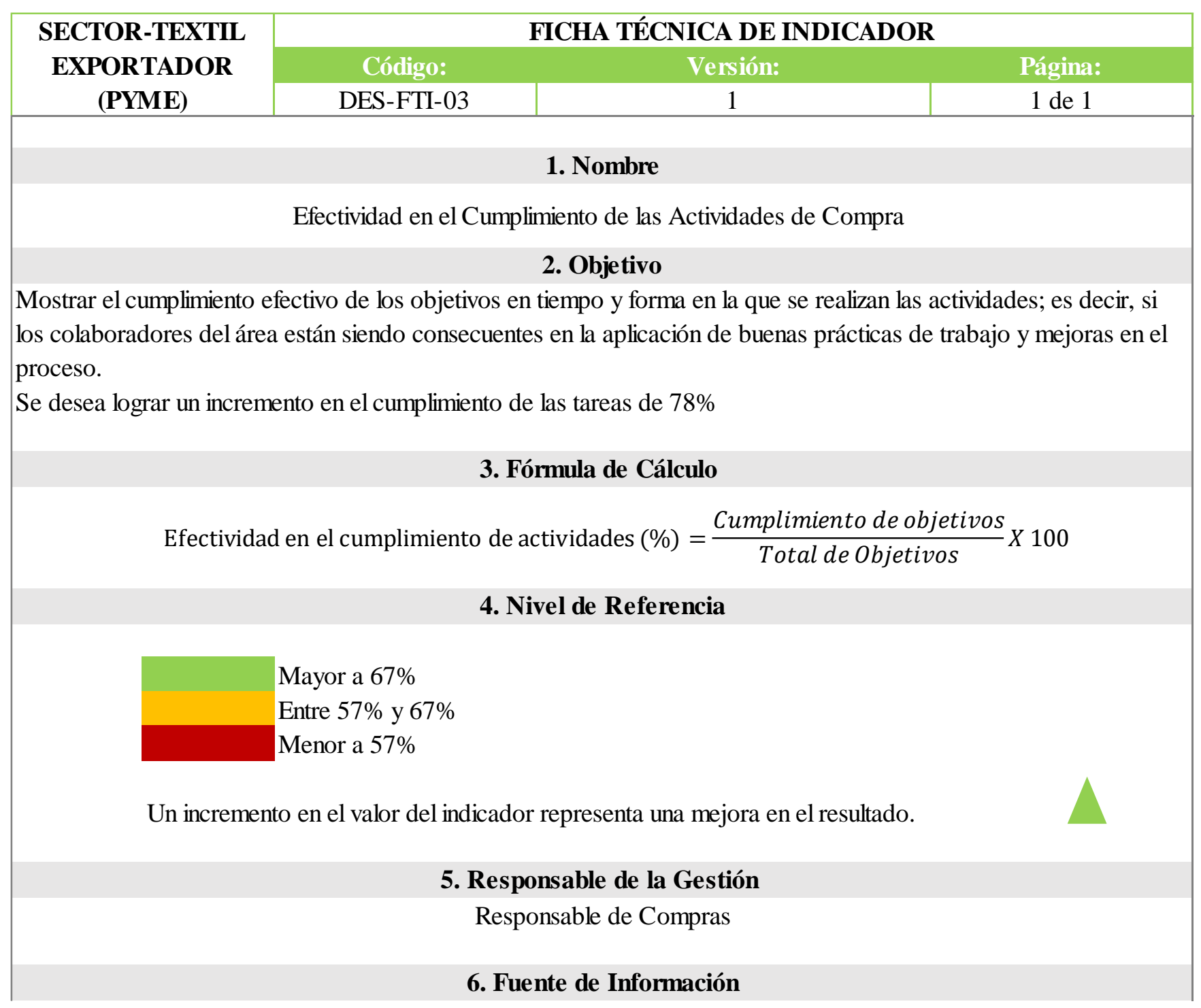

\begin{tabular}{|c|} 
Evaluación de desempeño del personal (PRO-ED-01) \\
7. Frecuencia de Medición \\
Semestral \\
8. Frecuencia de Reporte \\
Semestral \\
9. Responsable del Reporte \\
Responsable de Compras \\
10. Usuarios \\
Departamento de Compras \\
$\mathbf{1 1 . ~ O b s e r v a c i o n e s}$ \\
De comprobar la efectividad de las tareas se pueden crear incentivos para los trabajadores, de esa manera se les \\
motiva para realizar sus actividades de manera eficiente. \\
\hline
\end{tabular}




\begin{tabular}{|c|c|c|c|}
\hline \multirow{3}{*}{$\begin{array}{c}\text { SECTOR-TEXTIL } \\
\text { EXPORTADOR } \\
\text { (PYME) }\end{array}$} & \multicolumn{3}{|c|}{ FICHA TÉCNICA DE INDICADOR } \\
\hline & Código: & Versión: & Página: \\
\hline & DES-FTI-04 & 1 & 1 de 1 \\
\hline \multicolumn{4}{|c|}{ 1. Nombre } \\
\hline \multicolumn{4}{|c|}{ Sinergia entre el Departamento de Compras y Planeamiento de la Producción. } \\
\hline \multicolumn{4}{|c|}{ 2. Objetivo } \\
\hline \multicolumn{4}{|c|}{$\begin{array}{l}\text { Mostrar el nivel de organización y comunicación que tiene el departamento de compras con el planeamiento de la } \\
\text { producción. Se desea lograr un incremento en la sinergia entre ambos departamentos de } 89 \% \text {. }\end{array}$} \\
\hline \multicolumn{4}{|c|}{ 3. Fórmula de Cálculo } \\
\hline \multicolumn{4}{|c|}{ Sinergia entre el departamento de compras y planeamiento de la producción $(\%)=\frac{\text { Programaciones entregadas a tiempo }}{\text { Programaciones totales }} \times 100$} \\
\hline \multicolumn{4}{|c|}{ 4. Nivel de Referencia } \\
\hline \multicolumn{4}{|c|}{ Mayor a $67 \%$} \\
\hline \multicolumn{4}{|c|}{ Entre $57 \%$ y $67 \%$} \\
\hline \multicolumn{4}{|c|}{ Menor a $57 \%$} \\
\hline \multicolumn{4}{|c|}{ Un incremento en el valor del indicador representa una mejora en el resultado. } \\
\hline \multicolumn{4}{|c|}{ 5. Responsable de la Gestión } \\
\hline \multicolumn{4}{|c|}{ Responsable de Compras } \\
\hline \multicolumn{4}{|c|}{ 6. Fuente de Información } \\
\hline
\end{tabular}

Nota de entrega de material (COMP-PDC-F3)

Cuestionario de evaluación de desempeño (PRO-CDP-01)

\section{Frecuencia de Medición}

$$
\text { Semestral }
$$

\section{Frecuencia de Reporte}

Semestral

\section{Responsable del Reporte}

Auxiliar / Asistente de Compras

\section{Usuarios}

Departamento de Compras

\section{Observaciones}

El incremento de este indicador, indica que el proceso de compra es eficiente siempre que se realicen las actividades de manera adecuada y en constante comunicación con los involucrados en la adquisición de materiales y servicios. 


\begin{tabular}{|c|c|c|c|}
\hline \multirow{3}{*}{$\begin{array}{l}\text { SECTOR-TEXTIL } \\
\text { EXPORTADOR } \\
\text { (PYME) }\end{array}$} & \multicolumn{3}{|c|}{ FICHA TÉCNICA DE INDICADOR } \\
\hline & Código: & Versión: & Página: \\
\hline & DES-FTI-05 & 1 & 1 de 1 \\
\hline \multicolumn{4}{|c|}{ 1. Nombre } \\
\hline \multicolumn{4}{|c|}{ Ciclo de la Orden de Compra } \\
\hline \multicolumn{4}{|c|}{ 2. Objetivo } \\
\hline \multicolumn{4}{|c|}{$\begin{array}{l}\text { Controlar el tiempo que transcurre entre el momento en que el cliente realiza el pedido y el momento en que éste recibe } \\
\text { fisicamente la mercancía. } \\
\text { Se desea lograr una reducción en el ciclo de la orden de compra a } 25 \%\end{array}$} \\
\hline \multicolumn{4}{|c|}{ 3. Fórmula de Cálculo } \\
\hline \multicolumn{4}{|c|}{ Ciclo de la Orden de Compra $(\%)=\frac{* \text { Promedio de los tiempo de atención de los pedidos }}{\frac{\text { Pedidos entregados }}{\text { Recibidos en elperiodo } X}} \times 100$} \\
\hline \multicolumn{4}{|c|}{$\begin{array}{l}\text { *El tiempo de atención de cada pedido se calcula como la diferencia entre la fecha de recepción de la mercadería y la } \\
\text { fecha de la generación de la orden de compra. }\end{array}$} \\
\hline \multicolumn{4}{|c|}{ 4. Nivel de Referencia } \\
\hline \multicolumn{4}{|c|}{$\begin{array}{l}\text { Mayor a } 67 \% \\
\text { Entre } 57 \% \text { y } 67 \% \\
\text { Menor a } 57 \%\end{array}$} \\
\hline \multicolumn{4}{|c|}{ La reducción en el valor del indicador representa una mejora en el resultado. } \\
\hline \multicolumn{4}{|c|}{ 5. Responsable de la Gestión } \\
\hline \multicolumn{4}{|c|}{ Responsable de Compras } \\
\hline \multicolumn{4}{|c|}{ 6. Fuente de Información } \\
\hline \multicolumn{4}{|c|}{$\begin{array}{l}\text { Nota de entrega de material (COMP-PDC-F3) } \\
\text { Seguimiento de Compras }\end{array}$} \\
\hline \multicolumn{4}{|c|}{ 7. Frecuencia de Medición } \\
\hline \multicolumn{4}{|c|}{ Anual } \\
\hline \multicolumn{4}{|c|}{ 8. Frecuencia de Reporte } \\
\hline \multicolumn{4}{|c|}{ Anual } \\
\hline \multicolumn{4}{|c|}{ 9. Responsable del Reporte } \\
\hline \multicolumn{4}{|c|}{ Responsable de Compras } \\
\hline \multicolumn{4}{|c|}{ 10. Usuarios } \\
\hline \multicolumn{4}{|c|}{ Departamento de Compras } \\
\hline \multicolumn{4}{|c|}{ 11. Observaciones } \\
\hline $\begin{array}{l}\text { Este indicador debe } \\
\text { urgentes y los pedidos } \\
\text { que mide es la longitud }\end{array}$ & $\begin{array}{l}\text { ar el ciclo norn } \\
\text { nados. Este ind } \\
\text { po de la caden }\end{array}$ & $\begin{array}{l}\text { lo tanto deb } \\
\text { de a la capa } \\
\text { teniendo er } \\
\text { lor. }\end{array}$ & $\begin{array}{l}\text { o los pedidos } \\
\text { un proveedor, lo } \\
\text { stablecidos entre }\end{array}$ \\
\hline
\end{tabular}




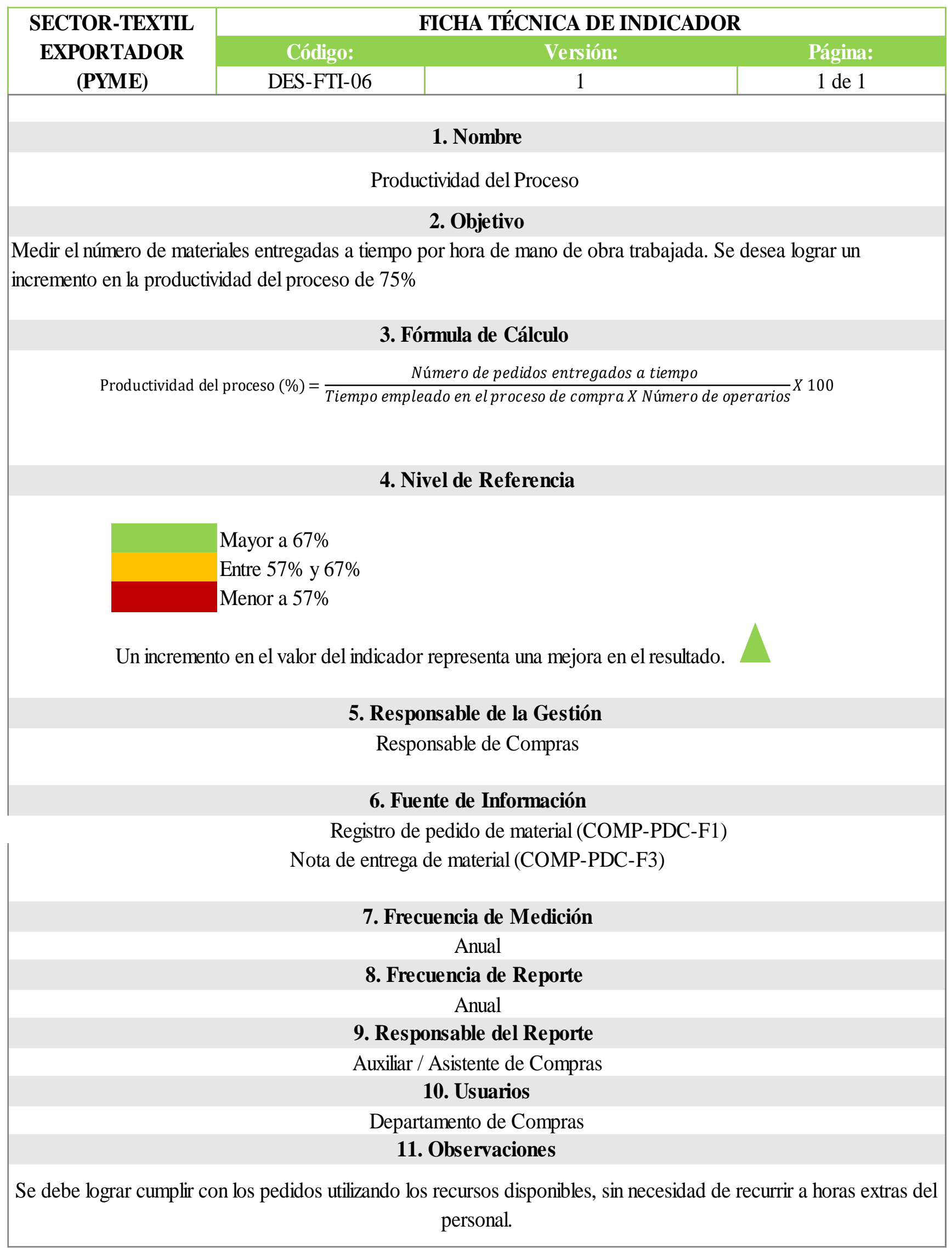




\section{Anexo 19. Formato de Entrevista para medir el desempeño}

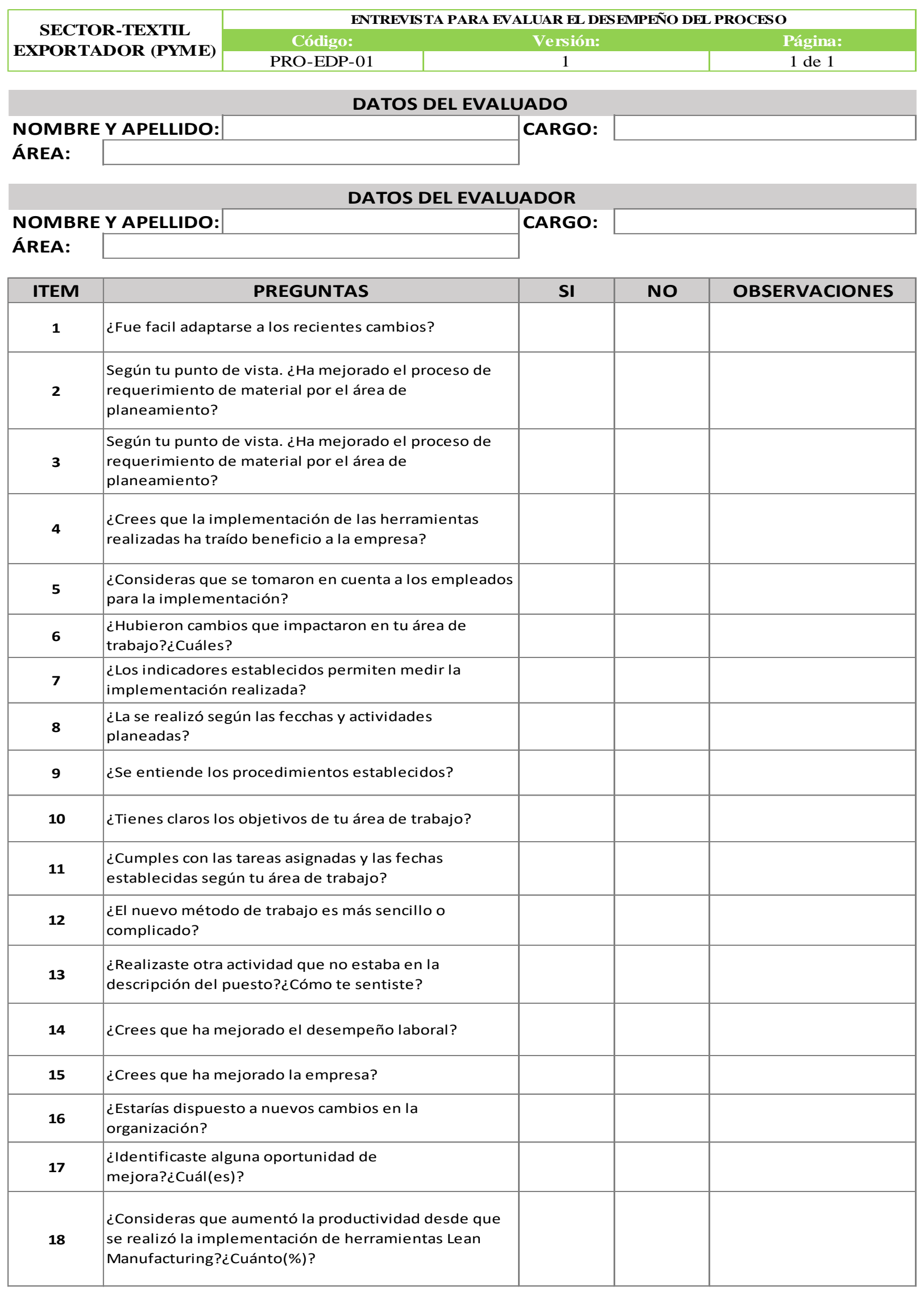




\section{Anexo 20. Cuestionario de Evaluación de Desempeño}

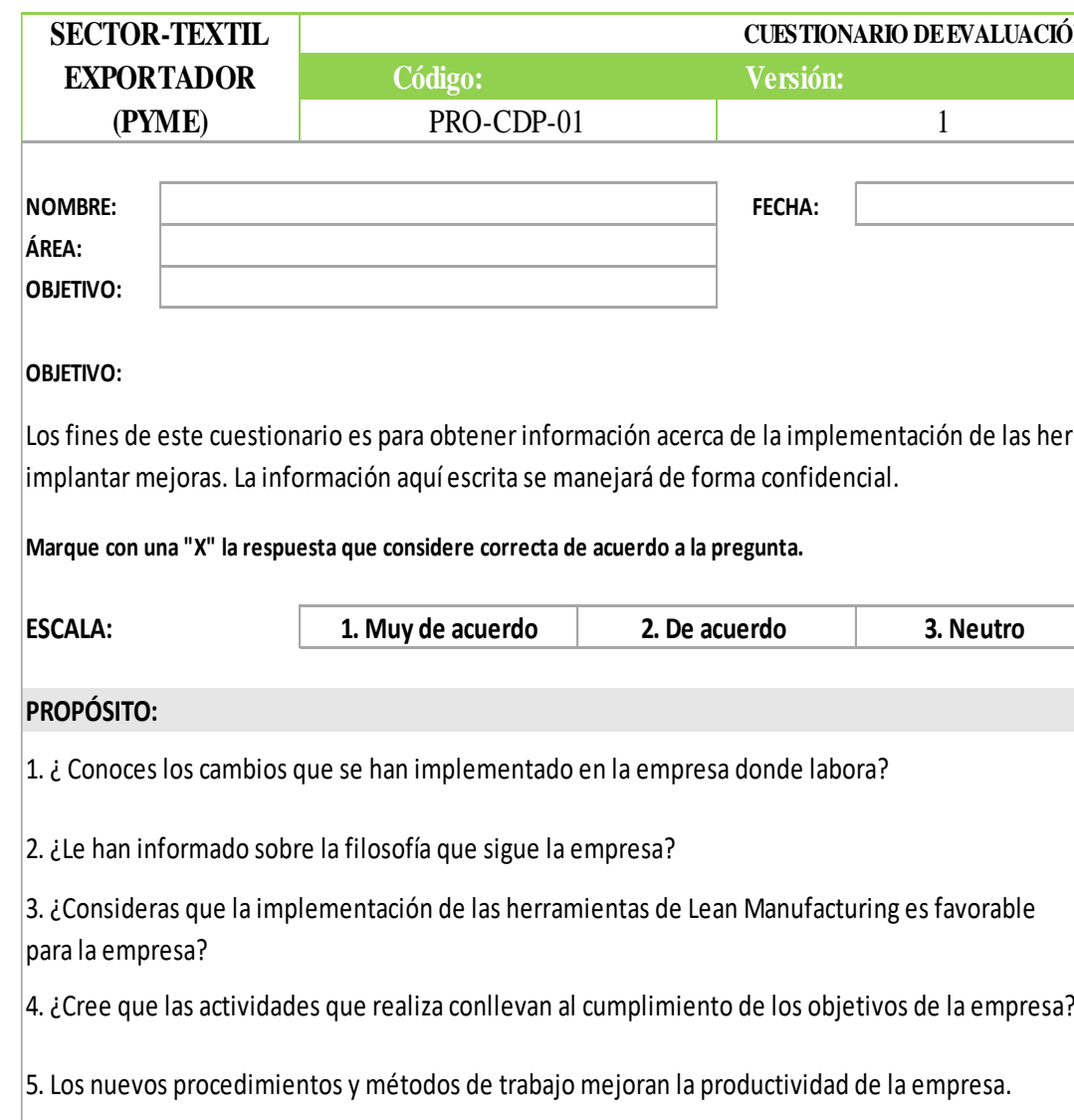

\section{ESTRUCTURA:}

1. Las actividades que realiza son congruentes a su puesto.

2. La división de las áreas de trabajo son adecuadas para el buen funcionamiento de la empresa.

3. Su puesto permite que desarrolle al máximo todas sus habilidades.

4. El personal con el que cuenta la empresa es suficiente para llevar a cabo todas sus operaciones.

\begin{tabular}{|l|l|l|l|l|}
\hline 1 & 2 & 3 & 4 & 5 \\
\hline 1 & 2 & 3 & 4 & 5 \\
\hline 1 & 2 & 3 & 4 & 5 \\
\hline 1 & 2 & 3 & 4 & 5 \\
\hline 1 & 2 & 3 & 4 & 5 \\
\hline
\end{tabular}

\section{RELACIONES}

1. La comunicación entre usted y su jefe es frecuente.

2. La confianza entre sus compañeros de trabajo es buena.

3. El trabajo en equipo es indispensable para llevar a cabo sus áreas asignadas.

4. El ambiente laboral en el trabajo es satisfactorio.

\begin{tabular}{|l|l|l|l|l|}
\hline 1 & 2 & 3 & 4 & 5 \\
\hline 1 & 2 & 3 & 4 & 5 \\
\hline 1 & 2 & 3 & 4 & 5 \\
\hline 1 & 2 & 3 & 4 & 5 \\
\hline
\end{tabular}

\section{RECOMPENZAS}

1. La empresa recompensa a los empleados por un trabajo bien hecho.

2. He recibido reconocimientos por un esfuerzo extra de mi parte.

3.La compañía ofrece incentivos para incrementar su desempeño.

\begin{tabular}{|l|l|l|l|l|}
\hline 1 & 2 & 3 & 4 & 5 \\
\hline 1 & 2 & 3 & 4 & 5 \\
\hline 1 & 2 & 3 & 4 & 5 \\
\hline 1 & 2 & 3 & 4 & 5 \\
\hline
\end{tabular}

\section{LIDERAZGO}

1. Los directivos supervisan las actividades que realizan los empleados.

2. Me interesa influir en los demás aportando nuevos conocimientos.

3. La organización solicita sus ideas para mejorar su trabajo.

4. Se ofrecen programas de capacitación para desarrollar bien sus actividades.

\begin{tabular}{|l|l|l|l|l|}
\hline 1 & 2 & 3 & 4 & 5 \\
\hline 1 & 2 & 3 & 4 & 5 \\
\hline 1 & 2 & 3 & 4 & 5 \\
\hline
\end{tabular}

\section{TECNOLOGÍA}

1. Los medios tecnológicos proporcionados por la empresa para realización de su trabajo son adecua

2. La empresa frecuentemente se actualiza a los avances tecnológicos

3. La tecnología ayuda a incrementar su rendimiento.

\begin{tabular}{|l|l|l|l|l|}
\hline 1 & 2 & 3 & 4 & 5 \\
\hline 1 & 2 & 3 & 4 & 5 \\
\hline 1 & 2 & 3 & 4 & 5 \\
\hline 1 & 2 & 3 & 4 & 5 \\
\hline
\end{tabular}




\section{Anexo 21. Cuadro Comparativo de Indicadores}

\begin{tabular}{|c|c|c|c|c|c|}
\hline Problemas frecuentes/desperdicios & Indicador & Fórmula & \% Inicial del indicador & \% Final del indicador & \% de Variación \\
\hline 1.Retraso de atención de los requerimientos & 1.a. Índice de eficacia en el proceso de compras & 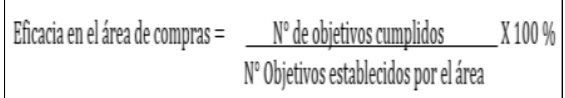 & & & \\
\hline 2. Espera para aprobación de requerimiento & 2.a. Efectividad en el cumplimiento de tareas & 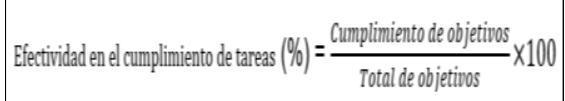 & & & \\
\hline \multirow{2}{*}{ 3. Retraso de proveedor } & 3.a. Pedidos entregados a tiempo & 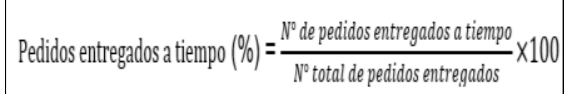 & & & \\
\hline & 3.b. Nivel de cumplimiento de proveedores & 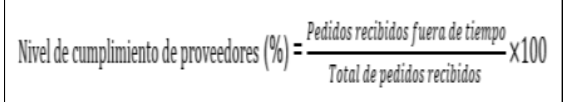 & & & \\
\hline 4. Defectos en los materiales recepcionados. & 4.a. Pedidos devueltos al proveedor & 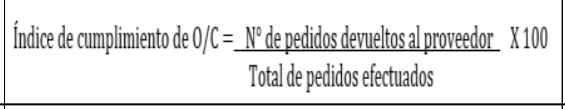 & & & \\
\hline \multirow{3}{*}{ 5. Reproceso de $0 / C$ por error de cálculo } & 5.a. Sinergia entre el departamendo de Compras y Planeamiento de la producción & 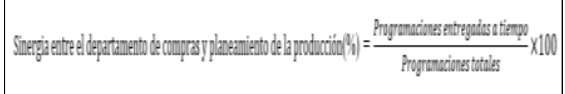 & & & \\
\hline & 5.b. Ciclo de la Orden de compra & 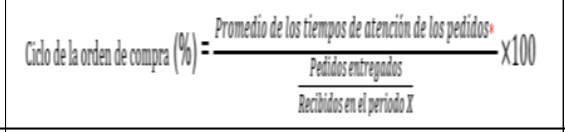 & & & \\
\hline & 5.c. Calidad de los pedidos generados & 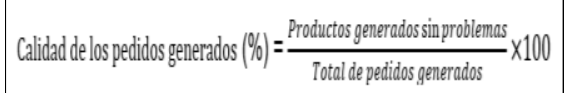 & & & \\
\hline
\end{tabular}


Anexo 22. Programa de Educación Just in Time PROGRAMA DE EDUCACIÓN 


\begin{tabular}{|c|c|c|}
\hline Código: & Versión: & Página: \\
\hline COMP-PE-01 & 01 & 2 de 4 \\
\hline
\end{tabular}

\section{OBJETIVO:}

Establecer los lineamientos necesarios para desarrollar conocimientos acerca del sistema Just in Time en el área de compras, y asegurar el entendimiento y desarrollo del mismo.

\section{RESPONSABILIDAD Y ALCANCE:}

El presente procedimiento es realizado por el encargado de compras con apoyo de los colaboradores del área, este aplica a desde la programación de las actividades de educación hasta su ejecución y evaluación.

\section{DESCRIPCIÓN DE LAS ACTIVIDADES}

\subsection{Planificación de temas a desarrollar:}

El cambio en la cultura constituye un proceso prolongado, por ello se deben realizar capacitaciones, ya que permite asegurar la ejecución satisfactoria del trabajo y además constituyen una herramienta para adaptarse a los cambios.

\section{PARTICIPANTES}

Todos los involucrados en la organización

Personal que trabaja en los procesos a implementarse

\section{CARACTERISTICAS}

Filosofía JIT.

Manera como JIT opera dentro del sistema de manufactura.

Los beneficios a obtener.

La razón por la que el JIT es importante para el éxito empresarial.

Nuevos métodos de trabajo.

Necesidades de las áreas involucradas en el proceso de compras.

Mencionar los posibles efectos que puedan suceder a raíz del desarrollo de la

\section{OBSERVACIONE}

\section{S}

La realización de las actividades mencionadas dependerá de la empresa que adopte esta nueva cultura. 
metodología.

Todos los involucrados

Definición

de en la organización responsabilidades.

PROGRAMA DE EDUCACIÓN EXPORTADOR (PYME)

\begin{tabular}{|c|c|c|}
\hline Código: & Versión: & Página: \\
\hline COMP-PE-01 & 01 & 3 de 4 \\
\hline
\end{tabular}

\subsection{Poner el Sistema en marcha}

NOTA: El coordinador y ejecutor de este programa debe de conocer las técnicas de comunicación y las del JIT, poseer habilidades educativas, poseer perseverancia y paciencia y ser capaz de manejar cambios. Se debe tomar en cuenta lo siguiente:

- Llevar a cabo reuniones con los empleados y dar a conocer lo que es el JIT.

- Realizar los procedimientos establecidos.

- Notificar los cambios que puedan esperarse durante el programa.

- El entrenamiento debe de incluir la adquisición de habilidades, el conocimiento de los principios JIT y su aplicación práctica, para lograr contribuir a un cambio positivo de la actitud de los empleados

- Deben de preparar su centro de trabajo con la filosofía JIT y planificar el centro de trabajo, éste debe ser sencillo, eliminando todos aquellos elementos innecesarios, al mismo tiempo que situando convenientemente los que se requieran para el mejor desarrollo de las actividades

- Resolver dudas sobre la cultura JIT.

\subsection{Obtener mejoras en el proceso}

- Se busca la flexibilización del proceso productivo, que implica una respuesta más rápida a la demanda tanto interna como externa.

- Personal capacitado y preparado bajo la cultura de JIT.

- Fuerza laboral capaz de detectar y resolver problemas que se presente perjudicando el flujo continuo de producción.

- Personal alineado con la cultura JIT que facilita la implementación de procedimientos y métodos nuevos de trabajos.

\subsection{Seguimiento del programa}

- Realizar el seguimiento continuo a los trabajadores para verificar la adaptación de la nueva cultura de trabajo.

- Verificar si existe instrucciones precisas sobre los métodos y perspectivas que se indicaron en las capacitaciones.

- Control de las actividades realizadas por los empleados adaptándose a la nueva cultura propuesta. 
- Identificar los problemas repetitivos que impiden el desarrollo del programa.

- Medir el progreso de la implementación y cambio de la cultura laboral basado en JIT.

\section{PROGRAMA DE EDUCACIÓN}

\begin{tabular}{|c|c|c|}
\hline Código: & Versión: & Página: \\
\hline COMP-PE-01 & 01 & 4 de 4 \\
\hline
\end{tabular}

3.5. Ampliar la relación cliente/proveedor

- La educación de los proveedores debe de estará alineada a lo que busca cada organización.

- Basar el sistema de entrega JIT en la disposición y capacidad de los proveedores para cumplir con los requerimientos. Se puede realizar contrato a largo plazo bajo constante evaluación y de esa forma se alineen al proceso productivo.

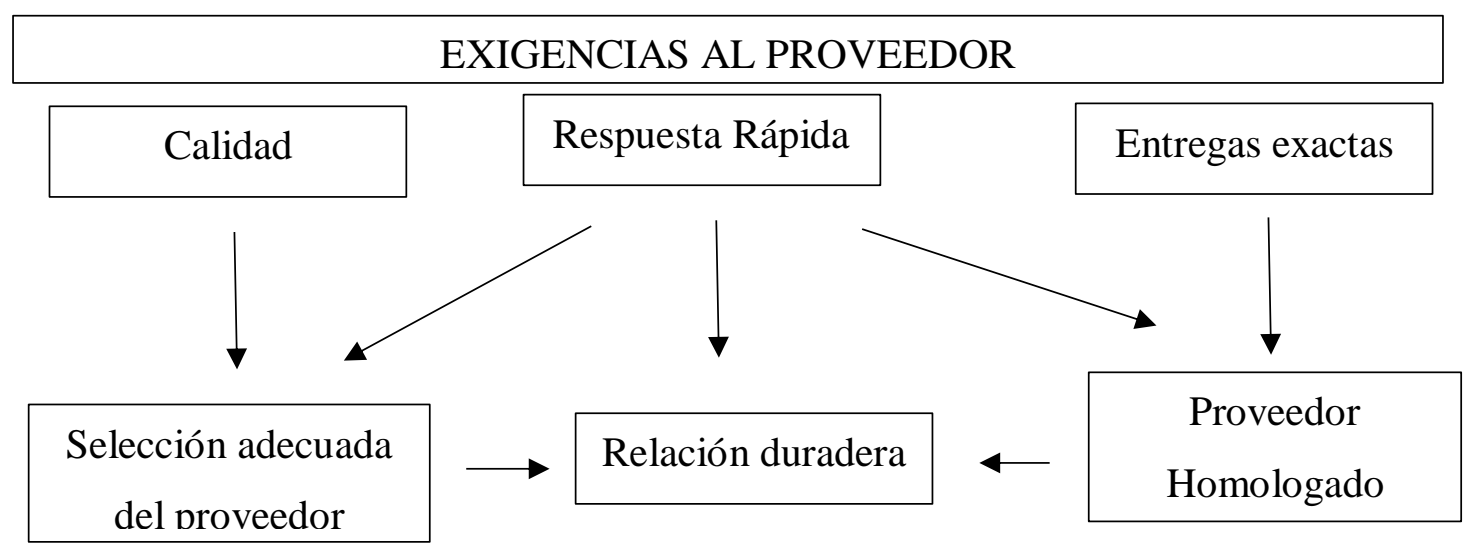


Anexo 23. Programación de Notificación Tipo Pull

SECTOR-TEXTIL EXPORTADOR

(PYME)
PROGRAMACIÓN DE NOTIFICACIÓN TIPO PULL

\begin{tabular}{c|c|c|}
\hline Código: & Versión: & Página: \\
\hline COMP-PNP-01 & 01 & 1 de 4 \\
\hline
\end{tabular}

\section{PROGRAMACIÓN}

\section{DE}

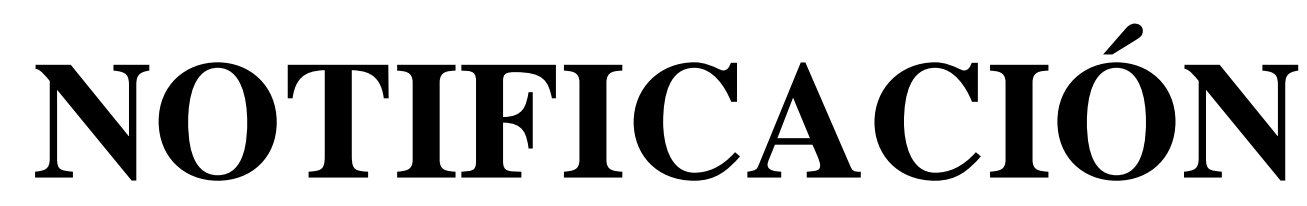

\section{TIPO PULL}




\begin{tabular}{|c|c|c|}
\hline Código: & Versión: & Página: \\
\hline COMP-PNP-01 & 01 & 2 de 4 \\
\hline
\end{tabular}

\section{OBJETIVO:}

Realizar un mapeo de los productos y las compras, a través de la programación de notificaciones se puede tener un registro de la frecuencia con la que se pide un mismo producto y generar una programación más exacta para el siguiente pedido. Para el desarrollo de la programación se puede utilizar Excel o softwares de fácil manejo.

2. RESPONSABILIDAD Y ALCANCE:

El presente procedimiento es realizado por el encargado de compras con apoyo de los colaboradores del área, este aplica a desde la adquisición del producto hasta el despacho del mismo a las áreas usuario.

\section{DESCRIPCIÓN DE LAS ACTIVIDADES}

\section{Programación de Notificación Tipo Pull}

Lista de necesidades específicas declaradas en el tiempo de artículos de compra, activada a partir del Planeamiento de requerimiento de materiales (PRM) y de la gestión de almacenes.

Los pasos se realizan automáticamente en función de los parámetros y políticas establecidas en la empresa.

\subsection{Gererar la Programación de Compras}

Se genera una programación de compras en la sesión de Programa de abastecimiento, de este programa se va a generar el pedido, el cual va a poseer un código de identificación, con este código de identificación se creará una programación de notificación tipo Pull con el mismo número de programación que el programa de abastecimiento tipo Pull. De esta forma los datos de previsión y los datos de orden están separados.

\subsection{Generar líneas de programación}

Las líneas de programación se generan en la sesión Líneas de programación de compras.

Si la programación de notificación tipo Pull se activa desde Gestión de almacenes o Producción, las líneas de programación detalladas en la sesión Líneas de programación de compras se generan de inmediato tomando en cuenta el código de la transacción.

Líneas de programación de compras tipo Pull: Se deben generar automáticamente.

Los estatus del producto que se pueden manejar son:

- Crear: El estatus de una línea de programación puede cambiarse a Creado a partir de los estatus Aprobado y No aprobado.

Aprobar: El estatus de una línea de programación puede cambiarse a Aprobado a partir 


\begin{tabular}{|c|c|c|}
\hline Código: & Versión: & Página: \\
\hline COMP-PNP-01 & 01 & 3 de 4 \\
\hline
\end{tabular}

de los estatus Creado y No aprobado.

- No aprobar: Un estatus de línea de programación puede cambiarse por No aprobado, a partir de los estatus Aprobado y Creado.

- Cancelar: El estatus de una línea de programación puede cambiarse a Cancelado a partir de los estatus Creado, Aprobado, No aprobado y Orden generada. Si desea cancelar una línea para la que se ha realizado un envío, la línea original adquiere el estatus Cancelado y se crea un envío nuevo para la línea con el fin de informar al proveedor sobre su cancelación.

Nota: No se pueden borrar líneas de programación con el estatus Recepción parcial, Recepción final o Facturado

\subsection{Generar un envío de compras}

Un envío de compras es un registro de las compras que se están realizando. Aquí se genera un registro de detalle de línea de envío de compras, en este se especifican los siguientes puntos:

- Fecha de programación del pedido

- Artículo

- Precio

- Estatus de pedido

- Detalles: Kilogramos, metraje, color, otras especificaciones

- Cantidad de pedido confirmada

- Fecha de confirmación

- Fecha de finalización de entrega

- Cantidad de material comprado con posterioridad

\subsection{Listar el envío de Compras}

Una vez realizado el pedido se le coloca "Pedido Finalizado".

3.5. Insertar detalles de recepción

Los detalles de la recepción se insertan en una pestaña nueva de nombre "Programación de compras- Recepciones"

Una vez confirmada las recepciones en almacén, se procede a realizar la inspección final del producto.

En esta pestaña, se podrá observar las recepciones parciales o totales que se realizan para una determinada programación de compras. En esta sección se debe registrar:

- Cantidad de notas de entrega

- Cantidad recibida

- Cantidad rechazada y aprobada 
3.6. Actualizar historia y datos

La programación de compras debe ser actualizada en cada pedido realizado, para dar por finalizada la compra se debe colocar en la tabla donde se almacenaron los datos del pedido "Recepción final" y "Facturado". 


\section{Anexo 24. Ejemplo de Compras Calendarizadas}

Planeamiento de Producción emite una Solicitud de requerimiento al Área de Compras el día 06/06/2017, para abastecer un pedido de 10000 unidades de T-SHIRTS de punto de algodón color rojo. El pedido debe ser enviado al cliente final en 45 días. A continuación, se presenta la Solicitud de requerimiento (PRO-SR-01) elaborado por el cliente interno, en este caso Producción.

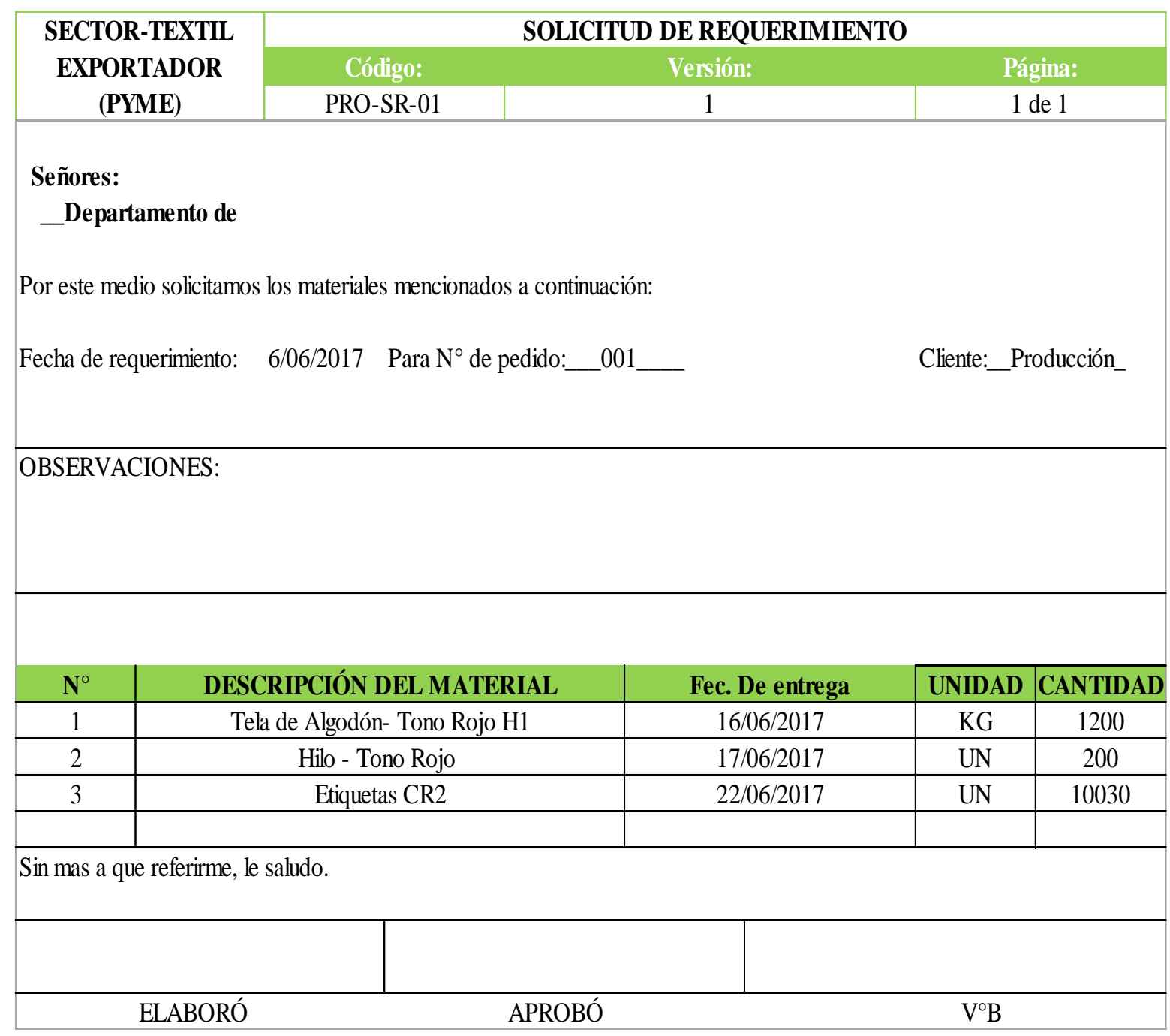

El departamento de compras elabora el Plan calendarizado de compras para los tres productos más importantes para el proceso de Confección (tela, hilo y etiquetas), para este estudio se pone énfasis en el abastecimiento de la Tela, por tal motivo la Orden de 
Compra se genera primero. Desde la recepción del requerimiento, recurren 3 días para la emisión de la Orden de compra, por ello se emite la O/C de la Tela el día 09/06/2017, la cantidad de tela requerida por Producción es de $1200 \mathrm{~kg}$, pero se tiene en almacén $80 \mathrm{~kg}$ del tipo de tela solicitado, por ello solo se realizará la compra de $1120 \mathrm{~kg}$. El proveedor abastece el producto luego de 6 días, antes de la estandarización del proceso, el abastecimiento tomaba 8 días, de los cuales 2 días representaban retraso del proveedor por defectos en la información transferida y la falta de planificación. En el caso del hilo, se emite la O/C el día 15/05, debido a que este se utiliza en el proceso de Costura, similar es el caso de las etiquetas, para las cuales se emite la O/C el día 17/06/17, estas se utilizan al término del proceso de costura, para este caso se pide $30 \%$ más de etiquetas para atender defectos por si hubiera fallas al colocarlas en las prendas.

PROGRAMA DE ABASTECIMIENTO PARA PEDIDO DE 10000 T-SHIRTS

\begin{tabular}{|c|c|c|c|c|c|c|c|c|c|c|c|c|}
\hline & $\begin{array}{c}\text { Solicitud de } \\
\text { Requerimiento }\end{array}$ & $\mathrm{N}^{\circ} \mathrm{DE} \mathrm{O} / \mathrm{C}$ & $\begin{array}{c}\text { Fecha de Emisión } \\
\text { de } 0 / C\end{array}$ & DESCRIPCIÓN DEL MATERIAL & $\begin{array}{r}\text { CANTIDAD } \\
\text { REQUERIDA } \\
\end{array}$ & ALMACÉN & $\begin{array}{c}\text { CANTIDAD } \\
\text { A } \\
\text { COMPRAR } \\
\end{array}$ & UNIDAD & $\begin{array}{l}\text { Abastecimiento } \\
\text { del proveedor }\end{array}$ & $\begin{array}{l}\text { Recepción y } \\
\text { verificación }\end{array}$ & $\begin{array}{c}\text { Fecha de entrega } \\
\text { programada }\end{array}$ & $\begin{array}{c}\text { Fecha de } \\
\text { entrega real }\end{array}$ \\
\hline \multirow{3}{*}{ PRO-SR-01 } & \multirow{3}{*}{ 6/06/2017 } & 001 & \begin{tabular}{|l|}
$09 / 06 / 2017$ \\
\end{tabular} & TELA DE ALGODÓN-TONO ROJO H1 & 1200 & \begin{tabular}{|l|}
80 \\
\end{tabular} & 1120 & KG & 6 días & 1día & $16 / 06 / 2017$ & $16 / 06 / 2017$ \\
\hline & & 002 & $15 / 06 / 2017$ & HILO-TONOROJO & 200 & 12 & 188 & UN & 2 días & 1 día & $17 / 06 / 2017$ & 18/06/2017 \\
\hline & & 003 & $17 / 06 / 2017$ & ETIQUETAS CR2 & 10030 & 0 & 10030 & UN & 5 días & 1 día & $22 / 06 / 2017$ & $23 / 06 / 2017$ \\
\hline
\end{tabular}

Las fechas de entrega reales se han colocado con un margen de demora de 1 día, para considerar percances que pueda tener el proveedor.

Luego de realizar el planeamiento del abastecimiento se procede a realizar las órdenes de compra por tipo de producto o también se puede emitir una sola $\mathrm{O} / \mathrm{C}$ para los tres productos. 


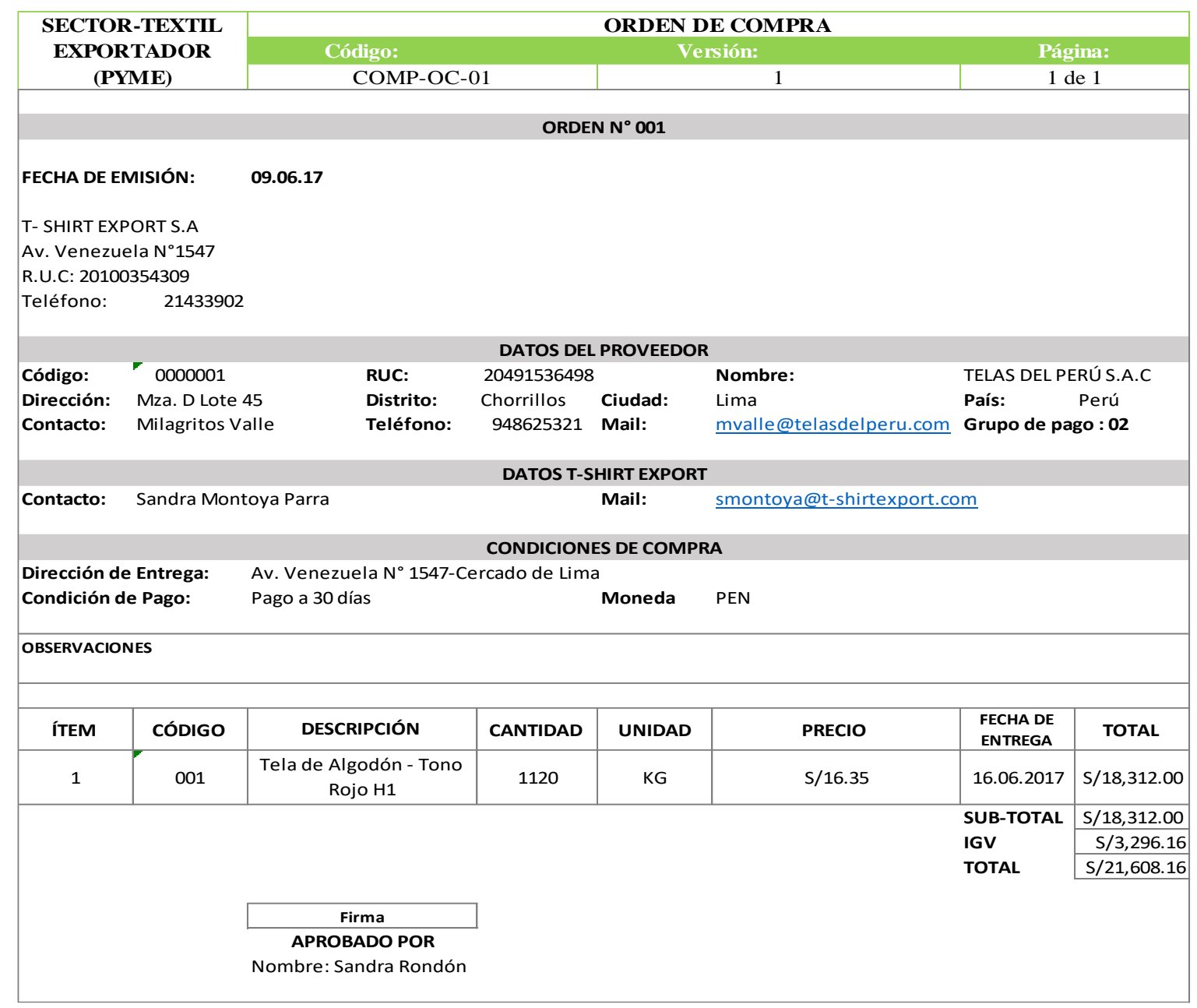




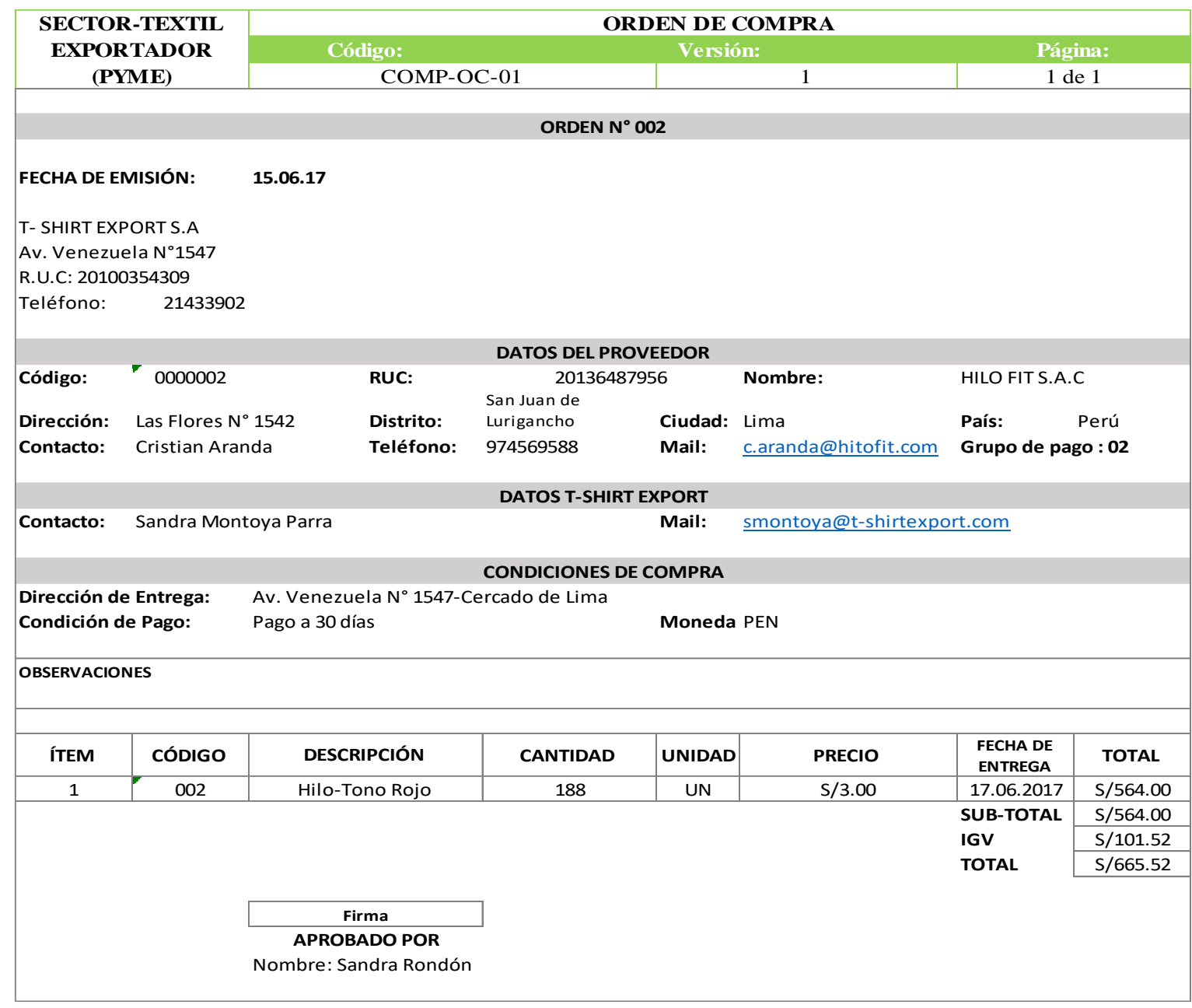

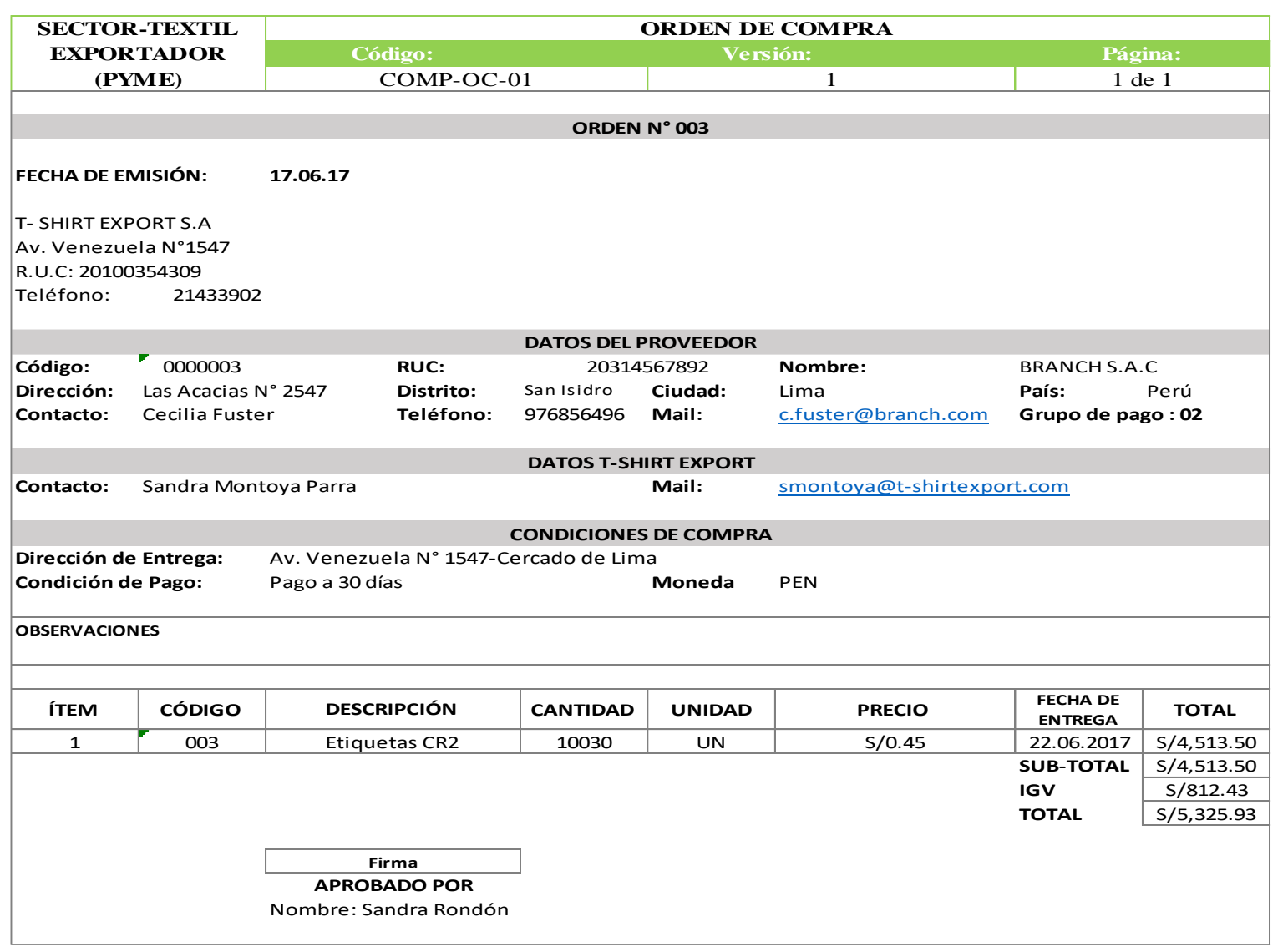


Para demostrar gráficamente el plan de abastecimiento se realiza un Diagrama de Gantt, el cual nos muestra las fechas en el que se debe realizar el pedido y además las fechas de abastecimiento por parte del proveedor.

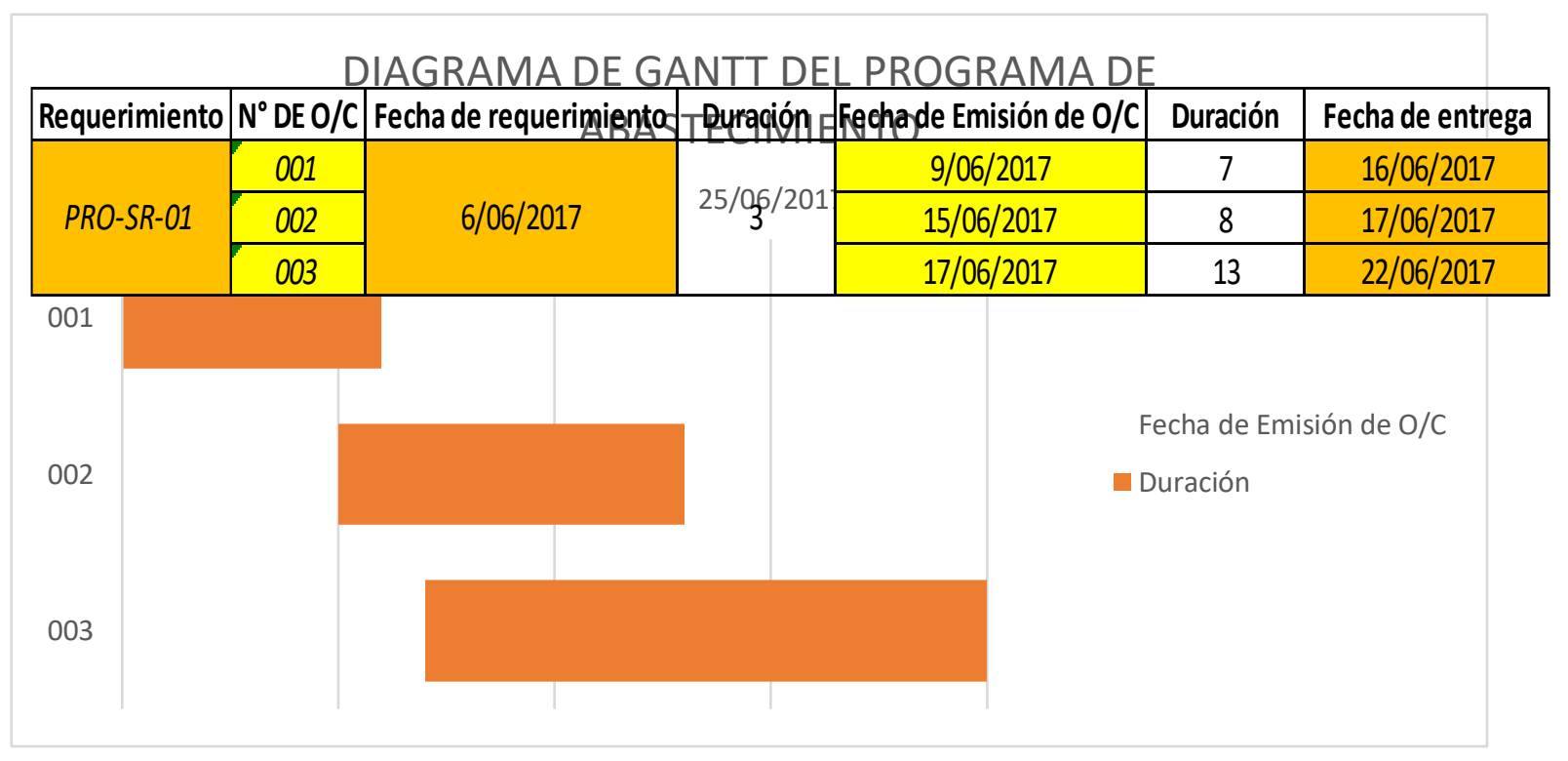

De esta manera el Departamento de compras tiene una visión general de las fechas de abastecimiento del pedido, así como también el plazo máximo que estará sujeto el proveedor para la entrega de los materiales. Asimismo, esta herramienta se utiliza como referencia para el desarrollo del PRM, ya que la información se encuentra ordenada y lista para ser empleada. 


\section{Anexo 25. Ejemplo de Planeamiento de Requerimiento de Materiales}

Tomando como referencia la Solicitud de requerimiento del ejemplo anterior, el Departamento de compra debe realizar el PRM para dicha solicitud.

Es importante señalar los materiales requeridos para producir 10000 T-SHIRTS solicitados en el ejemplo.

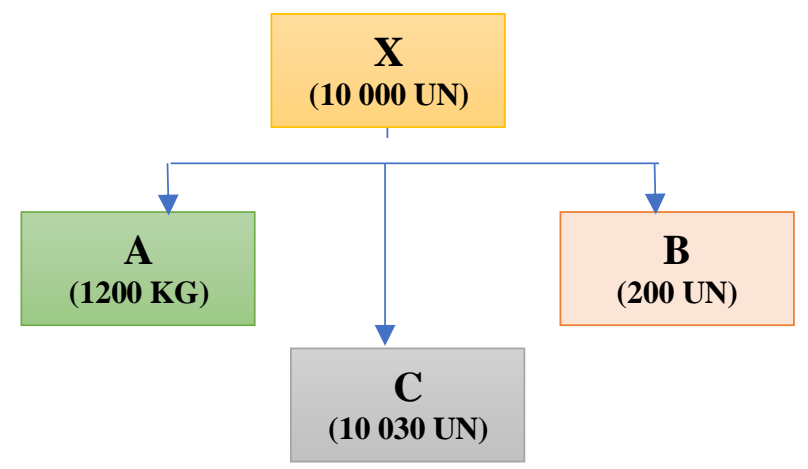

Para facilitar el desarrollo del PRM se le asigna una letra a cada material solicitado por Producción, en la tabla 23.1 se muestran las cantidades y unidades en las que se encuentra cada material.

Tabla 23.1

\begin{tabular}{|c|c|c|c|}
\hline & PRODUCTO & UNIDAD & CANTIDAD \\
\hline$x$ & T-SHIRT & unidades & 10000 \\
\hline A & Telas & $\mathrm{Kg}$ & 1200 \\
\hline B & Hilo & unidades & 200 \\
\hline C & Etiquetas & unidades & 10030 \\
\hline
\end{tabular}

Como se observa en la tabla 23.2, se realiza la planificación por cada material requerido. Por ejemplo, en el caso de la Tela, se requiere $1200 \mathrm{~kg}$ (Necesidad bruta) para el día 16/06/2017, pero se cuenta con $80 \mathrm{~kg}$ en el almacén (Saldo disponible proyectado), por lo cual solo se tiene una Necesidad Neta de $1120 \mathrm{~kg}$ de Tela. Para esta cantidad se tiene que emitir la Orden de compra (Expedición de pedido planeado) el día 09/06/2017, ya que el tiempo de abastecimiento de este producto es de 6 días.Para realizar el PRM, es esencial haber realizado el Plan de compras calendarizadas previamente, ya que este facilita la información su desarrollo. 
Tabla 23.2: PLANEAMIENTO DE REQUERIMIENTO DE MATERIAL (PRM)

$\begin{array}{llllllllllllllllllllll}7 / 06 / 2017 & 8 / 06 / 2017 & 9 / 06 / 2017 & 10 / 06 / 2017 & 11 / 06 / 2017 & 12 / 06 / 2017 & 13 / 06 / 2017 & 14 / 06 / 2017 & 15 / 06 / 2017 & 16 / 06 / 2017 & 17 / 06 / 2017 & 18 / 06 / 2017 & 19 / 06 / 2017 & 20 / 06 / 2017 & 21 / 06 / 2017 & 22 / 06 / 2017\end{array}$ DÍAS

X

\begin{tabular}{|c|c|c|c|c|c|c|c|c|c|c|c|c|c|c|c|c|}
\hline PRODUCTO & 1 & 2 & 3 & 4 & 5 & 6 & 7 & 8 & 9 & 10 & 11 & 12 & 13 & 14 & 15 & 16 \\
\hline Necesidades Brutas & & & & & & & & & & & $* 1200 \mathrm{~kg}$ & & & & & \\
\hline \multicolumn{17}{|l|}{ Entradas programadas } \\
\hline \multicolumn{17}{|l|}{ Existencias del pedido } \\
\hline \multicolumn{17}{|l|}{ Necesidades netas } \\
\hline \multicolumn{17}{|l|}{ Entradas de pedidos planeadas } \\
\hline \multicolumn{17}{|l|}{ Expedición de pedidos planeados } \\
\hline Necesidades Brutas & & & & & & & & & & 1200 & & & & & & \\
\hline \multicolumn{17}{|l|}{ Entradas programadas } \\
\hline Existencias del pedido & 80 & 80 & 80 & 80 & 80 & 80 & 80 & 80 & 80 & 0 & & & & & & \\
\hline Necesidades netas & & & & & & & & & & 1120 & & & & & & \\
\hline Entradas de pedidos planeadas & & & & & & & & & & 1120 & & & & & & \\
\hline Expedición de pedidos planeados & & & 1120 & & & & & & & & & & & & & \\
\hline Necesidades Brutas & & & & & & & & & & & 200 & & & & & \\
\hline \multicolumn{17}{|l|}{ Entradas programadas } \\
\hline Existencias del pedido & 12 & 12 & 12 & 12 & 12 & 12 & 12 & 12 & 12 & 12 & 0 & & & & & \\
\hline Necesidades netas & & & & & & & & & & & 188 & & & & & \\
\hline Entradas de pedidos planeadas & & & & & & & & & & & 188 & & & & & \\
\hline Expedición de pedidos planeados & & & & & & & & & 188 & & & & & & & \\
\hline Necesidades Brutas & & & & & & & & & & & & & & & & 10030 \\
\hline \multicolumn{17}{|l|}{ Entradas programadas } \\
\hline Existencias del pedido & 0 & 0 & 0 & 0 & 0 & 0 & 0 & 0 & 0 & 0 & 0 & 0 & 0 & 0 & 0 & 0 \\
\hline Necesidades netas & & & & & & & & & & & & & & & & 10030 \\
\hline Entradas de pedidos planeadas & & & & & & & & & & & & & & & & 10030 \\
\hline Expedición de pedidos planeados & & & & & & & & & & & 10030 & & & & & \\
\hline
\end{tabular}

NOTA: * $1200 \mathrm{Kg}$ para iniciar a producir los 10000 T-SHIRTS 


\section{Anexo 26. Plan Estratégico con Proveedores}

SECTOR-TEXTIL EXPORTADOR (PYME)
PLAN ESTRATÉGICO CON PROVEEDORES

\begin{tabular}{|c|c|c|}
\hline Código: & Versión: & Página: \\
\hline COMP-PEP-01 & 01 & 1 de 4 \\
\hline
\end{tabular}

\section{PLAN}

\section{ESTRATÉGICO}

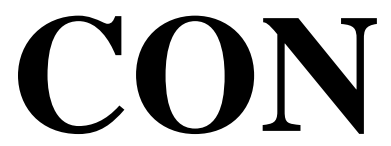

PROVEEDORES 


\section{OBJETIVO:}

Proveer información sobre los procedimientos a seguir para establecer relaciones con los proveedores que permitan mejorar la sinergia entre el departamento de compras y los proveedores, de esta manera la empresa se asegura de la ejecución adecuada en la entrega de productos, todo ello a base de confianza y cumplimiento de los reglamentos establecidos. Asimismo, busca brindar una retroalimentación a los proveedores para mejorar su rendimiento

\section{ALCANCE:}

Este Plan estratégico tiene como alcance a todo el proceso donde interfiere directamente el proveedor; es decir, desde la firma del contrato con el proveedor hasta el abastecimiento completo del producto.

\section{DESCRIPCIÓN DE LAS ACTIVIDADES}

\subsection{Acuerdos de Pago:}

Se plantea las condiciones de pago en la Política de pago a proveedores (COMP-PPP-01).

\subsection{Programa de asociación con proveedores:}

Se definen estrategias de negociación con los proveedores aplicando la negociación colaborativa "Yo gano, tu ganas".

\section{Términos legales y comerciales:}

Se lleva a cabo el contrato de Compra-venta el cual es de suma importancia para iniciar el proceso de compra.

Obligaciones del proveedor:

- Entrega a tiempo del producto.

- Garantía del producto frente a ciertas contingencias.

- Entrega completa del producto.

- Entrega de productos cumpliendo los estándares de calidad solicitado por el cliente.

Obligaciones del comprador:

- Pago del precio acordado.

- Cumplimiento del tiempo de pago.

- Cumplimiento del medio o lugar de pago. 


\section{Tiempo:}

De acuerdo al contrato, el tiempo determinado para la compra del producto se determina en los contratos acordados, las fechas estipuladas, de manera que no habrá atrasos de pagos de ambas partes.

\section{Otras consideraciones:}

La empresa y el proveedor pueden llegar a un acuerdo para que la empresa realice adelanto de pago al proveedor por entrega del pedido con días de adelanto.

La empresa puede brindar al proveedor retroalimentación para que este mejore su proceso y reduzca su tiempo de entrega.

Se puede incluir a los proveedores en algunas charlas y capacitaciones que se brinden en la empresa, de esta manera se contribuye a mejorar la calidad de sus productos y procesos lo cual genera una ventaja competitiva para el proveedor.

La empresa puede adelantar sus pagos al proveedor como incentivo por cumplimiento de los requerimientos, tiempo de entrega, condiciones de compra y calidad.

\section{Cierre de acuerdos:}

El cierre de la negociación puede ser con acuerdo o sin él. Es decir, se debe cerciorar que no queda ninguna duda o confusión de ambas partes.

Una vez cerrado el acuerdo se debe recoger por escrito todos los aspectos del mismo.

Hay que tener en cuenta los detalles del documento para evitar problemas futuros que puedan llegar a una disputa legal.

\subsection{Plan de auditoría in Situ:}

Se plantean las actividades a realizar para llevar a cabo la auditoría en las instalaciones del proveedor, de esa manera se evalúa la capacidad del sistema productivo de este. El Plan de auditoría (COMP-PA-01) complementa al Procedimiento de Seguimiento de los proveedores para asegurar el cumplimiento de los requerimientos del material y las entregas a tiempo, este se debe realizar por cada visita a la planta o local del proveedor. Para llevar a cabo el Plan de auditoría in Situ se utilizan los lineamientos de la Guía básica para la auditoría (COMP-GA-01).

\section{Anexos}


SECTOR-TEXTIL EXPORTADOR

(PYME)

\section{PLAN ESTRATÉGICO CON PROVEEDORES}

\begin{tabular}{c|c|c|}
\hline Código: & Versión: & Página: \\
\hline COMP-PEP-01 & 01 & 4 de 4 \\
\hline
\end{tabular}

Anexo 1: COMP-PA-01 "Plan de Auditoría In Situ"

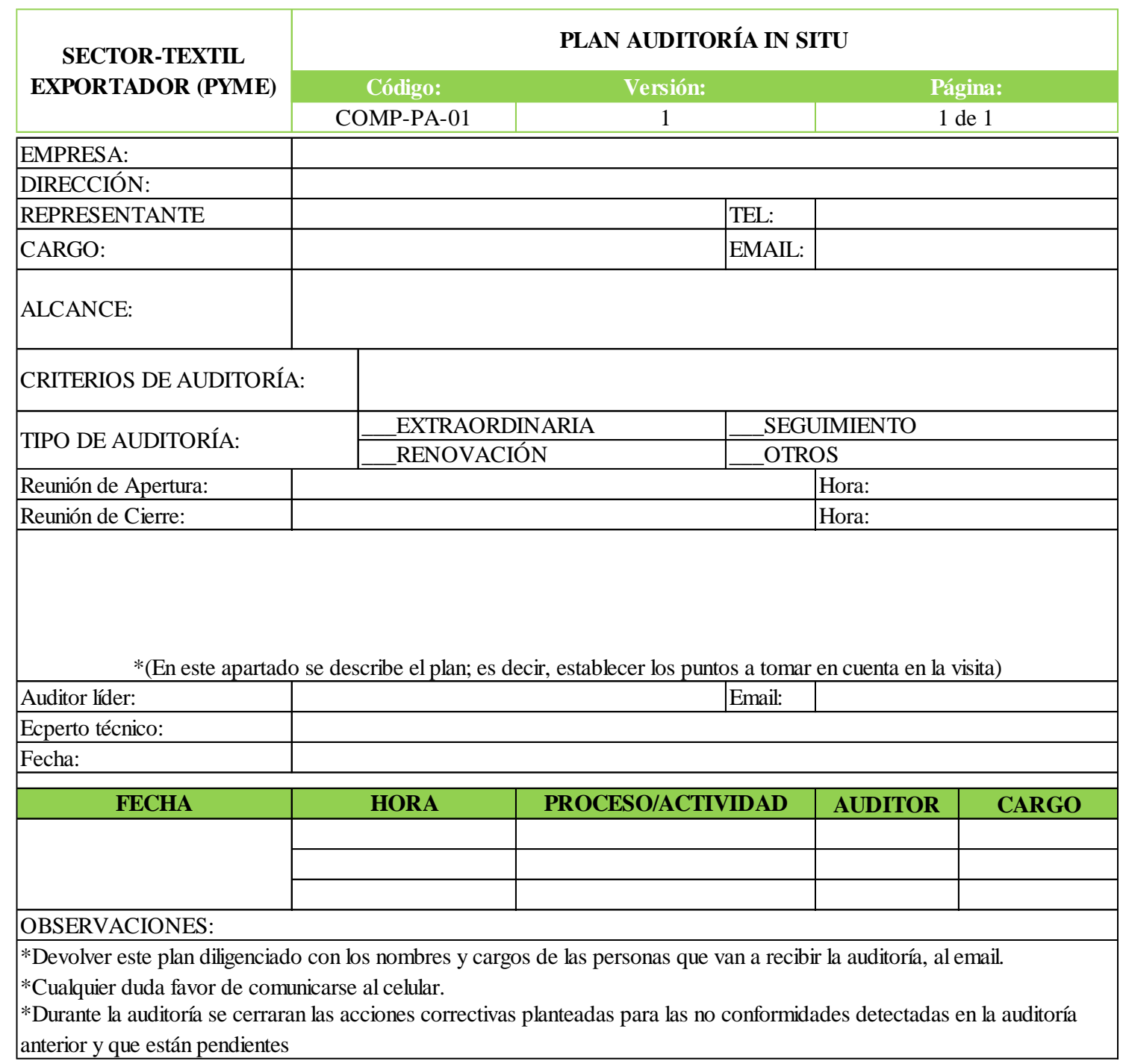




\section{Anexo 27. Política de Pago a Proveedores}

SECTOR-TEXTIL EXPORTADOR (PYME)
POLÍ́TICA DE PAGO A PROVEEDORES

\begin{tabular}{|c|c|c|}
\hline Código: & Versión: & Página: \\
\hline COMP-PPP-01 & 01 & 1 de 4 \\
\hline
\end{tabular}

\section{POLÍTICA DE}

PAGO A

PROVEEDORES 


\begin{tabular}{|c|c|c|}
\hline Código: & Versión: & Página: \\
\hline COMP-PPP-01 & 01 & 2 de 4 \\
\hline
\end{tabular}

\section{OBJETIVO:}

Mantener las buenas relaciones comerciales con los proveedores de la empresa a través del cumplimiento de las condiciones pactadas.

2. ALCANCE:

Este Plan de Contingencia tiene como alcance a todos aquellos eventos que pueden generar algún problema para el desarrollo normal de los procedimientos de compras.

\section{DEFINICIONES}

- Proveedores: Personas naturales o jurídicas que suministran bienes y servicios a la empresa.

- Matriz de proveedores: Conjunto clasificado de personas naturales o jurídicas habilitadas para abastecer insumos, productos y servicios a la empresa.

\section{POLÍTICA DE PAGO}

Se establece la siguiente política dentro del pago a proveedores:

La empresa cancelará el dinero adeudado a sus proveedores de bienes y servicios, tomando en cuenta las siguientes condiciones:

- La programación de pagos estará a cargo de contabilidad, bajo la dirección y firma de Administración o Gerencia.

- Se realizarán los pagos de acuerdo a los plazos establecidos con los proveedores que puede ser pago a treinta días o cuarenta y cinco días, contados a partir de la fecha de recibo de la factura y/o cuenta de cobro en las instalaciones de la empresa, siempre y cuando se tenga la disponibilidad de caja.

- El proveedor puede realizar un convenio con alguna entidad financiera para poder adquirir adelanto de pago si lo requiere.

- Aprovechamiento de descuentos: La administración, gerencia o área contable analizará y procurará, en la medida en que su liquidez lo permita, aprovechar los descuentos por pronto pago ofrecidos por proveedores, siempre y cuando estos superen las tasas de rentabilidad ofrecidas por el mercado financiero.

- Se exceptúan de la política general, los pagos de bienes o servicios exclusivos, es decir, aquellos que, por condición especial de su naturaleza, despacho, transporte o manejo por un único proveedor, exigen la cancelación en un plazo diferente al que fija la política general (ejemplo: impuestos, servicios públicos, seguros y algunos honorarios)

Procedimiento de pago: La cancelación de facturas y/o cuentas de cobro a los proveedores se 


\begin{tabular}{|c|c|c|}
\hline Código: & Versión: & Página: \\
\hline COMP-PPP-01 & 01 & 3 de 4 \\
\hline
\end{tabular}

hará con la presentación de la factura, validando previamente que el número de la Orden de compra figure en la factura y guías, también se debe verificar la solicitud o justificación del producto o servicio, la disponibilidad presupuestal, el contrato, el acta de recibo a satisfacción donde aplique.

- Para la aceptación de su factura deberá adjuntar copia de la Orden de compra, guías y certificados.

- La empresa no se hace responsable por demora del pago por error documentario del proveedor.

- Solo se aceptarán facturas hasta 90 días después de emitida la conformidad.

Días de pago: Se exceptúan los pagos de aquellos bienes y servicios que por tener reglamentaciones específicas exigen el pago en fechas preestablecidas.

\section{Términos y condiciones}

1.- Se deja establecido que el PROVEEDOR otorga su conformidad respecto de todas y cada una de las disposiciones contenidas en el presente documento a la recepción de este por alguno de sus representantes, mantenga o no las facultados estatutarias correspondientes, salvo que en un plazo no mayor a 24 horas de haberla recibido haya manifestado por escrito su disconformidad con algún o todos los puntos del documento.

2.- Para el despacho de los artículos o prestación de servicios el PROVEEDOR observará el lugar y oportunidad señalada en la ORDEN. En caso no se observen las referidas condiciones, LA EMPRESA, según el caso, podrá a su discreción cancelar el pedido o rechazar el entregable, sin estar obligado a indemnizar a el PROVEEDOR por ningún concepto. En caso de aceptar el entregable, LA EMPRESA se encuentra facultado a aplicar una penalidad ascendente a $0.1 \%$ del monto total de la ORDEN por cada día de atraso. Las circunstancias de casos fortuitos o fuerza mayor serán comunicadas a LA EMPRESA para su evaluación y aprobación.

3.- En caso que se pacte la entrega a EL PROVEEDOR de un adelanto, EL PROVEEDOR entregará una Carta Fianza a satisfacción de la EMPRESA por dicho monto, incluido el IGV. La referida Carta Fianza será otorgada por una institución bancaria de primera línea, solidaria, incondicional e irrevocable y de realización automática, sin beneficio de excusión, ejecutable a simple requerimiento (carta simple) por parte de LA EMPRESA.

4. LA EMPRESA se reserva el derecho a inspeccionar las instalaciones de EL PROVEEDOR (oficinas, plantas y bodegas de almacenaje) donde la mercancía objeto de la ORDEN es elaborada o almacenada a efectos de constatar el cumplimiento de normas y buenas prácticas de producción. Cualquier daño que sufra la mercadería por defecto de empaque o manipuleo u otra circunstancia será de cuenta de EL PROVEEDOR.

5.- Cualquier derecho de EL PROVEEDOR que no esté expresamente consignado en el 


\begin{tabular}{|c|c|c|}
\hline Código: & Versión: & Página: \\
\hline COMP-PPP-01 & 01 & 4 de 4 \\
\hline
\end{tabular}

presente documento no será exigible a LA EMPRESA.

6.- Para efectos de cualquier notificación, las partes constituyen como su domicilio fiscal el consignado en la ORDEN.

7.- En lo previsto, ambas se someten a lo establecido por las normas del Código Civil Peruano y demás del sistema jurídico que resulten aplicables.

8.- En caso de que las partes no hubieran suscrito un contrato que regule el objeto de la presente ORDEN, queda establecido que el contenido de la ORDEN contendrá la totalidad de las estipulaciones vinculantes entre las partes y dejará sin efecto cualquier acuerdo preexistente o comunicación verbal o escrita entre las partes o sus representantes autorizados o no. En el supuesto que las partes hayan suscrito un contrato, se deja claramente determinado que lo establecido en dicho contrato regulará íntegramente las relaciones entre las partes para el cumplimiento del suministro de bienes o servicios que brindará el PROVEEDOR, entendiéndose que para fines de facilitar el suministro consecutivo de bienes o servicios que brindará EL PROVEEDOR, entendiéndose que para fines de facilitar el suministro consecutivo de bienes o servicios, las partes suscribirán ORDENES que formarán parte de este contrato. En caso de discrepancia entre las estipulaciones establecidas en el contrato y la ORDEN prevalecerá lo establecido en el Contrato.

\section{Lineamientos para la implementación de la política:}

- Considerar tanto la satisfacción del cliente como del proveedor con el cumplimiento de los acuerdos contractuales.

- Prevenir riesgos de liquidez y de imagen con un buen relacionamiento con el proveedor.

\section{Resultados esperados de la política:}

- Satisfacer las necesidades del cliente interno, pero también del proveedor

- Uso eficiente de los recursos.

\section{Indicadores:}

- $\quad$ Satisfacción de proveedores

- Pagos realizados al mes 
Anexo 28. Guía Básica para la Auditoría

SECTOR-TEXTIL

EXPORTADOR

(PYME)
GUÍA BÁSICA PARA LA AUDITORÍA
Página:

1 de 4

\section{GUÍA BÁSICA}

PARA LA

AUDITORÍA 


\begin{tabular}{|c|c|c|}
\hline Código: & Versión: & Página: \\
\hline COMP-GA-01 & 01 & 2 de 4 \\
\hline
\end{tabular}

\section{OBJETIVO:}

Proporcionar al auditado la oportunidad de mejorar su proceso.

La evaluación de la capacidad del sistema del proveedor, para asegurar el cumplimiento de los requerimientos y las condiciones establecidas entre la empresa y proveedor.

\section{RAZONES PARA REALIZAR UNA AUDITORÍA:}

Sirve como herramienta de percepción del estado en que se encuentra la entidad a evaluar, para proceder con la calificación respectiva.

3. VISIÓN GENERAL DE LAS ACTIVIDADES DE AUDITORÍA:

\begin{tabular}{|c|}
\hline Inicio de la auditoría \\
\hline Designación del auditor jefe \\
\hline $\begin{array}{c}\text { Definición de los objetivos, el alcance y los criterios } \\
\text { de auditoría }\end{array}$ \\
\hline Selección del equipo auditor \\
\hline $\begin{array}{l}\text { Establecimiento del contacto inicial con el auditado } \\
\text { (proveedor) }\end{array}$ \\
\hline Revisión de los procesos y del producto \\
\hline $\begin{array}{l}\text { Revisión del proceso productivo del material } \\
\text { solicitado }\end{array}$ \\
\hline $\begin{array}{c}\text { Inspección del producto antes y después de ser } \\
\text { procesado }\end{array}$ \\
\hline Preparación de las actividades de auditoría in situ \\
\hline Preparación del plan de auditoría \\
\hline Asignación de tareas al equipo auditor \\
\hline Preparación de los documentos de trabajo \\
\hline Realización de las actividades de in situ \\
\hline Realización de la reunión de apertura \\
\hline Comunicación durante la auditoría \\
\hline $\begin{array}{l}\text { Papel y responsabilidades de los observadires y } \\
\text { gupias }\end{array}$ \\
\hline Generación de hallazgos de la auditoría \\
\hline Realización de la reunión de cierre \\
\hline $\begin{array}{c}\text { Preparación, aprobación y distribución del } \\
\text { informe de la auditoría }\end{array}$ \\
\hline Preparación del informe de la auditoría \\
\hline Aprobación y distribución del informe de la auditoría \\
\hline $\begin{array}{c}\text { Finalización de la auditoría } \\
\text { Actividades de seguimiento al proveedor }\end{array}$ \\
\hline
\end{tabular}




\begin{tabular}{|c|c|c|}
\hline Código: & Versión: & Página: \\
\hline COMP-GA-01 & 01 & 3 de 4 \\
\hline
\end{tabular}

\section{CUALIFICACIÓN DE LOS AUDITORES:}

- Cualidades Personales: Personas abiertas, maduras, con sentido común, tenacidad, realistas y con capacidad de análisis. Aptitud para ver las situaciones complejas desde un punto de vista general y con espíritu cooperativo y comunicativo.

- Formación y Experiencia: Estudios secundarios, técnicas de evaluación de pruebas, apreciaciones y de informes.

- Mantenimiento de la aptitud: Participar en cursos de formación y/o perfeccionamiento, estar sometido al examen de sus actuaciones por el comité.

\section{RESPONSABILIDADES DE LOS AUDITORES:}

- Auditor líder: Conviene confiar a un auditor las responsabilidades del equipo auditor si es el caso.

- Responsabilidades:

- Planear y gerenciar todos los pasos de la auditoría.

- Conducir la auditoría.

- Acompañar en la selección del equipo y en su instrucción.

- Controlar los conflictos y propiciar la superación de situaciones difíciles.

- Conducir y controlar todas las reuniones con el equipo auditado.

- Tomar decisiones en la auditoría.

- Comunicar los resultados de las auditorías sin atraso.

- Comunicar los mayores obstáculos encontrados.

- Comunicar inmediatamente las no conformidades críticas.

- Tener la habilidad de comunicación eficaces.

- Informar los resultados, conclusiones, recomendaciones finales de la auditoría.

\section{RESPONSABILIDADES DE LOS AUDITORES:}

- Informar al personal afectado, sobre el objetivo y finalidad de la auditoría; designar al personal de apoyo que acompañará al equipo auditor en determinadas actividades de la auditoría.

- Poner a disposición del equipo auditor, los medios necesarios para asegurar el desarrollo óptimo de la auditoría.

- Cooperar con los auditores para alcanzar los objetivos de la auditoría. 
- Establecer e implementar las acciones correctivas, atendiendo al informe de la auditoría.

\section{ETAPAS DEL PROCESO DE AUDITORÍA:}

- Preparación de la auditoría: Consiste en una serie de diferentes elementos como:

- Determinar el alcance de la auditoría.

- Estudio de los documentos importantes.

- Acordar el itinerario o programa de auditoría.

- Preparación de listas de verificación y cuestionarios.

- Ejecución de la auditoría: Los responsables de la gestión del programa de auditoría deben:

- Establecer los objetivos y la extensión del programa de auditoría.

- Establecer las responsabilidades, los recursos y los procedimientos.

- Asegurarse de la implementación del programa de auditoría.

- Controlar, revisar y mejorar el programa de auditoría.

\section{- Informe de la auditoría}

- La elaboración del informe es responsabilidad del auditor líder que representa al Departamento de compras.

- El informe tiene por objeto exponer los hechos, analizar las causas y recomendar acciones correctoras.

- En caso de duda sobre alguna situación auditada, es necesario aclararla antes de presentar el informe.

- Debe contener: objetivo, alcance, observaciones de No conformidad.

\section{RECOMENDACIONES PRÁCTICAS:}

- El líder o el equipo auditor deben adoptar comportamientos que aseguren el éxito de la auditoría.

- No emitir apreciaciones personales, deben basar sus apreciaciones en hechos.

- Mejorar a la mejora de las No conformidades encontradas ya sea en el proceso o el producto.

- Hacer preguntas consistentes que identificar fallas o mejoras.

- Permitir al entrevistado responder y dar aportes. Además, demostrar paciencia y nunca calificar y descalificar y adaptarse a la situación y auditado. 
Anexo 29. Plan de Contingencia

SECTOR-TEXTIL EXPORTADOR

(PYME)
PLAN DE CONTINGENCIA

\begin{tabular}{c|c|c}
\hline Código: & Versión: & Página: \\
\hline COMP-PCG-01 & 01 & 1 de 4 \\
\hline
\end{tabular}

PLAN DE

CONTIGENCIA 
PLAN DE CONTINGENCIA

\begin{tabular}{|c|c|c|}
\hline Código: & Versión: & Página: \\
\hline COMP-PCG-01 & 01 & 2 de 4 \\
\hline
\end{tabular}

\section{OBJETIVO:}

Proveer información sobre los procedimientos a seguir para enfrentar adecuadamente posibles contingencias durante el desarrollo del proceso de compras y de esta forma minimizar los impactos que puedan ocasionarse sobre la organización, los trabajadores y los clientes, poniendo énfasis en el siguiente punto:

- Contar con los mecanismos y las directrices necesarias para brindar una eficiente respuesta a situaciones de emergencia durante el desarrollo de las actividades diarias que se realizan.

- Preparar al personal involucrado en el proceso de compra para afrontar un evento que pueda dar origen a un problema en la entrega del pedido al cliente.

\section{ALCANCE:}

Este Plan de Contingencia tiene como alcance a todos aquellos eventos que pueden generar algún problema para el desarrollo normal de los procedimientos de compras.

\section{DESCRIPCIÓN DE LAS ACTIVIDADES:}

3.1 Medidas de carácter preventivo:

- Se sigue de manera estricta los procedimientos establecidos para la realización del proceso de compra.

- Se realiza el seguimiento de proveedores y compras establecido.

3.2 Medidas ante eventualidades durante el proceso de compras:

\section{- Compras:}

Si mientras se realiza el proceso de compra ocurre algún error (cantidades, fechas y especificaciones), el encargado de compra o responsable de generar la O/C deberá corregirlo de inmediato y comunicar los cambios tanto al cliente interno (PCP) y al proveedor si es que el la O/C ya se aprobó y llego a él.

Si para la aprobación de la $\mathrm{O} / \mathrm{C}$ no se cuenta con la firma para terminar la emisión de la $\mathrm{O} / \mathrm{C}$ se acude de inmediato al encargado (representante elegido) para que de esa forma se termine y concrete la emisión de la $\mathrm{O} / \mathrm{C}$ sin necesidad de esperar. 
PLAN DE CONTINGENCIA

\begin{tabular}{|c|c|c|}
\hline Código: & Versión: & Página: \\
\hline COMP-PCG-01 & 01 & 3 de 4 \\
\hline
\end{tabular}

\section{- Proveedor:}

Frente a la fecha de abastecimiento por parte del proveedor la empresa tendrá que volver a evaluar al proveedor para ver la factibilidad de que vuelva a compra.

Si es que ocurriera algún problema durante el abastecimiento el proveedor comunica de manera oportuna detalladamente los cambios y métodos que se tomaran para la solución.

\section{- Planeamiento de la Producción:}

Si es que no se calcula y describe detalladamente los requisitos de compra para elaborar el pedido, compras deberá de realizar el cálculo para saber qué cantidades pedir según los requerimientos de materiales para el pedido.

\section{ORGANIZACIÓN DE RESPONSABILIDADES:}

El área de compras es el responsable del plan de contingencia. Las funciones básicas son: programar, dirigir, ejecutar, y evaluar el desarrollo del plan.

Al producirse eventualidades, los miembros responsables del área de compras deberán de dirigir el plan de contingencia mediante las actividades descritas.

\section{ESTRUCTURA DE RESPONSABILIDADES}

La estructura permite establecer y tener una visión clara de a quién acudir en el momento de algún hecho anormal o cuando suceda alguna eventualidad saber a quién acudir.

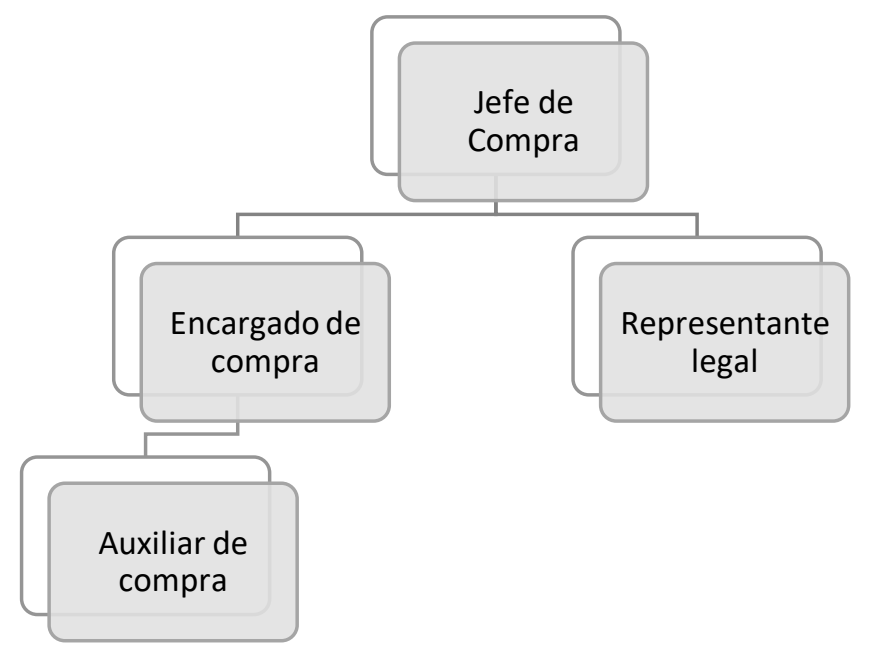


PLAN DE CONTINGENCIA

\begin{tabular}{|c|c|c|}
\hline Código: & Versión: & Página: \\
\hline COMP-PCG-01 & 01 & 4296 de 4 \\
\hline
\end{tabular}

6. INFORMACIÓN QUE DEBE PROPORCIONAR

- Proceso, lugar, fecha y hora de la eventualidad de lo que ha ocurrido.

- Acciones a tomar para la solución.

- Persona responsable de la ejecución y seguimiento para controlar y mitigar las eventualidades durante el proceso de compras.

- Todo el personal de las áreas involucradas debe conocer el plan de contingencia y acciones que se deben de realizar. 


\section{Anexo 30. Validación de Modelos por Experto}

-Validación del Jefe de Sistemas de Textiles of Perú S.A.C: El día miércoles 6 de Setiembre del 2017, la persona encuestada, también desempeña otros roles en la empresa como es la compra de materiales, responsable de recursos humanos y otras actividades. Luego de ser expuesto las propuestas y de describir cada uno de los criterios definidos en la matriz, el Ing.

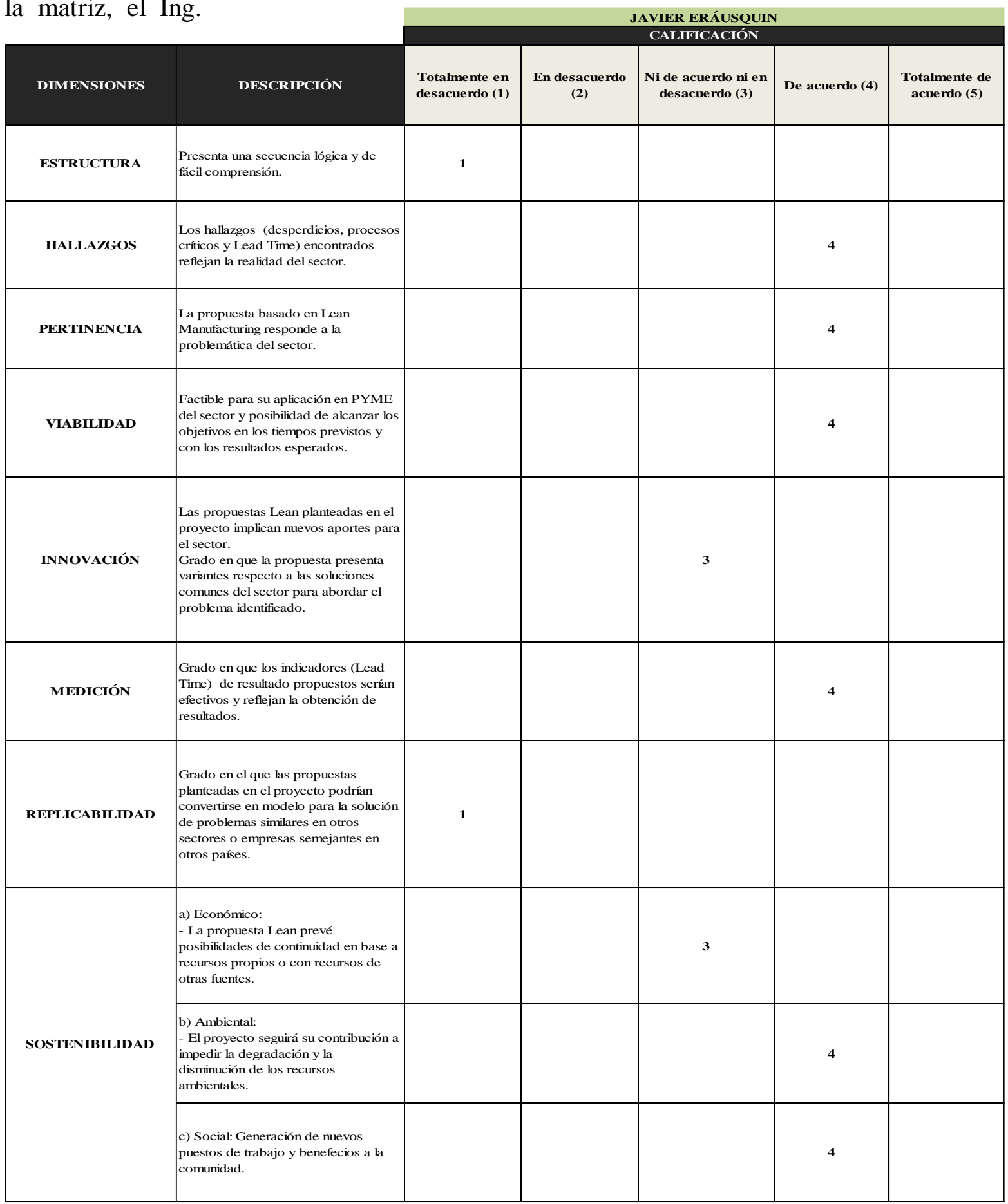

Javier Eráusquin, Jefe de Sistemas de Textiles of Perú, evaluó las propuestas de la siguiente manera. 
-Validación de la Jefa de Compras de Rainbow Textile S.A.C: El día lunes 18 de setiembre del 2017, luego de ser expuesto las propuestas y de describir cada uno de los criterios definidos en la matriz, la Ing. Prisilla Quezada, Jefe de Compras de Rainbow Textile, evaluó las propuestas de la siguiente manera.

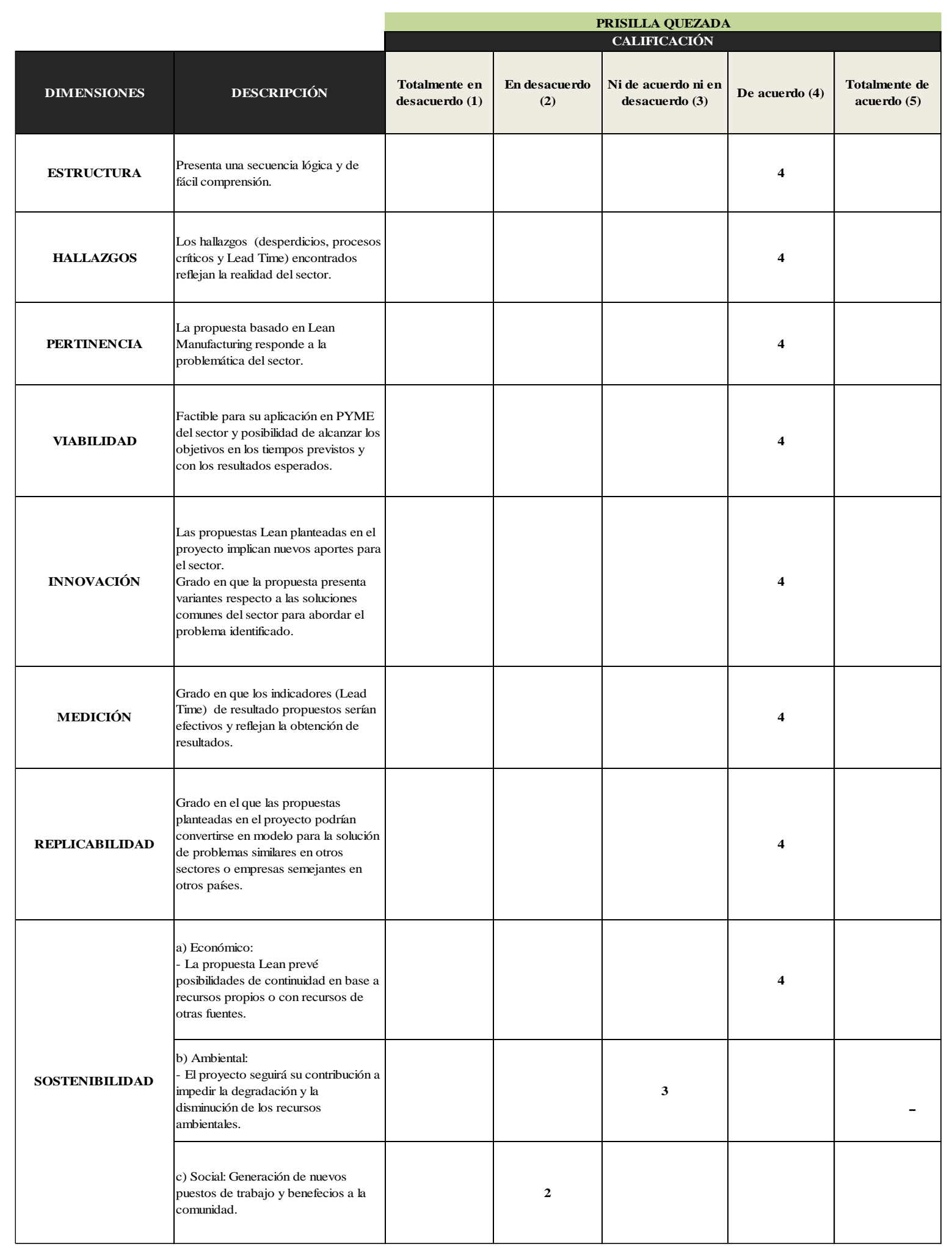

Validación del Dr. Azharul Kharim: El día lunes 14 de agosto del 2017, luego de ser expuesto las propuestas y de describir cada uno de los criterios definidos en la matriz, el 
Dr. Azharul Kharim, Profesor en Queensland University Technology (Australia), respondió vía correo electrónico, evaluando las propuestas de la siguiente manera.

\begin{tabular}{|c|c|c|c|c|c|c|}
\hline & \multirow[b]{3}{*}{ DESCRIPCIÓN } & \multicolumn{5}{|c|}{ AZHARUL KHARIM } \\
\hline & & \multicolumn{5}{|c|}{ CALIFICACIÓN } \\
\hline DIMENSIONES & & $\begin{array}{l}\text { Totalmente en } \\
\text { desacuerdo (1) }\end{array}$ & $\begin{array}{l}\text { En desacuerdo } \\
\text { (2) }\end{array}$ & $\begin{array}{c}\text { Ni de acuerdo ni en } \\
\text { desacuerdo (3) }\end{array}$ & De acuerdo (4) & $\begin{array}{l}\text { Totalmente de } \\
\text { acuerdo (5) }\end{array}$ \\
\hline ESTRUCTURA & $\begin{array}{l}\text { Presenta una secuencia lógica y de } \\
\text { fácil comprensión. }\end{array}$ & & & & 4 & \\
\hline HALLAZGOS & $\begin{array}{l}\text { Los hallazgos (desperdicios, procesos } \\
\text { críticos y Lead Time) encontrados } \\
\text { reflejan la realidad del sector. }\end{array}$ & & & 3 & & \\
\hline PERTINENCIA & $\begin{array}{l}\text { La propuesta basado en Lean } \\
\text { Manufacturing responde a la } \\
\text { problemática del sector. }\end{array}$ & & & & 4 & \\
\hline VIABILIDAD & $\begin{array}{l}\text { Factible para su aplicación en PYME } \\
\text { del sector y posibilidad de alcanzar los } \\
\text { objetivos en los tiempos previstos y } \\
\text { con los resultados esperados. }\end{array}$ & & & & 4 & \\
\hline INNOVACIÓN & $\begin{array}{l}\text { Las propuestas Lean planteadas en el } \\
\text { proyecto implican nuevos aportes para } \\
\text { el sector. } \\
\text { Grado en que la propuesta presenta } \\
\text { variantes respecto a las soluciones } \\
\text { comunes del sector para abordar el } \\
\text { problema identificado. }\end{array}$ & & 2 & & & \\
\hline MEDICIÓN & $\begin{array}{l}\text { Grado en que los indicadores (Lead } \\
\text { Time) de resultado propuestos serín } \\
\text { efectivos y reflejan la obtención de } \\
\text { resultados. }\end{array}$ & & & & 4 & \\
\hline REPLICABILIDAD & \begin{tabular}{|l|} 
Grado en el que las propuestas \\
planteadas en el proyecto podrían \\
convertirse en modelo para la solución \\
de problemas similares en otros \\
sectores o empresas semejantes en \\
otros países.
\end{tabular} & & & 3 & & \\
\hline \multirow{3}{*}{ SOSTENIBILIDAD } & $\begin{array}{l}\text { a) Económico: } \\
\text { - La propuesta Lean prevé } \\
\text { posibilidades de continuidad en base a } \\
\text { recursos propios o con recursos de } \\
\text { otras fuentes. }\end{array}$ & & & 3 & & \\
\hline & $\begin{array}{l}\text { b) Ambiental: } \\
\text { - El proyecto seguirá su contribución a } \\
\text { impedir la degradación y la } \\
\text { disminución de los recursos } \\
\text { ambientales. }\end{array}$ & & & & 4 & \\
\hline & $\begin{array}{l}\text { c) Social: Generación de nuevos } \\
\text { puestos de trabajo y benefecios a la } \\
\text { comunidad. }\end{array}$ & & & 3 & & \\
\hline
\end{tabular}

Validación del Dr. Gulshan Chauhan: El día sábado 26 de agosto del 2017, luego de ser expuesto las propuestas y de describir cada uno de los criterios definidos en la matriz, el Dr. Gulshan Chauhan, Director en Panipat Institute of Engineering \& Technology (India), respondió vía correo electrónico, evaluando las propuestas de la siguiente manera. 


\begin{tabular}{|c|c|c|c|c|c|c|}
\hline & & \multirow{2}{*}{\multicolumn{5}{|c|}{$\begin{array}{l}\text { GULSHAN CHAUHAN } \\
\text { CALIFICACIÓN }\end{array}$}} \\
\hline & & & & & & \\
\hline DIMENSIONES & DESCRIPCIÓN & $\begin{array}{l}\text { Totalmente en } \\
\text { desacuerdo (1) }\end{array}$ & $\begin{array}{l}\text { En desacuerdo } \\
\text { (2) }\end{array}$ & $\begin{array}{c}\text { Ni de acuerdo ni en } \\
\text { desacuerdo (3) }\end{array}$ & De acuerdo (4) & $\begin{array}{l}\text { Totalmente de } \\
\text { acuerdo (5) }\end{array}$ \\
\hline ESTRUCTURA & $\begin{array}{l}\text { Presenta una secuencia lógica y de } \\
\text { fácil comprensión. }\end{array}$ & & & & 4 & \\
\hline HALLAZGOS & $\begin{array}{l}\text { Los hallazgos (desperdicios, procesos } \\
\text { crificos y Lead Time) encontrados } \\
\text { reflejan la realidad del sector. }\end{array}$ & & & & 4 & \\
\hline PERTINENCIA & $\begin{array}{l}\text { La propuesta basado en Lean } \\
\text { Manufacturing responde a la } \\
\text { problemática del sector. }\end{array}$ & & & & 4 & \\
\hline VIABILIDAD & \begin{tabular}{|l} 
Factible para su aplicación en PYME \\
del sector y posibilidad de alcanzar los \\
objetivos en los tiempos previstos y \\
con los resultados esperados.
\end{tabular} & & & & 4 & \\
\hline INNOVACIÓN & $\begin{array}{l}\text { Las propuestas Lean planteadas en el } \\
\text { proyecto implican nuevos aportes para } \\
\text { el sector. } \\
\text { Grado en que la propuesta presenta } \\
\text { variantes respecto a las soluciones } \\
\text { comunes del sector para abordar el } \\
\text { problema identificado. }\end{array}$ & & & & 4 & \\
\hline MEDICIÓN & $\begin{array}{l}\text { Grado en que los indicadores (Lead } \\
\text { Time) de resultado propuestos serían } \\
\text { efectivos y reflejan la obtención de } \\
\text { resultados. }\end{array}$ & & & & & 5 \\
\hline REPLICABILIDAD & \begin{tabular}{|l|} 
Grado en el que las propuestas \\
planteadas en el proyecto podrín \\
convertirse en modelo para la solución \\
de problemas similares en otros \\
sectores o empresas semejantes en \\
otros páses.
\end{tabular} & & & & 4 & \\
\hline \multirow{3}{*}{ SOSTENIBILIDAD } & $\begin{array}{l}\text { a) Económico: } \\
\text { - La propuesta Lean prevé } \\
\text { posibilidades de continuidad en base a } \\
\text { recursos propios o con recursos de } \\
\text { otras fuentes. }\end{array}$ & & & & 4 & \\
\hline & \begin{tabular}{|l|} 
b) Ambiental: \\
- El proyecto seguirá su contribución a \\
impedir la degradación y la \\
disminución de los recursos \\
ambientales.
\end{tabular} & & & & 4 & \\
\hline & $\begin{array}{l}\text { c) Social: Generación de nuevos } \\
\text { puestos de trabajo y benefecios a la } \\
\text { comunidad. }\end{array}$ & & & & & 5 \\
\hline
\end{tabular}

-Validación del Dr. S. Nallusamy: El día miércoles 30 de agosto del 2017, luego de ser expuesto las propuestas y de describir cada uno de los criterios definidos en la matriz, el Dr S. Nallusamy, Profesor en Educational Research Institute University (India), respondió vía correo electrónico, evaluando las propuestas de la siguiente manera. 


\begin{tabular}{|c|c|c|c|c|c|c|}
\hline & \multirow[b]{3}{*}{ DESCRIPCIÓN } & \\
\hline & & \multicolumn{5}{|c|}{$\begin{array}{l}\text { NALLUSAMY } \\
\text { CALIFICACIÓN }\end{array}$} \\
\hline DIMENSIONES & & $\begin{array}{l}\text { Totalmente en } \\
\text { desacuerdo (1) }\end{array}$ & $\begin{array}{l}\text { En desacuerdo } \\
\text { (2) }\end{array}$ & $\begin{array}{c}\text { Ni de acuerdo ni en } \\
\text { desacuerdo (3) }\end{array}$ & De acuerdo (4) & $\begin{array}{l}\text { Totalmente de } \\
\text { acuerdo (5) }\end{array}$ \\
\hline ESTRUCTURA & $\begin{array}{l}\text { Presenta una secuencia lógica y de } \\
\text { fácil comprensión. }\end{array}$ & & & & 4 & \\
\hline HALLAZGOS & $\begin{array}{l}\text { Los hallazgos (desperdicios, procesos } \\
\text { criticos y Lead Time) encontrados } \\
\text { reflejan la realidad del sector. }\end{array}$ & & & & 4 & \\
\hline PERTINENCIA & $\begin{array}{l}\text { La propuesta basado en Lean } \\
\text { Manufacturing responde a la } \\
\text { problemática del sector. }\end{array}$ & & & & 4 & \\
\hline VIABILIDAD & $\begin{array}{l}\text { Factible para su aplicación en PYME } \\
\text { del sector y posibilidad de alcanzar los } \\
\text { objetivos en los tiempos previstos y } \\
\text { con los resultados esperados. }\end{array}$ & & & & 4 & \\
\hline INNOVACIÓN & $\begin{array}{l}\text { Las propuestas Lean planteadas en el } \\
\text { proyecto implican nuevos aportes para } \\
\text { el sector. } \\
\text { Grado en que la propuesta presenta } \\
\text { variantes respecto a las soluciones } \\
\text { comunes del sector para abordar el } \\
\text { problema identificado. }\end{array}$ & & & 3 & & \\
\hline MEDICIÓN & $\begin{array}{l}\text { Grado en que los indicadores (Lead } \\
\text { Time) de resultado propuestos serían } \\
\text { efectivos y reflejan la obtención de } \\
\text { resultados. }\end{array}$ & & & 3 & & \\
\hline REPLICABILIDAD & \begin{tabular}{|l} 
Grado en el que las propuestas \\
planteadas en el proyecto podrín \\
convertirse en modelo para la solución \\
de problemas similares en otros \\
sectores o empresas semejantes en \\
otros países.
\end{tabular} & & & 3 & & \\
\hline \multirow{3}{*}{ SOSTENIBILIDAD } & $\begin{array}{l}\text { a) Económico: } \\
\text { - La propuesta Lean prevé } \\
\text { posibilidades de continuidad en base a } \\
\text { recursos propios o con recursos de } \\
\text { otras fuentes. }\end{array}$ & & & & 4 & \\
\hline & \begin{tabular}{|l|} 
b) Ambiental: \\
- El proyecto seguirá su contribución a \\
impedir la degradación y la \\
disminución de los recursos \\
ambientales.
\end{tabular} & & & & 4 & \\
\hline & $\begin{array}{l}\text { c) Social: Generación de nuevos } \\
\text { puestos de trabajo y benefecios a la } \\
\text { comunidad. }\end{array}$ & & & 3 & & \\
\hline
\end{tabular}

Validación del Dr. Juan Vanegas: El día miércoles 29 de agosto del 2017, luego de presentar las propuestas y describir cada uno de los criterios definidos en la matriz, el Dr. Juan Vanegas, Profesor en el Tecnológico de Antioquía (Colombia), respondió vía correo electrónico, evaluando las propuestas de la siguiente manera. 


\begin{tabular}{|c|c|c|c|c|c|c|}
\hline & & & & LIFICACIÓ| & & \\
\hline DIMENSIONES & DESCRIPCIÓN & $\begin{array}{l}\text { Totalmente en } \\
\text { desacuerdo (1) }\end{array}$ & $\begin{array}{l}\text { En desacuerdo } \\
\text { (2) }\end{array}$ & \begin{tabular}{|r|}
$\mathbf{N i}$ de acuerdo ni \\
en desacuerdo (3)
\end{tabular} & $\begin{array}{l}\text { De acuerdo } \\
\text { (4) }\end{array}$ & $\begin{array}{l}\text { Totalmente de } \\
\text { acuerdo (5) }\end{array}$ \\
\hline ESTRUCTURA & $\begin{array}{l}\text { Presenta una secuencia lógica y } \\
\text { de fácil comprensión. }\end{array}$ & & & & 4 & \\
\hline HALLAZGOS & $\begin{array}{l}\text { Los hallazgos (desperdicios, } \\
\text { procesos críticos y Lead Time) } \\
\text { encontrados reflejan la realidad } \\
\text { del sector. }\end{array}$ & & & 3 & & \\
\hline PERTINENCIA & $\begin{array}{l}\text { La propuesta basado en Lean } \\
\text { Manufacturing responde a la } \\
\text { problemática del sector. }\end{array}$ & & & & & 5 \\
\hline VIABILIDAD & $\begin{array}{l}\text { Factible para su aplicación en } \\
\text { PYME del sector y posibilidad de } \\
\text { alcanzar los objetivos en los } \\
\text { tiempos previstos y con los } \\
\text { resultados esperados. }\end{array}$ & & & & 4 & \\
\hline INNOVACIÓN & $\begin{array}{l}\text { Las propuestas Lean planteadas en } \\
\text { el proyecto implican nuevos } \\
\text { aportes para el sector. } \\
\text { Grado en que la propuesta } \\
\text { presenta variantes respecto a las } \\
\text { soluciones comunes del sector } \\
\text { para abordar el problema } \\
\text { identificado. }\end{array}$ & & & 3 & & \\
\hline MEDICIÓN & $\begin{array}{l}\text { Grado en que los indicadores } \\
\text { (Lead Time) de resultado } \\
\text { propuestos serían efectivos y } \\
\text { reflejan la obtención de } \\
\text { resultados. }\end{array}$ & & & 3 & & \\
\hline REPLICABILIDAD & $\begin{array}{l}\text { Grado en el que las propuestas } \\
\text { planteadas en el proyecto podrían } \\
\text { convertirse en modelo para la } \\
\text { solución de problemas similares } \\
\text { en otros sectores o empresas } \\
\text { semejantes en otros países. }\end{array}$ & & & & 4 & \\
\hline \multirow{3}{*}{ SOSTENIBILIDAD } & $\begin{array}{l}\text { a) Económico: } \\
\text { - La propuesta Lean prevé } \\
\text { posibilidades de continuidad en } \\
\text { base a recursos propios o con } \\
\text { recursos de otras fuentes. }\end{array}$ & & & 3 & & \\
\hline & $\begin{array}{l}\text { b) Ambiental: } \\
\text { - El proyecto seguirá su } \\
\text { contribución a impedir la } \\
\text { degradación y la disminución de } \\
\text { los recursos ambientales. }\end{array}$ & & & & 4 & \\
\hline & $\begin{array}{l}\text { c) Social: Generación de nuevos } \\
\text { puestos de trabajo y benefecios a } \\
\text { la comunidad. }\end{array}$ & & & 3 & & \\
\hline
\end{tabular}




\section{Anexo 31. Matriz de Competencias}

\begin{tabular}{|c|c|c|c|c|}
\hline Alumno & $\begin{array}{l}\text { Ramos Valle, Milagritos } \\
\text { Oré Mayorga, Elia Victoria }\end{array}$ & $\begin{array}{l}201213618 \\
201213497\end{array}$ & PIA 1 & PIA2 \\
\hline Competencia & \multicolumn{4}{|c|}{ Aplicación en el trabajo final } \\
\hline \multirow{5}{*}{$\begin{array}{l}\text { a. Aplica los conocimientos de } \\
\text { matemáticas, ciencia e ingeniería, } \\
\text { para la solución de problemas de } \\
\text { ingeniería industrial. }\end{array}$} & \multicolumn{4}{|c|}{$\begin{array}{l}\text { En la selección del sector y específicamente en la determinación de la cantidad de empresas a encuestar. } \\
\text { Esto se pudo lograr mediante fórmulas de estadísticas desarrolladas con un nivel de confianza establecido } \\
\text { y porcentaje de error. }\end{array}$} \\
\hline & \multicolumn{4}{|c|}{$\begin{array}{l}\text { En el procesamiento de la data obtenida a través de las encuestas realizadas con la finalidad de analizar el } \\
\text { sector estudiado calculando los promedios de tiempos externos, tiempos internos y cantidades de } \\
\text { producción por cada proceso en el sector. }\end{array}$} \\
\hline & \multicolumn{4}{|c|}{$\begin{array}{l}\text { Se desarrolló el análisis de la situación actual mediante el planteamiento de herramientas e ingeniería } \\
\text { como: VSM, Pareto y diagrama causal. Ello permitió orientar la solución que permita disminuir o } \\
\text { erradicar los desperdicios encontrados. }\end{array}$} \\
\hline & \multicolumn{4}{|c|}{$\begin{array}{l}\text { La aplicación de las herramientas de ingeniería como: Estandarización y Just in time permitió el desarrollo } \\
\text { de las soluciones óptimas para eliminar los problemas presentados en el sector. }\end{array}$} \\
\hline & \multicolumn{4}{|c|}{$\begin{array}{l}\text { En el cálculo del impacto económico para el sector se desarrolló ejemplos que mediante las cifras } \\
\text { obtenidas se observaba el gran impacto económico positivo que tendrían los sectores si es que seguían } \\
\text { con las propuestas que planteamos. }\end{array}$} \\
\hline \multirow{5}{*}{$\begin{array}{l}\text { b. Diseña y conduce } \\
\text { experimentos, analiza e interpreta } \\
\text { datos. }\end{array}$} & \multicolumn{4}{|c|}{$\begin{array}{l}\text { En el trabajo de campo (encuestas a las empresas) se obtuvieron datos que fueron procesados, } \\
\text { analizados e interpretados para diseñar estrategias que permitan solucionar los problemas observados. }\end{array}$} \\
\hline & \multicolumn{4}{|c|}{$\begin{array}{l}\text { En la parte del desarrollo de las alternativas de solución se diseñó módulos estratégicos y de soporte el } \\
\text { cual permitía la reducción del lead time. Esto se analizó detalladamente para proyectar e interpretar los } \\
\text { datos futuros del sector gracias a las propuestas. }\end{array}$} \\
\hline & \multicolumn{4}{|c|}{$\begin{array}{l}\text { Para la etapa de validación de la tesis se hizo bajo la metodología de juicios de expertos donde se } \\
\text { obtuvieron puntajes con la calificación tanto al proyecto como al impacto generado. Pues ello, permitió el } \\
\text { análisis de los resultados e interpretar los puntajes y además considerar observaciones para el proyecto } \\
\text { en base a la conocimiento de los expertos. }\end{array}$} \\
\hline & \multicolumn{4}{|c|}{$\begin{array}{l}\text { Se desarrolló dos sistemas de compras para la solución a los problemas observados en el sector. Dentro } \\
\text { de los sistemas se consideraron tanto módulos estratégicos (que atacan directamente las causas) y } \\
\text { módulos de soporte (que contemplan los riesgos del sistema propuesto) para que de esa forma las } \\
\text { propuestas sean sostenible a través del tiempo. }\end{array}$} \\
\hline & \multicolumn{4}{|c|}{$\begin{array}{l}\text { Se determinó las consideraciones a tener en cuenta para el desarrollo de los sistemas contemplando el } \\
\text { modelo del sector actual, riesgos y restricciones presentes. }\end{array}$} \\
\hline \multirow{2}{*}{$\begin{array}{c}\text { d. Se integra en equipos } \\
\text { multidisciplinarios reconociendo } \\
\text { la importancia del trabajo en } \\
\text { equipo. }\end{array}$} & \multicolumn{4}{|c|}{$\begin{array}{l}\text { Para el inicio del proyecto se desarrolló el trabajo de campo en grupo de } 10 \text { personas, ello facilitó la } \\
\text { ejecución de las entrevistas a las PYME’s, además de recabar información extra para cada proceso. El } \\
\text { trabajo en equipo permitió enlazar la información para el desarrollo de cada trabajo ya que los procesos } \\
\text { se relacionan directamente. }\end{array}$} \\
\hline & \multicolumn{4}{|c|}{$\begin{array}{l}\text { El trabajo en pareja se llevó acabo durante todo el proyecto de investigación, la importancia de esta } \\
\text { modalidad de trabajo es que facilita la toma de decisiones y se comparten ideas distintas en mejora del } \\
\text { proyecto. }\end{array}$} \\
\hline $\begin{array}{l}\text { e. Identifica, formula y resuelve } \\
\text { problemas de ingeniería. }\end{array}$ & \multicolumn{4}{|c|}{$\begin{array}{l}\text { Identificación de la problemática en el sector textil exportador y planteamiento y desarrollo de las } \\
\text { herramientas de Lean Manufacturing para eliminar los desperdicios identificados en el proceso crítico de } \\
\text { compras. }\end{array}$} \\
\hline $\begin{array}{l}\text { f. Desarrolla sus actividades con } \\
\text { responsabilidad ética y } \\
\text { profesional del ingeniero. }\end{array}$ & \multicolumn{4}{|c|}{$\begin{array}{l}\text { Se evita el plagio de información citando las fuentes correspondientes a datos o información utilizada en el } \\
\text { proyecto y se realiza la entrega a tiempo de los documentos solicitados por el docente en la plataforma } \\
\text { Blackboard de la UPC. }\end{array}$} \\
\hline $\begin{array}{l}\text { g. Se comunica de manera clara } \\
\text { y efectiva utilizando el lenguaje } \\
\text { técnico y de empresa. }\end{array}$ & \multicolumn{4}{|c|}{ Se demuestra en las exposiciones internas y externas del proyecto en el salón de clase. } \\
\hline $\begin{array}{l}\text { h. Investiga el Impacto de } \\
\text { soluciones de ingeniería dentro } \\
\text { de un contexto global, } \\
\text { económico, ambiental y social. }\end{array}$ & \multicolumn{4}{|c|}{$\begin{array}{l}\text { Se plantea el impacto económico mediante un ejemplo y se realiza la evaluación de impacto de las } \\
\text { propuestas a través de la Matriz de Leopold con la información obtenida de la validación de expertos. }\end{array}$} \\
\hline $\begin{array}{c}\text { i. Pertenece vigente y actualizado } \\
\text { en su profesión, reconociendo la } \\
\text { importancia del aprendizaje } \\
\text { continuo. }\end{array}$ & \multicolumn{4}{|c|}{$\begin{array}{l}\text { En el desarrollo de todo el proyecto, se utiliza información actualizada de diversas fuentes y se aplican los } \\
\text { conocimientos adquiridos a lo largo de la carrera. }\end{array}$} \\
\hline $\begin{array}{l}\text { J.Conoce temas } \\
\text { comtemporáneos que le permita } \\
\text { mayor dominio en el campo } \\
\text { profesional. }\end{array}$ & \multicolumn{4}{|c|}{$\begin{array}{l}\text { A lo largo del proyecto, principalmente en el estado del arte, se adquiere información de artículos } \\
\text { científicos y otros medios. }\end{array}$} \\
\hline $\begin{array}{l}\text { K. Usa técnicas, destrezas y } \\
\text { herramientas modernas } \\
\text { necesarias en la práctica de la } \\
\text { ingeniería. }\end{array}$ & \multicolumn{4}{|c|}{$\begin{array}{l}\text { Se utilizaron herramientas de Ingeniería Industrial, tales como el VSM, diagramas de flujo, PRM } \\
\text { (Planificación de requerimiento de material), diagrama causal, diagrama de gant para graficar e identificar } \\
\text { la materia prima más importante en el proceso. Asimismo, se desarrollaron indicadores para medir el } \\
\text { desempeño del proceso y del personal, y procedimientos para el proceso de compras. }\end{array}$} \\
\hline
\end{tabular}

